FHWA/IN/JTRP-2004/13

Final Report

PERFORMANCE-RELATED SPECIFICATIONS (PRS) FOR CONCRETE PAVEMENTS IN INDIANA

VOLUME 2

TECHNICAL REPORT

Cole Graveen

Eric Falker

Micah Beaver

Narayanan Neithalath

Jason Weiss

Jan Olek

Tommy Nantung

Lee Gallivan

January 2009 
Final Report

FHWA/IN/JTRP-2004/13

\title{
Performance Related Specifications (PRS) for Concrete Pavements in Indiana Volume 2: Technical Report
}

\author{
by \\ Cole Graveen \\ Graduate Research Assistant \\ Eric Falker \\ Graduate Research Assistant \\ Micah Beaver \\ Graduate Research Assistant \\ Narayanan Neithalath \\ Graduate Research Assistant \\ Jason Weiss \\ Assistant Professor \\ Jan Olek \\ Associate Professor \\ School of Civil Engineering \\ Purdue University \\ West Lafayette, Indiana \\ and \\ Tommy Nantung \\ Section Manager \\ INDOT Research Division \\ Lee Gallivan \\ Pavement/Materials Engineer \\ FHWA-Indiana Division \\ Joint Transportation Research Program \\ Project No. C-36-46R \\ File No. 5-11-18 \\ DTFH7299-0599 \\ Conducted in cooperation with the \\ Indiana Department of Transportation and \\ the U.S. Department of Transportation \\ Federal Highway Administration
}

The contents of this paper reflect the views of the authors, who are responsible for the facts and the accuracy of the data presented herein, and do not necessarily reflect the official views or policies of the Federal Highway Administration and the Indiana Department of Transportation, nor do the contents constitute a standard, specification, or regulation. 


\begin{tabular}{|c|c|}
\hline $\begin{array}{l}\text { 1. Report No. } \\
\text { FHWA/IN/JTRP-2004/13 }\end{array}$ & 3. Recipient's Catalog No. \\
\hline \multirow[t]{2}{*}{$\begin{array}{l}\text { 4. Title and Subtitle } \\
\text { Performance-Related Specifications (PRS) for Concrete Pavements in Indiana }\end{array}$} & $\begin{array}{l}\text { 5. } \quad \text { Report Date } \\
\text { January } 2009\end{array}$ \\
\hline & 6. Performing Organization Code \\
\hline $\begin{array}{l}\text { 7. Author(s) } \\
\text { Cole Graveen, Eric Falker, Micah Beaver, Narayanan Neithalath, Jason Weiss, } \\
\text { Jan Olek. Tommv Nantung. Lee Gallivan. }\end{array}$ & $\begin{array}{l}\text { 8. Performing Organization Report No. } \\
\text { FHWA/IN/JTRP-2004/13 }\end{array}$ \\
\hline \multirow[t]{2}{*}{$\begin{array}{l}\text { 9. Performing Organization Name and Address } \\
\text { Joint Transportation Research Program } \\
1284 \text { Civil Engineering Building } \\
\text { Purdue University } \\
\text { West Lafayette, IN 47907-1284 }\end{array}$} & 10. Work Unit No. \\
\hline & $\begin{array}{l}\text { 11. Contract or Grant No. } \\
\text { DTFH-7299-0599 }\end{array}$ \\
\hline \multirow[t]{2}{*}{$\begin{array}{l}\text { 12. Sponsoring Agency Name and Address } \\
\text { Indiana Department of Transportation } \\
\text { State Office Building } \\
100 \text { North Senate Avenue } \\
\text { Indianapolis, IN } 46204\end{array}$} & $\begin{array}{l}\text { 13. Type of Report and Period Covered } \\
\text { Final Report }\end{array}$ \\
\hline & 14. Sponsoring Agency Code \\
\hline
\end{tabular}

\section{Supplementary Notes}

Prepared in cooperation with the Indiana Department of Transportation and Federal Highway Administration.

\section{Abstract}

Performance-Related Specifications (PRS) are specifications that base pavement acceptance and pay adjustment on the projected performance and predicted life-cycle cost (LCC) for a specific pavement. PRS relate measurable quality characteristics with pavement performance through computer simulations that incorporate physical distress models. Previously, work at ERES consultants by Darter and co-workers developed prototype PRS for jointed plain portland cement concrete pavements (PCC) through Federal Highway Administration (FHWA) through a series of research projects. However, before this research program began, pavements have not been constructed using these specifications.

This report describes the Indiana Department of Transportation's (INDOT) experience with developing and implementing the first and second Level 1 PRS projects during the re-construction of a portion of I-465 east of Indianapolis and I-65 north of Clarksville, respectively. This report includes an overview of the concepts behind PRS, the process of developing a Level 1 PRS, lessons learned from implementing the first PRS in the construction of the pavement outside Indianapolis during the summer of 2000, lessons learned from implementing the second PRS in the construction of the pavement outside Clarksville during the summer of 2002, the use of non-destructive testing procedures to obtain measures of pavement quality, sample specifications, and conclusions and recommendations. In general, this specification was well received by both the agency and the contractors. It is believed that lessons learned on these projects will enable future modifications to the development of performance related specifications with the hope that these specifications will enable longer lasting, more cost effective pavements to be constructed.

17. Key Words

concrete, pavement, life-cycle cost, specifications

\section{Distribution Statement}

No restrictions. This document is available to the public through the National Technical Information Service, Springfield, VA 22161
19. Security Classif. (of this report)

Unclassified
20. Security Classif. (of this page)

Unclassified
21. No. of Pages

422 


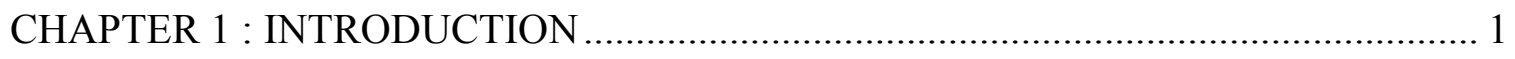

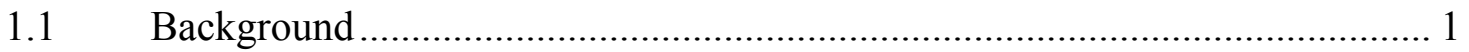

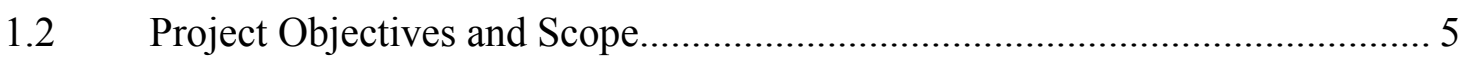

CHAPTER 2 : IMPLEMENTATION OF PERFORMANCE-RELATED SPECIFICATIONS (PRS) IN INDIANA …………………………………………………………….... 7

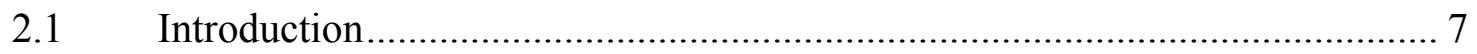

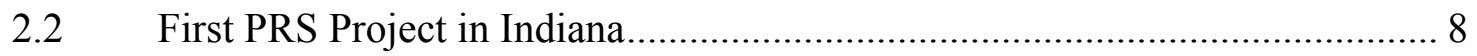

2.2.1 Project Scope and Objective …………………..................................... 8

2.2.2 Development of Data Input for Computer Simulation ............................... 9

2.2.3 Creating the First PRS .................................................................... 10

2.2.4 Implementing the First PRS In Indiana ................................................ 13

2.3 Second PRS Project in Indiana ............................................................. 14

CHAPTER 3 : REVIEW OF LIFE-CYCLE COST ANALYSIS..................................... 15

3.1 Definition of Life-Cycle Cost Analysis ....................................................... 16

3.2 Previous Application of Life-Cycle Cost Analysis.......................................... 18

3.3 Benefits and Limitations of Life-Cycle Cost Analysis ..................................... 19

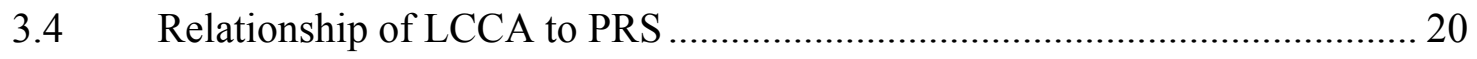

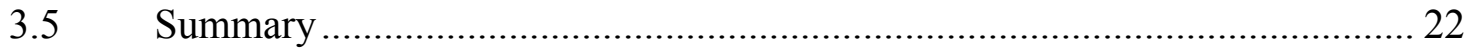

CHAPTER 4 : PAVEMENT DISTRESS MODELING_.................................................. 24 


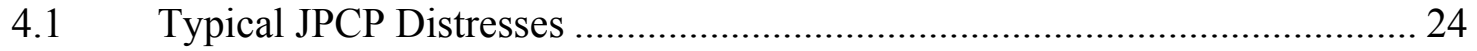

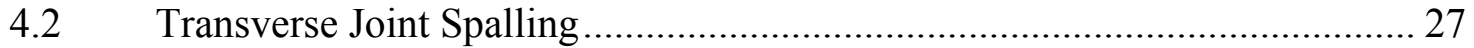

$4.3 \quad$ Transverse Joint Faulting .......................................................................... 28

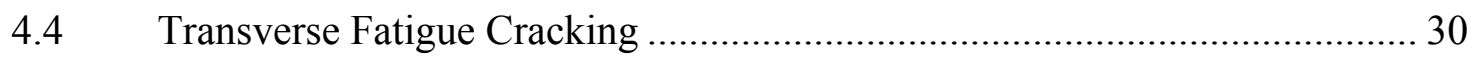

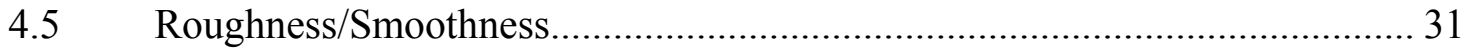

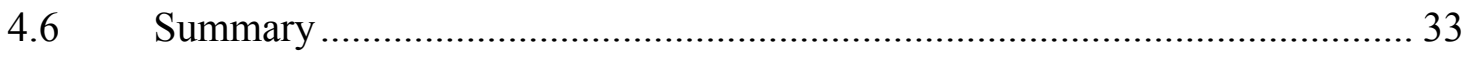

CHAPTER 5 : INNOVATIVE CONTRACTING STRATEGIES FOR HIGHWAY

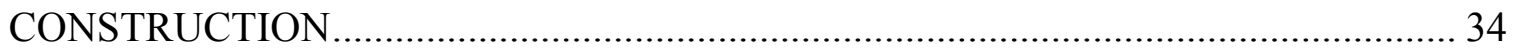

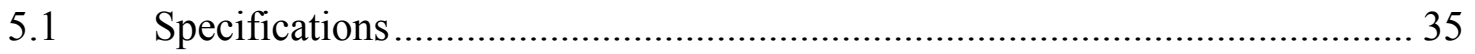

5.1.1 Prescriptive Specifications............................................................... 37

5.1.2 Quality Assurance Specifications …………………………………...... 38

5.1.3 Performance-Related Specifications ........................................................ 40

5.1.4 Performance-Based Specifications …………………………………..... 42

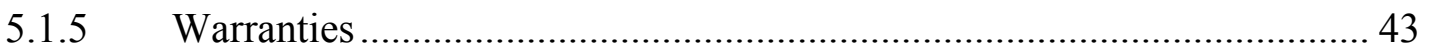

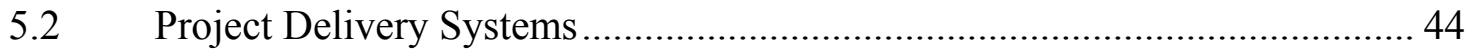

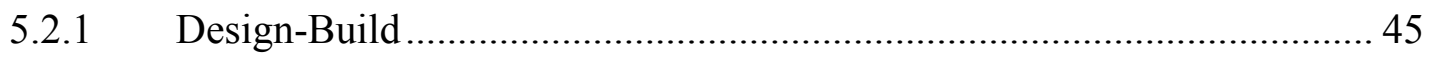

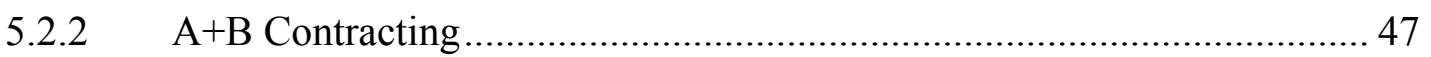

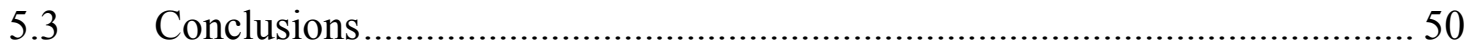

CHAPTER 6 : ASSESSING PRS SOFTWARE, PART I: PROJECT, PAVEMENT, TRAFFIC,

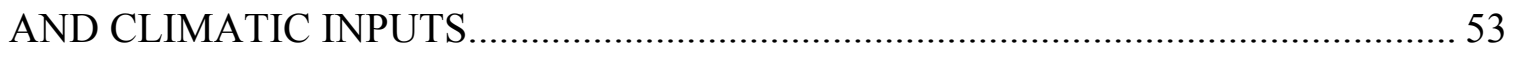

6.1 Background on PRS software ……………............................................ 54

6.2 Description of Base Case ............................................................................ 57

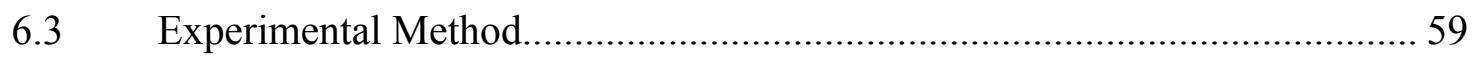

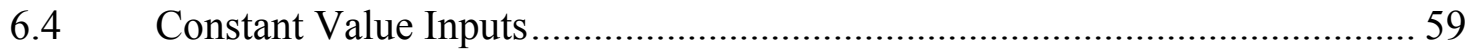

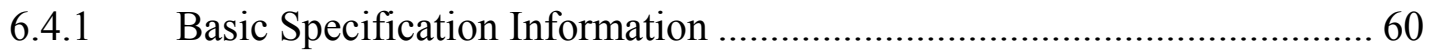

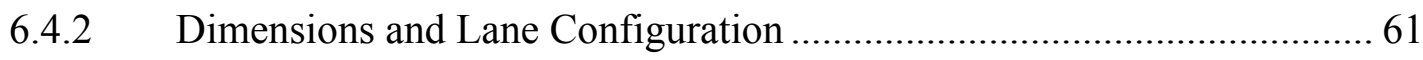

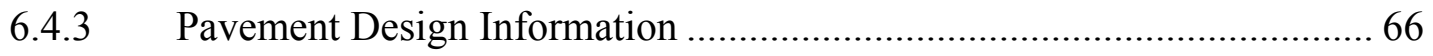

6.4.3.1 General Pavement Design Inputs......................................................... 66

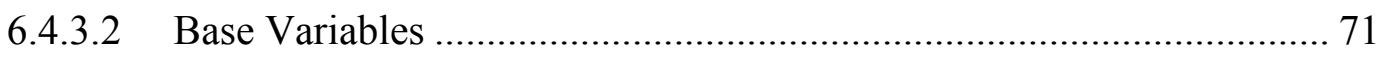


6.4.4 Design Traffic Information ................................................................ 73

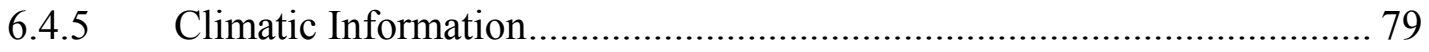

6.5 Summary of Project and Design-Related Inputs.............................................. 86

CHAPTER 7 : ASSESSING PRS SOFTWARE, PART II: ACCEPTANCE QUALITY CHARACTERISTICS, LIFE-CYCLE AND REPAIR AND MAINTENANCE MODELS87

7.1 Definition of Pavement Performance.............................................................. 87

7.2 AQC Sampling and Testing Information...................................................... 92

7.3 AQC As-designed Target Value Definition.................................................. 93

7.4 Maintenance and Rehabilitation Plan Information ........................................... 99

7.4.1 Regular Maintenance ............................................................................. 99

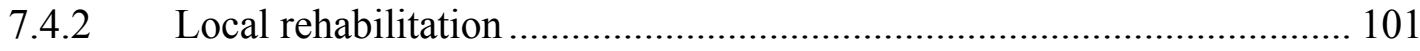

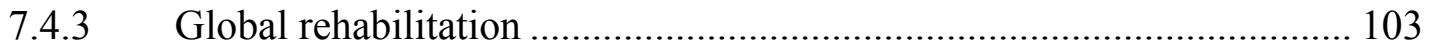

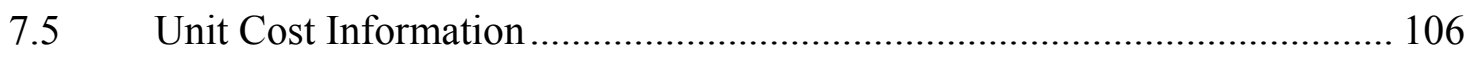

7.5.1 Maintenance and Rehabilitation Costs.................................................... 106

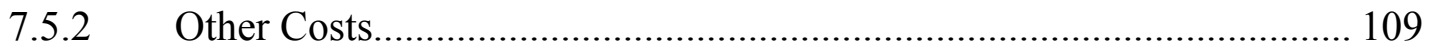

7.6 Simulation Control Information.......................................................... 112

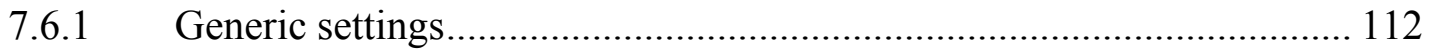

7.6.2 Simulation control - AQCs .............................................................. 116

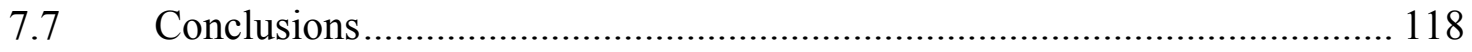

CHAPTER 8 : IMPACTS OF PERFORMANCE RELATED SPECIFICATIONS ON AGENCIES AND CONTRACTORS ................................................................ 119

8.1 Comparison of PRS Projects in Indiana........................................................ 119

8.2 Setting AQC Targets........................................................................... 121

8.2.1 Setting Strength AQC in Project \#1 ..................................................... 122

8.2.2 Setting Strength AQC in Project \#2 ...................................................... 124

8.3 Modifying Pay Factor Curves in Projects \#1 and \#2 ................................. 125

8.4 Variability and Performance ............................................................... 128

8.5 Cost Function for Strength and Thickness................................................. 130

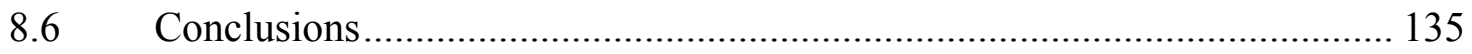


CHAPTER 9 : REVIEW OF NON-DESTRUCTIVE TEST METHODS 136

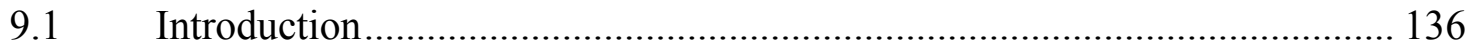

9.2 Test Methods to Determine Slab Thickness ….......................................... 137

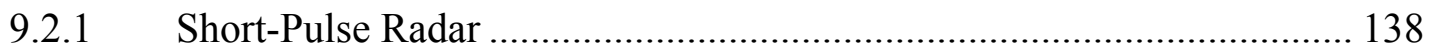

9.2.2 Stress Wave Propagation Methods ………………………………….... 140

9.2.2.1 Spectral Analysis of Surface Waves (SASW) .................................... 142

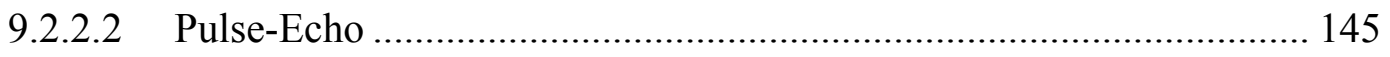

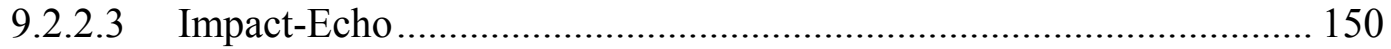

9.3 Test Methods to Determine Concrete Strength............................................. 153

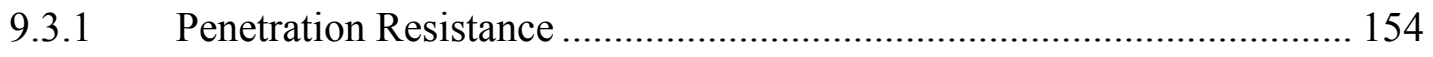

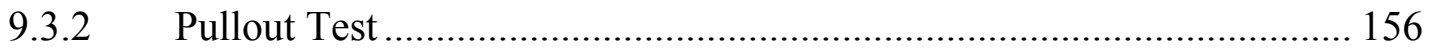

9.3.3 Stress Wave Test Methods................................................................ 158

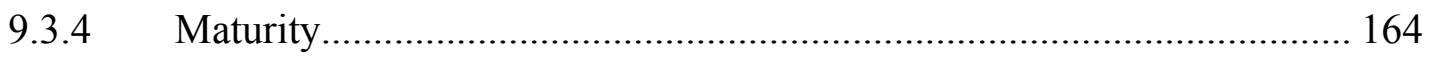

9.4 Test Methods Selected for Further Investigation........................................ 170

CHAPTER 10 : EXPERIMENTAL PROGRAM AND TEST PROCEDURES............. 172

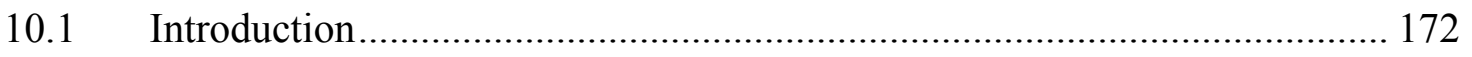

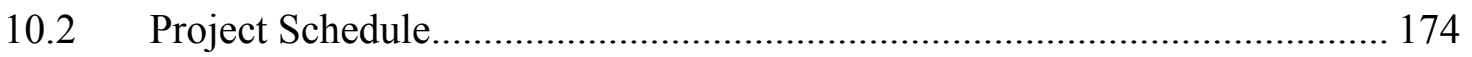

$10.3 \quad$ Pre-Construction Test Program................................................................. 174

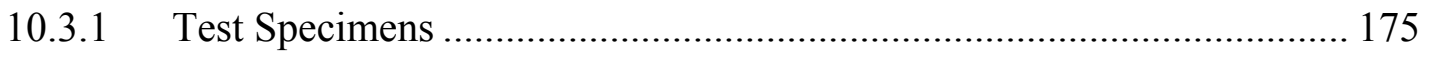

10.3.2 Concrete Mixing and Transportation Procedures .................................... 176

10.3.3 Casting and Curing Procedure ............................................................ 179

10.3.4 Test Specimen Identification .............................................................. 183

10.3.5 Testing Procedures and Equipment ………………………………...... 184

10.3.5.1 Standard Strength Tests ............................................................... 186

10.3.5.2 Measurement of Compression Wave (P-wave) Velocity.................. 187

10.3.5.3 Impact-Echo Test Method to Determine Thickness ......................... 193

10.3.5.4 Time-Temperature Measurements ................................................. 194

10.3.5.5 Slab Thickness Determination By Coring ..................................... 194

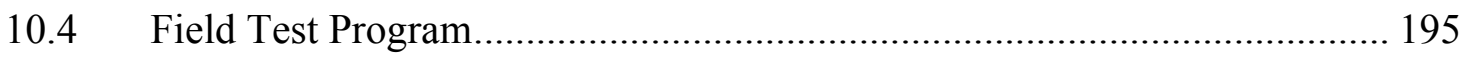


10.4.1 Description of INDOT Project R-24432 Procedures ............................. 195

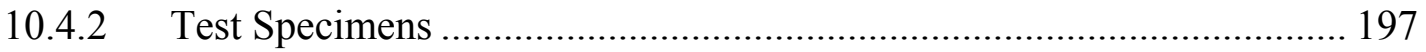

10.4.3 Mixing and Sampling Procedure ......................................................... 199

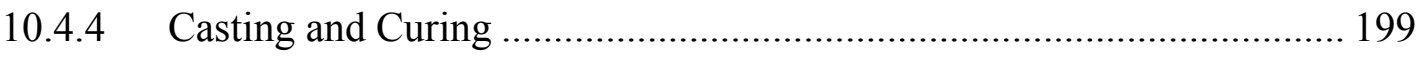

10.4.5 Testing Procedure and Equipment .................................................... 203

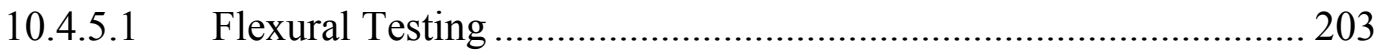

10.4.5.2 Measurement of Compression Wave (P-wave) Velocity................ 204

10.4.5.3 Impact-Echo Test Method to Determine Thickness ...................... 204

10.4.5.4 Time-Temperature Measurements ............................................... 204

10.4.5.5 Pavement Cores ..................................................................... 205

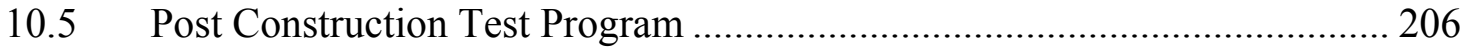

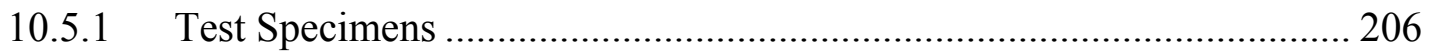

10.5.2 Mixing, Casting, and Curing Procedures ............................................ 207

10.5.3 Testing Procedure and Equipment ................................................... 208

CHAPTER 11 : PRE-CONSTRUCTION EXPERIMENTAL RESULTS .................... 210

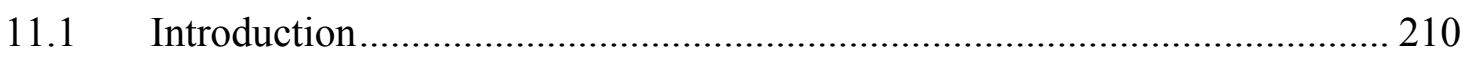

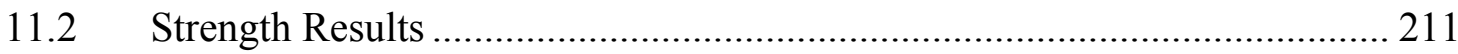

$11.3 \quad$ Temperature Measurement Results....................................................... 218

11.4 Strength to Maturity Relationship......................................................... 220

11.4.1 Determining the Strength to Maturity Relationship............................. 220

11.4.2 Predicted Slab Strength Using the Strength to Maturity Relationship ... 224

11.5 Compression Wave (P-wave) Velocity Results ....................................... 226

11.5.1 Measurement of Beam and Cylinder Specimens ................................. 226

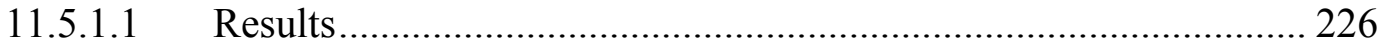

11.5.1.2 Effect of Systematic Error ......................................................... 229

11.5.1.3 Comparison of Test Methods................................................. 230

11.5.2 The Strength to Compression Wave (P-wave) Velocity Relationship.... 231

11.5.3 Measurement of Slab Specimens ..................................................... 236

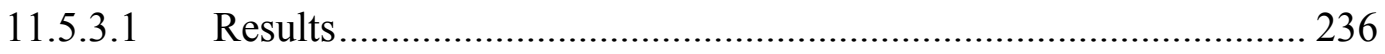

11.5.3.2 Comparison of Test Methods.................................................... 236 
11.5.3.3 Compression Wave (P-wave) Versus Age Relationship ............... 239

11.5.3.4 Effect of Surface Tining........................................................... 240

11.5.3.5 Comparison to Other Test Methods.......................................... 240

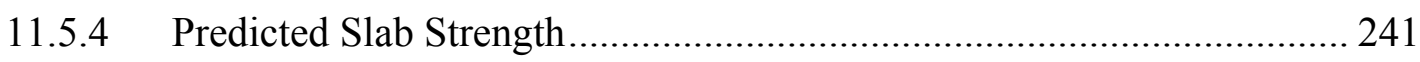

11.6 Slab Thickness by Coring Results ................................................... 242

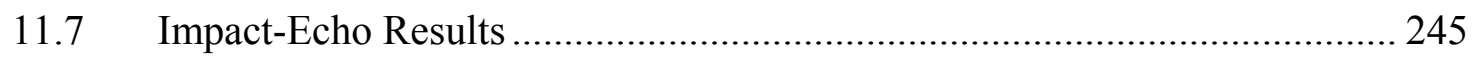

11.7.1 Testing and Analysis of Recorded Data............................................ 245

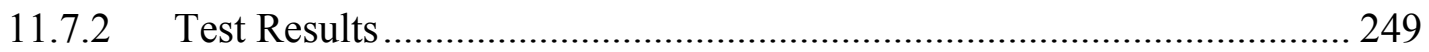

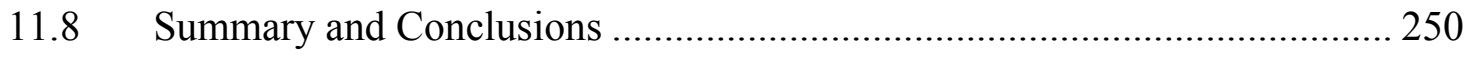

CHAPTER 12 : FIELD TESTING EXPERIMENTAL RESULTS ............................. 254

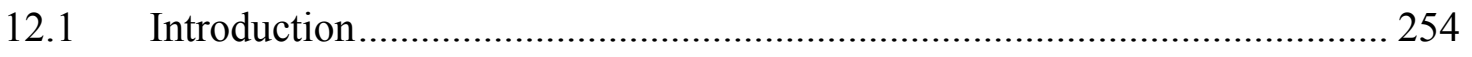

12.2 Explanation of Field Test Program Results .......................................... 255

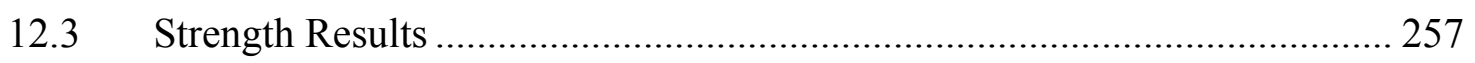

12.4 Temperature Measurement Results.......................................................... 262

12.5 Strength to Maturity Relationship......................................................... 264

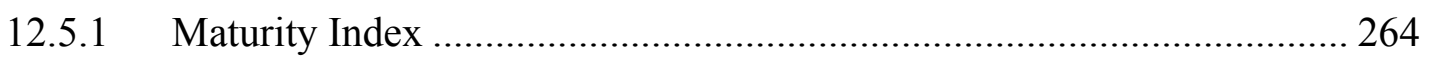

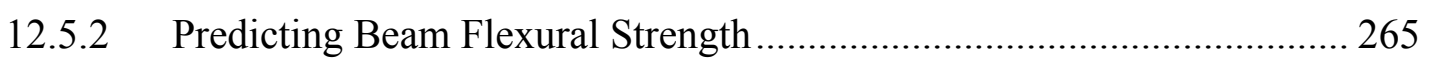

12.5.3 Predicting Pavement Flexural Strength .......................................... 270

12.6 Measurement of Compression Wave (P-wave) Velocity Results................ 272

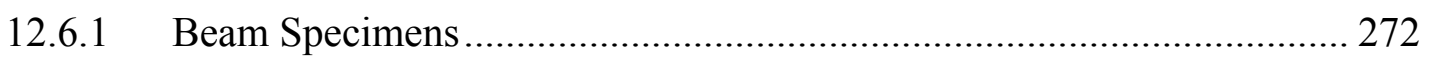

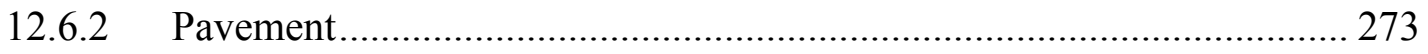

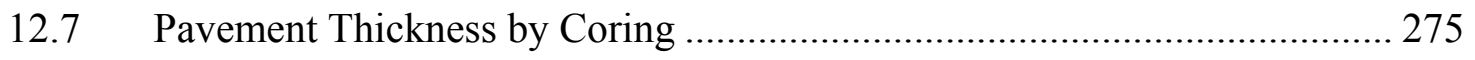

12.8 Pavement Thickness Using Impact-Echo ............................................. 277

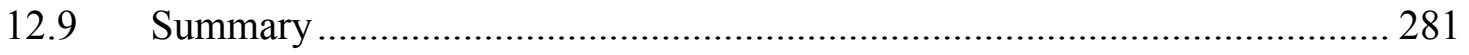

CHAPTER 13 : POST CONSTUCTION EXPERIMENTAL RESULTS ..................... 284

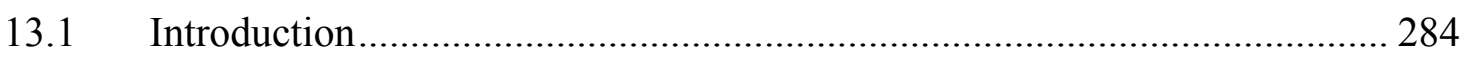

13.2 Datum Temperature and Activation Energy Results ............................... 285

13.3 Mixture Proportion Variation Results..................................................... 290

13.4 Analysis of Maturity and P-Wave Velocity Test Methods .......................... 297 
13.4.1 Methods of Implementation................................................................. 297

13.4.1.1 Stand Alone Maturity................................................................... 297

13.4.1.2 Combined Maturity and P-Wave Velocity Measurements ............. 298

13.4.1.3 Early-Age Test Result In Combination With Nondestructive Test 301

13.4.2 Maturity Test Method Implementation Issues ........................................... 303

13.4.3 Measurement of P-Wave Velocity Implementation Issues...................... 304

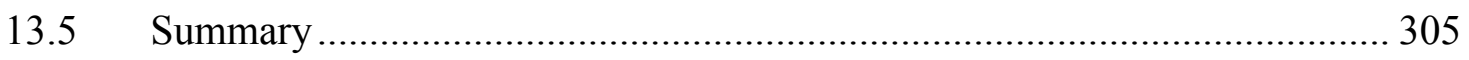

CHAPTER 14 : CONCLUSIONS AND RECOMMENDATIONS ………………….... 308

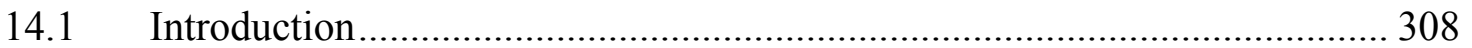

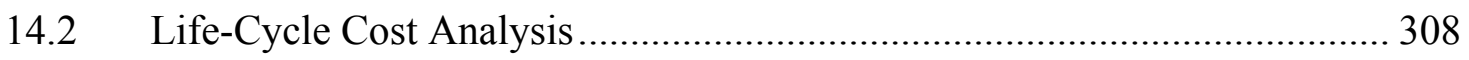

14.3 Pavement Distress Modeling ................................................................... 309

14.4 PRS and Other Innovative Contracting Strategies.......................................... 309

$14.5 \quad$ Life-Cycle Cost Analysis Software Inputs …………………………......... 310

14.6 Impacts on Agencies and Contractors....................................................... 310

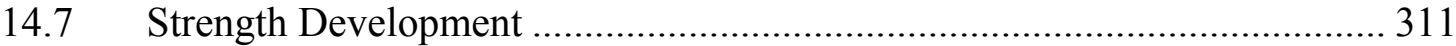

$14.8 \quad$ Temperature and Heat Development .......................................................... 312

$14.9 \quad$ Maturity Test Method ............................................................................... 312

14.10 Measurement of Compression Wave (P-wave) Velocity................................ 313

14.11 Flexural Strength-P-Wave Velocity Relationship ........................................ 314

14.12 Impact-Echo Test Method.......................................................................... 315

14.13 Recommendations for Further Study ……….......................................... 317

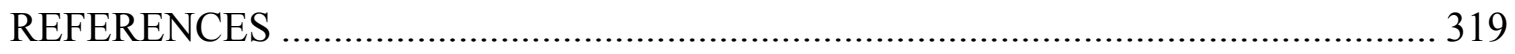

APPENDIX A PERFORMANCE-RELATED SPECIFICATION DEFINITIONS .. 330 APPENDIX B SOFTWARE (PAVESPEC VERSION 2.5) INPUT DATA............... 334

APPENDIX C SOFTWARE (PAVESPEC VERSION 3.0) INPUT DATA............... 339 APPENDIX D INDOT AGGREGATE GRADATION ……..................................... 349

APPENDIX E PRE-CONSTRUCTION MIXTURE DESIGN ……………………..... 351

APPENDIX F FRESH CONCRETE PROPERTIES (PRE-CONSTRUCTION \& FIELD

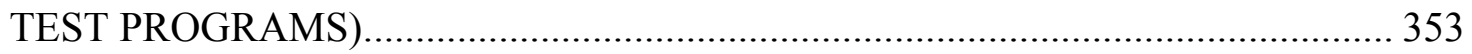


APPENDIX G PRE-CONSTRUCTION CASTING AND CURING PROCEDURES355 APPENDIX H COMPRESSIVE STRENGTH TEST PROCEDURES 359 APPENDIX I FLEXURAL TEST PROCEDURES …………………………........... 361 APPENDIX J SPLIT TENSILE TEST PROCEDURES.......................................... 363 APPENDIX K ELASTIC MODULUS AND POISSON'S RATIO TEST PROCEDURES 365 APPENDIX L PRE-CONSTRUCTION RESULTS 367 APPENDIX M PRE-CONSTUCTION IMPACT-ECHO TEST RESULTS 371 APPENDIX N INDOT CONCRETE STRENGTH RESULTS (PROJECT R-24432)384 APPENDIX O FIELD TEST PROGRAM P-WAVE VELOCITY RESULTS .......... 388 APPENDIX P INDOT PAVEMENT THICKNESS RESULTS (PROJECT R-24432)391 APPENDIX Q FIELD TEST PROGRAM IMPACT-ECHO RESULTS 395 APPENDIX R POST-CONSTRUCTION TEST RESULTS 397 APPENDIX S FIELD TEST PROGRAM IMPACT-ECHO RESULTS 400 APPENDIX T CONTRACT FROM PRS PROJECT \#1 - INDIANAPOLIS, IN (PROJECT R24432) 402 APPENDIX U CONTRACT FROM PRS PROJECT \#2 - CLARKESVILLE, IN (PROJECT R-25715) 425 APPENDIX V FINAL PAY FACTORS AND EXTRA PAY FOR PRS PROJECT \#2 CLARKSVILLE, IN (PROJECT R-25715) 434 


\section{LIST OF TABLES}

Table

Page

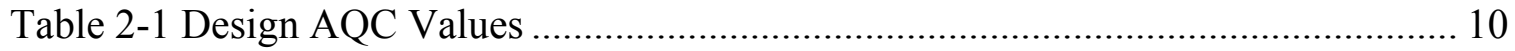

Table 3-1 Comparison of LCCA Software Programs .................................................. 22

Table 4-1 Summary of Distress Types Occurring on 37 Plain Jointed Concrete Pavements

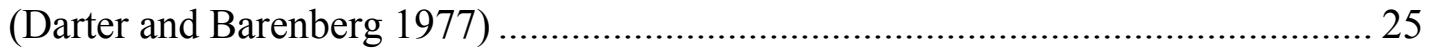

Table 5-1 Summary of Innovative Pavement Contracting Methods ............................ 51

Table 6-1 Distress Indicator Models in PaveSpec 3.0 .................................................. 55

Table 6-2 Design AQC Values (from INDOT Project R-25715) .................................. 58

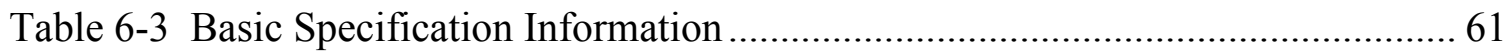

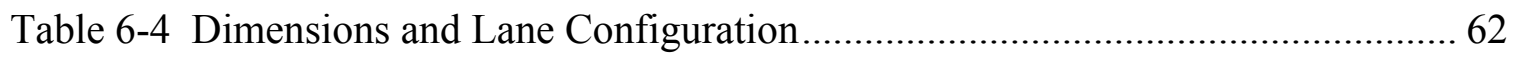

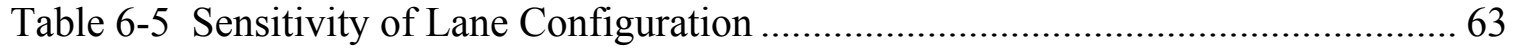

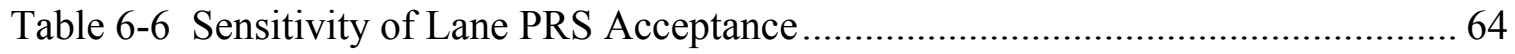

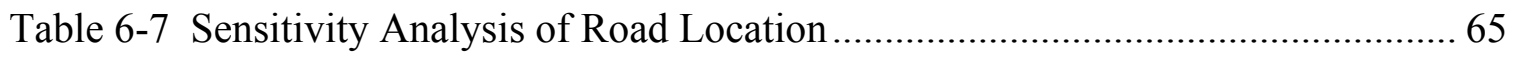

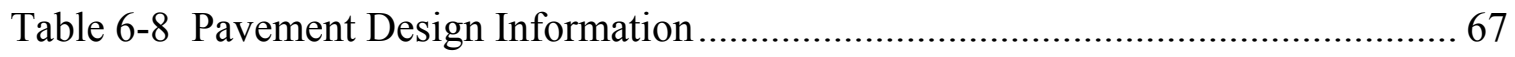

Table 6-9 Sensitivity Analysis of Pavement Type and Dowel Size .............................. 68

Table 6-10 Sensitivity Analysis of Joint Spacing Variations ....................................... 69

Table 6-11 Sensitivity Analysis of Joint Sealant Type ............................................. 70

Table 6-12 Sensitivity Analysis of Water-Cement Ratio ........................................ 70

Table 6-13 Pavement Base Design Information ..................................................... 72

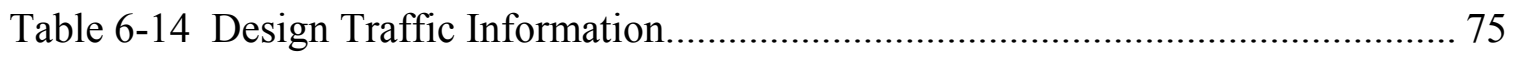

Table 6-15 Sensitivity Analysis of Traffic Loading ................................................. 76

Table 6-16 Sensitivity Analysis of Traffic Growth Rate ............................................ 78

Table 6-17 Sensitivity Analysis of Traffic Growth Rate Type..................................... 78 


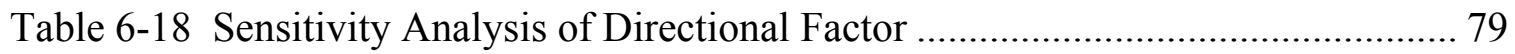

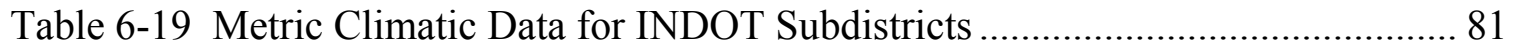

Table 6-20 English Climatic Data for INDOT Subdistricts......................................... 82

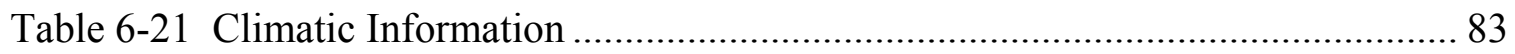

Table 6-22 Sensitivity Analysis of Annual Air Freeze-Thaw Cycles Variation ............. 84

Table 6-23 Summary of Most Significant Constant Value Inputs in PRS .................... 86

Table 7-1 Definition of Pavement Performance .......................................................... 88

Table 7-2 Sensitivity Analysis of Variation in Distress Model Inclusion ....................... 89

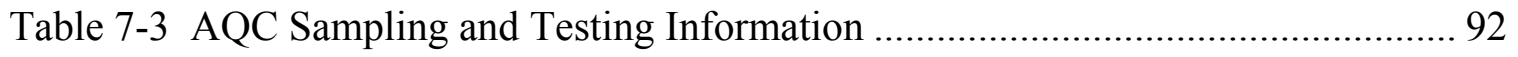

Table 7-4 AQC As-Designed Target Value Definition ............................................... 94

Table 7-5 Sensitivity of Analysis Method .................................................................. 95

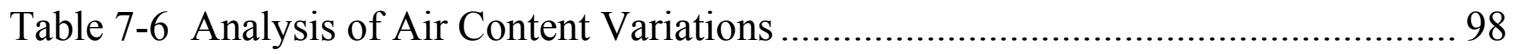

Table 7-7 Analysis of Initial Smoothness Variations ................................................ 98

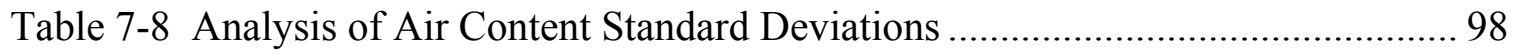

Table 7-9 Analysis of Smoothness Standard Deviations ............................................. 99

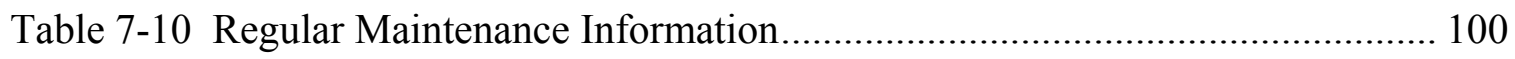

Table 7-11 Analysis of Regular Maintenance Options............................................ 101

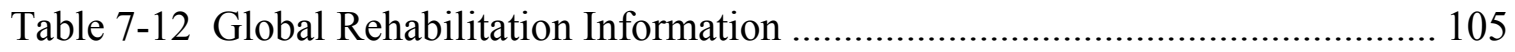

Table 7-13 Estimated Regular Maintenance Unit Costs.......................................... 107

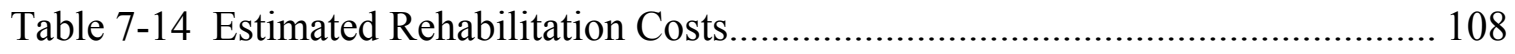

Table 7-15 Other Life-Cycle Cost Analysis Variables ............................................ 110

Table 7-16 Simulation Control Information: Generic Settings.................................. 113

Table 7-17 Analysis of Number of Simulations per Lot............................................ 114

Table 8-1 Design AQC Values for PRS Projects in Indiana ................................... 121

Table 8-2 Cost Functions for Two Pavement Designs ........................................... 135

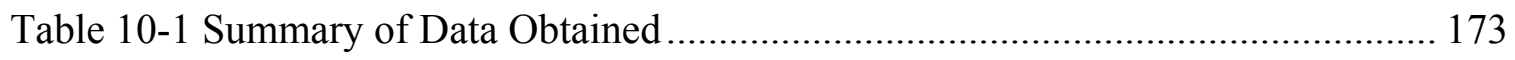

Table 10-2 Pre-Construction Test Specimen Identification......................................... 184

Table 10-3 Summary of Pre-Construction Tests ................................................... 185

Table 10-4 Error in the Calculation of P-Wave Velocity for AE Surface Test Method. 192

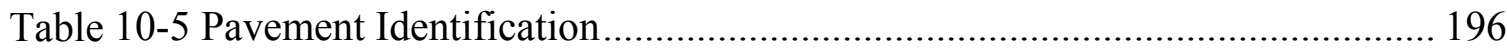


Table 10-6 Field Test Specimens.............................................................................. 198

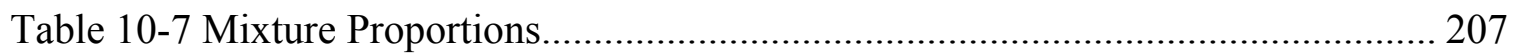

Table 11-1 Pre-Construction Average Strength.......................................................... 212

Table 11-2 Pre-Construction Modulus of Elasticity \& Poisson's Ratio .......................... 212

Table 11-3 Average Strength/7-Day Strength ............................................................... 213

Table 11-4 Standard Deviation/Average Strength ...................................................... 215

Table 11-5 Average Strength/Flexural Strength ......................................................... 217

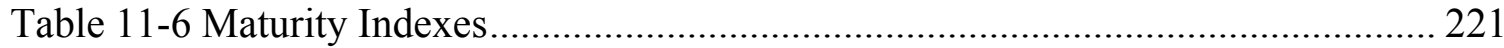

Table 11-7 Strength-Temperature-Time Factor Relationship....................................... 222

Table 11-8 Strength-Equivalent Age (at $23{ }^{\circ} \mathrm{C}$ ) Relationship ..................................... 222

Table 11-9 Predicted Flexural Strength From Temperature-Time Factor ....................... 225

Table 11-10 Predicted Flexural Strength From Equivalent Age (at $23{ }^{\circ} \mathrm{C}$ ).................... 225

Table 11-11 Predicted Slab Strength to Measured Beam Strength................................... 225

Table 11-12 Predicted Slab Strength to Measured Beam Strength.................................. 226

Table 11-13 Pre-Construction Average P-Wave Velocity................................................ 227

Table 11-14 Systematic Error in Measurement of P-Wave Velocity .............................. 230

Table 11-15 Systematic Error in Measurement of P-Wave Velocity ............................... 230

Table 11-16 Strength to P-Wave Velocity Relationships ............................................... 232

Table 11-17 Confidence Interval for Strength-P-Wave Velocity Relationship.............. 235

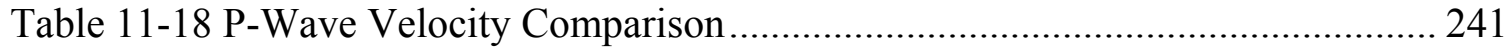

Table 11-19 Flexural Strength From P-Wave Velocity ………………………….......... 242

Table 11-20 Predicted Slab Strength to Measured Beam Strength.................................. 242

Table 11-21 Core Thickness ................................................................................... 244

Table 11-22 Impact-Echo Testing ........................................................................... 249

Table 11-23 Percent Error Due to Frequency Resolution............................................... 250

Table 12-1 Standard Deviation Correction Factors ……………………………….... 256

Table 12-2 Combined Seven Day Flexural Strength Results (INDOT \& Contractor)... 258

Table 12-3 Beam Casting Location Comparison-Strength ............................................. 260

Table 12-4 Beam Casting Location Comparison-Maturity ………………………….... 260

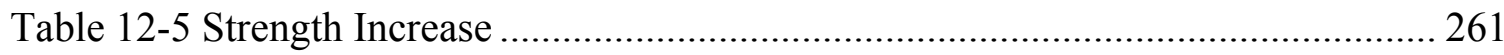


Table 12-6 Flexural to Split Tensile Strength (Seven Days) ...................................... 262

Table 12-7 Field Test Program Maturity Indexes......................................................... 264

Table 12-8 Beam Flexural Strength From Temperature-Time Factor.......................... 267

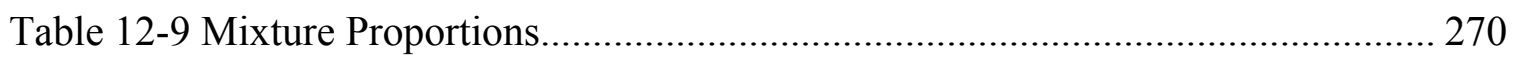

Table 12-10 Pavement Strength From Temperature-Time Factor............................... 271

Table 12-11 Pavement Strength From Equivalent Age (at $23{ }^{\circ} \mathrm{C}$ ) .............................. 271

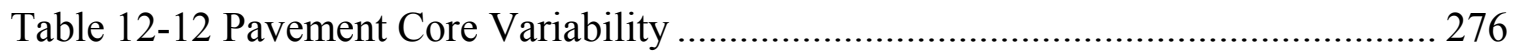

Table 12-13 Predicted Pavement Thickness .................................................................. 279

Table 12-14 Error in Thickness Due to P-wave Velocity .......................................... 281

Table 13-1 Beam Flexural Strength From Temperature-Time Factor.......................... 289

Table 13-2 Pavement Strength From Temperature-Time Factor.................................. 290

Table 13-3 Pavement Strength From Equivalent Age (at $23{ }^{\circ} \mathrm{C}$ ) ................................ 290

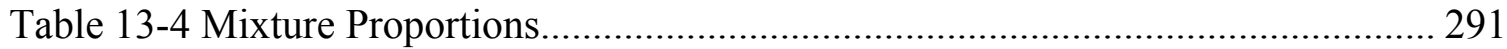

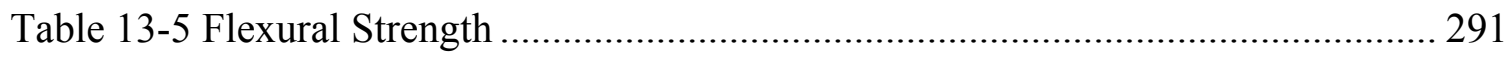

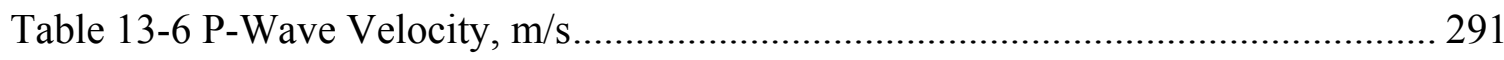

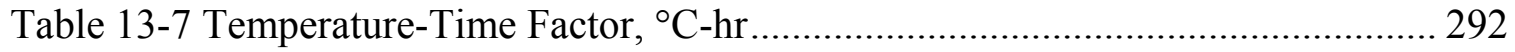

Table 13-8 Mixture Proportion Variation Flexural Strength Comparison..................... 295

Table 13-9 Combined Maturity and P-Wave Velocity - Method 1 ............................. 299

Table 13-10 Combined Maturity and P-Wave Velocity - Method 2 ............................ 300

Table 13-11 Combined Method of Analysis............................................................. 301

Table 13-12 Early-Age Test Result Method .................................................................. 302

Table B-1 Input Data for PaveSpec (Version 2.5) ................................................ 335

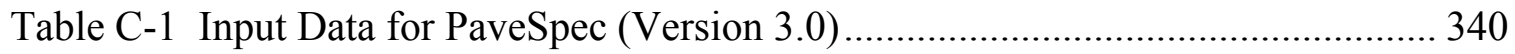

Table D-1 INDOT Coarse Aggregate Gradation ..................................................... 350

Table D-2 INDOT Fine Aggregate Gradation ...................................................... 350

Table E-1 Design Factors $\quad 352$ 
Table E-2 Materials

Table E-3 Batch Proportions $\left(7.25 \mathrm{~m}^{3}, 9.48 \mathrm{yd}^{3}\right)$

Table F-1 Pre-Construction Test Program Fresh Concrete Properties ......................... 354

Table F-2 Field Test Program Fresh Concrete Properties ......................................... 354

Table L-1 Pre-Construction Strength and P-Wave Velocity Results........................... 368

Table L-2 Pre-Construction P-Wave Velocity Results, m/s (Slabs)............................ 370

Table L-3 Pre-Construction Elastic Modulus and Poisson's Ratio Results................... 370

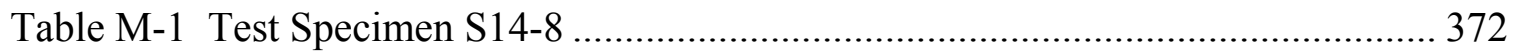

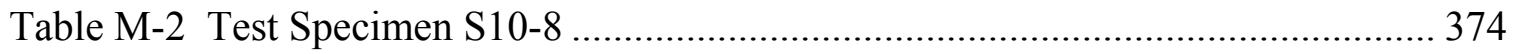

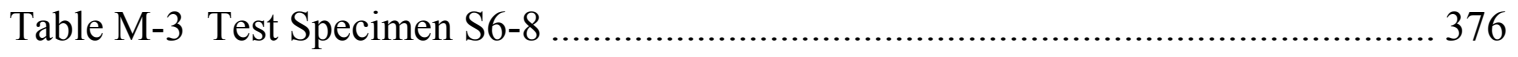

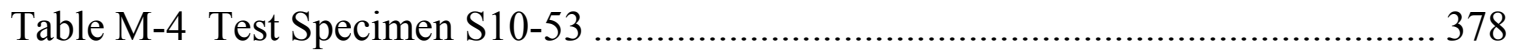

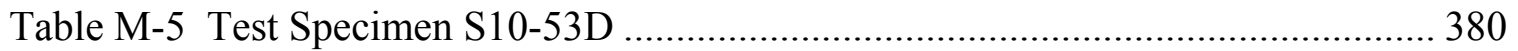

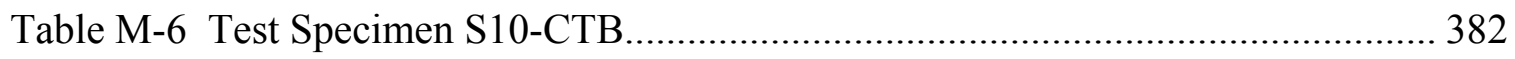

Table N-1 INDOT Flexural Strength-Mainline Pavement with Fly Ash .................... 385

Table N-2 INDOT Flexural Strength-Shoulder Pavement with Fly Ash ..................... 386

Table N- 3 INDOT Flexural Strength-Mainline Pavement without Fly Ash ............... 386

Table N- 4 INDOT Flexural Strength-Shoulder Pavement without Fly Ash ............... 387

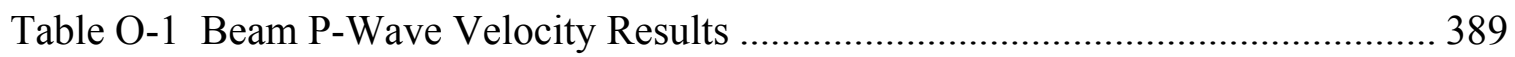

Table O-2 Pavement P-Wave Velocity Results ..................................................... 390

Table P-1 INDOT Thickness-Mainline Pavement with Fly Ash................................ 392

Table P-2 INDOT Thickness-Shoulder Pavement with Fly Ash................................ 393

Table P-3 INDOT Thickness-Mainline Pavement without Fly Ash........................... 393

Table P-4 INDOT Thickness-Shoulder Pavement without Fly Ash............................ 394 


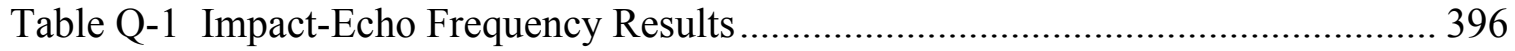

Table Q-2 Impact-Echo Frequency Results ........................................................... 401

Table R-1 Mixture Variation Test Results.............................................................. 398 


\section{LIST OF FIGURES}

Figure

Page

Figure 1-1 Historical Timeline of Specifications in the United States (Kopac 2002) ....... 1

Figure 2-1 Strength Pay Factor Chart .............................................................................. 11

Figure 2-2 Thickness Pay Factor Chart ………………......................................... 12

Figure 2-3 Smoothness Pay Factor Chart .............................................................. 12

Figure 3-1 The Life-Cycle Cost of a Pavement (Weiss 2001)....................................... 17

Figure 4-1 Results of Survey of Common Rigid Pavement Distress in Indiana ............. 27

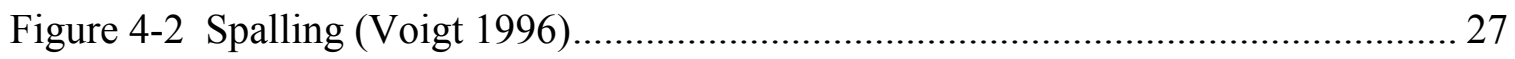

Figure 4-3 Faulting (Voigt 1996)......................................................................... 29

Figure 4-4 Transverse Cracking (Voigt 1996)............................................................ 30

Figure 5-1 Distribution of Risk for Various Specifications ............................................ 35

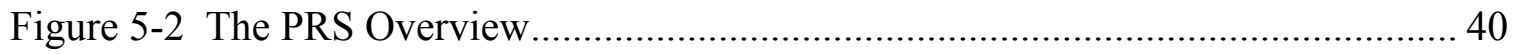

Figure 6-1 Use of Models in PRS (Kopac 2002) ...................................................... 55

Figure 6-2 Approximate Location of INDOT Project R-25715 ……………………..... 58

Figure 6-3 Input Categories in PRS ...................................................................... 59

Figure 6-4 Input Screen for Basic Specification Information........................................... 60

Figure 6-5 Input Screen for Dimensions and Lane Configuration .................................. 62

Figure 6-6 Input Screen for Pavement Design Information............................................ 67

Figure 6-7 Input Screen for Pavement Base Design Information................................... 72

Figure 6-8 Input Screen for Design Traffic Information ................................................ 74

Figure 6-9 28-Day Flexural Strength Pay Factors for Different Traffic Volumes .......... 77

Figure 6-10 Input Screen for Climatic Information....................................................... 83

Figure 6-11 Pay Factors in Different Freeze-Thaw Climates ......................................... 85

Figure 7-1 Input Screen for Defining Pavement Performance ....................................... 88

Figure 7-2 Maximum Predicted Faulting versus Pavement Thickness ........................... 90

Figure 7-3 Air Content AQC Pay Factor Graphs............................................................. 91

Figure 7-4 Input Screen for Defining AQC As-Designed Target Values........................ 93

Figure 7-5 Present Worth Life-Cycle Cost versus AQC Target Means ........................... 95 
Figure 7-6 Maximum Predicted Cracking versus Pavement Thickness ......................... 96

Figure 7-7 Present Worth Life-Cycle Cost versus AQC Target Standard Deviation ...... 97

Figure 7-8 Input Screen for Defining Regular Maintenance ...................................... 100

Figure 7-9 Input Screen for Defining Local Rehabilitation Plan and Sublot Failure .... 102

Figure 7-10 Input Screen for Defining Global Rehabilitation Scenarios ..................... 104

Figure 7-11 Input Screen for Regular Maintenance Unit Cost Information ................. 107

Figure 7-12 Input Screen for Rehabilitation Unit Cost Information............................. 108

Figure 7-13 Input Screen for Other Life-Cycle Cost Analysis Information .................. 110

Figure 7-14 Life-Cycle Costs versus User Cost Percentage Included ........................ 111

Figure 7-15 Input Screen for Simulation Control Information ................................. 113

Figure 7-16 Pay Factor Variation with Bid Price .................................................. 115

Figure 7-17 Bid Price versus Pavement Thickness................................................. 116

Figure 7-18 Input Screen for Defining Strength Pay Factor Ranges .......................... 117

Figure 13-1 Agency Quality Targets and Contractor Responses................................ 123

Figure 13-2 PRS Offset Strength Target and Contractor Responses ........................... 124

Figure 13-3 Strength Pay Factor Chart, Project \#1 ................................................ 125

Figure 13-4 Strength Pay Factor Chart, Project \#2 .................................................. 126

Figure 13-5 As-Constructed Life-Cycle Cost versus Strength ................................... 127

Figure 13-6 Pay Factors versus As-Constructed Strength ...................................... 128

Figure 13-7 Effect of Variability on Life-Cycle Cost................................................. 129

Figure 13-8 Concrete Material Cost versus Compressive Strength ............................. 130

Figure 13-9 Concrete Material Cost versus Flexural Strength .................................. 131

Figure 13-10 Relative Concrete Material Cost versus Flexural Strength ..................... 132

Figure 13-11 Cost versus Thickness of Indiana Pavements ...................................... 133

Figure 13-12 Contours of Constant Life-Cycle Cost for PRS AQCs .......................... 134

Figure 8-1 Schematic of Short-Pulse Radar............................................................... 138

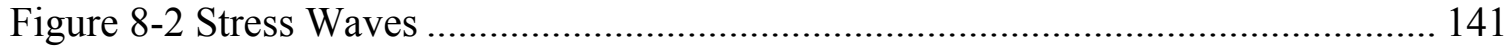

Figure 8-3 Impact-Echo Frequency Spectrum .................................................... 151

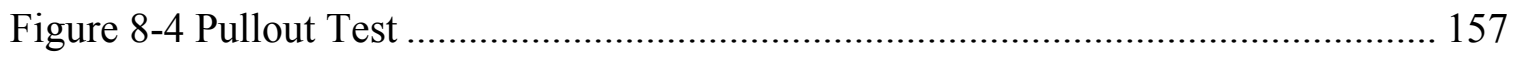

Figure 8-5 Pulse Velocity Modes of Transmission.................................................... 160 
Figure 9-1 Mold For Slab Test Specimen With Compacted Base Course .................... 176

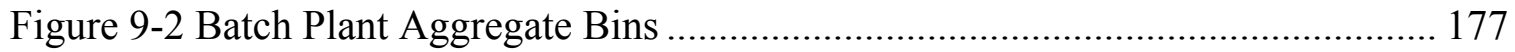

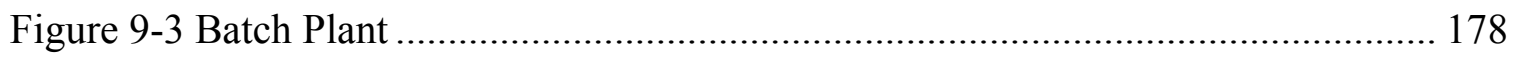

Figure 9-4 Fresh Concrete Ready for Transportation ................................................ 178

Figure 9-5 Fresh Concrete Delivered by Contractor................................................ 179

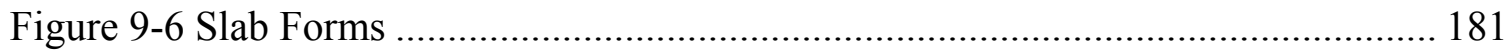

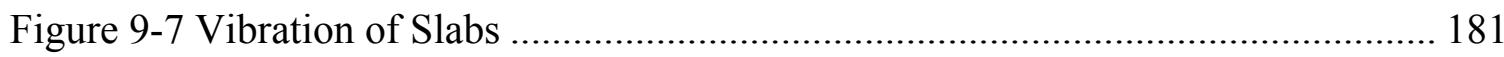

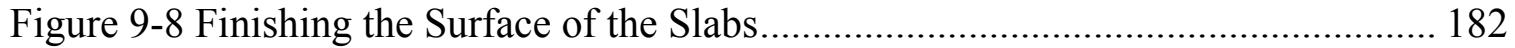

Figure 9-9 Cylinder and Beam Forms Inside Building.......................................... 182

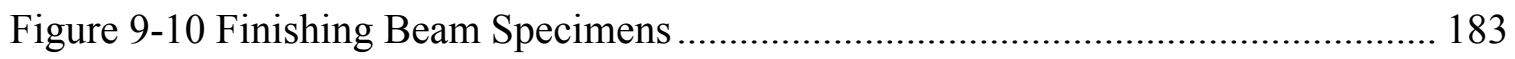

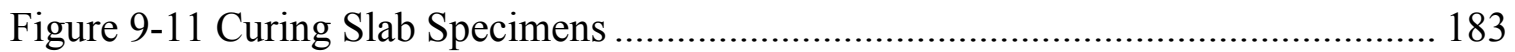

Figure 9-12 Compressive Strength Test .............................................................. 186

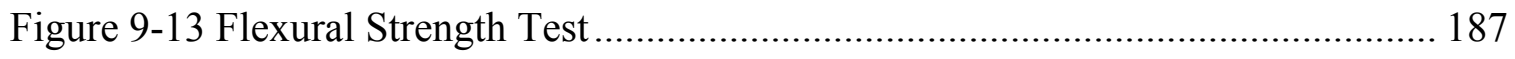

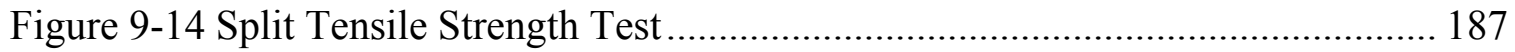

Figure 9-15 Surface Transmission Pulse Velocity...................................................... 188

Figure 9-16 Impact-Echo Test System ….......................................................... 189

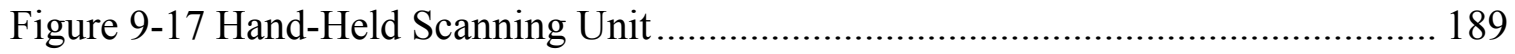

Figure 9-18 Arrival of P-wave Incorrectly Indicated by Threshold ............................ 191

Figure 9-19 Arrival of P-wave Correctly Indicated by Threshold .............................. 191

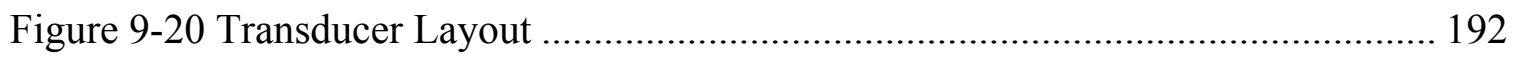

Figure 9-21 Obtaining Cores from Slab Specimens ................................................ 195

Figure 9-22 Core Measurement Apparatus............................................................. 197

Figure 9-23 Specimens Cast Next to Pavement...................................................... 200

Figure 9-24 Concrete Dumped Onto Conveyor Belt .............................................. 201

Figure 9-25 Concrete Spread Over Base ............................................................... 201

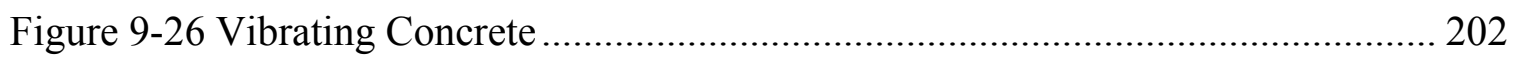

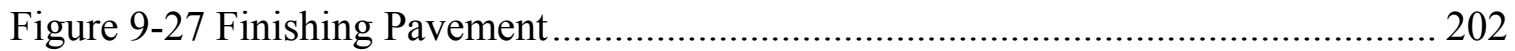

Figure 9-28 Tined Pavement is Covered with Curing Compound ….......................... 203

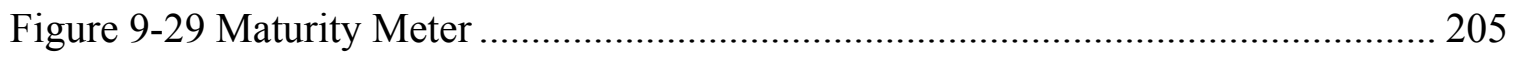

Figure 9-30 Obtaining Pavement Cores.................................................................. 206 
Figure 10-1 Modulus of Rupture Development......................................................... 213

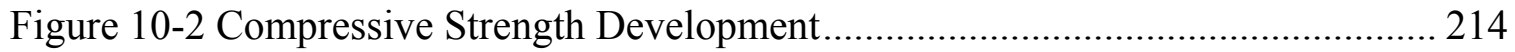

Figure 10-3 Split Tensile Strength Development .................................................... 214

Figure 10-4 Flexural to Compressive Strength Relationship....................................... 216

Figure 10-5 Flexural to Split Tensile Strength Relationship ..................................... 217

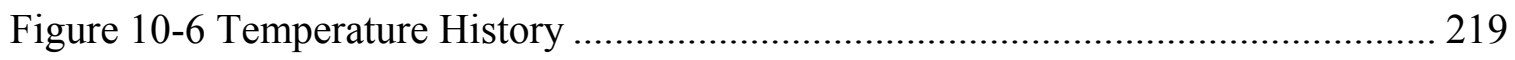

Figure 10-7 Modulus of Rupture Versus Temperature-Time Factor............................ 223

Figure 10-8 Compressive Strength Versus Temperature-Time Factor......................... 223

Figure 10-9 Split Tensile Strength Versus Temperature-Time Factor ......................... 224

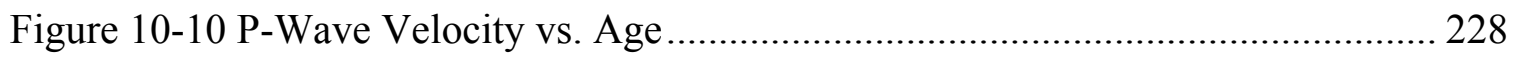

Figure 10-11 Modulus of Rupture Versus P-Wave Velocity........................................ 233

Figure 10-12 Compressive Strength Versus P-Wave Velocity.................................... 234

Figure 10-13 Split Tensile Strength Versus P-Wave Velocity .................................... 234

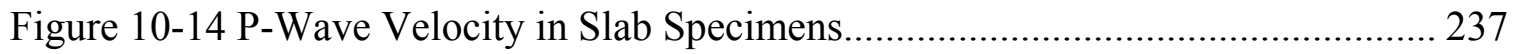

Figure 10-15 Cores Extracted From S6-8 ................................................................. 244

Figure 10-16 Cores Extracted From S10-53D ................................................... 245

Figure 10-17 Valid Surface Displacement Waveform............................................. 246

Figure 10-18 Frequency Spectrum with a Single High Amplitude Peak...................... 248

Figure 10-19 Frequency Spectrum with Multiple High Amplitude Peaks .................... 248

Figure 11-1 Variability of Strength Results (Mainline Pavement With Fly Ash) ......... 259

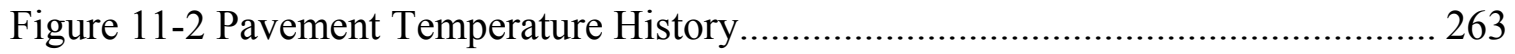

Figure 11-3 Strength-Maturity Relationship From Partial Data ................................. 266

Figure 11-4 Strength-Maturity Relationship From Field Specimens ......................... 268

Figure 11-5 P-Wave Velocity Versus Strength (Field Specimens) ............................. 273

Figure 11-6 Pavement Frequency Spectrum ....................................................... 278

Figure 11-7 Pavement Impact-Echo Results............................................................. 280

Figure 12-1 Strength-Maturity Relationships Using Temperature-Time Factor ........... 287

Figure 12-2 Strength-Maturity Relationships Using Equivalent Age......................... 288

Figure 12-3 Strength-Maturity Relationship........................................................ 292

Figure 12-4 Modulus of Rupture Versus Water-to-Cement Ratio at Seven Days.......... 293 
Figure 12-5 Modulus of Rupture Versus Water-to-Cement Ratio at 28 Days .............. 294

Figure 12-6 Ratio of Predicted Versus Actual Flexural Strength ................................. 295

Figure 12-7 Strength-P-Wave Velocity Relationships ............................................. 296 


\section{CHAPTER 1: INTRODUCTION}

\subsection{Background}

One of the key factors affecting highway construction quality is the type of specification used. Specifications determine the allowable methods, materials, and equipment that a contractor may use in project construction. They enable specific targets for quality and performance to be set in terms of measurable results.

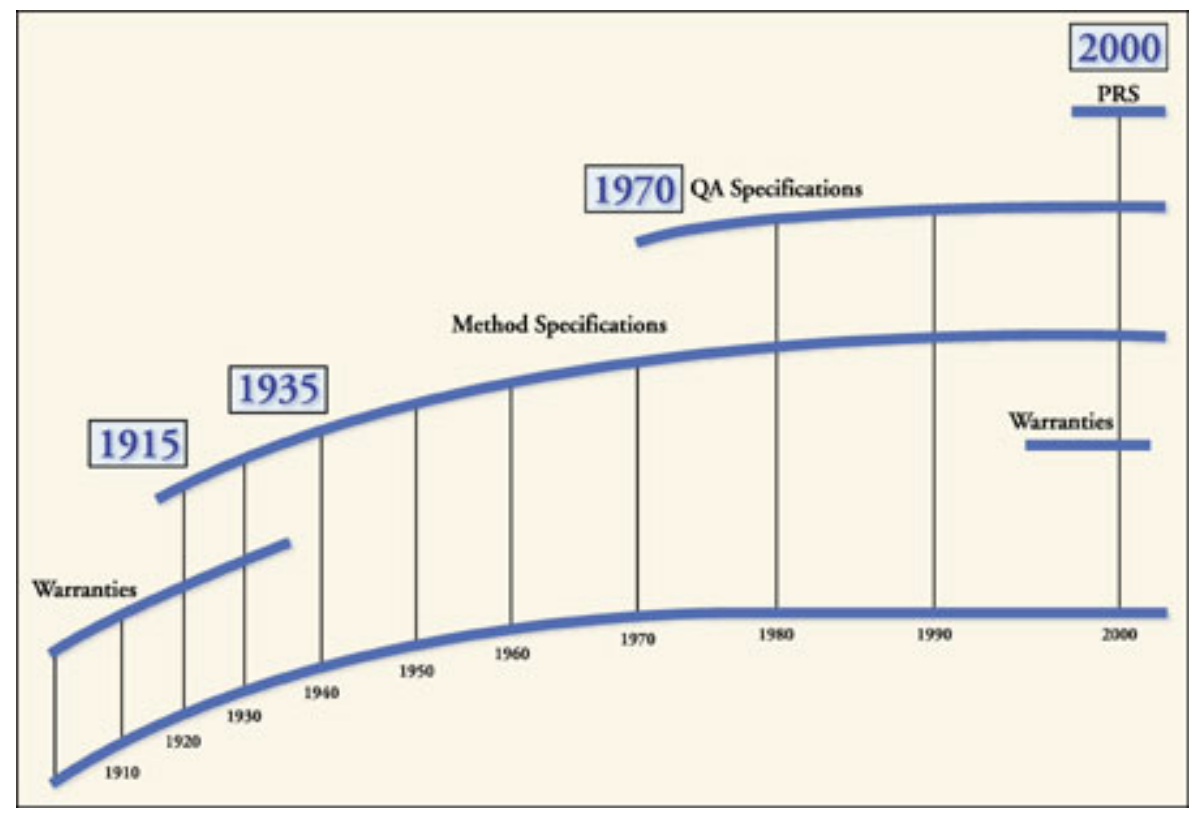

Figure 1-1 Historical Timeline of Specifications in the United States (Kopac 2002)

As shown in Figure 1-1, the earliest specifications used in the construction of concrete highways were warranties. For example, the first American concrete pavement in Bellefontaine, Ohio, in 1891, was constructed with performance bond and a guarantee that it would last five years (Portland Cement Association 1991). In the early days of road construction in the United 
States, it was normal for a governing agency to require a performance guarantee due to a lack of information and experience with concrete pavements (Kopac 2002).

With the increase in road construction in the following years, agencies began to increase their knowledge of pavement performance and to replace guarantees with prescriptive (or method) specifications. These specifications provided the contractor with a detailed description that outlined exactly how the road was to be built and with what materials. By 1935, most state and local agencies had dropped guarantees in favor of prescriptive specifications (Kopac 2002). By assuming total responsibility for the pavement, agencies avoided costly litigation that arose out of enforcing a warranty.

Unfortunately, prescriptive specifications failed to address the acceptable variability that can occur in the construction of concrete pavements. According to Hughes (1996), in the 1960's virtually no materials or construction properties met the specifications $100 \%$ of the time and some met the specifications less than $50 \%$ of the time. Furthermore, prescriptive specifications did not always provide the desired end results, even when properly followed (Chamberlin 1995).

To address these deficiencies, statistical quality assurance specifications were developed in the 1970s. These specifications were spurred on by two factors: the results of the American Association of State Highway Officials (AASHO) Road Test (1956-1962) and the growth of the interstate highway system (Chamberlin 1995). Quality Assurance (QA) specifications replaced some of the prescribed methods with descriptions of desirable material properties (Kopac 2002). Also, QA specifications helped to accommodate technological innovation that would have otherwise been prevented by method specifications. Contractors increased their control over the quality of the pavement, while the agencies switched their role to quality assurance, requiring fewer inspectors.

In the 1980s, many QA specifications began to include disincentives for failing to meet the specified quality targets (Kopac 2002). These pay adjustments were based on subjective experience and intuition. The variation between different state highway agencies could result in 
the development of two specifications in which the same construction performance would result in $100 \%$ acceptance in one and rejection in another.

The problem with QA specifications that included disincentives is that they fail to adequately define the relationship between quality and performance. It can be argued that performance is really what state highway agencies desire. While warranties have been proposed as a way to specify performance, they may not be perceived as an equitable solution. One difficulty with warranties is that they do not address the situation where the highway design underestimates the traffic volume. This leads to replacement for reasons other than the structural capacity of the highway. Another difficulty is that in the case of warranties, the risk for performance belongs solely to the contractor. A more viable solution that has been proposed is to relate the quality of the pavement to its performance through the use of a life-cycle simulation. Specifications that do this are called Performance Related Specifications.

Performance-Related Specifications (PRS) can be thought of in part as an evolution of QA specifications. PRS specify quality and materials in the same manner as QA specifications. However, PRS relate certain key Acceptable Quality Characteristics (AQCs) with the predicted performance of the pavement through the use of life-cycle cost models. AQCs in PRS include strength, thickness, smoothness, and air content. Through simulation models, a prediction of the difference in post-construction life-cycle costs between the as-constructed pavement and asdesigned pavement is possible. An incentive is then provided for a product that performs better than the one the agency designed, and similarly, a disincentive is assessed for a product that does not. Whereas QA specifications are based on intuition only, PRS add a rational, defensible step to the pay adjustment process. In addition, PRS provide an incentive to contractors to take even more responsibility for quality control than in an ordinary QA specification.

In PRS, only those AQCs directly under the contractor's control are tested and used in determining pay adjustments. In this study, concrete strength, thickness, air content, and initial smoothness are monitored. These properties are then mathematically linked to four pavement distress models: transverse cracking, transverse joint faulting, joint spalling, and decreasing 
smoothness. The deterioration of the pavement and the maintenance required to keep it at an acceptable level of service are predicted, resulting in a total life-cycle cost.

The life-cycle cost software, PaveSpec 3.0, is available to both the agencies and the contractors, making all parties privy to the information used to assess quality. Contractors have the ability to run sensitivity analyses to determine the costs and benefits of certain changes to their design. With PRS, the contractor is rewarded for good quality control (low standard deviations), whereas in a quality assurance specification, only the test results are measured, without concern for variability. This is important because high variability leads to pavements with inconsistent performance and localized problems, attracting public attention and meriting whole sections being replaced.

The ability of a PRS to accurately predict performance of the constructed pavement and to fairly adjust payment is therefore greatly dependant upon both the accuracy of the mathematical models and the accuracy of the test methods utilized to measure pavement characteristics. Ideally, test methods that determine the in-situ pavement quality, are preferred. In-situ tests are more likely to represent the true quality of the pavement than tests performed on either fresh concrete or on test specimens cast from a sample of concrete. Errors in sampling procedures can result in specimens that are not representative of the pavement section. Test specimens cast from a sample of concrete are not compacted in the same manner or with the same energy as the pavement. Concrete test specimens in general also experience curing conditions that are different from the pavement. All of these conditions can result in detectable differences between the sample and the pavement. The difference between the value of the characteristic from the sample and the value of the characteristic in the pavement can result in errors in the estimate of pavement performance in a PRS.

Ideal test methods would also be non-destructive, have low variability, and could be performed and analyzed rapidly. The damage caused by destructive in-situ tests must be repaired and many result in a reduction in long-term pavement performance. Rapid test methods with low variability would make it easier to test a larger portion of the pavement than is typically possible 
in QC/QA programs, thereby improving the reliability of the estimation of performance. Test methods that are performed and analyzed quickly can also provide feedback to the contractor sooner, allowing adjustments to be made, if necessary, to improve pavement quality. Rapid nondestructive tests also have the potential to be less expensive to perform than traditional tests.

\subsection{Project Objectives and Scope}

This research was conducted as a part of the project to implement PRS concepts in Indiana (described in detail in Chapter 2). It was conducted in conjunction with the development and implementation of two simplified versions of a PRS for two different interstate highway projects in Indiana. The objectives of this research were

1) to evaluate the sensitivity of life-cycle cost model inputs in PRS,

2) to investigate the use of in-situ, nondestructive test methods to determine concrete pavement quality characteristics for use in a PRS, and

3) to investigate the impact of PRS on contractors and agencies in the construction of concrete pavements.

The work performed as a part of this study is divided as shown below:

- Chapter 2 provides an overview of PRS including the implementation of the first PRS in Indiana.

- Chapter 3 presents a review of life-cycle cost modeling concepts.

- Chapter 4 provides a review of the deterioration models that are used in PRS.

- Chapter 5 discusses different contracting strategies and specifications, noting the benefits and disadvantages when compared to PRS.

- Chapter 6 and Chapter 7 present a two-part sensitivity analysis of the PRS software used in this research.

- Chapter 8 discusses implications of using PRS for the contractor, agencies and users. 
- Chapter 9 presents the results of a critical review of available literature on nondestructive test methods to determine two of the commonly used pavement quality characteristics, concrete strength and slab thickness.

- Chapter 10 provides an outline of the experimental testing program that was conducted to further assess the use of promising non-destructive test methods to determine concrete strength and pavement thickness.

- Chapter 11 presents experimental results from the pre-construction test program, the first of three phases of an overall test program conducted in conjunction with the implementation of the first PRS. The general objective of this test program was to assess the use of the impact-echo, compression wave (P-wave) velocity, and maturity test methods to determine concrete strength and pavement thickness.

- Chapter 12 presents the experimental results from the field test program, the second of three phases of an overall test program conducted in conjunction with the implementation of the first PRS. The general objective of this test program was to assess the use of the impact-echo, measurement of P-wave velocity, and maturity test methods under field conditions.

- Chapter 13 presents the experimental results from the post-construction test program, the third phase of the overall test program conducted conjunction with the implementation of the first PRS. It included testing to experimentally determine the values of the datum temperature and activation energy for use in the maturity test method and testing to assess how variations in the water-to-cement ratio (w/c) and amount of air entraining agent influence the strength estimate from strength-P-wave and strength-maturity relationships.

- Chapter 14 presents conclusions from this study and recommendations for further research. 


\section{CHAPTER 2: IMPLEMENTATION OF PERFORMANCE-RELATED SPECIFICATIONS (PRS) IN INDIANA}

\subsection{Introduction}

This chapter provides an overview of performance-related specifications (PRS) for use in concrete pavements. A PRS is a specification that describes the desired levels of key materials and construction acceptance quality characteristics (AQCs) that have been found to correlate strongly with long-term pavement performance (Hoerner et al., 1999). A PRS can be viewed as an improved quality control/quality assurance (QC/QA) specification since both types of specifications specify the desired pavement quality rather than the desired pavement performance. However, unlike in a QC/QA specification, in a PRS the level of performance is directly related to the pavement quality. PRS use mathematical models and life-cycle cost (LCC) analysis to directly relate the pavement quality to the overall pavement performance. The ability to predict the performance and LCC permits the optimum levels of pavement quality to be identified and provides a rational basis for adjusting compensation to the contractor when the measured quality is different from the specified quality.

Section 2.2 describes the development and implementation of the first PRS in the state of Indiana. Section 2.3 describes the second PRS project. Definitions for a number of PRS-related terms appear in Hoerner et al. (1999). These definitions were adapted as necessary by the Indiana Department of Transportation (INDOT) for inclusion in the contract documents for the first PRS project. The adapted definitions relevant to this study are provided in Appendix A. 


\subsection{First PRS Project in Indiana}

Although prototype PRS were developed for jointed plain concrete pavements, a pavement has not been constructed using these specifications. In 1999, the INDOT, the Federal Highway Administration (FHWA), and Purdue University began a project to implement PRS for concrete pavements in Indiana. The project is using a two-step process to transform the existing INDOT QC/QA specification for jointed plain concrete pavements to a PRS utilizing the PRS software previously developed by Hoerner et al. (1999). The specification is being gradually modified over a period of three years, first transitioning from the current QC/QA format to a simplified PRS and then to a second, more robust PRS. Each revised specification will be implemented on a construction project.

This research was conducted in conjunction with the development and implementation of the PRS. The following paragraphs describe the scope and objectives of the project to implement PRS in Indiana, the input used in the simulations, the pay factor curves used in the contract, specification development, and the implementation of the PRS.

\subsubsection{Project Scope and Objective}

The project scope and objective, and the tasks necessary to accomplish this objective, were determined in initial group meetings including representatives from all three agencies (INDOT, FHWA, and Purdue University). The objective for the first project was to develop a simplified

PRS for implementation on a construction project for the 2000 construction season. The decision was made to begin with a simplified PRS because it utilized as much of the existing INDOT QC/QA specifications as possible, making the transition for the agency and contractors as easy as possible.

A specific construction project was then selected, a section of pavement on I-465 on the east side of Indianapolis, and the development of the PRS followed. The tasks necessary to develop the PRS included: reviewing existing FHWA research on PRS, reviewing the existing computer software package, reviewing the existing INDOT QC/QA specification, identifying and 
collecting the required input data pertaining to the construction project for computer simulation, and creating the simplified PRS.

\subsubsection{Development of Data Input for Computer Simulation}

The software package (PaveSpec version 2.5) requires a large amount of input data in order to conduct the simulations to estimate pavement performance and life-cycle cost. In order to facilitate the collection of all of the data, a table was created for distribution to the entire research group. The table listed each required input, the options available in the software package to satisfy each input, and the most likely source of the data. The INDOT had previously decided to measure concrete strength, slab thickness, and initial smoothness. Therefore, input data pertaining to the remaining two AQCs, entrained air content and percent consolidation around dowels, was not required and was not included in the table. The completed table of input values is contained in Appendix B.

Several departments within the INDOT were contacted in order to obtain the necessary input information. The divisions of Roadway Management, Operations Support, Research, and Materials and Tests were each involved. Much of the information required by the software package was directly available from one of the divisions within the INDOT, such as pavement design, traffic design, project identification, and AQC sampling and testing information. Some information was not directly available from one of the divisions of the INDOT, and additional investigation was performed in order to obtain the information. This included unit cost, climate, and AQC as-designed target value information. Particular difficulty was experienced in determining the maintenance and rehabilitation plan inputs. These inputs require rigidly defining the type and frequency of routine maintenance, localized rehabilitation, and global rehabilitation activities. However the type and frequency of these activities are not so rigidly defined by the INDOT in actual practice. After careful deliberation, input information was selected by a committee that appeared the most appropriate to what typically occurs in actual practice. 


\subsubsection{Creating the First PRS}

The input data was used to perform a simulation with the software package. The output from the simulation includes pay factor charts for each AQC. Each chart contains a series of curves with each curve specific to a particular standard deviation. The initial simulation did not produce pay factor charts that were acceptable to the research group. After refining the input values and discussions with the software developer, ERES Consultants, revised charts were produced. While more reasonable, these charts did not appear to be directly implementable into a specification. Therefore, a series of simulations were performed by Purdue University. The simulations systematically varied one of a small number of selected inputs to determine the effect of the variation on the pay factor charts. After reviewing the effects of the simulations on the pay factor charts, it appeared that the design procedures used by the INDOT may have target AQC values higher than what the software would typically use. This resulted in pay factor charts that contained very little incentive for producing pavement with AQC values greater than the target values determined by the INDOT. However, there was significantly greater penalty for producing pavement with AQC values less than the target values determined by the INDOT. After reviewing design information for recently constructed sections of similar pavement, the group decided to maintain the target, minimum, and maximum AQC values as originally set, refer to Table 2-1.

Table 2-1 Design AQC Values

\begin{tabular}{|l|c|c|c|c|}
\hline \multicolumn{1}{|c|}{$\begin{array}{c}\text { AQC } \\
\text { Value }\end{array}$} & $\begin{array}{c}\text { Target } \\
\text { Mean }\end{array}$ & $\begin{array}{c}\text { Target } \\
\text { Standard } \\
\text { Deviation }\end{array}$ & $\begin{array}{c}\text { Rejectable } \\
\text { Quality Limit } \\
\text { (RQL) }\end{array}$ & $\begin{array}{c}\text { Maximum } \\
\text { Quality Limit } \\
\text { (MQL) }\end{array}$ \\
\hline Strength & $665 \mathrm{psi}$ & $50 \mathrm{psi}$ & $<570 \mathrm{psi}$ & $760 \mathrm{psi}$ \\
\hline Thickness & $14 \mathrm{in}$ & $0.5 \mathrm{in}$ & $<13 \mathrm{in}$ & $15 \mathrm{in}$ \\
\hline Smoothness & $7 \mathrm{in} / \mathrm{mile}$ & $3 \mathrm{in} / \mathrm{mile}$ & $>10 \mathrm{in} / \mathrm{mile}$ & $5 \mathrm{in} / \mathrm{mile}$ \\
\hline
\end{tabular}

The research group decided to modify the pay factor charts as produced by the software package. Realizing that it was unlikely that contractors would bid on a project with little incentive and significant opportunity for penalty, the pay factor charts were modified to include more incentive. While the disincentive portion of the charts were smoothed and maintained as determined by the software, the maximum pay factors were set at $105 \%$ for concrete strength and 
slab thickness, and 103\% for initial smoothness. The pay factor charts are shown in Figure 2-1, Figure 2-2, and Figure 2-3. In order to eliminate difficulties that could arise from reading the exact pay factor off of the graph, a pay factor table was created. While both the graph and table appeared in the specification, the table was used to determine the pay adjustment while the graph was only used to illustrate the trends in the table.

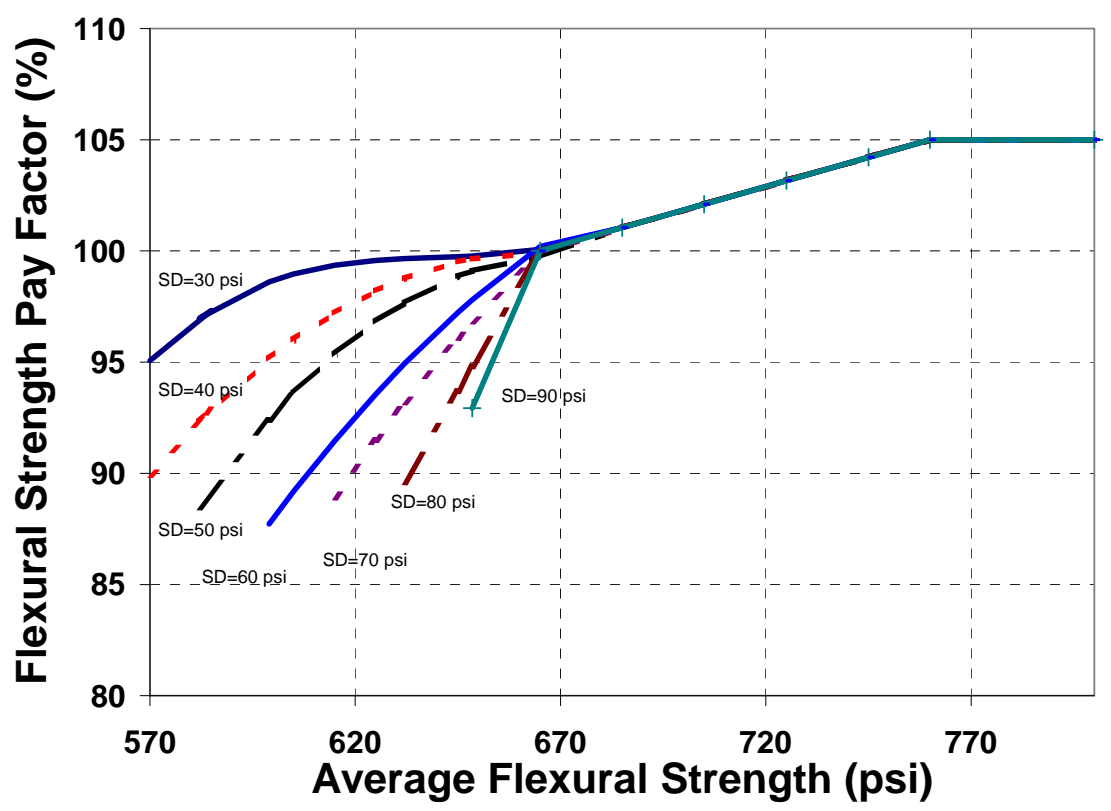

Figure 2-1 Strength Pay Factor Chart 


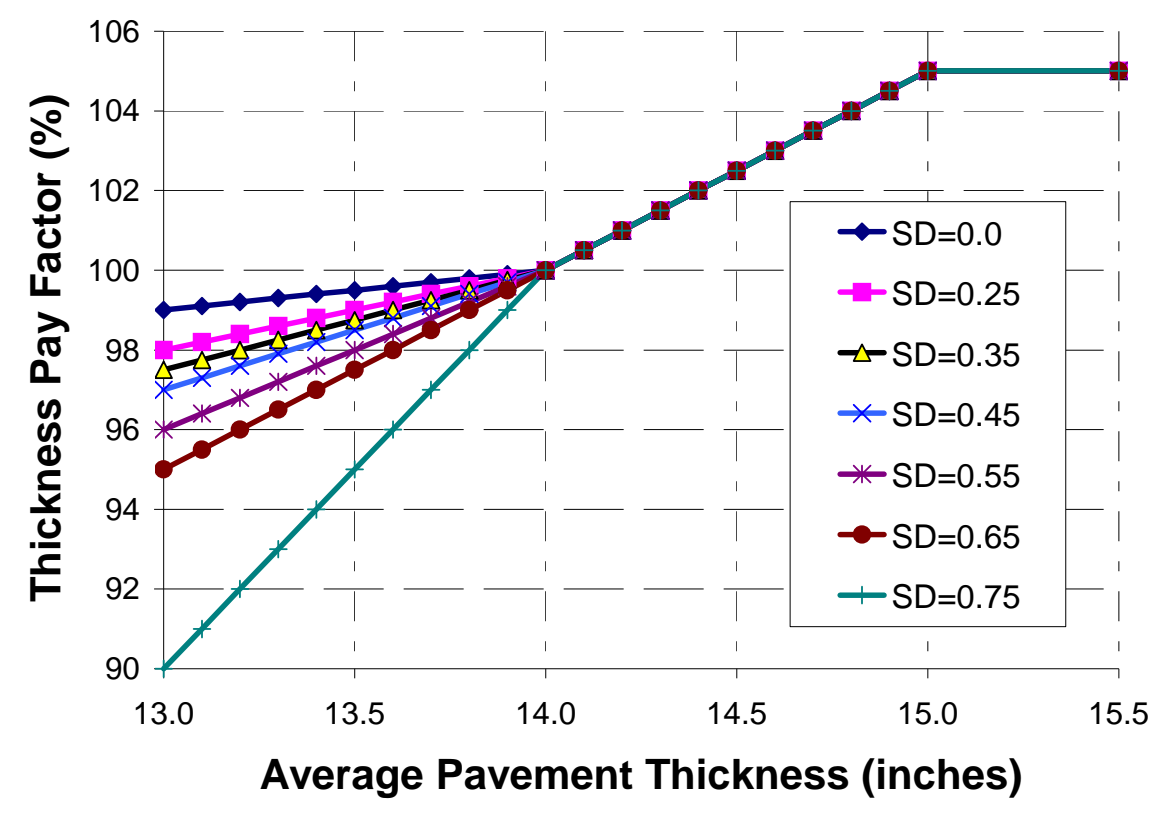

Figure 2-2 Thickness Pay Factor Chart

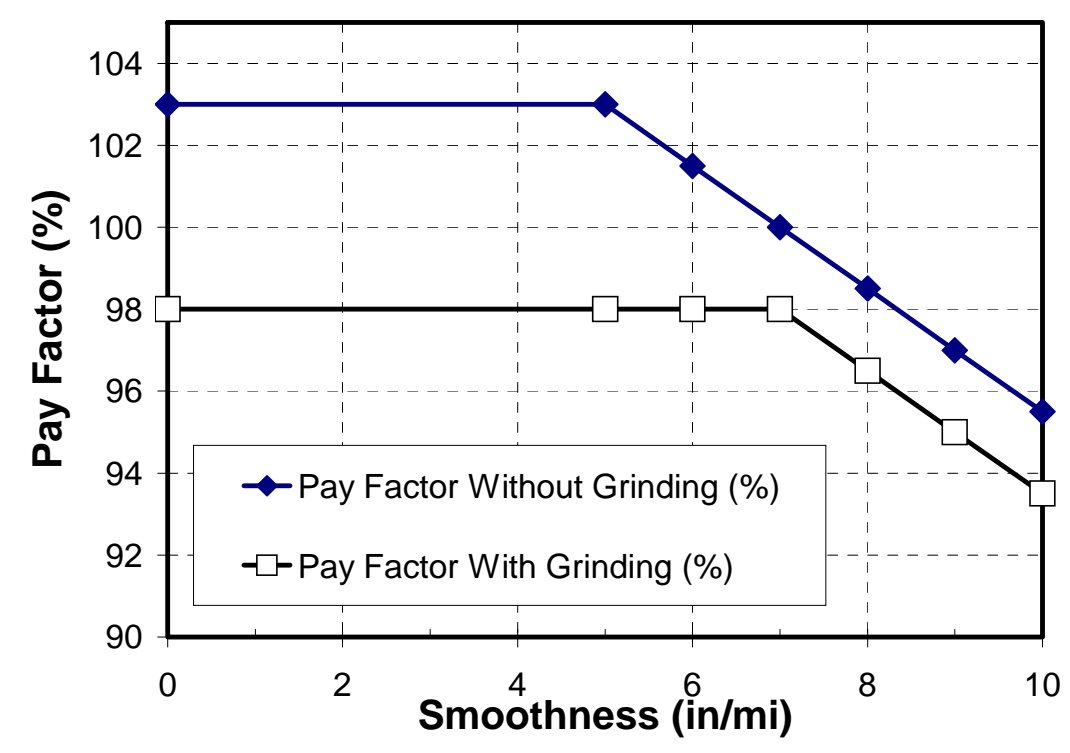

Figure 2-3 Smoothness Pay Factor Chart

A composite pay factor equation determines the final pay factor for each lot based on the pay factors for each AQC for that lot. The INDOT decided to use a straight average of the pay factors as the composite pay factor equation for the first PRS. The composite pay factor equation for the mainline pavement therefore included the pay factors for all three AQCs, however the 
composite pay factor equation for the shoulder pavement only included the pay factors for two AQCs. The initial smoothness of the shoulder pavement is not measured by the INDOT.

Creating the first PRS also required revising the existing INDOT QC/QA specification. In order to accommodate the desire of the INDOT to minimize the changes to the existing QC/QA specification, the PRS information specific to this construction project was placed in an appendix to the specification. This had the additional benefit of not requiring changes be made to the body of the specification if a second PRS was created at a later date. A second appendix was added which contained definitions of PRS terms. The revision process included an initial draft. The draft was circulated to the research team members for their review. Potential revisions were submitted by the team members and discussed in meetings as necessary. The accepted changes were then implemented. This process was repeated several times. The final copy of the PRS was given to INDOT for formatting in accordance with INDOT format requirements and inclusion in the bid documents. The project governed by the bid contract included pavement that was governed by the PRS and pavement that was governed by a traditional QC/QA specification. Therefore the bid documents contained both specifications.

\subsubsection{Implementing the First PRS In Indiana}

The process of implementing the Level 1 PRS relied heavily on the use of both formal and informal meetings with the contactors to explain and discuss the proposed new specifications. The American Concrete Paving Association, Indiana Chapter, assisted in facilitating a discussion with the local contractors at their annual meeting while the Joint Transportation Research Program assisted to facilitate a discussion with contractor and agency personnel at their annual Road School meeting. Presentations were made to both of these groups to outline upcoming changes in the specification. After several informal meetings the contract containing the PRS was let, bids were received, and the contract was awarded. However, additional steps were taken to ensure that the PRS concepts in the contract were clearly understood by contractors. Special time was devoted to assisting the agencies and contractors involved to understand the differences associated with PRS at the pre-bid, pre-construction and partnering meetings. 


\subsection{Second PRS Project in Indiana}

At the conclusion of the first PRS project, it was decided to continue to develop PRS for the second project in much of the same manner as the first. The results of the final pay factors and extra pay for percent entrained air, flexural strength, thickness, and smoothness of the pavement are presented in Appendix V, as given by the contractor in February, 2004. Some significant changes occurred between the two projects, which include the following:

- $\quad$ An updated version of the PRS software, PaveSpec 3.0, was used.

- $\quad$ The second project location was on I-65 in Clarksville, in southern Indiana, which had a slightly different climate that the first PRS project.

- $\quad$ A different district office of INDOT and a different contractor were responsible for the construction and testing of the second project.

- $\quad$ Air content was added as the fourth AQC. Other AQCs included strength, thickness, and initial smoothness.

- Smoothness measurements were changed to simplify PRS implementation. One average smoothness measurement was calculated for one entire lot and figured into the composite factor for the lot. Other AQCs were measure as in the first project, using the average of tests of three sublots to compute the overall pay factor for the lot.

- A slightly lower strength target mean value and a slightly higher mean thickness were specified. A discussion of these changes in found in Chapter 8. 


\section{CHAPTER 3: REVIEW OF LIFE-CYCLE COST ANALYSIS}

Life-Cycle Cost Analysis (LCCA) is a process used to assess the initial project cost as well as the future costs of a design, allowing for objective comparisons of different design options to determine which is most economical. In Performance-Related Specifications (PRS) for concrete pavements, the quality of a pavement is linked to its anticipated performance through the use of LCCA simulation. PRS recognize that the contractor has an important impact on the quality of the pavement, which directly impacts the life-cycle cost of the pavement. The use of LCCA modeling gives PRS the ability to assess the value of different levels of construction quality and balance the costs of higher quality with the resulting increase in product performance.

Therefore, knowledge of the use of LCCA in PRS is crucial to understanding the impacts of PRS on concrete pavement construction.

To help clarify that relationship, a literature review was performed to identify the key issues in LCCA. Section 3.1 presents a definition of LCCA. Section 3.2 discusses the types of projects for which LCCA is used. Section 3.3 presents some of the benefits and limitations of LCCA. Section 3.4 explains the relation of LCCA to PRS. Section 3.5 concludes with a summary of this chapter. In comparison to conventional LCCA, two distinctions are noted for the way in which LCCA is used in PRS:

1) conventional LCCA is most often used in the design phase of a project; however in PRS, LCCA is applied primarily in the construction phase of a project, and

2) conventional LCCA includes the initial costs in the total life-cycle cost; however in PRS, initial costs are omitted. 


\subsection{Definition of Life-Cycle Cost Analysis}

Life-cycle cost analysis is defined as "a process for evaluating the total economic worth of a usable project segment by analyzing initial costs and discounted future costs ... over the life of the project segment" (Transportation Equity Act for the $21^{\text {st }}$ Century (TEA-21) 1998). The basic LCCA methodology steps described by the Federal Highway Administration (FHWA 2003) are:

- establish alternative design strategies,

- determine activity timing,

- estimate agency costs,

- estimate user costs, and

- determine the life-cycle cost.

Life-cycle costs typically include all direct and indirect costs associated with a project. In commercial construction, this typically covers items such as the real-estate purchase, materials and labor, operating and maintenance costs, financing costs, and even resale value. In infrastructure projects, however, the cost incurred by the public using the facility is a very important portion of the life-cycle cost. For instance, the life-cycle cost of a pavement can include not only the price of construction, maintenance, repair, and rehabilitation, but also cost of the users on the road in terms of accidents, delays, and wear on the vehicle as the pavement deteriorates. A graphical example of the life-cycle cost of a pavement is shown in Figure 3-1. 


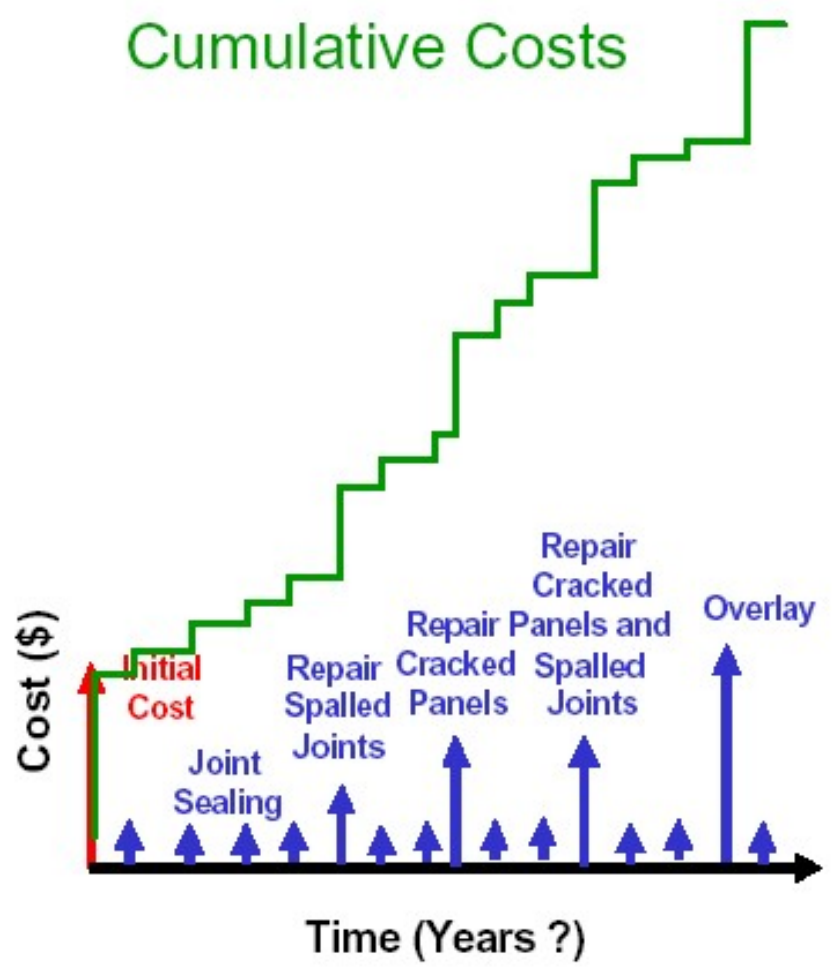

Figure 3-1 The Life-Cycle Cost of a Pavement (Weiss 2001)

In addition to considering all the constituents of a life-cycle cost, to understand LCCA, one must realize that the value of money changes over time. As a result, expenditures made at different times are not equal (Zimmerman et al. 2000). A simple economic principle is that money loses value over time due to inflation, but it can also be invested and earn interest. In LCCA, future costs are discounted to present-day costs using a Present Worth (PW) factor, shown in Equation 3-1.

$$
\mathrm{PW}=\frac{1}{(1+\mathrm{i})^{\mathrm{N}}}
$$

where

$\mathbf{i}=$ Discount rate (interest rate minus the inflation rate) and $\mathbf{N}=$ Number of periods (usually years) from the analysis year to the year when the cost is incurred. 


\subsection{Previous Application of Life-Cycle Cost Analysis}

LCCA is often used to evaluate competing initial design alternatives. For example, the U.S. Department of Energy (DOE) has published a guide to use LCCA in evaluating innovative environmental technologies for DOE site cleanup (U.S. DOE 1998). In 1998, the FHWA produced Demonstration Project 115, "Life-Cycle Cost Analysis in Pavement Design" and presented workshops in over 40 States (Walls and Smith 1998). LCCA has also been used to evaluate bridge repair strategies (Frangopol et al. 1997; Hastak and Halpin 2000; Zayed et al. 2002). Other books and reports are available in the areas of engineering economic analysis and life-cycle cost analysis (American Concrete Pavement Association 2002; Kirk and Dell'Isola 1995).

In the transportation industry, a number of studies have created methodologies to perform LCCA on pavements. Papagiannakis and Delwar (2001) developed a computer model to evaluate existing roadways at the project and network level, using LCCA to determine the most effective maintenance treatments. Similarly, a study by Al-Mansour and Sinha (1994) used LCCA to evaluate pavement preventative maintenance. Computer software has been developed to apply LCCA to bridge design (Ehlen 1999) and the design of concrete structures susceptible to chloride attack and corrosion (Thomas and Bentz 2000). Embacher and Snyder (2001) used LCCA to compare existing asphalt and concrete pavements, which in turn could be used in the selection of pavement type for new construction. Harrison, Waalkes and Wilde (1999) promoted the use of LCCA for the design of rigid pavements within the Texas Department of Transportation. This analysis included costs of noise, and air quality in the LCC.

Despite this information, there still appears to be a lack of LCCA use in infrastructure management. At least one survey reported that only $40 \%$ of city governments responding indicated that LCCA was used to some extent in planning (Arditi and Messiha 1999). The report further indicated that in the bidding and contracting phase, less than one third of these cities used LCCA. However, the federal government has encouraged the use of LCCA in legislation such as 
the Intermodal Surface Transportation Efficiency Act (ISTEA 1991), the Transportation Equity Act for the $21^{\text {st }}$ Century (TEA-21 1998), Executive Order 13123 (U.S. DOE 2000).

The available LCCA literature often discusses the use of LCCA as a tool to aid in decision making during the design phases of a project or for the programming network maintenance. However, LCCA can also be used as a means of evaluating the contractor's performance during the construction phase of the project. This and other benefits of LCCA are discussed in the Section 3.3

\subsection{Benefits and Limitations of Life-Cycle Cost Analysis}

LCCA can be a useful economic tool for comparing competing project alternatives (Slater 1994). The most important benefit is LCCA's ability to compare projects on an equivalentdollar basis. The life-cycle costs of projects with different design lives, initial costs, and annual maintenance costs can each be expressed as a single PW value, and those PW values can then be compared. Executive Order 12893 indicated that LCCA leads to wise investments in infrastructure facilities (Slater 1996).

Another benefit of LCCA is that it places the focus on costs occurring not just initially but also during the whole life of a project. For highway construction, this not only shifts the emphasis to the expected repair and maintenance costs, but it also causes one to consider the costs to the public that uses the highways. This can be a limitation to LCCA, however, because user costs are often difficult to estimate. Although the computation of user costs can frequently be controversial, the FHWA believes that user cost savings comprise the most important benefit in justifying highway improvements and therefore ought to be included in any LCCA (Slater 1996).

Another limitation of LCCA is that the results of the analysis are dependent on the selection of the discount rate. The purchasing power of money changes due to inflation and interest rate fluctuation, making straight comparisons of real present and future dollars misleading. The 
discount rate accounts for this time value of money. However, the discount rate is determined by the judgment of the engineer in charge of the analysis. Although there is no fixed value for discount rate in LCCA, government agencies do provide guidance for selection of the proper discount rate (Slater 1996).

Despite some potential limitations, LCCA still remains a useful tool for providing a basis to evaluate project alternatives. LCCA can also provide a rational basis for making pay adjustments based on construction quality. For example, one measurement of construction quality in pavements is slab thickness. Pay adjustments for excesses or deficiencies can be arbitrary based on engineering judgment and best guesses, or a simulation model can determine the impact of the thickness on the LCCA, therefore providing a quantifiable measurement of the impact of construction on the performance of the pavement. Using LCCA to rationally quantify the expected performance is the primary reason for the development of PRS, as explained in the next section.

\subsection{Relationship of LCCA to PRS}

In PRS, LCCA is used to compare the performance of the pavement as-designed with the performance of the pavement as-constructed (Hoerner et al. 2000). The total life-cycle cost consists of two cost categories: agency costs and user costs.

The agency must provide the funds to maintain the highway. For the purposes of PRS, these maintenance outlays are divided into three areas: Routine Maintenance, Local Rehabilitation or Repair, and Global Rehabilitation. Routine Maintenance includes those regularly occurring procedures that do not fundamentally address pavement deterioration, such as crack and joint

sealing. Local Rehabilitation or Repair procedures address localized pavement distress with slab replacement and joint repair. Global Rehabilitations are applied to the entire pavement and include concrete and asphalt overlaying and diamond grinding.

Highway user costs generally include vehicle operating costs, accident costs, and delayrelated costs (Slater 1994). A study by McFarland (1972) categorized user costs into four 
categories: travel time, vehicle operation, accidents, and discomfort. These costs were first linked to the pavement serviceability index for different speed conditions. Then, actual costs were calculated assuming an actual speed for specific highway types. These costs are included in the current PRS software by extrapolating the estimated values to the appropriate year using a user-defined inflation rate.

In PRS, the LCC of a highway is computed without using the initial cost of the pavement. In contrast, previously discussed LCCA applications are based on a "cradle-to-the-grave" methodology. The assumption in PRS is that the initial cost of the pavement is equal to the contractor's bid price, and therefore does not change, from the agency's perspective, once the contract is awarded. Therefore, the as-designed and as-constructed LCCs can be compared without the calculation of the initial pavement cost.

An illustration of the difference between LCCA in PRS and in other applications is found by comparing three LCCA programs, PaveSpec, Bridge LCC and Life365 (Hoerner and Darter 2000; Ehlen 1999; Thomas and Bentz 2000). An overview of these programs is shown in Table 3-1. 
Table 3-1 Comparison of LCCA Software Programs

\begin{tabular}{|c|l|l|l|}
\hline $\begin{array}{c}\text { Software } \\
\text { Name }\end{array}$ & \multicolumn{1}{|c|}{ PaveSpec } & \multicolumn{1}{c|}{ BridgeLCC } & \multicolumn{1}{c|}{ Life365 } \\
\hline Purpose & $\begin{array}{l}\text { Develop PRS for rigid } \\
\text { pavements }\end{array}$ & $\begin{array}{l}\text { Assist bridge designers } \\
\text { in determining the cost } \\
\text { effectiveness of new, } \\
\text { alternate construction } \\
\text { materials }\end{array}$ & $\begin{array}{l}\text { Provide guidance } \\
\text { for planning and } \\
\text { designing concrete } \\
\text { structures exposed } \\
\text { to chlorides in } \\
\text { service }\end{array}$ \\
$\begin{array}{c}\text { Prediction } \\
\text { Modeling }\end{array}$ & $\begin{array}{l}\text { Post-construction } \\
\text { pavement performance } \\
\text { due to loading and } \\
\text { durability and resulting } \\
\text { repair schedule }\end{array}$ & $\begin{array}{l}\text { Concrete service life } \\
\text { based on chloride } \\
\text { concentration and } \\
\text { concrete properties }\end{array}$ & $\begin{array}{l}\text { Onset of corrosion } \\
\text { due to chloride } \\
\text { penetration and the } \\
\text { associated repair } \\
\text { schedule }\end{array}$ \\
\hline $\begin{array}{c}\text { Costs included } \\
\text { in LCCA }\end{array}$ & $\begin{array}{l}\text { Maintenance and } \\
\text { repair } \\
\text { User costs }\end{array}$ & $\begin{array}{l}\text { Agency (initial) } \\
\text { costs } \\
\text { Operation, } \\
\text { maintenance and } \\
\text { repair } \\
\text { Disposal }\end{array}$ & $\begin{array}{l}\text { Initial material } \\
\text { costs } \\
\text { Maintenance } \\
\text { and repair }\end{array}$ \\
\hline
\end{tabular}

The primary distinction between PaveSpec and the other two programs is seen in the purpose for each: PaveSpec is used to develop construction documents, while the other two programs are used to guide the decisions of designers. The prediction model in PaveSpec is largely driven by loading, whereas BridgeLCC and Life365 are primarily driven by chloride concentration. However, Life 365 does not include the impact of the structure's deterioration on costs incurred by the user. All three programs do account for the future costs to the structure in terms of maintenance and repair.

\subsection{Summary}

Because of the inclusion of future costs and the emphasis on performance, LCCA is a useful tool for objectively evaluating different design alternatives. LCCA has been researched extensively, and several methodologies and computer programs have been developed for use in 
infrastructure management. LCCA has some limitations due to the dependency on the assumed discount rate and user costs.

The use of LCCA in PRS has several unique distinctions compared to other applications. In PRS, the initial project costs are assumed to be identical for the as-designed and as-constructed cases and are therefore omitted from the LCCA calculation. In PRS, LCCA is used to objectively evaluate the value of construction quality; other applications use LCCA only to optimize design decisions or maintenance procedures. By relating the construction quality to product performance, LCC in PRS provides a rational basis for pay adjustment based on the quality of the pavement that is provided, while other LCCA applications are largely used for investment decisions. 


\section{CHAPTER 4: PAVEMENT DISTRESS MODELING}

To effectively use Performance-Related Specifications (PRS), the agency must be able to define the performance of the pavement in terms of measurable distresses or deterioration. Different pavements exhibit different distresses. For example, flexible pavements may undergo rutting or alligator cracking, while rigid pavements may experience faulting and spalling. The scope of this study was limited to Jointed Plain Concrete Pavements (JPCP). This study focused on assessing PRS software, PaveSpec 3.0, which was designed for dowelled and undowelled JPCP only (Hoerner et al. 2000).

This chapter provides in-depth background on the distress models used in PaveSpec 3.0. It is essential that agencies using PRS determine which distress models to include in their Life-Cycle Cost Analysis (LCCA) and corresponding specification. Section 4.1 identifies typical JPCP distresses. Four of these distresses, transverse joint spalling, transverse joint faulting, transverse fatigue cracking, and increasing roughness, are currently used in PaveSpec 3.0. Sections 4.2 through 4.5 follow with an in-depth look at each of these four distress models. Conclusions are presented in Section 4.6.

\subsection{Typical JPCP Distresses}

JPCP distresses can include material-related distresses (such as pop-outs, "D” cracking, map cracking, scaling, shrinkage cracking, thermal cracking, aggregate polishing, and alkali-silica reaction) and functional distresses (such as corner breaks, fatigue cracking, joint-seal damage, joint spalling, blowups, faulting, and pumping) (State Highway Research Program (SHRP) 1993; Weiss 2003). In addition to these distresses, increasing importance is given to the roughness/smoothness of the pavement, because of its direct impact on the road user. Roughness 
can be measured using a variety of objective methods, but the most widely accepted index is the International Roughness Index, or IRI (Hoerner et al. 2000; Queiroz et al. 1984).

For accuracy in PRS, it is important to model pavement distresses that commonly occur. A study by Darter and Barenberg (1977), which sampled 37 pavements nationally, outlines distresses that typically occur in JPCP. They include joint faulting, transverse and longitudinal cracking, corner cracking, "D” cracking, joint and corner spalling, joint seal damage, and settlement. Table 4-1 is extracted from this report.

Table 4-1 Summary of Distress Types Occurring on 37 Plain Jointed Concrete Pavements (Darter and Barenberg 1977)

\begin{tabular}{|l|c|c|}
\hline \multicolumn{1}{|c|}{ Type of Distress } & Distressed/Total & Maintained/Distressed \\
\hline Joint Faulting $(>0.05$ in.) & $16 / 37$ & $3 / 16$ \\
\hline Transverse Cracking & $12 / 37$ & $10 / 12$ \\
\hline Longitudinal Cracking at Joint & $3 / 37$ & $0 / 3$ \\
\hline Corner Cracking & $1 / 37$ & $0 / 1$ \\
\hline "D” Cracking at Joint & $16 / 37$ & $16 / 16$ \\
\hline Joint and Corner Spalling ( $>3$ in. dia.) & $8 / 37$ & $5 / 8$ \\
\hline Joint Seal Damage & $35 / 37$ & $29 / 35$ \\
\hline Settlement & $27 / 37$ & $3 / 27$ \\
\hline
\end{tabular}

1 in. $=25.4 \mathrm{~mm}$

From Table 4-1, it can be seen that joint seal damage, settlement, faulting, "D" cracking, and transverse cracking are the most common distresses in concrete pavements. Additionally, pavements with transverse cracking, "D" cracking, spalling, and joint seal damage were most often maintained when distressed. In PaveSpec 3.0, faulting, spalling, cracking, and roughness are predicted. The similarities between the most common distresses in Table 4-1 and the distress prediction models used in PaveSpec provide support that PaveSpec adequately reflects actual pavement performance.

With respect to " $D$ " cracking distress, the Indiana Department of Transportation (INDOT) made substantial changes in its specifications since 1991 in an attempt to correct the problem. These changes include the use of aggregate specifications that limit the aggregates that can be used in the concrete. It should be noted however that material-related distresses such as " $D$ " 
cracking and Alkali Silica Reactivity do not appear in the prediction models in PaveSpec. Joint seal damage may influence spalling, and likewise, settlement influences faulting, so other distresses are indirectly included in PRS.

A survey of transportation engineers in Indiana was also conducted to identify the most commonly occurring distresses in rigid pavements. Eight engineers were asked to estimate the frequency of 18 different distresses using the following five-point system:

- Almost Never (less than $20 \%$ ) $=0$ points

- Seldom $(20-40 \%)=1$ point

- Sometimes $(40-60 \%)=2$ points

- Often $(60-80 \%)=3$ points

- Almost always (more than $80 \%)=4$ points.

Four responses to the survey were received. Therefore, the maximum possible total score for any one distress is 16 points. The results for each distress are tabulated in Figure 4-1.

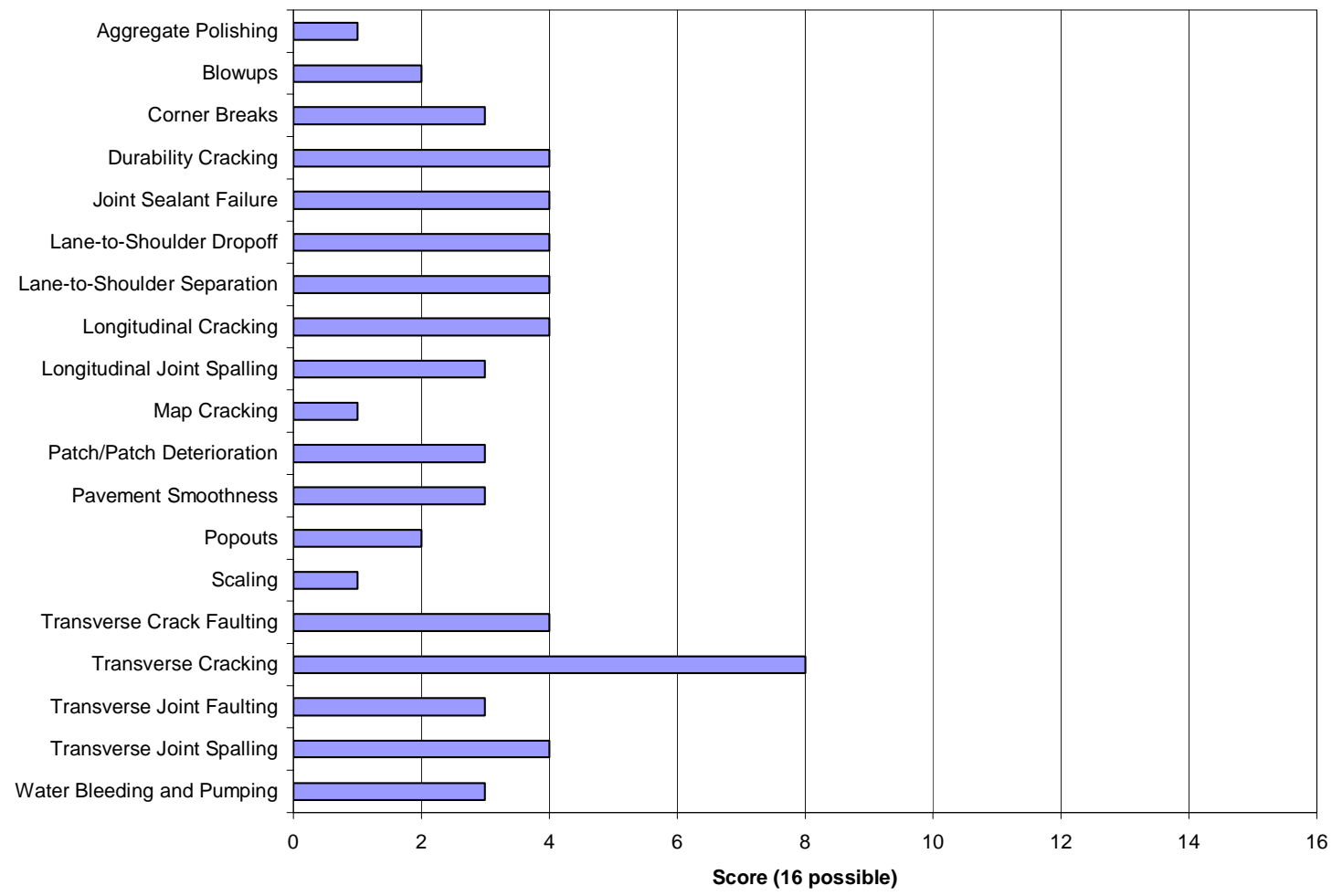




\section{Figure 4-1 Results of Survey of Common Rigid Pavement Distress in Indiana}

Although not conclusive due to the limited number of responses, the results of the survey still show that transverse cracking is among the commonly occurring distresses in rigid pavements in Indiana. Joint sealant failure was added to the survey responses by one engineer as occurring "very often."

The study from Darter and Barenberg (1977) and the survey shown in Figure 4-1 indicate some of the common distress in rigid pavements. For the most part, they correlate well with the four distress indicators are considered in PaveSpec 3.0: transverse cracking, transverse joint spalling, transverse joint faulting, and decreasing smoothness.

The four distress models in PaveSpec were selected based on their significance to concrete pavement quality and performance, and the availability and accuracy of the prediction models (Hoerner et al. 2000). However, it is noted that the models predict distress independently of one another; there is no interaction between faulting and cracking, for example. These distress prediction models are discussed separately in Sections 4.2-4.5.

\subsection{Transverse Joint Spalling}

Spalling in concrete pavements is defined as cracking, breaking, chipping, or fraying of the slab edges within $0.6 \mathrm{~m}$ (2 ft) of the transverse joint (SHRP 1993), as shown in Figure 4-2.

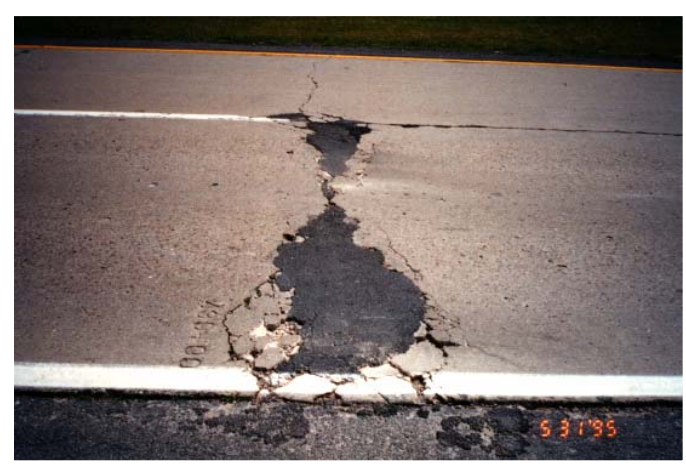

Figure 4-2 Spalling (Voigt 1996) 
Previous research has indicated that spalling is caused by incompressible particles entering the joint, freeze-thaw cycling and traffic loading (Senadheera and Zollinger 1994; Zollinger et al. 1994; Wang and Zollinger 2000; Titus-Glover et al. 2001). The advantage to including spalling as a measure of pavement performance in PRS is that spalling can be directly attributed to measurable Acceptance Quality Characteristics (AQCs) such as air content, slab thickness, and strength. These factors are under the contractor's control, thereby providing a direct relation between the construction quality and the performance of the pavement.

The spalling model included in PRS is based on Equation 4-1 (Hoerner et al. 2000):

$$
\% \mathrm{SPALL}=\left[\frac{\mathrm{AGE}}{\mathrm{AGE}+0.01}\right]\left[\frac{100}{1+1.005^{\left(-12^{*} \mathrm{AGE}+\mathrm{SF}\right)}}\right]
$$

Equation 4-1

where

$$
\begin{aligned}
\% \mathrm{SPALL}= & \text { Percentage of joints spalled } \\
\mathrm{AGE}= & \text { Time since construction, years, and } \\
\mathrm{SF}= & \text { Scaling factor based on air content, strength, thickness, AGE, joint } \\
& \text { sealant, w/c, and average number of air freeze-thaw cycles. }
\end{aligned}
$$

One disadvantage of the spalling model is that it does not address the issue of drainage, which can impact the spalling of a pavement. Despite the fact that the model is admittedly empirical (developed using mechanistic-based inputs) (Titus-Glover et al. 2001), it is recommended that the agency use spalling as a measure of performance in future PRS.

\subsection{Transverse Joint Faulting}

Joint faulting, shown in Figure 4-3, is defined as any difference in elevation across a joint (SHRP 1993). Faulting can be caused by repeated heavy loading, poor load transfer across the dowels, water in the pavement structure, and erosion of base and subgrade materials (Wu et al. 1993; Rao et al. 1999). Two models were developed and calibrated for inclusion in PRS: one 
taking into account the percent consolidation of concrete around the dowels, and the other without (Hoerner et al. 2000). This allows the agency to use the faulting distress as a measure of performance in PRS, regardless of whether or not percent consolidation is measured. Without consideration of percent consolidation, slab thickness is the only AQC used to predict faulting (among other fixed design values.) Otherwise, both thickness and percent consolidation would be considered.

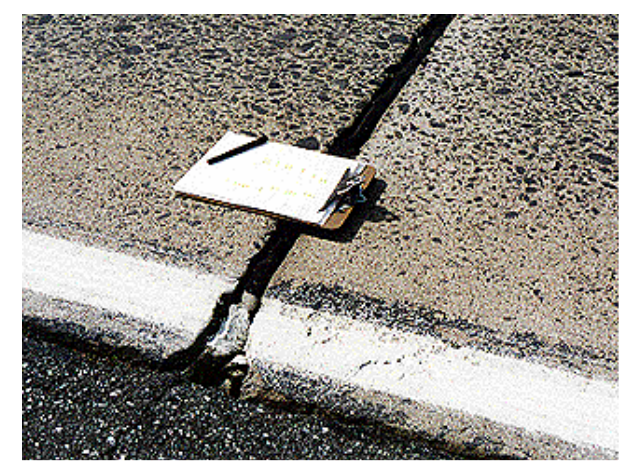

Figure 4-3 Faulting (Voigt 1996)

The present faulting model in PRS is based on Equation 4-2 (Hoerner et al. 2000):

$$
\mathrm{FAULT}=\mathrm{DAMAGE}^{0.275} \times(0.1741-0.0009911 \times \mathrm{DAYS} 90+0.001082 \times \mathrm{PRECIP})
$$

Equation 4-2

where

FAULT $=$ Average transverse joint faulting per joint, inches,

DAMAGE $=$ Ratio of actual number of applied cumulative ESALs ${ }^{1}$ to allowable number of cumulative ESALs,

DAYS90 $=$ Number of days per year with the maximum temperature greater than $32^{\circ} \mathrm{C}\left(90^{\circ} \mathrm{F}\right)$, and

PRECIP $=$ Average annual precipitation, inches.

The DAMAGE variable represents the degree to which the pavement has reached its maximum allowable load. It is based on the erodibility and permeability of the base, the

\footnotetext{
${ }^{1}$ ESAL $=$ Equivalent Single-Axle Loading
} 
diameter of the dowels, the subgrade reaction, the modulus of elasticity of the concrete, the joint spacing, and the slab thickness.

A variation of the joint faulting model in the PRS software can also be used to account for the percent of concrete consolidation around the pavement dowels, which is an optional AQC. When the option is chosen, the DAMAGE variable calculation reflects this information. It was decided not to include percent consolidation in the PRS created under this study, and therefore this AQC was not analyzed. However, agencies can choose to include it in the prediction models if they choose and if the testing is available.

Joint faulting was an option in the PRS software for both PRS contracts created by INDOT, however, it was not used to predict pavement performance in either project. This is further discussed in Section 7.1.

\section{4 $\underline{\text { Transverse Fatigue Cracking }}$}

Transverse cracks, shown in Figure 4-4, are defined as cracks that are predominately perpendicular to the pavement centerline (SHRP 1993). The primary causes of fatigue cracking are thermal and traffic loading (Darter et al. 2001; Hoerner et al. 2000; Khazanovich et al. 1997).

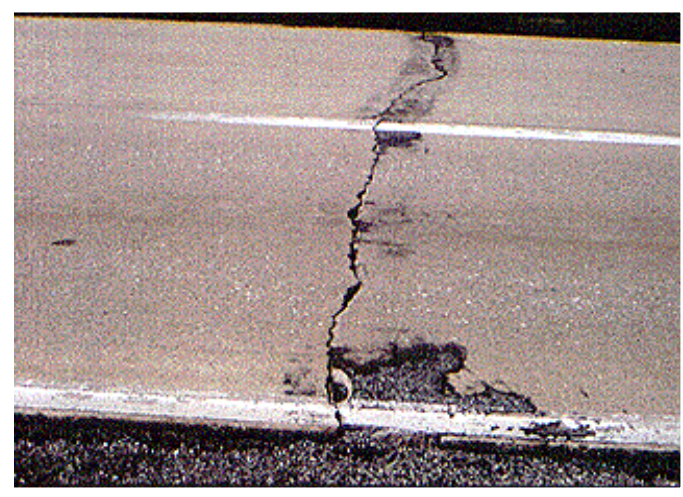

Figure 4-4 Transverse Cracking (Voigt 1996)

The cracking model is based on the S-shaped function, calculated in Equation 4-3 (Hoerner et al. 2000): 


$$
\% \mathrm{CRACKED}=\left[\frac{100}{1+1.16 \mathrm{FD}^{(-1.3)}}\right]
$$

where

\section{Equation 4-3}

$\%$ CRACKED $=$ Percentage of cracked slabs, and $\mathrm{FD}=$ Fatigue damage

The fatigue damage is an empirical function that has been related to the slab thickness, concrete strength, climatic zone, base thickness and modulus of elasticity, concrete modulus of elasticity, subgrade reaction, shoulder type, load transfer efficiency, joint spacing, and whether or not the base is bonded. Similar to the faulting model, the fatigue damage is based on the ratio of actual-to-allowable traffic loading.

The PaveSpec 3.0 software incorporates two AQCs in the current fatigue cracking model: slab thickness and concrete flexural strength (Hoerner et al. 2000). The current model only predicts fatigue cracking from the bottom of the slab upwards; other ongoing research is being conducted to develop top-down cracking models (Hoerner et al. 2000).

Fatigue cracking is a fairly common response to the loading on the roadway. Cracking in turn affects the smoothness of the pavement, which has implications in terms of user costs and hastening the need to rehabilitate the pavement. For these reasons, it is strongly recommended that the fatigue cracking model be used as part of the performance prediction in PRS.

\subsection{Roughness/Smoothness}

In the 1950s, the invention of the California profilograph allowed pavement smoothness to be measured for the first time (Waalkes 2001). Although not part of the structural integrity of the pavement, smoothness is nonetheless a crucial factor to pavement performance in PRS. Smoothness impacts the user costs that make up a substantial portion of the life-cycle cost of the pavement. 
It should be noted that "increasing roughness" and "decreasing smoothness" are interchangeable terms. A qualitative definition is offered by Sayers, et al. (1986): "Roughness is the variation in surface elevation that induces vibrations in traversing vehicles." In the current PRS model, smoothness is measured using the International Roughness Index, or IRI. The units are given in $\mathrm{mm}$ per $\mathrm{km}$ or inches per mile.

The roughness model in the PRS software is based on Equation 4-4 (Hoerner et al. 2000):

$$
\mathrm{IRI}=\mathrm{IRI}_{0}+(0.013 \times \% \mathrm{CRACKED})+(0.007 \times \% \mathrm{SPALL})+(0.001 \times \mathrm{TFAULT})+(0.03 \times \mathrm{SITE})
$$

where

$$
\begin{aligned}
\mathrm{IRI} & =\text { Pavement smoothness, } \mathrm{m} / \mathrm{km}, \\
\mathrm{IRI}_{0} & =\text { Initial pavement smoothness, } \mathrm{m} / \mathrm{km}, \\
\% \mathrm{CRACKED}= & \text { Percentage of cracked slabs, } \\
\% \mathrm{SPALL}= & \text { Percentage of spalled joints, } \\
\mathrm{TFAULT}= & \text { Total cumulative joint faulting per } \mathrm{km}, \mathrm{mm}, \text { and } \\
\mathrm{SITE}= & \text { Site factor based on age, freezing index, and percent subgrade passing } \\
& \text { the } \# 200 \text { sieve } .
\end{aligned}
$$

In PRS, pavement roughness is a function of the initial smoothness and the other three previously mentioned distress models, namely, spalling, faulting, and cracking. This means that roughness is indirectly a function of all the AQCs in PRS, not just initial smoothness. However, as Equation 3-4 shows, the initial smoothness (IRI $I_{0}$ is the most significant $\mathrm{AQC}$ for this model.

The pavement smoothness is used in PRS to attribute a cost to each car that traverses the highway, using tables developed by McFarland (1972). The costs are adjusted by means of an annual inflation rate input by the user.

Roughness has great impacts on the perceived quality of the road by the user. Additionally, increases in the smoothness quality of the road in PRS are directly related to a decrease in user cost and an overall increase in pavement performance. By including smoothness in PRS as a 
measure of pavement performance, the agency provides pay adjustments to the contractor, whereby encouraging the contractor is use innovation and improved quality. For example, the Kansas Department of Transportation introduced smoothness specification in 1985 (Swanlund 2000). The pavement roughness model is thus an important part of measuring pavement performance and should be included in the definition of pavement performance in PRS.

\subsection{Summary}

The review of distress modeling has shown that the four distress models used in the PRS software - joint spalling, joint faulting, cracking, and roughness - are closely related to commonly observed stresses in JPCP. Based on a thorough review of current literature, it is recommended that all of the existing models be included in new PRS. Based on its impact on user costs and relation to the other three models, pavement roughness appears to be the most significant of the four models. 


\section{CHAPTER 5: INNOVATIVE CONTRACTING STRATEGIES FOR HIGHWAY CONSTRUCTION}

Two important elements of highway contracting are the contract specifications and the project delivery system. Each can impact the quality of construction and the opportunity for innovation during the project. This chapter presents the spectrum of specifications for highway contracting, including Prescriptive, Quality Assurance, Performance-Related, PerformanceBased, and Warranty specifications, and two types of innovative project delivery systems, Design-Build and $\mathrm{A}+\mathrm{B}$ bidding. For each, the impacts on agencies and contractors are noted.

Innovative contracting strategies are presented as a way to achieve better quality and equitability in highway contracting. By either changing the contract delivery system or including innovative specifications in the contract documents, the agency can overcome some of the limitations of traditional contracting. It was found that the use of Performance Related Specifications (PRS) is one of the more defensible and useful innovative contracting strategies, although their use on pavement construction has been limited.

The sections in this chapter are divided by innovative strategy type. Section 5.1 presents five different types of specifications, ranging from prescriptive to warranty specifications. Section 5.2 discusses two project delivery systems, Design-Build and A+B Bidding. A summary chart in Section 5.3 compares each of these contracting strategies to PRS. 


\subsection{Specifications}

Specifications are written instructions concerning project requirements (Clough 1986). Specifications complement the information presented in contract drawings, describing the allowable materials and construction techniques, the levels of quality to be achieved, and/or the desired performance level.

In highway contracting, different specifications place varying amounts of responsibility on the contractor to produce high quality pavement. The relationships between risk and specification type are portrayed in Figure 5-1.

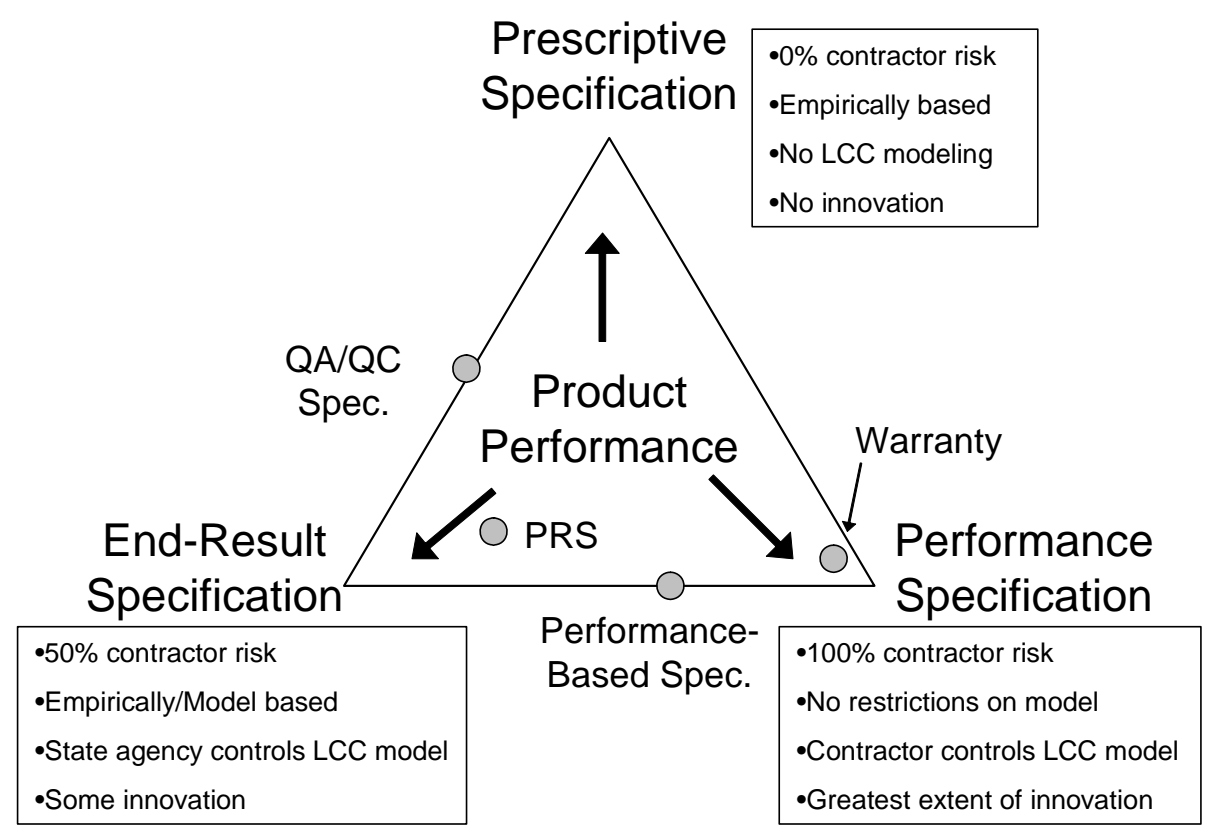

Figure 5-1 Distribution of Risk for Various Specifications

Before Figure 5-1 is discussed, the point must be made that actual contract specifications usually do not fit neatly into well-defined categories, but rather they can contain features from several categories (TRB Circular E-C037 2002). However, the use of general specification categories facilitates discussion. 
Specifications can be grouped into three categories, as shown in Figure 5-1: prescriptive, end-result, and performance specifications. The TRB Circular E-C037 (2002) provides the following definitions:

- $\quad$ Prescriptive: "Specifications that direct the contractor to use specified materials in definite proportions and specific types of equipment and methods to place the material."

- End-Result: "Specifications that require the contractor to take the entire responsibility for supplying a product or an item of construction. The highway's agency's responsibility is to either accept or reject the final product or to apply a price adjustment commensurate with the degree of compliance with the specifications."

- Performance: "Specifications that describe how the finished product should perform over time."

As Figure 5-1 shows, each specification places a different amount on risk on the agency and the contractor. In pavement construction, the risk can be defined as the responsibility for the long-term performance of the pavement. So, for example, the agency assumes $100 \%$ of the risk with prescriptive specifications, while the contractor's risk approaches $100 \%$ under a performance specification. (Most pavement warranties are shorter than the design life of the pavement, making 100\% contractor risk very improbable.)

The type of specification used also effects the staffing requirements for the agency. By specifying that the contractor take responsibility for quality control, the agency relieves pressure from shrinking staff resources and increasing costs (Hancher 1999). The agency requires less inspectors as aggregate producers are certified, materials lists are approved, the contractor's materials history is reviewed, and the contractor establishes a quality control certification plan. The agency's staffing limitations can play a role in the type of specification chosen: during the late 1980's and early 1990's, many professionals who started their careers at the onset of the Interstate highway expansion era began to retire (FHWA 2001). 
The specifications shown in Figure 5-1 are discussed next, starting with prescriptive specifications.

\subsubsection{Prescriptive Specifications}

Prescriptive specifications (also known as prescribed specifications, materials and methods specifications, recipe specifications, and even “cookbook" specifications), are the earliest specifications written for highway construction. They were developed in the 1900s as agencies began to increase their understanding of road building and move away from guarantees (Kopac 2002). They were prevalent in highway construction until the 1970s (TRB Circular \#494 1999).

On a job with prescriptive specifications, the contractor follows step-by-step instructions, designed by the agency, and is not allowed to deviate. With prescriptive specifications, the agency assumes that their design is adequate and that the contractor, by following the specification to the letter, will construct exactly the pavement intended. Should the pavement be somehow deficient, resulting in the pavement having to be replaced earlier than expected, the owner has little or no recourse after construction has been approved, if the contractor followed the specification exactly (TRB Circular \#494 1999).

The crucial point of prescriptive specifications is that the agency assumes all the risk of construction and quality deficiencies. Contractors merely have to follow the specification to receive full payment.

Besides failing to address the contractor's impact on the quality and performance of the pavement, prescriptive specifications create confusion when the material does not conform to the specification (TRB Circular \#494 1999). Prescriptive specifications were developed before extensive testing of concrete materials was performed, and therefore the specifications do properly address the material variability of concrete. Prescriptive specifications also prevent use of experience and innovation by restricting contractor options. 
Owners and contractors, however, may be very comfortable in using these specifications, since they have been in existence for many years. Their familiarity makes the implementation of prescriptive specifications straightforward. For many small, simple projects such as routine repairs, prescriptive specifications are quite adequate. However, for large highway projects, prescriptive specifications have too many short-comings to be practical.

\subsubsection{Quality Assurance Specifications}

Quality Assurance (QA) specifications, also known as Quality Control/Quality Assurance (QC/QA) specifications, are a combination of end result specifications and prescriptive specifications (TRB Circular \#E-C037 2002). Mindess and Young (1981) define quality assurance as all of the steps taken to ensure adequate confidence that the final product will perform satisfactorily in service. Quality assurance is therefore the responsibility of the owner; quality control, on the other hand, is the responsibility of the contractor. Quality control refers to the steps taken to measure the properties of the concrete and control them within the established specifications.

QA specifications attempt to shift focus from the "how" to the "why" in pavement construction. Instead of telling the contractor exactly what to do, the owner describes a minimum quality expected to be achieved, using experience and engineering judgment to relate that quality with the desired performance of the pavement. Penalties are assessed in varying degrees for failing to reach that quality. This causes the contractor to initiate a quality control plan, to ensure that the desired pavement is produced.

To complement the contractor's quality control plan, the owner provides quality assurance testing to instill adequate confidence that the product quality is as specified. To do this requires the resources of quality managers and testing facilities, but in general, the state needs fewer inspectors to oversee the projects than under prescriptive specifications. Shrinking staff resources was one of the reasons for the development of QA specifications in the 1960s (Kopac 2002). 
Under QA specifications, the owner assumes the risk that the quality of the pavement specified will be sufficient to provide the intended serviceability throughout its life. However, with QA, the agency can safely know that a pavement that fails to meet the minimum quality level (i.e. strength, thickness, air content) is rejected, giving the contractor a choice of nonpayment or bearing the cost of replacing the pavement. Pavement that falls below the specified target level may be subject to penalties. In all, the quality levels in a QA specification are set in such a way to balance two risks: the producer's risk, which is that satisfactory concrete will be rejected, and the consumer's risk, which is that inferior concrete will be accepted (Mindess and Young 1981).

In a QA specification, the contractor is assuming risk by targeting quality. Depending on how well the contractor knows their product, the contractor spends more money to produce a higher quality concrete to be certain that it will pass and full payment can be received. An example would be if the contractor changed the mix proportions of the concrete to ensure that the proper strength criteria are met, at the expense of increasing the material cost of each batch of concrete.

In reality, QA specifications still retain parts of prescriptive specifications (TRB Circular \#494 1999). The desired quality level is described in statistical terms for certain properties such as strength and thickness, but procedures, equipment, and materials are still regulated in the QA specification.

Contractors and agencies that are familiar with QA specifications in Indiana have been able to use them well (Nantung 2002). However, it is generally acknowledged that agencies ultimately desire highways with good performance (TRB Circular \#494 1999). QA specifications fail to address the specified performance of the highway. Although QA specifications are more adequate at addressing the agency's intentions than prescriptive specifications, they still fail to add a rational basis for incentives and disincentives included in the contract. Under QA specifications, pay reductions could arbitrarily range from the percent 
that a quality characteristic is defective ( $90 \%$ of the target thickness results in $90 \%$ pay) to a predetermined formula based on the normal distribution and statistics of the testing results $(70 \%$ of results of defective $=70 \%$ payment) (Getting Beyond the Talk 2003). To overcome the deficiencies in QA specifications, performance-related specifications were developed in the 1990s (Kopac 2002).

\subsubsection{Performance-Related Specifications}

Performance-Related Specifications (PRS), according to the Transportation Research Circular E-C037 (2002), are "QA specifications that describe the desired levels of key materials and construction quality characteristics that have been found to correlate with fundamental engineering properties that predict performance. These characteristics... are amenable to acceptance testing at the time of construction." In PRS, measurements of concrete strength, slab thickness, air content, and initial smoothness are used to determine the overall pay factor of a section of pavement by employing a quantified relationship between the quality characteristics and the as-constructed pavement performance. The PRS overview is shown in Figure 5-2.

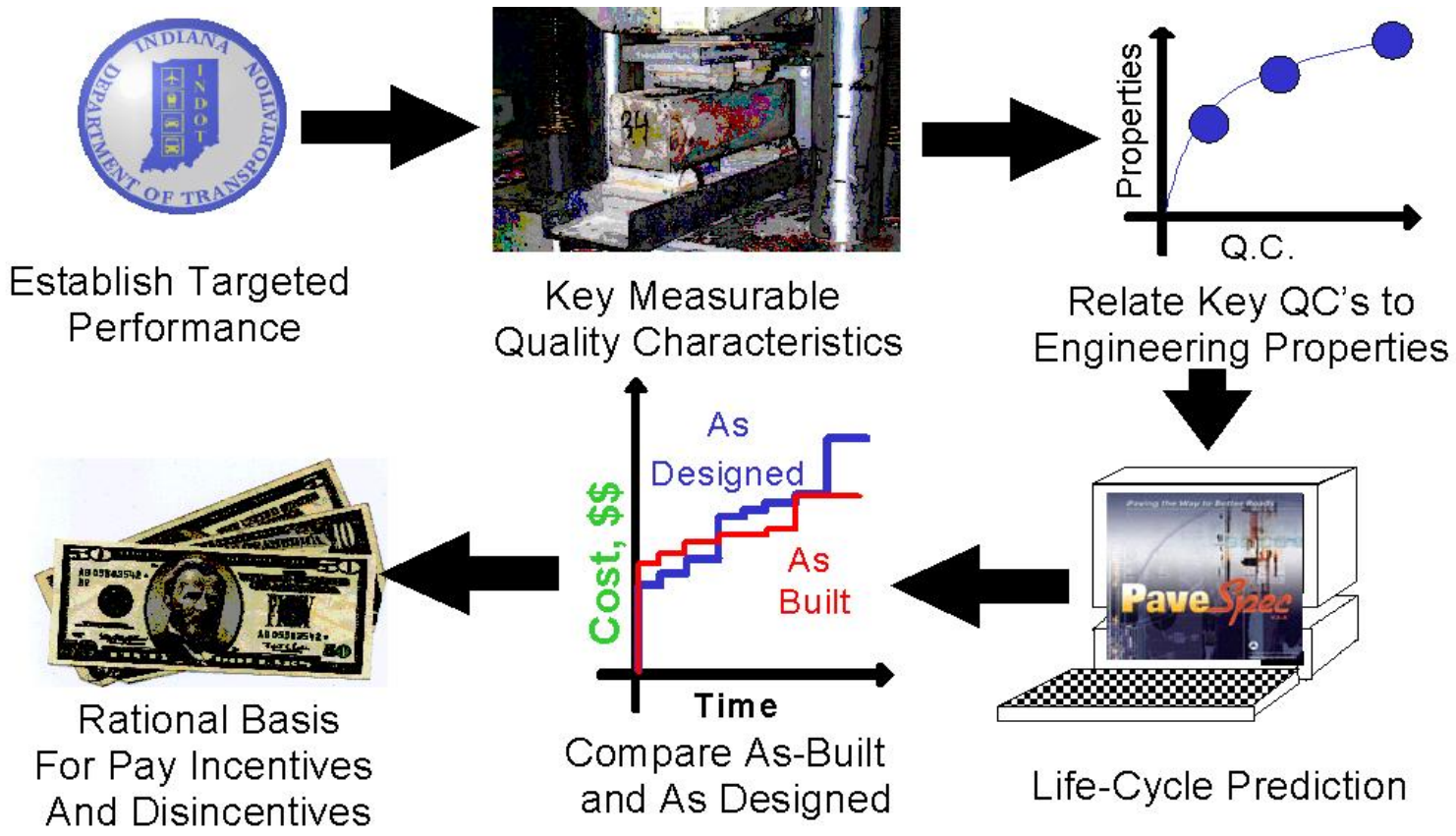

Figure 5-2 The PRS Overview 
PRS differ from ordinary QA specifications in that they employ life-cycle cost analysis and mathematical modeling, instead of relying on engineering judgment and intuition. The long-term benefit of PRS is to give the producers and contractors a better understanding of their product and more flexibility in making it (TRB Circular \#494 1999). This translates into increased awareness of what elements of quality control are important for achieving the specified performance, making concrete pavement construction more cost-effective. PRS attempt to shift the contractor's focus from simply meeting the minimum quality standards to emphasizing consistency in their production processes.

However, changing their production processes involves risk. Risks can never be totally eliminated in pavement specifications because of the inherent variability in pavements and the use of random sampling (Gharaibeh et al. 2002). In PRS, the contractor risk is quantified as the probability of achieving a certain pay factor when the contractor targets a certain level of quality. For example, if the contractor targets the agency specified values of quality and variability, the contractor has a $50 \%$ chance of receiving at least full payment. While increasing the quality will result in an increase in pay to the contractor, it likely also increases the cost of initial construct (Gharaibeh et al. 2002). Construction scenarios should be evaluated taking both considerations into account.

To adequately use PRS, a computer program capable of running deterioration models and life-cycle cost analysis is required. As with QA specifications, the contractor must establish a quality control program, and the agency must decide how quality assurance will be established. The agency can use the results from the contractor's QC tests if they are accredited, or can choose to run its own tests.

Expertise for PRS implementation is very important. It was anticipated that attempts to change QA specifications over to PRS would be met with resistance, even though the prototypes for PRS were based on rational concepts (Hoerner and Darter 1999). However, if a state agency already uses QA specification, transitioning to PRS can be smoothed by modifying the original QA documents to include the appropriate PRS methodology. 
PRS has two major advantages. One, it creates a primary relationship between quality and performance. Two, it requires the use of life-cycle cost analysis in decision making. PRS is well suited for rapid, non-destructive testing, to provide contractors with early feedback on the pay adjustments. By comparing the quality of the pavement produced by the contractor with the one designed by the agency, PRS ensure that the contractor is only judged on the aspects of the project that they have control over. For example, pay is adjusted based on the air content in the pavement. However, if the drainage is poorly designed on the project, the contractor will not be penalized, since the life-cycle cost of both the as-designed and as-constructed project will take this into account.

PRS in its current form has a few obstacles to overcome. One of the most significant is the level of education and awareness of PRS. Using the results of interviews with industry professionals, Ohrn and Schexnayder (1997) drew the conclusion that outside of those directly involved in PRS, there is a paucity of understanding the exact definition of PRS. To overcome this obstacle, training is required for both contractors and agencies to implement PRS. Additionally, the industry's understanding of materials and construction quality is incomplete. PRS is expected to continually improve this (Kopac 1997). Lastly, the testing methods associated with PRS, especially non-destructive testing, will need to be improved to take full advantage of PRS.

\subsubsection{Performance-Based Specifications}

Performance-based specifications are QA specifications that describe the desired levels of fundamental engineering properties (e.g. resilient modulus, creep properties, and fatigue properties) that are predictors of performance and appear in primary prediction relationships (i.e., models that can be used to predict pavement stress, distress, or performance form combinations of predictors that represent traffic, environmental, roadbed, and structural conditions) (TRB Circular \#E-C037 2002). Although a research program has been suggested for establishing performance-based specifications, these specifications have not found application in highway 
construction due to the fact that most fundamental engineering properties associated with pavements are not currently amenable to timely acceptance testing (Shilstone 2000; TRB Circular \#E-C037 2002.)

\subsubsection{Warranties}

Warranties are a type of performance specifications. In true performance specifications, the actual performance of the pavement is measured and used for pay adjustments or for invoking repairs, which are paid for by the contractor. Other than warranties, performance specifications have not been used for highway pavements because the appropriate non-destructive tests to measure long-term performance immediately after construction have not been developed (TRB Circular \#E-C037 2002).

A warranty is a guarantee expressed by the contractor to repair or replace the highway if it does not perform as specifically stated in the contract. In terms of highway construction, warranties usually only cover items entirely within the contractor's control, such as hot mix asphalt and bridge decks (Utah Technology Transfer Center (UTTC) 2003). However, warranties can be applied to concrete pavement maintenance, such as on a Design-Build project on I-15 in Utah, which included a 10-year warranty that covered cracks, spalled and faulted joints, and polished pavement (Nelson 1997).

Warranties in government projects currently consist of a performance bond during construction and up to one year following completion (Hancher 1999). Warranties lower agency risk by ensuring that the contractor will correct early failures, and give the agency and user the benefit of decreased highway life-cycle costs. Warranties also assist the contractor in providing incentive for innovation and allow quicker acceptance of new, untested technology and construction methods.

Most difficulties with warranties stem from their relative absence in highway contracting. For example, Indiana has only awarded one concrete pavement warranty project. Extended 
warranties meet stiff resistance from contractors and surety companies because contractors are not able to predict pavement performance accurately over the long periods, resulting in higher warranty costs. Small companies have difficulty even obtaining sufficient bonds to cover the warranty. Also, for highway warranties to work, they must be clearly defined and within the contractor's control. Poorly defined or misused warranties can lead to an increase in disputes between the agency and the contractor. Finally, the warranty is only as good as the integrity of the firm behind it (Clough 1986).

Contract bonds guarantee that "the work will be completed in accordance with the contract documents and that all construction costs will be paid" (Clough 1986). The obligations of the bond are identical with the provisions of the contract. They are also the same length of term as the contract. By law, contractors must be bonded to bid on public projects (Clough 1986). For private construction, bonding might be easily procured, as the length of the bond may only be a two or three years. However, a pavement with a design life of 40 years might include a 10-20 year warranty. Finding a bonding company to cover that period is difficult and expensive.

One advantage of PRS over warranties is that the risk is more evenly split between the contractor and the agency within PRS. The inclusion of a warranty on a highway project places all of the responsibility of the performance of the pavement on the contractor. However, recent warranty specifications have included QA testing and other provisions to minimize the risks assumed by contractors, who should not be held fully responsible for performance (TRB Circular \#494 1999).

\subsection{Project Delivery Systems}

While the specifications affect the potential for innovation and quality of a project, the project delivery system itself also impacts the quality of the highway. The traditional project delivery system in highway construction is the Design-Bid-Build method (Hancher 1999). In this method, the agency creates a complete design, for which contractors submit competitive lump-sum bids, and the award is given to the lowest-responsive bidder. While this system is 
well understood and accepted, it may not be the most desirable, as it places all the emphasis on initial cost and none on quality or life-cycle performance. Therefore, two innovative project delivery systems are reviewed, Design-Build and A+B Bidding, and their impacts on quality are discussed, as well as their potential for combination with PRS.

\subsubsection{Design-Build}

The Design-Build project delivery system, also known as Design-Construct, is used when an agency contracts with a single firm to provide both the final design and the construction of the project (Clough 1986). With Design-Build, the agency provides only preliminary details of the project and then requests proposals. The contract is then awarded based on criteria that include not only the estimated price but also the quality of the proposal and previous experience of the contractor. In some projects, the bidding phase is a two-tiered process: first, each contractor submits a statement of qualification, which the agency uses to develop a short list of firms (between three and five, typically) (UTTC 2003). Second, short-listed firms are allowed to submit proposals. Once the contractor is selected, the Design-Build method requires the contractor work closely with the agency to provide a suitable end-product.

Design-Build is often employed in the private sector, but is used infrequently in the highway construction, since most governments require public projects to use the traditional lowestresponsive-bid system (Hancher 1999). For example, the Indiana Department of Transportation has only completed five projects using Design-Build (Tymvios et al. 2002). Nationally, slightly less than half of the 50 state departments of transportation have used Design-Build in at least one highway construction project (FHWA 2003).

Despite its disuse, the agency has several potential benefits from the use of Design-Build. One is that the total project time can be shortened considerably, due to the overlapping of design and construction periods (UTTC 2003). Reducing the project delivery time helps avoid many user costs such as delay, fuel consumption, and accidents. Another benefit of Design-Build is that multiple project aspects, such as quality, cost, and schedule, are controlled by one entity, 
reducing communication difficulties (UTTC 2003). Hiring the contractor early in the project allows him to share his expertise with the agency (Gordon 1994), which is especially critical if the agency's workforce is shrinking.

The initial price of a Design-Build project can exceed a traditionally bid project in some cases due to the loss of competitive lump-sum bidding and in-house design, but the user cost savings due to early completion typically justify the increase in price for a non-traditional contract (Bower 1988). The total cost of a Design-Build may also exceed original estimates due to greater levels of uncertainty in the design and potential for utility conflicts, unforeseen traffic control, or the use of new technology. In other cases, Design-Build can actually save the agency money by making construction more efficient. Economies of cost and time can be realized when design and construction are combined and provided by the same firm (Clough 1986).

Contractors may prefer Design-Build to traditional contracting because with Design-Build, the contractor has greater flexibility in using innovative designs and construction techniques (UTTC 2003). Additionally, the Design-Build method increases the liability of the industry (Weseman and Erickson 1988). The removal of the "lump-sum bid" leaves the contractor with smaller financial risk. However, contractors may not prefer Design-Build simply if they lack the necessary experience or bonding capacity for large projects. For example, a survey of contractors in Indiana found that Design-Build had excluded many contractors due to the size of the project being too large (Tymvios et al. 2002).

One example of a successful Design-Build contract occurred north of Toronto, Ontario. After the Canadian government first requested bids in 1993, a 36-km highway was completed and opened in 1997, with estimated savings of $\$ 300$ million over original estimate. The savings were largely attributed to the feedback encouraged by the Design-Build format. Bower (1988) noted that internationally, Saudi Arabia, Sweden, France, and Australia have successfully built major projects with the turnkey approach (a form of Design-Build where the contractor also procures financing and right-of-way for the project) and Great Britain has constructed several bridges with the Design-Build concept. The US primarily has used Design-Build on mass transit 
projects, but it has also been used in highway construction, such as Interstate 15 in Utah, a fastpaced highway job that was completed in five years before the 2002 Winter Olympic Games (Hancher 1999; Nelson 1997). In two Design-Build projects successfully completed by INDOT, cost overruns of $2.08 \%$ and $0.88 \%$ were experienced; however, the average overrun for a traditional project has typically been greater than $5 \%$ (Tymvios et al. 2002).

Like traditional projects, Design-Build projects must include specifications that allow the owner to assess the quality of construction. These can take the form of QA/QC, PRS, or warranty specifications. Prescriptive specifications are for the main part excluded, since they would not encourage innovation in design and construction (Nelson 1997). The main purpose of Design-Build is to draw on the contractor's knowledge and experience to design the pavement.

PRS are project-specific; therefore, it is currently easier for agencies to compose the specifications with their penalties and incentives prior to the letting, allowing the contractor to formulate a knowledgeable bid. Although the first two PRS projects completed in Indiana were completed under Design-Bid-Build, there is nothing about PRS that prevents them from use with Design-Build. In fact, using PRS in Design-Build would give the contractor a greater chance to analyze design and construction impacts on the life-cycle cost, without the inclusion of a warranty.

\subsubsection{A+B Contracting}

Besides Design-Build, A+B bidding, or cost-plus-time contracting, is another alternative to traditional contracting. In this contracting form, the bidder is not selected on the basis of price alone, but through a combination of price (A) and time (B). The user costs are multiplied by the time needed to complete project and added to the contractor's bid. This is demonstrated in Equation 5-1 (UTTC 2003):

Total cost for evaluation $=\mathrm{A}+(\mathrm{B} \times \mathrm{UC})$

where

Equation 5-1 


$$
\begin{aligned}
& A=\text { contractor's bid price }(\$), \\
& B=\text { contractor's estimate of time to complete the project (\# of days), and } \\
& U C=\text { user costs (\$/day). }
\end{aligned}
$$

The contractor with the lowest total cost is awarded the contract. Note the total cost is for the selection of the contractor only, and does not determine the final payment amount. In addition to the contractor's bid price, often an incentive or penalty is attached to completion of the project (Hancher 1999).

This main purpose behind $\mathrm{A}+\mathrm{B}$ contracting is to accelerate the pace of construction. This can lead to sacrificing quality for the sake of time. However, if PRS were used in conjunction with $\mathrm{A}+\mathrm{B}$, then the agency would have the added benefit of paying for the quality and performance as-constructed.

In $\mathrm{A}+\mathrm{B}$ bidding, the agency assumes more financial risk than in traditional contracting. $\mathrm{A}$ contractor with the ability to speed up construction may have a higher bid than a slower contractor, but is selected under $\mathrm{A}+\mathrm{B}$ bidding by merit of the lowest total cost. As a result, the price of the contract most likely exceeds the predicted cost of a traditional contract. Nonetheless, the user benefits from an early completion of the project.

Conditions impacting the user may warrant the use of an $\mathrm{A}+\mathrm{B}$ contract. In urban areas where traffic restrictions, lane closures, and detours would result in high user costs, or where safety issues are paramount, $\mathrm{A}+\mathrm{B}$ bidding provides advantages by expediting the contract. Therefore, projects with high public interest for early completion are prime candidates for $\mathrm{A}+\mathrm{B}$ contracts.

Contractors can earn a maximum specified incentive in an $\mathrm{A}+\mathrm{B}$ contract. The incentive is usually a certain amount per day of early completion, determined by the agency, taking into account the user costs. Since the intent of $A+B$ bidding is primarily to lessen the impact of construction on the users, the contractor may have to make several concessions. For a timely 
finish, this may entail weekend, night and holiday shifts, overtime costs, and increased administration costs. In the same manner, the agency may have to extend their hours, too.

One problem with $\mathrm{A}+\mathrm{B}$ bidding is the inclusion of incentives and disincentives (penalties). Incentives and disincentives are a controversial issue in highway construction. Bower (1988) notes that, while "the resistance to change [in the public sector] is strong," the private sector already employs innovative contracting with incentives with great success. Though controversial, incentives are seen by many to assure and improve quality, meet tight deadlines, improve safety, improve communication and relations between owner and contractor, promote agency savings, and increase user benefits from higher quality and earlier finish (Clough 1986; Neil, 1991; Knutson, 1988).

The key to successful $\mathrm{A}+\mathrm{B}$ bidding is to include the proper incentives, realizing that they affect a contractor's internal process. In the study of economics, one assumption that works well is that firms and individuals do only what they perceive to be in their self-interest (Howard et al. 1997). This notion leads to effective contracting strategies and does not rule out unselfish behavior. For example, the broad notion of self-interest can include reputation and desire for repeat business. Incentives in $\mathrm{A}+\mathrm{B}$ bidding should therefore be related to the user cost savings associated with early completion and included in such a way as to make it in the contractor's best interest to finish in a punctual manner.

$\mathrm{A}+\mathrm{B}$ bidding has a similar goal to traditional bidding in that the lowest cost is important, but is also concerned with the time to completion (Hancher 1999). The methodology for selecting a contractor can be problematic since the estimated daily user cost is often a difficult and uncertain estimation. Another variation of this contract form is the multi-parameter $(A+B+C)$ contract, which can include quality, warranty, safety, or any other performance measure the agency selects. Each one of these parameters is assigned a monetary value for purposes of contract evaluation, in the same manner as the B portion of an $\mathrm{A}+\mathrm{B}$ contract. 
$\mathrm{A}+\mathrm{B}$ bidding has other potential pitfalls besides the faulty user cost estimates. For an $\mathrm{A}+\mathrm{B}$ contract to function successfully, the agency must have all utility conflicts and right-of-way issues resolved, and be fairly confident that the design will not change. At an accelerated pace, the construction process is much less flexible. Contractor-independent delays in $\mathrm{A}+\mathrm{B}$ bidding can be much more expensive than in traditional contracting, since in those cases the agency will not be able to subtract penalty fees from the contractor's payment. Contractors, too, must be prepared to deal with the accelerated pace of construction.

$\mathrm{A}+\mathrm{B}$ bidding is compatible with PRS. The inclusion of bonuses and penalties associated with contract completion are not in conflict with the pay factors associated with quality in PRS. In fact, they are complimentary. Since the goal of $A+B$ bidding is to increase the speed of construction, the use of PRS provides some assurance that quality is not being sacrificed for the sake of time. The downside of using PRS and $\mathrm{A}+\mathrm{B}$ bidding together is that PRS does require quality testing, which takes time and resources to complete.

\subsection{Conclusions}

The various contracting methods discussed in the preceding sections are summarized in comparison to PRS in Table 5-1. 


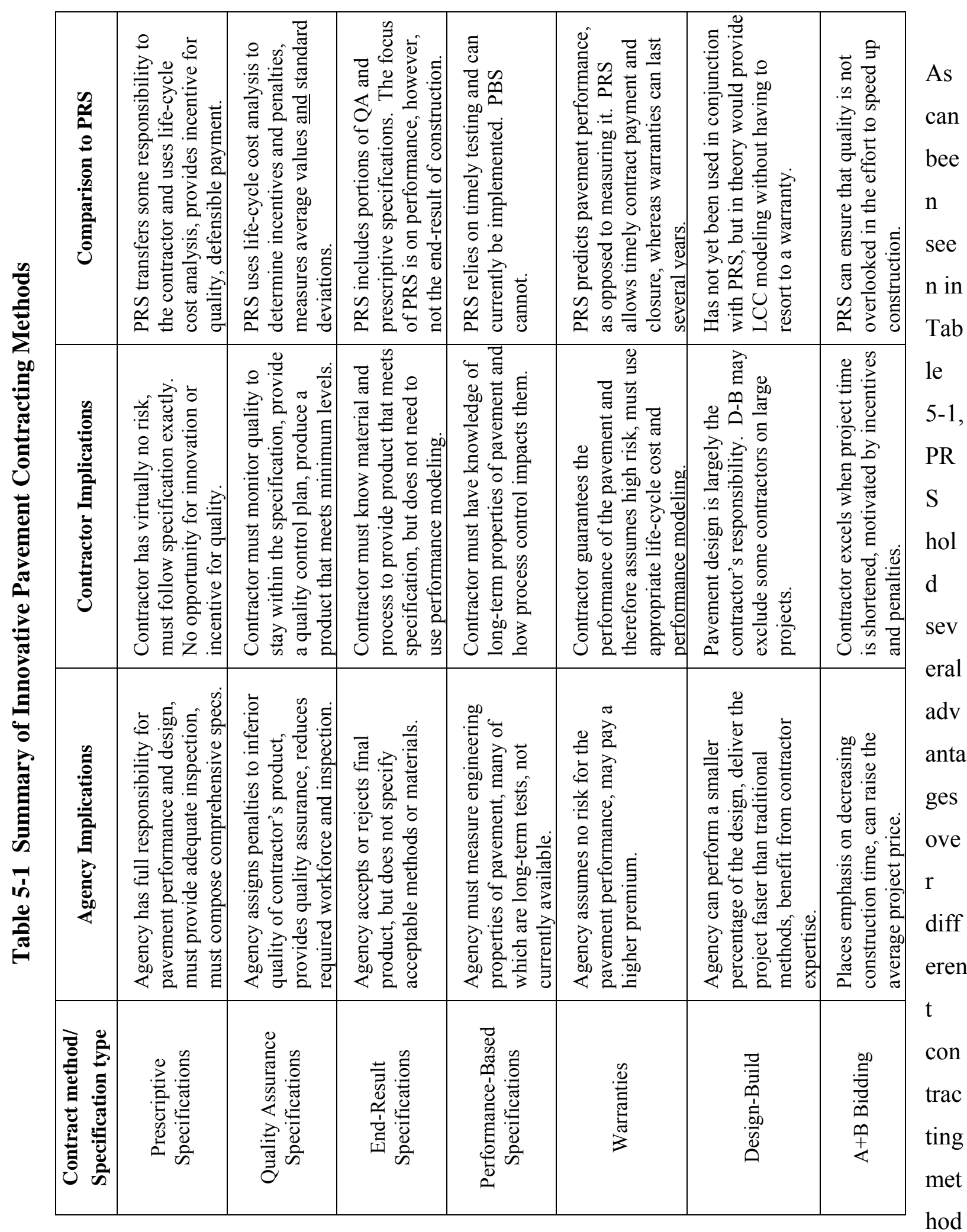


s and other specifications, but does not stand out as the only method for ideal pavement construction. Agencies must carefully consider the impacts and risks associated with each method as outlined in this chapter. 


\section{CHAPTER 6: ASSESSING PRS SOFTWARE, PART I: PROJECT, PAVEMENT, TRAFFIC, AND CLIMATIC INPUTS}

This chapter presents the first half of a two-part investigation of the influence of life-cycle cost model inputs on Performance-Related Specifications (PRS). An explanation of PRS and its evolution from Quality Assurance (QA) specifications was previously presented in Section 5.1. This chapter and the next now focus attention on the software required to develop PRS.

PRS utilize simulation models to predict life-cycle costs, requiring a large volume of engineering and design information before a state agency can proceed in developing new PRS. It is the hypothesis of this document that the process of developing PRS can be tremendously simplified if those responsible for performing the life-cycle modeling know the sources of this information, the ranges of values to expect, and the possible implications those values have on the calculation of the life-cycle cost. For this reason, this investigation was conducted to assess the role of the PRS inputs. It is believed that the results of the investigation can aid in developing future PRS in Indiana and other states by identifying the sources of inputs that are required to run the life-cycle cost analysis.

The investigation into the assessment of PRS software is described in Chapter 6 and Chapter 7; Chapter 6 discusses the constant-value inputs related to project and pavement design, and while Chapter 7 discusses the inputs that determine performance definitions, quality levels, and life-cycle cost related information.

The organization of this chapter is as follows. Section 6.1 presents an introduction to the PRS software. Section 6.2 describes the base case used for the investigation. Section 6.3 explains the experimental method by which the inputs are analyzed. Section 6.4 explains the 
constant-value inputs that are required to run the software, in the order in which they appear in the program, and discusses the impacts of variations of the inputs. The results of sensitivity analyses highlight which values have the greatest impact on the total life-cycle cost of the asdesigned pavement and the pay adjustments assigned to the contractor. Section 6.5 concludes the chapter with a comprehensive discussion of the most significant constant-value inputs for developing PRS.

\subsection{Background on PRS software}

This investigation was performed using PaveSpec, a life-cycle cost analysis program for developing PRS. PaveSpec was first created in 1993 by ERES Consultants in a FHWA-funded project to develop prototype PRS for portland cement concrete pavement (Hoerner et al. 2000). Since then it has undergone several revisions. The investigation in this study was performed using PaveSpec version 3.0.

PRS can be broken into two types of models: performance-prediction models and maintenance-cost models (Office of Asset Management 2001). These models are combined to calculate the pavement's life-cycle cost, as shown in Figure 6-1.

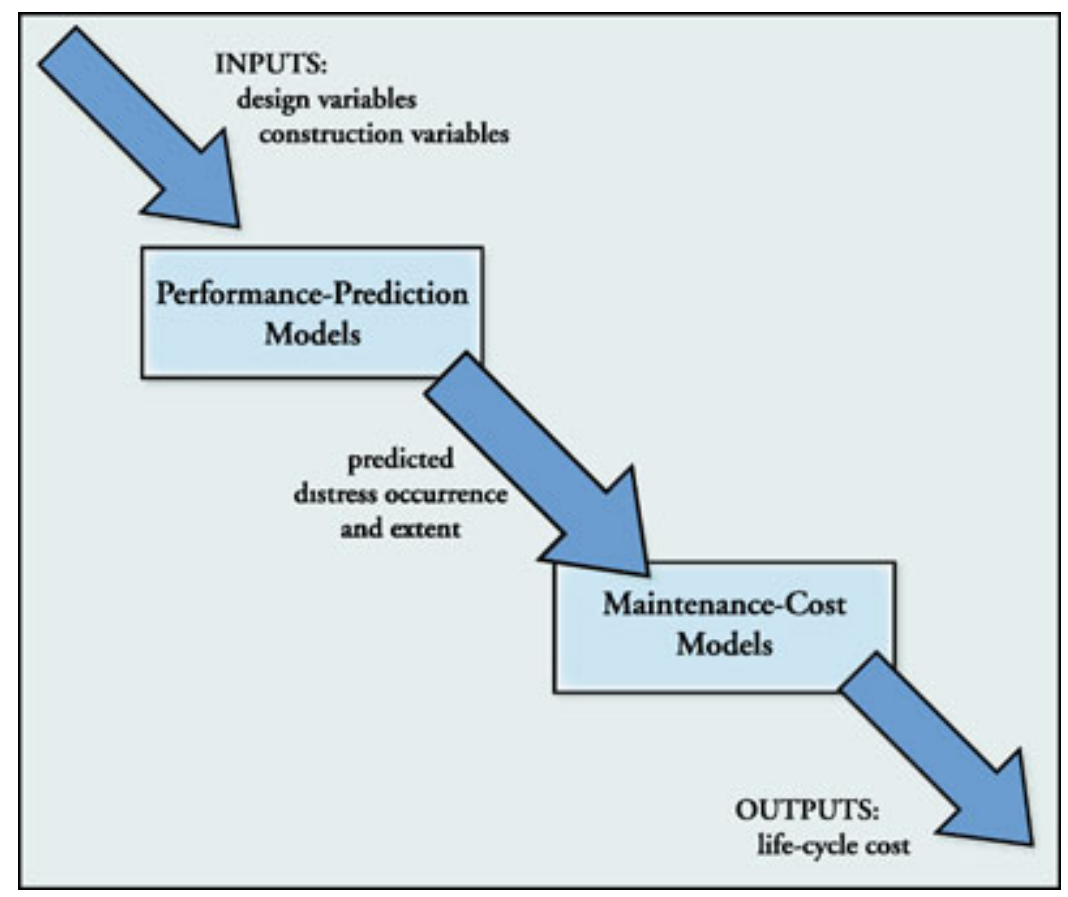


Figure 6-1 Use of Models in PRS (Kopac 2002)

The four performance-prediction models, e.g. distress models, included in PaveSpec 3.0 are shown in Table 6-1. A table similar to this originally appeared in the guide for a previous version of PaveSpec (Hoerner and Darter 1999). However, this was updated for the latest version of the software as used in this project. Chapter 4 presented an in-depth discussion of the distress models in PaveSpec.

Table 6-1 Distress Indicator Models in PaveSpec 3.0

\begin{tabular}{|c|c|c|c|}
\hline $\begin{array}{l}\text { Distress } \\
\text { Indicator }\end{array}$ & Constant Value (Input) & $\begin{array}{l}\text { Acceptance Quality } \\
\text { Characteristics } \\
\text { (Input) }\end{array}$ & $\begin{array}{c}\text { Distress } \\
\text { Indicator Units } \\
\text { (Output) }\end{array}$ \\
\hline $\begin{array}{l}\text { Transverse } \\
\text { Joint } \\
\text { Faulting }\end{array}$ & $\begin{array}{ll}\text { - } & \text { Cumulative ESALs } \\
\text { - } & \text { Presence of dowel bars } \\
\text { - } & \text { Dowel bar diameter } \\
\text { - } & \text { Transverse joint spacing } \\
\text { - } & \text { Average annual \# of days }>32{ }^{\circ} \mathrm{C} \\
\text { - } & \text { Average annual precipitation } \\
\text { - } & \text { Erodibility factor } \\
\text { - } & \text { Modulus of subgrade reaction } \\
\text { - } & \text { Base permeability } \\
\text { - } & \text { PCC modulus of elasticity } \\
\end{array}$ & $\begin{array}{l}\text { - } \\
\text { - } \\
\text { Percent } \\
\text { consolidation } \\
\text { around dowels } \\
\text { (optional) }\end{array}$ & $\begin{array}{l}\text { Average faulting } \\
\text { per joint, } \\
\text { mm or in. }\end{array}$ \\
\hline $\begin{array}{l}\text { Transverse } \\
\text { Slab } \\
\text { Cracking }\end{array}$ & $\begin{array}{ll}\text { - } & \text { Cumulative ESALs } \\
\text { - } & \text { Climatic zone } \\
\text { - } & \text { PCC modulus of elasticity } \\
\text { - } & \text { Base modulus of elasticity } \\
\text { - } & \text { Modulus of subgrade reaction } \\
\text { - } & \text { Shoulder type } \\
\text { - } & \text { Load transfer efficiency } \\
\text { - } & \text { Transverse joint spacing } \\
\text { - } & \text { Presence of bonded base } \\
\end{array}$ & $\begin{array}{l}\text { - } \quad \text { Slab thickness } \\
\text { - } \quad \text { Concrete } \\
\text { strength }\end{array}$ & $\begin{array}{c}\text { Percent of } \\
\text { cracked slabs, \% }\end{array}$ \\
\hline $\begin{array}{l}\text { Transverse } \\
\text { Joint } \\
\text { Spalling }\end{array}$ & $\begin{array}{ll}\text { - } & \text { Age } \\
\text { - } & \text { Joint sealant type } \\
\text { - } & \text { Water-cement ratio } \\
\text { - } & \text { Average annual air freeze-thaw } \\
& \text { cycles }\end{array}$ & $\begin{array}{ll}\text { - } & \text { Air content } \\
\text { - } & \text { Concrete } \\
\text { strength } \\
\text { - } & \text { Slab thickness } \\
\end{array}$ & $\begin{array}{l}\text { Percent of } \\
\text { spalled joints, \% } \\
\text { (medium and } \\
\text { high severity) }\end{array}$ \\
\hline $\begin{array}{l}\text { Pavement } \\
\text { Smoothness } \\
\text { (IRI) }\end{array}$ & $\begin{array}{ll}- & \text { Age } \\
\text { - } & \text { Freezing index } \\
\text { - } & \text { Percent subgrade material passing } \\
& \text { the } 0.075 \mathrm{~mm}(\# 200) \text { sieve }\end{array}$ & $\begin{array}{l}\quad \text { Initial IRI } \\
\text { (Note: the outputs } \\
\text { from the cracking, } \\
\text { spalling, and faulting } \\
\text { models are also } \\
\text { inputs into the IRI } \\
\text { model) }\end{array}$ & $\begin{array}{c}\text { IRI, } \\
\mathrm{mm} / \mathrm{km} \text { or in } / \mathrm{mi}\end{array}$ \\
\hline
\end{tabular}

ESAL $=$ Equivalent Single-Axle Loading

$32{ }^{\circ} \mathrm{C}=90^{\circ} \mathrm{F}$

IRI = International Roughness Index 
Table 6-1 shows that the inputs for the performance-prediction models can be grouped into two categories: constant-value inputs and Acceptance Quality Characteristics (AQCs). AQCs are measures of construction quality that are related to the performance of the pavement through the models as shown. The AQCs currently used in PRS are concrete flexural strength, slab thickness, air content, and initial smoothness. Consolidation around the dowels is an optional AQC which was not used in this study.

As seen in Figure 6-1, the output of the distress models is entered into a maintenance-cost model. The maintenance-cost model then estimates the total post-construction life-cycle cost; in other words, the cost of maintenance and rehabilitation that will be necessary for the project life of the pavement (Office of Asset Management 2001). The life-cycle cost also includes a certain percentage of user costs, which are functions of the smoothness of the pavement.

Using the process shown in Figure 6-1, PaveSpec simulates the as-designed pavement performance and as-constructed pavement performance to form the basis for pay adjustments. Individual lot pay factors are created for each AQC by comparing the as-designed life-cycle cost with the as-constructed life-cycle cost as shown in Equation 6-1 (Hoerner and Darter 1999):

$$
\mathrm{PF}_{\text {lot }}=100 \times \frac{\mathrm{BID}+\left(\mathrm{LCC}_{\mathrm{DES}}-\mathrm{LCC}_{\mathrm{CON}}\right)}{\mathrm{BID}}
$$

Equation 6-1

where

$\mathrm{PF}_{\text {lot }}=$ Overall pay factor for the as-constructed lot, percent, $\mathrm{BID}=$ Representative contractor's unit bid price for the lot, $\$ / \mathrm{km}$,

$\mathrm{LCC}_{\mathrm{DES}}=\mathrm{As}$-designed life-cycle unit cost for the lot (computed using target AQCs), presentworth $\$ / \mathrm{km}$, and

$\mathrm{LCC}_{\mathrm{CON}}=\mathrm{As}$-constructed life-cycle unit cost for the lot (computed using AQC test results from the as-constructed lot), present-worth $\$ / \mathrm{km}$. 
The importance of the Equation 5-1 is twofold. First, it reveals that a decrease in the lifecycle cost of an as-constructed pavement results in an increase in contractor pay. Second, Equation 6-1 impacts the effectiveness of PRS. The performance-prediction models do not have to be $100 \%$ accurate for PRS to be effective. Examining the method for calculating payment adjustment in Equation 6-1 shows that PRS perform a comparative assessment of the life-cycle costs. Errors in the life-cycle cost prediction for as-designed pavements and as-constructed pavement will tend to offset one another.

Using Equation 6-1, the PRS software, PaveSpec, helps create the pay factor charts for individual AQCs to include in the contract documents. The life-cycle costs and the pay factor charts are the means of comparison for this analysis. The base case of this investigation is described in the next section.

\subsection{Description of Base Case}

The base case for this investigation was a previously-constructed concrete pavement, Project R-25715, which was designed by the Indiana Department of Transportation (INDOT) and let for bid in 2002. Project R-25715 is a three kilometer section of I-65 in Clarksville, Indiana, shown in Figure 6-2. This section of pavement was the second concrete pavement that was constructed using PRS in Indiana and was only the second PRS used in the United States.

To assist INDOT in the data collection for this project, the inputs for the life-cycle cost analysis software were identified and organized into a table, which is included in Appendix C. 


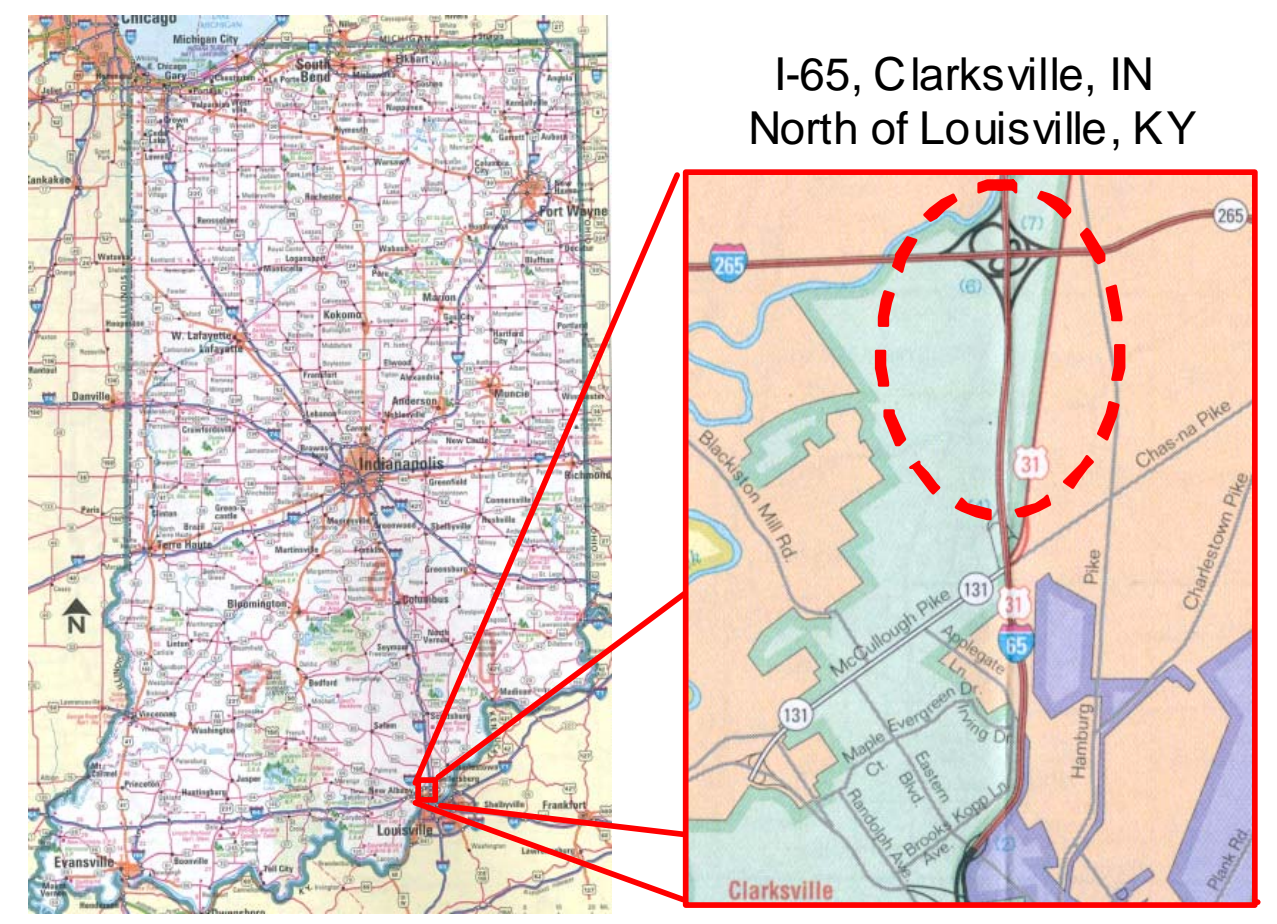

Figure 6-2 Approximate Location of INDOT Project R-25715

Project R-25715 was a traditional Design-Bid-Build project, with the agency responsible for $100 \%$ of the design. Therefore, INDOT chose the targets and ranges of the AQCs used in the project, which are shown in Table 6-2.

Table 6-2 Design AQC Values (from INDOT Project R-25715)

\begin{tabular}{|l|l|l|l|l|}
\hline $\begin{array}{l}\text { AQC } \\
\text { Value }\end{array}$ & $\begin{array}{l}\text { Target } \\
\text { Mean }\end{array}$ & $\begin{array}{l}\text { Target Standard } \\
\text { Deviation }\end{array}$ & $\begin{array}{l}\text { Rejectable Quality } \\
\text { Limit (RQL) }\end{array}$ & $\begin{array}{l}\text { Maximum } \\
\text { Quality Limit } \\
\text { (MQL) }\end{array}$ \\
\hline $\begin{array}{l}\text { 28-day Flexural } \\
\text { Strength }\end{array}$ & $\begin{array}{l}4.48 \mathrm{MPa} \\
(650 \mathrm{psi})\end{array}$ & $\begin{array}{l}0.28 \mathrm{MPa} \\
(40 \mathrm{psi})\end{array}$ & $\begin{array}{l}<3.96 \mathrm{MPa} * \\
(<575 \mathrm{psi})^{*}\end{array}$ & $\begin{array}{l}5.52 \mathrm{MPa} \\
(800 \mathrm{psi})\end{array}$ \\
\hline Thickness & $\begin{array}{l}381 \mathrm{~mm} \\
(15.0 \mathrm{in} .)\end{array}$ & $\begin{array}{l}13 \mathrm{~mm} \\
(0.5 \mathrm{in} .)\end{array}$ & $\begin{array}{l}<356 \mathrm{~mm} \\
(<14.0 \mathrm{in} .)\end{array}$ & $\begin{array}{l}406 \mathrm{~mm} \\
(16.0 \mathrm{in} .)\end{array}$ \\
\hline Air Content & $6.5 \%$ & $0.5 \%$ & $<4.0 \mathrm{or}>10.0 \%$ & None \\
\hline Smoothness & $\begin{array}{l}110 \mathrm{~mm} / \mathrm{km} \\
(0.7 \mathrm{in} . / 0.1 \mathrm{mile})\end{array}$ & $\begin{array}{l}50 \mathrm{~mm} / \mathrm{km} \\
(0.3 \mathrm{in} . / 0.1 \mathrm{mile})\end{array}$ & $\begin{array}{l}>160 \mathrm{~mm} / \mathrm{km} \\
(>1.0 \mathrm{in} / 0.1 \mathrm{mile})\end{array}$ & $\begin{array}{l}50 \mathrm{~mm} / \mathrm{km} \\
(0.3 \mathrm{in} . / 0.1 \mathrm{mile})\end{array}$ \\
\hline
\end{tabular}

* depends on standard deviation 


\subsection{Experimental Method}

A total of 163 inputs into the PRS software were collected and analyzed for Project R-25715. These inputs can be divided into three general groups, as shown in Figure 6-3.
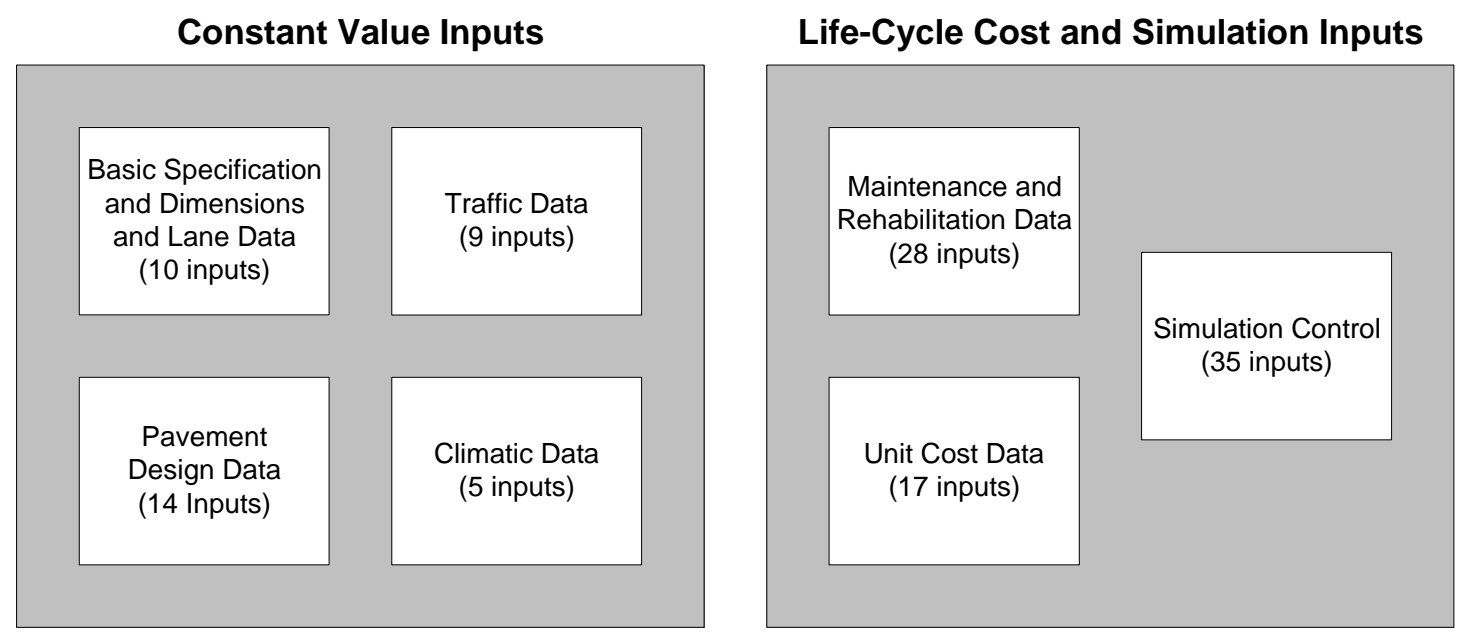

AQC-Related Inputs

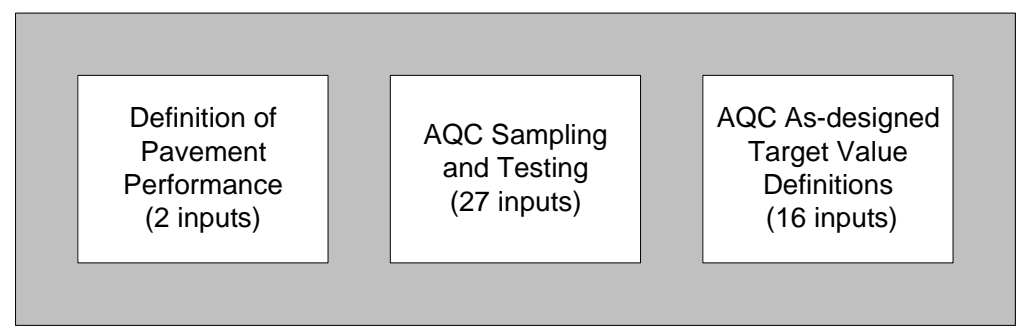

Figure 6-3 Input Categories in PRS

The constant value inputs for the Basic Specification and Dimensions and Lane Information, Traffic Data, Pavement Design Data, and Climatic Data are analyzed in Chapter 6. The LifeCycle Cost Information and AQC-Related Inputs are analyzed in Chapter 7. Not all of the inputs are required to run the PRS software, and some of the inputs have very significant impacts, while others have almost no impact on the life-cycle cost of the pavement.

\subsection{Constant Value Inputs}

To run a life-cycle simulation for PRS using PaveSpec software, information must be entered into a series of input screens. The inputs discussed in the following section are constant value 
inputs related to the project location, pavement and base design, and traffic and climatic conditions. As the analysis is described, the inputs screens from PaveSpec are shown within the software are shown for clarity in describing the position of each input in the program.

\subsubsection{Basic Specification Information}

The first series of inputs presented describe the specification and identify the project.

Although the life-cycle software has several data-entry fields in the first section, only two inputs are noted in the assembled table in Appendix C. Figure 6-4 shows the input screen with data from project R-25715.

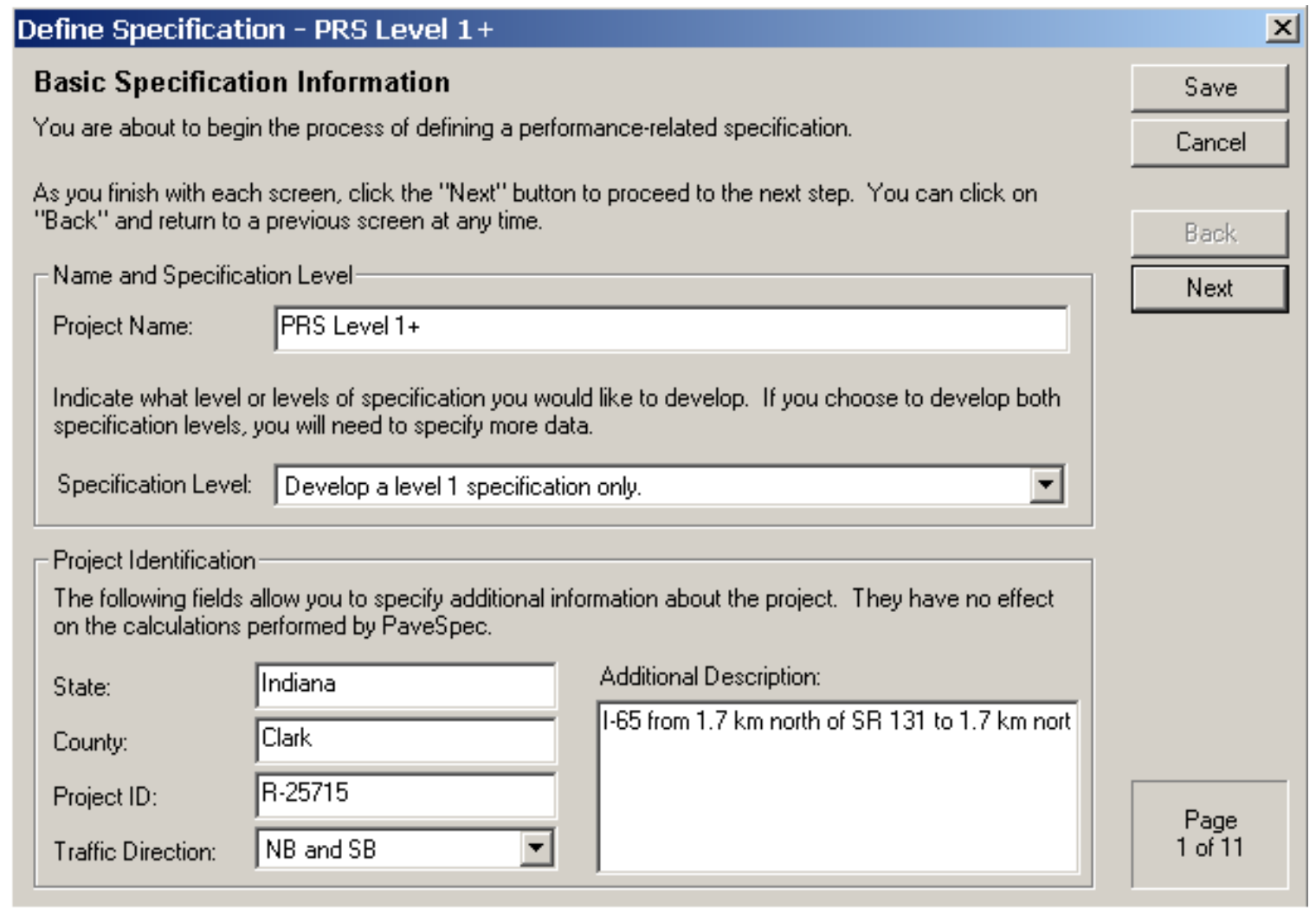

Figure 6-4 Input Screen for Basic Specification Information

Figure 6-4 correlates with Table 2-1, which shows the values for inputs \#1 and \#2, as used in project R-25715. 
Table 6-3 Basic Specification Information

\begin{tabular}{|c|c|c|c|c|}
\hline No. & Input & Ranges & Project Value & Source \\
\hline 1 & Specification Level & $\begin{array}{c}\text { Level 1 only, } \\
\text { Level 1 and Level 2 }\end{array}$ & $\begin{array}{c}\text { Develop a level 1 } \\
\text { specification only }\end{array}$ & User \\
\hline 2 & Traffic direction & $\begin{array}{c}\text { E, W, N, S, } \\
\text { E\&W, N\&S }\end{array}$ & North and south bound & Pavement Design \\
\hline
\end{tabular}

The basic specification information includes inputs for identification purposes. This information came from the INDOT's Pavement Design department. The project specific information should include the location of the project and the project number for easy identification. However, this information is purely informational and does not affect the lifecycle cost simulations.

As seen from input \#1 in Table 2-1, the scope of this project was limited to Level 1 PRS only. In a Level 1 PRS, separate pay factor charts are developed for each AQC. In Level 2 PRS, the actual as-constructed AQCs for one lot are entered into the program, and a comprehensive pay factor for the lot is determined directly from computer simulation. This allows for the AQCs to interact, for example, a deficiency in thickness maybe offset by higher strength. However, Level 2 PRS have not yet been implemented in any projects; therefore, its impacts on highway construction have not yet been observed.

\subsubsection{Dimensions and Lane Configuration}

The second series of inputs define the dimensions and configuration of the new highway, as shown in Figure 6-5. The Pavement Design department provided the values used in project R25715 . 


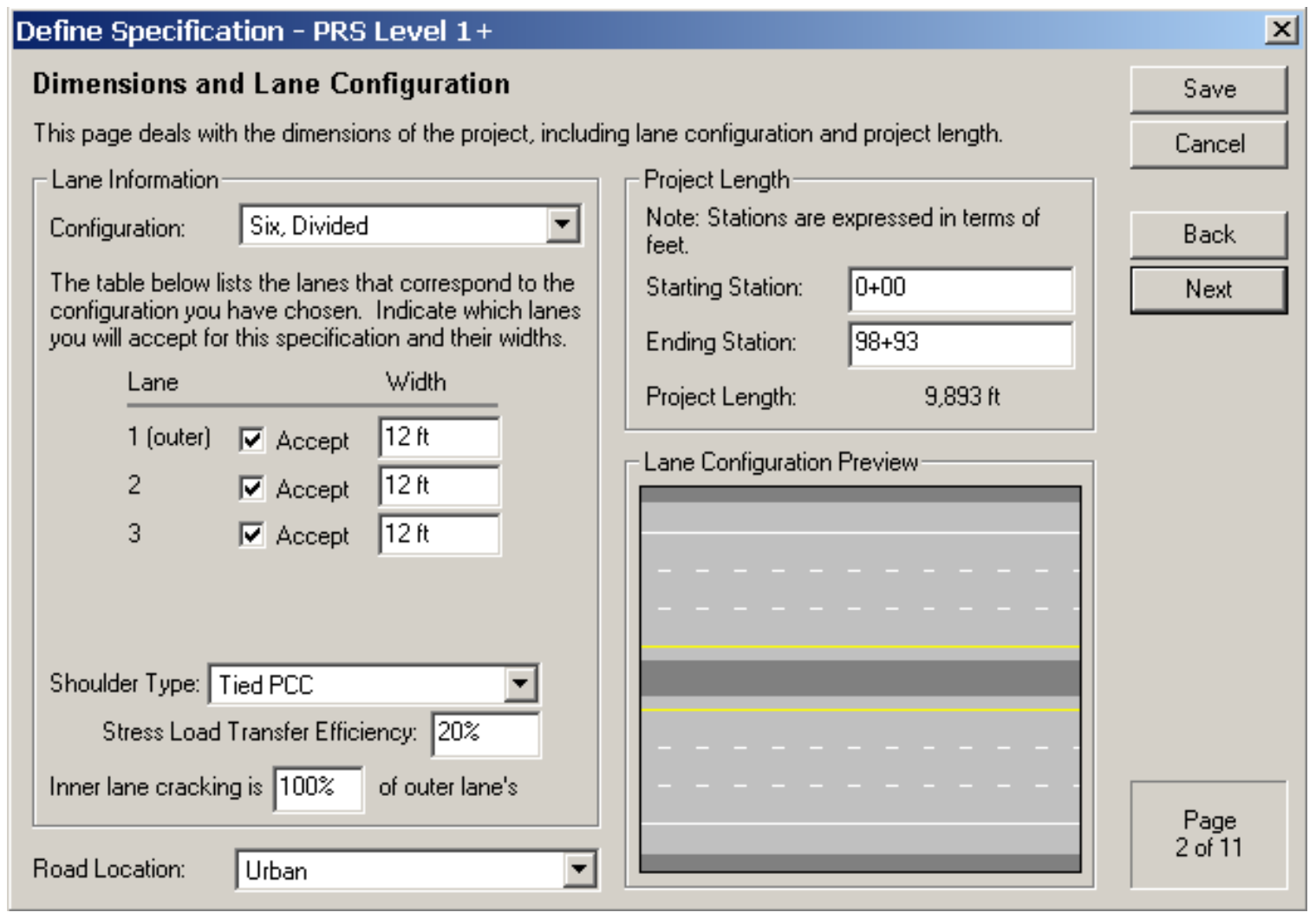

Figure 6-5 Input Screen for Dimensions and Lane Configuration

Table 6-4 shows the values for inputs \#3 through \#10 as used on Project R-25715.

Table 6-4 Dimensions and Lane Configuration

\begin{tabular}{|c|c|c|c|c|}
\hline No. & Input & Typical Ranges & Project Value & Source \\
\hline 3 & Lane configuration & 2-10 lanes, (un)divided & 6 lanes, divided & Pavement Design \\
\hline 4 & Lane width & $9-12$ feet* & 12 feet & Pavement Design \\
\hline 5 & $\begin{array}{c}\text { Lanes to be accepted } \\
\text { by PRS }\end{array}$ & All / Some & All & Pavement Design \\
\hline 6 & Shoulder type & $\begin{array}{c}\text { Widened lane / Tied PCC } \\
/ \text { Asphalt / Other }\end{array}$ & Tied PCC & Pavement Design \\
\hline 7 & $\begin{array}{c}\text { Stress load transfer } \\
\text { efficiency }\end{array}$ & $5-24 \%$ & $20 \%$ & Pavement Design \\
\hline 8 & $\begin{array}{c}\text { Inner lane cracking as } \\
\% \text { of outer lane }\end{array}$ & $0-100 \%$ & $100 \%$ & Pavement Design \\
\hline 9 & Road location & Urban / Rural & Urban & Pavement Design \\
\hline 10 & Project length & - & 9893 feet & Pavement Design \\
\hline
\end{tabular}

* Office of Highway Policy Information (OHPI), 2002

The first input analyzed is the lane configuration (input \#3). This input is used to determine the user costs in the life-cycle calculation. The ranges used for the analysis include all six possibilities included in the software. 
Table 6-5 Sensitivity of Lane Configuration

\begin{tabular}{|c|c|c|c|}
\hline $\begin{array}{c}\text { Lane } \\
\text { configuration }\end{array}$ & $\begin{array}{c}\text { Number of } \\
\text { lanes }\end{array}$ & $\begin{array}{c}\text { Present Worth Life- } \\
\text { Cycle Cost per mile }\end{array}$ & $\begin{array}{c}\text { \% change in LCC } \\
\text { from default }\end{array}$ \\
\hline Undivided & 2 & $\$ 13,154,092$ & $190 \%$ \\
\hline Undivided & 4 & $\$ 10,448,434$ & $130 \%$ \\
\hline Divided & 4 & $\$ 4,512,048$ & $-1 \%$ \\
\hline Divided & 6 & $\$ 4,537,481$ & - \\
\hline Divided & 8 & $\$ 4,562,913$ & $1 \%$ \\
\hline Divided & 10 & $\$ 4,588,346$ & $1 \%$ \\
\hline
\end{tabular}

Presently, PRS have only been used in the construction of interstates, which are divided highways, although the software is capable is analyzing a variety of roads. As seen in Table 6-5, the total life-cycle cost for undivided roads is higher than for divided roads, assuming all other project characteristics, including traffic, are constant. This is due to the values of user costs used in the model, which are higher for undivided roads than for divided roads, largely due to the average decreased speed of cars on undivided roads.

The difference in life-cycle cost between divided roads with a different number of lanes is within one percent of the default value, noting that the cost of initial construction is not included in the life-cycle cost. Further examination revealed little change in the pay factors produced by the software. This analysis shows that as long as divided highways are analyzed, the number of lanes is not a crucial input in the life-cycle cost software. However, the number of lanes can have other impacts, such as increasing the area of required repair, changing the traffic re-routing during construction, and increasing the overall project size.

The next input, the lane width (input \#4) is not used in any of the distress models within the life-cycle software. However, it could affect the cost of global rehabilitations later in the road's life. Since the cost of overlays is determined per area, a decrease in the lane width results in a lower life-cycle cost. In simulations, when the lane width was varied from nine to twelve feet, the life-cycle cost of the pavement varied within $1 \%$, and usually the pavement only required one 
overlay. The conclusion is that for pavements which require few or no rehabilitations, this input is not critical in the calculations of life-cycle cost.

The acceptance of lanes by the PRS specification (input \#5) allows the user to designate all or some of the lanes as PRS driven. When varied from zero to all, it was found that the life-cycle cost changed proportionally with the number of lanes, but the individual pay factors for the AQCs did not change. Table 6-6 shows that the software is sensitive to the number of lanes accepted by PRS. Note that the program cannot be run when no lanes are accepted by PRS.

Table 6-6 Sensitivity of Lane PRS Acceptance

\begin{tabular}{|c|c|c|}
\hline $\begin{array}{c}\text { Number of lanes } \\
\text { accepted by PRS }\end{array}$ & $\begin{array}{c}\text { Present Worth Life- } \\
\text { Cycle Cost per mile }\end{array}$ & $\begin{array}{c}\text { \% change in LCC } \\
\text { from default }\end{array}$ \\
\hline 3 & $\$ 4,537,481$ & - \\
\hline 2 & $\$ 3,015,175$ & $-34 \%$ \\
\hline 1 & $\$ 1,517,255$ & $-67 \%$ \\
\hline 0 & $\mathrm{~N} / \mathrm{A}$ & $\mathrm{N} / \mathrm{A}$ \\
\hline
\end{tabular}

It is logical that the agency would accept all lanes with PRS if any were accepted, to avoid confusion of working with two different specifications on one project. For this reason, the default value is that all lanes are accepted with PRS. It was noted in the simulations, however, that the pay factors assigned to the various AQCs remained unchanged during the simulations. Therefore, while this input affects the calculated life-cycle cost, it is not critical because it does not impact the pay factors produced by the software.

The next inputs, shoulder type and stress load transfer efficiency (inputs \#6 and \#7), are used in the fatigue cracking distress calculation. Shoulder type possibilities in the software are defined as tied Portland Cement Concrete (PCC), asphalt, widened lanes, and other. If tied PCC shoulders are specified, the stress load transfer efficiency must also be entered. According to Hoerner and Darter (2000), the stress load transfer efficiency typically varies between $5 \%$ and $50 \%$, with the recommendations of $20 \%$ if the shoulder and traffic lanes are constructed separately and $40 \%$ if they are constructed at the same time. However, trials revealed that the 
software actually only allows values between $0 \%$ and $24 \%$. Based on the construction practice in Indiana, the default value is $20 \%$.

When the shoulder type was ranged within the given values, no effect was observed in the life-cycle cost, since cracking was not observed. Therefore, it is determined that this input does not critically impact the life-cycle cost simulations.

Similarly, the sensitivity analysis of input \#8, the inner lane cracking as a percentage of the outer lane, revealed that for the given ranges, this input does not impact the life-cycle cost simulations.

The next input analyzed is the road location (input \#9), which, like the lane configuration, is used to calculate the user costs in the model. This value has a small impact on the model. The predicted life-cycle cost of a road in an urban location is slightly lower than one in a rural location with the same traffic volume, as shown in Table 6-7.

Table 6-7 Sensitivity Analysis of Road Location

\begin{tabular}{|c|c|c|}
\hline Location & $\begin{array}{c}\text { Present Worth Life- } \\
\text { Cycle Cost per mile }\end{array}$ & $\begin{array}{c}\text { \% change in LCC } \\
\text { from default }\end{array}$ \\
\hline Urban & $\$ 4,537,481$ & - \\
\hline Rural & $\$ 4,720,636$ & $4 \%$ \\
\hline
\end{tabular}

This shows that, all other inputs considered equal, the software predicts slightly higher user costs in rural areas than in urban areas. While road location has a slight impact on the software simulation, it is not considered a crucial input in life-cycle cost simulation.

The last input analyzed in this section was the project length, input \#10. The project length is not involved in any of the distress models or life-cycle cost models. Since the life-cycle cost is computed per unit length (per mile or per kilometer), this input does not impact the life-cycle software. Project length can impact the contractor in other ways; for example, providing an economy of scale of large projects, slightly lowering the bid price.

In conclusion, of all the inputs in the Dimensions and Lane Configuration section, only road location and PRS acceptance have a significant impact on the life-cycle simulations. Shoulder 
type and percentage of inner lane cracking may impact simulations if the pavement exhibits transverse fatigue cracking.

\subsubsection{Pavement Design Information}

The third series of inputs represent the pavement design information. These inputs describe many variables in the pavement design that are not measures of final pavement quality like the four AQCs, but these inputs are still used in the pavement distress calculations in the software. The pavement design inputs are divided into two sections: general design inputs and base variables. The general design inputs are discussed in Section 6.4.3.1 and the base variables are discussed in Section 6.4.3.2. Much of this data came from the Pavement Design and Materials and Tests divisions of INDOT.

\subsubsection{General Pavement Design Inputs}

The General Pavement Design inputs (\#11 to \#19) include items such as joint spacing, sealant, and dowel bar diameter. These inputs are shown in Figure 6-6 and in Table 6-8. These inputs are typically part of a concrete pavement design and may be addressed in the contract specifications, but they are not part of quality testing. Each input is identified with the distress calculations in which it is used. 


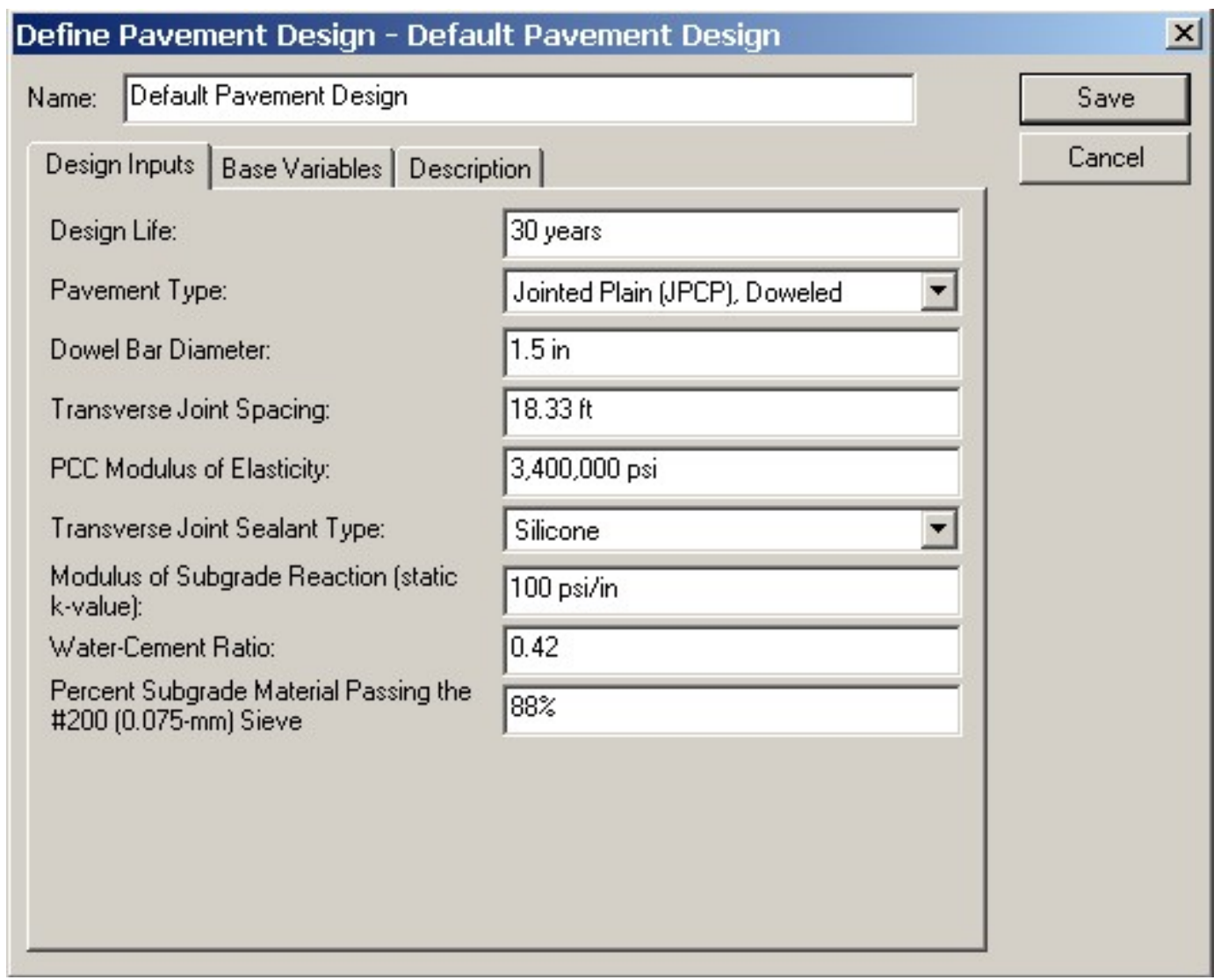

Figure 6-6 Input Screen for Pavement Design Information

Table 6-8 Pavement Design Information

\begin{tabular}{|c|c|c|c|c|}
\hline No. & Input & Typical Ranges & $\begin{array}{c}\text { Project } \\
\text { Value }\end{array}$ & Source \\
\hline 11 & Design life & $20-30$ years* & 30 years & $\begin{array}{c}\text { INDOT Pavement Design } \\
\text { Manual }\end{array}$ \\
\hline 12 & $\begin{array}{c}\text { Pavement Type (Jointed Plain } \\
\text { Concrete Pavement, only) }\end{array}$ & Doweled / Undoweled & Doweled & Pavement Design \\
\hline 13 & Dowel bar diameter & $1.0-1.5$ in $* *$ & $1.5 \mathrm{in}$. & Pavement Design \\
\hline 14 & Transverse joint spacing & $6-18 \mathrm{ft} * *$ & $18 \mathrm{ft}$ & Pavement Design \\
\hline 15 & PCC modulus of elasticity & $2 \times 10^{6}-6 \times 10^{6} \mathrm{psi}^{* * *}$ & $3.4 \times 10^{6} \mathrm{psi}$ & Pavement Design \\
\hline 16 & Joint sealant type & $\begin{array}{c}\text { None } / \text { Liquid asphalt } / \\
\text { Silicone } / \text { Preformed } \\
\text { compression seal }\end{array}$ & Silicone & Materials and Tests \\
\hline 17 & $\begin{array}{c}\text { Modulus of Subgrade } \\
\text { Reaction (static k-value) }\end{array}$ & $45-1200 \mathrm{psi} /$ in & $100 \mathrm{psi} / \mathrm{in}$ & Pavement Design \\
\hline 18 & water-cement ratio & $0.36-0.50$ & 0.42 & Pavement Design \\
\hline 19 & $\begin{array}{c}\text { Percent Subgrade Material } \\
\text { passing the \#200 sieve }\end{array}$ & $0-100 \%$ & $88 \%$ & Pavement Design \\
\hline
\end{tabular}

*American Concrete Pavement Association (2002)

** INDOT 1999 Standard Specifications

*** Mindess and Young (1981) 
The first input, design life (input \#11), is not part of any distress and life-cycle cost calculations. When varied within the given ranges, no change in the life-cycle cost was observed. Therefore design life is not crucial to PaveSpec simulations.

The next two inputs, pavement type and dowel bar diameter, (inputs \#12 and \#13), are values that determine the transverse joint faulting distress. Therefore a sensitivity analysis was performed to determine the effects on the pavement's life-cycle cost. In this analysis, faulting was used as a measure of pavement performance.

Table 6-9 Sensitivity Analysis of Pavement Type and Dowel Size

\begin{tabular}{|c|c|c|c|}
\hline Pavement Type & $\begin{array}{c}\text { Dowel size } \\
\text { (inch) }\end{array}$ & $\begin{array}{c}\text { Present Worth Life- } \\
\text { Cycle Cost per mile }\end{array}$ & $\begin{array}{c}\text { \% change } \\
\text { in LCC }\end{array}$ \\
\hline Doweled JPCP & 1.5 & $\$ 4,580,358$ & - \\
\hline Undoweled JPCP & 0 & $\$ 4,715,456$ & $2.9 \%$ \\
\hline Doweled JPCP & 0.75 & $\$ 4,713,943$ & $2.9 \%$ \\
\hline Doweled JPCP & 1 & $\$ 4,654,255$ & $1.6 \%$ \\
\hline Doweled JPCP & 1.25 & $\$ 4,596,510$ & $0.4 \%$ \\
\hline
\end{tabular}

As seen in Table 6-9, the presence and size of dowel bars does impact the life-cycle simulations slightly. Because faulting also depends on pavement thickness and percent consolidation around the dowels, dowel bar size will become even more important for thinner pavements. For this reason, the dowel bar dimensions are a crucial input in life-cycle simulations, if joint faulting is used as a measure of pavement performance. If joint faulting is not used, these inputs are not critical.

Joint spacing, (item \#14), like dowel bar diameter, is used in the transverse joint faulting prediction. However, joint spacing also plays a role in the prediction of fatigue cracking in PaveSpec. As a result thinner pavements, which are more susceptible to cracking and faulting, are more sensitive to joint spacing variations. For comparison, trials were run using the INDOT specified joint spacing of 18 feet for project R-25715 as a default. The sensitivity analysis of is summarized Table 6-10. 
Table 6-10 Sensitivity Analysis of Joint Spacing Variations

\begin{tabular}{|c|c|c|c|}
\hline $\begin{array}{c}\text { Joint Spacing } \\
\text { (feet) }\end{array}$ & $\begin{array}{c}\text { \% change in } \\
\text { Joint Spacing }\end{array}$ & $\begin{array}{c}\text { Present Worth Life- } \\
\text { Cycle Cost per mile }\end{array}$ & $\begin{array}{c}\text { \% change } \\
\text { in LCC }\end{array}$ \\
\hline 18 & - & $\$ 4,537,481$ & - \\
\hline 10 & $-45 \%$ & $\$ 4,575,148$ & $0.8 \%$ \\
\hline 12 & $-35 \%$ & $\$ 4,561,319$ & $0.5 \%$ \\
\hline 15 & $-18 \%$ & $\$ 4,547,513$ & $0.2 \%$ \\
\hline 20 & $9 \%$ & $\$ 4,533,712$ & $-0.1 \%$ \\
\hline 25 & $36 \%$ & $\$ 4,525,618$ & $-0.3 \%$ \\
\hline 30 & $64 \%$ & $\$ 4,521,717$ & $-0.3 \%$ \\
\hline
\end{tabular}

As seen in Table 6-10, when the joint spacing increases, the total life-cycle cost decreases. This disagrees with Hoerner et al. (2000), who concluded from their sensitivity analysis that an increase in joint spacing would result in an increase in slab cracking, and hence, overall lifecycle costs. It is noted in the simulation, however, that the PRS software predicts no cracking in any of the slabs using the current INDOT design. However, a slight increase is seen in the regular maintenance costs with a decrease in joint spacing. For example, the model predicts maintenance for the pavement with an 18-foot joint spacing to be $\$ 10,257$ every 5 years, while for the $12 \mathrm{ft}$. joint spacing, it is $\$ 12,883$ every 5 years. The conclusion is that a smaller joint spacing results in more joints per length, and hence, increased maintenance costs. However, due to its insignificant impact on the calculated life-cycle cost, joint spacing is not a crucial input in the life-cycle cost simulation.

Input \#15, the modulus of elasticity of the concrete, is also used in both the cracking and faulting models. Given the fact that INDOT's current design did not include faulting and resulted in zero predicted fatigue cracking, it was not unusual to see that the concrete modulus of elasticity had no effect on the trials. This input is therefore not crucial to life-cycle simulations.

The next input, joint sealant type (item \#16), affects the way spalling is predicted in the software. Although several joint sealant options are listed, an inspection of the spalling model calculation reveals that effectively only two options exist: preformed and non-preformed seals (Hoerner et al. 2000). Non-preformed seals include liquid asphalt, silicone, and the absence of 
seals. Therefore, an analysis is only necessary to examine the impact of preformed seals on the model.

Table 6-11 Sensitivity Analysis of Joint Sealant Type

\begin{tabular}{|c|c|c|c|}
\hline $\begin{array}{c}\text { Joint Sealant } \\
\text { Type }\end{array}$ & $\begin{array}{c}\text { Maximum Spalling } \\
\text { Predicted } \\
\text { (70 years) }\end{array}$ & $\begin{array}{c}\text { LCC (PW) } \\
\text { per mile }\end{array}$ & $\begin{array}{c}\text { \% change } \\
\text { from } \\
\text { standard }\end{array}$ \\
\hline Silicone & $86 \%$ & $\$ 5,028,605$ & - \\
\hline $\begin{array}{c}\text { Preformed } \\
\text { Compression Seals }\end{array}$ & $0.01 \%$ & $\$ 4,494,704$ & $-11 \%$ \\
\hline
\end{tabular}

As shown in Table 6-11, within a standard range of the flexural strengths, the impact of joint sealant is large. If preformed compression seals are used for joint sealant instead of silicone (current model input), the model effectively predicts no spalling. This causes a large decrease in the life-cycle cost, over $10 \%$. According to this sensitivity analysis joint sealant type is a crucial input in the life-cycle cost simulations.

The modulus of subgrade reaction (input \#17) is also known as the static k-value. This input is used in the cracking and faulting prediction models. Using the current PRS in Indiana, which does not consider faulting and predicts zero cracking, it is seen that this input does not significantly impact the life-cycle cost simulations.

Input $\# 18$, the water-cement ratio, is an element of the spalling distress calculation. However, within the typical ranges of w/c, trials showed no significant impact on the model, as shown in Table 6-12.

Table 6-12 Sensitivity Analysis of Water-Cement Ratio

\begin{tabular}{|c|c|c|c|}
\hline $\begin{array}{c}\text { Water-cement } \\
\text { ratio }\end{array}$ & $\begin{array}{c}\text { \% change } \\
\text { in w/c }\end{array}$ & $\begin{array}{c}\text { Present Worth Life- } \\
\text { Cycle Cost per mile }\end{array}$ & $\begin{array}{c}\text { \% change } \\
\text { in LCC }\end{array}$ \\
\hline 0.42 & - & $\$ 4,537,481$ & - \\
\hline 0.36 & $-14 \%$ & $\$ 4,524,316$ & $-0.3 \%$ \\
\hline 0.5 & $19 \%$ & $\$ 4,563,935$ & $0.6 \%$ \\
\hline
\end{tabular}


The last input in the general pavement design section is input \#19, the percent subgrade material passing the \#200 sieve. This input is part of the International Roughness Index, or IRI, model. For the given ranges, this input does not significantly affect the life-cycle simulations.

Of the inputs analyzed in this section, it is concluded that only joint spacing, dowel bar size, and joint sealant have significant impacts on the current life-cycle cost simulations, and therefore require increased attention when assembling the needed life-cycle simulation input data. The accuracy of the other inputs is not crucial to the model due to limited joint faulting and fatigue cracking distress prediction.

\subsubsection{Base Variables}

The next series of inputs describe the pavement base design. Figure 6-7 shows this input screen, which correlates to inputs \#20 to \#24 in Table 6-13. 


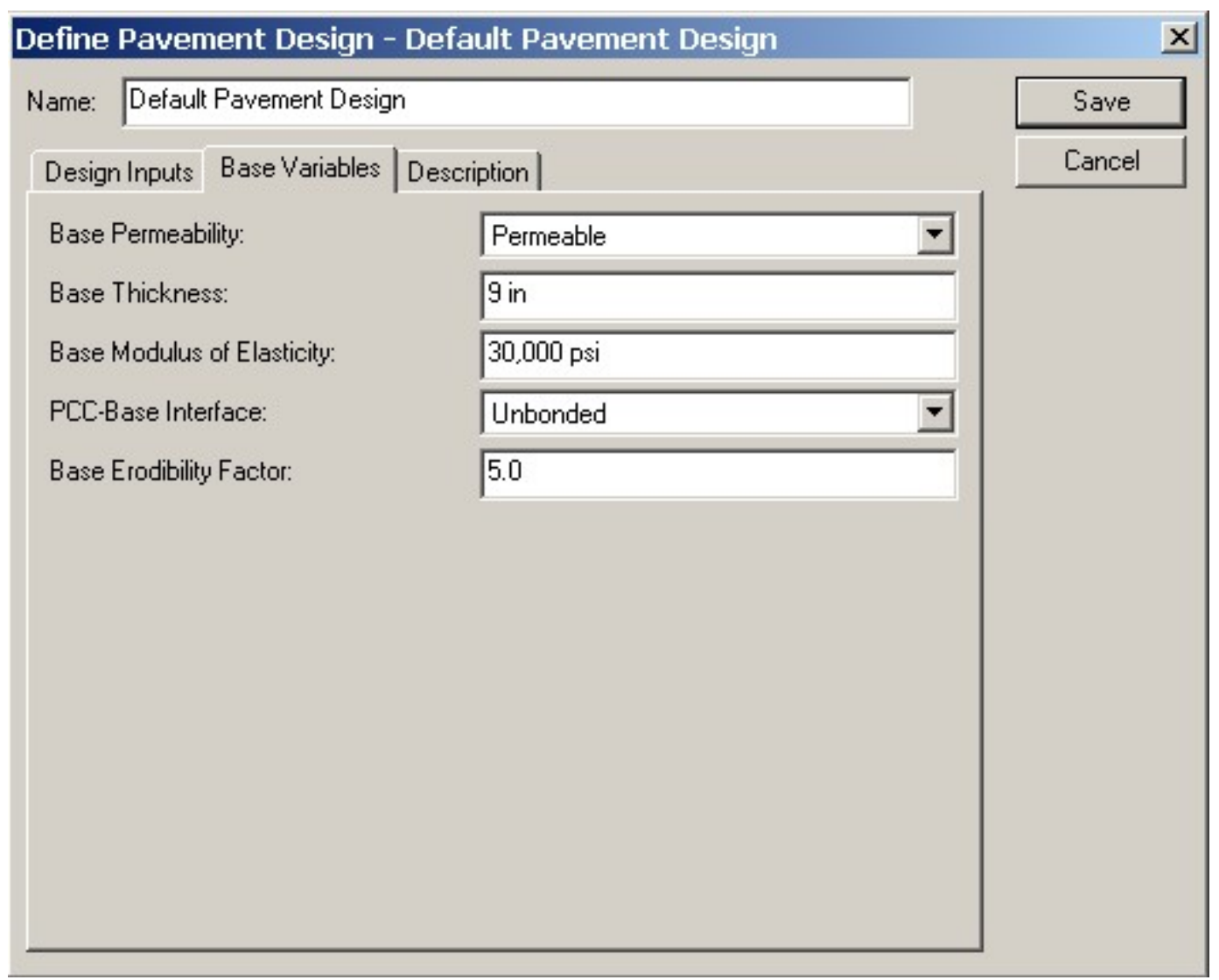

Figure 6-7 Input Screen for Pavement Base Design Information

Table 6-13 Pavement Base Design Information

\begin{tabular}{|c|c|c|c|c|}
\hline No. & Input & Typical Ranges & $\begin{array}{c}\text { Project } \\
\text { Value }\end{array}$ & Source \\
\hline 20 & Base permeability & (Non)permeable & Permeable & $\begin{array}{c}\text { Indiana Standard } \\
\text { Specifications }\end{array}$ \\
\hline 21 & Base thickness & $0-12$ in. * & 9 in. & $\begin{array}{c}\text { Indiana Standard } \\
\text { Specifications }\end{array}$ \\
\hline 22 & Base modulus of elasticity & $30,000-50,000 \mathrm{psi}^{* *}$ & $30,000 \mathrm{psi}$ & Pavement Design \\
\hline 23 & PCC-base interface & (Un)bonded & Unbonded & Pavement Design \\
\hline 24 & Base erodibility factor & $0.5-5.0$ & 5.0 & $\begin{array}{c}\text { Pavement Design and } \\
\text { FHWA-RD-00-131 }\end{array}$ \\
\hline
\end{tabular}

* Huang (1993)

** Dave (2001), assuming gravel or crushed aggregate is used.

Base permeability (input \#20) and the base erodibility factor (input \#24) are both inputs in the joint faulting distress model in PaveSpec. As such, they do not impact life-cycle simulations if joint faulting is not considered as a pavement performance measure. Base permeability in the 
current model is a yes-or-no input. The erodibility factor, described in the PaveSpec 3.0 User's Guide (Hoerner and Darter 2000), indicates the potential that the base will erode based on base and subbase material. Although the ranges given in the guide are from 0.5 to 7.5 , the software only allows a maximum value of five.

The other three inputs in the base design information page include the base thickness, the base modulus of elasticity, and the PCC-base interface (inputs \#21, \#22, and \#23, respectively). These inputs are part of the fatigue cracking model. As with previous inputs, these inputs are not critical to the life-cycle simulation due to the low amount of cracking predicted.

In conclusion, with the current model, none of the base variables are considered crucial to the development of PRS, as joint faulting and fatigue cracking are not predicted in the base case.

\subsubsection{Design Traffic Information}

The next series of inputs analyzed define the expected traffic loading. Traffic loading affects life-cycle simulation in two different manners. First, the fatigue cracking and transverse joint faulting distress models are load-driven, so as the traffic increases, more distress is predicted. Second, the software calculates a percentage of the user costs to include with the life-cycle cost of the highway. Therefore, higher traffic volumes will translate to higher life-cycle costs and steeper pay factors charts. Each of the traffic inputs is further explained and analyzed in this section. Figure 6-8 and Table 6-14 show the inputs used for traffic design in project R-25715. 


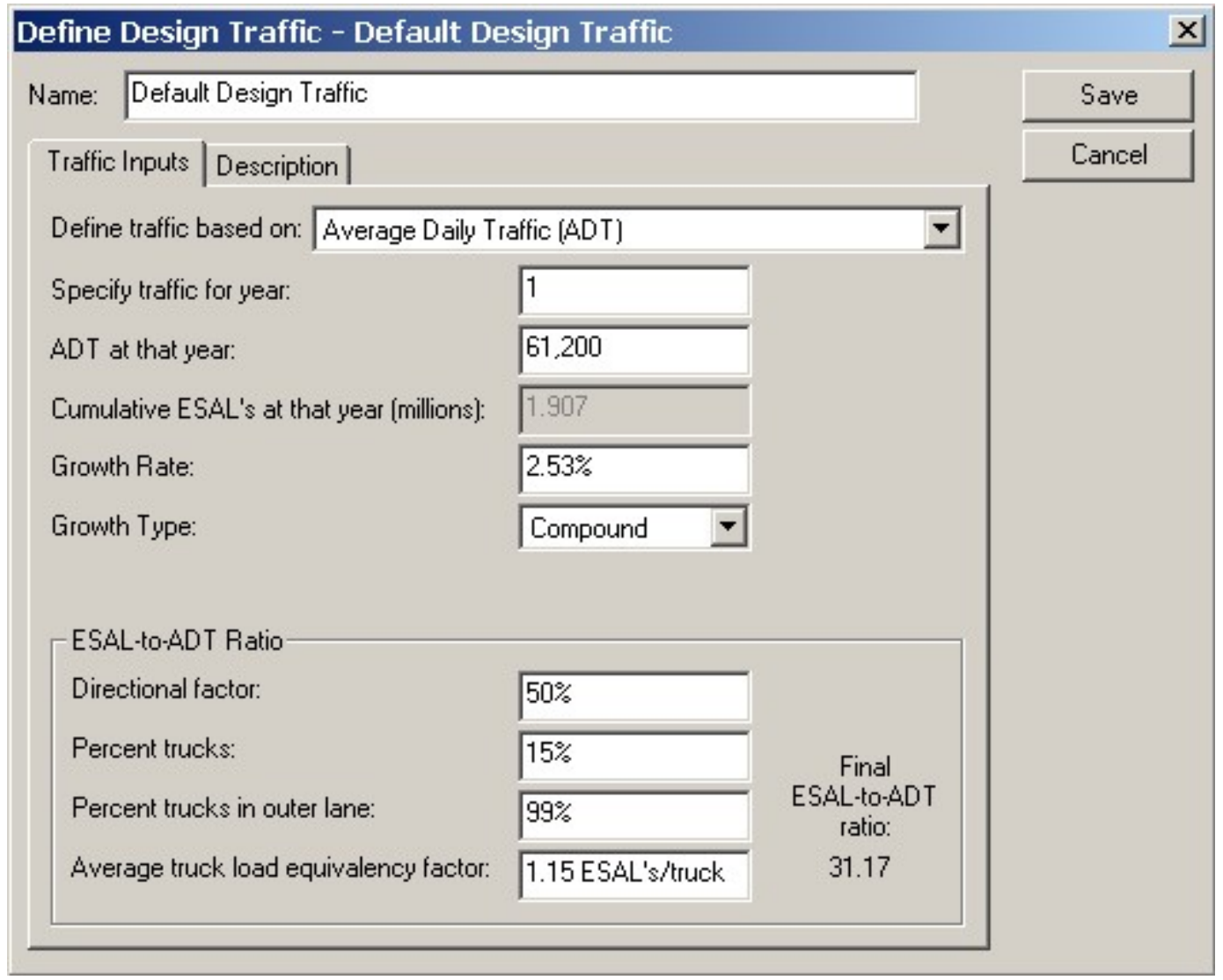

Figure 6-8 Input Screen for Design Traffic Information 
Table 6-14 Design Traffic Information

\begin{tabular}{|c|c|c|c|c|}
\hline No. & Input & Typical Ranges & Project Value & Source \\
\hline 25 & $\begin{array}{c}\text { Design traffic measure } \\
\text { to be used }\end{array}$ & ESAL / ADT* & ADT & Pavement Design \\
\hline 26 & $\begin{array}{c}\text { Year of traffic } \\
\text { information considered }\end{array}$ & $1-100$ & 1 & User \\
\hline 27 & Traffic loading at that year & $\begin{array}{c}10,000-200,000 \\
\text { ADT** }\end{array}$ & ADT $=61,200$ & Pavement Design \\
\hline 28 & Traffic growth rate & $0-9 \%$ & $2.53 \%$ & Pavement Design \\
\hline 29 & Traffic growth type & Simple / Compound & Compound & Materials and Tests \\
\hline 30 & $\begin{array}{c}\text { ESAL:ADT }- \\
\text { directional factor }\end{array}$ & $0-100 \%$ & $50 \%$ & Materials and Tests \\
\hline 31 & Percentage of trucks & $0-100 \%$ & $15 \%$ & Pavement Design \\
\hline 32 & $\begin{array}{c}\text { Percentage of trucks } \\
\text { in outer lane }\end{array}$ & $0-100 \%$ & $99 \%$ & Pavement Design \\
\hline 33 & $\begin{array}{c}\text { Average truck load } \\
\text { equivalency factor }\end{array}$ & $0.9-2.0 * * *$ & $\begin{array}{c}1.15 \text { ESALs } \\
\text { per truck }\end{array}$ & Pavement Design \\
\hline
\end{tabular}

* Equivalent Single-Axle Loading and Average Daily Traffic, respectively.

** INDOT 2000 Traffic Data

*** Gulen et al. (2000)

Input \#25, the type of traffic measure used, does not have to be analyzed. This option is solely provided to give the agency greater flexibility in defining the traffic volume. INDOT typically expresses traffic loading with Average Daily Traffic, or ADT, values. Since the lifecycle calculations rely on cumulative Equivalent Single-Axle Loadings (ESALs), if the traffic is entered in terms of ADT, the program simply converts to the appropriate measure.

The first input analyzed in this section is the year of traffic information considered (input \#26). This value represents the year for which the given traffic volume is entered. Although it can impact the software calculations, it is not considered important to the model because it does not define the traffic volume itself. This value is merely included for the convenience of the programmer. Therefore year of traffic is not as important as the traffic volume, the next input.

The design value for the traffic loading (input \#27) is one of the most critical inputs in PRS. These values are generally are set by the Pavement Design division of INDOT, thereby avoiding confusion as to what values to use in the PRS. However, changing the traffic loading can result 
in changes in the total life-cycle cost of the pavement. Simulations were run for the typical ranges of traffic volumes for Indiana interstate highways (INDOT 2000).

Table 6-15 Sensitivity Analysis of Traffic Loading

\begin{tabular}{|c|c|c|c|}
\hline $\begin{array}{c}\text { Traffic Loading } \\
\text { at year 1 }\end{array}$ & $\begin{array}{c}\text { \% change in } \\
\text { traffic loading }\end{array}$ & $\begin{array}{c}\text { Present Worth Life- } \\
\text { Cycle Cost per mile }\end{array}$ & $\begin{array}{c}\text { \% change } \\
\text { in LCC }\end{array}$ \\
\hline 12,000 ADT & $-80 \%$ & $\$ 956,781$ & $-79 \%$ \\
\hline 45,900 ADT & $-25 \%$ & $\$ 3,423,970$ & $-25 \%$ \\
\hline 61,200 ADT & $0 \%$ & $\$ 4,535,397$ & - \\
\hline 76,500 ADT & $+25 \%$ & $\$ 5,650,991$ & $+25 \%$ \\
\hline 100,000 ADT & $+63 \%$ & $\$ 7,361,285$ & $+62 \%$ \\
\hline 166,000 ADT & $+171 \%$ & $\$ 12,164,662$ & $+168 \%$ \\
\hline
\end{tabular}

As seen in Table 6-15, the amount of traffic has a great effect on the total life-cycle cost on the pavement. This is, to some extent, due to the increased deterioration of the pavement under higher loading. However, the life-cycle cost is impacted to a much greater extent by the rise in user costs as the traffic volume increases. Similarly, if the total number of users decreases, the total life-cycle cost decreases proportionally. Correct traffic volume, therefore, is of high importance to an engineer creating a PRS.

It can be deduced that as the traffic volume increases, the incentives and disincentives for the various AQCs will also increase. This is because higher volumes of traffic correspond to greater impacts on the users when the pavement deteriorates due to lower quality. This is illustrated in the Figure 6-9. 


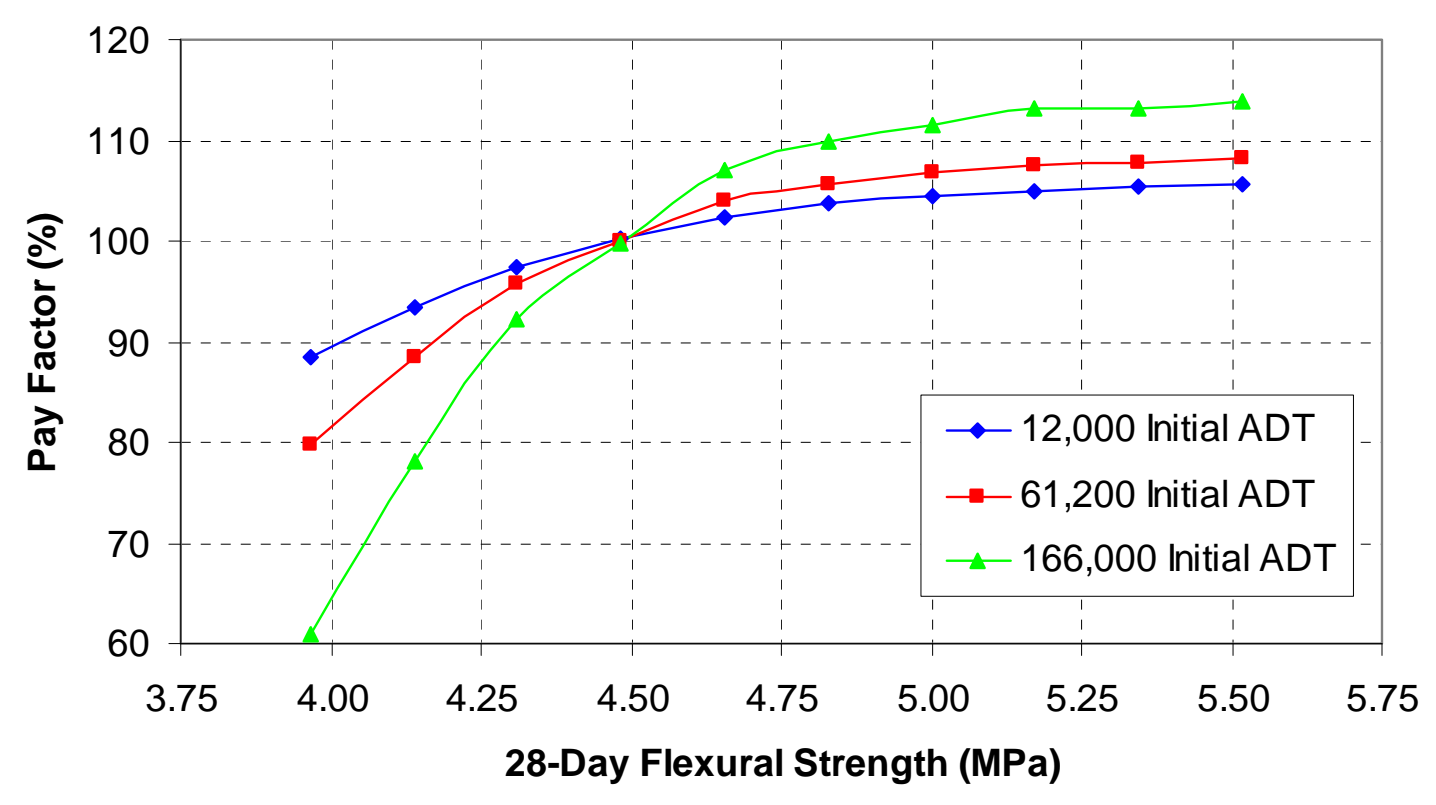

Figure 6-9 28-Day Flexural Strength Pay Factors for Different Traffic Volumes

In Figure 6-9, quality is measured by the 28-day flexural strength of the pavement. The values are shown for a standard deviation of $0.27 \mathrm{MPa}(40 \mathrm{psi})$. The pay factor (PF) awarded to the contractor is on the left axis. Under different traffic volumes, pavements constructed with the same strength earn different bonuses. As seen in the figure, higher traffic volumes lead to higher pay adjustments. PRS then can potentially make an even greater impact on quality in areas with high traffic volumes.

Traffic growth rate (input \#28), is equally as important to the model as the predicted traffic loading. National urban traffic growth rates, up to $9 \%$, were modeled in the software (Wendell Cox Consultancy 2003). The default growth rate of $2.53 \%$ was based on the initial and 10-year predicted traffic volumes for the project, provided by INDOT. 
Table 6-16 Sensitivity Analysis of Traffic Growth Rate

\begin{tabular}{|c|c|c|c|}
\hline Growth Rate & $\begin{array}{c}\text { \% change } \\
\text { in G.R. }\end{array}$ & $\begin{array}{c}\text { Present Worth Life- } \\
\text { Cycle Cost per mile }\end{array}$ & $\begin{array}{c}\text { \% change in } \\
\text { LCC }\end{array}$ \\
\hline $2.53 \%$ & - & $\$ 4,535,481$ & - \\
\hline$-1.00 \%$ & $-140 \%$ & $\mathrm{~N} / \mathrm{A}$ & $\mathrm{N} / \mathrm{A}$ \\
\hline $0.00 \%$ & $-100 \%$ & $\$ 2,304,641$ & $-49 \%$ \\
\hline $5.00 \%$ & $98 \%$ & $\$ 10,976,937$ & $142 \%$ \\
\hline $9.00 \%$ & $256 \%$ & $\$ 66,418,179$ & $1364 \%$ \\
\hline
\end{tabular}

The first conclusion noted from the sensitivity analysis in Table 6-16 is that the software does not allow negative growth rates. The effects of changing the growth rate are similar to changing the traffic volume. A small increase in the growth rate can result in a large change in the life-cycle cost. The traffic growth rate is as critical as the traffic volume in the simulation. High growth areas can lead to accelerating distress, making initial pavement quality even more important.

Input \#29 is the traffic growth type, defined as either simple or compound. The default value for this input is compound. A sensitivity analysis is shown in Table 6-17.

Table 6-17 Sensitivity Analysis of Traffic Growth Rate Type
\begin{tabular}{|c|c|c|}
\hline Growth Rate & $\begin{array}{c}\text { Present Worth Life- } \\
\text { Cycle Cost per mile }\end{array}$ & $\begin{array}{c}\text { \% change in } \\
\text { LCC }\end{array}$ \\
\hline Compound & $\$ 4,535,481$ & - \\
\hline Simple & $\$ 3,612,099$ & $-20 \%$ \\
\hline
\end{tabular}

Table 6-17 shows the effects of changing the growth rate from compound to simple, still using the same inputs for traffic loading and the growth rate. The simple growth rate results in a smaller total loading, and therefore, a smaller life-cycle cost.

As mentioned earlier, the user has the option of using either ADT or ESAL as the method of traffic measurement. If ADT is selected, inputs \#30 through \#33 are used to determine the ESAL to ADT ratio. Input \#30 is the ESAL:ADT directional factor. This input expresses the percentage of traffic that is found in the design direction. For one-way streets, this value is $100 \%$, for two-way roads, it is $50 \%$. 
Table 6-18 Sensitivity Analysis of Directional Factor

\begin{tabular}{|c|c|c|c|}
\hline $\begin{array}{c}\text { Directional } \\
\text { Factor }\end{array}$ & $\begin{array}{c}\text { \% change } \\
\text { in DF }\end{array}$ & $\begin{array}{c}\text { Present Worth Life- } \\
\text { Cycle Cost per mile }\end{array}$ & $\begin{array}{c}\text { \% change } \\
\text { in LCC }\end{array}$ \\
\hline $0 \%$ & $-100 \%$ & $\$ 368,743$ & $-92 \%$ \\
\hline $25 \%$ & $-50 \%$ & $\$ 2,305,018$ & $-49 \%$ \\
\hline $50 \%$ & - & $\$ 4,535,481$ & - \\
\hline $75 \%$ & $50 \%$ & $\$ 6,753,930$ & $49 \%$ \\
\hline $100 \%$ & $100 \%$ & $\$ 8,991,522$ & $98 \%$ \\
\hline
\end{tabular}

As seen in Table 6-18, the directional factor has a large impact on the life-cycle simulations. The change in life-cycle cost is proportional to the change in the directional factor. Although this is a crucial input in the software, the value is fixed by INDOT at 50\% and should not require additional analysis (INDOT Pavement Design Manual 2002).

The next three inputs, \#31 through \#33, are variables related to the truck traffic. These inputs do not affect the total number of users on the highway, but they do impact the joint faulting and fatigue cracking distress models through changing the loading. Using the current model, no significant impacts on the life-cycle costs were found within the expected ranges of each input, due to the fact that joint faulting was not considered and that no fatigue cracking was predicted. It should be noted, regardless of the model, that none of these inputs should be set to zero, as this causes the program to err.

In conclusion, the traffic inputs which related directly to the number of users on the highway (traffic volume, growth rate, and the directional factor), are important to the life-cycle simulations due to their large impact on the user-costs' portion of the life-cycle cost. Factors that influence the pavement loading are not crucial if the model predicts little to no faulting and cracking. Increased traffic volumes lead to higher payment adjustments, and therefore will impact the submitted bid prices in PRS.

\subsubsection{Climatic Information}

The next series of inputs are entered in the climatic data module in PaveSpec. Climatic information only includes five inputs, but during the course of the project, it was realized that 
some of the information can be difficult to obtain. To make data collection easier, climatic values were collected for the state of Indiana, and the sources given for other national data centers.

Two useful sources of climatic information were uncovered during the course of this investigation. One was the Midwestern Regional Climate Center (MRCC), whose website contains climatic data collected from many cities across the Midwest (MRCC 2002).

Precipitation and temperature data could be obtained from this database. The second data source was the National Snow and Ice Data Center (NSIDC), which publishes global freezing indices based on latitude and longitude coordinates, rounded to the nearest 0.5 degree (NSIDC 2002). From this database, the freezing index values for Indiana were obtained.

Most of the climatic data can be obtained in a direct fashion; however the average annual air freeze-thaw cycles (input \#36) could not. The MRCC does not list values for freeze-thaw cycles; however, included in the climatic data are the total days annually when the maximum and minimum temperatures are below freezing $\left(0^{\circ} \mathrm{C}, 32^{\circ} \mathrm{F}\right)$. Taking the difference between these two values gives the number of days when the minimum temperature is below freezing and the maximum temperature is above freezing, hence, the total annual air freeze-thaw cycles.

Example climatic data for Indiana Department of Transportation (INDOT) subdistricts is shown in Table 6-19 and Table 6-20. 
Table 6-19 Metric Climatic Data for INDOT Subdistricts

\begin{tabular}{|c|c|c|c|c|c|c|c|}
\hline \multirow[b]{2}{*}{ INDOT District } & \multirow[b]{2}{*}{ Subdistrict (City)* } & \multicolumn{4}{|c|}{ 1971-2000 average annual normals } & \multirow[b]{2}{*}{$\begin{array}{l}\text { Freezing } \\
\text { Index }\end{array}$} & \multirow[b]{2}{*}{ Climate } \\
\hline & & Precipitation & $\begin{array}{c}\text { Daily } \\
\text { Temperature }\end{array}$ & $\begin{array}{c}\text { Days } \\
T \_ \text {max }>32\end{array}$ & $\begin{array}{l}\text { Air F-T } \\
\text { cycles }\end{array}$ & & \\
\hline & & $(\mathrm{cm})$ & (deg. C) & & & (deg. C-days) & \\
\hline Laporte & $\begin{array}{l}\text { Laporte } \\
\text { Gary (Hobart) } \\
\text { Plymouth } \\
\text { Winamac } \\
\text { Rensselaer } \\
\text { Monticello (Delphi) }\end{array}$ & $\begin{array}{c}104 \\
97 \\
101 \\
95 \\
97 \\
96\end{array}$ & $\begin{array}{c}9.8 \\
9.6 \\
9.6 \\
9.8 \\
10.0 \\
10.9\end{array}$ & $\begin{array}{l}11.2 \\
21.2 \\
12.4 \\
12.2 \\
19.2 \\
20.4\end{array}$ & $\begin{array}{l}78.0 \\
96.3 \\
83.7 \\
91.3 \\
86.9 \\
86.5\end{array}$ & $\begin{array}{l}256 \\
244 \\
230 \\
247 \\
238 \\
198\end{array}$ & $\begin{array}{l}\text { wet freeze } \\
\text { wet freeze } \\
\text { wet freeze } \\
\text { wet freeze } \\
\text { wet freeze } \\
\text { wet freeze }\end{array}$ \\
\hline Fort Wayne & $\begin{array}{l}\text { Angola } \\
\text { Goshen } \\
\text { Warsaw } \\
\text { Fort Wayne } \\
\text { Wabash } \\
\text { Bluffton }\end{array}$ & $\begin{array}{l}95 \\
93 \\
93 \\
93 \\
98 \\
93\end{array}$ & $\begin{array}{c}9.8 \\
10.3 \\
9.4 \\
9.9 \\
9.4 \\
9.9\end{array}$ & $\begin{array}{c}7.5 \\
13.5 \\
10.1 \\
15.4 \\
13.9 \\
12.2\end{array}$ & $\begin{array}{l}97.2 \\
82.7 \\
88.7 \\
83.9 \\
99.4 \\
87.5\end{array}$ & $\begin{array}{l}266 \\
262 \\
223 \\
224 \\
172 \\
171\end{array}$ & $\begin{array}{l}\text { wet freeze } \\
\text { wet freeze } \\
\text { wet freeze } \\
\text { wet freeze } \\
\text { wet freeze } \\
\text { wet freeze }\end{array}$ \\
\hline \begin{tabular}{|l|} 
Greenfield \\
\end{tabular} & $\begin{array}{l}\text { Tipton } \\
\text { Albany (Muncie) } \\
\text { Indianapolis } \\
\text { Greenfield } \\
\text { Centerville (Richmond) }\end{array}$ & $\begin{array}{c}94 \\
99 \\
104 \\
110 \\
100\end{array}$ & $\begin{array}{c}9.6 \\
10.4 \\
11.4 \\
10.9 \\
10.4\end{array}$ & $\begin{array}{l}10.0 \\
16.0 \\
17.5 \\
19.1 \\
13.7\end{array}$ & $\begin{array}{l}94.7 \\
86.7 \\
81.3 \\
86.8 \\
93.7\end{array}$ & $\begin{array}{c}132 \\
126 \\
60 \\
64 \\
78\end{array}$ & $\begin{array}{l}\text { wet freeze } \\
\text { wet freeze } \\
\text { wet freeze } \\
\text { wet freeze } \\
\text { wet freeze }\end{array}$ \\
\hline Crawfordsville & $\begin{array}{l}\text { Fowler (West Lafayette) } \\
\text { Frankfort } \\
\text { Crawfordsville } \\
\text { Cloverdale (Greencastle) } \\
\text { Terre Haute }\end{array}$ & $\begin{array}{c}95 \\
101 \\
101 \\
112 \\
108\end{array}$ & $\begin{array}{l}10.3 \\
10.4 \\
10.1 \\
11.4 \\
11.7\end{array}$ & $\begin{array}{l}15.0 \\
14.9 \\
18.9 \\
24.2 \\
28.2\end{array}$ & $\begin{array}{c}89.4 \\
88.7 \\
102.1 \\
82.8 \\
91.2\end{array}$ & $\begin{array}{c}137 \\
145 \\
73 \\
74 \\
32\end{array}$ & $\begin{array}{l}\text { wet freeze } \\
\text { wet freeze } \\
\text { wet freeze } \\
\text { wet freeze } \\
\text { wet freeze }\end{array}$ \\
\hline Seymour & $\begin{array}{l}\text { Bloomington } \\
\text { Columbus } \\
\text { Aurora (Vevay) } \\
\text { Madison } \\
\text { Falls City (Louisville, KY) }\end{array}$ & $\begin{array}{l}114 \\
107 \\
115 \\
117 \\
113\end{array}$ & $\begin{array}{l}11.7 \\
11.7 \\
13.2 \\
12.6 \\
13.8\end{array}$ & $\begin{array}{l}20.4 \\
19.6 \\
34.7 \\
26.6 \\
33.2\end{array}$ & $\begin{array}{l}82.3 \\
90.6 \\
81.3 \\
77.5 \\
65.0\end{array}$ & $\begin{array}{c}18 \\
25 \\
26 \\
0 \\
0\end{array}$ & $\begin{array}{l}\text { wet freeze } \\
\text { wet freeze } \\
\text { wet non-freeze } \\
\text { wet freeze } \\
\text { wet non-freeze }\end{array}$ \\
\hline Vincennes & $\begin{array}{l}\text { Linton (Crane) } \\
\text { Paoli } \\
\text { Vincennes } \\
\text { Tell City } \\
\text { Evansville } \\
\text { Dale (Tell City) }\end{array}$ & $\begin{array}{l}123 \\
121 \\
113 \\
121 \\
112 \\
121\end{array}$ & $\begin{array}{l}12.9 \\
11.7 \\
11.9 \\
13.2 \\
13.3 \\
13.2\end{array}$ & $\begin{array}{l}28.6 \\
30.9 \\
35.0 \\
34.2 \\
41.9 \\
34.2\end{array}$ & $\begin{array}{l}77.8 \\
98.2 \\
87.2 \\
73.4 \\
73.5 \\
73.4\end{array}$ & $\begin{array}{c}32 \\
3 \\
9 \\
0 \\
0 \\
0\end{array}$ & $\begin{array}{l}\text { wet freeze } \\
\text { wet freeze } \\
\text { wet freeze } \\
\text { wet non-freeze } \\
\text { wet non-freeze } \\
\text { wet non-freeze }\end{array}$ \\
\hline
\end{tabular}

*note: Cities in parantheses are the nearest available weather stations. 
Table 6-20 English Climatic Data for INDOT Subdistricts

\begin{tabular}{|c|c|c|c|c|c|c|c|}
\hline \multirow[b]{2}{*}{ INDOT District } & \multirow[b]{2}{*}{ Subdistrict (City)* } & \multicolumn{4}{|c|}{$1971-2000$ average annual normals } & \multirow[b]{2}{*}{ Freezing Index } & \multirow[b]{2}{*}{ Climate } \\
\hline & & Precipitation & $\begin{array}{c}\text { Daily } \\
\text { Temperature }\end{array}$ & $\begin{array}{c}\text { Days } \\
\text { T_max }>90\end{array}$ & $\begin{array}{l}\text { Air F-T } \\
\text { cycles }\end{array}$ & & \\
\hline & & (inches) & (deg. F) & & & (deg. F-days) & \\
\hline \multirow{6}{*}{ Laporte } & Laporte & 40.8 & 49.7 & 11.2 & 78.0 & 461 & wet freeze \\
\hline & Gary (Hobart) & 38.0 & 49.2 & 21.2 & 96.3 & 439 & wet freeze \\
\hline & Plymouth & 39.8 & 49.2 & 12.4 & 83.7 & 414 & wet freeze \\
\hline & Winamac & 37.4 & 49.7 & 12.2 & 91.3 & 445 & wet freeze \\
\hline & Rensselaer & 38.4 & 50.0 & 19.2 & 86.9 & 428 & wet freeze \\
\hline & Monticello (Delphi) & 37.9 & 51.7 & 20.4 & 86.5 & 356 & wet freeze \\
\hline \multirow[t]{6}{*}{ Fort Wayne } & Angola & 37.3 & 49.7 & 7.5 & 97.2 & 479 & wet freeze \\
\hline & Goshen & 36.6 & 50.5 & 13.5 & 82.7 & 472 & wet freeze \\
\hline & Warsaw & 36.7 & 49.0 & 10.1 & 88.7 & 401 & wet freeze \\
\hline & Fort Wayne & 36.6 & 49.9 & 15.4 & 83.9 & 403 & wet freeze \\
\hline & Wabash & 38.6 & 49.0 & 13.9 & 99.4 & 310 & wet freeze \\
\hline & Bluffton & 36.5 & 49.9 & 12.2 & 87.5 & 308 & wet freeze \\
\hline \multirow[t]{5}{*}{ Greenfield } & Tipton & 37.2 & 49.2 & 10.0 & 94.7 & 238 & wet freeze \\
\hline & Albany (Muncie) & 38.9 & 50.8 & 16.0 & 86.7 & 227 & wet freeze \\
\hline & Indianapolis & 41.0 & 52.5 & 17.5 & 81.3 & 108 & wet freeze \\
\hline & Greenfield & 43.4 & 51.6 & 19.1 & 86.8 & 115 & wet freeze \\
\hline & Centerville (Richmond) & 39.6 & 50.8 & 13.7 & 93.7 & 140 & wet freeze \\
\hline \multirow[t]{5}{*}{ Crawfordsville } & Fowler (West Lafayette) & 37.3 & 50.5 & 15.0 & 89.4 & 247 & wet freeze \\
\hline & Frankfort & 39.6 & 50.7 & 14.9 & 88.7 & 261 & wet freeze \\
\hline & Crawfordsville & 39.7 & 50.1 & 18.9 & 102.1 & 131 & wet freeze \\
\hline & Cloverdale (Greencastle) & 44.2 & 52.6 & 24.2 & 82.8 & 133 & wet freeze \\
\hline & Terre Haute & 42.5 & 53.1 & 28.2 & 91.2 & 58 & wet freeze \\
\hline \multirow[t]{5}{*}{ Seymour } & Bloomington & 44.9 & 53.1 & 20.4 & 82.3 & 32 & wet freeze \\
\hline & Columbus & 41.9 & 53.1 & 19.6 & 90.6 & 45 & wet freeze \\
\hline & Aurora (Vevay) & 45.1 & 55.7 & 34.7 & 81.3 & 47 & wet non-freeze \\
\hline & Madison & 46.1 & 54.7 & 26.6 & 77.5 & 0 & wet freeze \\
\hline & Falls City (Louisville, KY) & 44.5 & 56.9 & 33.2 & 65.0 & 0 & wet non-freeze \\
\hline \multirow[t]{6}{*}{ Vincennes } & Linton (Crane) & 48.3 & 55.3 & 28.6 & 77.8 & 58 & wet freeze \\
\hline & Paoli & 47.6 & 53.0 & 30.9 & 98.2 & 5 & wet freeze \\
\hline & Vincennes & 44.4 & 53.4 & 35.0 & 87.2 & 16 & wet freeze \\
\hline & Tell City & 47.8 & 55.8 & 34.2 & 73.4 & 0 & wet non-freeze \\
\hline & Evansville & 44.3 & 56.0 & 41.9 & 73.5 & 0 & wet non-freeze \\
\hline & Dale (Tell City) & 47.8 & 55.8 & 34.2 & 73.4 & 0 & wet non-freeze \\
\hline
\end{tabular}

This climatic information was not available at the time of the second PRS contract letting, and therefore the simulations were run using estimated numbers, which did not match the information presented in Table 6-19 and Table 6-20. Figure 6-10 shows the climatic data as entered for the project, inputs \#34 through \#38. The ranges and data sources for these inputs are shown in Table 6-21. 


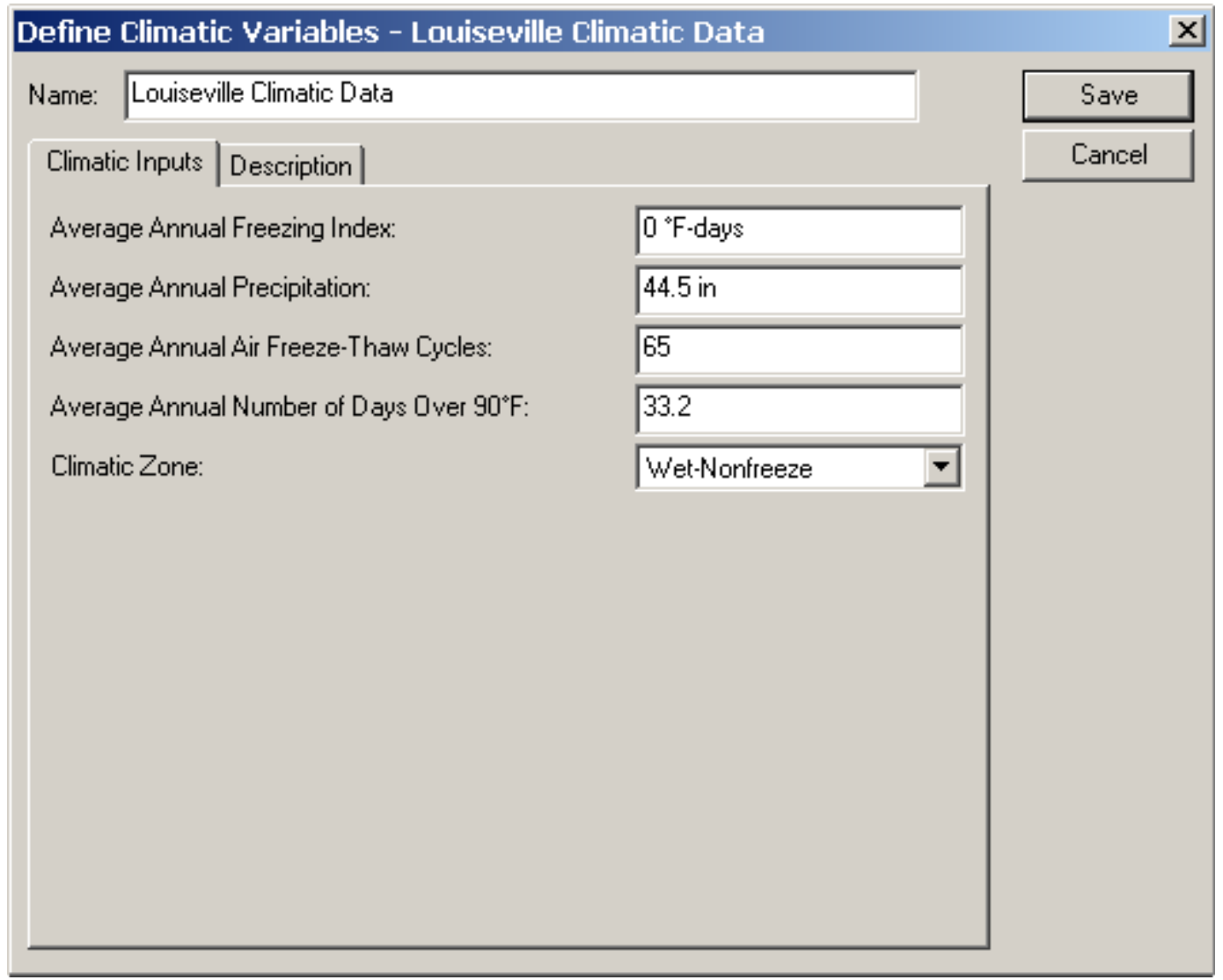

Figure 6-10 Input Screen for Climatic Information

Table 6-21 Climatic Information

\begin{tabular}{|c|c|c|c|c|}
\hline No. & Input & Typical Ranges & Project Value & Source \\
\hline 34 & $\begin{array}{c}\text { Average annual } \\
\text { freezing index }\end{array}$ & $\begin{array}{c}0-3000^{\circ} \mathrm{F} \text {-days (national) } \\
0-500^{\circ} \mathrm{F} \text {-days (Indiana) }\end{array}$ & 0 ${ }^{\circ} \mathrm{F}$-days & $\begin{array}{c}\text { National Snow and Ice } \\
\text { Data Center }\end{array}$ \\
\hline 35 & $\begin{array}{c}\text { Average Annual } \\
\text { Precipitation }\end{array}$ & $\begin{array}{c}2-137 \text { inches (national) } \\
36-49 \text { inches (Indiana) }\end{array}$ & 44.5 inches & $\begin{array}{c}\text { Midwestern Regional } \\
\text { Climate Center }\end{array}$ \\
\hline 36 & $\begin{array}{c}\text { Average annual air freeze- } \\
\text { thaw cycles }\end{array}$ & $\begin{array}{c}0-110 \text { (national) } \\
65-102 \text { (Indiana) }\end{array}$ & 15 cycles* & $\begin{array}{c}\text { Midwestern Regional } \\
\text { Climate Center }\end{array}$ \\
\hline 38 & $\begin{array}{c}\text { Average annual number of } \\
\text { days over } 90^{\circ} \mathrm{F} / 32^{\circ} \mathrm{C}\end{array}$ & $\begin{array}{c}0-189 \text { (national) } \\
7-42 \text { (Indiana) }\end{array}$ & $\begin{array}{c}\text { Midwestern Regional } \\
\text { Climate Center }\end{array}$ \\
\hline
\end{tabular}

* Value was later determined to be 65 cycles

** Value was later determined to be 33 days

*** Value was later determined to be Wet-Non-freeze

The average annual freezing index (input \#34), is used in the smoothness distress model in the software. The freezing index for Clarksville, IN, the project site, is zero. However, 
simulations show that when the freezing index is varied throughout the range of values given for Indiana, the resulting variations in the life-cycle costs are always within $1 \%$ of the original value. Therefore, this input has no significant impact on the life-cycle simulations.

The average annual precipitation (input \#35), is used in the prediction of transverse joint faulting distress. However, simulations show that within the given ranges, less than $1 \%$ change in the life-cycle cost is observed. Given the abundance of precipitation information, this input should pose no problem for data collection, and its accuracy is not significant to the model.

The annual number of freeze-thaw cycles (input \#36) is a crucial input in the transverse joint spalling model. It is, in fact, the driving force behind the distress.

Table 6-22 Sensitivity Analysis of Annual Air Freeze-Thaw Cycles Variation

\begin{tabular}{|c|c|c|}
\hline Air Freeze-Thaw Cycles & $\begin{array}{c}\text { Present Worth Life- } \\
\text { Cycle Cost per mile }\end{array}$ & \% change in LCC \\
\hline 0 & $\$ 4,555,351$ & $-11.5 \%$ \\
\hline 30 & $\$ 4,739,965$ & $-8.0 \%$ \\
\hline 65 & $\$ 5,150,071$ & - \\
\hline 90 & $\$ 5,346,460$ & $3.8 \%$ \\
\hline 102 & $\$ 5,427,069$ & $5.4 \%$ \\
\hline 110 & $\$ 5,476,466$ & $6.4 \%$ \\
\hline
\end{tabular}

The results in Table 6-22 show that as climates become more severe in terms of freezing and thawing, the life-cycle costs associated with those pavements will increase. This is due to pavements showing an increase in spalling in these climates. Since the spalling model includes the AQCs of strength, thickness, and air content, increased freeze-thaw cycles will impact the pay factor graphs. This is especially evident in the air content pay factors, as shown in Figure 6-11. Therefore, freeze-thaw cycles are a very important input in PRS. Pavements constructed in freeze-thaw susceptible climates will be heavily influenced by the air content AQC. 


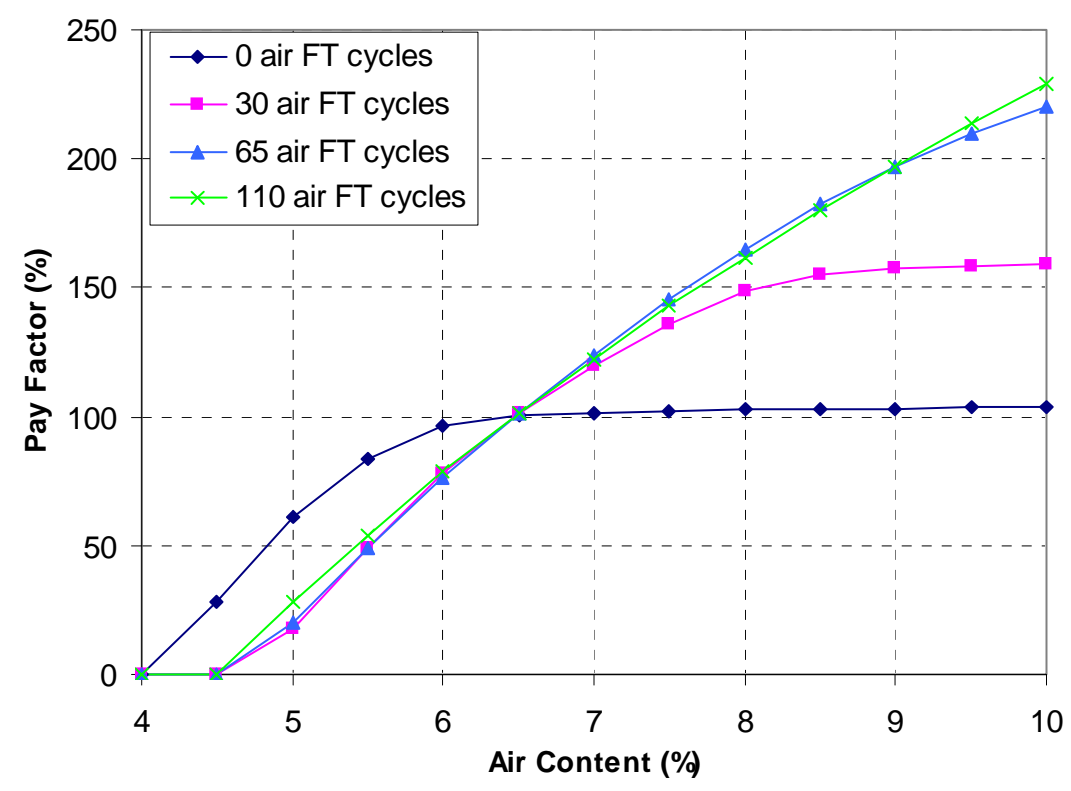

Figure 6-11 Pay Factors in Different Freeze-Thaw Climates

The next input, the average annual number of hot days (input \#37), is also an input into the joint faulting distress model, like the annual precipitation. Simulations show that for the typical ranges of this input, no change in the life-cycle cost is observed. Unless different project conditions indicate a moderate amount of predicted joint faulting, this input in not among the critical inputs for PRS.

The last climatic input, the climatic zone description (input \#38), requires the knowledge of the average annual temperature and precipitation of the project location. The climatic zone is used in the fatigue cracking distress model. Given that the project had zero predicted cracking, this input did not affect the life-cycle cost for the given ranges in the simulations.

In conclusion, the only critical input in the climatic section, under the conditions used in the simulations, is the average annual freeze-thaw cycles, which strongly impacts the spalling model and air content pay factor graphs. 


\subsection{Summary of Project and Design-Related Inputs}

The following table is a summary of the most critical project and design-related inputs as discussed in this chapter. The results show that the inputs which determine traffic loading and impact the spalling model are the most significant in PRS.

Table 6-23 Summary of Most Significant Constant Value Inputs in PRS
\begin{tabular}{|c|c|}
\hline Input name & $\begin{array}{c}\text { Maximum observed change in Life-cycle } \\
\text { cost for given range in simulations }\end{array}$ \\
\hline Dowel Size & $2.9 \%$ \\
\hline Joint Sealant & $-11 \%$ \\
\hline Traffic loading & $168 \%$ \\
\hline Traffic Growth Rate & $1364 \%$ \\
\hline Traffic Growth Type & $20 \%$ \\
\hline ESAL:ADT Directional Factor & $98 \%$ \\
\hline Annual Air Freeze-Thaw Cycles & $-11.5 \%$ \\
\hline
\end{tabular}

PRS projects which occur in high-traffic areas will see higher pay adjustments for certain quality levels. Projects in areas with severe freezing and thawing will also have high adjustments associated with the air content pay factors. 


\section{CHAPTER 7: ASSESSING PRS SOFTWARE, PART II: ACCEPTANCE QUALITY CHARACTERISTICS, LIFE-CYCLE AND REPAIR AND MAINTENANCE MODELS}

Performance Related Specifications (PRS) rely on the assembly of a large amount of engineering and project data to run life-cycle cost analysis models. Some of these inputs are used to describe the project characteristics, pavement design, traffic, and climate. Chapter 6 examined these inputs and their impact on the life-cycle cost software, PaveSpec, used to create PRS. This chapter continues the examination of inputs in PaveSpec, but focuses now on inputs that affect the quality levels, life-cycle costs, and repair and maintenance modules in the PRS software.

\subsection{Definition of Pavement Performance}

PRS assess pavement performance through the use of distress prediction models. When using the life-cycle software, the user has the option to include four different prediction models and the Acceptable Quality Characteristics (AQCs) which are required to run those models. The input screen indicating where information is to be entered into the program is shown in Figure 7-1 with a summary of the inputs in Table 7-1. 


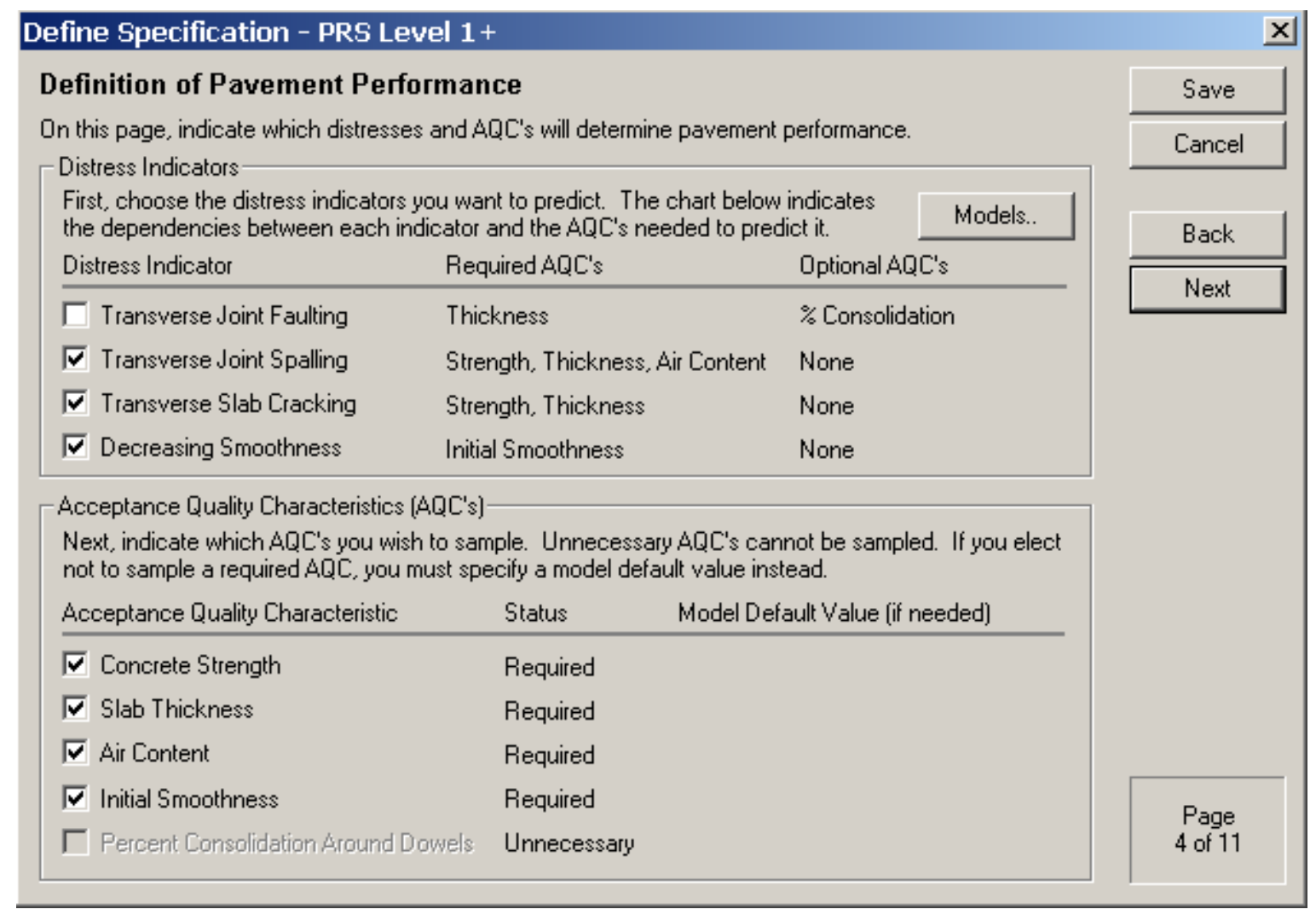

Figure 7-1 Input Screen for Defining Pavement Performance

Table 7-1 Definition of Pavement Performance

\begin{tabular}{|c|c|c|c|c|}
\hline No. & Input & Options & Project Value & Source \\
\hline \multirow{3}{3}{39} & $\begin{array}{c}\text { Distress indicators to } \\
\text { be modeled }\end{array}$ & $\begin{array}{c}\text { Transverse Joint Faulting, } \\
\text { Transverse Joint Spalling, } \\
\text { Transverse Slab Cracking, } \\
\text { Decreasing Smoothness }\end{array}$ & $\begin{array}{c}\text { Transverse Joint Spalling, } \\
\text { Transverse Slab Cracking, } \\
\text { Decreasing Smoothness }\end{array}$ & User \\
\hline \multirow{3}{*}{40} & $\begin{array}{c}\text { Concrete Strength, } \\
\text { Slab Thickness, } \\
\text { Acceptance quality } \\
\text { characteristics to be } \\
\text { considered }\end{array}$ & $\begin{array}{c}\text { Air Content, } \\
\text { Initial Smoothness, } \\
\end{array}$ & $\begin{array}{c}\text { Concrete Strength, } \\
\text { Slab Thickness, } \\
\text { Air Content, } \\
\text { around Dowels }\end{array}$ & User \\
& & Initial Smoothness & \\
\hline
\end{tabular}

${ }^{1}$ Spalling Model coefficient A $=0.5$

The definition of pavement performance is a fundamentally important part of PRS. The distress models are directly related to the design inputs and AQCs (strength, thickness, air content, initial smoothness, and percent consolidation around the dowels). 
As a default, all four distress models are selected. However, the agency can choose not to include some models and even modify others. For example, on the Indiana PRS project, it was decided to limit the effects of the spalling model on the second PRS project. It should be noted that the faulting model was not used as a measure of pavement performance in the Indiana projects.

Using joint faulting as a measure of pavement performance had little effect on the life-cycle simulations, as shown in Table 7-2. This may be explained by the fact that the design thickness chosen by INDOT is conservative, and the pavement is doweled, both of which reduce faulting in pavements.

One option in the model is to consider the percent concrete consolidation around the pavement dowels. This option is included for purposes of measuring the variation of the lifecycle cost software. However, it should be noted that Indiana does not measure the percent consolidation. Even if the percent consolidation is chosen to be included as an AQC and therefore allowed to vary within the ranges of the simulations, the life-cycle cost variations were still less than $1 \%$.

Table 7-2 Sensitivity Analysis of Variation in Distress Model Inclusion

\begin{tabular}{|c|c|c|c|}
\hline $\begin{array}{c}\text { Faulting Model } \\
\text { Included? }\end{array}$ & $\begin{array}{c}\text { \% Consolidation } \\
\text { Measured? }\end{array}$ & $\begin{array}{c}\text { Present Worth Life- } \\
\text { Cycle Cost per mile }\end{array}$ & \% change in LCC \\
\hline No & No & $\$ 4,535,397$ & - \\
\hline Yes & No & $\$ 4,579,497$ & $1 \%$ \\
\hline Yes & Yes & $\$ 4,579,697$ & $1 \%$ \\
\hline
\end{tabular}




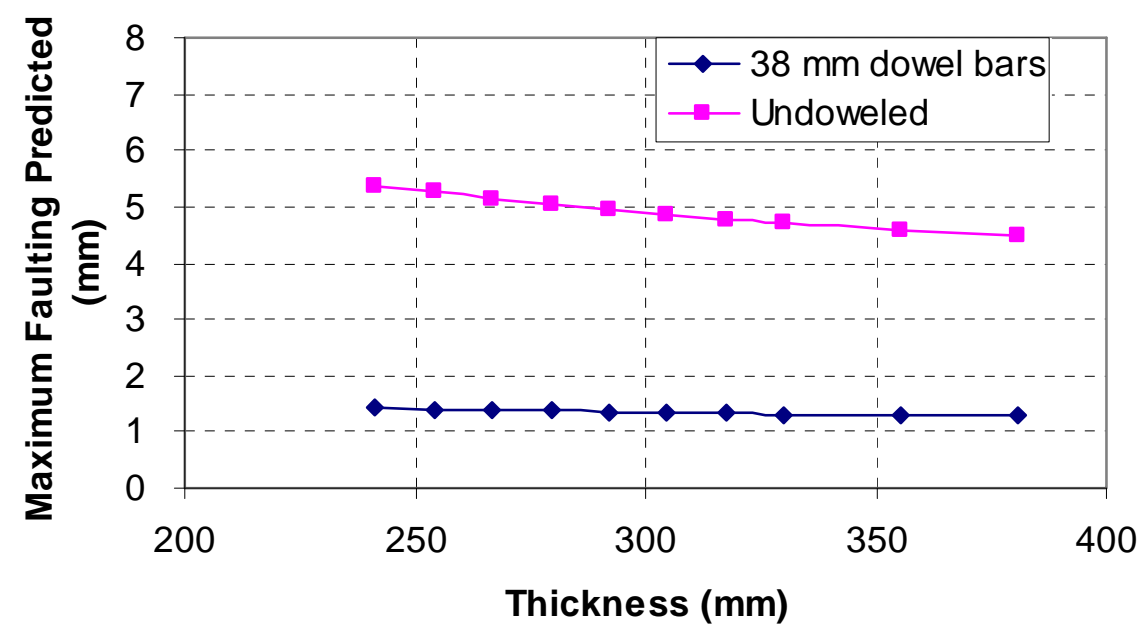

Figure 7-2 Maximum Predicted Faulting versus Pavement Thickness

Several simulations were performed to determine the impact of pavement thickness on the maximum observed joint faulting (Figure 7-2). For doweled pavements, joint faulting is relatively unaffected by pavement thickness. For undoweled pavements, however, joint faulting increased as the pavement was thinned. However, it should be noted that the faulting predicted is still below the failure threshold for joint faulting in the program (6 mm, see Section 7.4.2.)

Although the joint faulting may initially appear to be insignificant to the model, it should be noted that the faulting model is an important input in the smoothness distress model. Therefore, joint faulting is an important measure of pavement performance, and for either type of pavement, it is recommended that the joint faulting model be included in the distress models.

The second distress model analyzed was the transverse joint spalling model, which is the only distress model that uses air content as an input. While examining trials at the beginning of the project, it was felt that the pay factors generated for air content were too steep and would result in unrealistic contractor pay adjustment. The spalling model was modified within the software, to change modify the spalling model to effectively reduce the predicted spalling by $50 \%$. This had the effect of softening the pay factor curves for air content. Figure 7-3 shows how the pay factors for the air content AQC changed as the spalling was modified in the 
program, and how those pay factors compared to original INDOT values for percent pay as previously written in the 1999 Standard Specifications.

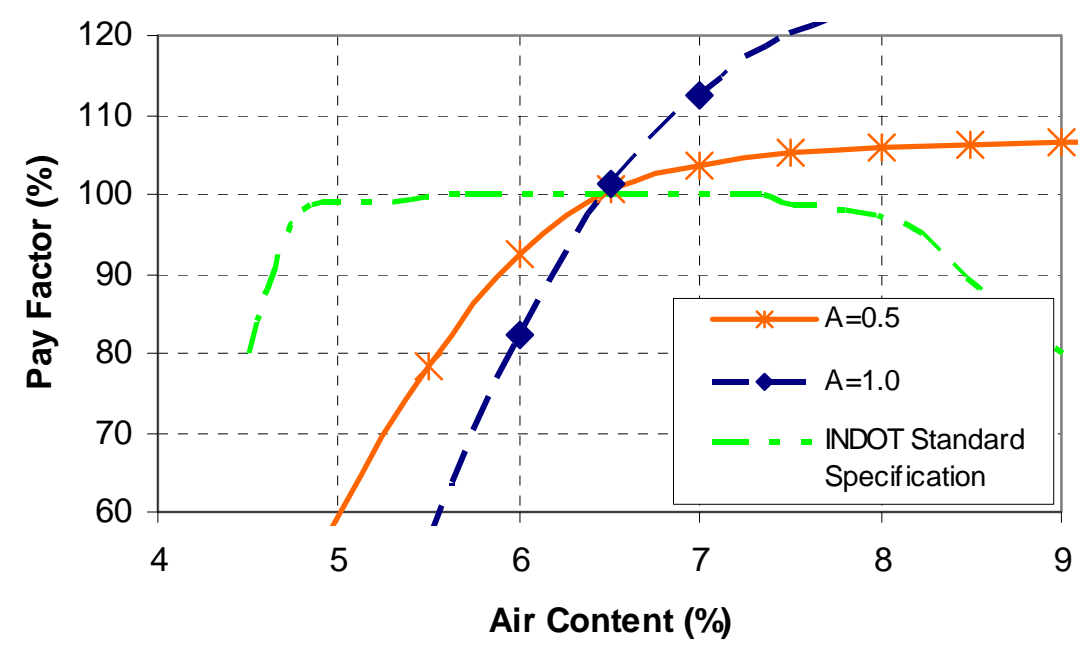

Figure 7-3 Air Content AQC Pay Factor Graphs

In changing the spalling model, a more realistic specification was provided. It was felt that if the penalties for low air contents were too severe, there would be an adverse impact on the contractor's willingness to bid the project. However, after the simulations were run, it appeared that the pay factors for air content did not reflect the performance of concrete pavement in the field, and therefore the pay factors were further modified from the software output to the published specification. Additionally, the pay factors in the actual contract were not allowed to continually increase, but in fact decreased slightly at air content values approaching $9 \%$.

In addition to selecting the pavement distress models, the software requires the identification of which AQCs need to be sampled (input \#40). These AQCs should be selected to reflect the current state of testing in the agency's non-PRS specifications. This allows for an easier transition into PRS and helps avoid confusion concerning sampling and testing. Since the current specifications in Indiana accounted for strength, thickness, air content, and smoothness testing, those four AQCs were chosen. If the agency chooses to leave out any AQCs that are required based on the chosen distress models, then an assumed mean value for the AQC must be entered into the software. 


\subsection{AQC Sampling and Testing Information}

Inputs \#41 through \#67 are used to define the sample and testing plan. The AQC sampling and testing information contains information necessary for developing the quality testing program in PRS. The inputs in this section do not directly affect the calculations of life-cycle cost in PaveSpec. For this reason, no sensitivity analysis was performed. However, the type of testing will affect the target values, standard deviations, and limits of the AQCs. For example, different values are determined for strength if it is measured with cores (compressive) or with beams (flexural).

The information included in this portion of the program comes from Indiana Standard Specifications. In 2002, INDOT included tests to measure strength, thickness, air content, and initial smoothness. Although INDOT chose not to measure percent consolidation, it can be included in PRS. Since the current PRS does not include it, there are no inputs necessary for the testing procedures for percent consolidation. For more information, see Appendix C. Some inputs in the program are not required, depending on the test method. These are marked N/A in Appendix C.

Table 7-3 AQC Sampling and Testing Information

\begin{tabular}{|c|c|c|c|}
\hline AQC Value & $\begin{array}{c}\text { Samples and Test } \\
\text { Procedure }\end{array}$ & $\begin{array}{c}\text { Sample Locations } \\
\text { per Sublot }\end{array}$ & $\begin{array}{c}\text { Number of } \\
\text { Samples at Each } \\
\text { Location. }\end{array}$ \\
\hline Strength & Beams & 1 & 2 \\
\hline Thickness & Cores & 2 & 1 \\
\hline Air Content & $\begin{array}{c}\text { AASHTO } \\
\text { T } 152\end{array}$ & 1 & 1 \\
\hline Smoothness & $\begin{array}{c}\text { Profile Index (0.2 } \\
\text { in blanking band })\end{array}$ & $\begin{array}{c}\text { 1 pass/lane } \\
\text { RWP }\end{array}$ \\
\hline
\end{tabular}

Table 7-3 shows the sampling methods currently used by INDOT and included in the PRS contracts. 


\subsection{AQC As-designed Target Value Definition}

The inputs defining the AQC target values are found in Figure 7-4 (inputs \#68 to \#83). This is one of the most critical aspects of PRS because it sets the goals that the contractor tries to achieve, and these values will greatly impact the pay factors. The targets define the quality value for which the agency is willing to pay $100 \%$ of the bid price to the contractor. Also, the simulations are run using the assumed targets and standard deviations. Table 7-4 shows the values used on project R-25715. The targets were set by the Pavement Design division, while the standard deviations were provided by the Research division.

\begin{tabular}{|c|c|c|c|c|c|}
\hline \multicolumn{5}{|c|}{ Define Specification - PRS Level 1+ } & \\
\hline \multirow{2}{*}{\multicolumn{5}{|c|}{$\begin{array}{l}\text { AQC As-Designed Target Value Definition } \\
\text { AQC as-designed target values are required for the distress indicator models you have selected to define } \\
\text { pavement performance. The chosen values will be used in the determination of the as-designed LCC's. }\end{array}$}} & Save \\
\hline & & & & & Cancel \\
\hline \multicolumn{6}{|l|}{ Level 1 Settings } \\
\hline \multirow{3}{*}{\multicolumn{5}{|c|}{$\begin{array}{l}\text { Determine target LCC by: } \text { Estimate LCC Through Simulation } \\
\text { Enter the appropriate AQC means and standard deviations (if required) that define the as-designed } \\
\text { target pavement quality corresponding to the chosen } \mathrm{AQC} \text { sampling and testing plan. }\end{array}$}} & Back \\
\hline & & & & & Next \\
\hline & & & & & \\
\hline $\mathrm{AQC}$ & Sample Method & Mean & Std Dev & Sampling and Testing Summary & \\
\hline $\begin{array}{l}\text { Concrete } \\
\text { Strength }\end{array}$ & Distribution & $7650 \mathrm{psi}$ & $40 \mathrm{psi}$ & $\begin{array}{l}\text { Flexural strength testing of beams } \\
\text { at } 28 \text { days }(n=1, m=2) \text {. }\end{array}$ & \\
\hline Slab Thickness & Distribution & $\nabla 15$ in & 0.5 in & Independent cores $(n=2, m=1)$. & \\
\hline Air Content & Distribution & $7.5 \%$ & $0.5 \%$ & Air pressure meter $(n=2, m=1)$. & \\
\hline $\begin{array}{l}\text { Initial } \\
\text { Smoothness }\end{array}$ & Distribution & $77 \mathrm{in} / \mathrm{mi}$ & $3 \mathrm{in} / \mathrm{mi}$ & $\begin{array}{l}\text { Profile Index [0.2-in blanking } \\
\text { band, } n=1, m=2 \text { ]. }\end{array}$ & \\
\hline $\begin{array}{l}\text { Percent Consol. } \\
\text { Around Dowels }\end{array}$ & & $\sqrt{N / A}$ & $N / A$ & $N / A$ & $\begin{array}{l}\text { Page } \\
6 \text { of } 11\end{array}$ \\
\hline
\end{tabular}

Figure 7-4 Input Screen for Defining AQC As-Designed Target Values 
Table 7-4 AQC As-Designed Target Value Definition

\begin{tabular}{|c|c|c|c|c|}
\hline No. & Input & Typical Ranges & Project Value & Source \\
\hline 68 & Determine target LCC... & $\begin{array}{c}\text { Through } \\
\text { Simulation / } \\
\text { Using AQC } \\
\text { Means Only }\end{array}$ & $\begin{array}{l}\text { Estimate LCC through } \\
\text { simulation }\end{array}$ & User \\
\hline 69 & $\begin{array}{l}\text { Concrete strength sample } \\
\text { method }\end{array}$ & $\begin{array}{l}\text { Means only / } \\
\text { Distribution }\end{array}$ & Distribution & User \\
\hline 70 & $\begin{array}{l}\text { Concrete strength mean (psi, } \\
\mathrm{MPa})\end{array}$ & - & 650 psi (flexural) & Pavement Design \\
\hline 71 & $\begin{array}{l}\text { Concrete strength standard } \\
\text { deviation }(\mathrm{psi}, \mathrm{MPa})\end{array}$ & $20-80$ psi & 40 psi & Research \\
\hline 72 & Slab thickness sample method & $\begin{array}{l}\text { Means only / } \\
\text { Distribution }\end{array}$ & Distribution & User \\
\hline 73 & Slab thickness mean (in, mm) & $10-16$ in. & $15.0 \mathrm{in}$ & Pavement Design \\
\hline 74 & $\begin{array}{l}\text { Slab thickness standard } \\
\text { deviation (in, } \mathrm{mm} \text { ) }\end{array}$ & $0-1$ in. & $0.5 \mathrm{in}$. & Research \\
\hline 75 & Air content sample method & $\begin{array}{l}\text { Means only / } \\
\text { Distribution }\end{array}$ & Distribution & User \\
\hline 76 & Air content mean & $4-10 \%$ & $6.50 \%$ & Pavement Design \\
\hline 77 & Air content standard deviation & $0-2 \%$ & $0.5 \%$ & Research \\
\hline 78 & $\begin{array}{l}\text { Initial smoothness sample } \\
\text { method }\end{array}$ & $\begin{array}{l}\text { Means only / } \\
\text { Distribution }\end{array}$ & Distribution & User \\
\hline 79 & $\begin{array}{l}\text { Initial smoothness mean } \\
\text { (in } / \mathrm{mile}, \mathrm{mm} / \mathrm{km})\end{array}$ & $0-20$ in./mile & $7 \mathrm{in} / \mathrm{mile}$ & Pavement Design \\
\hline 80 & $\begin{array}{l}\text { Initial smoothness standard } \\
\text { deviation (in/mile, } \mathrm{mm} / \mathrm{km} \text { ) }\end{array}$ & $0-10$ in. $/$ mile & 3 in. $/$ mile & Research \\
\hline 81 & $\begin{array}{l}\text { Percent consolidation around } \\
\text { dowels sample method }\end{array}$ & $\begin{array}{l}\text { Means only / } \\
\text { Distribution }\end{array}$ & N/A & $\mathrm{N} / \mathrm{A}$ \\
\hline 82 & $\begin{array}{l}\text { Percent consolidation around } \\
\text { dowels mean }\end{array}$ & $\mathrm{N} / \mathrm{A}$ & N/A & $\mathrm{N} / \mathrm{A}$ \\
\hline 83 & $\begin{array}{l}\text { Percent consolidation around } \\
\text { dowels standard deviation }\end{array}$ & $\mathrm{N} / \mathrm{A}$ & $\mathrm{N} / \mathrm{A}$ & $\mathrm{N} / \mathrm{A}$ \\
\hline
\end{tabular}

Input \#68, the method of determining the life-cycle cost, is "through simulation", by default. If this input is set to "using AQC means only," the software does not take the standard deviations of the AQC values into account. This can be useful if the program is being used to analyze pavement distress. The purpose of using simulation, however, is to model the actual construction of the pavement as realistically as possible. Using AQC targets only, as shown in Table 7-5, results in a slight decrease in the life-cycle cost. The variation of the AQCs, therefore, is important to the model. 


\section{Table 7-5 Sensitivity of Analysis Method}

\begin{tabular}{|c|c|c|}
\hline Analysis Method & $\begin{array}{c}\text { Present Worth Life- } \\
\text { Cycle Cost per mile }\end{array}$ & \% change in LCC \\
\hline Simulation & $\$ 5,030,564$ & - \\
\hline AQC targets only & $\$ 4,958,549$ & $-1.4 \%$ \\
\hline
\end{tabular}

Inputs \#69 through \#83 define the target values and standard deviations of the AQCs. When the "targets only" analysis method is selected, the target AQC values alone are used to calculate the as-designed life-cycle cost. However, in the default analysis method (with simulation), the AQC target values and the target standard deviations are used in combination to simulate many pavements, from which an average as-designed life-cycle cost is taken.

The target values for strength (input \#70) and thickness (input \#73) were varied and the resulting life-cycle costs plotted in Figure 7-5.

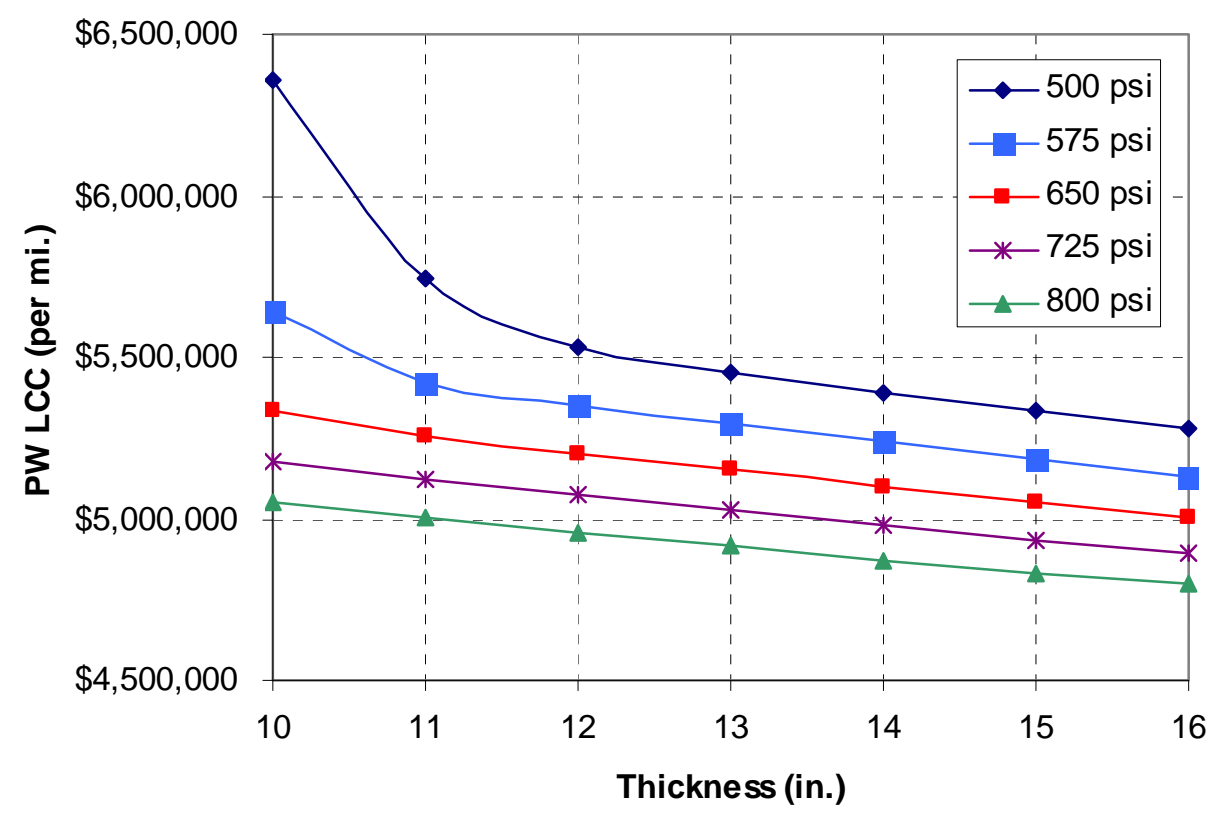

Figure 7-5 Present Worth Life-Cycle Cost versus AQC Target Means

As can be seen in Figure 7-5, the life-cycle costs tend to increase as the quality levels (strength, thickness) decrease. This is the rational basis for the pay factors. It is also seen that according to the software, a change of 75 psi has a greater affect than one whole inch of thickness. 


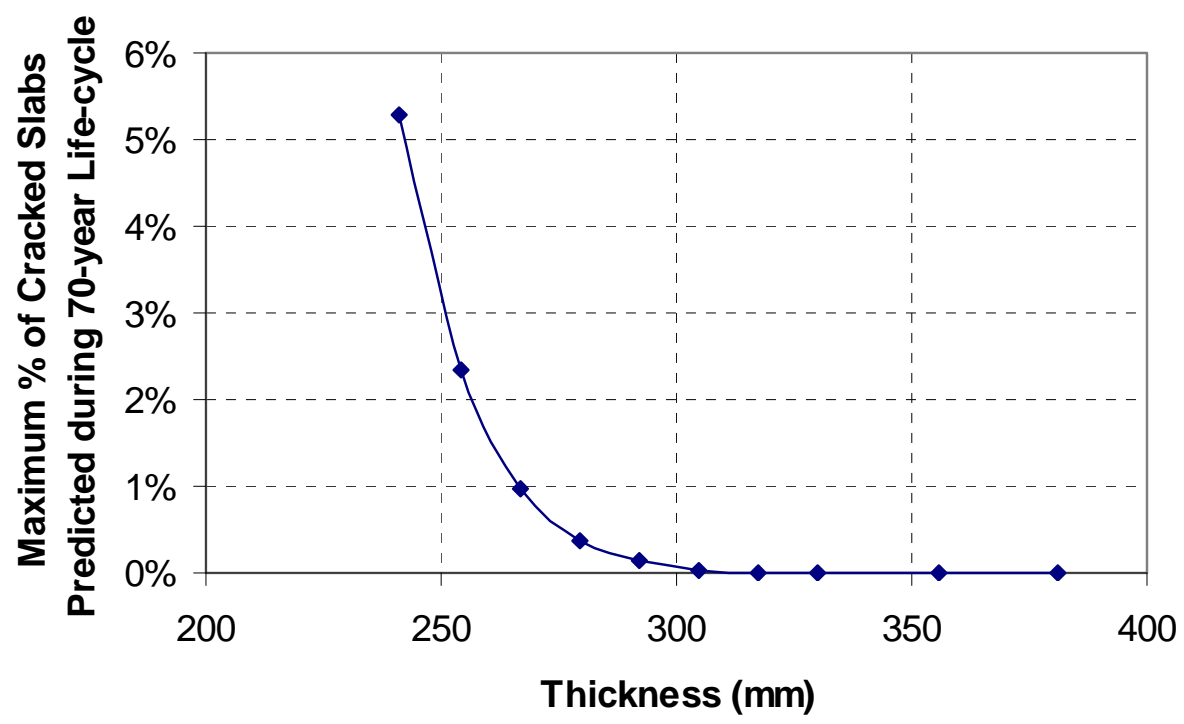

Figure 7-6 Maximum Predicted Cracking versus Pavement Thickness

An experiment was run to determine the thickness at which point cracking becomes an issue for current model. Using the mean values only of the AQCs (air content $=6.5 \%, 28$ flexural strength $=650 \mathrm{psi}$, initial smoothness $=7 \mathrm{in} . / \mathrm{mi}$.), ten simulations were run, and the maximum predicted cracking was plotted against the thickness of the pavement. Figure 7-6 shows that maximum cracking begins to increase in pavements which are about $275 \mathrm{~mm}$ thick or less.

The target AQC mean is important to PRS. However, the standard deviation of the AQC can play as important role as well. Figure 7-7 shows the impact of the standard deviation on the lifecycle cost. 


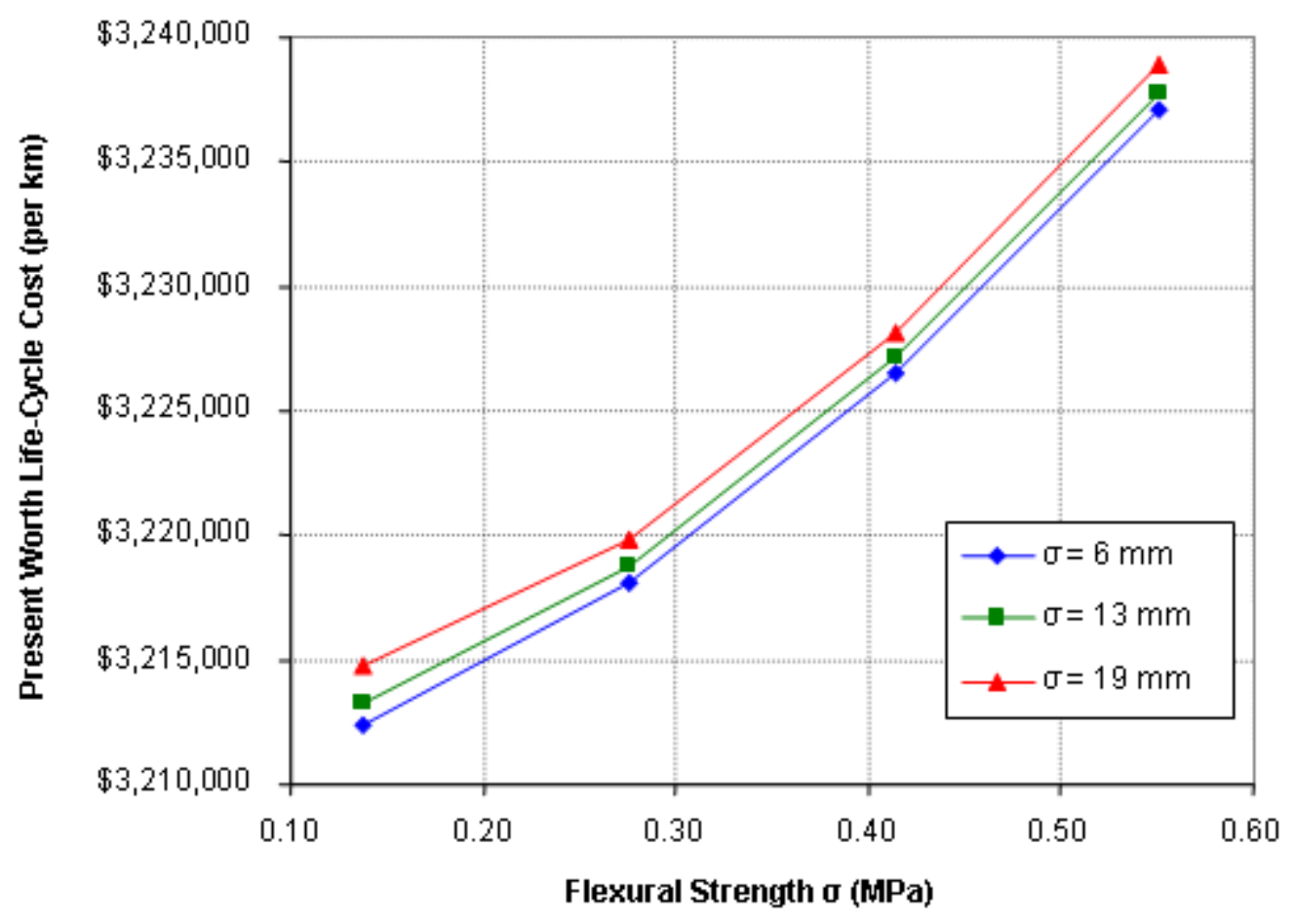

\section{Figure 7-7 Present Worth Life-Cycle Cost versus AQC Target Standard Deviation}

As seen in Figure 7-7, as standard deviations become smaller, the total life-cycle cost decreases. The notion of sublot failure is the driving force behind this phenomenon. For example, if three sublots were constructed, one with average quality, one slightly above-average, and one slightly-below average, the life-cycle costs would not be proportional to the quality level. That is, the difference in costs between the below-average sublot and the average sublot would be disproportionately more than the difference between the above-quality sublot and the average one. PRS enters an important concept into concrete construction, that not just the average quality level matters, but the quality control, as well. This can be shown further in the analyses for smoothness and air content. 
Table 7-6 Analysis of Air Content Variations

\begin{tabular}{|c|c|c|}
\hline Air Content & $\begin{array}{c}\text { Present Worth Life- } \\
\text { Cycle Cost per mile }\end{array}$ & \% change in LCC \\
\hline $4 \%$ & $\$ 5,183,973$ & $14 \%$ \\
\hline $5 \%$ & $\$ 4,860,269$ & $7 \%$ \\
\hline $6 \%$ & $\$ 4,643,331$ & $3 \%$ \\
\hline $7 \%$ & $\$ 4,527,944$ & - \\
\hline $8 \%$ & $\$ 4,501,676$ & $-1 \%$ \\
\hline $9 \%$ & $\$ 4,497,194$ & $-1 \%$ \\
\hline $10 \%$ & $\$ 4,495,509$ & $-1 \%$ \\
\hline
\end{tabular}

Decreases in the average air content, as shown in Table 7-6, show that as the air content decreases, the life-cycle cost increases. As was the case for strength and thickness, as the standard deviation decreases, the life-cycle cost increases. PRS therefore rewards increased quality control that leads to lower standard deviations.

Table 7-7 Analysis of Initial Smoothness Variations

\begin{tabular}{|c|c|c|}
\hline $\begin{array}{c}\text { Initial } \\
\text { Smoothness }\end{array}$ & $\begin{array}{c}\text { Present Worth Life- } \\
\text { Cycle Cost per mile }\end{array}$ & \% change in LCC \\
\hline 3 in./mi. & $\$ 4,488,895$ & $-1.0 \%$ \\
\hline 4 in./mi. & $\$ 4,499,287$ & $-0.7 \%$ \\
\hline 5 in./mi. & $\$ 4,508,402$ & $-0.5 \%$ \\
\hline 6 in./mi. & $\$ 4,520,752$ & $-0.3 \%$ \\
\hline 7 in./mi. & $\$ 4,532,706$ & - \\
\hline 8 in. $/ \mathrm{mi}$. & $\$ 4,549,369$ & $0.4 \%$ \\
\hline 9 in. $/ \mathrm{mi}$. & $\$ 4,559,320$ & $0.6 \%$ \\
\hline $10 \mathrm{in} . / \mathrm{mi}$. & $\$ 4,572,288$ & $0.9 \%$ \\
\hline
\end{tabular}

Table 7-8 shows how the life-cycle cost changes with initial smoothness. As the initial smoothness improves, the life-cycle cost decreases, resulting in a bonus to the contractor.

Table 7-8 Analysis of Air Content Standard Deviations

\begin{tabular}{|c|c|c|}
\hline $\begin{array}{c}\text { Air Content } \\
\text { Standard } \\
\text { Deviation }\end{array}$ & $\begin{array}{c}\text { Present Worth Life- } \\
\text { Cycle Cost per mile }\end{array}$ & \% change in LCC \\
\hline $0.5 \%$ & $\$ 4,532,980$ & - \\
\hline $1 \%$ & $\$ 4,573,096$ & $1 \%$ \\
\hline $1.5 \%$ & $\$ 4,636,819$ & $2 \%$ \\
\hline $2 \%$ & $\$ 4,700,229$ & $4 \%$ \\
\hline
\end{tabular}


Table 7-8 shows the standard deviation of the air content also has a large impact on the lifecycle cost. As the standard deviation increase, the life-cycle cost also increases.

Table 7-9 Analysis of Smoothness Standard Deviations

\begin{tabular}{|c|c|c|}
\hline $\begin{array}{c}\text { Smoothness } \\
\text { Standard } \\
\text { Deviation }\end{array}$ & $\begin{array}{c}\text { Present Worth Life- } \\
\text { Cycle Cost per mile }\end{array}$ & \% change in LCC \\
\hline 0 & $\$ 5,148,919$ & $0.0 \%$ \\
\hline 2 & $\$ 5,148,436$ & $0.0 \%$ \\
\hline 3 & $\$ 5,146,457$ & $0.0 \%$ \\
\hline 4 & $\$ 5,145,177$ & $0.0 \%$ \\
\hline 6 & $\$ 5,150,961$ & $0.1 \%$ \\
\hline 8 & $\$ 5,161,722$ & $0.3 \%$ \\
\hline 10 & $\$ 5,159,679$ & $0.3 \%$ \\
\hline
\end{tabular}

As the AQC values are made more favorable (increased in the case of thickness, strength, and air content, but lowered in the case of initial smoothness), the as-designed, or simulated, lifecycle cost will decrease. This in turn will impact the pay factors substantially

\subsection{Maintenance and Rehabilitation Plan Information}

The inputs in the next section make up the Maintenance and Rehabilitation Plan, which includes three categories: Regular Maintenance, Local Rehabilitation (i.e. Repair), and Global Rehabilitation. The information defines the responses to the predicted distresses, which is used to determine the agency's cost for upkeep of the pavement.

\subsubsection{Regular Maintenance}

Regular Maintenance in the software is limited to transverse joint sealing, longitudinal joint sealing, and transverse crack sealing. Figure 7-8 shows the window where the data is entered, corresponding with inputs \#84 through \#92. 


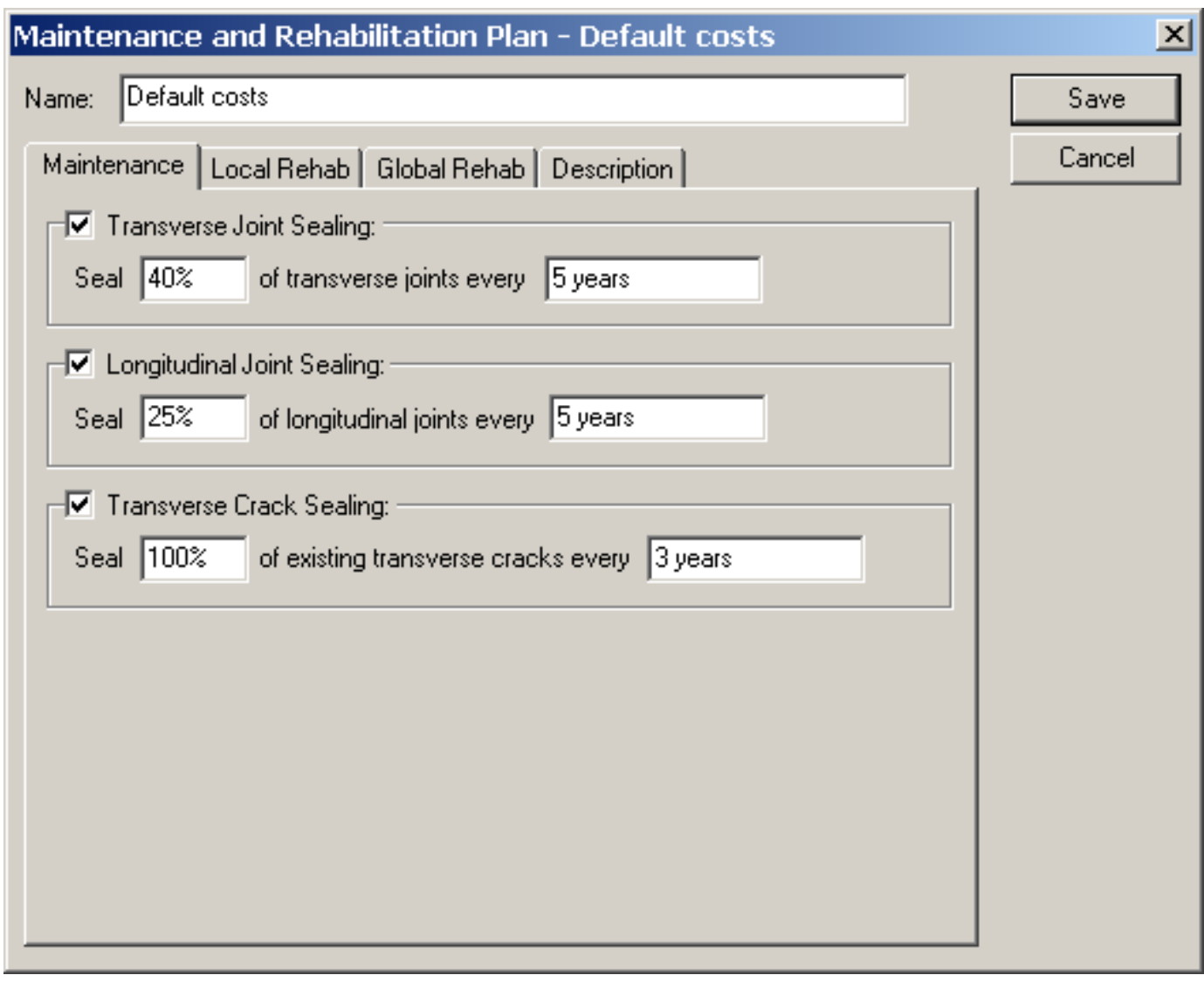

Figure 7-8 Input Screen for Defining Regular Maintenance

Table 7-10 Regular Maintenance Information

\begin{tabular}{|c|c|c|c|c|}
\hline No. & Input & Typical Ranges & $\begin{array}{c}\text { Project } \\
\text { Value }\end{array}$ & Source \\
\hline 84 & Maintain transverse joints & Yes / No & Yes & Pavement Management \\
\hline 85 & $\begin{array}{c}\text { \% of transverse joints to be } \\
\text { sealed }\end{array}$ & $0-100 \%$ & $40 \%$ & Pavement Management \\
\hline 86 & Regularity of maintenance & $5-15$ years & 5 years & Pavement Management \\
\hline 87 & Maintain longitudinal joints & Yes / No & Yes & Pavement Management \\
\hline 88 & $\begin{array}{c}\text { \% of longitudinal joints to be } \\
\text { sealed }\end{array}$ & $0-100 \%$ & $25 \%$ & Pavement Management \\
\hline 89 & Regularity of maintenance & $5-15$ years & 5 years & Pavement Management \\
\hline 90 & Maintain transverse cracks & Yes / No & Yes & Pavement Management \\
\hline 91 & $\begin{array}{c}\% \text { of transverse cracks to be } \\
\text { sealed }\end{array}$ & $0-100 \%$ & $100 \%$ & Pavement Management \\
\hline 92 & Regularity of maintenance & $3-10$ years & 3 years & Pavement Management \\
\hline
\end{tabular}

Table 7-10 presents the inputs as used on project R-25715. For simulation purposes, these values are designated as "normal." The maximum maintenance plan for any activity would be 
$100 \%$ every year. With this in mind, five trials were run to determine the impacts of the maintenance plan on the model. The maintenance plans simulated ranged from the maximum activity to none at all.

Table 7-11 Analysis of Regular Maintenance Options

\begin{tabular}{|c|c|c|c|c|c|}
\hline $\begin{array}{c}\text { Transverse } \\
\text { Joint Sealing }\end{array}$ & $\begin{array}{c}\text { Longitudinal } \\
\text { Joint Sealing }\end{array}$ & $\begin{array}{c}\text { Transverse } \\
\text { Crack } \\
\text { Sealing }\end{array}$ & $\begin{array}{c}\text { Present } \\
\text { Worth Life- } \\
\text { Cycle Cost } \\
\text { per mile }\end{array}$ & $\begin{array}{c}\text { Time until } \\
\text { first global } \\
\text { rehabilitation }\end{array}$ & $\begin{array}{c}\text { \% change } \\
\text { in LCC }\end{array}$ \\
\hline "normal" & "normal" & "normal" & $\$ 5,150,071$ & 39 years & - \\
\hline maximum & maximum & maximum & $\$ 5,866,981$ & 39 years & $14 \%$ \\
\hline none & none & none & $\$ 5,107,632$ & 39 years & $-1 \%$ \\
\hline maximum & "normal" & "normal" & $\$ 5,410,976$ & 39 years & $5 \%$ \\
\hline "normal" & maximum & "normal" & $\$ 5,606,074$ & 39 years & $9 \%$ \\
\hline "normal" & "normal" & maximum & $\$ 5,150,074$ & 39 years & $0 \%$ \\
\hline
\end{tabular}

The first conclusion from the simulations is that the regular maintenance does not affect the distress or timing of other repairs in the model. That is, the distress models are independent of regular maintenance. However, the life-cycle costs are not independent. As seen in Table 7-11, a $14 \%$ increase in the life-cycle cost is predicted when all activities are done $100 \%$ every year. It is further seen that the longitudinal joint sealing has the greatest impact on the model, followed by the transverse joint sealing. Simulations show that joint sealing is also applied independently of the predicted distresses. Due to the fact that little cracking is predicted in the simulations, the crack sealing regularity has no impact on the model. Although joint sealing impacts the model's predicted life-cycle cost, it does not impact the pay factors and therefore is not critical to the pay factors produced by the simulation.

\subsubsection{Local rehabilitation}

The local rehabilitation plan (input \#93) is potentially the most confusing input in PRS because rehabilitation plans are not always rigidly defined as they must be in the software. The plan is defined in a series of steps (usually five), entered in the window as shown in Figure 7-9. 


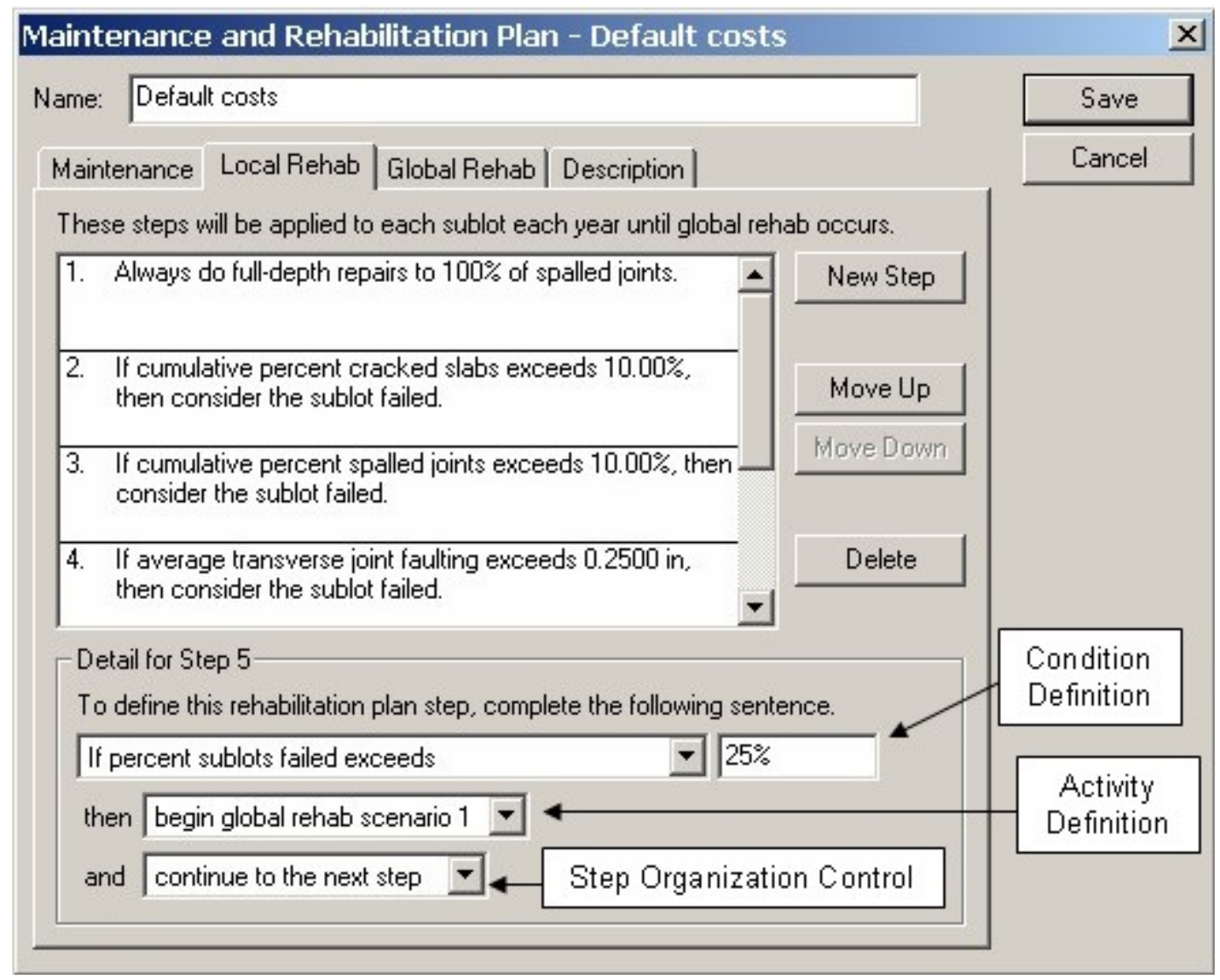

\section{Figure 7-9 Input Screen for Defining Local Rehabilitation Plan and Sublot Failure}

The goal of the local rehabilitation menu is threefold. First, the cracked slabs and spalled joints can be addressed with a local rehabilitation step, if desired. The distresses can either be repaired at regular intervals, or when a certain percentage of distress is exceeded. The second purpose is to determine which sublots have failed, thereby enabling a global rehabilitations to be planned. According to the PRS methodology, global rehabilitations are applied when a certain percentage of sublots have failed. This is important, especially since in the public's eye, one poorly performing sublot can ruin an entire stretch of road.

Because of the wide variety of information on the local rehabilitation plan tab, input \#93 is considered an individual entry in the table in Appendix C. The simulation requires a rigidly defined maintenance and repair plan. Although INDOT does not rigidly define these inputs, input data was selected that most appropriate modeled what occurs in actual practice (Graveen 2001). That plan is as follows: 
Step 1. Always do full-depth repairs to $100 \%$ of spalled joints.

Step 2. If cumulative percentage of cracked slabs exceeds $10 \%$ then consider the sublot failed.

Step 3. If cumulative percentage of spalled joints exceeds $10 \%$ then consider the sublot failed.

Step 4. If average transverse joint faulting exceeds 0.25 inch then consider the sublot failed.

Step 5. If percent failed sublots exceeds $25 \%$ then begin global rehabilitation Scenario 1.

It is recommended that the local rehabilitation tab remain unchanged for future PRS projects. However, an engineer familiar with pavement management can adjust this input to realistically model the current pavement management plan. This input was not analyzed due to its complexity.

\subsubsection{Global rehabilitation}

The last portion of the maintenance and repair plan is the global rehabilitation plan (inputs \#94 through \#111). These values were also determined by the Roadway Management department of INDOT. It is recommended that the default values be used for further projects. 


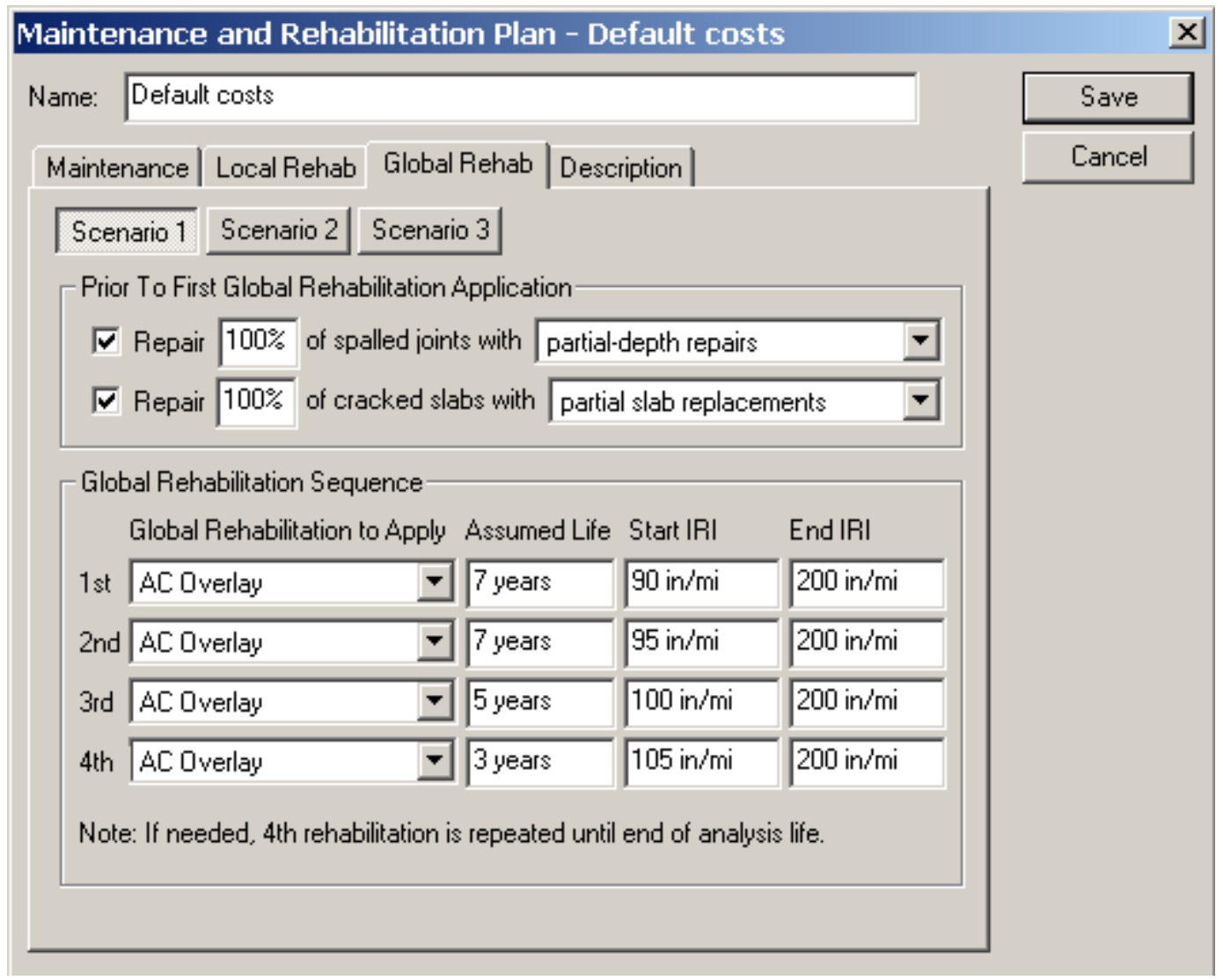

Figure 7-10 Input Screen for Defining Global Rehabilitation Scenarios 
Table 7-12 Global Rehabilitation Information

\begin{tabular}{|c|c|c|c|c|}
\hline No. & Input & Typical Ranges & $\begin{array}{l}\text { Project } \\
\text { Value }\end{array}$ & Source \\
\hline 94 & $\begin{array}{c}\text { Repair spalled joints prior to global } \\
\text { rehabilitation }\end{array}$ & Yes / No & Yes & $\begin{array}{c}\text { Roadway } \\
\text { Mgmt }\end{array}$ \\
\hline 95 & $\begin{array}{l}\% \text { of spalled joints to be repaired } \\
\text { (if required) }\end{array}$ & $0-100 \%$ & $100 \%$ & $\begin{array}{l}\text { Roadway } \\
\text { Mgmt }\end{array}$ \\
\hline 96 & $\begin{array}{l}\text { Description of repair to be } \\
\text { undertaken (if required) }\end{array}$ & $\begin{array}{l}\text { Partial depth repairs/ Full } \\
\text { depth repairs }\end{array}$ & $\begin{array}{l}\text { Partial depth } \\
\text { repairs }\end{array}$ & $\begin{array}{l}\text { Roadway } \\
\text { Mgmt }\end{array}$ \\
\hline 97 & $\begin{array}{c}\text { Repair cracked slabs prior to global } \\
\text { rehabilitation }\end{array}$ & Yes / No & Yes & $\begin{array}{c}\text { Roadway } \\
\text { Mgmt }\end{array}$ \\
\hline 98 & $\begin{array}{l}\% \text { of cracked slabs to be repaired } \\
\text { (if required) }\end{array}$ & $0-100 \%$ & $100 \%$ & $\begin{array}{l}\text { Roadway } \\
\text { Mgmt }\end{array}$ \\
\hline 99 & $\begin{array}{l}\text { Description of repair to be } \\
\text { undertaken (if required) }\end{array}$ & $\begin{array}{l}\text { Partial slab replacements/ } \\
\text { Full slab replacements }\end{array}$ & $\begin{array}{l}\text { Partial slab } \\
\text { replacements }\end{array}$ & $\begin{array}{c}\text { Roadway } \\
\text { Mgmt }\end{array}$ \\
\hline 100 & $\begin{array}{l}\text { Description of 1st global } \\
\text { rehabilitation to apply }\end{array}$ & $\begin{array}{l}\text { AC overlay/ PCC overlay/ } \\
\text { Diamond grinding }\end{array}$ & AC overlay & $\begin{array}{l}\text { Roadway } \\
\text { Mgmt }\end{array}$ \\
\hline 101 & $\begin{array}{l}\text { Assumed life of 1st global } \\
\text { rehabilitation }\end{array}$ & $3-12$ years & 7 years & $\begin{array}{l}\text { Roadway } \\
\text { Mgmt }\end{array}$ \\
\hline 102 & $\begin{array}{l}\text { Smoothness at start and end of } 1^{\text {st }} \\
\text { global rehabilitation (in/mile) }\end{array}$ & IRI values & $\begin{array}{l}90-200 \\
\text { in } / \text { mile }\end{array}$ & $\begin{array}{l}\text { Roadway } \\
\text { Mgmt }\end{array}$ \\
\hline 103 & $\begin{array}{l}\text { Description of 2nd global } \\
\text { rehabilitation to apply (if required) }\end{array}$ & $\begin{array}{l}\text { AC overlay/ PCC overlay/ } \\
\text { Diamond grinding }\end{array}$ & AC overlay & $\begin{array}{c}\text { Roadway } \\
\text { Mgmt }\end{array}$ \\
\hline 104 & $\begin{array}{c}\text { Assumed life of } 2 \text { nd global } \\
\text { rehabilitation }\end{array}$ & $3-12$ years & 7 years & $\begin{array}{l}\text { Roadway } \\
\text { Mgmt }\end{array}$ \\
\hline 105 & $\begin{array}{l}\text { Smoothness at start and end of } 2^{\text {nd }} \\
\text { global rehabilitation }\end{array}$ & $50-300 \mathrm{in} / \mathrm{mile}$ & $\begin{array}{l}95-200 \\
\text { in } / \text { mile }\end{array}$ & $\begin{array}{c}\text { Roadway } \\
\text { Mgmt }\end{array}$ \\
\hline 106 & $\begin{array}{l}\text { Description of 3rd global } \\
\text { rehabilitation to apply (if required) }\end{array}$ & $\begin{array}{l}\text { AC overlay/ PCC overlay/ } \\
\text { Diamond grinding }\end{array}$ & AC overlay & $\begin{array}{c}\text { Roadway } \\
\text { Mgmt }\end{array}$ \\
\hline 107 & $\begin{array}{l}\text { Assumed life of 3rd global } \\
\text { rehabilitation (years) }\end{array}$ & $3-12$ years & 5 years & $\begin{array}{c}\text { Roadway } \\
\text { Mgmt }\end{array}$ \\
\hline 108 & $\begin{array}{l}\text { Smoothness at start and end of } 3^{\text {rd }} \\
\text { global rehabilitation }\end{array}$ & $50-300 \mathrm{in} / \mathrm{mile}$ & $\begin{array}{l}100-200 \\
\text { in } / \text { mile }\end{array}$ & $\begin{array}{l}\text { Roadway } \\
\text { Mgmt }\end{array}$ \\
\hline 109 & $\begin{array}{l}\text { Description of 4th global } \\
\text { rehabilitation to apply (if required.) }\end{array}$ & $\begin{array}{l}\text { AC overlay/ PCC overlay/ } \\
\text { Diamond grinding }\end{array}$ & AC overlay & $\begin{array}{l}\text { Roadway } \\
\text { Mgmt }\end{array}$ \\
\hline 110 & $\begin{array}{l}\text { Assumed life of 4th global } \\
\text { rehabilitation (years) }\end{array}$ & $3-12$ years & 3 years & $\begin{array}{l}\text { Roadway } \\
\text { Mgmt }\end{array}$ \\
\hline 111 & $\begin{array}{l}\text { Smoothness at start and end of } 4^{\text {th }} \\
\text { global rehabilitation }\end{array}$ & $50-300 \mathrm{in} / \mathrm{mile}$ & $\begin{array}{l}105-200 \\
\text { in } / \mathrm{mile}\end{array}$ & $\begin{array}{c}\text { Roadway } \\
\text { Mgmt }\end{array}$ \\
\hline
\end{tabular}

PaveSpec allows the user to define up to three global rehabilitation scenarios, each with four steps. However, the INDOT repair and rehabilitation planned necessitated only one global rehabilitation plan. These inputs are also not analyzed. 


\subsection{Unit Cost Information}

Inputs \#112 through \#128 define the Unit Cost Information. The information explained here is used to calculate the life-cycle costs of maintenance, rehabilitation, and other activities. The inputs considered in this section grouped into three areas:

- Maintenance costs (three inputs)

- Rehabilitation costs (seven inputs)

- Other costs (seven inputs)

Maintenance refers to actions that are applied to the pavement at regular intervals, regardless of pavement condition. Rehabilitation refers to actions that are applied in response to the deterioration of the pavement and include various repairs and overlays. The inputs in "Other costs" include discount rates, assumed width of repairs, and percentage of user costs included.

\subsubsection{Maintenance and Rehabilitation Costs}

Inputs \#112 through \#114, as shown in Figure 7-11 and Table 7-13, were used in project R25715 for INDOT maintenance costs. The cost of maintenance was determined from an average of previous contracts provided by the Contracts and Construction division of INDOT. 


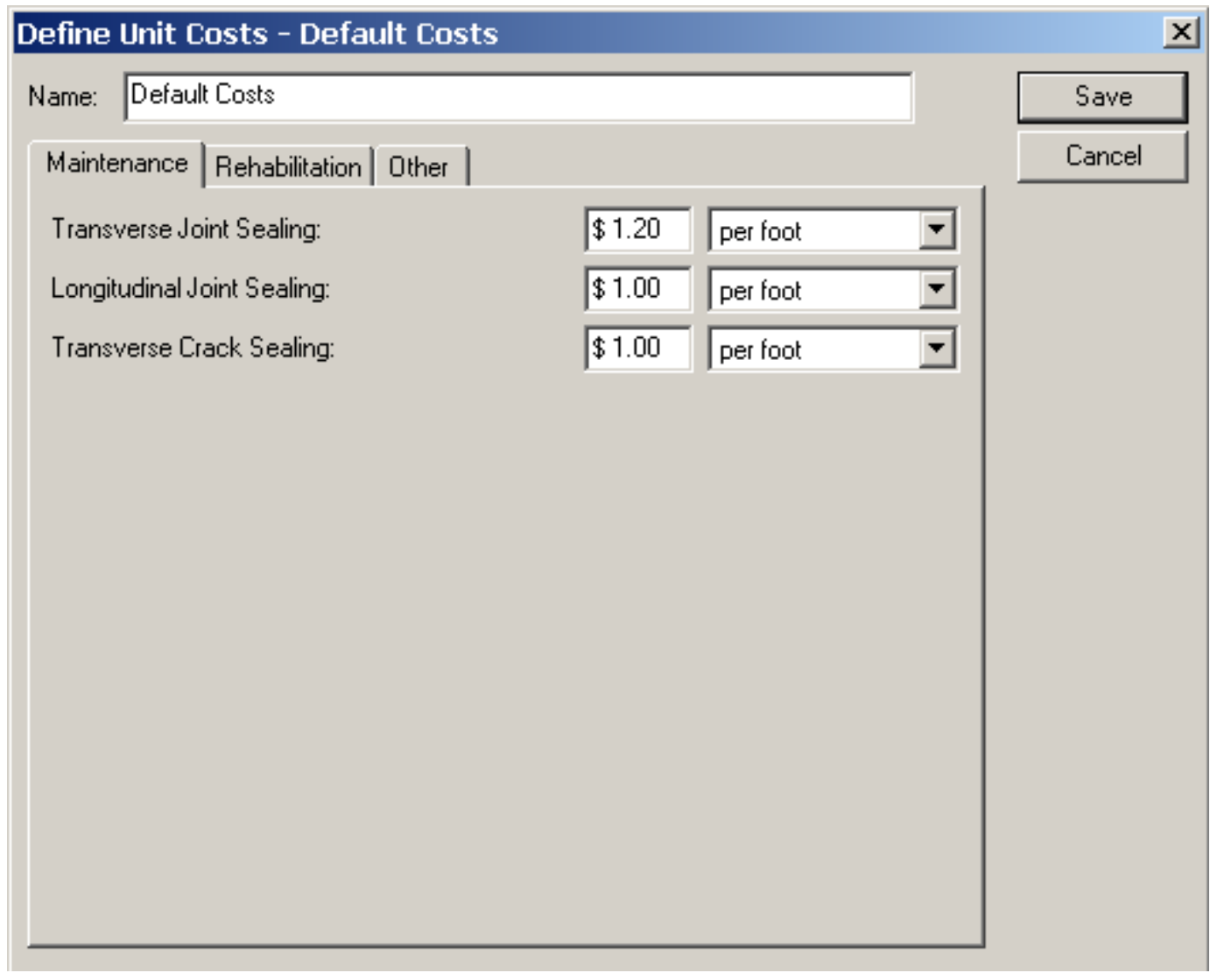

Figure 7-11 Input Screen for Regular Maintenance Unit Cost Information

Table 7-13 Estimated Regular Maintenance Unit Costs

\begin{tabular}{|c|c|c|c|c|}
\hline No. & Input & Ranges & $\begin{array}{c}\text { Project } \\
\text { Value }\end{array}$ & Source \\
\hline 112 & Transverse joint sealing & $\begin{array}{c}\$ 0.99-\$ 1.50 \\
\text { per } \mathrm{ft} .\end{array}$ & $\$ 1.20$ per $\mathrm{ft}$ & $\begin{array}{c}\text { Contracts and } \\
\text { Construction }\end{array}$ \\
\hline 113 & Longitudinal joint sealing & $\begin{array}{c}\$ 0.99-\$ 1.09 \\
\text { per } \mathrm{ft} .\end{array}$ & $\$ 1.00$ per $\mathrm{ft}$ & $\begin{array}{c}\text { Contracts and } \\
\text { Construction }\end{array}$ \\
\hline 114 & Transverse crack sealing & $\begin{array}{c}\$ 0.50-\$ 2.85 \\
\text { per } \mathrm{ft} .\end{array}$ & $\$ 1.00$ per $\mathrm{ft}$ & $\begin{array}{c}\text { Contracts and } \\
\text { Construction }\end{array}$ \\
\hline
\end{tabular}

The values in Figure 7-12 and Table 7-14 were used in project R-25715 for INDOT repair and rehabilitation costs. The cost of repair and rehabilitation was determined from an average of previous contracts provided by the Contracts and Construction division of INDOT and by reports from the FHWA. Note, due to the repair scheme selected by INDOT, some values are unnecessary. 


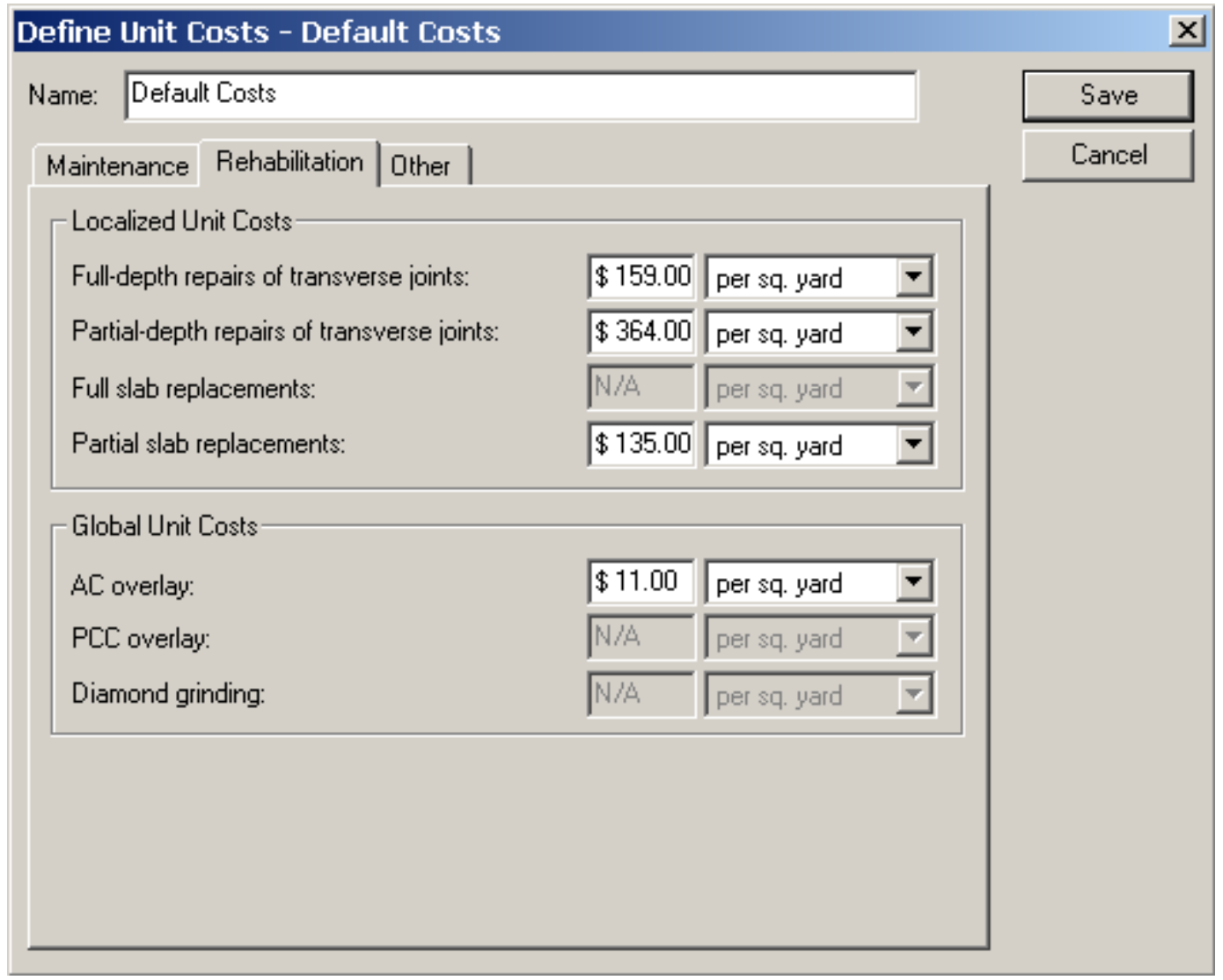

Figure 7-12 Input Screen for Rehabilitation Unit Cost Information

Table 7-14 Estimated Rehabilitation Costs

\begin{tabular}{|c|c|c|c|c|}
\hline No. & Input & Typical Ranges & $\begin{array}{c}\text { Project } \\
\text { Value }\end{array}$ & Source \\
\hline 115 & $\begin{array}{c}\text { Full-depth repairs of } \\
\text { transverse joints }\end{array}$ & $\begin{array}{c}\$ 40-\$ 287 \\
\text { per sq. yd }\end{array}$ & $\begin{array}{c}\$ 159 \\
\text { per sq. yd }\end{array}$ & $\begin{array}{c}\text { Contracts and } \\
\text { Construction }\end{array}$ \\
\hline 116 & $\begin{array}{c}\text { Partial-depth repairs of } \\
\text { transverse joints }\end{array}$ & $\begin{array}{c}\$ 65-\$ 126 \\
\text { per sq. yd }\end{array}$ & $\begin{array}{c}\$ 364 \\
\text { per sq. yd }\end{array}$ & $\begin{array}{c}\text { Contracts and } \\
\text { Construction }\end{array}$ \\
\hline 117 & Full slab replacement & N/A & N/A & N/A \\
\hline 118 & Partial slab replacement & $\begin{array}{c}\$ 25-\$ 125 \\
\text { per sq. yd }\end{array}$ & $\begin{array}{c}\$ 135 \\
\text { per sq. yd }\end{array}$ & $\begin{array}{c}\text { Contracts and } \\
\text { Construction }\end{array}$ \\
\hline 119 & Asphalt concrete overlay & $\begin{array}{c}\$ 6-\$ 26 \\
\text { per sq. yd }\end{array}$ & $\begin{array}{c}\$ 11 \\
\text { per sq. yd }\end{array}$ & $\begin{array}{c}\text { Contracts and } \\
\text { Construction }\end{array}$ \\
\hline 120 & $\begin{array}{c}\text { Portland cement concrete } \\
\text { overlay }\end{array}$ & N/A & N/A & N/A \\
\hline 121 & Diamond grinding & N/A & N/A & N/A \\
\hline
\end{tabular}

Each of the inputs in the first two areas, Maintenance and Rehabilitation costs, is an estimate of the cost of the upkeep on the pavement to maintain a reasonable level of service and to 
counteract deterioration. From experience on the first PRS contract in Indiana, it was seen that these costs are often times difficult for INDOT to estimate. Analyses show, however, that none of the inputs in the first two areas of the Unit Cost Information have a substantial effect on the total life-cycle cost of the pavement. Rather, the inputs in the "Other costs" area need the most attention, particularly the percentage of user costs included. Simulations showed that even if the rehabilitation and repair costs were changed to double their estimated values, there will be a less than one percent increase on the life-cycle cost of the pavement. The conclusion is that the estimates for repair and rehabilitation costs are also sufficient for to estimate the total life-cycle cost of the pavement.

\subsubsection{Other Costs}

The last section of the Unit Cost Information page, entitled "Other costs," has the most critical inputs in the PaveSpec program, according to the analysis. The inputs (\#122 through \#128), are shown in Figure 7-13 and Table 7-15 


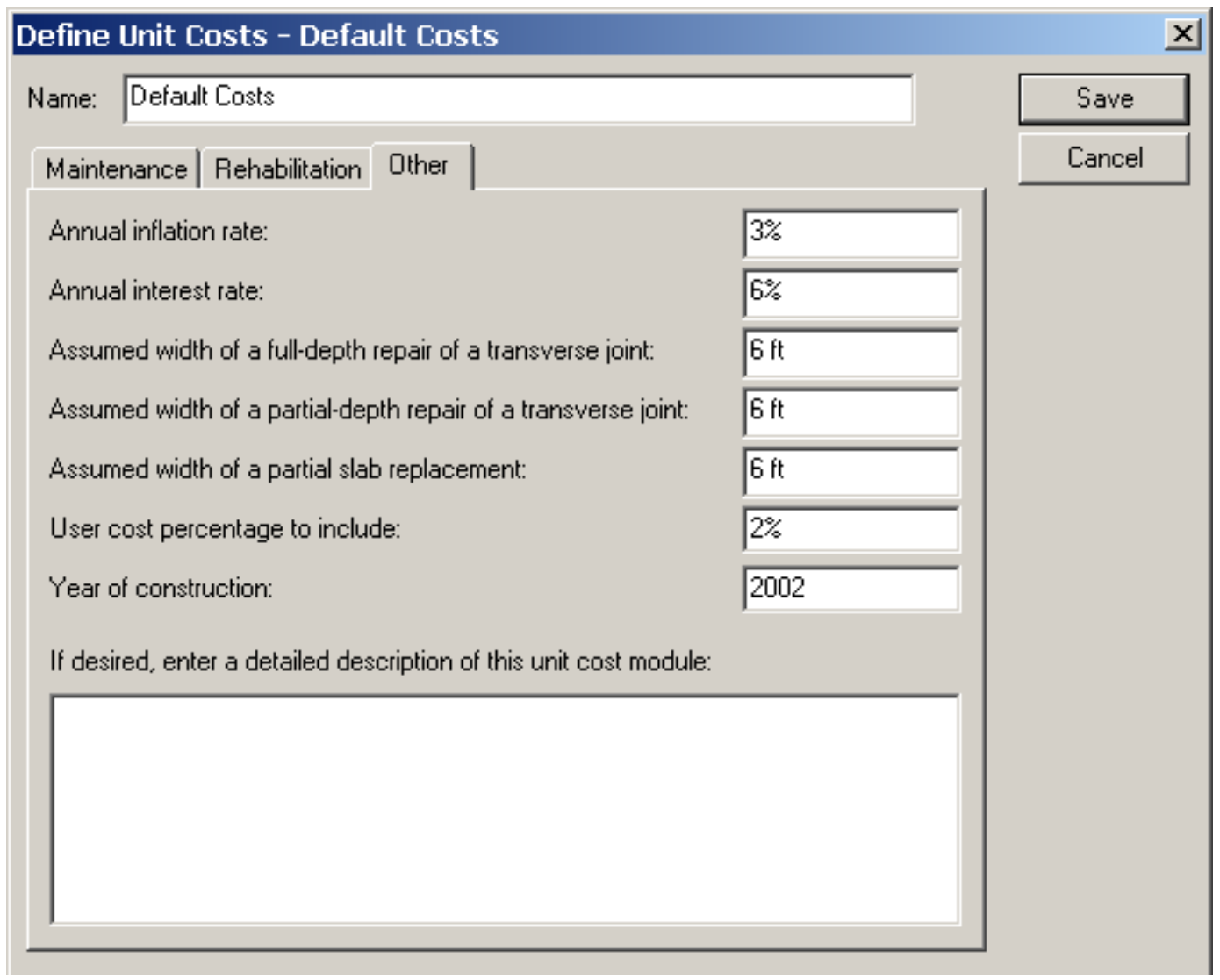

Figure 7-13 Input Screen for Other Life-Cycle Cost Analysis Information

Table 7-15 Other Life-Cycle Cost Analysis Variables

\begin{tabular}{|c|c|c|c|c|}
\hline No. & Input & $\begin{array}{c}\text { Typical } \\
\text { Ranges }\end{array}$ & $\begin{array}{c}\text { Project } \\
\text { Value }\end{array}$ & Source \\
\hline 122 & Annual inflation rate & - & $3 \%$ & User \\
\hline 123 & Annual interest rate & - & $6 \%$ & User \\
\hline 124 & $\begin{array}{c}\text { Assumed width of full depth repair of } \\
\text { transverse joint }\end{array}$ & - & $6 \mathrm{ft}$ & User \\
\hline 125 & $\begin{array}{c}\text { Assumed width of partial depth repair } \\
\text { of transverse joint }\end{array}$ & - & $6 \mathrm{ft}$ & User \\
\hline 126 & Assumed partial slab replacement & - & $6 \mathrm{ft}$ & User \\
\hline 127 & User cost percentage to include & $0-5 \%$ & $2 \%$ & User \\
\hline 128 & Year of construction & - & 2002 & User \\
\hline
\end{tabular}

Annual inflation and interest rates (inputs \#122 and \#123) were estimated by the research committee as being average values expected for highway agencies. These values have a minor effect on the estimated life-cycle costs; an increase in the inflation rate will increase the life- 
cycle cost, and an increase in the interest rate will result in a decrease in life-cycle costs. However, it is recommended that the values as shown be used.

The previous analysis in Section 7.5.1 has shown that the values affecting the repairs will not significantly affect the total life-cycle cost of the pavement. Therefore, the width of assumed repairs (inputs \#124 through \#126) will also not noticeably affect the life-cycle cost. The values were taken to be half of the lane width (input \#4).

The greatest effect on the life-cycle cost of the pavement is the percentage of user costs included (input \#127). User costs are defined by McFarland (1977) and include travel-time, vehicle operation, accidents, and discomfort costs. Hoerner and Darter note that the inclusion of user costs is a controversial issue (2000, Vol. II), but the FHWA believes that they are a necessary part of life-cycle cost analysis since user cost savings "are the single most important benefit in justification of most highway improvements" (Slater 1996).

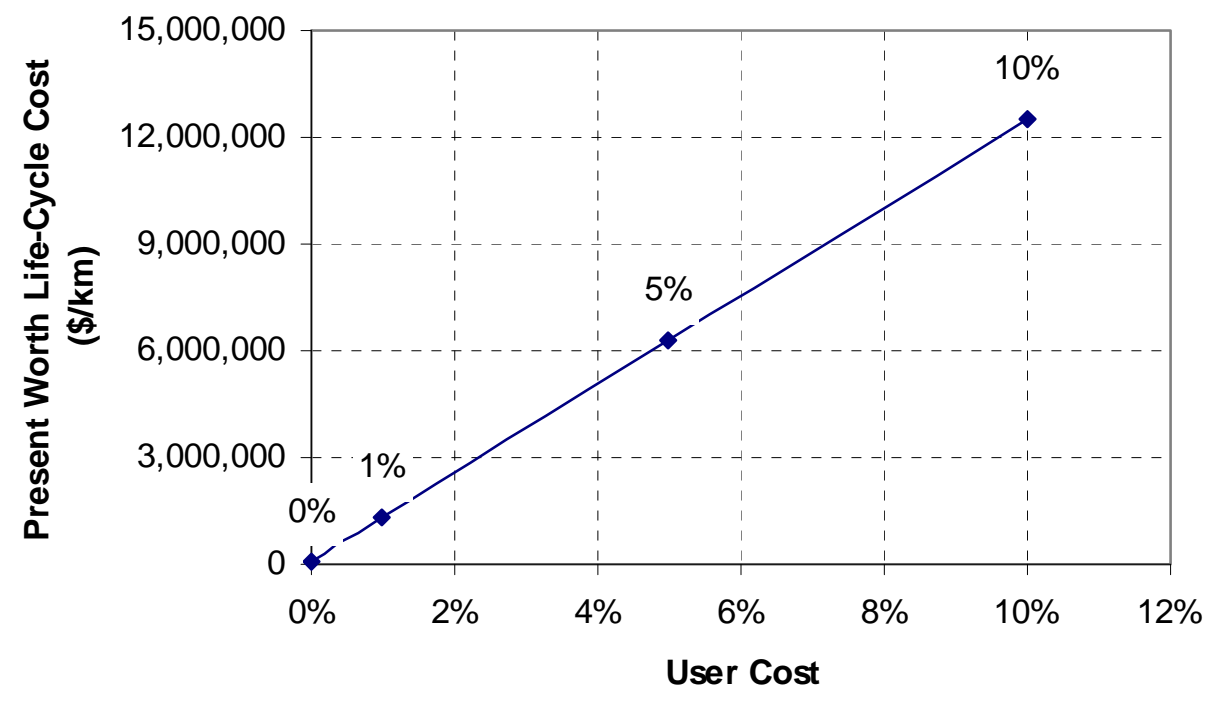

Figure 7-14 Life-Cycle Costs versus User Cost Percentage Included

As seen in Figure 7-14, higher percentages included tend to make the overall life-cycle cost so high as to render the analysis moot. Hoerner and Darter (2000) stated that user cost percentages up to $5 \%$ was reasonable, but INDOT has found that reasonable pay factors were 
generated when the percentage was set at $2 \%$. User cost percentage to be included is a highly subjective input. It is recommended that the user run several trials with varying percentages and select the one which generates pay factors that match the agencies experience and expectations.

The year of construction (input \#128) is used to inflate the user costs to a present day value. User costs are calculated from tables created by McFarland in 1972, and so PaveSpec adjusts the user costs to reflect the value of a dollar at the year of construction.

The most important conclusion to draw from this sensitivity analysis is that the percentage of user costs to include in the life-cycle cost analysis is the most significant variable for impacting the total life-cycle cost, when compared with the standard inputs for INDOT. Inputs relating to the cost of certain repairs and maintenance can be estimated, but little concern should be placed on whether or not the values are exactly right. More effort should be placed on determining the user cost percentage that INDOT is comfortable including, and assuring that the inflation rate and discount rate are the accepted values for use within the department.

\section{6 $\underline{\text { Simulation Control Information }}$}

The simulation control information includes the last inputs in the PaveSpec program. Simulation control inputs are broken into two sections: Generic settings, which control the computer simulations, and AQC settings, which control the appearance of the pay factors produced by the software.

\subsubsection{Generic settings}

Inputs \#129 through \#133 are used to define the number of lots simulated and the bid price and analysis life to be used. These inputs are shown in Figure 7-15 and Table 7-16. 


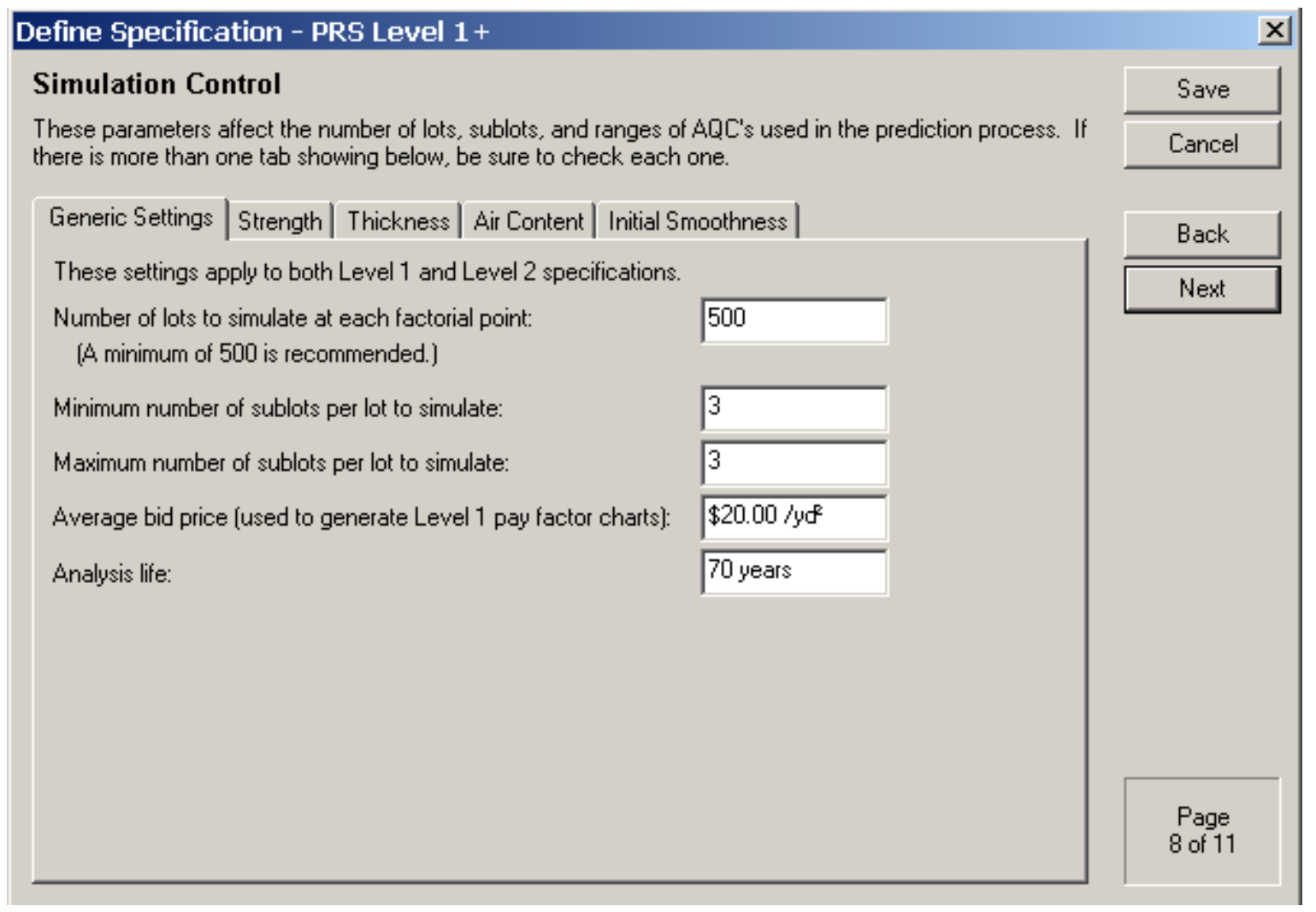

Figure 7-15 Input Screen for Simulation Control Information

Table 7-16 Simulation Control Information: Generic Settings

\begin{tabular}{|c|c|c|c|c|}
\hline No. & Input & Typical Ranges & Project Value & Source \\
\hline 129 & $\begin{array}{c}\text { Number of lots to simulate at each } \\
\text { factorial point }\end{array}$ & $500-1000$ & 500 & FHWA-RD-00-131 \\
\hline 130 & $\begin{array}{c}\text { Minimum number of sublots per } \\
\text { lot to simulate }\end{array}$ & N/A & 3 & $\begin{array}{c}\text { Indiana Standard } \\
\text { Specifications }\end{array}$ \\
\hline 131 & $\begin{array}{c}\text { Maximum number of sublots per } \\
\text { lot to simulate }\end{array}$ & N/A & 3 & $\begin{array}{c}\text { Indiana Standard } \\
\text { Specifications }\end{array}$ \\
\hline 132 & $\begin{array}{c}\text { Average bid price per pavement } \\
\text { area }\end{array}$ & $\$ 18-\$ 40 /$ sq. yd.* & $\$ 20 /$ sq.yd. & Contracts and Const. \\
\hline 133 & Analysis life & $40-100$ years & 70 years & User \\
\hline
\end{tabular}

* Provided by Mike Byers, ACPA (2002)

The number of lots to simulate (inputs \#129) is important for controlling the actual time it takes a computer to perform an entire simulation. Hoerner and Darter (2000) recommend that this number be set equal to 500 as a minimum. 
Table 7-17 Analysis of Number of Simulations per Lot

\begin{tabular}{|c|c|c|c|c|}
\hline $\begin{array}{c}\text { Number of } \\
\text { simulations per lot }\end{array}$ & $\begin{array}{c}\text { Present Worth } \\
\text { Life-Cycle Cost } \\
\text { (per mile) }\end{array}$ & $\begin{array}{c}\text { Standard } \\
\text { Deviation } \\
\text { (per mile) }\end{array}$ & $\begin{array}{c}\text { \% change } \\
\text { in LCC }\end{array}$ & $\begin{array}{c}\text { file size } \\
\text { (KB) }\end{array}$ \\
\hline 1 & $\$ 4,526,545$ & - & $-0.23 \%$ & 202 \\
\hline 10 & $\$ 4,551,331$ & $\$ 54,533$ & $0.32 \%$ & 213 \\
\hline 100 & $\$ 4,543,067$ & $\$ 40,517$ & $0.14 \%$ & 322 \\
\hline 250 & $\$ 4,537,202$ & $\$ 36,678$ & $0.01 \%$ & 504 \\
\hline 500 & $\$ 4,537,481$ & $\$ 37,120$ & $0.01 \%$ & 978 \\
\hline 600 & $\$ 4,537,840$ & $\$ 36,893$ & $0.02 \%$ & 929 \\
\hline 750 & $\$ 4,536,978$ & $\$ 36,065$ & $0.00 \%$ & 1080 \\
\hline 1000 & $\$ 4,536,801$ & $\$ 36,201$ & - & 1380 \\
\hline
\end{tabular}

As shown in Table 7-17, life-cycle costs and standard deviations tend to converge at sizes of even 250 simulations per lot. However, it was noticed that the pay factors did not converge at values less than 500. If file size is a concern, the number of simulations can be reduced from 500 to save disk space. In general, however, 500 simulations per lot should be used for the analysis.

Inputs \#130 and \#131 are used to set the boundaries of the number of sublots per lot. Normally, three sublots make up one whole lot in pavement construction, so both of these inputs are set to equal three. If these numbers are not equal, the software will calculate pay schedule for all AQCs for each case of X sublots per lot. To avoid confusion and minimize the time for simulation, it is recommended to leave these inputs as is. If the agency incorporates more sublots per lot, then both input \#130 and \#131 should be set to that value.

Bid price (input \#132) plays an important role in the generation of the level one pay factors. The pay factors are calculated from the difference in the as-designed and the as-constructed postconstruction life-cycle cost. That difference is taken as a percentage of the bid price. So, with smaller bid prices, the incentives increase. With larger bid prices, the incentives decline. This is shown in Figure 7-16. This has a profound effect on the agency, as the average bid price should be used for PRS purposes. This information, however, is an estimate, since in level one PRS, the pay factors must be included in the bid document. An advantage in level two PRS is that the pay 
factors are calculated by the program as the construction progresses and test results are entered. The bid price used in level two is the actual bid price the contractor submitted.

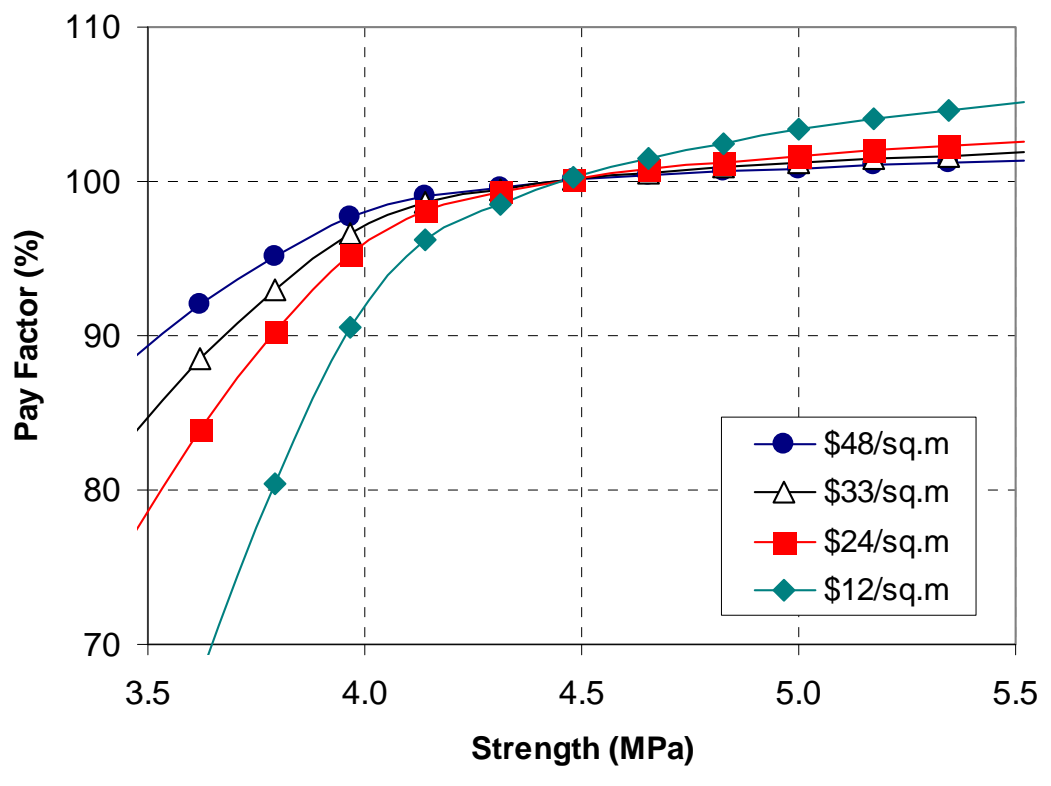

Figure 7-16 Pay Factor Variation with Bid Price

An important conclusion about the pay factors is that they become closer to $100 \%$ with an increase in bid price. Although the pay factors are fixed into the contract in level 1 PRS, in Level 2 PRS, they are a function of the bid price, because the bid price is not fixed until the contract is signed. Therefore, the contractor has incentive to submit a competitive bid, because the positive pay factors (bonuses) actually increase with the lower bids.

Using data collected from previous concrete projects in Indiana, an equation was developed to estimate the bid price per the thickness of the pavement. This is shown in Figure 7-17. 


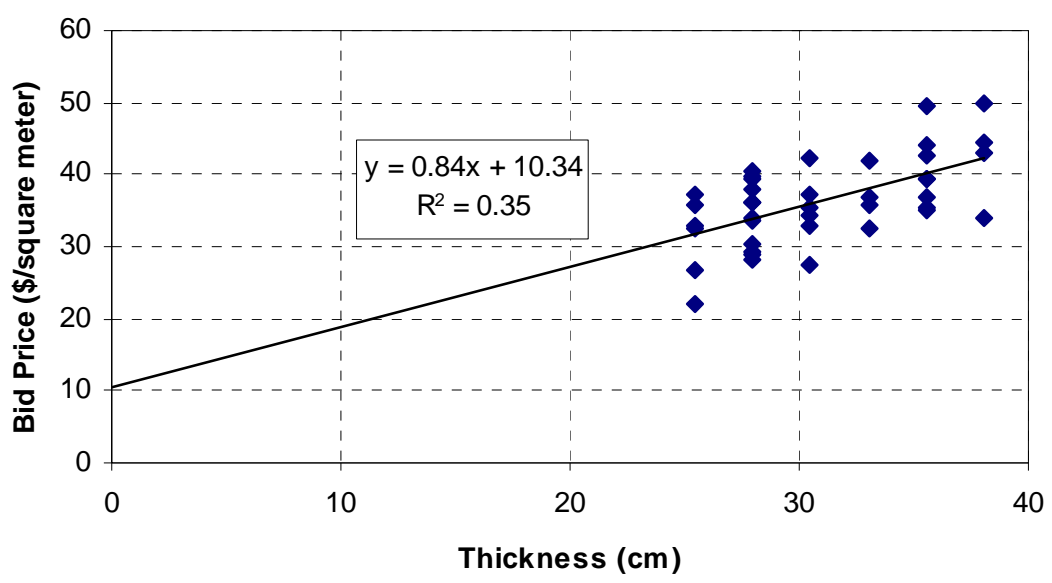

Figure 7-17 Bid Price versus Pavement Thickness

The analysis life (input \#133) should not be confused with the design life of the pavement. They are in fact not the same. The design life of the pavement is the engineer's estimate of how long the pavement will perform under the expected loading without requiring major rehabilitation, such as an asphalt overlay. The analysis period is the length of time during which all life-cycle costs are considered. This should include user costs and maintenance costs, as well as the cost to rehabilitate the pavement when it reaches the end of its design life. In PRS, the analysis period is approximately twice the design life, 30 and 60 years, respectively. However, the model should be reviewed to ensure that the analysis life is long enough to include at least one rehabilitation. In the case of the most recent project in Indiana, the analysis life was changed to 70 years for this reason.

\subsubsection{Simulation control - AQCs}

The simulation control settings for strength are shown in Figure 7-18. 


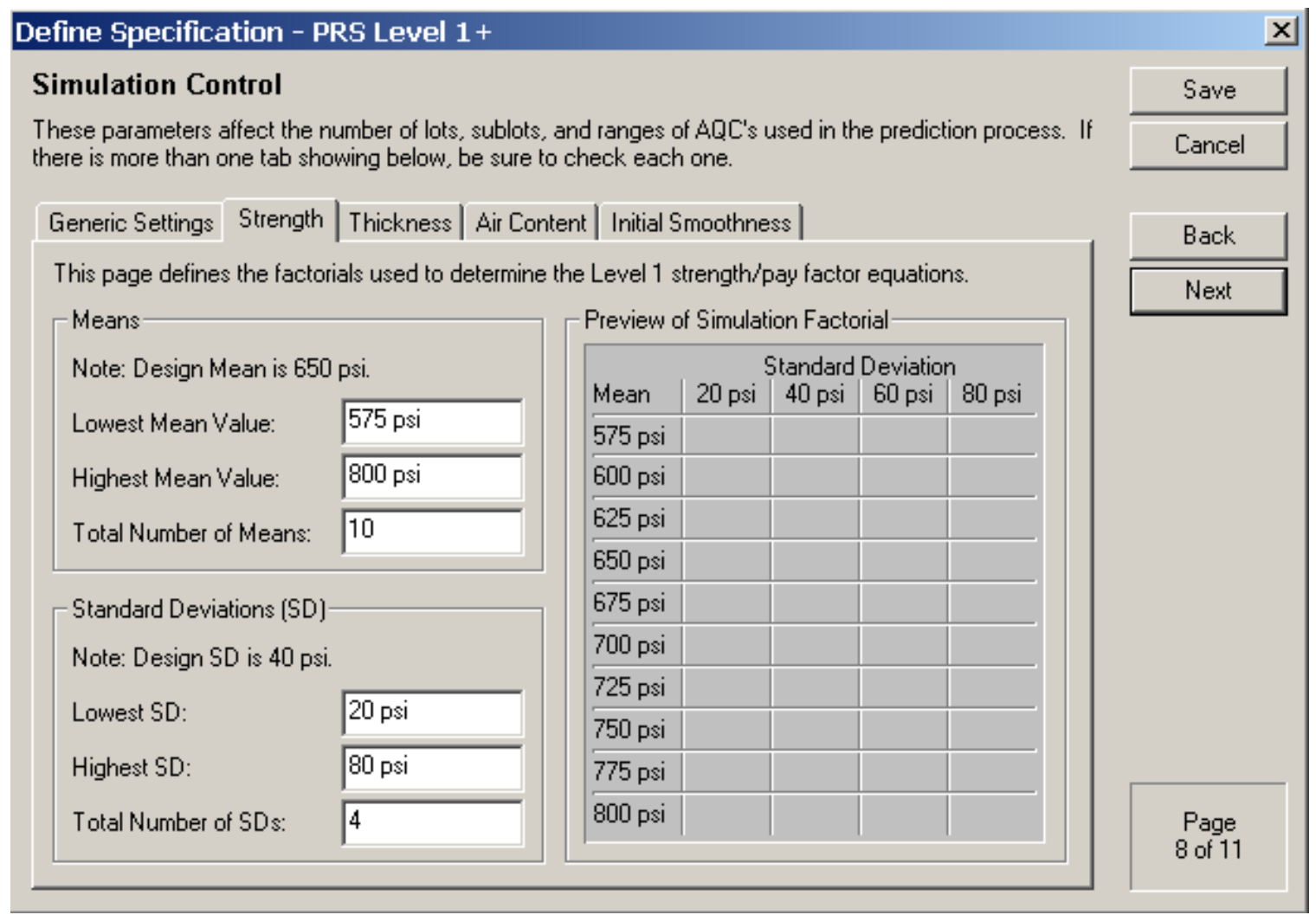

Figure 7-18 Input Screen for Defining Strength Pay Factor Ranges

The thickness, air content, and initial smoothness tabs should be filled out in the same fashion as the strength tab, but with the appropriate values. Each window for each AQC is identical.

Since INDOT chose not to include joint faulting as a pavement distress, no consolidation around the dowels is measured. If it were to be included, however, the simulation control would be set in a similar fashion to the other four AQCs.

The inputs in these last windows are used to set the minimum and maximum quality levels in the PRS. They are termed the Rejectable Quality Limit and Maximum Quality Limit, or RQL and MQL. The proximity of these numbers can also have an impact on how the contractor controls quality. RQLs that are near to the target will encourage better quality control, and 
influence how well they can "toe the line." The agency can limit the pay factors at a certain maximum percentage.

\subsection{Conclusions}

This chapter has discussed the inputs in the life-cycle cost simulation for PRS that deal with quality levels, maintenance, unit costs, and simulation. The most significant inputs, as revealed by this investigation, as the distress models included, the AQC targets chosen, the interest and inflation rates, the percentage of user costs included in the simulation, and the average bid price. The setting of the AQC targets is further discussed in Chapter 8, as well as the impacts of PRS on the agency and the contractor. 


\section{CHAPTER 8: IMPACTS OF PERFORMANCE RELATED SPECIFICATIONS ON AGENCIES AND CONTRACTORS}

Performance Related Specifications (PRS) have only been used for concrete pavement construction since 1999. As a result, the impacts of PRS are not as familiar to the highway industry as are the impacts of other specifications. Two projects incorporating PRS have been completed in Indiana. These two projects have provided several lessons that are beneficial to the general development of PRS.

This chapter describes the key concepts and impacts of PRS on agencies and contractors as learned in the two PRS projects in Indiana. This chapter is organized as follows. Section 8.1 presents a comparison of the two PRS projects in Indiana. Section 8.2 explains how the selection of design quality target values in PRS differs from setting minimum quality levels in a Quality Control/Quality Assurance (QC/QA) specification. Section 8.3 discusses the impacts of modifying pay adjustment factors in PRS. Section 8.4 discusses the relation of variability and performance in PRS. Section 8.5 introduces a cost equation that can be used to optimize production with PRS. Section 8.6 presents the summary and conclusions of this chapter.

\subsection{Comparison of PRS Projects in Indiana}

Although prototype PRS have been developed for jointed plain concrete pavements since 1996, only two projects have been constructed with PRS as of 2003, both in Indiana. The first PRS project in Indiana was constructed in the summer of 2000 on I-465 on the east side of Indianapolis. As part of the project, a research committee was formed to assist the Indiana Department of Transportation (INDOT) in transitioning from Quality Control/Quality Assurance 
(QC/QA) specifications to PRS. After the completion of the first project, several shortcomings were noted in the PRS and improvements were suggested. Then a second PRS project was constructed, beginning in the summer of 2002, on a portion of I-65 in Clarksville, Indiana, just north of Louisville, Kentucky. The implementation of the second PRS project was improved based on the lessons learned in the first PRS project. Those lessons included:

- $\quad$ Proper determination of the AQC target mean values

- $\quad$ Consideration of contractor behavior on setting quality targets.

- $\quad$ Simplifying smoothness measurements

The projects had different design characteristics, allowing for some comparison between the PRS use in each. For example, the first year design traffic volume from project \#1 to project \#2 decreased 33\% from 90,700 ADT to 61,200 $\mathrm{ADT}^{2}$. The second project was located approximately $180 \mathrm{~km}$ (110 miles) south of the first, having a slightly milder climate. A different contractor was awarded the second contract, and a different district office of INDOT was responsible for the project administration. This increased the number of personnel having been involved on at least one PRS project and provided different perspectives and reactions to the use of PRS.

In addition to the project design conditions, the computer software also changed between projects. PRS require performance prediction models to simulate the life-cycle of the pavement, allowing for a comparison between the as-designed and as-constructed life-cycle costs. The software package used to run the life-cycle cost simulations, PaveSpec, was employed in both projects. However, the first project used version 2.0, while the second project used the updated version 3.0. Specific changes were made in version 3.0 to update the pavement distress models used in PaveSpec (Hoerner et al. 2000). These improvements made data acquisition easier, provided increased accuracy, and correlated better with specific site characteristics. Additionally, many software bugs were fixed.

The design of the two projects was not identical, although the projects were similar. Each was an interstate project in an urban setting. However, different contractor quality targets, otherwise known as Acceptable Quality Characteristics (AQCs), were chosen for each project.

\footnotetext{
${ }^{2}$ Average Daily Traffic
} 
AQCs are measurable pavement characteristics that are related to pavement performance and under the direct control of the contractor. Table 8-1 summarizes the design AQC values for the two PRS projects in Indiana.

Table 8-1 Design AQC Values for PRS Projects in Indiana

\begin{tabular}{|c|c|c|c|c|}
\hline & \multicolumn{2}{|c|}{$1^{\text {st }}$ Project: R-24432 } & \multicolumn{2}{|c|}{$2^{\text {nd }}$ Project: R-25715 } \\
\hline $\begin{array}{l}\text { AQC } \\
\text { Value }\end{array}$ & $\begin{array}{l}\text { Target } \\
\text { Mean }\end{array}$ & $\begin{array}{c}\text { Target } \\
\text { Standard } \\
\text { Deviation }\end{array}$ & $\begin{array}{l}\text { Target } \\
\text { Mean }\end{array}$ & $\begin{array}{c}\text { Target } \\
\text { Standard } \\
\text { Deviation }\end{array}$ \\
\hline $\begin{array}{l}\text { 7-day Flexural } \\
\text { Strength }\end{array}$ & $\begin{array}{l}4.6 \mathrm{MPa} \\
(665 \mathrm{psi})\end{array}$ & $\begin{array}{c}0.34 \mathrm{MPa} \\
(50 \mathrm{psi})\end{array}$ & $\begin{array}{l}4.3 \mathrm{MPa} \\
(620 \mathrm{psi})\end{array}$ & $\begin{array}{c}0.28 \mathrm{MPa} \\
(40 \mathrm{psi})\end{array}$ \\
\hline $\begin{array}{l}\text { 28-day Flexural } \\
\text { Strength }\end{array}$ & $\begin{array}{l}4.8 \mathrm{MPa} \\
(700 \mathrm{psi})\end{array}$ & $\begin{array}{c}0.34 \mathrm{MPa} \\
(50 \mathrm{psi})\end{array}$ & $\begin{array}{l}4.5 \mathrm{MPa} \\
(650 \mathrm{psi})\end{array}$ & $\begin{array}{c}0.28 \mathrm{MPa} \\
(40 \mathrm{psi})\end{array}$ \\
\hline Thickness & $\begin{array}{r}360 \mathrm{~mm} \\
(14 \mathrm{in} .)\end{array}$ & $\begin{array}{l}13 \mathrm{~mm} \\
(0.5 \mathrm{in} .)\end{array}$ & $\begin{array}{l}380 \mathrm{~mm} \\
(15 \mathrm{in} .)\end{array}$ & $\begin{array}{l}13 \mathrm{~mm} \\
(0.5 \mathrm{in} .)\end{array}$ \\
\hline Air Content & not used & not used & $6.5 \%$ & $0.5 \%$ \\
\hline Smoothness & $\begin{array}{l}110 \mathrm{~mm} / \mathrm{km} \\
(7 \mathrm{in} . / \mathrm{mile})\end{array}$ & $\begin{array}{l}50 \mathrm{~mm} / \mathrm{km} \\
(3 \mathrm{in} . / \mathrm{mile})\end{array}$ & $\begin{array}{l}110 \mathrm{~mm} / \mathrm{km} \\
(7 \mathrm{in} . / \mathrm{mile})\end{array}$ & $\begin{array}{l}50 \mathrm{~mm} / \mathrm{km} \\
(3 \mathrm{in} . / \mathrm{mile})\end{array}$ \\
\hline
\end{tabular}

Several changes in the design of the two projects can be seen in Table 8-1. First is the decrease in the target strength mean and standard deviation from the first to the second project. This change is explained in Section 8.2. Second, the mean target thickness was increased 7\% from the first to the second project. The Pavement Design Division of the INDOT was responsible for this decision. Third, the air content was not designated as an AQC for the first PRS project, but instead it was governed by INDOT's existing QC/QA specifications. The average value for air content from the QC/QA specifications, 6.5\%, was used as the target AQC mean for the second project. Lastly, the target smoothness values between projects were not changed, but the procedure to incorporate the smoothness measurements was modified. The requirement of three individual sublot smoothness measurements was reduced to one overall lot measurement, simplifying the implementation.

\section{2 $\underline{\text { Setting AQC Targets }}$}

An important part of creating PRS is the selection of the target AQC means and standard deviations by the highway agency. According to Hoerner and Darter (2001), the target AQC 
defines the desired quality for which the agency is willing to pay $100 \%$ of the contractorsubmitted bid price. The target AQC values are used to simulate the as-designed life-cycle of the pavement. This life-cycle cost defines target performance the agency desires. The contractor's quality, defined in terms of as-constructed AQCs, is used to predict the actual life-cycle cost of the payment. The pay adjustments for various values of the contractor's quality are based on the difference between these two life-cycle costs and are expressed in the PRS contract as a percentage of the contractor's bid price.

The initial determination of the as-designed AQC values can be made from expected-pay curves, design procedures, and published data (Hoerner and Darter, 2001). The target standard deviations can be based on data from past projects (Hoerner and Darter 2001). In the first PRS project, a conservative approach was used to compute the AQCs. Recent INDOT projects were reviewed to assess what standard deviations and means were obtained by contractors. The means and standard deviations were then selected for inclusion in the first PRS project. Although it was determined that the INDOT selected design values may have been higher than what the simulation software typically would use, the INDOT values were maintained for the first contract (Graveen 2001). The effectiveness of this decision is discussed in the Section 8.2.1.

\subsubsection{Setting Strength AQC in Project \#1}

Strength is an important AQC in the PRS projects, as three out of four pavement performance models in the life-cycle simulation software require it as an input, as discussed in Chapter 4. Currently, the strength AQC is measured in the INDOT using the AASHTO T 97 test for 7-day flexural strength. In the QC/QA specifications, the lowest value of strength from a contractor's QA test cannot be less than 570 psi (3.9 MPa) at 7-days, and standard deviations are not measured. In the development of PRS for the first project, it was assumed that the flexural strength increased 5\% from 7-days to 28-days (Graveen 2001). Therefore, the QC/QA minimum 28-day strength was assumed equal to $600 \mathrm{psi}(4.1 \mathrm{MPa})$.

The target mean strength in the first PRS project was assumed to be equal to the minimum flexural strength specified in the QC/QA specification plus two standard deviations, using the 
approach set forth by the American Concrete Institute (1997). The value of the standard deviation was taken from the average variation of past projects in Indiana. It was assumed on the first project that this standard deviation was equal to $50 \mathrm{psi}(0.34 \mathrm{MPa})$. The target AQC for 28day strength, as calculated in Equation 7-1, was therefore:

$$
600 \mathrm{psi}+2 *(50 \mathrm{psi})=700 \mathrm{psi}
$$

\section{Equation 8-1}

which is equivalent to $4.8 \mathrm{MPa}$.

The selection of AQC target strength mean in PRS has a profound impact on the agency and contractors because it involves a substantial shift in current approach of setting minimum values in QC/QA specifications. It is generally conceded that the contractor's goal is to optimize the production process to maximize profit. In QC/QA specifications, the only way to optimize the production is to ensure that the sampled material meets or exceeds the minimum specified value. In QC/QA specifications, payment is independent of the magnitude by which the sample exceeds the minimum specified value. Therefore, contractors use the strategy of approaching this minimum value while having as few samples as possible fail to meet the specification, as shown in Figure 8-1(a). In the figure, the minimum specified strength is indicated by the arrow, and a solid normal curve indicates the range of responses that the agency expects. The contractor's optimal response is shown by the dashed curve.

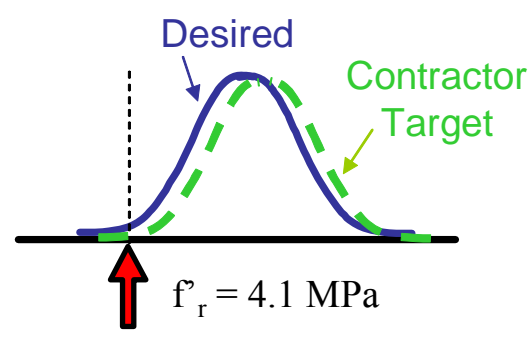

(a) QC/QA Specification, Intended Response

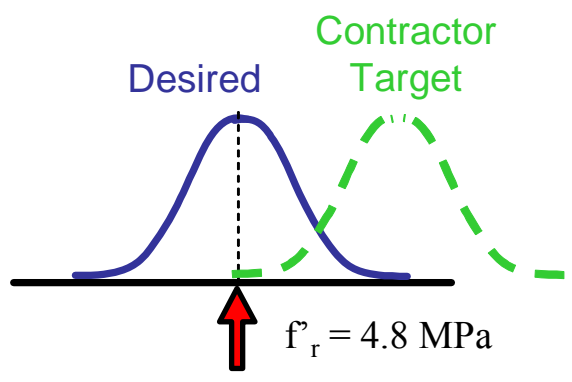

(b) PRS, Unintended Response

Figure 8-1 Agency Quality Targets and Contractor Responses

In contrast to QC/QA specifications, PRS specify the target mean strength as opposed to the minimum strength. If the contractor adjusts production to achieve material above the target strength, the results will appear as in Figure 8-1(b). Although in PRS a bonus payment can be awarded if the material achieves a strength greater than the target mean, it is not the intended 
purpose of PRS to raise the overall strength of the pavement. Rather, PRS should provide an incentive for a contractor to improve quality control. The second PRS contract applied this lesson to the selection of the second strength AQC.

\subsubsection{Setting Strength AQC in Project \#2}

The performance of the contractor in the first PRS project had an impact on the selection of the target mean strength in the second project. The first contractor had a standard deviation lower than the target standard deviation. The conservative approach of assuming a high target standard deviation for strength in the first project resulted in a specification that did not provide incentive for the contractor to change their quality control processes.

The second PRS project corrected this problem by assuming a lower standard deviation of 25 psi $(0.17 \mathrm{MPa})$ for the purpose of calculating the target mean strength. The resulting target mean strength, as shown in Equation 7-2, was therefore

$$
600 \mathrm{psi}+2 *(25 \mathrm{psi})=650 \mathrm{psi}
$$

\section{Equation 8-2}

which is equivalent to 4.5 $\mathrm{MPa}$. However, the target standard deviation for strength as specified in the contract was only reduced by $20 \%$ from $50 \mathrm{psi}(0.34 \mathrm{MPa})$ to $40 \mathrm{psi}(0.28 \mathrm{MPa})$. The selection of this "offset" target mean strength and the intended ranges that should be targeted by the contractors are shown in Figure 8-2.

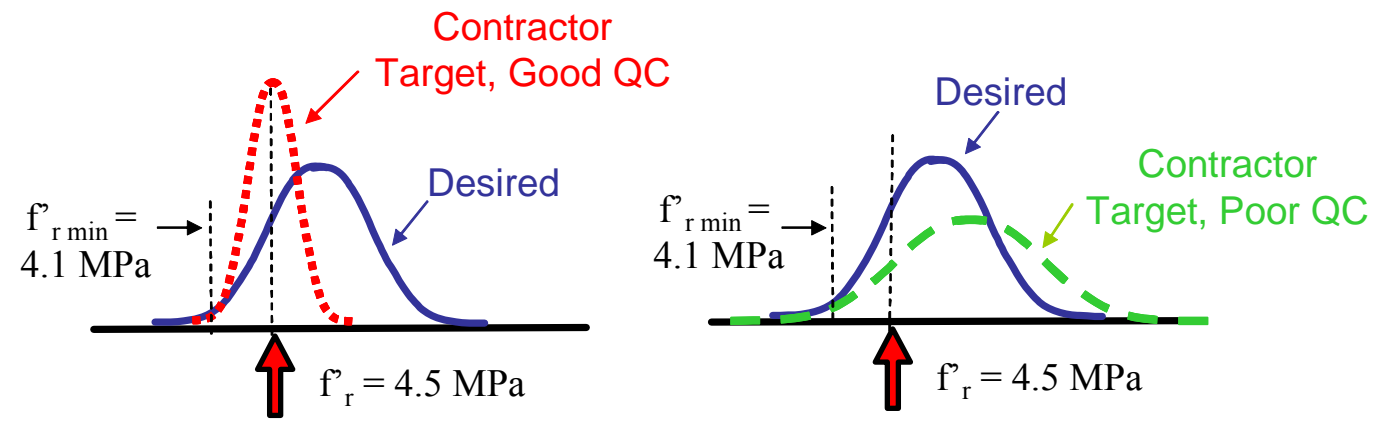

Figure 8-2 PRS Offset Strength Target and Contractor Responses

Figure 8-2 illustrates the difference in contractor responses as a result of the target mean strength AQC in PRS. Because the minimum specified strength remains the same in all INDOT specifications, each contractor must produce a material that exceeds 4.1 MPa. However, a 
contractor with good quality control, and therefore a low standard deviation, will be able to aim for the specified mean and still be confident that the material passes according to the specification. Conversely, a contractor with poor quality control must target a value higher than the AQC mean in order to ensure that the material meets the specification. If the contractor wishes to target a lower mean strength value, the contractor must first improve the quality control of the production and reduce the standard deviation.

\subsection{Modifying Pay Factor Curves in Projects \#1 and \#2}

The PRS software package, PaveSpec, produces a set of pay adjustments for each AQC based on the results of life-cycle simulation. These pay adjustments, termed pay factors, are then included in the specification documents. One lesson learned in the creation of the PRS for each project was that the pay factors produced by the program were not always deemed acceptable for the contract and may have to be modified.

The pay factors as included the first PRS contract are graphically portrayed in Figure 8-3. The actual contract documents from the first project listed the pay factors in tabular format to avoid confusion that would result from reading an exact number off of a graph.

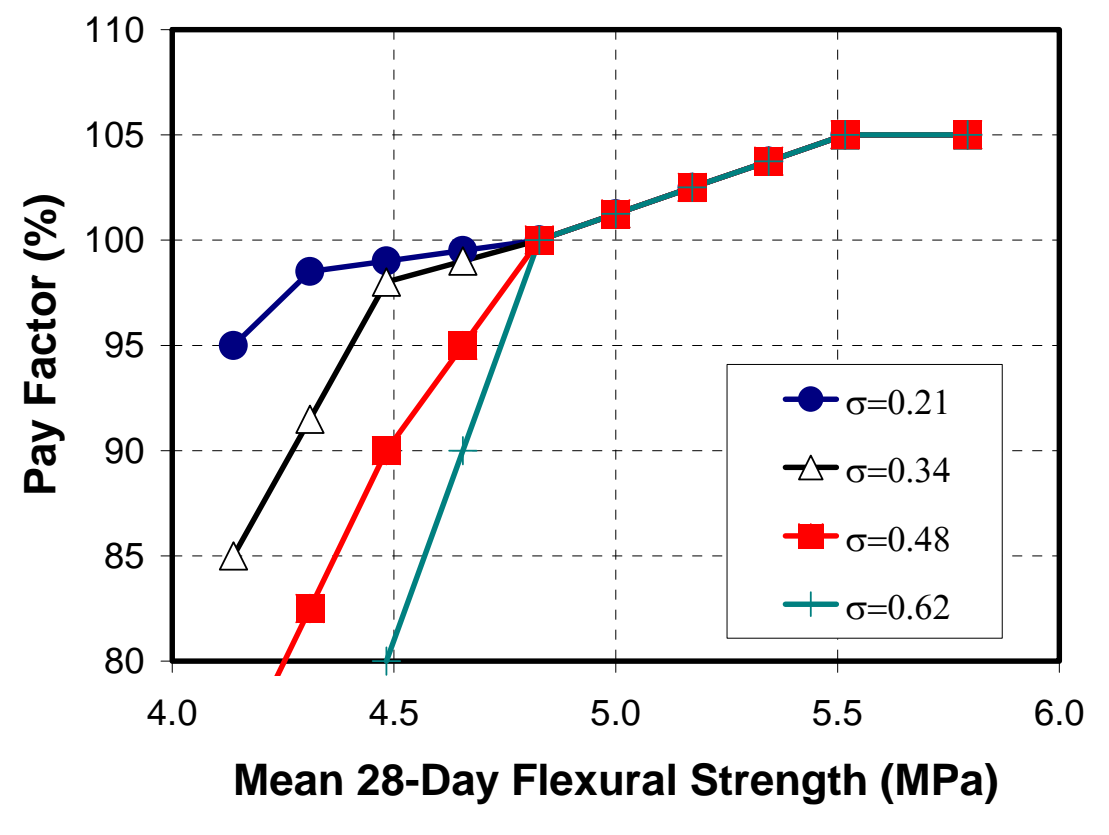

Figure 8-3 Strength Pay Factor Chart, Project \#1 
Figure 8-3 shows the pay factors as included in the first PRS contract. It was found in the first PRS project that using $700 \mathrm{psi}(4.8 \mathrm{MPa})$ as the target mean 28-day strength and 50 psi $(0.34$ $\mathrm{MPa}$ ) as the target standard deviation resulted in pay factor charts that offered very little incentive for better-than-targeted strength, yet significantly greater penalty for failing to achieve the target mean (Graveen 2001). Therefore, the pay factors were modified to include a maximum incentive of $105 \%$, while the disincentive portion of the chart was smoothed (Graveen 2001).

As discussed in Section 8.2.2, the target mean 28-day strength AQC was reduced by 7\% from $700 \mathrm{psi}(4.8 \mathrm{MPa})$ to $650 \mathrm{psi}(4.5 \mathrm{MPa})$ from the first to the second PRS project. Also, the target standard deviation was reduced $25 \%$ from $50 \mathrm{psi}(0.34 \mathrm{MPa})$ to $40 \mathrm{psi}(0.28 \mathrm{MPa})$. The software package then produced pay factors, which were smoothed and capped at $110 \%$, and placed in the second PRS contract as shown in Figure 8-4.

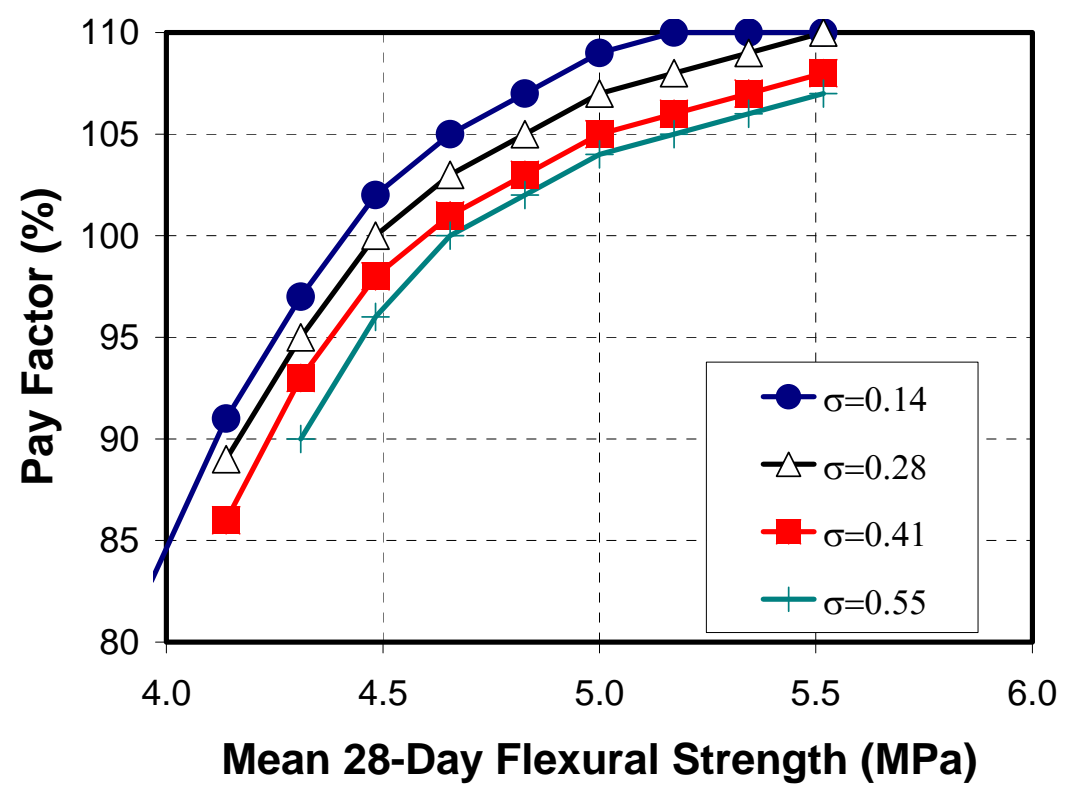

Figure 8-4 Strength Pay Factor Chart, Project \#2

Figure 8-4 shows that the pay factors tend to increase as the standard deviation decreases. In the second PRS project, the lower specified target strength resulted in pay factor charts that rewarded contractors for better quality control. The lowest standard deviation, $0.14 \mathrm{MPa}$ (20 psi) correlates to the highest pay factors on the chart. In addition to rewarding contractors with good 
quality control, these pay factors provide additional incentive for contractors with poor quality control to change their operations.

One concern that an agency might have is that by lowering the target strength in the specification, the pavement performance will decrease. However, an important PRS concept is that the pavement performance is only indirectly related to the specified target strength, but it is very dependent on the as-constructed pavement quality. This can be shown with two simple lifecycle simulations. In the first simulation, the target mean strength is set equal to $3.8 \mathrm{MPa}$. In the second, the target is $4.5 \mathrm{MPa}$, but all other inputs are left unchanged. The resulting asconstructed life-cycle costs are then plotted versus the contractor's material strength, as shown in Figure 8-5.

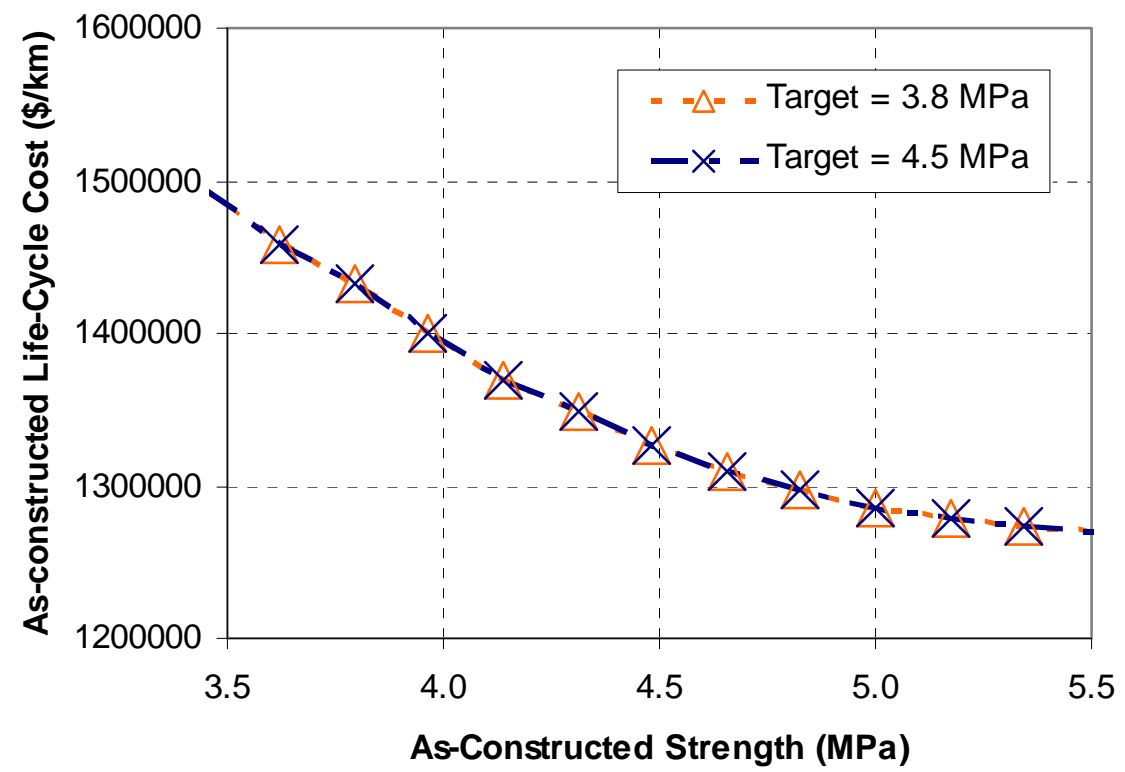

Figure 8-5 As-Constructed Life-Cycle Cost versus Strength

As seen in Figure 8-5, the calculation of the actual life-cycle cost is independent of the design strength specified. However, the pay factors are not, as shown in Figure 8-6. 


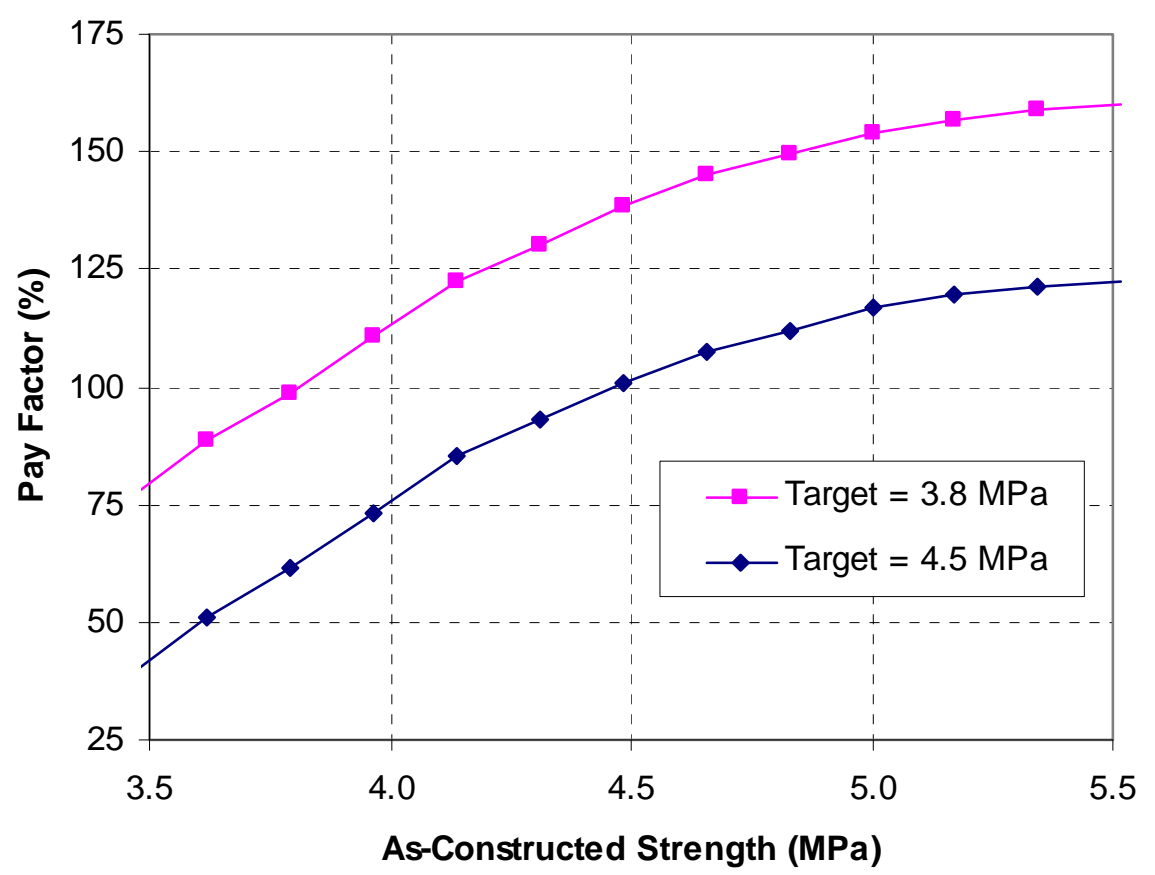

Figure 8-6 Pay Factors versus As-Constructed Strength

As seen in Figure 8-6, the target strength affects the pay factors dramatically. Lower target strengths generally increase the overall pay factors. Because the pay factors impact what strength the contractor targets, setting the design strength has a major impact on the contractor's response to PRS. Therefore, the target strength should be selected not solely based on the design of the pavement, but with consideration for the contractor's response to the specified strength and the pay factors related to it.

\subsection{Variability and Performance}

As the choice of the AQC targets in PRS impacts the contractor's target production and quality control, it is important to understand the relation of variability to performance in pavement. This relationship can be quantified through the use of life-cycle cost analysis.

Twelve simulations were run using the life-cycle simulation software to illustrate the impact of variability on performance. In each simulation, the standard deviations for strength and 
thickness were modified slightly, but the average values were held constant. The average lifecycle cost was then plotted versus the strength deviation, as shown in Figure 8-7.

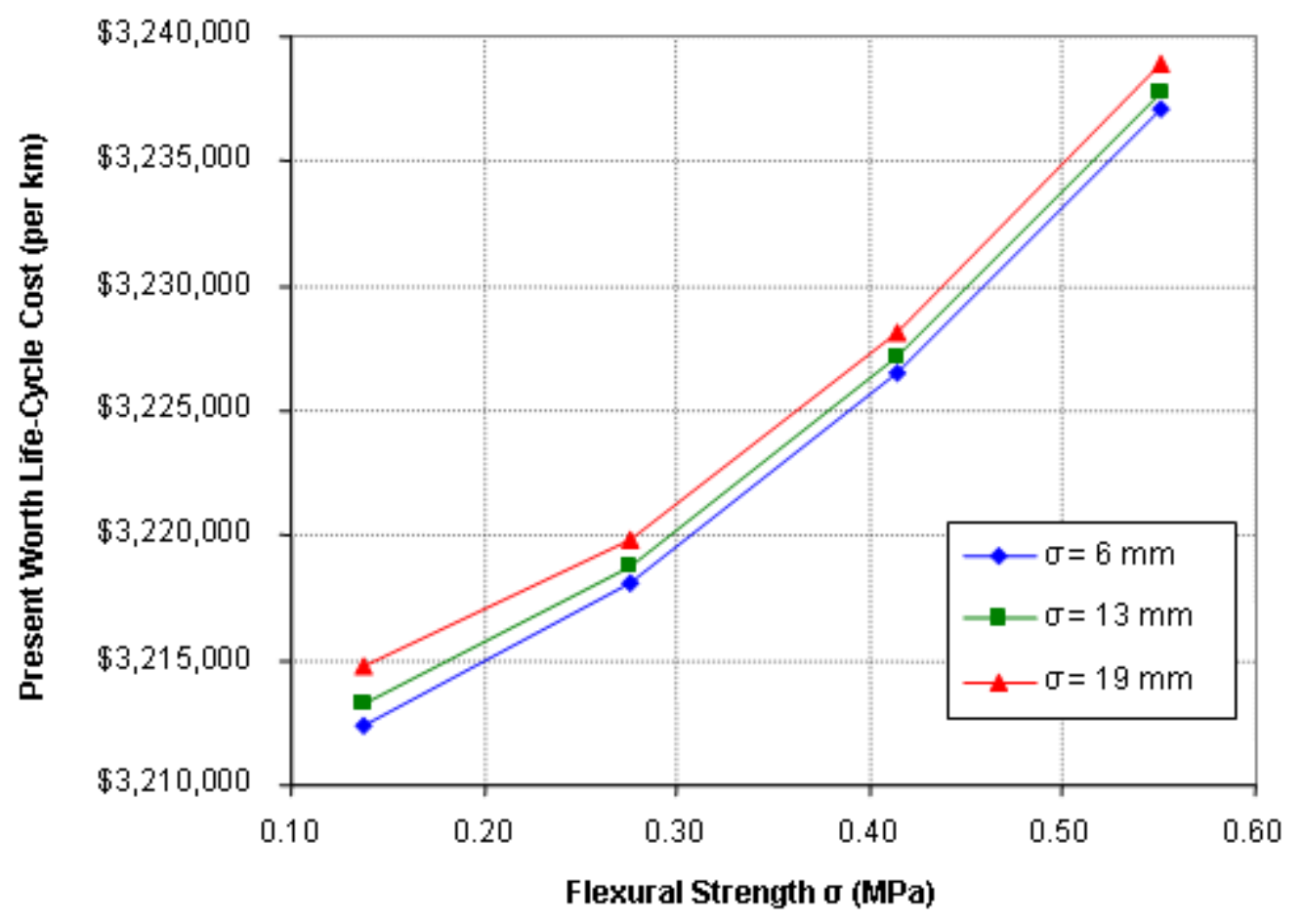

Figure 8-7 Effect of Variability on Life-Cycle Cost

In the simulations, the thickness was set at $330 \mathrm{~mm}$ (13 inches) and the 28-day flexural strength at 4.5 $\mathrm{MPa}(650 \mathrm{psi})$. The standard deviation of thickness was then allowed to vary from $6 \mathrm{~mm}$ to $19 \mathrm{~mm}$ ( 0.25 inches to 0.75 inches), and the standard deviation of strength varied from 0.14 MPa to $0.55 \mathrm{MPa}(20$ psi to $80 \mathrm{psi}$ ).

As seen in Figure 8-7, as the standard deviations increased, so did the predicted life-cycle costs. The reason for this is, as the variability increases, so does the difference in performance of constructed pavement segments, or lots. High variability will increase the likelihood of having several lots perform poorly. Even if the majority of lots are perform exceptionally well, these few deteriorating ones will drive the total pavement life-cycle cost much higher. Additionally, the public perception can be that the whole highway is falling apart, based on a small section. 


\subsection{Cost Function for Strength and Thickness}

Using PRS on a project provides incentive to optimize the performance based on the interaction of multiple AQCs. Whereas in QC/QA specifications, the pavement properties such as strength and thickness are judged independently, in PRS they interact through the use of a simulation model to predict a total life-cycle cost of the pavement. Using this information and the knowledge of the target life-cycle cost of the pavement, the contractor can optimize the production process to target a specific performance in the most efficient manner.

Cost data for strength and thickness were collected to illustrate this concept and develop an equation for estimating the contractor's cost based on the targeted flexural strength and pavement thickness. To begin, the unit volume costs for concrete mixes of different specified compressive strengths were obtained from RSMeans Heavy Construction Cost Data (2000), using national averages. The data are shown in Figure 8-8.

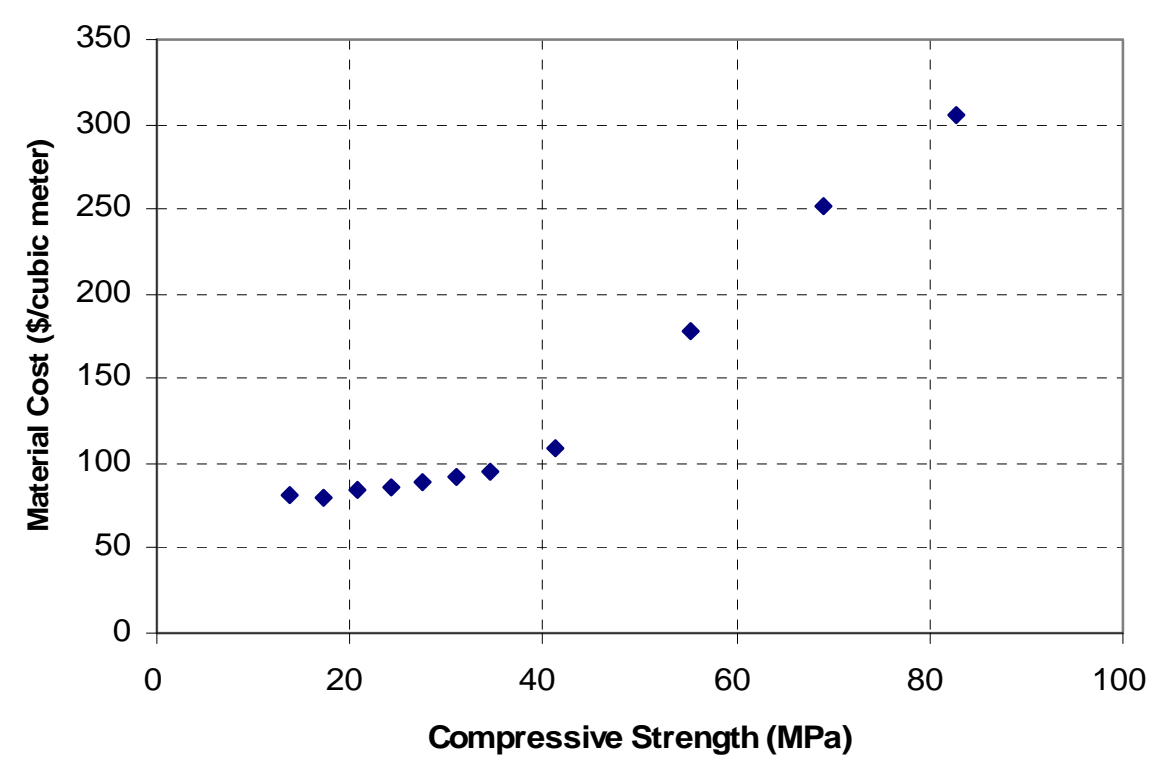

Figure 8-8 Concrete Material Cost versus Compressive Strength

Because specifications in Indiana use flexural strength, it was necessary to convert the data in Figure 8-8 from compressive to flexural strength. Mindess and Young (1981) provide a generally accepted formula for this conversion, shown in Equation 7-3: 


$$
\sigma_{\text {flexural }}=0.62\left(\sigma_{\text {compressive }}\right)^{0.5}
$$

\section{Equation 8-3}

where $\sigma$ (strength) is measured in MPa. The resulting graph is shown in Figure 8-9.

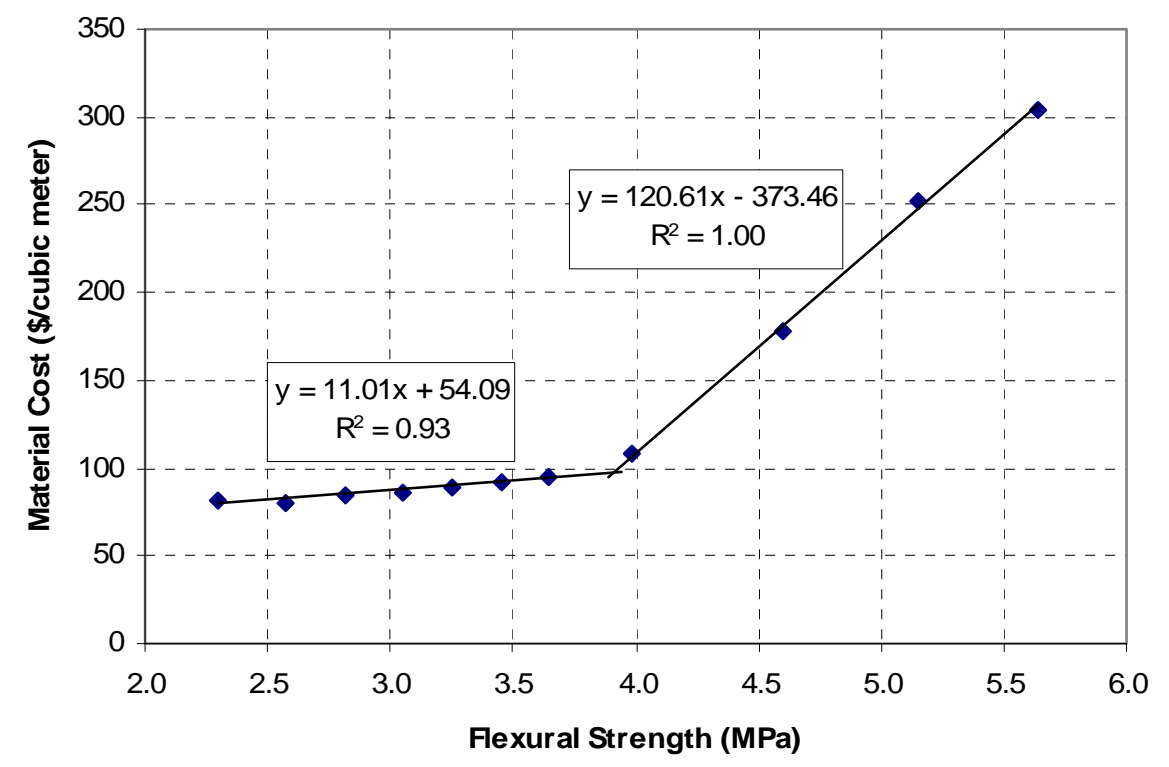

Figure 8-9 Concrete Material Cost versus Flexural Strength

Figure 8-9 shows the data and the trend lines assuming linear relationships. It can be seen that above $3.9 \mathrm{MPa}$, the cost for producing higher strength concrete increases more dramatically than below $3.9 \mathrm{MPa}$.

Current INDOT specifications specify a minimum 7-day flexural strength of 4.0 MPa. As discussed in Section 8.2.1, this is equivalent to $4.1 \mathrm{MPa}$ at 28-days. If it is assumed that the material cost of 4.1 MPa concrete is 1.0, the data in Figure 8-9 can be normalized to show the relative change in material cost at various flexural strengths. This is shown in Figure 8-10. 


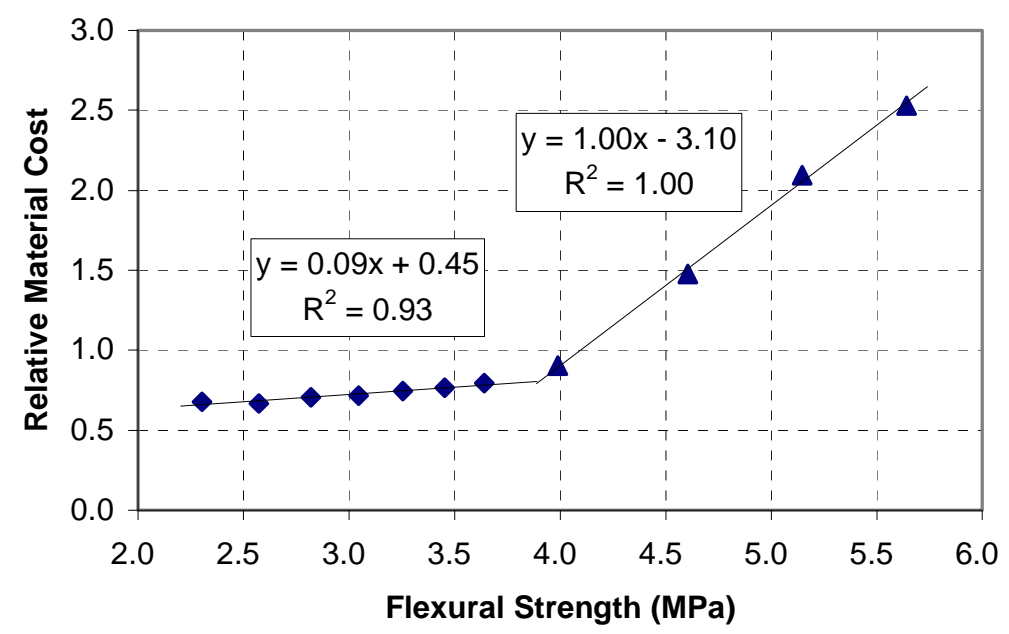

\section{Figure 8-10 Relative Concrete Material Cost versus Flexural Strength}

Figure 8-10 expresses the relative cost of a concrete with a certain specified flexural strength to a concrete with a flexural strength of 4.1 MPa at 28 days. Using this relationship between relative cost and flexural strength in Figure 8-10, two equations can be developed to create a cost factor based on the specified flexural strength. At strengths above 3.9 MPa, the cost factor can be calculated as shown in Equation 7-4:

where

$$
\text { Cost factor }=\mathrm{STR}-3.1
$$

\section{Equation 8-4}

$\mathrm{STR}=$ desired concrete strength $(\mathrm{MPa})$

Cost factor $=$ ratio of the cost of desired concrete to the cost of 4.1 MPa concrete

At strengths equal to and below 3.9 $\mathrm{MPa}$, the cost factor can be calculated as shown in Equation 7-5:

$$
\text { Cost factor }=0.09 * \mathrm{STR}+0.45
$$

\section{Equation 8-5}

using the same units as Equation 7-4.

Now that the cost factor for flexural strength has been determined, a second function is needed to estimate the cost of pavement versus thickness. To accomplish this, cost information was gathered for projects in Indiana according to the pavement thickness. The American Concrete Pavement Association provided data on concrete pavement projects in Indiana from 
October 1998 to June 2001 (Byers 2002). Forty pavements were indexed according to thickness, as shown in Figure 8-11.

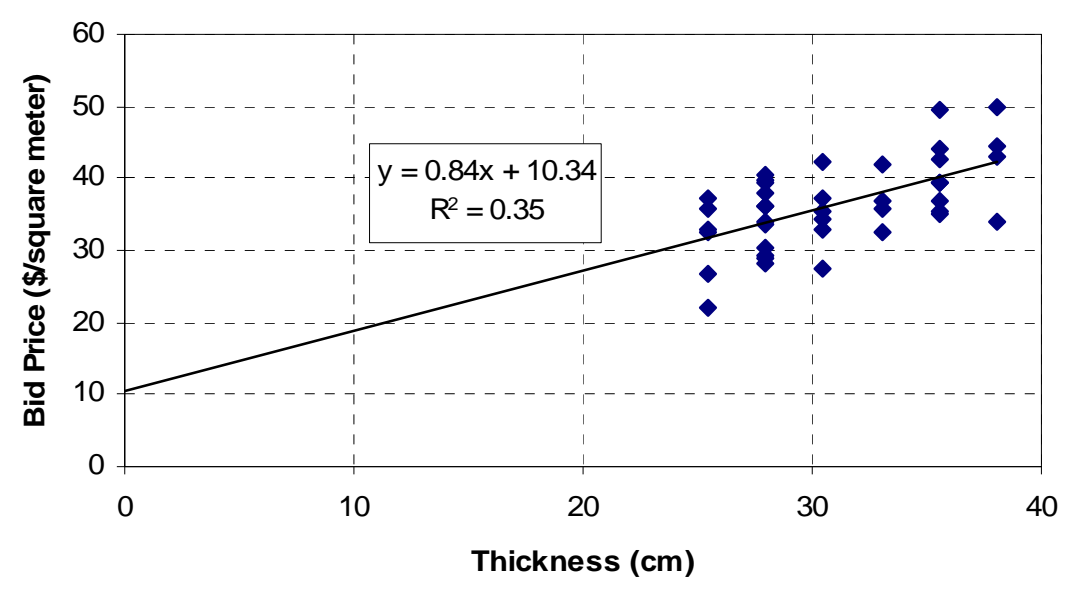

Figure 8-11 Cost versus Thickness of Indiana Pavements

A trend line was fit to the data shown in Figure 8-11. The data shows that there is an initial setup cost off approximately $\$ 10.34$ per square meter, plus an additional cost of $\$ 0.84$ per square meter per centimeter of thickness. This data can be combined with the cost factor for flexural strength to provide an overall cost function for the pavement based on thickness and strength, assuming that the strength and thickness costs are independent.

The cost function consists of two equations to account for the change in the strength cost factor calculation above and below 3.9 MPa. The cost function is shown in Equation 7-6:

If $\mathrm{STR}>3.9 \mathrm{MPa}$

$$
\mathrm{COST}=\$ 10.34+\$ 0.84(\mathrm{THK}) *(\mathrm{STR}-3.1)
$$

Equation 8-6a

If $\mathrm{STR} \leq 3.9 \mathrm{MPa}$

$$
\mathrm{COST}=\$ 10.34+\$ 0.84(\mathrm{THK}) *[0.09(\mathrm{STR})+0.45] \quad \text { Equation 8-7b }
$$

where

COST $=$ cost of the pavement, $\$$ per square meter,

$\mathrm{THK}=$ thickness of the pavement, $\mathrm{cm}$, and 
$\mathrm{STR}=28$-day flexural strength of the pavement, MPa.

This cost function can be used to optimize cost versus performance using the output from PRS software. In the following example, the cost function is demonstrated on a series of pavement simulations run using PaveSpec 3.0. Using the second PRS project as a base case, thirty-five trials were run using various strengths and thicknesses, and the life-cycle cost of the pavement was found for each. The result is shown in Figure 8-12 with contours of equivalent present worth life-cycle cost (expressed in $\$ / \mathrm{km}$ ). The service life was 70 years.

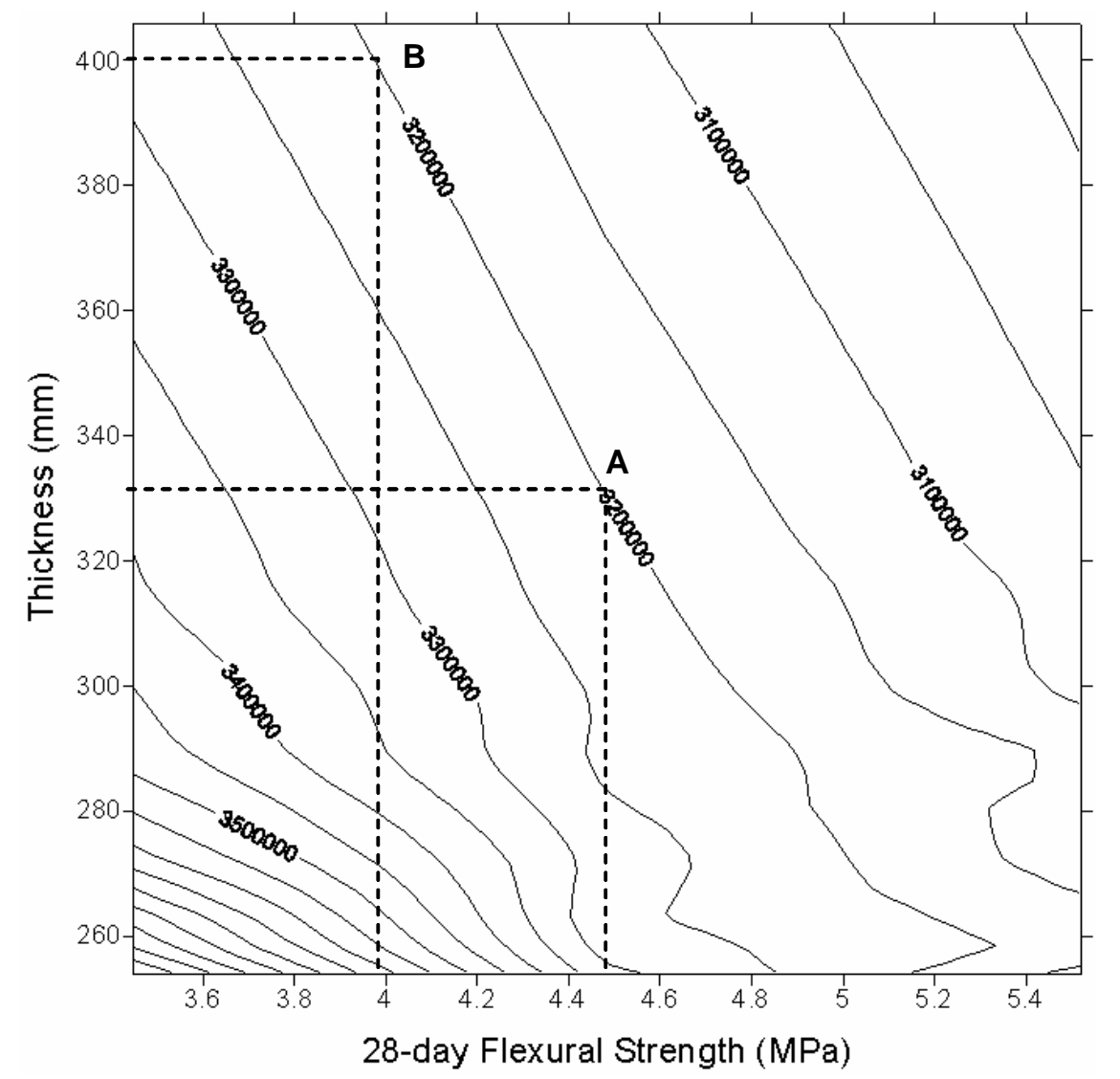

Figure 8-12 Contours of Constant Life-Cycle Cost for PRS AQCs

Figure 8-12 shows that for different designs, the tradeoff between strength and thickness is not constant. Some waving of the contours can be attributed to the interpolation function of the graphing software. At lower strengths, the change in strength is more significant than the change in thickness, as shown by the decreasing slopes of the life-cycle cost contour. Similarly, changes in thickness become more significant at lower thickness. 
Taking a life-cycle cost contour, an example is done for determining the optimal design of strength and thickness. Assume that the target life-cycle cost is $\$ 3,200,000 / \mathrm{km}$. This cost can be achieved with Design A: a combination of 4.5 MPa and $330 \mathrm{~mm}$, or Design B: a combination of 4.0 MPa and $390 \mathrm{~mm}$. The cost function for each alternative is shown in Table 8-2.

Table 8-2 Cost Functions for Two Pavement Designs

\begin{tabular}{|c|c|c|c|}
\hline Design & Strength & Thickness & Cost \\
\hline & $\mathbf{( M P a )}$ & $\mathbf{( c m )}$ & $\mathbf{( \$ / \mathbf { m } ^ { \mathbf { 2 } } )}$ \\
\hline A & 4.5 & 33 & 49.15 \\
\hline B & 4.0 & 39 & 39.82 \\
\hline
\end{tabular}

As seen in Table 8-2, Design B is more cost-efficient than Design A at providing the same level of performance. In a manner similar to what was presented in this example, contractors and agencies can optimize design and production of concrete pavement to target a specific life-cycle performance.

\section{6 $\underline{\text { Conclusions }}$}

This chapter presented a review of the first two PRS contracts in Indiana, comparing differences in site conditions and describing some of the lessons learned from the first project that were applied to the second. It also described how the strength AQCs were chosen and presented an array of contractor responses. The modification of the pay factors for inclusion in the contract documents was explained. The relation of variability to performance was described. Lastly, a cost function was developed to optimize a pavement design for strength and thickness, and an example was presented on how to apply this function to optimize cost versus performance using a graph of equivalent life-cycle cost contours for a given range of designs. 


\section{CHAPTER 9: REVIEW OF NON-DESTRUCTIVE TEST METHODS}

\subsection{Introduction}

Many of the test methods currently used to measure the properties of concrete pavement are problematic since they frequently cause damage to the pavement that must be repaired, require large numbers of test specimens to be cast in the field, do not measure the in-situ properties of the pavement, are labor intensive, or evaluate only a small section of the as-constructed pavement. For these reasons, an ideal performance-related specification (PRS) includes the use of non-destructive test methods to determine the quality of the as-constructed pavement. Nondestructive test methods are preferred to destructive test methods because they can be performed in-situ without resulting in damage to the pavement. Non-destructive tests can also be less labor intensive, require less time to conduct, ultimately cost less, and can be just as accurate as conventional destructive tests. Non-destructive test methods that require less time to conduct and cost less can be used to perform more tests on a given section of pavement. This increase in the number of sampling locations for a given section of pavement statistically provides a greater confidence in the measured pavement property.

The acceptance quality characteristics (AQC's) contained in the first PRS created for the Indiana Department of Transportation (INDOT) are concrete flexural strength, slab thickness, and initial smoothness. The test methods used to measure these AQC's for the first PRS created for INDOT are the same as the existing test methods contained in the INDOT Standard Specifications. The slab thickness is determined by coring the pavement, the flexural strength is determined by third-point loading of standard size beams, and the initial smoothness is determined using a 0.2 -inch blanking board, profilograph. 
This chapter presents the results of a review of available literature on non-destructive test methods to determine concrete strength and slab thickness. The use of a profilograph is already an in-situ and non-destructive method of determining initial smoothness; therefore investigation of additional test methods to determine initial smoothness was not conducted. Continuing research regarding profilograph advancements is currently being conducted by other parties and as such is outside the scope of this project.

In-situ and non-destructive test methods have the potential to reduce or eliminate the negative aspects of the current test methods used to determine the slab thickness and flexural strength of the pavement. Coring the pavement to determine the slab thickness is timeconsuming, expensive, and damages the pavement. Determining the flexural strength by thirdpoint loading of beams requires numerous beam test specimens to be cast, cured, and tested to failure. This process is time-consuming and expensive. In addition, the flexural testing of beam specimens does not directly measure the strength of the in-situ pavement. The casting and curing conditions experienced by the beam specimens are not the same as the conditions experienced by the pavement.

\subsection{Test Methods to Determine Slab Thickness}

The thickness of concrete pavements has been traditionally determined by measuring cores extracted from the pavement. Section 501.08 of the INDOT Standard Specifications requires 2 cores to taken per sublot, 2,000 $\mathrm{m}^{2}\left(2,400 \mathrm{yd}^{2}\right)$ of concrete, in accordance with Indiana Test Method (ITM) 404. This practice of coring the pavement is time consuming, labor intensive, evaluates only 2 locations per sublot, and creates holes in the pavement that must be repaired. Placing holes in newly constructed concrete pavement can only negatively affect the performance of the pavement.

A review of available literature was performed to indicate non-destructive test methods capable of determining slab thickness. Based on this review the short-pulse radar, spectral analysis of surface waves (SASW), pulse-echo, and impact-echo test methods appear to be 
promising test methods to determine slab thickness. The following sections provide an overview of these test methods. The overview of each test method includes a section describing the basics of the test method and a section reviewing previous research concerning the test method. Results are presented when applicable.

\subsubsection{Short-Pulse Radar}

\section{$\underline{\text { Test Method }}$}

Short-pulse radar, also called ground-penetrating radar (GPR), consists of transmitting an electromagnetic wave into a medium and receiving the reflected waves as shown in Figure 9-1. The reflected waves are portions of the transmitted wave that are reflected to the surface after striking an interface, or boundary, between materials of different dielectric constants. The portion of the transmitted wave that is not reflected penetrates through the interface and propagates through the material. When the penetrating wave reaches another boundary, a portion of the wave will again be reflected. The time it takes each of the reflected waves to arrive back at the receiving antenna is a function of the depth of the interface and the dielectric constant of the material.

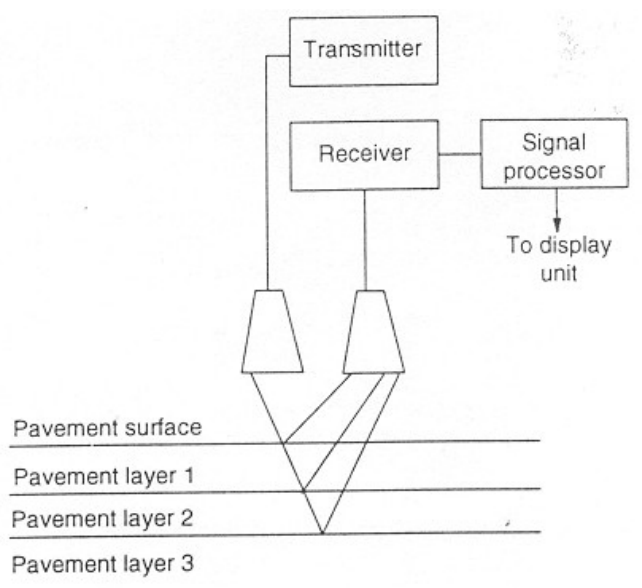

Figure 9-1 Schematic of Short-Pulse Radar 
The thickness of concrete pavement can be determined using short-pulse radar by one of two methods (Clemena, 1991). The first approach is to calculate the relative dielectric constant of the pavement at each test location from the surface reflectivity. The thickness of the pavement can then be calculated from the relative dielectric constant at the test location and the measured transit time, the time it takes the wave to travel to and back from the bottom of the pavement. The second approach is to determine the calibration between the pavement thickness and measured transit time by measuring the thickness, by coring for example, at a selected number of radar test locations. The measured thickness and the corresponding transit time are then used to establish a calibration line from which the pavement thickness at all of the other radar test locations can be determined.

\section{$\underline{\text { Previous Research }}$}

Clemena and Steele (1988) determined that the successful use of radar to measure the thickness of concrete pavements depends upon the definitive identification of the reflection from the bottom of the slab in the recorded waveform. The presence of reinforcement and the existence of relatively small differences in the relative dielectric constants were found to make the reflection identification more difficult. Tests were conducted on concrete slabs built to simulate pavements and on actual continuously reinforced concrete pavement. The reflection for test slabs less than 8 inches was only slightly discernable and the reflection for test slabs 8 inches thick and greater was even weaker and could not be precisely identified. The attenuation of the reflection was found to increase with increasing thickness and with increasing moisture content of the test slab. Radar measurements conducted on the continuously reinforced pavement yielded mixed results. The reflection was easily identified at some locations, however the identification of the reflection at other locations could only be achieved with uncertainty. The radar results were within 1.1 inches of the coring results at a $95 \%$ confidence level. After a calibration of core length and measured transit time for seven locations was performed, the radar results were within 0.4 inches of the coring results at a $95 \%$ confidence level. The study used a transducer with a 900 $\mathrm{MHz}$ central frequency and a pulse width of $1.1 \mathrm{~ns}$. 
Maser (1994) conducted a study using GPR to find the thickness of research pavement sections. A $1 \mathrm{GHz}$ air-coupled horn antenna mounted to vehicle was unable to penetrate consistently through 7.5 and $9.5 \mathrm{in}$. thick concrete pavement to reveal the pavement-base interface. A $500 \mathrm{MHz}$ ground-coupled antenna had difficulties revealing the pavement-base interface for the 9.5 in. thick pavement. When the interface was detected, the average standard deviation between the radar and core data was 0.53 inches with an R-squared of 0.76 .

\section{Summary}

Successful determination of pavement thickness using short-pulse radar depends upon the definitive identification of the reflected wave from the bottom of the slab in the recorded waveform. The presence of reinforcement, small differences in the relative dielectric constants of the concrete and base, high attenuation of the electromagnetic waves in concrete, and longer path lengths (thicker slabs) can prevent the precise detection of the reflected wave from the bottom of the concrete. The literature reviewed indicates that the reliability of radar to determine concrete pavement thickness is variable. If the reflection can be identified in the waveform, the predicted thickness can still be different from the thickness determined by coring by as much as one inch (Clemena and Steele 1988). The literature also indicates that the calibration method of determining thickness, which requires destructive coring to be performed, is the more accurate method of determining thickness.

\subsubsection{Stress Wave Propagation Methods}

There are several non-destructive test methods that are based on the propagation of stress waves through concrete. The following section provides background information concerning stress wave propagation through concrete.

Stress waves propagate in concrete as dilatational waves, also known as compression waves (P-waves), as distortional waves, also known as shear waves (S-waves), and as Rayleigh waves, also known as surface waves (R-waves). P-waves and S-waves travel into the concrete while Rwaves travel along the surface of the concrete, as shown in Figure 9-2. When P- and S-waves 
encounter an interface, such as the boundary between the concrete and the underlying material or internal voids or flaws, the waves are partially reflected from the interface and partially refracted across the interface. The amplitudes of the reflected and refracted waves depend upon the relative differences in acoustic impedance (the product of the wave speed and density) between the two materials at the interface and the angle of incidence. In addition, the energy of the stress waves is reduced with increasing path length due to absorption and divergence of the wave as well as from reflection and refraction from mortar-aggregate interfaces. Therefore, the lower the frequency (longer the wavelength) of the wave, the less attenuation of wave energy will occur.

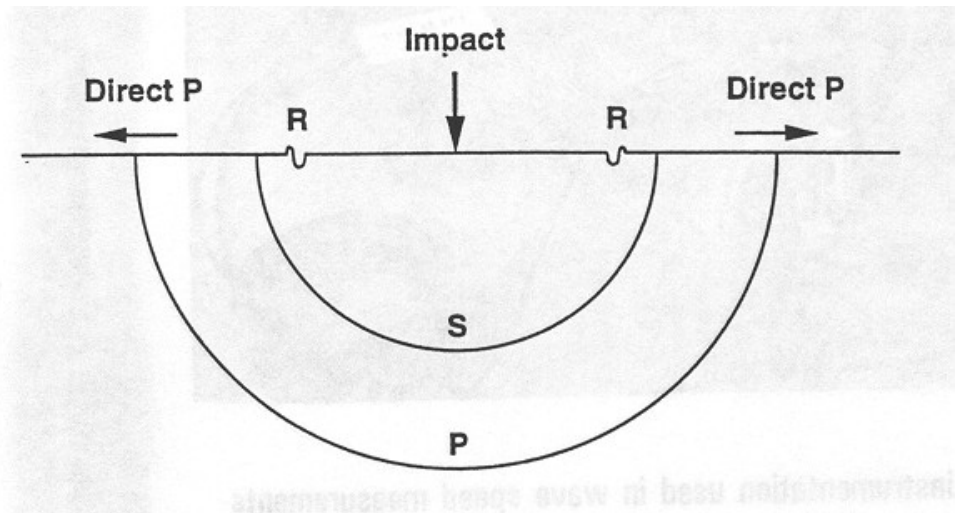

Figure 9-2 Stress Waves

In pavement applications, stress waves are created by an input pulse of finite duration. The stress waves are transient and the wave speed can be determined from the theory of wave propagation in isotropic elastic media. The $\mathrm{P}$-wave velocity, $\mathrm{C}_{\mathrm{p}}$, and the $\mathrm{S}$-wave velocity, $\mathrm{C}_{\mathrm{s}}$, are functions of Young's modulus of elasticity, E, density, $\rho$, and Poisson's ratio, $v$, as shown in Equations 3-1 and 3-2.

$$
C_{p}=\sqrt{\frac{E(1-v)}{(1+v)(1-2 v) \rho}}
$$




$$
C_{s}=\sqrt{\frac{E}{2(1+v) \rho}}
$$

Equation 9-2

It should be noted that the shear modulus of elasticity, G, can be used to simplify the expressions and is given by:

$$
G=\frac{E}{2(1+v)}
$$

The R-wave velocity, $\mathrm{C}_{\mathrm{R}}$, can be determined from either the S-wave or P-wave velocity as shown in Equations 3-4 and 3-5 respectively.

$$
\begin{gathered}
C_{R}=\frac{0.87+1.12 v}{1+v} C_{s} \\
C_{R}=\frac{(0.87+1.12 v) C_{P}}{1+v} / \sqrt{\frac{2(1-v)}{(1-2 v)}}
\end{gathered}
$$

Equation 9-4

Equation 9-5

It can be demonstrated that P-waves travel the fastest, followed by S-waves, and finally Rwaves. If Poisson's ratio is taken as 0.20 , a typical value for normal strength concrete, the Pwave velocity is $1.64 \cdot \mathrm{C}_{\mathrm{s}}$ and $1.80 \cdot \mathrm{C}_{\mathrm{R}}$.

\subsubsection{Spectral Analysis of Surface Waves (SASW)}

\section{$\underline{\text { Test Method }}$}

The SASW method consists of mechanically impacting the surface of an object and monitoring the resulting surface waves as they propagate past two receivers located on the surface of the test object. The surface waves contain a range of frequencies or components of different wavelengths. The higher frequency (short wavelength) components propagate within the top layer and travel with a speed determined by the properties of the top layer. The lower 
frequency (long wavelength) components penetrate more deeply into the underlying layers and their speed of propagation is affected by the properties of the underlying layers. The time it takes for each frequency component to travel past the two receivers is recorded, and the speeds, also called phase velocities, are determined. A plot of phase velocity versus wavelength, called a dispersion curve, is obtained.

The geometry and composition of the pavement profile can be determined from the dispersion curve using an inversion process. The thickness, density, Poisson's ratio, and S-wave speed for each layer are assumed, and a theoretical dispersion curve is calculated. An iterative process is used to refine the assumptions until the theoretical dispersion curve matches the experimental dispersion curve. When the two curves match, the stiffness profile, including the pavement thickness has been determined. This process is typically performed using a computer program.

The SASW method requires an impact source, two receivers, which are typically transducers or accelerometers, and a data acquisition system capable of recording the measured signals and processing the data. For concrete pavements, the impact source is typically a small hammer or a small diameter steel ball. At each test location the impact is repeated several times and the recorded data is averaged. The test is also repeated with different receiver spacings in order to develop a more reliable dispersion curve. The generation of the dispersion curve can also be assisted by the use of windows or filters that are contained in the processing software. The filters help to identify the recorded signals. A lunch-box sized device called the seismic pavement analyzer has been developed that performs the field tests in a fully automated manner (Nazarian et al., 1993).

\section{$\underline{\text { Previous Research }}$}

SASW tests performed by Nazarian et al. (1983) show that the test method has a high degree of reproducibility. A less than 9\% difference in dispersion curves between three tests conducted from August 1981 to May 1982 on a continuously reinforced concrete pavement test section was 
obtained. However, the value of Young's Modulus from the inversion procedure varied by $20 \%$ from the value obtained by crosshole seismic tests and by $25 \%$ from the value obtained by Dynaflect measurements. Thickness comparisons were not reported.

Roesset et al. (1990) modified the SASW test procedure to make field measurements quicker and results more rapidly available. The modified test method determined the stiffness and thickness of only the surface layer of pavement systems. Test performed on asphalt concrete pavement showed good correlation between predicted thickness and thickness from cores, 0.51 $\mathrm{ft}$. (predicted) compared to $0.58 \mathrm{ft}$. (from cores) in one case and 0.42 (predicted) compared to $0.42 \mathrm{ft}$. (from cores) in another case. Results were not reported for concrete pavements.

The original programs that performed the inversion process employed trial-and-error methods or optimization techniques, which make the inversion process computationally expensive and prone to numerical problems. However, an automated inversion procedure contained in a program called AutoSASW has been developed which has been demonstrated to give more reliable results for irregular profiles and some complex pavement systems and allows site characterization to larger depths (Ganji et al., 1998). The study did not report specific results on the accuracy of the pavement thickness as determined by the program.

\section{Summary}

The available literature indicates refinements in the test procedure and data processing procedures that appear promising for the use of the SASW test method for accurate pavement thickness determination. However, results of thickness determination for SASW tests performed on concrete pavements was not available in the literature. This method also requires complex data processing to be performed. 


\subsubsection{Pulse-Echo}

\section{Test Method}

The pulse-echo test method uses a vibrating transducer to transmit a stress pulse into a test specimen. The stress pulse travels through the specimen in the form of waves and is reflected back by boundaries as indicated in Section 9.2.2. The stress waves that are reflected back from the pavement-base interface are received by a transducer that is located close to the transmitter, on the pavement surface. Alternatively, the stress waves can be received by the transmitter, now acting as a receiver. When a separate transmitter and receiver are used the test is commonly referred to as pitch-catch. Both forms of the test method are generally referred to as pulse-echo, therefore in this document a distinction is made only when necessary. The received stress waves, time domain waveforms, are recorded and are displayed on an oscilloscope.

The time domain waveform displayed on the oscilloscope is used to determine the time $(\Delta \mathrm{t})$ it takes the $\mathrm{P}$-wave portion of the stress pulse, the component of the stress pulse that propagates the fastest, to travel from the pavement surface to the interface and back again. The thickness of the pavement $(\mathrm{T})$ is determined by:

$$
T=\frac{1}{2}(\Delta t) C_{p}
$$

Equation 9-6

The transducer(s) used to transmit and record the waveforms have traditionally used piezoelectric materials. Piezoelectric elements will generate stress waves by vibrating when subjected to an electrical signal supplied by an attached pulser-receiver unit, and will in turn generate an electrical signal when vibrated by deformations caused by stress waves. A fluid couplant is required between the transducer and pavement surface in order to prevent error in the measured transit time due to air pockets.

Pulse-echo systems require low frequency transducers that produce short duration focused stress pulses (Sansalone et al., 1991). Low frequency waves, as indicated previously, are 
attenuated less than higher frequency waves and can penetrate farther into the specimen. In addition, the attenuation of the wave causes background noise that masks the detection of reflected waves. Short duration pulses are required when one transducer acts as transmitter and receiver, so the arrival of the reflected wave does not occur before the vibration of the transducer has stopped. If the transducer is still vibrating it will not be able to detect the surface displacements caused by the echo. Focused stress pulses generate waveforms that are easier to interpret. As the pulse becomes less focused, it fans out and probes more of the specimen. Low frequency transducers, less than $150 \mathrm{KHz}$, that generate short duration focused pulses can be difficult to construct. Generally, the lower the frequency the less focused the pulse becomes. The focus of the pulse can be increased at a given wavelength if the diameter of the transducer is increased. However, this can result in large dimension transducers, making them difficult to use in the field and to couple to the pavement surface.

An important aspect of the pulse-echo test method, as well as the impact-echo test method that is discussed later, is accurately determining the P-wave speed. For best results, the P-wave velocity must be determined at each location where the pavement thickness will be determined because the P-wave velocity can vary from location to location in the pavement. Reports of efforts to determine the P-wave velocity are discussed in the following section.

\section{$\underline{\text { Previous Research }}$}

Various test setups and evaluation techniques have been developed to improve the pulse-echo test method for concrete. Krause et al. (1997) compared several systems commercially available in Germany, which incorporate some of these techniques. The systems included a pitch-catch system that utilizes an array of 7 receivers with a frequency range of $80-250 \mathrm{KHz}$, a system with a frequency range of $50-500 \mathrm{KHz}$ that can operate either as pitch-catch or pulse-echo, and two systems which generate an image, called a B-scan, of the pavement. All of the systems were within $8 \mathrm{~mm}(0.315 \mathrm{in})$ of the actual thickness of the test specimen with a maximum size aggregate of $8 \mathrm{~mm}(0.315 \mathrm{in})$. However systems failed to accurately determine the thickness of the test specimen with a maximum size aggregate of $32 \mathrm{~mm}$ (1.26 in) was not able to be clearly 
determined. Some of the systems were indicated to use low-pass filtering and/or signal amplification techniques, however the details of these techniques were not presented.

A frequently used method to improve the interpretation of the time domain waveform is to use a time averaging procedure. The test is repeated several times and the recorded time domain signals are averaged. This method reduces the incoherent noise that appears in received signals.

Karaoguz et al. (1999) demonstrated that split spectrum processing (SSP) can enhance the signal-to-noise ratio, thus helping to identify the reflected signals of interest, for high frequency signals. In SSP the received waveform is first passed through a filter to separate the signal into several frequencies. The filtered signals are then normalized and combined to create a waveform with less background noise.

The pulse duration, frequency, and bandwidth are characteristics of the piezoelectric material used in the transducer when the stimulating electrical signal is a voltage spike. Frequency modulated (FM) chirp electrical signals and amplitude modulated (AM) electrical signals have been used as an alternative source of stimulation for piezoelectric materials (Popovics et al., 1999). The advantage of these methods of stimulation is that the characteristics of the signal, not the characteristics of the piezoelectric material, primarily determine the characteristics of the stress wave.

FM chirp signals have a high bandwidth. This characteristic can be taken advantage of with the use of a correlation- or pulse-compression filter. The filter results in the correlation of the transmitted signal and the recorded waveform (Koehler et al., 1998). The energy of the waveform is increased by compressing it into a short pulse. This increase in amplitude does not result in an increase in background noise, thereby improving the interpretation of the waveform. A drawback of FM chirp signals is the need for an advanced random-signal synthesizer to generate the signal. 
AM signals can be generated by two basic waveform generators connected together. The signal can be used to stimulate a traditional piezoelectric transducer or an electromagnetic modal shaker. An electromagnetic modal shaker is mechanically different from a piezoelectric transducer, but performs the same function, converting electrical signal to mechanical vibrations. Popovics et al. (1999) demonstrated that AM driven piezoelectric transducers when used with signal averaging have a high signal-to-noise ratio and have an effective frequency range of 15 to $50 \mathrm{kHz}$. AM driven electromagnetic modal shakers also have high signal-to-noise ratios and have a frequency range of 0 to $10 \mathrm{kHz}$. Both $\mathrm{AM}$ driven devices generated sufficient energy to test a large concrete column.

As indicated earlier, accurate measurement of the P-wave velocity is key to the success of the pulse-echo and impact-echo test methods. The P-wave velocity can easily be determined when opposite sides of an object are accessible, however in pavement applications only one side is accessible. One method to get the P-wave speed in a pavement is to determine the P-wave speed of a core taken from the pavement. The P-wave speed of the core will accurately represent the area immediately surrounding the core. This P-wave speed may not accurately represent areas farther away from where the core was taken because the P-wave speed typically varies throughout a pavement.

The P-wave speed in a pavement can also be determined by recording the propagation of stress waves along the surface of the pavement. Several variations of the 'surface' method have been developed, however they all have the following in common. Two receiving transducers are placed in a line on the surface of the pavement. A stress wave is induced and the resulting surface displacements are recorded at each transducer. The arrival of the P-wave at each transducer is then determined. The arrival of the P-wave can generally be easily identified because it is the portion of the stress wave that travels the fastest and is therefore the first to arrive at each transducer. The first disturbance above a threshold amplitude value is generally taken as the arrival of the $\mathrm{P}$-wave. The $\mathrm{P}$-wave velocity, $\mathrm{C}_{\mathrm{p}}$, is then determined from the time it takes the P-wave to travel between the two receivers, $\Delta \mathrm{t}$, and the distance between the receivers, L. 


$$
C_{p}=\frac{L}{\Delta t}
$$

\section{Equation 9-7}

It has been reported that the P-wave velocity measured along the surface of an object is 9395\% of the P-wave velocity measured through the thickness of the object (Qixian et al., 1996). Popovics et al. (1998) developed one of the variations of the surface method for determining the velocity of stress waves in concrete. In this method, the arrival of the P-wave is determined using a technique to correct for pulse dispersion. Instead of taking the arrival of the P-wave as time at the threshold value, the wave is extrapolated back to the zero amplitude location and this time is taken as the $\mathrm{P}$-wave arrival. Using this technique, the calculated $\mathrm{P}$-wave velocity was significantly closer to the P-wave velocity determined by through thickness measurements when compared to the threshold method. The average reduction in error was $4 \%$.

The study by Popovics et al. (1998) also confirmed that the P-wave velocity is significantly affected by the moisture content of the concrete specimen. Higher moisture contents will result in increased P-wave velocity. The surface measurement technique was found to be more sensitive to the moisture content than techniques that use opposite faces of the test specimens. The sensitivity of the P-wave velocity to the moisture content indicates that the measurement of the P-wave velocity and the measurement of the thickness must be performed at the same location and at the same time.

\section{$\underline{\text { Summary }}$}

The available literature indicates that several methods are available by which the interpretation of the waveform generated in a pulse-echo test can be improved. Several pulseecho systems are also commercially available. The accurate determination of the P-wave velocity is an important aspect of the pulse-echo test method. Surface measurement of the P-wave velocity is necessary for pavement applications if coring is to be avoided. 


\subsubsection{Impact-Echo}

\section{Test Method}

The impact-echo test method consists of mechanically impacting the surface of the test object to introduce a stress pulse into the object. The $\mathrm{P}$ and $\mathrm{S}$-waves travel through the object and are partly reflected back by external boundaries or internal interfaces as shown in . A receiving transducer measures the surface displacements caused by the reflected waves at the surface where the impact was generated. The resulting time domain waveforms are recorded and displayed on an oscilloscope. The thickness of the object is determined from the P-wave speed and frequency. The impact-echo test method is the subject of ASTM C 1383-98, Standard Test Method for Measuring the P-Wave Speed and the Thickness of Concrete Plates Using the Impact-Echo Method.

The impact source is typically a steel ball attached to a steel spring rod. The diameter and impact speed of the ball determines the force and duration of the impact. The duration of the impact, also called the contact time, determines the frequency content of the stress pulse (Carino et al., 1986). As the contact time decreases, the range of frequencies in the pulse increases (wavelengths decrease). Shorter contact times can help locate smaller defects when using the impact-echo method to locate flaws, however the penetrating ability of the stress waves decrease and arrival of the P-wave can be more difficult to determine when contact times become to short (Sansalone et al., 1997a and Sansalone et al., 1988).

A frequency analysis of the recorded surface displacement waveforms is the quickest and most efficient method of data interpretation (Sansalone et al. 1988). A time domain analysis is possible, however the interpretation required in determining the arrival times of wave reflections is time consuming and can be difficult depending upon the geometry of the object (Sansalone et al., 1991, Sansalone et al., 1988, and Carino, 1984a). The principle of frequency analysis is as follows. The generated stress pulse is reflected back and forth between the top and bottom surfaces of the object. Each time the pulse arrives at the top surface it produces a characteristic periodic displacement. This displacement is monitored by a transducer and displayed on an 
oscilloscope. The P-wave portion of the pulse dominates the resulting waveform when the pulse is recorded close to the impact point (Sansalone et al., 1988). The period is the time between successive displacements and is equal to the travel path ( 2 times the thickness) divided by the Pwave speed. Since the frequency, $\mathrm{f}$, is the inverse of the period, the thickness, $\mathrm{T}$, can be determined by:

$$
T=\frac{C_{p}}{2 f}
$$

\section{Equation 9-8}

The frequency content of the recorded displacement waveforms is determined using the fast Fourier transform (FFT) technique. This technique is based on the principle of the Fourier transform which states that any waveform can be represented as a sum of sine curves, each with a particular amplitude, frequency, and phase shift. The FFT is used to calculate the amplitude spectrum, which gives the relative amplitude of the component frequencies in the waveform. Figure 9-3 is a typical amplitude spectrum for a concrete pavement with no voids (Sansalone et al., 1997). Typically, the FFT is programmed into the waveform analyzer used to store and process the received signals (Sansalone et al., 1988).

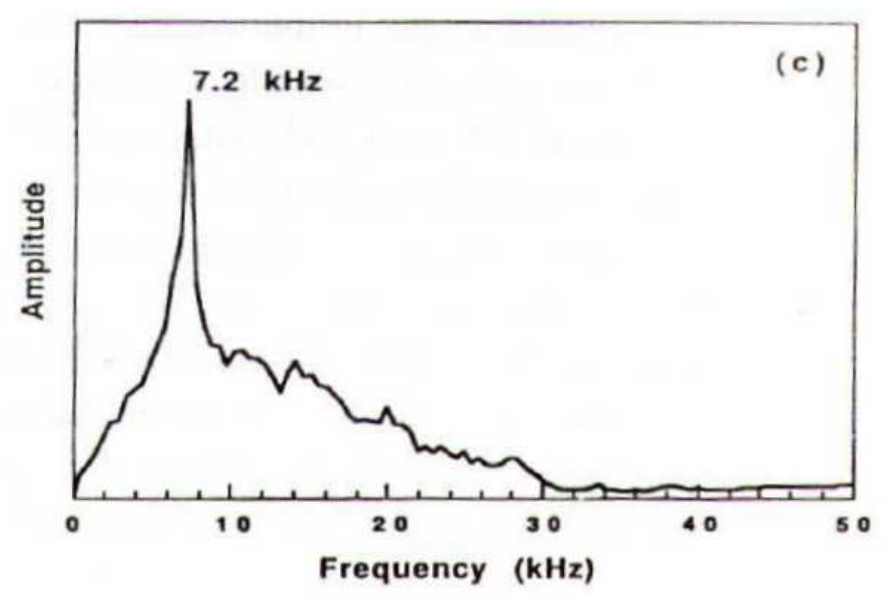

Figure 9-3 Impact-Echo Frequency Spectrum 


\section{$\underline{\text { Available Research }}$}

When the stress waves introduced in a concrete pavement strike an interface, the waves are partially reflected from the interface and partially refracted across the interface. The amplitudes of the reflected and refracted waves depend upon the relative differences in acoustic impedance between the two materials at the interface (Lin et al., 1994). The acoustic impedance of a material is the product of the P-wave speed and density of the material. Lin and Sansalone (1996) showed that the surface displacements and corresponding amplitude spectrum caused by the P-wave reflections from an interface can be clearly determined only when the relative difference in acoustic impedance between the top material and the underlying material is greater than 24 percent.

As indicated in Section 9.2.2.2, the accurate determination of the P-wave velocity is an important part of the impact-echo test method. Sansalone et al. (1997a and 1997b) conducted laboratory and field tests of the impact-echo test method using a surface method to measure the P-wave velocity. A mechanical impact was used to induce the stress wave. The resulting surface displacements were recorded at each transducer and the arrival of the P-wave was taken as the first disturbance above a threshold value. The calculated P-wave velocity from this surface method represents the P-wave velocity in an infinite medium. However it was found in previous studies that the P-wave velocity obtained from an impact-echo test on a plate is less than the Pwave velocity in an infinite medium (Lin et al., 1997). The P-wave velocity for an impact-echo test is about $96 \%$ of the $\mathrm{P}$-wave velocity in an infinite medium. Therefore the calculated P-wave

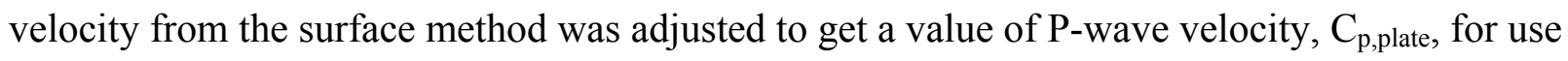
in Equation 3.8:

$$
C_{p, \text { plate }}=0.96 C_{p}
$$

\section{Equation 9-9}

The thickness of a laboratory test specimen was determined within $3 \mathrm{~mm}(0.12 \mathrm{in})$ of the actual thickness. Tests were also performed on a test section of pavement with two nominal thicknesses and three types of subbases. The maximum difference between the thickness determined by cores and the impact-echo thickness for the $0.2 \mathrm{~m}$ (7.87 in) thick section of 
pavement was $3 \mathrm{~mm}(0.12 \mathrm{in})$. The maximum difference between the thickness determined by cores and the impact-echo thickness for the $0.3 \mathrm{~m}$ (11.81 in) thick section of pavement was $9 \mathrm{~mm}$ $(0.35 \mathrm{in})$. The study indicated that the accuracy of the test method would improve with the use of newly developed PC-based data-acquisition hardware and software that allows for faster sampling rates. At the time of the field-studies, the new equipment was not yet available.

\section{$\underline{\text { Summary }}$}

The impact-echo test method appears to be a promising test method to determine pavement thickness. The accurate determination of the P-wave velocity by surface methods will improve the accuracy of the test method. The FFT is typically used to interpret the data from an impactecho test. This requires a software system to view the signals. A minimum $24 \%$ difference in acoustic impedance between layers is necessary to determine the depth of the layer interface. In addition, the utilization of new data-acquisition equipment could further improve the accuracy of the impact-echo test method.

\subsection{Test Methods to Determine Concrete Strength}

Strength is a measure of the amount of stress required to fail a material. The strength of concrete varies with the type of stress applied. The compressive strength of concrete is much greater than other types of strength for concrete, and the strength design of concrete elements is typically based on the compressive strength. The design of pavements however, is typically based on flexural strength as pavements are subjected to flexural loads. Accordingly, the default strength input for the models contained in the PRS is the flexural strength.

The distress indicator models require the concrete strength to be expressed in terms of 28-day flexural strength. The software does permit the compressive strength to be input into the program, however the software coverts the input compressive strength to flexural strength using a default relationship in the software. Alternatively, a user determined flexural-compressive strength relationship could be input into the software. The software also permits a less than 28day strength to be input into the program. If the input strength is indicated to be at less than 28- 
days, the program uses the default relationship or a user determined relationship to convert the early strength to a 28-day strength.

The INDOT currently determines the concrete flexural strength by third-point testing of beams in accordance with AASHTO T 97 (similar to ASTM C 78) after 7 days of curing. The test specimens are cured under standard conditions. This practice requires additional material, time, money, and effort to cast, cure, and test each specimen. In addition, the test specimens do not experience the same curing history as the pavement that it is supposed to represent. Therefore the flexural strength of the test specimens may not accurately represent the flexural strength of the pavement. The current practice also requires the relationship between the 7-day strength and the 28-day strength to be determined for the PRS software as indicated above.

A review of non-destructive strength-determining test methods was performed in order to find a more cost-effective, efficient, non-destructive test method that more accurately represents the flexural strength of the in-situ pavement. It was also desired to find a test method that could be used to determine the relationship between the early strength and the 28-day strength. The penetration resistance, pullout, pulse-velocity, impact-echo, and maturity test methods were reviewed. It should be noted that the review of non-destructive test methods included methods that are used to determine the compressive strength because the flexural-compressive strength relationship could be determined.

\subsubsection{Penetration Resistance}

\section{$\underline{\text { Test Method }}$}

Penetration resistance methods consist of driving a hardened steel probe into the concrete specimen and measuring the depth of penetration into the concrete. The probe, typically a rod or a pin, is driven by precision charge. The depth of the penetration or conversely the exposed length of the probe is empirically correlated to the compressive strength of the concrete. The probe penetration test method is the subject of ASTM C 803/C 803M-97, Standard Test Method for Penetration Resistance of Hardened Concrete. 
The accuracy of the estimated strength of the concrete is a function of the variability of the depth of penetration at a test location and the correlation relationship that converts the depth of penetration to the concrete strength. The variability of the depth of penetration at a test location, called the with-in test variability or repeatability, refers to the scatter of results that occurs when the test is repeated on identical concrete using the same test equipment, procedures, and personnel. For a given concrete, the repeatability of a test affects the number of tests required to establish, with a desired degree of certainty, the average value of the property being measured by the test. Three penetration tests performed at each location insure that the within-test variability is the similar to the variability of the average standard cylinder strength.

The correlation relationship between depth of penetration and concrete strength is typically provided by the manufacturer of the probe penetration test systems. The manufacturer usually publishes tables correlating the exposed length of the probe to the compressive strength of concrete. Malhotra, V. M. and Carette, G. G (1991) strongly recommend that correlations be specifically developed for each type of concrete. They indicate that the correlation between penetration and concrete strength has been demonstrated to be influenced by the hardness of the coarse aggregate, the type and size of the coarse aggregate, the degree of carbonation, and the age of concrete. Several studies are also cited where the manufacturers correlation tables have given unsatisfactory results. A separate correlation is also required by Section 4.2 of ASTM C 803.

\section{$\underline{\text { Available Research }}$}

Yun et al. (1988) conducted an investigation to determine the within-test variability and correlation to compressive strength of several non-destructive test methods, including probe penetration. Four tests were performed at each test location, with tests being performed at six different specimen ages. The coefficient of variation (COV) for the penetration tests was greater than compressive strength testing of standard cured cylinders, field cured cylinders, and cores. The COV increased with increased maximum aggregate size. Correlation between the 
compressive strength and the penetration resistance was determined by linear regression analysis. The correlation coefficient for penetration resistance was significantly reduced by increasing the coarse aggregate size.

\section{$\underline{\text { Summary }}$}

Malhotra and Carette (1991) indicate that the uncertainty of the estimated strength value when using the probe penetration method is, in general, relatively large and the test results may lack the degree of accuracy required for certain applications. The penetration resistance method also creates localized damaged areas that require repair.

\subsubsection{Pullout Test}

\section{$\underline{\text { Test Method }}$}

Pullout tests consist of measuring the force required to pullout an embedded metal insert with an enlarged head from the concrete specimen. In traditional pullout tests the metal insert is placed in the concrete at the time it is cast, however, there are pullout tests systems where the insert is placed into the concrete after it has set. The pullout mechanism is seated on a bearing ring that rests on the concrete surface surrounding the embedded insert. The bearing ring transfers the force to the concrete as shown in Figure 9-4 (Carino, N. J. 1991a). When the insert 'pulls' out, a conical shaped fragment of concrete is extracted. The pullout load is empirically correlated to the concrete strength. The pullout test method is the subject of ASTM C 900-94, Standard Test Method for Pullout Strength of Hardened Concrete. 


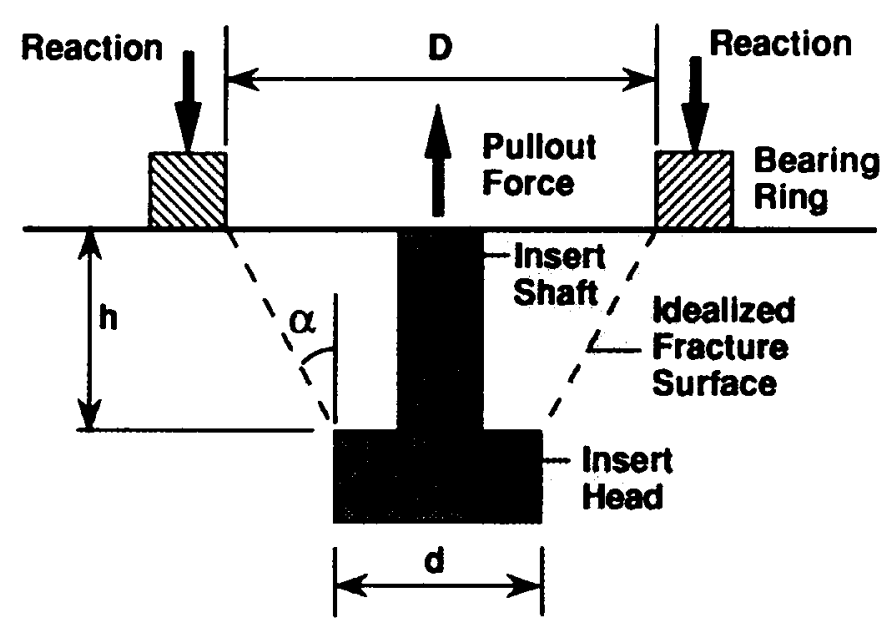

Figure 9-4 Pullout Test

Commercially available pullout systems include strength-pullout load correlation equations. These equations are typically linear and are applicable over a range of concrete strengths. Carino, N. J. (1991a) demonstrated that there is not a unique correlation relationship applicable to all concrete for a given test system and the correlation relationship is not necessarily linear. The most reliable estimates of concrete strength are obtained from correlation relationships that are developed for the specific concrete mixture and pullout system to be used.

The repeatability of the pullout test is characterized by the coefficient of variation (COV). Carino reported that the COV ranges from 4 to 15 percent with an average value of 8 percent. Tests performed on concrete with a maximum aggregate size less than the embedment depth tend to have variability in the lower end of the reported range. The average COV of the standard cylinder compression test is about $4 \%$. Carino indicates that for every $115 \mathrm{~m}^{3}\left(150 \mathrm{yd}^{3}\right)$ of concrete, eight pullout tests need to be performed in order to obtain a variability that is similar to the variability of the average standard cylinder strength when the average COV's for the pullout test and the standard cylinder test are as stated above. Section 6.2 of ASTM C 900 requires a minimum of 5 pullout tests for every $115 \mathrm{~m}^{3}\left(150 \mathrm{yd}^{3}\right)$ of concrete. 


\section{$\underline{\text { Previous Research }}$}

The study by Yun et al. (1988) cited in the previous section also included pullout and cut and pullout (CAPO) tests. Eight pullout and eight CAPO tests were performed on each specimen. The COV of the CAPO tests were greater than the COV of the pullout tests and the COV of both tests were greater than the COV of the compression testing of standard cured cylinders, field cured cylinders, and cores. The COV of both tests increased with an increase in maximum aggregate size. The correlation between strength and pullout tests for both tests was very good.

\section{$\underline{\text { Summary }}$}

The COV of pullout tests is greater than the COV of standard cylinder tests. Therefore a greater number of pullout tests are required to be performed to obtain comparable variability. The pullout test also requires planning prior to concrete placement to place the inserts in the pavement during concrete placement. CAPO tests do not require insertion during concrete placement. However, these systems have been shown to be cumbersome in the field and have a higher variability. Pullout tests also create surface damage that requires repair.

\subsubsection{Stress Wave Test Methods}

The velocity of a stress wave in concrete depends upon the elastic modulus of the concrete as indicated in Section 9.2.2. The elastic modulus of early-age concrete increases with age as the paste matures. Similarly, the velocity of stress waves in early age concrete increases as the concrete matures. Measuring the velocity of an induced stress wave in concrete can be used to estimate the strength of in-situ concrete. The stress wave velocity that is typically measured is the P-wave velocity. The strength is estimated from the measured P-wave velocity using a preestablished strength-velocity relationship. The relationship is not unique, it is affected by many factors including mix proportions, aggregate size, type and content, cement type and content, water-to-cement ratio, and moisture content (Sturrup et al, 1984). Therefore, strength-P-wave velocity relationships must be established by testing of the particular concrete mix and materials to be used in the project. 
The relationship between strength and P-wave velocity is established by laboratory testing using the given concrete mix and materials. The strength and P-wave velocity is measured at various ages and the resulting data is used to develop an empirical relationship between velocity and strength. This relationship and the measured P-wave velocity are then used to estimate the in-place concrete strength.

\section{$\underline{\text { Test Methods }}$}

The impact-echo and pulse velocity test methods are two methods by which the P-wave velocity can be measured. The impact-echo method uses a mechanical impact on the surface of the test object to introduce the stress wave. The P-wave frequency, $\mathrm{f}$, is determined from the recorded waveforms. Rearranging Equation 3.8 to solve for the P-wave speed, $\mathrm{C}_{\mathrm{p}}$, produces:

$$
C_{p}=2 T(f)
$$

\section{Equation 9-10}

where:

T equals the object thickness.

The impact-echo test method is described in more detail in Section 9.2.2.3

The pulse velocity test method uses a vibrating transducer to introduce a stress pulse into the test object. A second transducer is used to receive the stress pulse. The pulse velocity test equipment measures the time it takes the stress pulse to travel between the transmitter and the receiver. When the transducers are arranged in direct transmission, the $\mathrm{P}$-wave velocity, $\mathrm{C}_{\mathrm{p}}$, the component of the stress pulse that propagates the fastest, is determined from the distance between the transmitter and receiver (L) and the measured transit time (T).

$$
C_{p}=\frac{L}{T}
$$


The transducers can also be arranged in semi-direct transmission or surface transmission. Figure 9-5 (Naik and Malhotra, 1991) depicts the three modes of transmission. The surface transmission mode lends itself to pavement applications because only one surface is required to be accessible. However, this method is also more prone to errors because the amplitude of the received signal is much less than in the direct mode. (Naik and Malhotra, 1991) The method requires a series of transit time readings to be taken while incrementally increasing the distance between the two transducers. The P-wave velocity is determined from a plot of transit time versus distance between the two receivers.
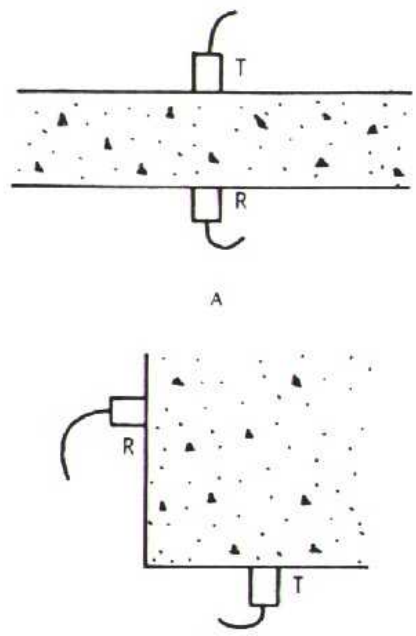

B

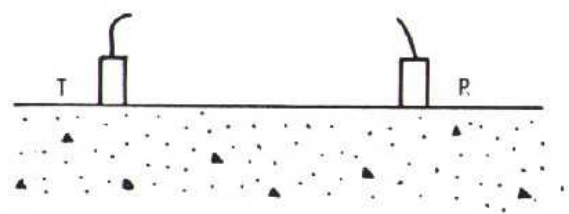

C

\section{Figure 9-5 Pulse Velocity Modes of Transmission}

Equations 3-10 and 3-11 show that the exact thickness of the test object is required to be known when using either the impact-echo or pulse velocity methods (direct transmission) to determine the P-wave speed. The thickness of a concrete pavement at any location is not known exactly without coring the pavement. One of the objectives of this research is to eliminate the 
need for coring the pavement, therefore, the traditional impact-echo and pulse velocity (direct transmission) test methods are not ideal for estimating the strength of pavements by measuring the P-wave velocity. The pulse velocity (surface transmission) method is also not considered ideal for the reasons indicated above.

Surface methods of measuring the velocity of stress waves do not require the thickness of the test object to be known. These test methods have been previously discussed in Section 9.2.2.2 and Section 9.2.2.3. They measure the propagation of stress waves along the surface of the pavement. Two receiving transducers are placed in a line on the surface of the pavement. A stress wave is induced and the resulting surface displacements are recorded at each transducer. The arrival of the $\mathrm{P}$-wave at each transducer is then determined. The $\mathrm{P}$-wave velocity is determined from the time it takes the P-wave to travel between the two receivers and the distance between the receivers. The following section reviews available literature on the P-wave velocitystrength relationship and surface P-wave measurement techniques.

\section{Previous Research}

In studies by Pessiki and Carino (1987 and 1988) the feasibility of using the impact-echo test method to estimate concrete strength was investigated. The study performed the impact-echo test on $102 \times 203 \mathrm{~mm}$ ( $4 \times 8$ in.) cylindrical test specimens. The influences of curing temperature, $\mathrm{w} / \mathrm{c}$ ratio, and aggregate content on the strength-P-wave velocity relationship were also examined. The P-wave velocity was found to be a sensitive indicator of the development of concrete strength up to about $60 \%$ of the 28 -day strength. At higher maturity, the P-wave velocity increases slowly relative to strength. Changes in the w/c ratio had no effect on the strength-velocity relationship, except at high maturity. An increase in the curing temperature from 20 to $35 \mathrm{C}(68$ to $95 \mathrm{~F}$ ) resulted in lower strength at a given velocity. The study also found that an increase in the volume fraction of aggregate from 0.67 to 0.71 caused a higher P-wave velocity at any given strength. 
Pessiki and Johnson (1996) continued the development of the impact-echo method as a means for evaluating the in-place strength of concrete. They performed impact-echo tests on 203 $\mathrm{mm}$ ( 8 in.) thick, $2.2 \times 2.2 \mathrm{~m}$ concrete slabs, prepared cylinders, and on cores taken from the slabs. Compression tests were performed on the cores and the cylinders. Three strength-velocity relationships were generated; cylinder strength vs. cylinder velocity, core strength vs. slab velocity, and core strength vs. core velocity. The scatter for all three relationships was reported as low, with the core strength vs. slab velocity data having the lowest average coefficient of determination at 0.9598 .

Impact-echo tests could be performed on the slabs when the slabs could withstand foot pressure. The P-wave velocity in the slabs was found to be greater than the P-wave velocity in the cores at a given strength. The slab to core velocity ratio changed from about 1.09 at low strengths to 1.05 at relatively higher strengths. Higher sampling frequencies (smaller sampling intervals and shorter duration records) produced better results at early maturity due to greater attenuation of the wave at early maturity. Using lower sampling frequencies at later maturity improved the accuracy to which the P-wave was determined.

As indicated in Section 9.2.2.2, the surface method of measuring wave velocity was modified in a study by Popovics et al (1998). The arrival of the P-wave at the transducers was corrected for pulse dispersion. The corrected arrival times are used to determine the time of travel between the two receivers, and the time of travel and the distance between the two receivers is used to calculate the P-wave velocity. In the study, the P-wave velocity is measured by the surface method (referred to as the threshold method), the modified surface method, and by using transducers on opposite sides of the test specimen (through thickness method). The concrete test specimens were $10.2 \times 22.9 \times 5.2 \mathrm{~mm}$ thick $(4.0 \times 9.0 \times 2.0$ in.) and 40.6 × $40.6 \times 10.2 \mathrm{~mm}$ thick ( $16.0 \times 16.0 \times 4.0$ in.). Compared to the threshold P-wave velocity, the modified P-wave velocity was significantly closer to the P-wave velocity determined by through thickness measurements. The average reduction in error was $4 \%$. 
Popovics et al. (1998) also used the modified surface and through thickness methods to monitor the strength gain of concrete specimens. He measured the P-wave velocity of two specimens, $40.6 \times 40.6 \times 10.2 \mathrm{~mm}$ thick ( $16.0 \times 16.0 \times 4.0$ in.), from one day after casting up to 28 days after casting. Repeated tests at the same specimen age showed that the consistency of the P-wave velocity by the modified surface method was much poorer than the $\mathrm{P}$-wave velocity from the through thickness method. However, the consistency of the R-wave velocity determined by the modified surface method was better than the P-wave velocity by the modified surface method. The study concluded that of the two one-sided velocity measurements, only the R-wave velocity measurement was suitable for monitoring the strength gain of early-age concrete.

However, this study by Popovics et al. (1998) also confirmed that the moisture content of the concrete specimen significantly affects $\mathrm{R}$ - and P-wave velocities determined by the surface method. Higher moisture contents result in increased R- and P-wave velocities. The sensitivity of the R- and P-wave velocities to the moisture content could present a problem if the moisture content of the pavement is not the same as the moisture content of the specimens used to determine the correlation between the strength and the pulse-velocity.

\section{Summary}

At early-ages there are relatively large changes in wave velocity with small changes in strength. Equations can be easily generated to represent the empirical strength-velocity relationships. Performing P-wave measurements directly on the pavement eliminates the need to fabricate test specimens during construction. The location of the measurements does not have to be planned prior to concrete placement. The method also permits the strength to be estimated at numerous locations per section of pavement compared to the current practice of two flexural test specimens per section of pavement.

The modified surface method appears to be the method best suited for measuring wave velocity in pavement applications. Unlike the impact-echo and pulse velocity methods, the thickness of the pavement is not required to be known to obtain accurate measurements of the 
wave velocity. The P-wave velocity from the modified surface method is also closer to the through thickness P-wave velocity than the unmodified (threshold) P-wave velocity. Since the study by Popovics et al. (1998) indicated that the R-wave velocity might be more suitable for estimating concrete strength, the use of both the R-wave and P-wave to estimate strength should be investigated.

The literature review of the measurement of wave speed raised several issues that must be considered in any field application. Empirical strength-velocity relationships determined from prepared cylinders or cores are not directly applicable to plate structures. The P-wave velocity in a slab, a plate structure, is greater than the P-wave velocity in a core or cylinder at a given strength. Therefore, if the velocity is measured directly on the pavement in the field, then the velocity should be measured on a plate structure in the lab. Care must be taken to ensure that the curing temperatures of the lab specimens are not significantly different from the curing temperatures of the field specimens. High curing temperatures have been shown to produce lower strengths at a given velocity than moderate curing temperatures. The P-wave velocity through concrete is also influenced by moisture content. If the moisture content of the lab specimens is not the same as the moisture content of the field specimen, the accuracy of the estimated strength can be affected.

\subsubsection{Maturity}

\section{$\underline{\text { Test Method }}$}

The strength development of a concrete mixture that has been properly placed, consolidated, and cured is a function of its age and temperature history. The maturity test method uses this characteristic of concrete to estimate concrete strength using the measured temperature history. A relationship is established between the strength development and the temperature history for a specific concrete mixture. This relationship can then be used to estimate the strength of identical concrete mixtures by measuring the temperature history. The maturity test method is the subject of ASTM C 1074-93, Standard Practice for Estimating Concrete Strength by the Maturity Method. 
A numerical index, called a maturity index, is used to quantify the temperature history. This index is determined using a maturity function. The maturity function converts the actual temperature history to the numerical maturity index. There are two basic types of maturity functions, the first produces a temperature-time index having units of degrees-time and the second produces an equivalent age index having units of time. The equivalent age index is considered a more flexible technique and is more widely recommend for use. It represents the duration of the curing period at a reference temperature that would result in the same maturity as the duration of the curing period at the actual measured temperatures. The general form of an equivalent age maturity function is:

$$
t_{e}=\sum\left(\frac{k_{T}}{k_{r}}\right) \Delta t=\sum \alpha \Delta t
$$

\section{Equation 9-12}

where:

$\mathrm{t}_{\mathrm{e}}=$ The equivalent age at the reference temperature.

$\mathrm{k}_{\mathrm{T}}=$ Value of the rate constant at the temperature, $\mathrm{T}$, during the time interval, $\Delta \mathrm{t}$.

$\mathrm{k}_{\mathrm{r}}=$ Value of the rate constant at the reference temperature, $\mathrm{T}_{\mathrm{r}}$.

$\alpha=$ Age conversion factor or (affinity ratio).

$\Delta \mathrm{t}=$ The time interval.

The age conversion factor is the ratio of the rate constants. The mathematical form of the rate constant, and thus the age conversion factor, depends upon the specific maturity function utilized. Many maturity functions have been proposed and several are discussed later in this section.

The relationship between the temperature history and the strength for a particular concrete mixture is established by preparing test specimens. The temperature history is recorded and strength is determined by testing at specific time intervals. The maturity index is calculated from the temperature history using the selected maturity function. The strengths are then plotted against the corresponding maturity index. The strength-maturity relationship is determined by drawing the best-fit smooth curve through the data. Alternatively, a curve can be fit to the data 
using a pre-existing strength-maturity relationship. Strength-maturity relationships that have been previously established contain constant(s) that are dependent on the concrete mixture. The value of the constant(s) is determined by regression analysis of the maturity and concrete strength data. These strength-maturity relationships approach a limiting strength with increasing maturity. The strength-maturity relationship can then be used to estimate the strength of identical concrete mixtures by measuring the temperature history and calculating the value of the maturity index at the time that the strength is to be estimated.

The maturity method assumes that the same concrete strength will occur when equal maturities are reached for specimens of identical concrete regardless of the temperature history. This assumption is approximate because it does not account for the effect of the initial curing temperature on the limiting strength. Higher early-age curing temperatures increase the initial rate of strength development and lower the limiting strength. Therefore there cannot be a unique strength-maturity relationship for a given concrete mixture. There is however, a unique relative strength vs. maturity relationship because the early-age curing temperature does not affect the relative strength. This means that while the determination of the absolute strength gain is approximate, the relative strength gain can be reliably estimated.

ASTM C 1074 assumes that the initial temperature of the concrete in the field is approximately the same as the initial temperature of the laboratory specimens. When these temperatures are approximately the same, the in-place strength will be reliably estimated. If the actual early-age temperatures (up to approximately 6 hours) are significantly greater than the temperature of the laboratory specimens, the limiting strength will be reduced and the in-place strength may be over estimated.

\section{$\underline{\text { Previous Research }}$}

Many different maturity functions have been proposed. ASTM C 1074 contains two maturity functions. The Nurse-Saul function that results in a temperature-time factor maturity index and a 
function based on the Arrhenius equation that results in an equivalent age factor. The Nurse-Saul function is given by:

$$
M=\sum k \Delta t=\sum\left(T-T_{0}\right) \Delta t
$$

\section{Equation 9-13}

where:

$\mathrm{M}=$ Maturity at age $\mathrm{t}$.

$\mathrm{T}=$ Average temperature during the time interval $\Delta \mathrm{t}$.

$\mathrm{T}_{\mathrm{o}}=$ Datum temperature.

The datum temperature is the lowest temperature at which strength gain is observed. The Nurse-Saul function assumes that the rate constant of cement hydration, $k$, is a linear function of temperature. However it has been shown that over wide temperature ranges the rate constant is not a linear function of temperature (Chengju, 1989 and Carino 1991b). Therefore the NurseSaul function does not reflect the influence of temperature on the rate of strength gain. The accuracy of the predicted strength gain will decrease the further the curing temperature is from the temperature at which the strength-maturity relationship was established. The rate constant of cement hydration (and therefore the predicted strength) will be underestimated at curing temperatures higher than the curing temperature at which the strength-maturity relationship was established and overestimated at curing temperatures lower than the curing temperature at which the strength-maturity relationship was established (Carino, 1991b).

The function based on the Arrhenius equation is given by:

$$
t e=\sum e^{\left[-\frac{E}{R}\left(1 / T^{-1 / T r}\right]\right.} \Delta t
$$

where:

$\mathrm{E}=$ Activation energy, $\mathrm{J} / \mathrm{mol}$.

$\mathrm{T}=$ Average absolute temperature of concrete.

$\mathrm{T}_{\mathrm{r}}=$ Reference temperature.

$\mathrm{R}=$ Gas constant, $\mathrm{J} /(\mathrm{mol} \mathrm{K})$. 
Hansen and Pedersen (1997) first presented the maturity function based on the Arrhenius equation. This function recognizes that the hydration of cement consists of a series of chemical reactions that accelerate nonlinearly with temperature rise. The maturity function based on the Arrhenius equation has been demonstrated to be able to account for the effects of temperature on strength gain over a wide range of temperatures (Carino, 1991b).

Many strength-maturity relationships have also been proposed. In a comprehensive review of the maturity test method, Carino (1991b) demonstrated that the offset hyperbolic equation, and empirical equations proposed by Lew and Richard, and Freiesleben Hansen and Pedersen accurately represented the strength gain of concrete. These equations are presented below.

Offset Hyperbolic Equation: $S=\frac{(M-M o)}{\frac{1}{A}+\frac{(M-M o)}{S_{\infty}}}$

Equation 9-15

Lew and Richard Equation: $S=\frac{K}{1+D[\log (M-16.7)]^{b}}$

Equation 9-16

Freiesleben Hansen and Pedersen Equation: $S=S_{\infty} e^{-\left(\frac{\tau}{M}\right)^{a}}$

Equation 9-17

where:

$\mathrm{S}=$ Estimated strength.

$S_{\infty}=$ The limiting strength.

$\mathrm{M}=$ Maturity.

$\mathrm{M}_{\mathrm{o}}=$ Offset Maturity.

$A=$ Initial slope of strength-maturity curve.

$\mathrm{D}, \mathrm{K}=$ Constants.

$\tau=$ Characteristic time constant.

$\mathrm{a}=$ Shape parameter.

$\mathrm{b}=$ Coefficient

In his review of the maturity test method, Carino demonstrated that under constant curing conditions, the strength gain of concrete can be represented by the following hyperbolic equation: 


$$
S=S_{\infty} \frac{k_{T}\left(t-t_{0}\right)}{1+k_{T}\left(t-t_{0}\right)}
$$

Equation 9-18

where:

$\mathrm{k}_{\mathrm{T}}=$ Value of the rate constant at constant curing temperature $\mathrm{T}$.

$\mathrm{t}_{\mathrm{o}}=$ Age when strength development is assumed to begin.

A study by Carino and Tank (1992) demonstrated that the Arrhenius function and an exponential equivalent age function accurately represented the rate constants for several different mixtures using the hyperbolic strength-maturity equation. The value of the affinity ratio for the exponential equivalent age function, shown in Equation 3-19, was a simpler expression compared to the value of the affinity ratio for the Arrhenius function, shown in Equation 3-20. Since the results of this study were obtained under isothermal curing conditions it was indicated that further verification was needed for variable curing conditions.

For the Arrhenius function: $\alpha=e^{-\frac{E}{R}\left(1 / T^{-1} / T_{r}\right)}$

For the exponential function: $\alpha=e^{B\left(T-T_{r}\right)}$

\section{Equation 9-19}

Equation 9-20

\section{$\underline{\text { Summary }}$}

The maturity test method can be used to directly determine the concrete flexural strength. This is an advantage over many of the nondestructive test methods that determine concrete strength because these methods directly measure the compressive strength and a compressiveflexural strength correlation is required to be developed. This test method is also capable of greatly reducing the number of test specimens. In addition, it and determines the in-situ pavement strength. However, the literature review indicates that the maturity test method should not be used independently to estimate concrete strength. 


\subsection{Test Methods Selected for Further Investigation}

The impact-echo, measurement of P-wave velocity, and maturity test methods were selected for further investigation to determine slab thickness and concrete strength. These test methods were selected based on the results of the literature review presented in the previous sections and the availability of test equipment.

The impact-echo test method was selected because previous field use of the test method in combination with a surface P-wave measurement technique has demonstrated the potential for success (Sansalone et al. 1997a). The results of prior research indicated that the difference in the estimated thickness from the thickness determined by cores was less than the systematic error inherent in the test method. Commercial impact-echo test equipment is available and was used for this study.

The maturity test method was selected for several reasons. First, because the concepts of the test method are already familiar to the INDOT and to Indiana based contractors. The INDOT currently permits the use of maturity concepts to determine when concrete pavements can be opened to traffic. INDOT ITM 402-99T permits concrete pavements to be opened to traffic when the temperature-time factor (TTF) of the pavement corresponding to a flexural strength of 3800 $\mathrm{kPa}$ (550 psi) is achieved. The strength-TTF relationship is established by prior laboratory testing. In addition, the equipment required for the maturity test method is easily operated and readily available. Another advantage of the test method is that it could be used to estimate the long-term strength from the strengths measured at earlier ages as discussed in Section 13.4.1.3. Earlier age testing provides faster feedback to the contractor and agency allowing adjustments to be made more quickly if necessary. The estimation of long-term strength from early age strength from the maturity method can also be used in the software used to create PRS.

The velocity of the P-wave in the concrete must be used to calculate the pavement thickness in the impact-echo test method. Surface measurement of the P-wave velocity was selected because it is a non-destructive method that can be performed quickly. This allows the velocity to 
be determined at each location that the impact-echo test method is performed. The surface measurement eliminates the need to core the pavement to determine the P-wave velocity by a traditional pulse velocity test (direct measurement). Coring the pavement is obviously undesirable due to the damage caused to the pavement and the required repair to a newly constructed pavement. The measurement of the P-wave velocity can also be used to estimate the concrete strength. This provides another method to estimate the in-situ strength of the pavement. The estimate of concrete strength from the measured P-wave velocity can be used in combination with estimate of strength from the maturity test method to increase the overall confidence in the strength estimate. 


\section{CHAPTER 10: EXPERIMENTAL PROGRAM AND TEST PROCEDURES}

\subsection{Introduction}

This chapter outlines the experimental testing program that was conducted to further assess the use of promising non-destructive test (NDT) methods to determine concrete strength and pavement thickness. As indicated in Section 9.4, the impact-echo, measurement of compression wave (P-wave) velocity, and maturity test methods were selected for further investigation. These test methods were selected based on the results of the literature review, contained in Chapter 4, and the availability of test equipment. These NDT methods have the potential to eliminate many of the problems associated with current test methods that are used to measure the properties of concrete pavement. They have the potential to measure the in-situ properties of the constructed pavement, without damaging the pavement. They can also be less labor intensive, require less time to conduct, ultimately cost less, and be just as accurate as the conventional destructive tests.

The testing program was conducted in conjunction with the implementation of a Level 1 Performance-Related Specification (PRS) on Indiana Department of Transportation (INDOT) Project R-24432. Details of Project R-24432 are contained in Section 2.2 and Table B-1 Input Data for PaveSpec (Version 2.5). The test program was performed in three phases, a preconstruction test program, a field test program, and a post-construction test program. The preconstruction test program began before construction of the pavement governed by the Level 1 PRS began. In this test program strength-maturity and strength-P-wave relationships for the concrete mixture were determined, the increase in strength and P-wave velocity with age were observed, the relationships between the measured strength types were observed, various surface methods of measuring the P-wave velocity were investigated and compared to the traditional 
direct method of measuring the P-wave velocity, and the effects of various base course material, slab thickness, and surface tining on the impact-echo test method were assessed.

The field test program was conducted during the construction of the pavement governed by the Level 1 PRS. This test program included testing to assess the field use of the NDT test methods including comparing the results to the results of the conventional destructive test methods. This program also demonstrated the effects of material and mix design changes on the strength-maturity and strength-P-wave relationships.

The post-construction test program was conducted after the field test program. This test program included testing to determine the datum temperature and activation energy for use in the maturity test method, and testing to assess the effects of small changes in the mix design on the strength-maturity and strength-P-wave velocity relationships. Table 10-1 provides a summary of the data obtained in each phase of the test program. The actual tests performed to obtain this data are indicated the detailed descriptions of each phase of the test program.

\section{Table 10-1 Summary of Data Obtained}

\begin{tabular}{|c|c|c|}
\hline Pre-Construction Program & Field Program & Post-Construction Program \\
\hline $\begin{array}{ll}\text { - } & \text { P-Wave Velocity from } \\
\text { - } & \text { Several Methods } \\
\text { - } & \text { Strength (3 Types) vs. Age } \\
\text { - } & \text { Strengerature vs. Time } \\
& \text { Relationships } \\
\text { - } & \text { Strength-P-Wave Velocity } \\
& \text { Relationships } \\
\text { - } & \text { Impact-Echo Tests of Test } \\
& \text { Slabs } \\
\text { - } & \text { Thickness Measurements of } \\
& \text { Test Slabs by Coring } \\
\end{array}$ & 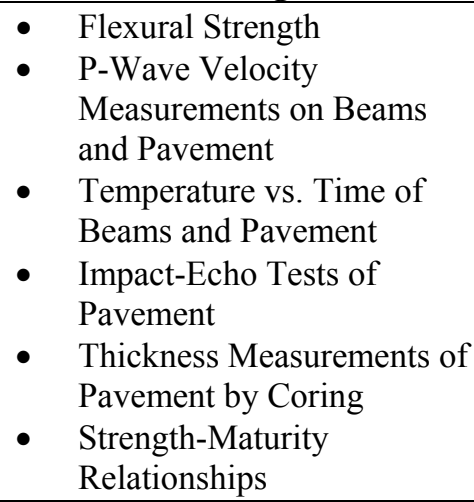 & $\begin{array}{l}\text { - } \text { Strength Testing of Mortar } \\
\text { Cubes to Determine } \\
\text { Maturity Test Method } \\
\text { Factors } \\
\text { - Effects of Small Mix } \\
\text { Design Changes on } \\
\text { Maturity Test Method }\end{array}$ \\
\hline
\end{tabular}

Prior to presenting the experimental program and test procedures, Section 10.2 briefly describes the schedule of INDOT Project R-24432. The three phases of the testing program are presented in the subsequent sections. The constituent materials, test equipment, casting and curing procedures, and the experimental procedures are presented for each portion of the testing 
program. The general data assessment procedures and the experimental results are presented in the subsequent chapters.

\section{2 $\quad$ Project Schedule}

INDOT Project R-24432 was located on the southeast side of Indianapolis, near the intersection of I-465 and I-74. The project included replacement of concrete pavement on I-465 and Brookville Road, as well as bridge and additional pavement construction. The reconstruction of I-465 was governed by a Level 1 PRS. The remaining construction, including the reconstruction of Brookville Road was governed by a Quality Control/Quality Assurance (QC/QA) specification.

The construction schedule was such that paving of Brookville Road began before paving of I465. This enabled test specimens to be prepared using materials and mixing procedures that would be similar to the materials and mixing procedures used in the construction of the Level 1 PRS pavement before construction of the Level 1 PRS began. The test specimens for the preconstruction test program were cast using a sample of concrete taken during the paving of Brookville Road. This approach was preferred since it permitted a large number of specimens to be cast from a single batch of concrete. The problems typically associated with limitations on the number of specimens that can be prepared in the laboratory were avoided. In addition, by using concrete that was mixed under field conditions the results are more directly applicable for use in the field as the problems of differences in mixing procedures are eliminated.

\subsection{Pre-Construction Test Program}

The Level 1 PRS created for this project contained acceptance quality characteristic (AQC) values in English units. Therefore, English units are predominately used in this document. Metric equivalents are presented in parenthesis. 


\subsubsection{Test Specimens}

The pre-construction test program was conducted at INDOT Materials and Tests Division in Indianapolis. The test specimens consisted of 25 beams, 6 × 6 × 21 inches $(152.4 \times 152.4 \times 533$ $\mathrm{mm}), 24$ cylinders, 6 × 12 inches ( $152.4 \times 305 \mathrm{~mm})$, and 6 slabs, $36 \times 36$ inches $(914 \times 914 \mathrm{~mm})$ with various thicknesses. Four of the slabs were approximately 10 inches $(254.0 \mathrm{~mm})$ thick, cast on four different INDOT aggregate bases, No. 8's, No. 53's, No. 53D's, and a cement-treated base course. The remaining two slabs were approximately 6 and 14 inches (152.4 and $356 \mathrm{~mm}$ ) thick, both cast on an INDOT No. 8 aggregate base. The base courses were 7 inches (177.8 mm) thick for all slabs. The INDOT specifications for the base courses, except the cement-treated base, are contained in Appendix D. The composition and construction of the cement-treated base is described later in this section.

The cylindrical test specimens were made with standard flexible single use molds complying with ASTM C 192. The rectangular beam test specimens were made with reusable steel molds. The steel molds complied with ASTM C 192 with the exception that the molds were not checked for watertightness, however no visible leakage through the joints was observed during casting. The forms for the slab test specimens were constructed from $3 / 4$ inch $(19.05 \mathrm{~mm})$ CDX plywood strengthened with 2 x 4 inch wooden studs as shown in Figure 10-1. The forms were sturdy and no deformation of the forms or leakage through joints was observed during casting.

The aggregate bases were placed and compacted in the slab forms two weeks before the slabs were cast, except for the cement-treated base. The construction of the cement-treated base is described in a following paragraph. The bases were placed in two layers, each approximately $3 \frac{1}{2}$ inches $(88.9 \mathrm{~mm})$ thick. Each layer was compacted using a $16 \mathrm{lb}(7.26 \mathrm{~kg})$ tamper with an $8 \times 8$ inch $(203.2 \times 203.2 \mathrm{~mm}$ ) steel end plate. The tamper was dropped from a height of 1 foot (305 $\mathrm{mm}$ ) an equal number of times over the entire surface layer until the drops appeared to produce no additional compaction of the layer. The top layer was leveled using a straight edge and markings on the sides of the forms. Figure 10-1 depicts one of the slab forms with the compacted base course in place. 
The cement-treated base consisted of 3 inches $(76.2 \mathrm{~mm})$ of cement-treated material on top of 4 inches $(101.6 \mathrm{~mm})$ of No. 8 material. The cement-treated base material was No. 8 material with a cement content of $200 \mathrm{lb} / \mathrm{yd}^{3}\left(356 \mathrm{~kg} / \mathrm{m}^{3}\right)$ and a water to cement ratio of 0.40 . The mixture was combined and mixed in a wheelbarrow and then placed on top of the 4 inches $(101.6 \mathrm{~mm})$ of compacted No. 8 material. After compaction, the base course was covered with a plastic membrane to reduce moisture loss. The cement-treated base was cast 9 days before the slabs were cast.

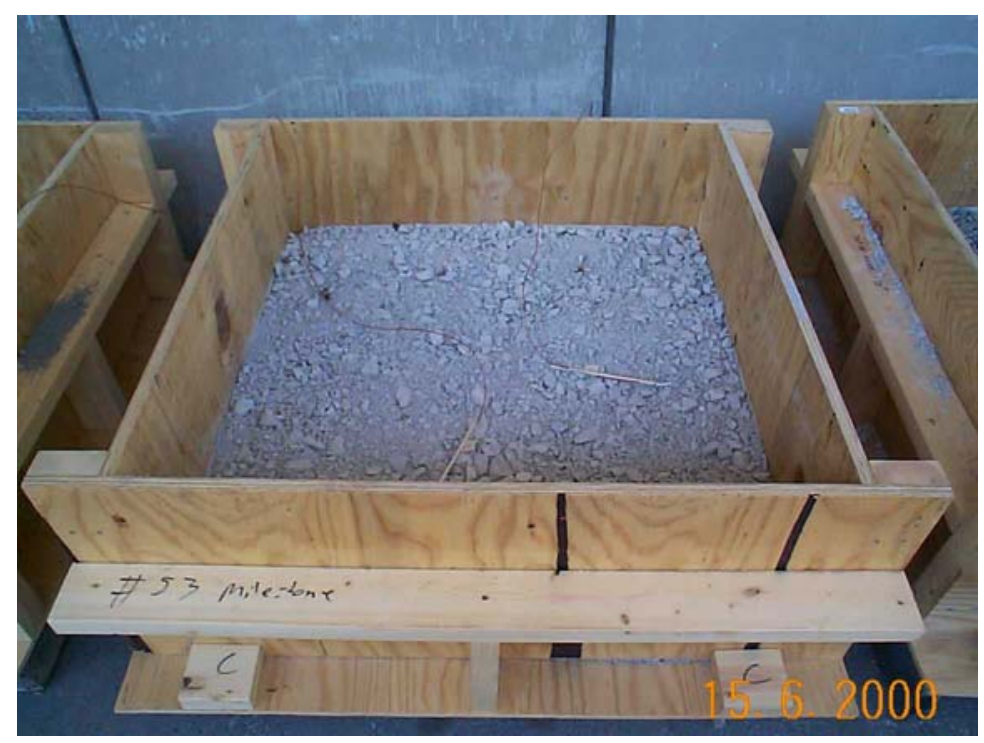

Figure 10-1 Mold For Slab Test Specimen With Compacted Base Course

\subsubsection{Concrete Mixing and Transportation Procedures}

The concrete was mixed by the pavement contractor (Berns Construction) at their jobsite batch plant located at the intersection of Brookville Road and Shadeland Road. The batch plant mixer was a rotary drum with a $7.25 \mathrm{~m}^{3}\left(9.48 \mathrm{yd}^{3}\right)$ capacity. The amounts of the materials and the sequence of their injection into the rotary drum were controlled by the contractor. The materials were mixed for approximately 1 minute before it was placed into a dump truck for transportation to the jobsite. The batch plant is depicted in the following series of figures. Figure 10-2 depicts the aggregate bins that feed into the mixer. The two outside bins hold identical 
coarse aggregate, INDOT No. 8, and the middle bin holds the fine aggregate, INDOT No. 23. Figure 10-3 depicts the opposite side of the batch plant. The semi-trailers connected to the batch plant by hoses contain the cement and fly ash. Figure 10-4 depicts the rotary drum as it is tilted to deliver the freshly mixed concrete into a dump truck for delivery to the jobsite.

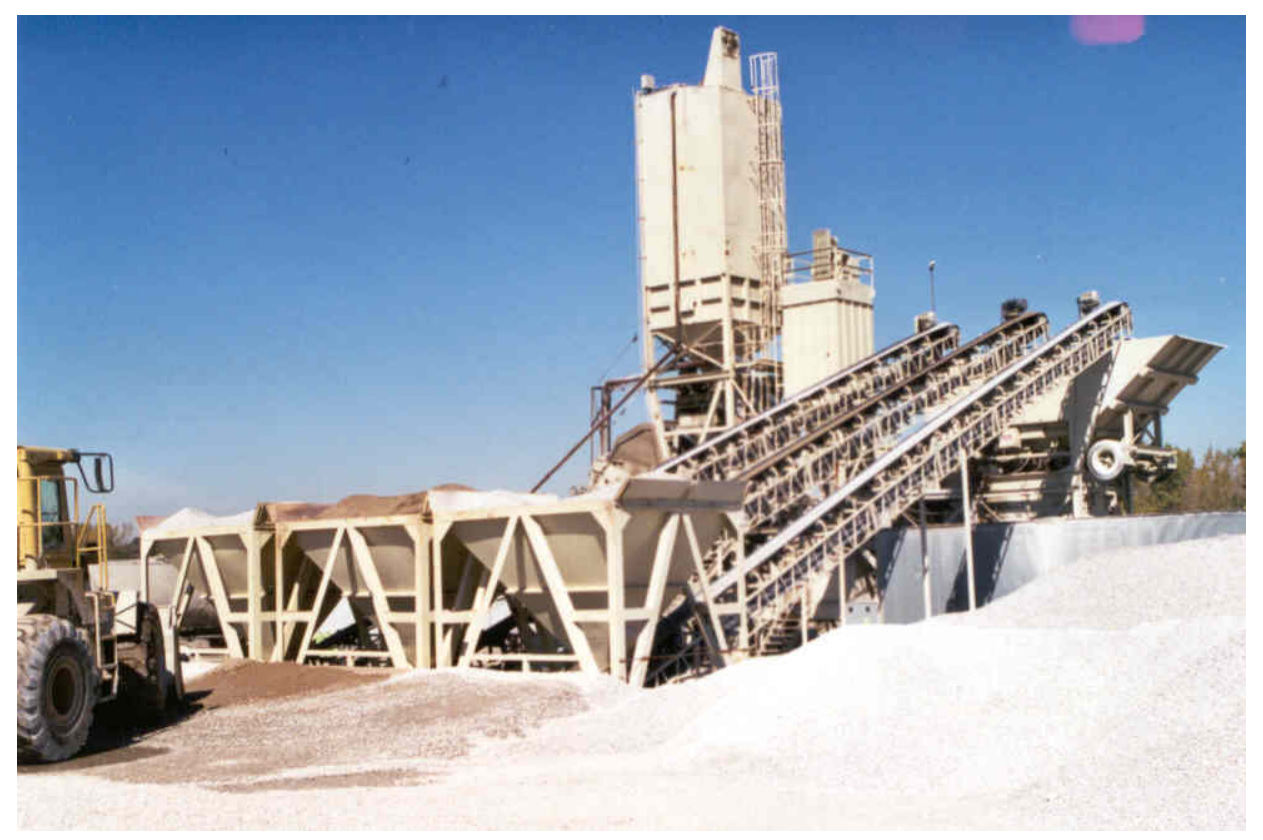

Figure 10-2 Batch Plant Aggregate Bins 


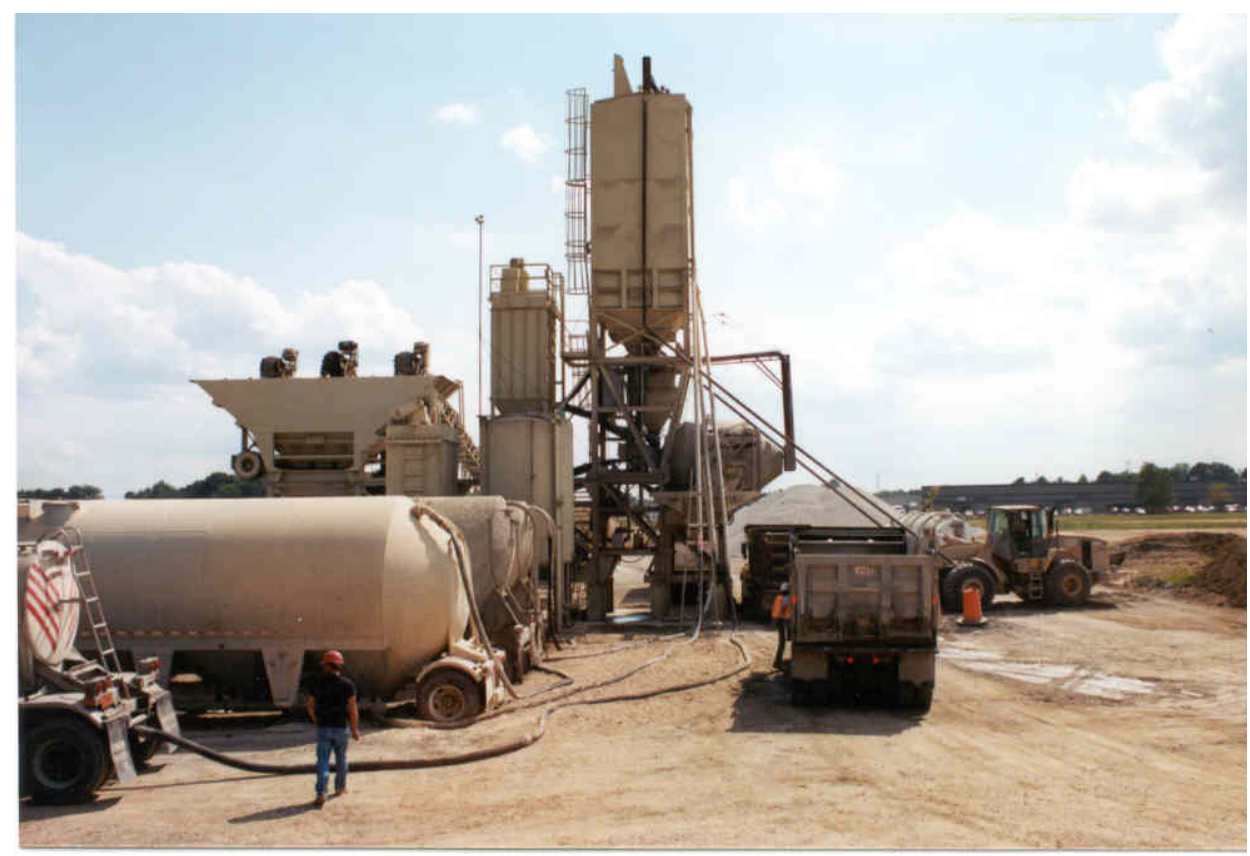

Figure 10-3 Batch Plant

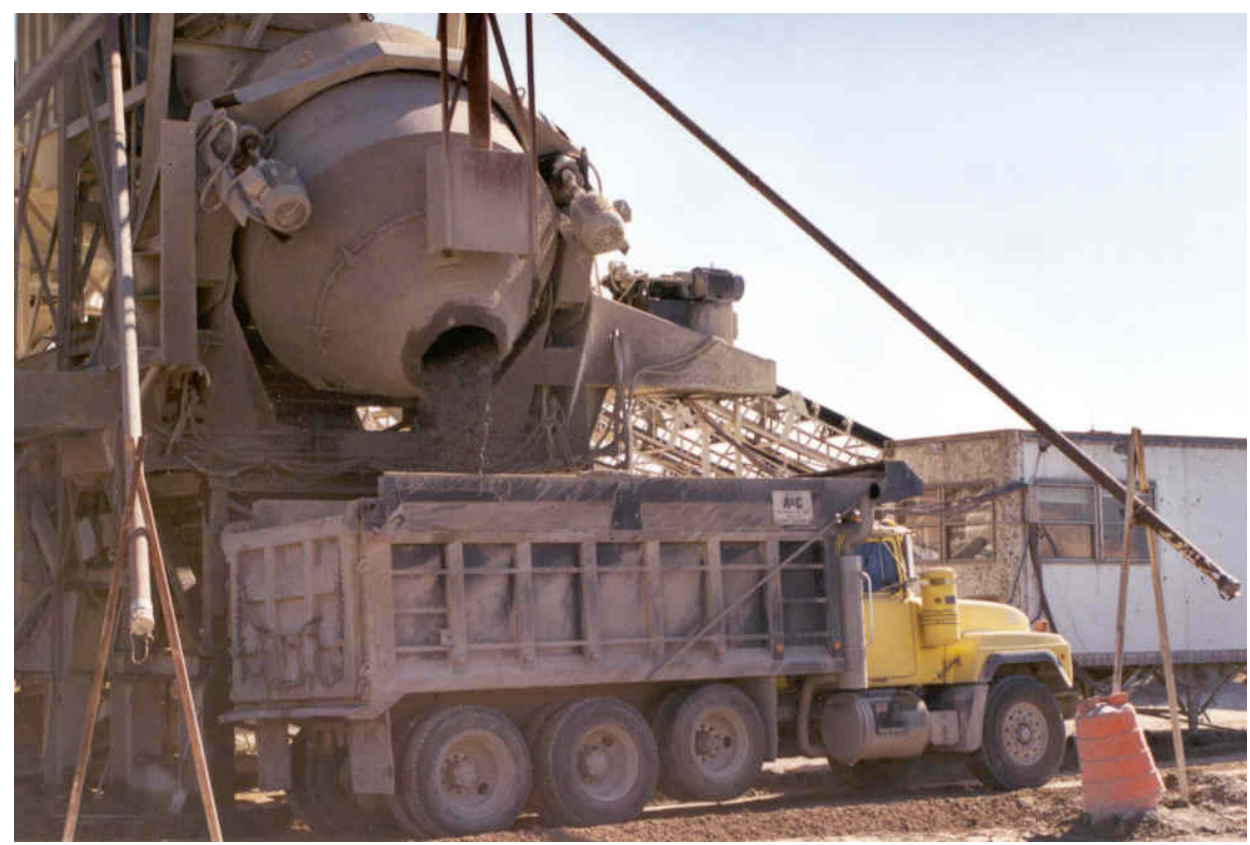

Figure 10-4 Fresh Concrete Ready for Transportation

The concrete used to cast the test specimens for the pre-construction test program was sampled from the batch plant mixer during construction of a section of Brookville Road. The materials and mixture proportions of this concrete are given in Appendix E. The sample was 
obtained from the mixer at 10:00 AM on June 15, 2000 and was approximately $3 \mathrm{yd}^{3}\left(2.29 \mathrm{~m}^{3}\right)$ in volume. The sample was transported by the contractor to the INDOT Materials and Tests Division, a distance of approximately 3 miles $(4.83 \mathrm{~km})$. This distance is only slightly longer than the average distance from the batch plant to the paving operations. The transportation time was approximately 5 minutes. The fresh concrete was dumped onto a sheet of plastic covering the ground as shown in Figure 10-5.

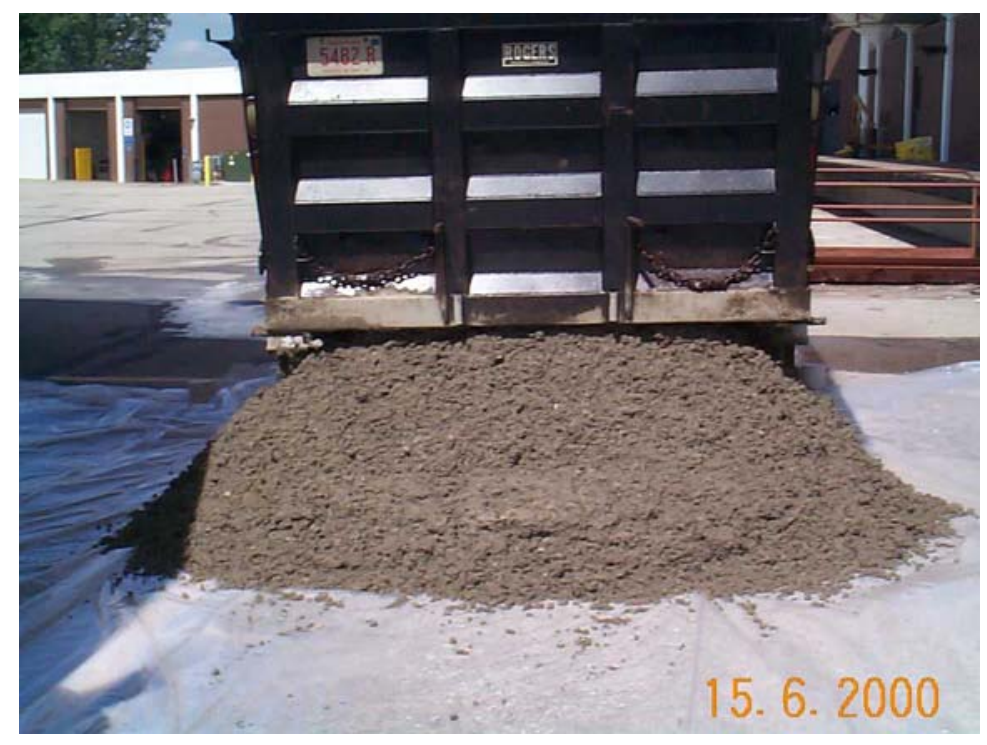

Figure 10-5 Fresh Concrete Delivered by Contractor

\subsubsection{Casting and Curing Procedure}

The fresh concrete arrived at the INDOT Materials and Tests Division at 10:15 AM on June 15,2000 . The weather was sunny with a temperature between 70 and $75^{\circ} \mathrm{F}\left(21.1\right.$ and $\left.23.9^{\circ} \mathrm{C}\right)$. To place the concrete as quickly as possible, a crew of 10 people were used to cast all of the test specimens simultaneously. The process took approximately 40 minutes. The unit weight, slump, and air content of the fresh concrete were measured immediately after the sample arrived. The measured fresh concrete properties were consistent with the properties measured by the contractor at the batch plant as shown in Appendix F. The temperature was measured in one beam, two cylinders, and in each slab specimen after casting using a thermocouple as described in Section 10.3.5.4. 
The forms for the slab specimens were located next to the sheet of plastic upon which the fresh concrete was deposited, as shown in Figure 10-6. Figure 10-7 and Figure 10-8 depict the placement, vibration, and finishing of the concrete slab specimens. The concrete was moved from the plastic sheets to the slab molds and was placed in two lifts using wheelbarrows and shovels. Each lift was vibrated using an internal vibrator. The top surface was screeded and then finished using a steel trowel. Tines were grooved into one-half of the surface of each slab with an INDOT approved tining rake.

The beam and cylinder forms were located inside the building as shown in Figure 10-9, to protect these specimens during initial curing. The fresh concrete was transported inside using wheelbarrows. The specimens were cast in accordance with ASTM C 192. Internal vibration was used to consolidate the specimens. Figure 10-10 depicts the finishing of the beam specimens.

All specimens were covered with nonabsorbent plastic and wet burlap after casting. The beam and cylinder specimens were cured inside the building. After 24 hours the specimens were removed from the molds, labeled and marked for testing to be performed later, and then placed in a saturated-lime water bath in a temperature controlled moist curing room. The slab specimens were cured outside. As shown in Figure 10-6, the slabs were located under an overhang and therefore were in shade throughout the day. The slabs were kept covered with plastic and burlap as shown in Figure 10-11, except during testing. The burlap was re-saturated after each day of testing up to Day 28. A complete description of the casting and curing procedures is provided in Appendix G. 


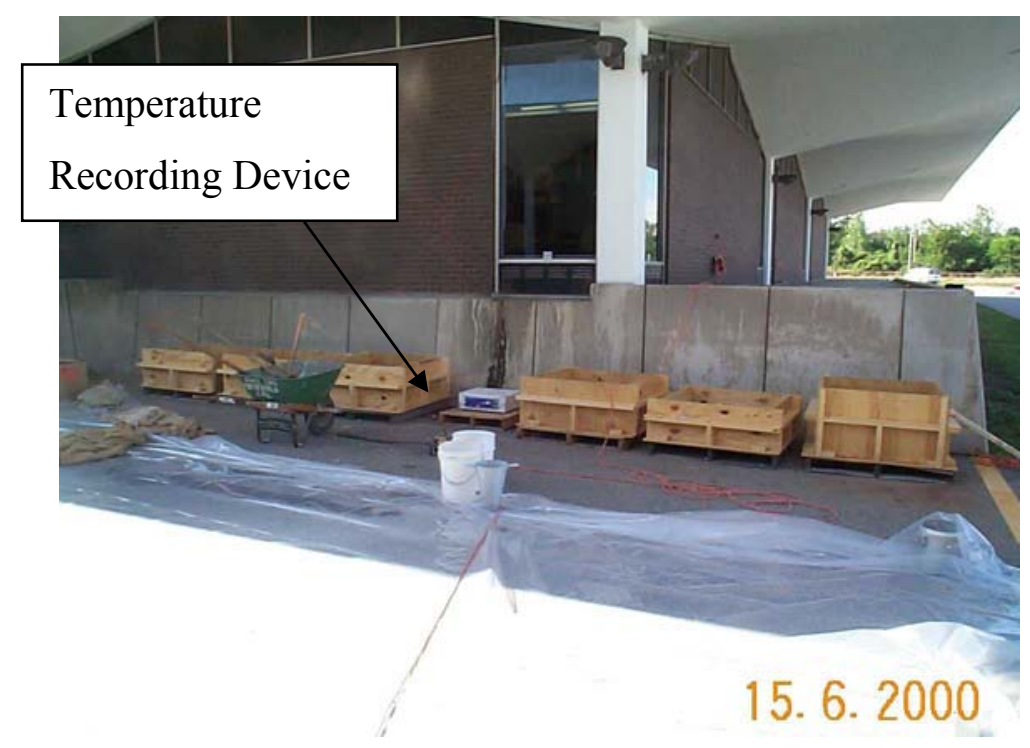

Figure 10-6 Slab Forms

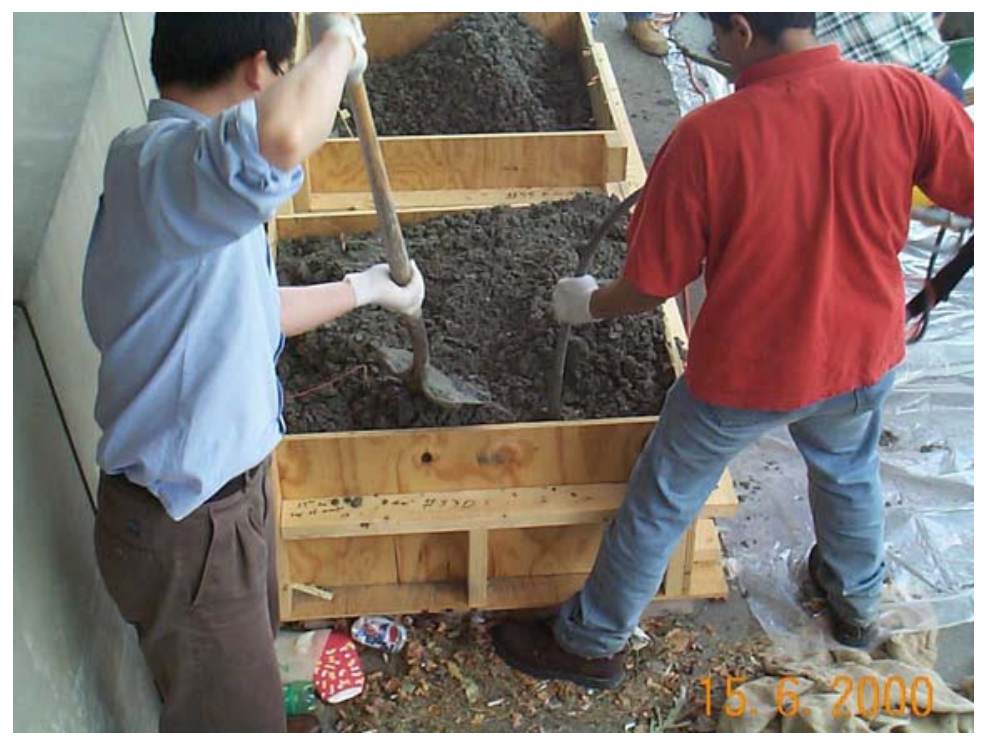

Figure 10-7 Vibration of Slabs 


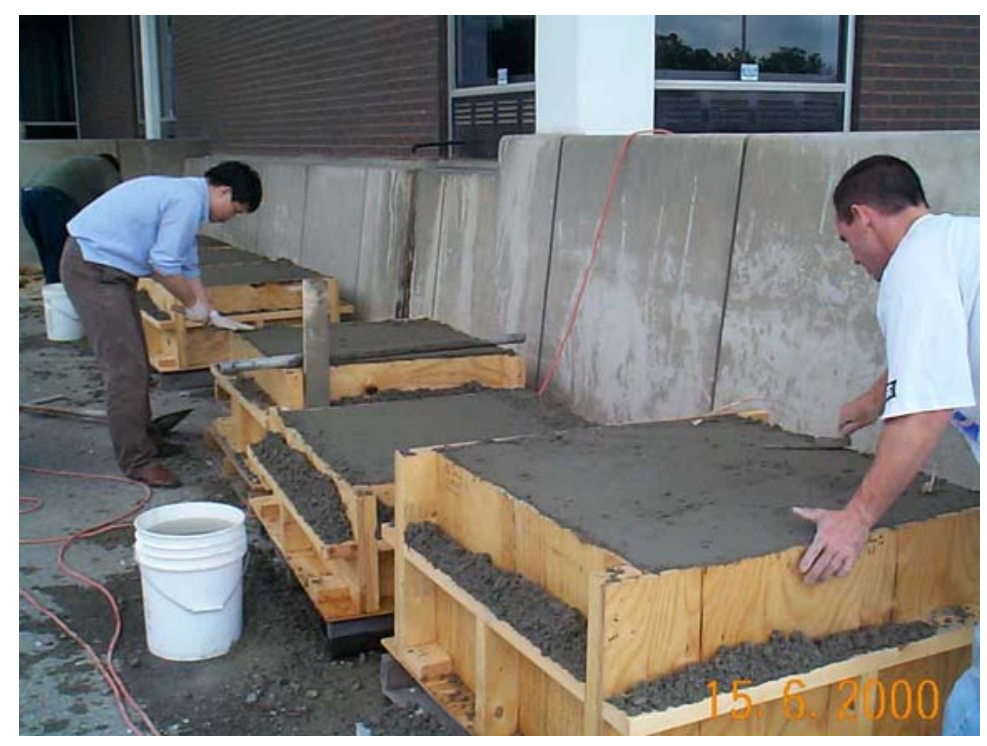

Figure 10-8 Finishing the Surface of the Slabs

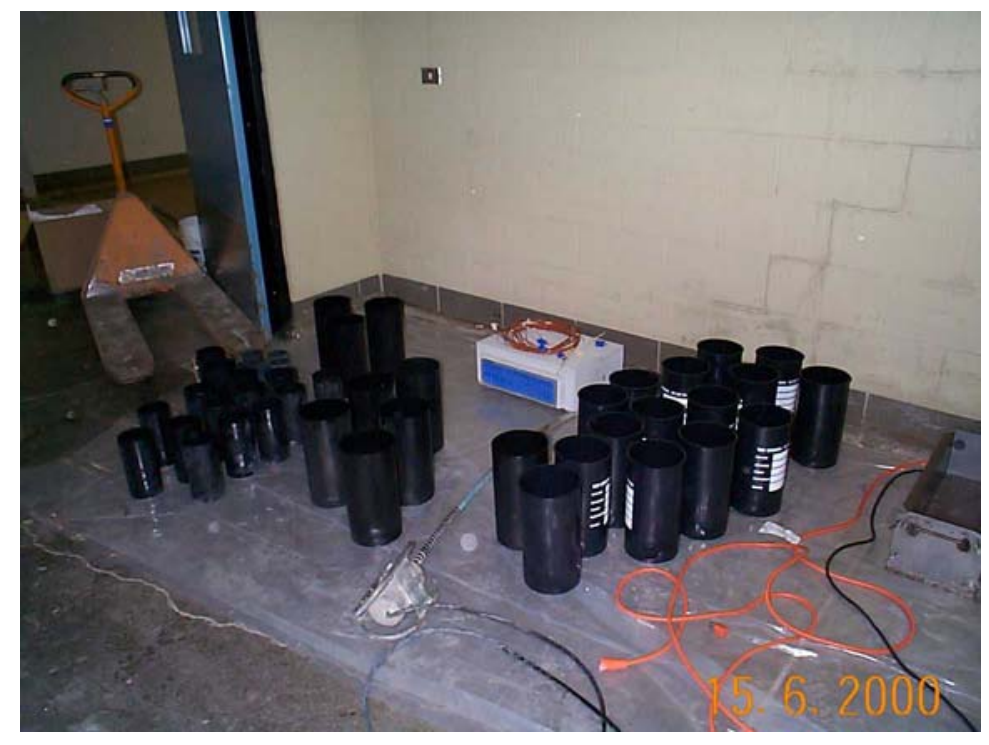

Figure 10-9 Cylinder and Beam Forms Inside Building 


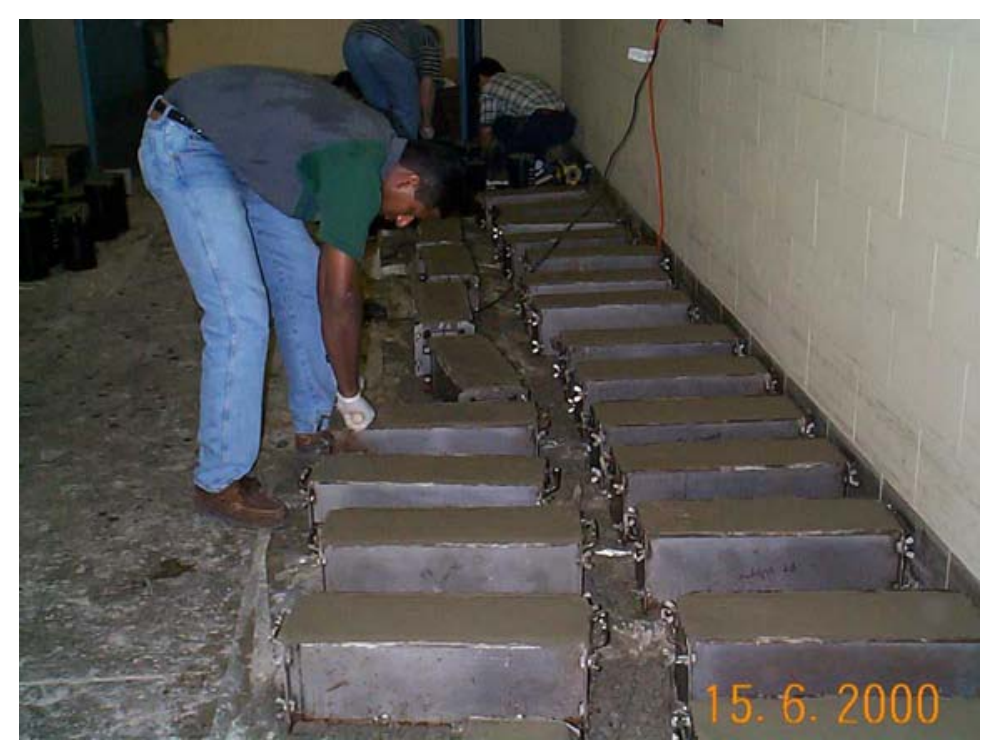

Figure 10-10 Finishing Beam Specimens

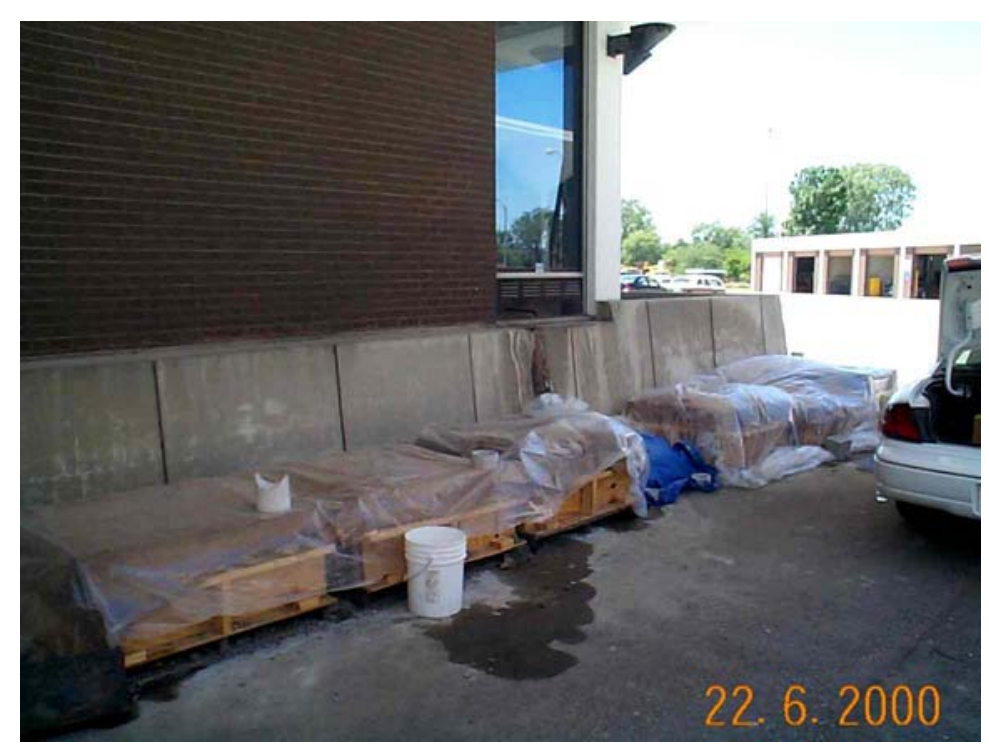

Figure 10-11 Curing Slab Specimens

\subsubsection{Test Specimen Identification}

All specimens for the pre-construction phase were identified with a label as shown in Table 10-2. The label started with a letter indicating the type of specimen. For the beam and cylinder test specimens an ID number followed the letter. The letter $\mathrm{C}$ followed the ID number if the specimen was one of the control specimens that were non-destructively tested at each test age. 
For the slab specimens the letter was followed by a number indicating the slab thickness in inches and then a number and/or letter indicating the base course. When relevant, a lowercase letter indicating the surface test location was included at the end of the slab test specimen identification.

Table 10-2 Pre-Construction Test Specimen Identification

\begin{tabular}{|c|c|c|c|c|c|}
\hline Specimen & Letter & $\begin{array}{c}\text { Number } \\
\text { Indicating } \\
\text { Thickness, in }\end{array}$ & - & $\begin{array}{c}\text { Number/Letter Indicating } \\
\text { Base Course }\end{array}$ & $\begin{array}{c}\text { Letter Indicating } \\
\text { Surface Location }\end{array}$ \\
\hline Slab & $\mathrm{S}$ & $\begin{array}{c}14 \\
10\end{array}$ & - & $\begin{array}{c}53 \text { No. 8's } \\
53 \text { No. 53's } \\
53 \mathrm{D}=\text { No. 53D's } \\
\text { CTB Cement Treated } \\
\text { Base }\end{array}$ & $\begin{array}{c}\mathrm{u}=\text { center of untined } \\
\text { half } \\
\mathrm{t}=\text { center of tined half } \\
\mathrm{m}=\text { middle of slab, on } \\
\text { untined surface }\end{array}$ \\
\hline Specimen & Letter & ID Number & & $\begin{array}{c}\text { Control Specimens } \\
\text { Indicated by: }\end{array}$ & $\sim$ \\
\hline Beam & $\mathrm{B}$ & $1,2,3$, etc. & & $\mathrm{C}$ & $\sim$ \\
\hline Cylinder & $\mathrm{C}$ & $1,2,3$, etc. & & $\mathrm{C}$ & $\sim$ \\
\hline
\end{tabular}

10.3.5 Testing Procedures and Equipment

All testing for this phase was performed at INDOT Materials and Tests Division. The tests included standard strength tests in addition to non-destructive tests. Table 10-3 contains a complete summary of the tests performed. For each test method that was performed, the specimens that were tested, the applicable test standard, and ages at which the test was performed are indicated. Two beams and two cylinders were designated as control specimens. At each test age, the non-destructive tests were performed on these control specimens and on the beam and cylinder specimens that were subsequently destructively tested to determine strength. 
Table 10-3 Summary of Pre-Construction Tests

\begin{tabular}{|c|c|c|c|}
\hline Test Method & Test Specimens & Test Standard & Test Age, Days \\
\hline Flexural Strength & 3 Beams & ASTM C 78 & $1,4,7,14,28,103$ \\
\hline Compressive Strength & 2 Cylinders & ASTM C 39 & $1,4,7,14,28,103$ \\
\hline Split Tensile Strength & 2 Cylinders & ASTM C 496 & $1,4,7,14,28,103$ \\
\hline $\begin{array}{l}\text { Elastic Modulus and } \\
\text { Poisson's Ratio }\end{array}$ & 1 Cylinder & ASTM C 469 & $4,7,14,28,103$ \\
\hline $\begin{array}{l}\text { Measurement of P-Wave } \\
\text { Velocity, Direct } \\
\text { Transmission Pulse Velocity }\end{array}$ & $\begin{array}{l}2 \text { Cylinders (Control } \\
\text { Specimens) } \\
2 \text { Beams (Control Specimens) } \\
2 \text { Cylinders (Comp. } \\
\text { Specimens) } \\
3 \text { Beams (Flex. Specimens) } \\
\text { Slab (S10-8) }\end{array}$ & ASTM C 597 & $\begin{array}{l}1,4,7,14,28,103 \\
1,4,7,14,28,103 \\
1,4,7,14,28,103 \\
1,4,7,14,28,103 \\
14,28\end{array}$ \\
\hline $\begin{array}{l}\text { Measurement of P-Wave } \\
\text { Velocity, Surface } \\
\text { Transmission Pulse Velocity }\end{array}$ & $\begin{array}{l}2 \text { Beams (Control Specimens) } \\
3 \text { Beams (Flex. Specimens) } \\
\text { All Slabs } \\
\text { Untined Location }^{1} \\
\text { Tined Location }^{2}\end{array}$ & $\sim$ & $\begin{array}{l}1,4,7,14,28,103 \\
1,4,7,14,28,103 \\
1,4,7,14,28 \\
7,14,28\end{array}$ \\
\hline $\begin{array}{l}\text { Measurement of P-wave } \\
\text { Velocity, INDOT Impact- } \\
\text { Echo }\end{array}$ & $\begin{array}{l}2 \text { Cylinders (Control } \\
\text { Specimens) } \\
2 \text { Beams (Control Specimens) } \\
2 \text { Cylinders (Comp. } \\
\text { Specimens) } \\
3 \text { Beams (Flex. Specimens) }\end{array}$ & $\sim$ & $\begin{array}{l}1,4,7,14,28 \\
1,4,7,14,28 \\
1,4,7,14,28 \\
1,4,7,14,28\end{array}$ \\
\hline $\begin{array}{l}\text { Measurement of P-wave } \\
\text { Velocity, AE Surface Wave }\end{array}$ & $\begin{array}{l}2 \text { Beams (Control Specimens) } \\
3 \text { Beams (Flex. Specimens) } \\
\text { All Slabs } \\
\text { Untined Location } \\
\text { Tined Location }\end{array}$ & $\sim$ & $\begin{array}{l}1,4,7,14,28,103 \\
1,4,7,14,28,103 \\
1,4,7,14,28 \\
1,4,7,14,28\end{array}$ \\
\hline $\begin{array}{l}\text { Measurement of P-wave } \\
\text { Velocity, FHWA Impact- } \\
\text { Echo Surface Method }\end{array}$ & $\begin{array}{l}\text { All Slabs } \\
\text { Middle Location }\end{array}$ & $\begin{array}{l}\text { ASTM C } 1383 \\
\text { Procedure A }\end{array}$ & 42 \\
\hline $\begin{array}{l}\text { Comparison of P-wave } \\
\text { Measurement Methods: } \\
\text { AE Surface Wave } \\
\text { FHWA Impact-Echo } \\
\text { Surface Method }\end{array}$ & $\begin{array}{l}\text { Slab S10-8 } \\
\text { Untined Location } \\
\text { Middle Location }\end{array}$ & $\begin{array}{l}\text { FHWA Method } \\
\text { Performed to } \\
\text { ASTM C } 1383 \\
\text { Procedure A }\end{array}$ & $\begin{array}{l}56 \\
56\end{array}$ \\
\hline INDOT Impact-Echo & $\begin{array}{l}\text { All Slabs } \\
\text { Untined Location }^{3} \\
\text { Tined Location }^{3} \\
\text { Middle Location }\end{array}$ & $\begin{array}{l}\text { ASTM C } 1383 \\
\text { Procedure B }\end{array}$ & $\begin{array}{l}1,4,7,14,28 \\
1,4,7,14,28 \\
7,14,28,42\end{array}$ \\
\hline FHWA Impact-Echo & $\begin{array}{l}\text { All Slabs } \\
\text { Middle Location }\end{array}$ & $\begin{array}{l}\text { ASTM C } 1383 \\
\text { Procedure B }\end{array}$ & 42 \\
\hline $\begin{array}{l}\text { Maturity (Temperature } \\
\text { Measurements) }\end{array}$ & $\begin{array}{l}1 \text { Beam (2 Locations) } \\
2 \text { Cylinders } \\
\text { All Slabs (2 Locations) }\end{array}$ & ASTM C1074 & $\begin{array}{l}\text { Cast to } 7 \\
\text { Cast to } 7 \\
\text { Cast to } 28\end{array}$ \\
\hline Slab Thickness & All Slabs & ITM 404 & 68 \\
\hline
\end{tabular}

\section{Notes:}

1. Only slabs S14-8, S10-8, and S6-8 were measured in the untined location on Day 1.

2. Only slabs S14-8, S10-8, and S6-8 were measured in the tined location.

3. Only slabs S14-8, S10-8, and S6-8 were tested in the untined and tined locations on Day 1. 


\subsubsection{Standard Strength Tests}

The flexural, compressive, and split tensile strengths, and the elastic modulus and Poisson's ratio were determined in accordance with the relevant test standard as indicated in Table 10-3. The test procedures that were followed are summarized in Appendix H, Appendix I, Appendix J, and Appendix K. All of the information required by the applicable test standard was recorded. The results are contained in Appendix L. The compressive strength tests were performed with unbonded neoprene caps. Figure 10-12 depicts a compressive strength test. The test machine is a Test Mark, model \#CM-4000D, with a 400,000 lb (178kN) capacity. Figure 10-13 depicts a flexural strength test and Figure 10-14 depicts a split tensile strength test. The test machine for both the flexural and compressive tests is a Riehle model \#RA27328, 400,000 lb capacity, retrofitted with a SATEC Mark III digital indicator.

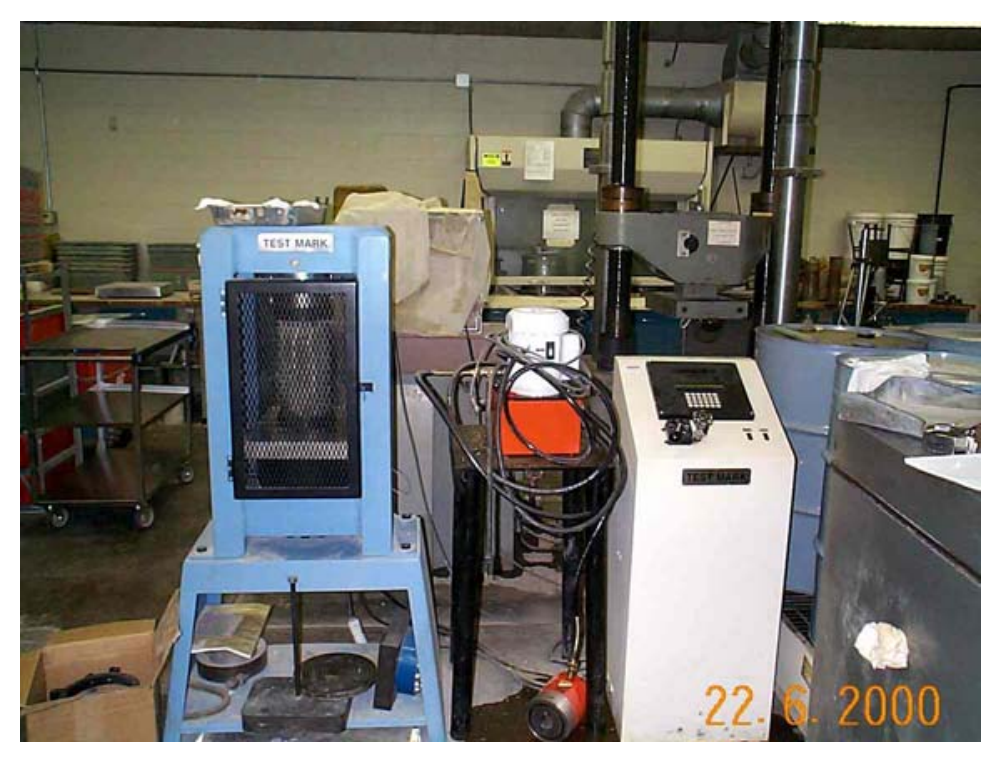

Figure 10-12 Compressive Strength Test 


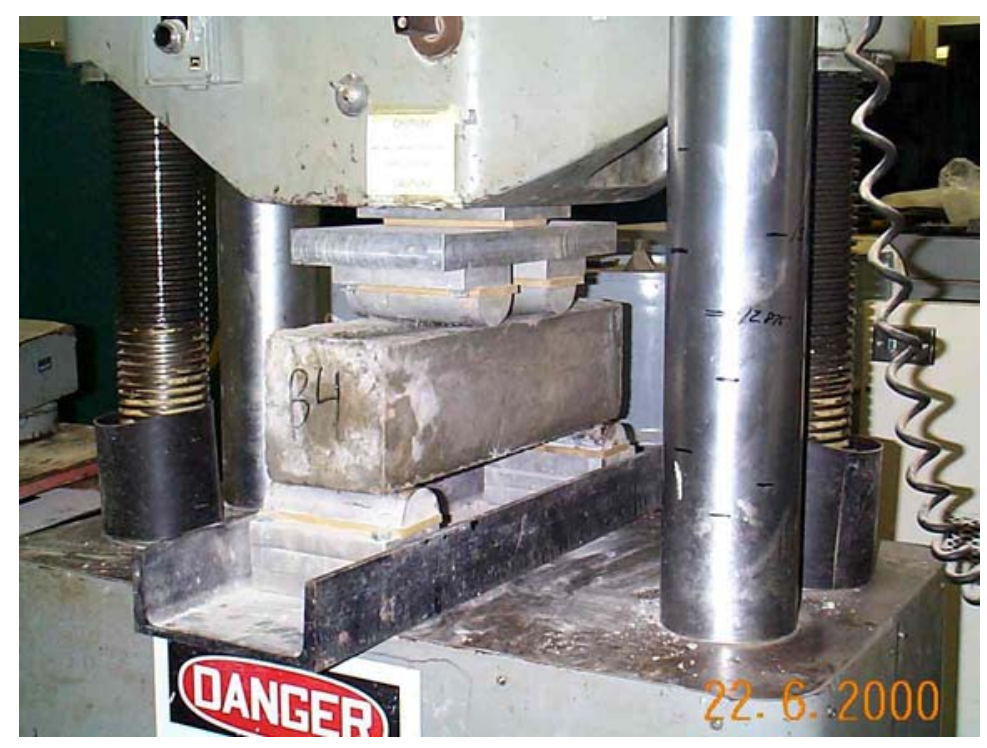

\section{Figure 10-13 Flexural Strength Test}

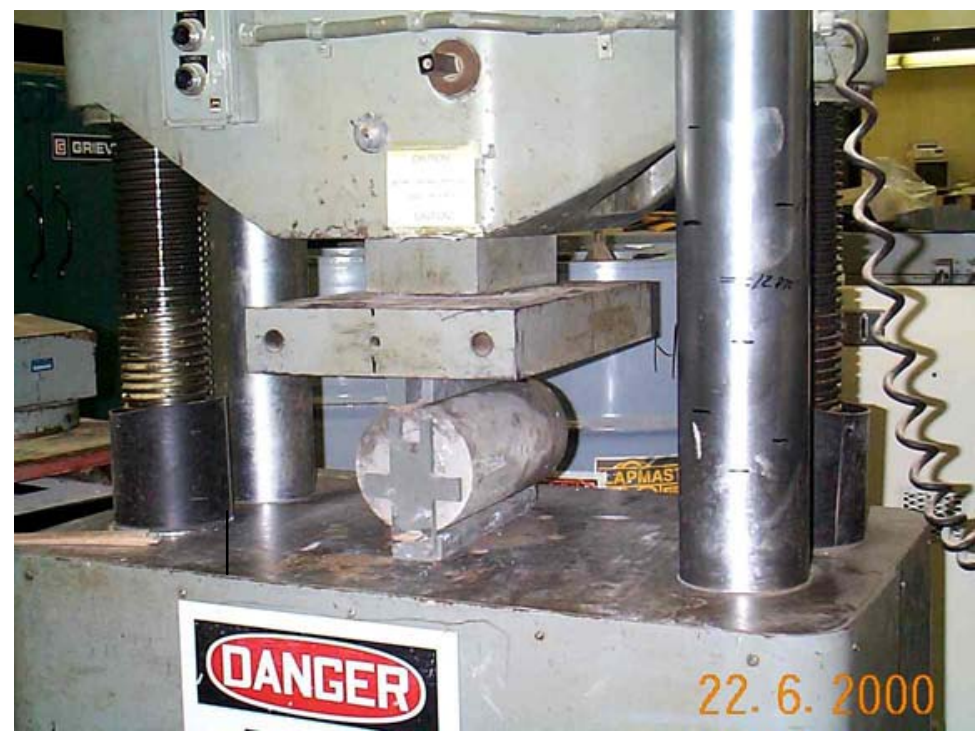

Figure 10-14 Split Tensile Strength Test

\subsubsection{Measurement of Compression Wave (P-wave) Velocity}

Several test methods were used to measure the velocity of the P-wave. These test methods included the use of a pulse velocity test apparatus in direct transmission and surface transmission, the impact-echo test method, a surface method using acoustic emission (AE) test 
equipment, and a surface method using equipment available from the Federal Highway Administration (FHWA).

A pulse velocity test apparatus was used to measure the P-wave velocity in the direct transmission and surface transmission modes (refer to Section 9.3.3.). Figure 10-15 depicts the surface transmission test being performed on a slab. Seven spacing increments were used in this mode, 60, 120, 180, 240, 300, 360, and $420 \mathrm{~mm}(2.36,4.72,7.09,14.2,16.5$ in.). Automotive grease was used to couple the transducers to the concrete surface. The P-wave velocity for both modes was determined as indicated in Section 9.3.3.

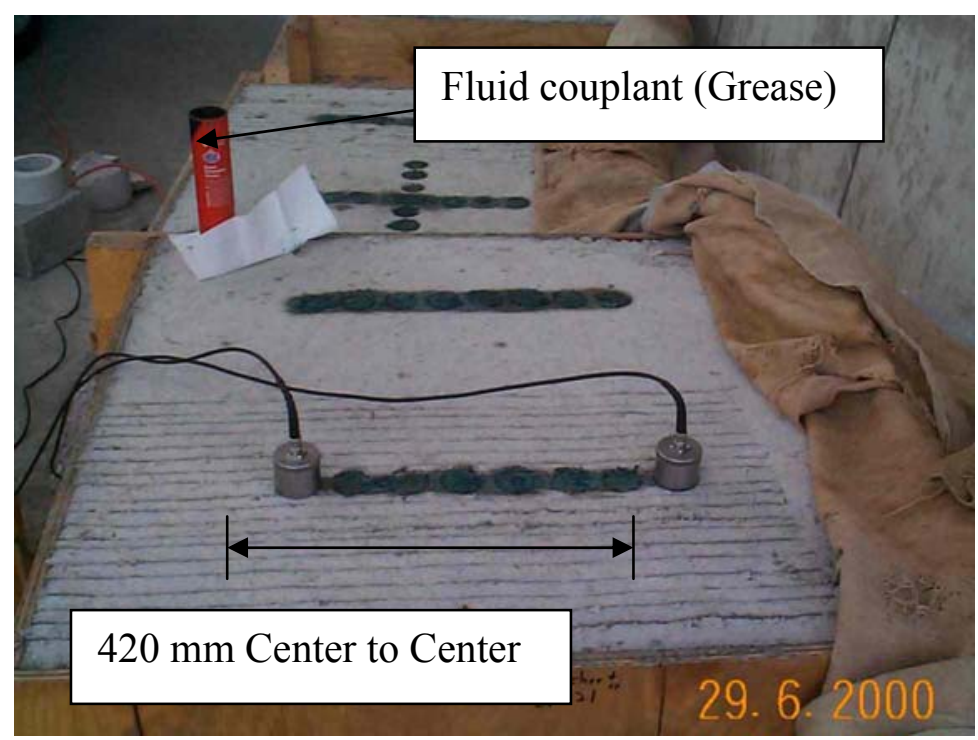

Figure 10-15 Surface Transmission Pulse Velocity

The P-wave velocity of the beam and cylinder test specimens was also measured using the impact-echo test method, refer to Section 9.3.3. The mechanical impact was performed on one end of the specimens and the resulting waveform was recorded. The P-wave velocity was calculated from the frequency determined from the recorded waveform and length of the specimens. An impact-echo test system available from the INDOT was used. The test system, manufactured by Germann Instruments, Inc., consists of a portable Grid 1535 computer with test control and analysis software, called SCAN, and a hand-held scanning unit containing six impactors and a transducer. The entire test system is shown in Figure 10-16, with Figure 10-17 
containing a close-up of the hand-held unit. The hand-held unit permits the adjustment of the force of the impact as well as the size of the impactor.

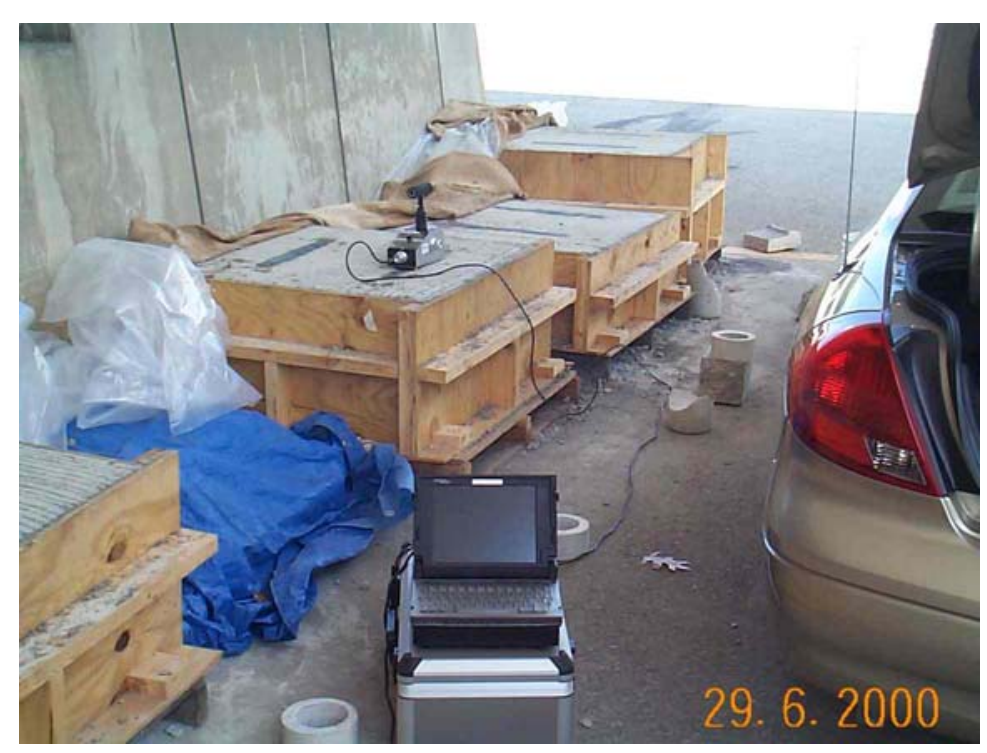

Figure 10-16 Impact-Echo Test System

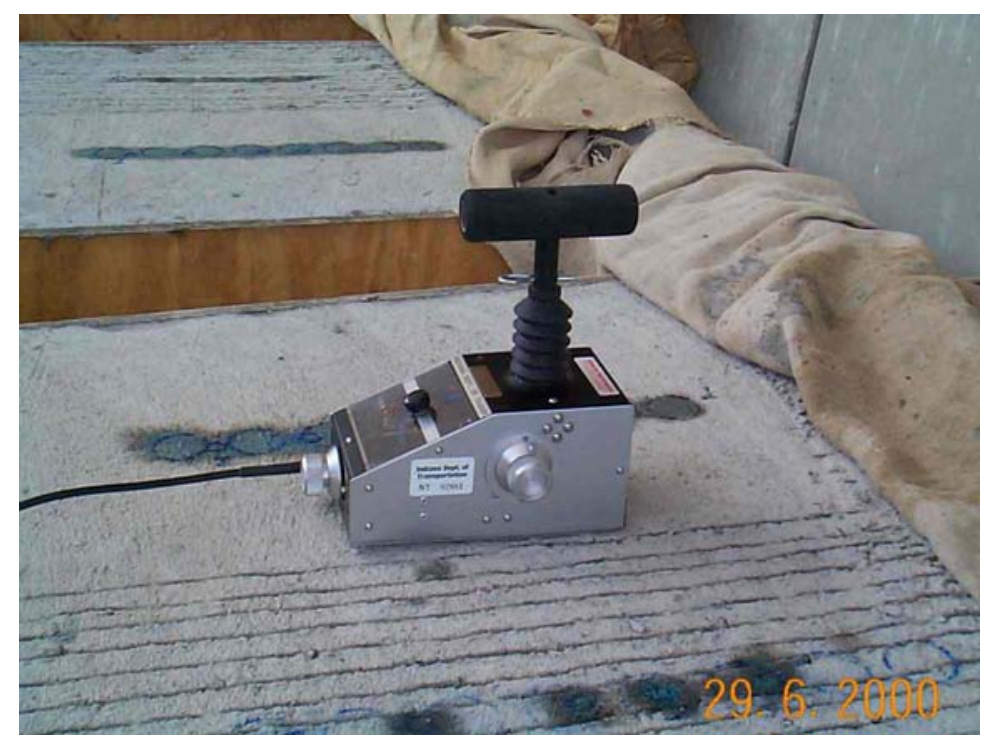

Figure 10-17 Hand-Held Scanning Unit

A surface test method of measuring the P-wave velocity was also performed using an AE test system manufactured by Vallen Systeme. The test system includes data acquisition and analysis software and four transducers. Typically, the arrival of the P-wave at the transducers in surface 
methods is determined by inspection of the surface displacement waveform at each transducer. However, the data acquisition system only permitted the recording of the surface displacement waveform at one of the transducers. The time of arrival of the wave at the other transducers is indicated by the system when a threshold displacement amplitude level is exceeded. Therefore, experimental testing was performed prior to the pre-construction test program to determine the most appropriate location of the transducer with the waveform recorder. The distances inbetween the transducers and between the impact location and the nearest transducer were also determined at this time. The following paragraphs describe the test-set up and the testing performed to determine that set-up.

The amplitude of the $\mathrm{P}$-wave decreases as the wave propagates through the specimen. It was found that the amplitude of the P-wave would diminish to such extent that its arrival would not exceed the threshold level of the transducers at a distance of approximately $125 \mathrm{~mm}$ from the impact location. Therefore the arrival of P-wave would not be accurately indicated by the test system at distances greater than approximately $125 \mathrm{~mm}$. Figure 10-18 is a waveform recorded at a distance from the impact location of greater than $125 \mathrm{~mm}$. It shows that the P-wave arrives about $3 \mu$ s before the threshold level is exceeded. The first transducer was therefore placed at a distance of $75 \mathrm{~mm}$ from the impact location. It was found that at this distance the arrival of the Pwave was indicated by the test system within $1 \mu$ s, as shown in Figure 10-19. A smaller distance was not used in order to ensure that the P-wave was able to separate from the other portions of the stress wave. 


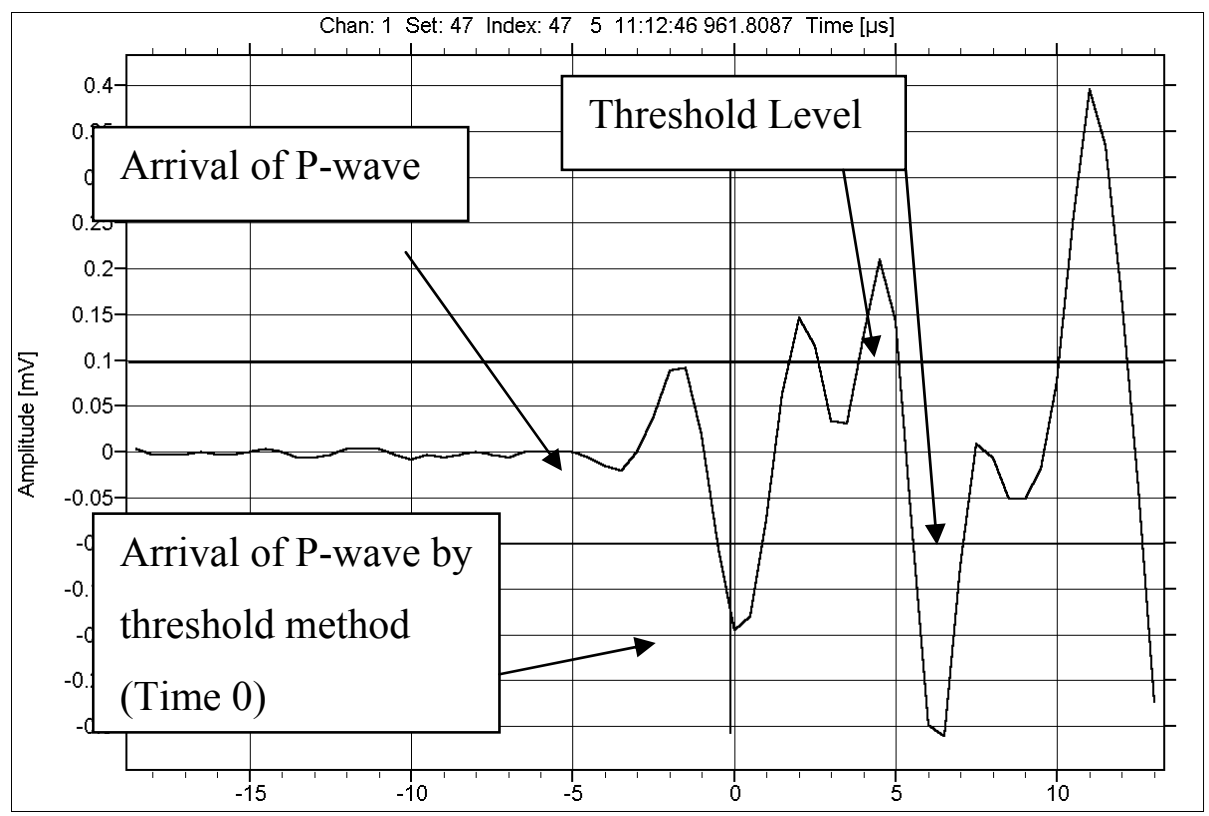

Figure 10-18 Arrival of P-wave Incorrectly Indicated by Threshold

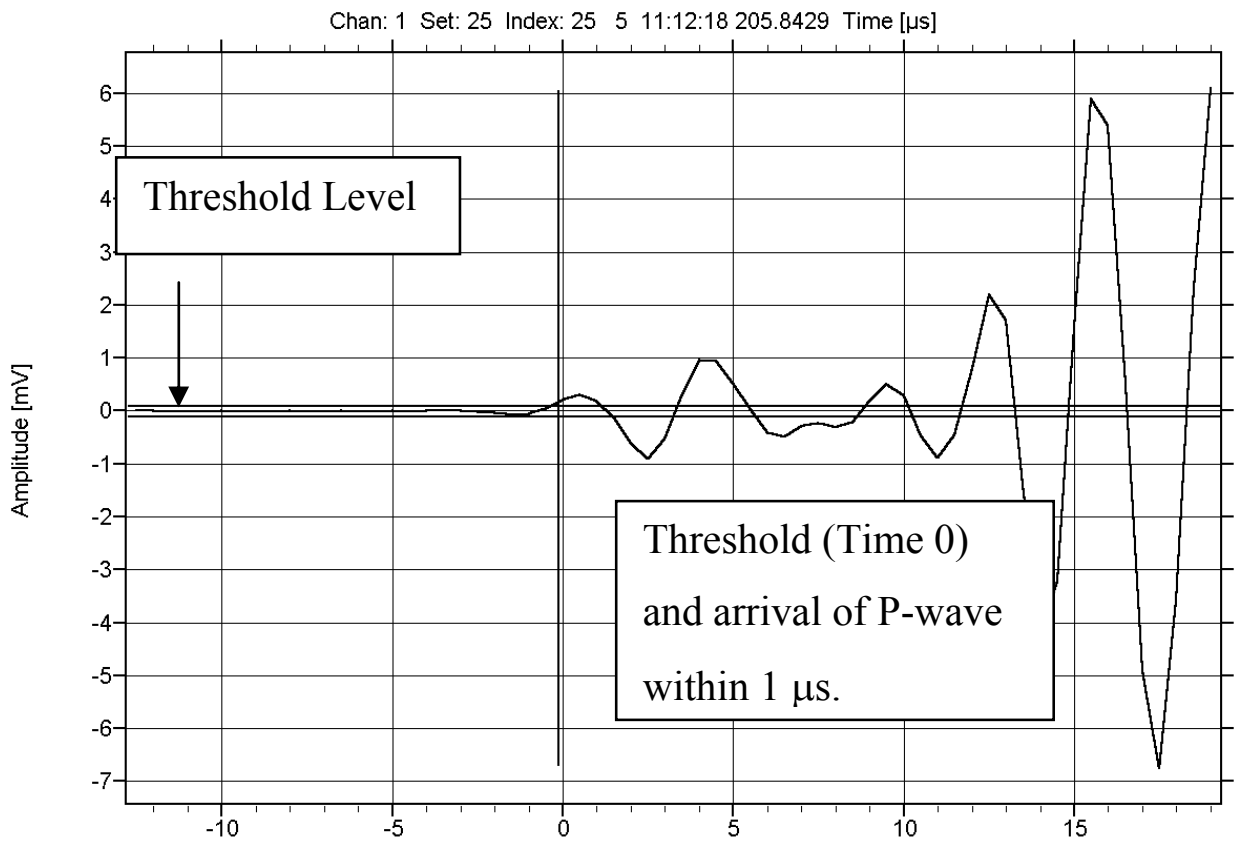

Figure 10-19 Arrival of P-wave Correctly Indicated by Threshold

The transducer with the waveform recorder was placed $300 \mathrm{~mm}$ from the impact source, 225 $\mathrm{mm}$ from the first transducer. This location was a compromise between minimizing the possible error in the calculation of the P-wave velocity and limitations imposed by the length of the test 
specimen and the diminishing amplitude of the P-wave. The possible error in the calculation of the P-wave velocity decreases as the distance between transducers increases as shown in Table 10-4. However, the distance of the furthest transducer from the impact location cannot be to large because the amplitude of the P-wave will diminish to the point where it can not be detected by the transducer. In addition, the length of the test specimens limits the length between the impact location and the furthest transducer.

The remaining two transducers were included in the test setup, as shown in Figure 10-20, however they were not used in the calculation of the P-wave velocity. The P-wave velocity was calculated from the distance between the first and last transducers and the arrival time of the Pwave at the first transducer, as indicated by the test system, and the arrival time of the P-wave at the last transducer, as determined from inspection of the waveform. A template was used to mark the transducer and impact locations on all specimens on Day 1. The breaking of a mechanical pencil lead on the surface of the test specimen was found to produce stress waves with relatively consistent energy.

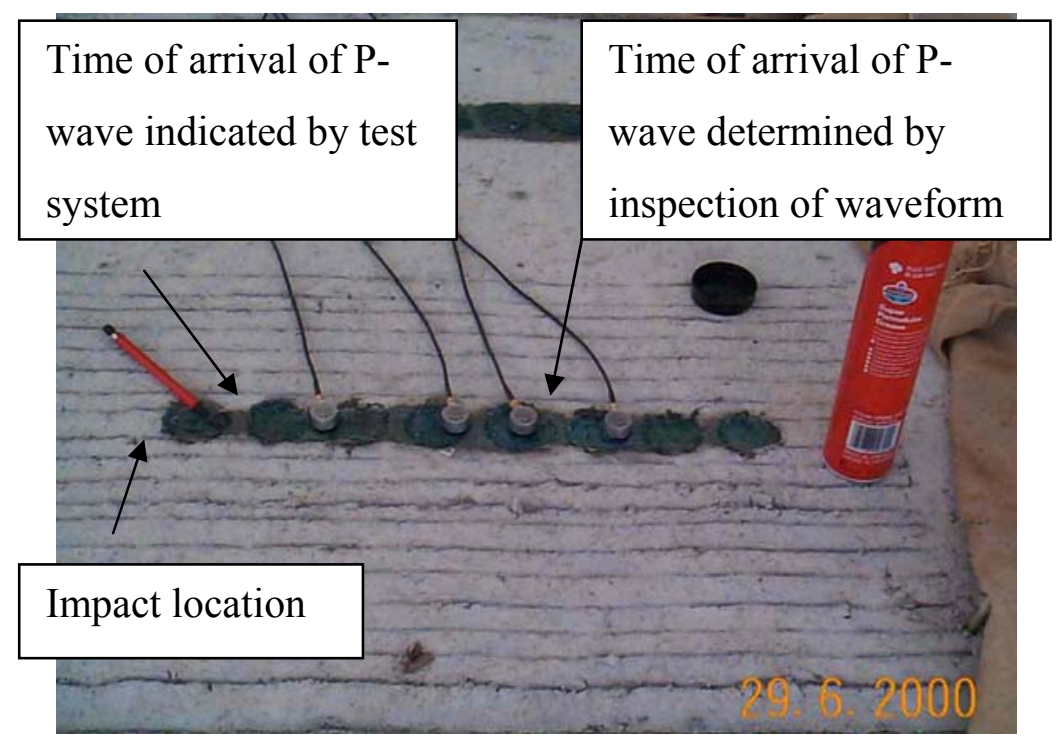

Figure 10-20 Transducer Layout 


\begin{tabular}{|c|c|c|c|}
\hline $\begin{array}{l}\text { Error in the calculation } \\
\text { - Misalignment o } \\
\text { - Size of transit ti } \\
\text { The magnitude of both ty } \\
\text { transducers increases. }\end{array}$ & $\begin{array}{l}\text { wave Velocit } \\
\text { nsducers } \\
\text { sampling inte } \\
\text { of error decr }\end{array}$ & 1 transit & nce between \\
\hline Distance Between & Maximum I & -wave & lignment of: \\
\hline Transducers, mm & $1 \mathrm{~mm}$ & $2 \mathrm{~mm}$ & $3 \mathrm{~mm}$ \\
\hline 100 & 1.01 & 2.04 & 3.09 \\
\hline 200 & 0.50 & 1.01 & 1.52 \\
\hline 300 & 0.33 & 0.67 & 1.01 \\
\hline 400 & 0.25 & 0.50 & 0.76 \\
\hline Total Transit Time us & Maximun & P-Wa & mpling of: \\
\hline Total Iramsit inme, $\mu \mathrm{s}$ & $0.5 \mu s$ & $1.0 \mu \mathrm{s}$ & $2.0 \mu \mathrm{s}$ \\
\hline 20 & 2.56 & 5.26 & 11.1 \\
\hline 40 & 1.27 & 2.56 & 5.26 \\
\hline 60 & 0.84 & 1.69 & 3.45 \\
\hline
\end{tabular}

The P-wave velocity of the slabs was also measured by a surface method using an impactecho test system available from the FHWA Mobile Concrete Laboratory. This system, model Mark II manufactured by Germann Instruments, Inc., is an updated version of the system available from the INDOT. It included the Echo Blue ${ }^{\mathrm{TM}}$ (version 1.3A) test control and analysis software, three hand-held transducers, and several steel ball impactors of different diameters. This system is capable of recording the surface displacement waveforms at two transducers. The P-wave velocity is then determined from the known distance between the transducers and the transit time of the P-wave as determined from the recorded waveforms. This system was only available for a limited time and was therefore only used on two occasions for the preconstruction test program. The system was used more extensively in the field test program as indicted in Section 10.4.

\subsubsection{Impact-Echo Test Method to Determine Thickness}

The impact-echo test method was performed on the slab test specimens. The impact-echo test system available from INDOT was used at each test age. The impact-echo test system available from the FHWA was used at one test age. (This test system was only available for a limited time and was used more extensively in the field test program as explained later.) Both test systems are described in more detail in Section 10.3.5.2. 


\subsubsection{Time-Temperature Measurements}

The temperature history of the test specimens was recorded for use in the maturity test method. One thermocouple was placed in two cylinders, two thermocouples were placed one beam, and two thermocouples were placed in each slab specimen. Each thermocouple was placed at the approximate mid-depth of the specimen. The temperature history of the cylinders and beam were recorded from the time of concrete placement until an age of seven days. After one day of room temperature curing and six days of curing in a limewater bath in a temperature controlled moist curing room, the temperature of these specimens was essentially constant and did not require further monitoring. The temperature history of the slab specimens, which were cured outside, was recorded from the time of casting until 28 days of curing. The temperature history of all of the specimens was recorded using a Campbell Scientific, Inc. CR10X Measurement and Control System. The system was programmed to measure the temperature at each thermocouple every minute and to record the average temperature every 10 minutes.

\subsubsection{Slab Thickness Determination By Coring}

Cores were extracted from the slab test specimens to obtain thickness measurements. The cores were taken using the apparatus pictured in Figure 10-21. Four inch diameter cores were taken as close to the middle of the untined portion of the slab and the middle of the slab as possible. These locations represent two of the three locations where impact-echo tests were performed. Cores could not be extracted from the third impact-echo test location, the middle of the tined portion of each slab, due to limitations of the coring apparatus. The length of the cores was determined by the same process that the INDOT uses to determine the length of pavement cores as described in Section 10.4.1. 


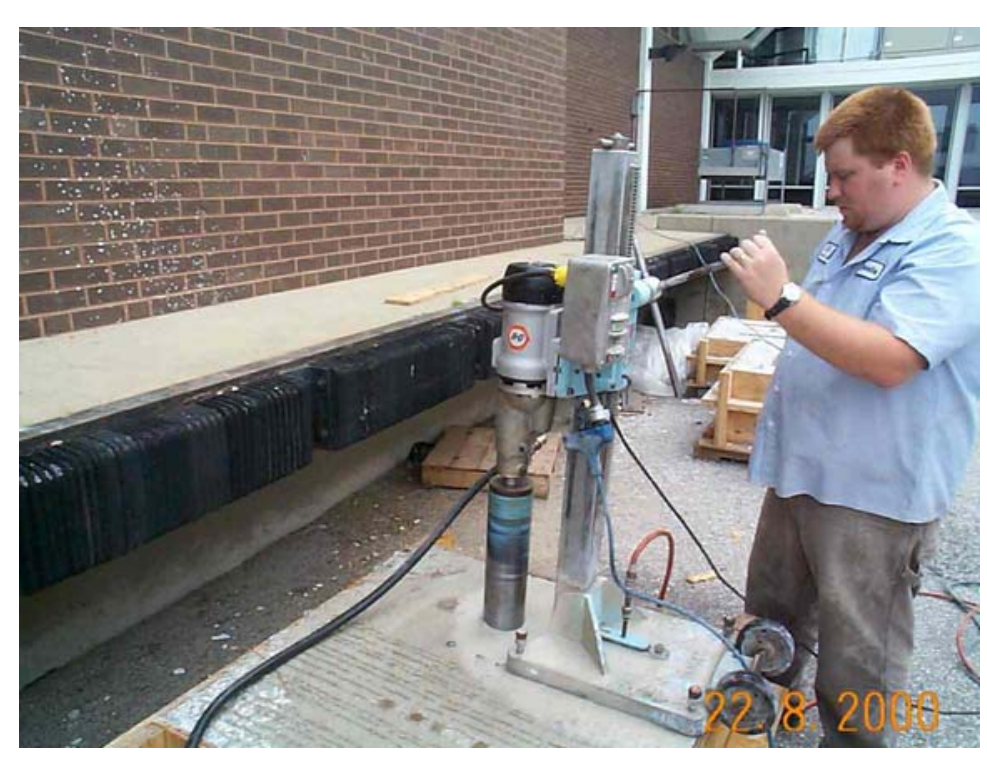

Figure 10-21 Obtaining Cores from Slab Specimens

\subsection{Field Test Program}

The field test program was conducted during the placement of the concrete pavement governed by the Level 1 PRS for Project R-24432. The description of the field test program is preceded by a description of the sampling procedures used for the determination of strength and thickness.

\subsubsection{Description of INDOT Project R-24432 Procedures}

For acceptance purposes, the concrete pavement is divided into discrete quantities termed lots. Each lot is defined as a maximum of $6000 \mathrm{~m}^{2}\left(7,200 \mathrm{yd}^{2}\right)$. Each lot is further subdivided into sublots of a maximum of $2000 \mathrm{~m}^{2}\left(2,400 \mathrm{yd}^{2}\right)$. Therefore a full lot will consist of 3 sublots. Table 10-5 indicates the lots and sublots governed by the Level 1 PRS for INDOT Project R24432. For this project the INDOT identified each lot and sublot as mainline or shoulder pavement and as pavement with fly ash or without fly ash. Fly ash is only permitted to be used in concrete mixes between April $1^{\text {st }}$ and October $15^{\text {th }}$. Each combination of designations, mainline/shoulder and with fly ash/without fly ash begins its numbering system with Lot 1, Sublot 1 as illustrated in Table 10-5. Therefore, in this report, the appropriate designation 
(mainline or shoulder, with fly ash or without fly ash) is indicated along with the lot and sublot designation to be consistent with the INDOT designation.

Table 10-5 Pavement Identification

\begin{tabular}{|l|c|c|c|}
\hline \multicolumn{2}{|c|}{ Mainline Pavement } & \multicolumn{2}{c|}{ Shoulder Pavement } \\
\hline \multicolumn{1}{|c|}{ With Fly Ash } & Without Fly Ash & With Fly Ash & Without Fly Ash \\
\hline Lot 1, Sublots 1, 2, 3 & Lot 1, Sublots 1, 2,3 & Lot 1, Sublots 1, 2, 3 & Lot 1, Sublots 1, 2, 3 \\
\hline Lot 2, Sublot 1, 2,3 & Lot 2, Sublot 1 & Lot 2, Sublot 1, 2,3 & Lot 2, Sublot 1, 2 \\
\hline Lot 3, Sublot 1, 2,3 & $\sim$ & $\sim$ & $\sim$ \\
\hline Lot 4, Sublot 1, 2,3 & $\sim$ & $\sim$ & $\sim$ \\
\hline Lot 5, Sublot 1, 2,3 & $\sim$ & $\sim$ & $\sim$ \\
\hline Lot 6, Sublot 1, 2,3 & $\sim$ & $\sim$ & $\sim$ \\
\hline Lot 7, Sublot 1 & $\sim$ & $\sim$ & $\sim$ \\
\hline
\end{tabular}

Samples are taken for each sublot for acceptance of the pavement for flexural strength, air content, unit mass (weight), water-to-cementitious ratio, smoothness, and thickness. A random number generator determines the location of each sample. The flexural strength, smoothness, and thickness are AQC's that are used to predict pavement performance and life-cycle cost in the Level 1 PRS. (Smoothness is not included in the predictions for shoulder pavement.) Air content, unit mass (weight), and water-to-cementitious ratio are characteristics that are accepted based on traditional INDOT QC/QA procedures in the Level 1 PRS for Project R-24432.

The flexural strength of each sublot is determined by testing two beam specimens. These beams are cast from fresh concrete sampled at the contractor's on-site batch plant. The beams are cured for 24 hours in a temperature controlled project trailer that is provided by the contractor. They are then placed in a limewater bath in the trailer until they are tested in third point loading at an age of 7 days. The pavement contractor for this project elected to cast two additional beam specimens from the same concrete sample every time the INDOT cast their beam specimens. Additional beam specimens were cast for the field test program as described in Section 10.4.2.

The thickness of the as-constructed pavement is determined by measurements taken on two cores extracted from each sublot. The procedures for obtaining the cores are contained in Section 501.26 of the 1999 INDOT Standard Specifications. The INDOT determines the locations at 
which the cores will be extracted for each sublot in an unbiased manner in accordance with ITM 802. The contractor obtains the cores using a drilling device that is mounted on a trailer. The INDOT takes possession of the cores after they are extracted from the pavement. The length of each core is determined by averaging ten separate measurements. The measurement process is described in detail in the governing specification, ITM 404. The measurement apparatus is shown in Figure 10-22.

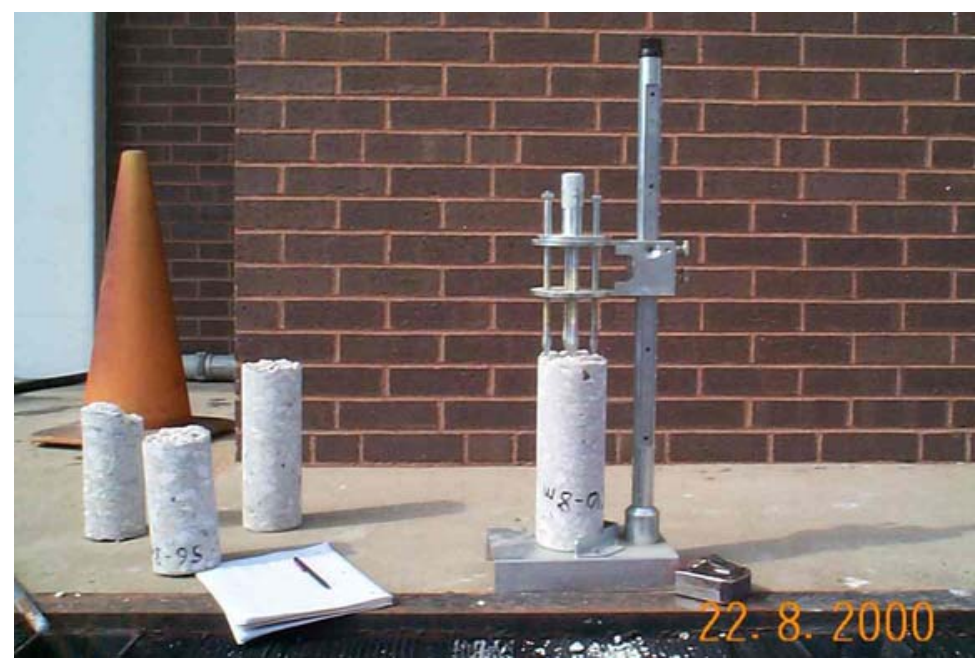

Figure 10-22 Core Measurement Apparatus

10.4.2 Test Specimens

Test specimens for the field test program included beam specimens, 6 × 6 × 21 inches $(152.4$ x 152.4 x $533 \mathrm{~mm}$ ) cast by Purdue University, the FHWA, the concrete pavement contractor, and by the INDOT and cylinder test specimens, $6 \times 12$ inches $(152.4 \times 305 \mathrm{~mm})$ cast by the FHWA. Table 10-6 contains a summary of the field test specimens. In this report, the test specimens are identified by which agency cast them, by lot and sublot designation, and by indicating the pavement type (mainline or shoulder, with fly ash or without fly ash). The INDOT and the contractor each cast two beams for each sublot over the entire project for testing at an age of seven days as mentioned in Section 10.4.1. The beams cast by Purdue University were tested at an age of 28 days. They were cast at the on-site batch plant from the same sample that the contractor and the INDOT cast their beams. The beam test specimens cast by Purdue University, 
the INDOT, and the contractor were made with reusable steel molds complying with ASTM C 192, with the exception that the molds were not checked for watertightness, however no visible leakage through the joints was observed during casting.

The beam specimens cast by the FHWA were cast next to the as-constructed pavement from concrete sampled directly in front of the paving machine. The sample taken in front of the paving machine was taken from the same batch of concrete that was sampled at the batch plant. This was accomplished by radio communication between the batch plant and the paving location. The cylindrical test specimens were made with flexible single use molds complying with ASTM C 192. The rectangular beam test specimens were made with reusable steel molds with the joints sealed with wax complying with ASTM C 192. The contractor and Purdue University also cooperatively cast additional beam specimens at the batch plant during the construction of mainline pavement with fly ash for Lot 6 , Sublot 2 , and during the construction of shoulder pavement without fly ash for Lot 1 , Sublot 2 . The purpose of these beams was to create strengthmaturity relationships as discussed later.

Table 10-6 Field Test Specimens

\begin{tabular}{|l|l|l|l|}
\hline Specimens Cast By & $\begin{array}{c}\text { Specimen Type } \\
\text { (Number) }\end{array}$ & \multicolumn{1}{|c|}{ Lot-Sublots } & \multicolumn{1}{|c|}{ Testing Age } \\
\hline INDOT & Beams (2) & All & 7 Days \\
\hline Contractor & Beams (2) & All & 7 Days \\
\hline Purdue University & Beams (2) & $\begin{array}{l}\text { Mainline Pavement with fly ash Lot } \\
\text { 1-Sublot 3 through Lot 2 Sublot 3 }\end{array}$ & 28 Days \\
\hline $\begin{array}{l}\text { Purdue University/ } \\
\text { Contractor }\end{array}$ & Beams (10) & $\begin{array}{l}\text { Shoulder Pavement with fly ash Lot } \\
\text { 6-Sublot 2 }\end{array}$ & $\begin{array}{l}\text { 1, 4, 7, 14, 28, Days } \\
\text { (2 at each age) }\end{array}$ \\
\hline $\begin{array}{l}\text { Purdue University/ } \\
\text { Contractor }\end{array}$ & Beams (4) & $\begin{array}{l}\text { Shoulder Pavement without fly ash } \\
\text { Lot 1-Sublot 2 }\end{array}$ & $\begin{array}{l}\text { 7 Days (2) } \\
\text { 28 Days (2) }\end{array}$ \\
\hline FHWA & Beams (4) & $\begin{array}{l}\text { Mainline Pavement with fly ash Lot } \\
\text { 2-Sublot 1 through Lot 4-Sublot 2 }\end{array}$ & $\begin{array}{l}\text { 7 Days (2) } \\
\text { 28 Days (2) }\end{array}$ \\
\hline FHWA & Cylinders (2) & $\begin{array}{l}\text { Mainline Pavement with fly ash Lot } \\
\text { 2-Sublot 1 through Lot 4-Sublot 2 }\end{array}$ & 7 Days \\
\hline
\end{tabular}

The as-constructed pavement was also a test specimen for the field test program. The tests performed on the pavement included temperature measurements, impact-echo tests, and the extraction of cores. The location of the tests on the pavement is described using the type of pavement, lot, and sublot label, and the appropriate station. 


\subsubsection{Mixing and Sampling Procedure}

The mixing of the concrete at the on-site batch plant is described in Section 10.3.2. After mixing, a front-end loader was used to take samples from the rotary drum mixer at the batch plant, see Figure 10-3. This sample was used to cast the specimens for Purdue University, INDOT, and the contractor. The remaining batch was dumped from the mixer into a dump truck. The dump truck delivered the concrete to the paving location and dumped it into the machine shown in Figure 10-24 that spreads the concrete on the sub-base. Before a second machine, which consolidates and forms the concrete reached the concrete, a sample was taken using a shovel and wheelbarrow to cast the beams made by the FHWA.

\subsubsection{Casting and Curing}

All of the beam specimens were cast in accordance with ASTM C 31. Internal vibration was used to consolidate all of the beams. The beam specimens cast by Purdue University, INDOT, and the contractor were covered with wet burlap after casting. The beams were cured for 24 hours in a temperature controlled project trailer that is provided by the contractor. After 24 hours, the beams are demolded and placed in a limewater bath in the trailer. The fresh concrete properties for the sublots sampled by Purdue University are contained in Appendix F.

The beams specimens cast by the FHWA were cured outside, next to the as-constructed pavement. Figure 10-23 shows the beams after casting. The beams were covered with wet burlap and nonabsorbent plastic after casting. After 24 hours, the beams were demolded and placed in a temperature controlled limewater bath located in the FHWA Mobile Concrete Laboratory. 


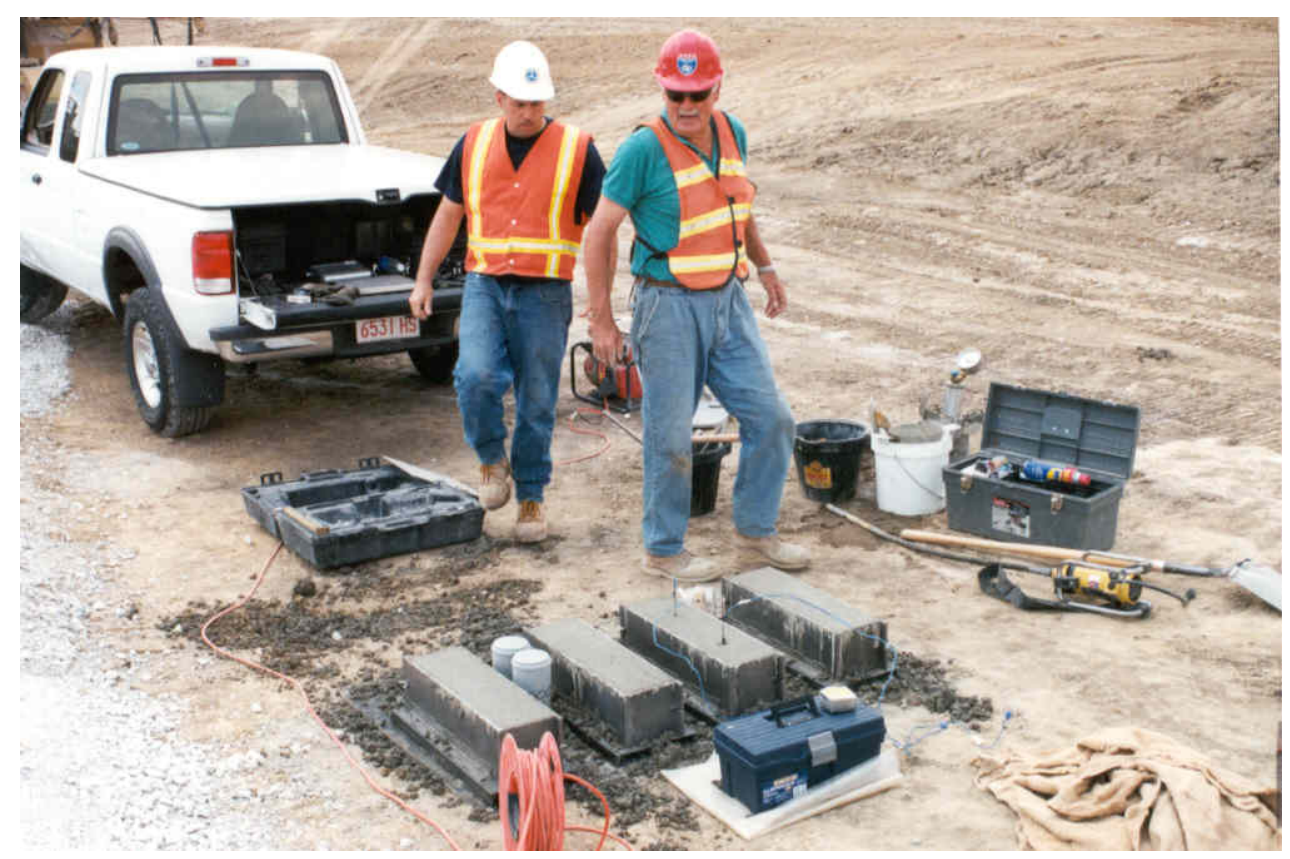

Figure 10-23 Specimens Cast Next to Pavement

The placement, shaping, compaction, finishing, and tining of the concrete pavement are primarily performed by machine. The fresh concrete is delivered to the site by dump trucks and then dumped onto a conveyor belt, see Figure 10-24. This belt delivers the concrete onto the subgrade, see Figure 10-25, in front of the first paving machine. This machine uses an auger to spread the concrete over the paving width. A second machine, shown in Figure 10-26, consolidates the concrete and shapes the pavement. The surface of the pavement is then finished using floats as shown in Figure 10-27. A third machine tines the pavement, see Figure 10-28. This machine also sprays the pavement with a liquid curing compound. 


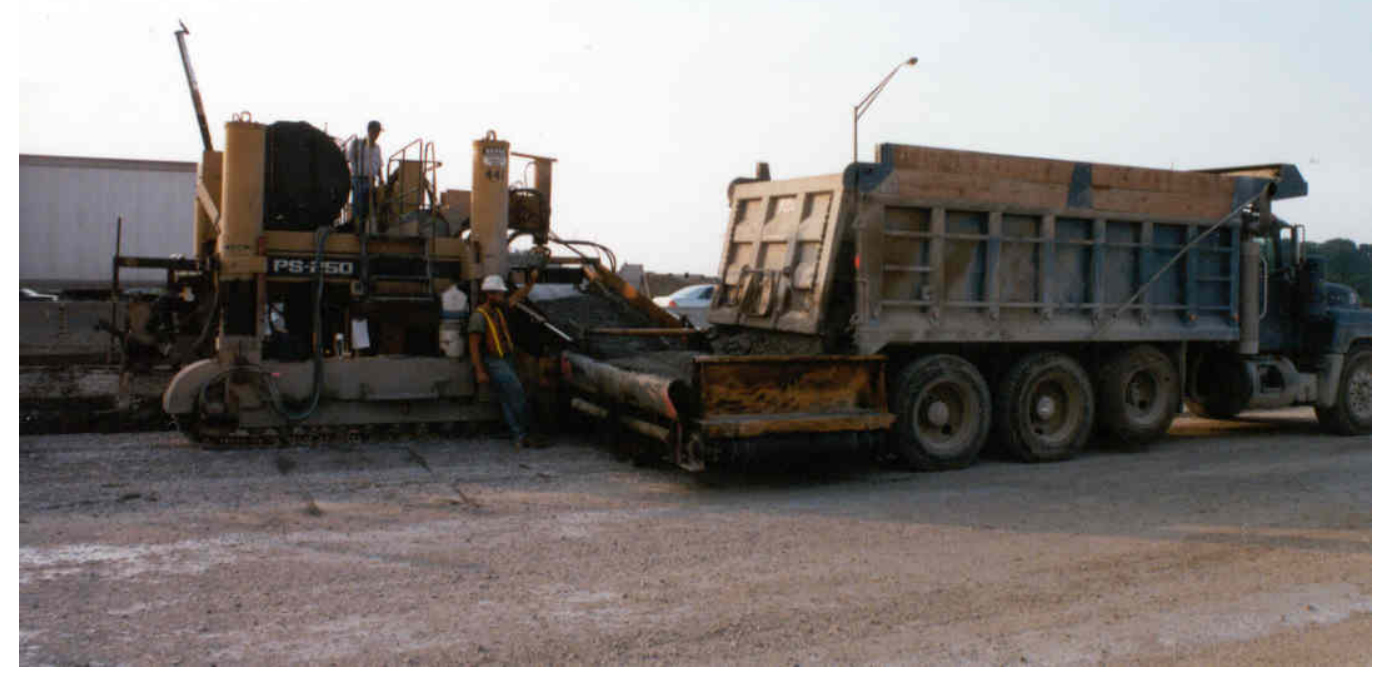

Figure 10-24 Concrete Dumped Onto Conveyor Belt

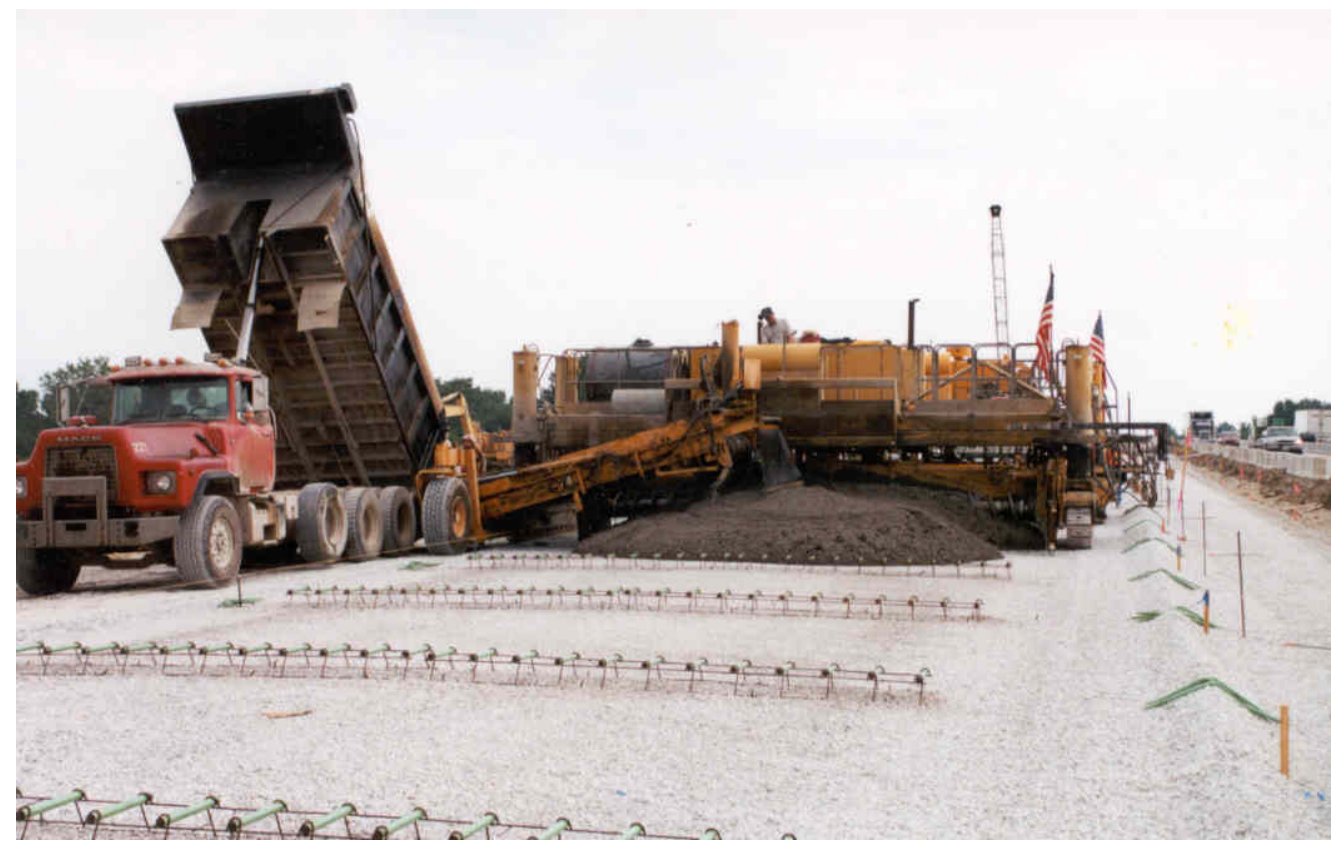

Figure 10-25 Concrete Spread Over Base 


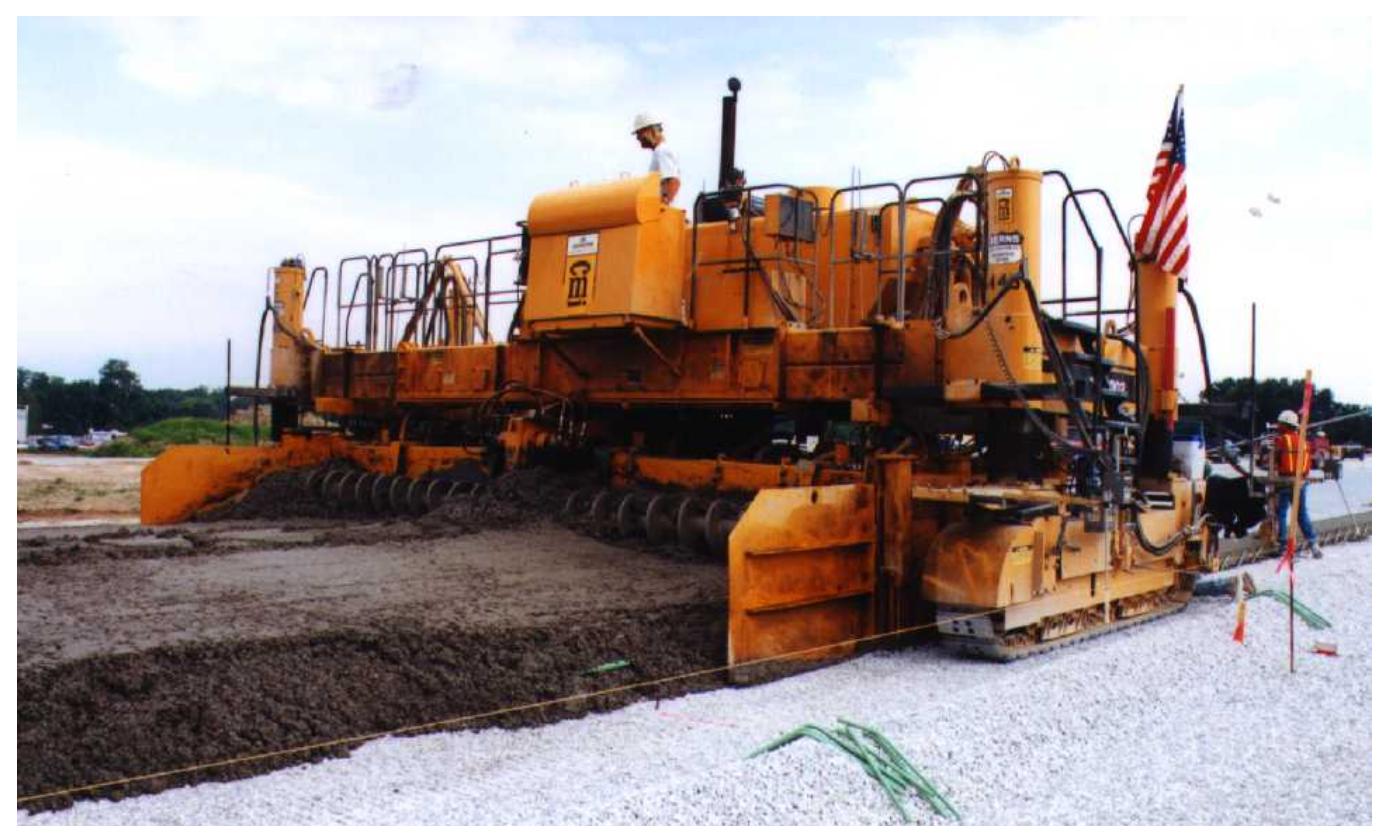

Figure 10-26 Vibrating Concrete

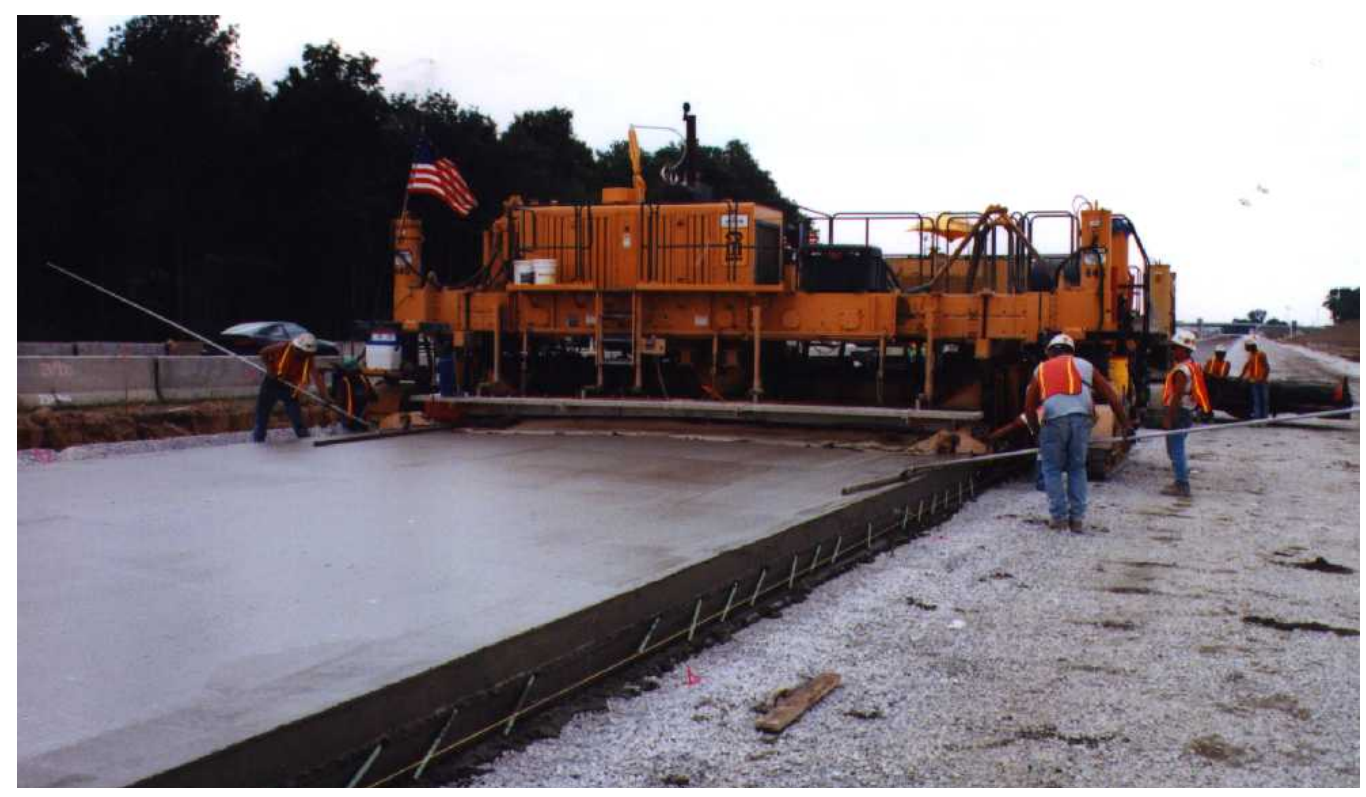

Figure 10-27 Finishing Pavement 


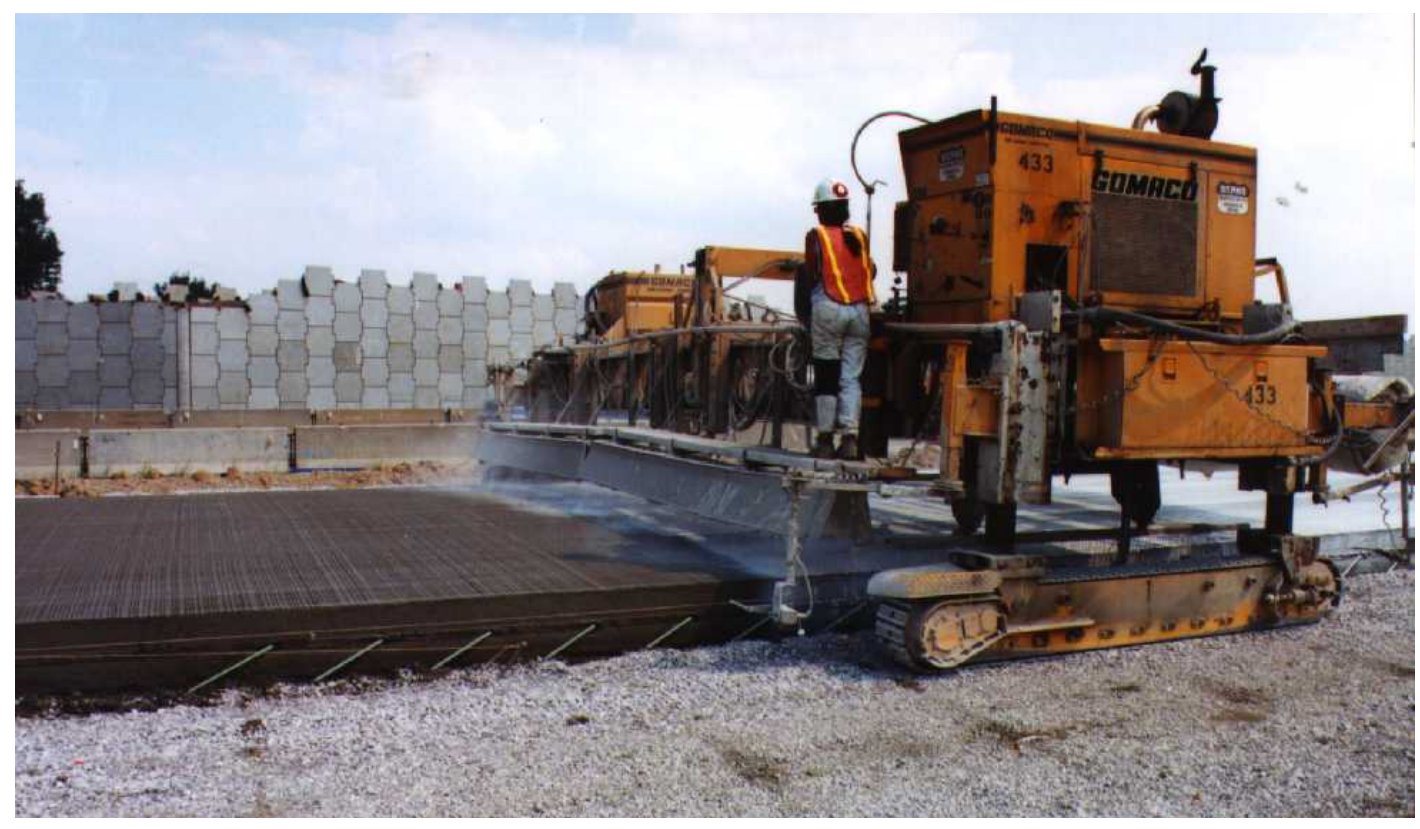

Figure 10-28 Tined Pavement is Covered with Curing Compound

\subsubsection{Testing Procedure and Equipment}

Testing for the field test program included flexural testing of beam specimens, tests to measure the P-wave velocity in beams and in the pavement, impact-echo tests on the pavement, the measurement of cores extracted from the pavement, and time-temperature measurements in beams and in the pavement for use in the maturity test method.

\subsubsection{1 $\quad$ Flexural Testing}

The flexural strength of the beam specimens was determined in general accordance with ASTM C 78. The specimens cast by the INDOT and by the contractor were tested at an age of 7 days. These specimens and the beams cast jointly by Purdue University and the contractor (which were tested at various ages) were tested on a hydraulic Rainhart Series 416 model testing machine that was located in the contractors project trailer. This machine has a 12,000 lb (53.4 $\mathrm{kN}$ ) capacity. The specimens cast by Purdue University were tested at an age of 28 days at INDOT Materials and Tests Division on the equipment described in Section 10.3.5.1. Two of the specimens cast by the FHWA at each location were tested at 7 days, the remaining two 
specimens were tested at 28 days. These specimens were tested with a $600 \mathrm{kip}(267 \mathrm{kN})$ capacity Forney compression machine with a LC-1 control unit.

\subsubsection{Measurement of Compression Wave (P-wave) Velocity}

The P-wave velocity was measured in the beam specimens cast by Purdue University and in the pavement. The beams cast by Purdue University were measured at 7 and 28 days using the $\mathrm{AE}$ test system and the pulse velocity test apparatus in the direct transmission mode. These beams were also measured using the pulse velocity test apparatus in surface transmission mode at 7 days.

The impact-echo equipment available from the FHWA was used to measure the surface Pwave velocity of the pavement. Measurements were taken at sixteen core locations in the mainline pavement with fly ash. Measurements were also taken at the two locations where the temperature history of the pavement was recorded.

\subsubsection{Impact-Echo Test Method to Determine Thickness}

The impact-echo test method was performed on the as-constructed pavement. The impactecho test equipment available from the FHWA was used to perform tests at 16 core locations in the mainline pavement with fly ash (Lot 2, Sublot 1 to Lot 4, Sublot 2) and at the two locations where the temperature history of the pavement was recorded. At each location, surface P-wave velocity measurements were taken immediately before the impact-echo tests were performed. The test equipment was powered by the automobile cigarette lighter using the provided adapter.

\subsubsection{Time-Temperature Measurements}

The temperature history of the pavement was recorded in two locations, in Sublots 2 and 3 of Lot 2 mainline pavement with fly ash. Temperature measurements were recorded every one-half hour for the first 48 hours and every 60 minutes afterwards up until the age of nine days using a Humbolt maturity meter, see Figure 10-29. At each location, four thermocouples were used. The 
thermocouples were taped to a wooden dowel that was placed in the pavement while the concrete was still fresh. The dowel was inserted 12 inches from the pavement edge. One thermocouple recorded the temperature of the ambient air. The other three thermocouples recorded the temperature of the pavement at one inch from the top of the pavement, the middle of the pavement, and 1 inch from the bottom of the pavement.

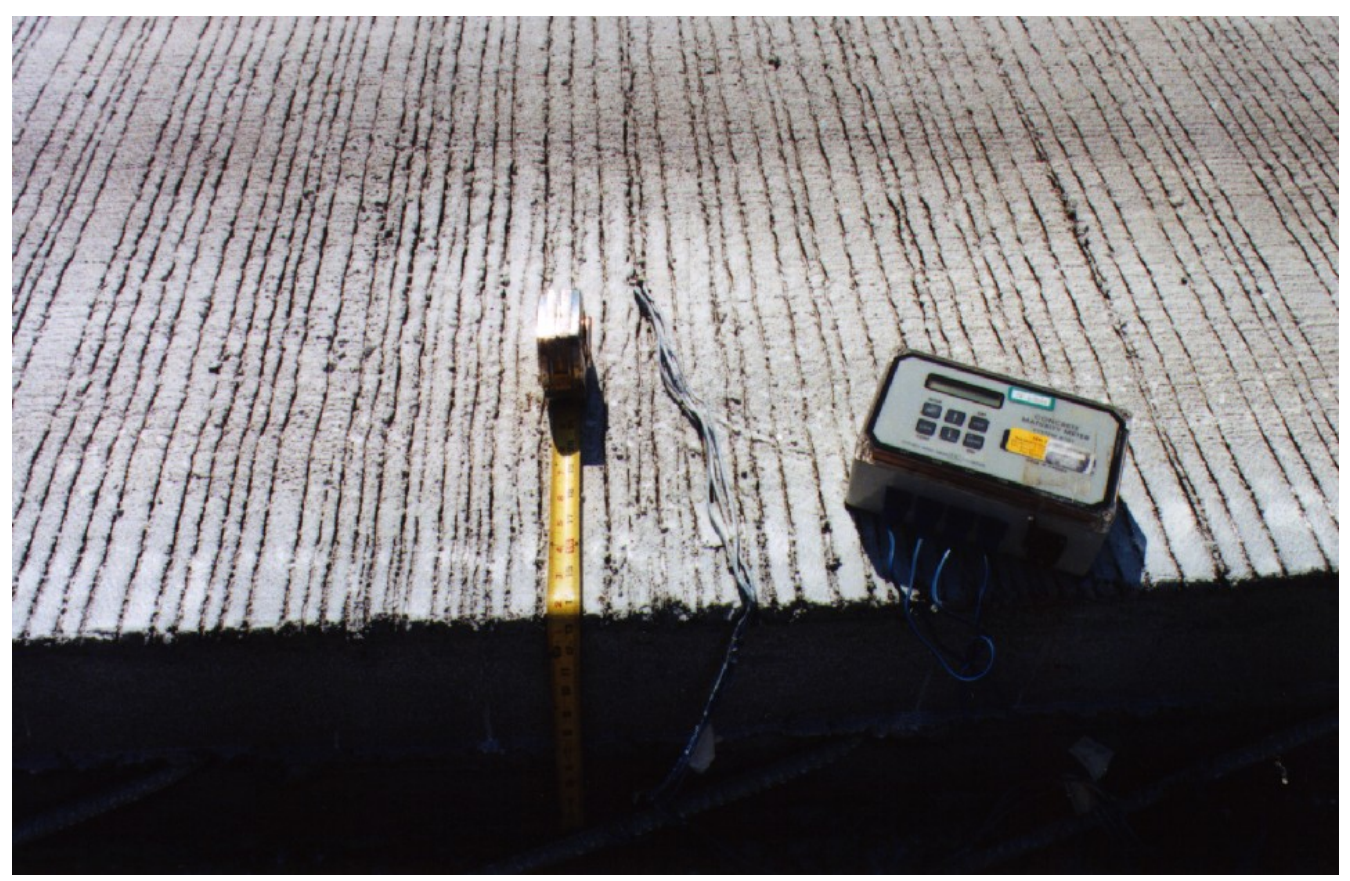

Figure 10-29 Maturity Meter

The temperature history of the beam specimens cast by Purdue University was also recorded. Two thermocouples were placed in one of the two beams cast for each sublot. The temperature history was recorded until the temperature of the specimens reached a constant value maintained by the temperature controlled water bath.

\subsubsection{Pavement Cores}

Two cores were extracted from each sublot to determine the thickness of the as-constructed pavement as discussed in Section 10.4.1. A core was also extracted near each of the two 
locations where the temperature history of the pavement was recorded. The cores were obtained by the contractor using a trailer mounted coring device, see Figure 10-30.

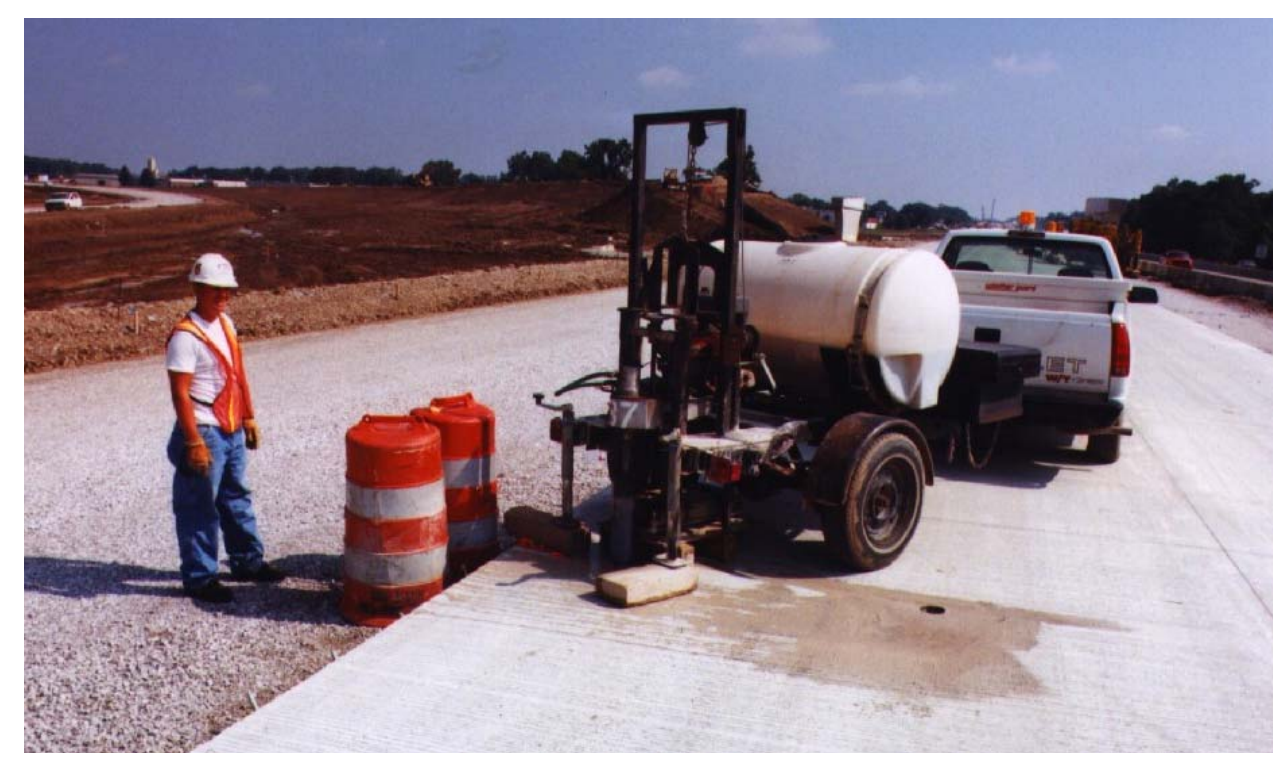

Figure 10-30 Obtaining Pavement Cores

\subsection{Post Construction Test Program}

The post-construction test program was conducted after the field test program. This test program included testing to determine the datum temperature and activation energy for use in the maturity test method, and testing to assess the effects of small variations in the mixture design on the strength-maturity and strength-P-wave velocity relationships.

\subsubsection{Test Specimens}

The datum temperature and activation energy were determined in accordance with the test method outlined in the Annex to ASTM C 1074. The test specimens included three sets of 2 inch $(50 \mathrm{~mm})$ mortar cube specimens, with 18 cubes per set. Watertight plastic molds that cast three cubes per mold were used. The fine aggregate, cement, water reducer, and air entraining agent used to cast the mortar specimens were the same materials that were used in the pre-construction test program, as shown in Appendix E. The mortar specimens contained a fine aggregate to 
cement ratio (by mass) that was the same as the coarse aggregate to cement ratio of the concrete used in the pre-construction test program. The amounts of admixtures, water, and cement were the same as in the pre-construction mix design.

Testing was also conducted to assess the effects of small variations in the water-to-cement ratio and in the amount of air entraining agent in the mixture on the strength-maturity and strength-P-wave velocity relationships. The beam test specimens, 6 × $6 \times 21$ inches $(152.4 \mathrm{x}$ 152.4 x $533 \mathrm{~mm}$ ), were made with reusable steel molds complying with ASTM C 192, with the exception that the molds were not checked for watertightness. Only minor leakage through the joints was observed during casting. The materials used were the same type and from the same source as the materials used during the construction of the Level 1 PRS pavement without fly ash. Seven different sets of mixture proportions were used as shown in Table 10-7. Mixture C represents the design mixture used by the contractor for the Level 1 PRS pavement without fly ash. The remaining mixtures represent slight changes in either water-to-cement ratio or the amount of air entraining agent.

Table 10-7 Mixture Proportions

\begin{tabular}{|l|c|c|c|c|c|c|c|}
\hline \multirow{2}{*}{$\begin{array}{c}\text { Mixture } \\
\text { Information }\end{array}$} & \multicolumn{7}{|c|}{ Mixture } \\
\cline { 2 - 8 } & A & B & C & D & E & F & G \\
\hline $\begin{array}{l}\text { Water/Cement } \\
\text { Ratio }\end{array}$ & 0.40 & 0.41 & 0.42 & 0.43 & 0.44 & 0.42 & 0.47 \\
\hline $\begin{array}{l}\text { Air Entraining } \\
\text { Agent, } \mathrm{ml} / \mathrm{m}^{3}\end{array}$ & 145 & 145 & 145 & 145 & 145 & 160 & 145 \\
\hline
\end{tabular}

Notes to Table 10-7:

- $\quad$ Cement Content $=540 \mathrm{lb} / \mathrm{yd}^{3}$

- Fine Aggregate/Coarse Aggregate Ratio 0.47

- Water Reducer $=2.44 \mathrm{ml} / \mathrm{kg}$ of cement

- $\quad$ Design Air Content $=6.5 \%$

\subsubsection{Mixing, Casting, and Curing Procedures}

The mortar for the cube specimens was mixed in accordance with ASTM C 305. The specimens were consolidated in two lifts using a vibratory table. The specimens were then leveled flush with the top of the mold and a tight fitting top was placed on the mold. Each set of cube specimens was cured in a water bath at a different temperature in accordance with the 
procedure outlined in ASTM C 1074. The temperature of the water baths, 39, 22.5, and $10{ }^{\circ} \mathrm{C}$ $\left(102,72.5,50^{\circ} \mathrm{F}\right)$, were essentially held constant by being placed in temperature-controlled rooms.

The beam specimens were cast in accordance with ASTM C 192. The concrete was machine mixed. The slump, unit weight, and air content by the pressure method, ASTM C 231, was measured for each batch of concrete. Internal vibration was used to consolidate all of the beams. After finishing, the beams were covered with wet burlap and a layer of plastic. The specimens were removed from the molds approximately 24 hours after casting and placed in a temperature controlled moist curing room.

\subsubsection{Testing Procedure and Equipment}

The mortar cube specimens were tested in accordance with the Annex to ASTM C 1074. For each set of cubes, the compressive strength of three cubes was determined in accordance with ASTM C 109 at the age when the compressive strength was approximately $580 \mathrm{psi}$ (4 MPa). A practice set of cube specimens was used to determine this test age. Subsequent compressive tests on three cubes from each set were performed at ages that were approximately twice the age of the previous tests. The specimens were tested on a SATEC Inc., hydraulically operated, computer controlled universal testing machine with a $100,000 \mathrm{lb}(445 \mathrm{kN})$ capacity.

The testing conducted on the beam specimens included recording the temperature history, measuring the P-wave velocity using a pulse velocity test apparatus in the direct transmission mode, and flexural strength testing. The temperature history of one beam from each batch of concrete was recorded by placing two thermocouples in the beam. The temperature history was recorded using a Campbell Scientific, Inc. CR10X Measurement and Control System. The system was programmed to measure the temperature at each thermocouple every minute and to record the average temperature every 10 minutes. The flexural strength of the beam specimens was determined in general accordance with ASTM C 78. The specimens were tested on a 
SATEC Inc., hydraulically operated, computer controlled universal testing machine with a $60,000 \mathrm{lb}(267 \mathrm{kN})$ capacity.

The flexural strength and P-wave velocity, direct transmission method, for Mixture $\mathrm{C}$ was determined at $1,1.5,3,7,14,28$, and 56 days. The flexural strength of the other mixtures was determined at 7 and 28 days, except for Mixture A which was only determined at 28 days and Mixture $\mathrm{G}$ which was only determined at 7 days. The P-wave velocity of the other mixtures was measured at 3, 7, and 28 days except for Mixture $G$ which was not measured at 28 days. In general, two beams were tested to at each test age. 


\section{CHAPTER 11: PRE-CONSTRUCTION EXPERIMENTAL RESULTS}

\subsection{Introduction}

This chapter presents experimental results from the pre-construction test program. This test program was the first of three phases of the overall test program conducted in conjunction with the implementation of a Level 1 Performance-Related Specification (PRS) on Indiana Department of Transportation (INDOT) Project R-24432. The type and number of test specimens and the mixing, casting, and curing procedures have been previously described in Sections 10.3.1 through 10.3.4. The test procedures and equipment have been previously described in Section 10.3.5 and a complete summary of the testing is contained Table 10-3.

The pre-construction test program was conducted at INDOT Materials and Tests Division. The construction schedule of Project R-24432, described in more detail in Section 10.2, was such that construction of similar pavement, governed by the Quality Control/Quality Assurance (QC/QA) specification, began before construction of the pavement governed by the Level 1 PRS. The test program location and the construction schedule permitted test specimens to be cast using the same batching, mixing, and transportation procedures that would be used in the construction of the Level 1 PRS. The original project schedule also indicated that the materials and mixture proportions would be the same as that used in the construction of the Level 1 PRS. However material and mixture proportion changes did occur. These changes are discussed more in Chapter 12.

The general objective of this test program was to assess the use of the impact-echo, measurement of compression wave (P-wave) velocity, and maturity test methods to determine concrete strength and pavement thickness. Specifically the objectives include: 
- Comparing direct and surface methods of measuring the P-wave velocity.

- Assessing the effects of surface roughness on the measurement of P-wave velocity.

- Assessing the effects of specimen thickness, base course material, and surface roughness on the impact-echo test method.

- Comparing the estimated thickness from the impact-echo test method to the actual thickness from core measurements.

- Comparing the maturity indexes from the Nurse-Saul and Arrhenius equations.

- Developing the strength-maturity and strength-P-wave velocity relationships for the concrete mixture.

- Comparing the estimated slab strengths from the strength-maturity relationship to the measured beam flexural strengths.

- Estimating the slab strengths from the strength-maturity relationships and from the strengthP-wave velocity relationships.

\subsection{Strength Results}

The beam and cylinder test specimens for the pre-construction test program were tested to determine the flexural $\left(\mathrm{f}_{r}^{\prime}\right)$, compressive $\left(\mathrm{f}_{\mathrm{c}} \mathrm{c}\right)$, and split tensile $\left(\mathrm{f}_{\mathrm{sp}}\right)$ strengths, and the modulus of elasticity (E) and Poisson's ratio $(\mu)$ at ages of $1,4,7,14,28$, and 103 days. Three beams were tested in third-point loading to determine the flexural strength, two cylinders were tested to determine the compressive strength, and two cylinders were tested to determine the split tensile strength at each age. Appendix L contains a complete list of the individual strength results determined in accordance with ASTM C 78 ( $\left.\mathrm{f}_{r}^{\prime}\right)$, C $39\left(\mathrm{f}_{\mathrm{c}} \mathrm{c}\right)$, and C $496\left(\mathrm{f}^{\prime}{ }_{\mathrm{sp}}\right)$. The average strength results and standard deviations for each age are presented in Table 11-1. The chord modulus of elasticity and Poisson's ratio results, determined in accordance with ASTM C 469, are presented in Table 11-2. 
Table 11-1 Pre-Construction Average Strength

\begin{tabular}{|c|c|c|c|c|c|c|c|c|}
\hline \multirow{2}{*}{$\begin{array}{c}\text { Strength } \\
\text { Type }\end{array}$} & & \multirow{2}{*}{ Units } & \multicolumn{6}{|c|}{ Age, Days } \\
\hline & & & 1 & 4 & 7 & 14 & 28 & 103 \\
\hline \multirow{4}{*}{ Flexural } & \multirow{2}{*}{ Strength } & psi & 520 & 747 & 788 & 860 & 879 & 900 \\
\hline & & $\mathrm{MPa}$ & 3.59 & 5.15 & 5.43 & 5.93 & 6.06 & 6.21 \\
\hline & \multirow{2}{*}{$\begin{array}{l}\text { Standard } \\
\text { Deviation }\end{array}$} & psi & 32.7 & 14.4 & 38.1 & 35.4 & 49.4 & 38.2 \\
\hline & & $\mathrm{MPa}$ & 0.226 & 0.099 & 0.263 & 0.244 & 0.341 & 0.263 \\
\hline \multirow{4}{*}{ Compressive } & \multirow{2}{*}{ Strength } & psi & 2978 & 4565 & 5720 & 6500 & 6848 & 8379 \\
\hline & & $\mathrm{MPa}$ & 20.53 & 31.47 & 39.44 & 44.82 & 47.22 & 57.77 \\
\hline & \multirow{2}{*}{$\begin{array}{c}\text { Standard } \\
\text { Deviation }\end{array}$} & psi & 60.8 & 457 & 4.24 & 81.3 & 51.6 & 197 \\
\hline & & $\mathrm{MPa}$ & 0.419 & 3.149 & 0.029 & 0.561 & 0.356 & 1.355 \\
\hline \multirow{4}{*}{ Split Tensile } & \multirow{2}{*}{ Strength } & psi & 273 & 387 & 508 & 501 & 458 & 526 \\
\hline & & $\mathrm{MPa}$ & 1.88 & 2.67 & 3.51 & 3.46 & 3.16 & 3.63 \\
\hline & \multirow{2}{*}{$\begin{array}{c}\text { Standard } \\
\text { Deviation }\end{array}$} & psi & 26.2 & 29.7 & 60.1 & 78.5 & 19.1 & 94.8 \\
\hline & & $\mathrm{MPa}$ & 0.180 & 0.205 & 0.414 & 0.541 & 0.132 & 0.653 \\
\hline
\end{tabular}

Table 11-2 Pre-Construction Modulus of Elasticity \& Poisson’s Ratio

\begin{tabular}{|c|c|c|c|c|c|c|}
\hline \multirow{2}{*}{ Property } & \multirow{2}{*}{ Units } & \multicolumn{5}{|c|}{ Age, Days } \\
\cline { 3 - 7 } & & $\mathbf{4}$ & $\mathbf{7}$ & $\mathbf{1 4}$ & $\mathbf{2 8}$ & $\mathbf{1 0 3}$ \\
\hline \multirow{2}{*}{ Elastic Modulus } & $\mathrm{psi}$ & $2.13 \times 10^{6}$ & $2.15 \times 10^{6}$ & $2.45 \times 10^{6}$ & $2.52 \times 10^{6}$ & $2.72 \times 10^{6}$ \\
\cline { 2 - 7 } & $\mathrm{GPa}$ & 14.66 & 14.88 & 16.91 & 17.38 & 18.78 \\
\hline Poisson's Ratio & None & 0.18 & 0.19 & 0.20 & 0.18 & 0.20 \\
\hline
\end{tabular}

The average strength is presented as ratio of the 7-day average strength in Table 11-3 to illustrate the relative strength gain over time. The relative strength gain is also shown in Figure 11-1, Figure 11-2, and Figure 11-3. The 28-day flexural strength is $112 \%$ of the 7 -day flexural strength. This development is noteworthy because in the development of the Level 1 PRS it was assumed that the flexural strength increased 5\% from 7 to 28 days. The difference between the actual increase and the assumed increase in strength indicates the need in future PRS to determine the typical strength gain of the proposed concrete mixture before construction occurs. Alternatively, the PRS software allows maturity functions to be used to predict the 28 day strength from the 7 day strength (Hoerner 1999).

In addition to showing the relative strength gain, Figure 11-1, Figure 11-2, and Figure 11-3 depict the variation in strength associated with each of the test methods. Each figure shows the individual strength results in addition to the average strength (represented by the solid line). The split tensile strength in general showed the most variation between specimens at each age. The variation is discussed more in the following paragraphs of this section. 
Table 11-3 Average Strength/7-Day Strength

\begin{tabular}{|l|c|c|c|c|c|c|}
\hline \multirow{2}{*}{$\begin{array}{c}\text { Strength } \\
\text { Type }\end{array}$} & \multicolumn{7}{|c|}{ Age, Days } \\
\cline { 2 - 7 } & $\mathbf{1}$ & $\mathbf{4}$ & $\mathbf{7}$ & $\mathbf{1 4}$ & $\mathbf{2 8}$ & $\mathbf{1 0 3}$ \\
\hline Flexural & 0.660 & 0.947 & 1.000 & 1.092 & 1.115 & 1.142 \\
\hline Compressive & 0.521 & 0.798 & 1.000 & 1.136 & 1.197 & 1.465 \\
\hline Split Tensile & 0.537 & 0.760 & 1.000 & 0.986 & 0.902 & 1.035 \\
\hline
\end{tabular}

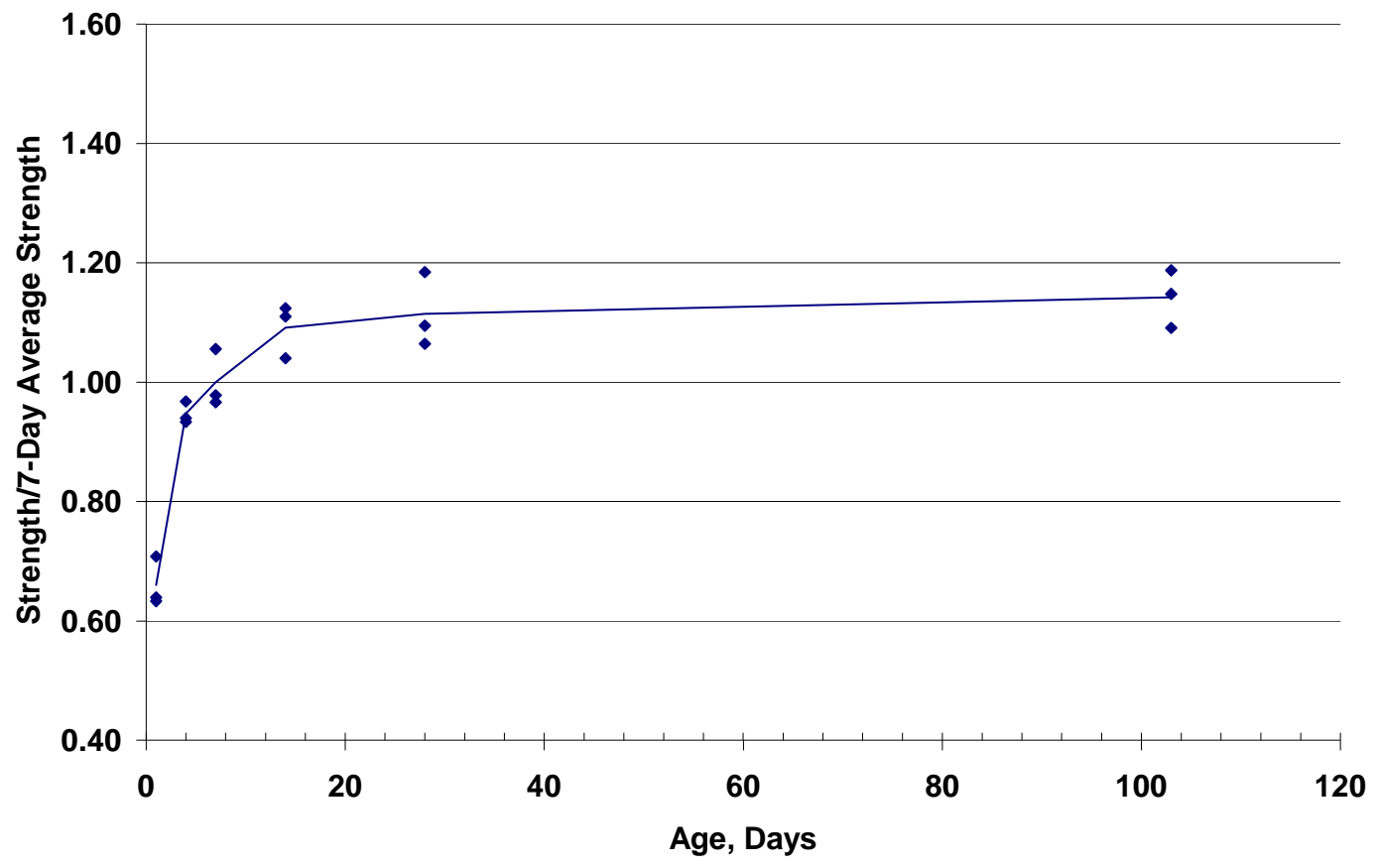

Figure 11-1 Modulus of Rupture Development 


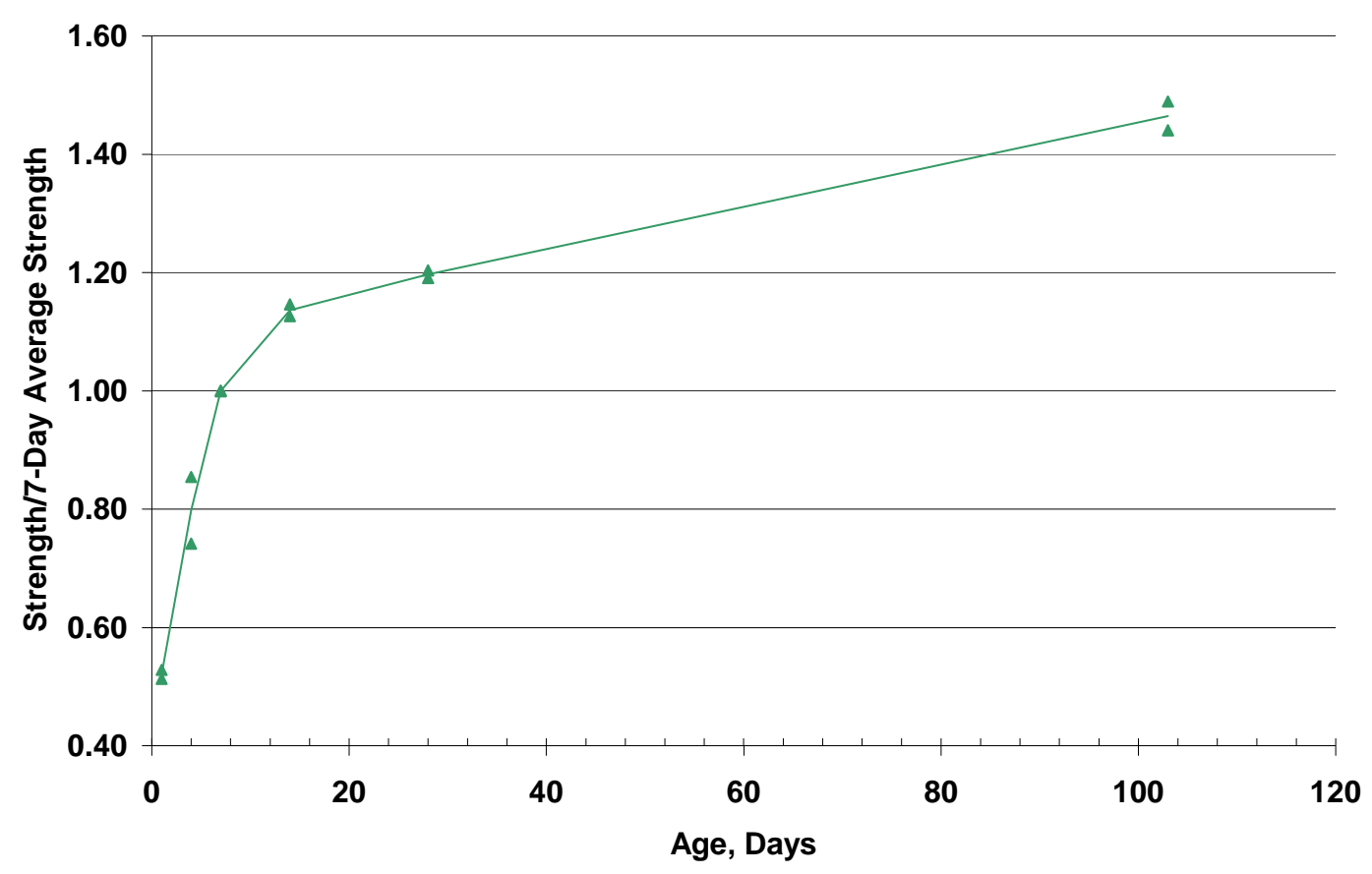

Figure 11-2 Compressive Strength Development

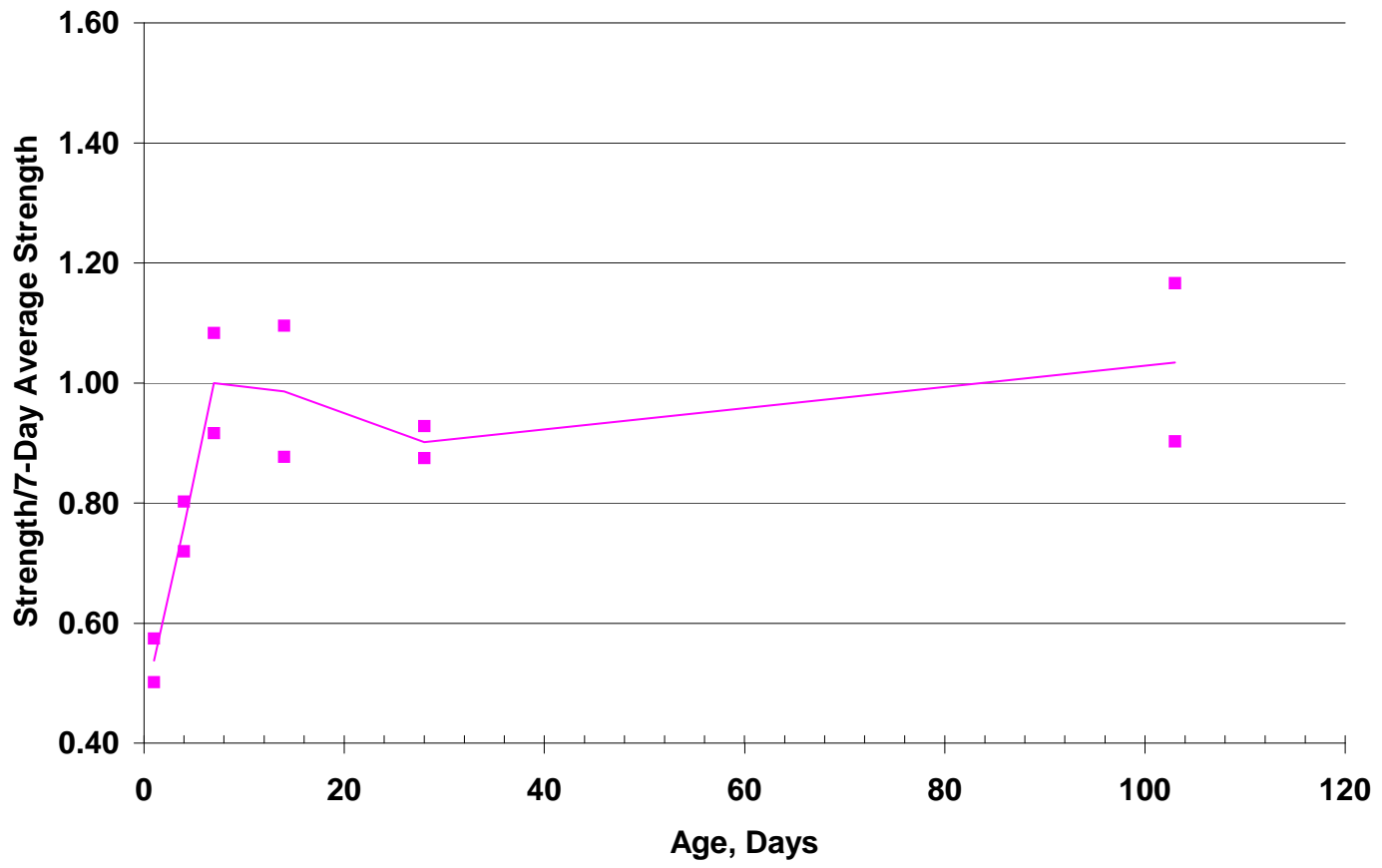

Figure 11-3 Split Tensile Strength Development 
The INDOT has expressed in interest in the use of the split tensile strength test method for acceptance quality characteristic (AQC) or QC/QA sampling and testing. The strength results indicate that the split tensile strength test method is not well suited for this purpose. The average strength results indicate that the split tensile strength did not increase with age as expected. The split tensile strength was virtually the same at 7 and 14-days, and decreased at 28-days. The strength then increased to greater than the 7-day strength at the age of 103-days. In addition, the strength results show that the split tensile strength test method had the highest variability of the three test methods. Table 11-4 shows the standard deviation in proportion to the average strength. The split tensile strength has the highest standard deviation in proportion to the average strength. Therefore sampling and testing a relatively larger number of test specimens at each age for this test method would be recommended.

Table 11-4 Standard Deviation/Average Strength

\begin{tabular}{|c|c|c|c|c|c|c|c|}
\hline \multirow{2}{*}{ Strength Type } & \multicolumn{6}{|c|}{ Age, Days } & \multirow{2}{*}{ Average } \\
\cline { 2 - 7 } & $\mathbf{1}$ & $\mathbf{4}$ & $\mathbf{7}$ & $\mathbf{1 4}$ & $\mathbf{2 8}$ & $\mathbf{1 0 3}$ & \\
\hline Flexural & 0.06 & 0.02 & 0.05 & 0.04 & 0.06 & 0.04 & 0.05 \\
\hline Compressive & 0.02 & 0.10 & 0.001 & 0.01 & 0.01 & 0.02 & 0.03 \\
\hline Split Tensile & 0.10 & 0.08 & 0.12 & 0.16 & 0.04 & 0.18 & 0.11 \\
\hline
\end{tabular}

Version 2.5 of the PRS software (PaveSpec) permits either the flexural or the compressive concrete strength to be sampled and tested. However the distress indicator models contained in the PRS software are based on the flexural strength. Therefore, if the compressive strength is measured, the relationship between the compressive and the flexural strength must be known and entered into the software.

The compressive and split tensile strengths were plotted against the flexural strengths to determine the relationship between the strengths (even though version 2.5 of PaveSpec does include the option of using the split tensile strength, the relationship between the split tensile and flexural strength is shown because of the interest expressed in the split tensile strength by the INDOT). The relationships between the compressive and the flexural strength, and between the split tensile and flexural strength are shown in Figure 11-4 and Figure 11-5 respectively. A 
second order polynomial was found to represent the flexural to compressive strength relationship well. The unexpected behavior of the split tensile strength at 14 and 28 days made it difficult to find an expression that represented the flexural to split tensile strength relationship well. A second order polynomial was fit to the data, however as evidenced by Figure 11-5, the polynomial does not fit the data as well as for the flexural to compressive strength data.

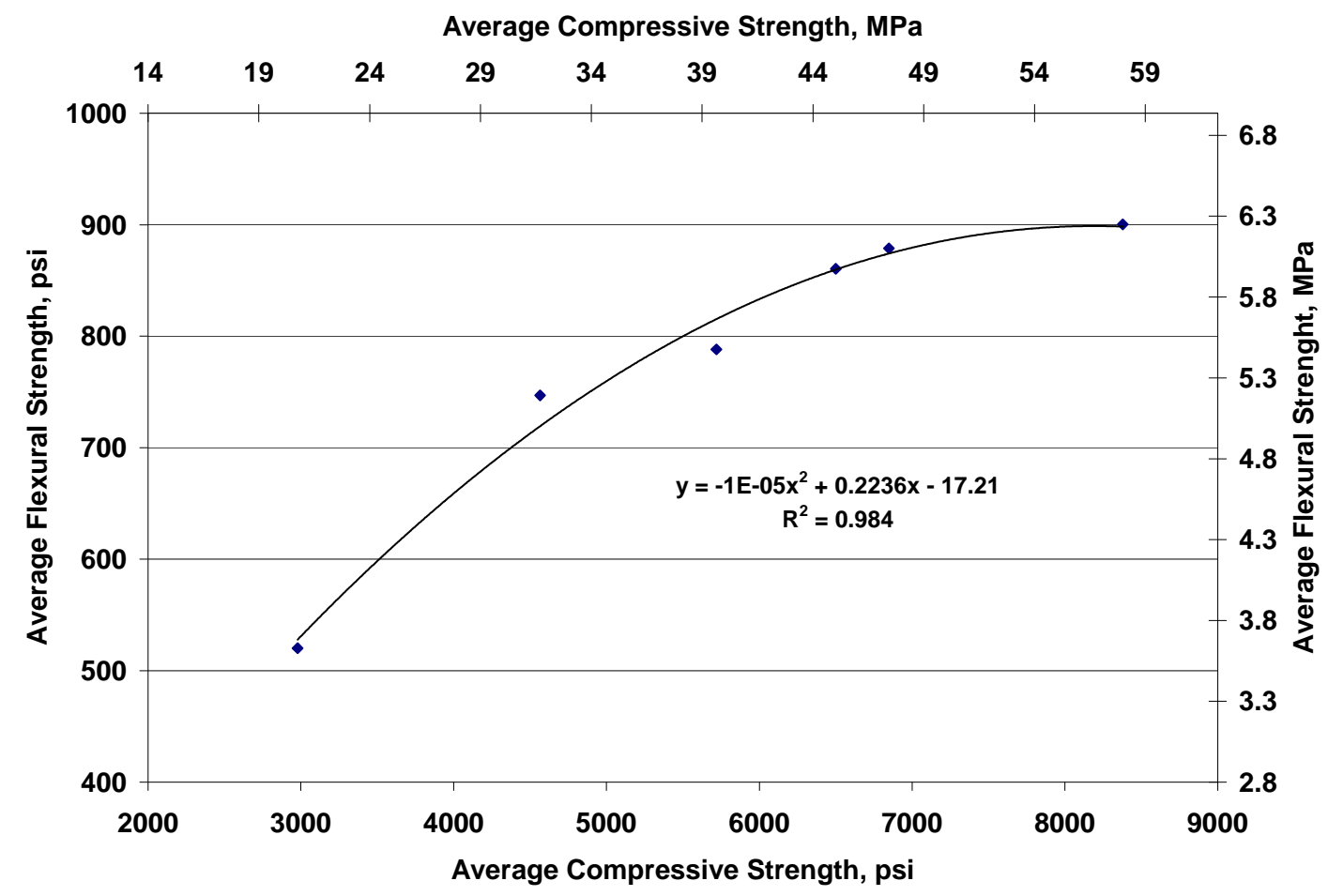

Figure 11-4 Flexural to Compressive Strength Relationship 


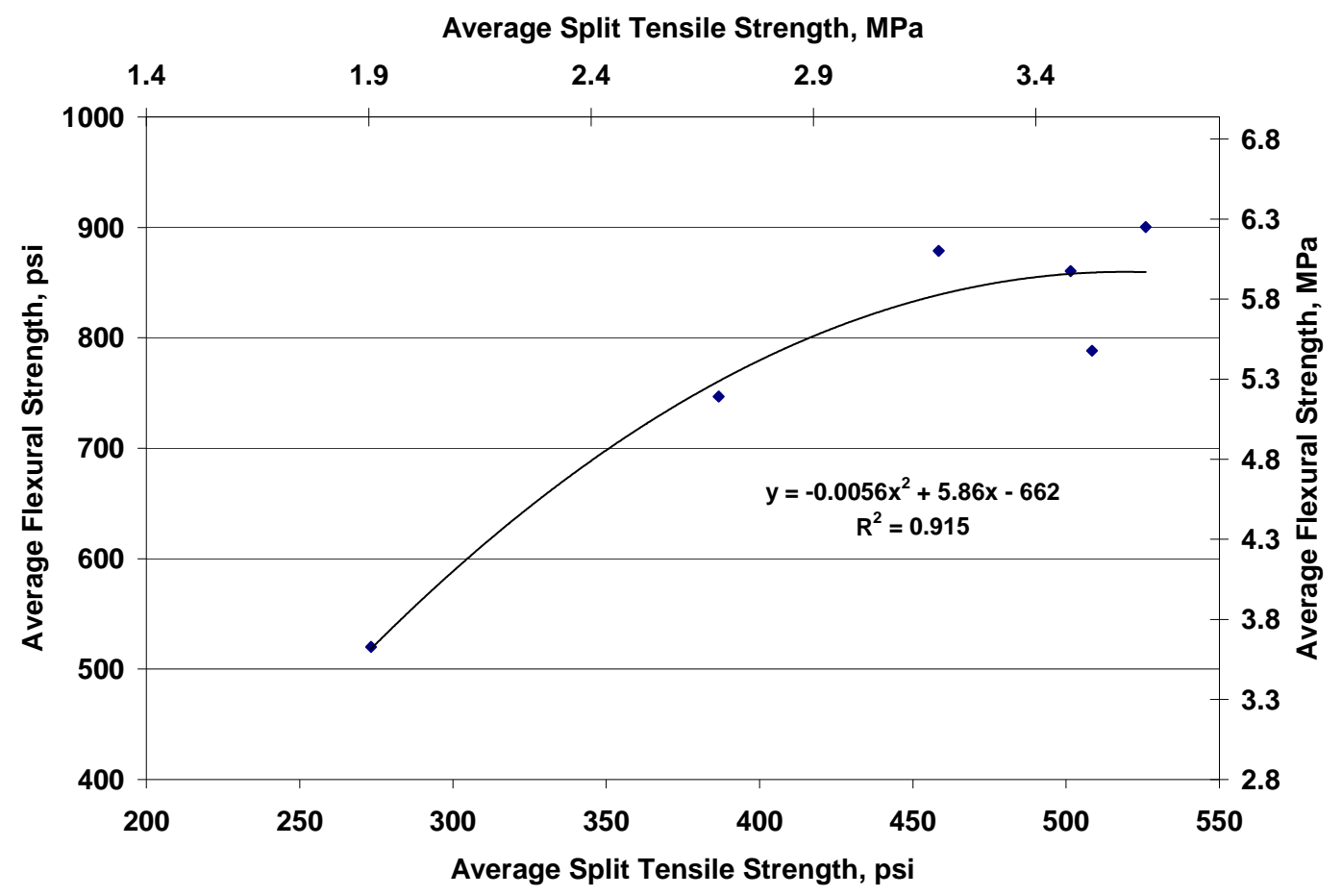

Figure 11-5 Flexural to Split Tensile Strength Relationship

The relationship of the compressive and split tensile strength to the flexural strength is also shown in Table 11-5. Table 11-5 presents the average compressive and split tensile strengths as a ratio of the average flexural strength. The data in Table 11-5 demonstrates that the relationship between the compressive strength and the flexural strength increases with age and the relationship between the split tensile strength and the flexural strength varies with no apparent trend with respect to age (varies from 0.518 to 0.645 ).

Table 11-5 Average Strength/Flexural Strength

\begin{tabular}{|l|c|c|c|c|c|c|}
\hline \multirow{2}{*}{\multicolumn{1}{|c|}{ Strength Type }} & \multicolumn{6}{c|}{ Age, Days } \\
\cline { 2 - 7 } & $\mathbf{1}$ & $\mathbf{4}$ & $\mathbf{7}$ & $\mathbf{1 4}$ & $\mathbf{2 8}$ & $\mathbf{1 0 3}$ \\
\hline Flexural & 1.0 & 1.0 & 1.0 & 1.0 & 1.0 & 1.0 \\
\hline Compressive & 5.73 & 6.11 & 7.26 & 7.56 & 7.79 & 9.31 \\
\hline Split Tensile & 0.525 & 0.518 & 0.645 & 0.583 & 0.522 & 0.584 \\
\hline
\end{tabular}




\section{$11.3 \quad$ Temperature Measurement Results}

The temperature history of the test specimens was recorded for use in the maturity test method. Two thermocouples were placed in two cylinders (one thermocouple in each cylinder), two thermocouples were placed one beam, and two thermocouples were placed in each slab specimen. The temperature at each thermocouple was measured every minute and every ten minutes the average temperature was recorded. The recorded temperatures from the two thermocouples for each specimen were averaged to get the temperature history of each specimen. The temperature history of three of the slab specimens and the beam and cylinder specimens for the first 14 days is shown in Figure 11-6.

Figure 11-6 shows that the temperature of the beam and cylinder specimens, which were cured in the temperature controlled moist curing room, changes very little after the early heat evolution due to cement hydration. Therefore the action of discontinuing the temperature measurements of the specimens cured in the temperature controlled moist curing room after 7 days was reasonable. Figure 11-6 also shows that the temperature of the slab specimens, which were cured outside, changes in response to the outdoor temperature after the early heat evolution due to cement hydration. The temperature of each slab specimen was measured until the age of 28 days. 


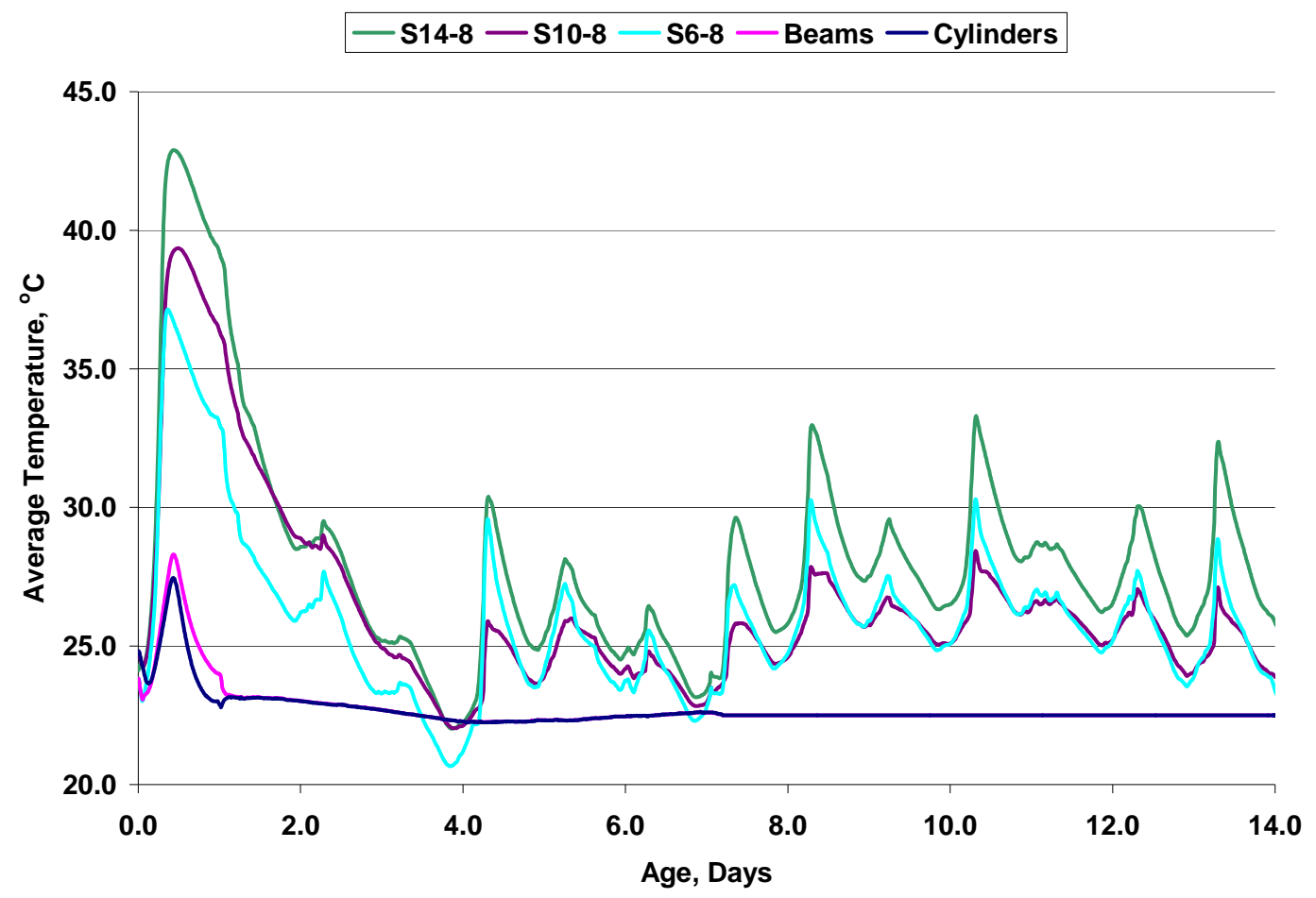

Figure 11-6 Temperature History

The change in temperature with time, due to both the early heat of hydration and in response to the outdoor temperature, demonstrates the need to measure the concrete temperature at regular, closely spaced, intervals. As the time in-between temperature measurements increases, so will the error in the estimate of temperature increase. Therefore test methods that use maturity concepts should required temperature measurements at regular, closely spaced, intervals. ASTM C 1074, Standard Practice for Estimating Concrete Strength by the Maturity Method, requires the concrete temperature to be measured every $1 / 2$ hour for the first 48 hours and every hour after that. However, Indiana Test Method (ITM) 402, Strength of Portland Cement Concrete Pavement (PCCP) Using The Maturity Method, does not specify the maximum length of time inbetween temperature measurements, except to require temperature measurements at the time of casting and when the concrete strength is measured or to be estimated. 


\subsection{Strength to Maturity Relationship}

\subsubsection{Determining the Strength to Maturity Relationship}

The temperature history of the specimens was used to calculate two different maturity indexes for each specimen. The Nurse-Saul function was used to determine the temperature-time factor, and the Arrhenius equation was used to determine the equivalent age at $23{ }^{\circ} \mathrm{C}$. The NurseSaul function was used to calculate a maturity index because this function is currently used by the INDOT in ITM 402-99T. The Arrhenius equation was also used to calculate a maturity index because it, unlike the Nurse-Saul function, has been demonstrated to be able to account for the affects of temperature on strength gain over a wide range of temperatures, see Section 9.3.4.

The datum temperature for the Nurse-Saul function was taken as the traditional value of -10 ${ }^{\circ} \mathrm{C}$. This value was used because it is the value currently used by the INDOT in ITM 402 . The value of the activation energy divided by the gas constant (Q) for the Arrhenius function was taken as $5000^{\circ} \mathrm{K}$. This value was used because it is the value recommended by ASTM C 1074. Additional discussion of the datum temperature and the $\mathrm{Q}$ value is contained in Chapter 13.

Table 11-6 contains both maturity indexes for three of the slab specimens and the beam and cylinder specimens. At each age, the highest maturity index corresponds to the largest specimen by volume (S14-8), with the index decreasing with decreasing specimen size. This trend was expected because a larger amount of heat is generated in the larger specimens, as shown in Figure 11-6. The corresponding higher temperatures result in a larger maturity index for bigger specimens at equal ages. 
Table 11-6 Maturity Indexes

\begin{tabular}{|l|c|c|c|c|c|c|}
\hline \multirow{3}{*}{ Specimen } & \multicolumn{3}{|c|}{$\begin{array}{c}\text { Average Temperature-Time Factor, } \\
{ }^{\circ} \text { C-hr, at: }\end{array}$} & \multicolumn{3}{c|}{$\begin{array}{c}\left.\text { Average Equivalent Age (at 23 }{ }^{\circ} \mathbf{C}\right) \text {, } \\
\text { hours, at: }\end{array}$} \\
\cline { 2 - 7 } & 3 Days & 7 Days & 28 Days & 3 Days & 7 Days & 28 Days \\
\hline S14-8 & 3093 & 6469 & 26946 & 128.1 & 237.2 & 1020 \\
\hline S10-8 & 3006 & 6278 & 26348 & 118.2 & 220.4 & 973.1 \\
\hline S6-8 & 2816 & 6073 & 26134 & 102.1 & 203.7 & 959.0 \\
\hline Beams & 2471 & 5583 & 21963 & 76.7 & 169.5 & 659.4 \\
\hline Cylinders & 2453 & 5564 & 21944 & 75.5 & 168.3 & 658.2 \\
\hline
\end{tabular}

The strength-maturity relationships were determined from the maturity indexes and the average strength results. The offset hyperbolic strength-maturity relationship has been found to accurately represent the strength gain (Carino 1991b). This function, shown in Equation 5-1, was found to fit the strength-maturity data very well. It should be noted that this function is not one of the forms of the strength-maturity relationship contained in the PRS software (Version 2.5) for when strength testing is performed before 28 days.

$$
S=S_{\infty} \frac{k_{T}\left(M-M_{o}\right)}{1+k_{T}\left(M-M_{o}\right)}
$$

where:

$\mathrm{S}_{\infty}=$ limiting strength

$\mathrm{k}_{\mathrm{T}}=$ rate constant

$\mathrm{M}=$ maturity

$\mathrm{M}_{\mathrm{o}}=$ offset maturity

The three parameters $\left(\mathrm{S}_{\infty}, \mathrm{k}_{\mathrm{T}}\right.$, and $\left.\mathrm{M}_{\mathrm{o}}\right)$ were determined for each strength-maturity relationship by the procedure suggested by Knudsen (1984) and presented in Carino 1991b. The parameters and the corresponding coefficient of determination $\left(\mathrm{R}^{2}\right)$ value for each relationship are presented in Table 11-7 and Table 11-8. The negative values of $\mathrm{M}_{\mathrm{o}}$ for the compressive and split tensile strength-maturity relationships were not expected. The value of $\mathrm{M}_{\mathrm{o}}$ represents the maturity at which strength development is assumed to begin. Since strength development begins after the constituents of the mixture have been combined, $\mathrm{M}_{\mathrm{o}}$ value less than zero does not physically make sense. However, since adjusting $\mathrm{M}_{\mathrm{o}}$ to be greater than or equal to zero would reduce the $R^{2}$ value for the relationship, the value of $M_{0}$ was not adjusted. 
The value of $\mathrm{M}_{\mathrm{o}}$ was obtained using the average strength and maturity values at the two earliest ages, 1 and 4 days, in accordance with the procedure suggested by Knudsen (1984). The value of $S /\left(S-S_{\infty}\right)$ was plotted against the value of maturity $(\mathrm{M})$ for these two ages. The linear regression line through these two points was then determined. The value of $\mathrm{M}_{\mathrm{o}}$ is equal to negative one times the $y$-intercept divided by the slope. A better estimate of $\mathrm{M}_{\mathrm{o}}$ would most likely be obtained from strength data taken at earlier ages. Carino indicates that the best estimate of $\mathrm{M}_{\mathrm{o}}$ is obtained from strength data at very early ages (1984b). An example of an estimate of $\mathrm{M}_{\mathrm{o}}$ using data at earlier ages is contained in Section 12.5.2.

Table 11-7 Strength-Temperature-Time Factor Relationship

\begin{tabular}{|c|c|c|c|c|}
\hline \multirow{2}{*}{ Strength Type } & \multicolumn{4}{|c|}{ Maturity Function Using the Nurse-Saul Equation } \\
\cline { 2 - 5 } & $\mathbf{S}_{\infty}, \mathbf{p s i}(\mathbf{M P a})$ & $\left.\mathbf{K}_{\mathbf{T}}, \mathbf{1} /{ }^{\mathbf{0}} \mathbf{C}-\mathbf{h r}\right)$ & $\mathbf{M}_{\mathbf{o}}{ }^{\mathbf{0}} \mathbf{C}-\mathbf{h r}$ & $\mathbf{R}^{\mathbf{2}}$ \\
\hline $\begin{array}{c}\text { Modulus of } \\
\text { Rupture }\end{array}$ & $915.7(6.314)$ & 0.00138 & 53.8 & 0.998 \\
\hline Compression & $8078(55.70)$ & 0.000316 & -911 & 0.993 \\
\hline Split Tensile & $521.2(3.594)$ & 0.000766 & -485 & 0.954 \\
\hline
\end{tabular}

Table 11-8 Strength-Equivalent Age (at $23^{\circ} \mathrm{C}$ ) Relationship

\begin{tabular}{|c|c|c|c|c|}
\hline \multirow{2}{*}{ Strength Type } & \multicolumn{4}{|c|}{ Maturity Function Using the Arrhenius Equation } \\
\cline { 2 - 5 } & $\mathbf{S}_{\infty}, \mathbf{p s i}(\mathbf{M P a})$ & $\mathbf{K}_{\mathrm{T}}, \mathbf{1} /$ (Hours) & $\mathbf{M}_{\mathbf{0}}$, Hours & $\mathbf{R}^{\mathbf{2}}$ \\
\hline $\begin{array}{c}\text { Modulus of } \\
\text { Rupture }\end{array}$ & $915.8(6.314)$ & 0.04591 & 3.64 & 0.998 \\
\hline Compression & $8084(55.74)$ & 0.01049 & -26.0 & 0.993 \\
\hline Split Tensile & $521.4(3.595)$ & 0.02543 & -13.2 & 0.953 \\
\hline
\end{tabular}

The strength-maturity relationships using the Nurse-Saul equation are graphically shown in Figure 11-7, Figure 11-8, and Figure 11-9. The plots show that the offset hyperbolic relationship fits the experimental data very well for the flexural and compressive strength-maturity results. Despite the high $\mathrm{R}^{2}$ value, Figure 11-9 indicates that the offset hyperbolic relationship does not fit the split tensile strength-maturity results very well. As indicated in Section 11.2, the split tensile test method does not appear to be well suited for AQC or QC/QA testing sampling and testing. 


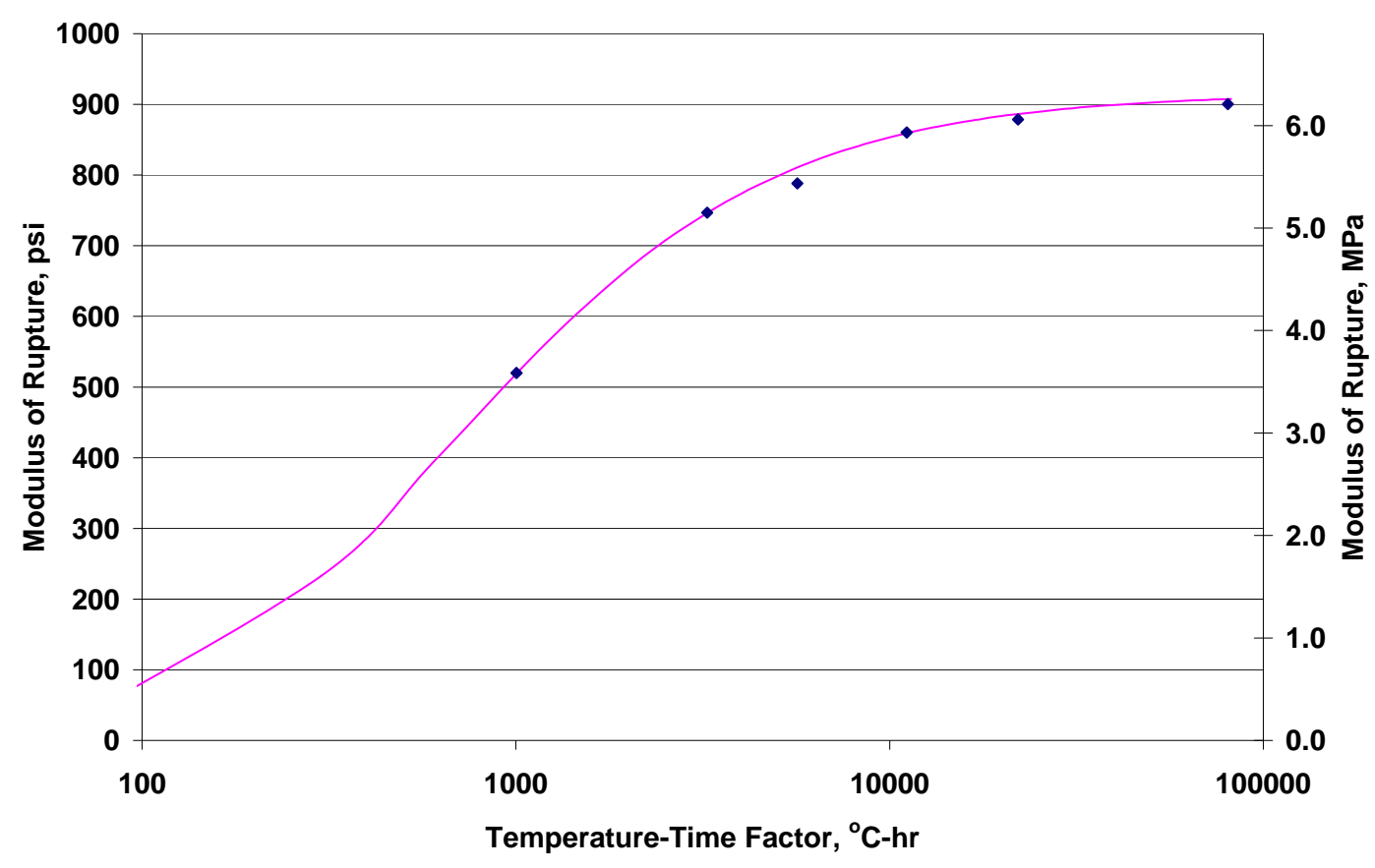

Figure 11-7 Modulus of Rupture Versus Temperature-Time Factor

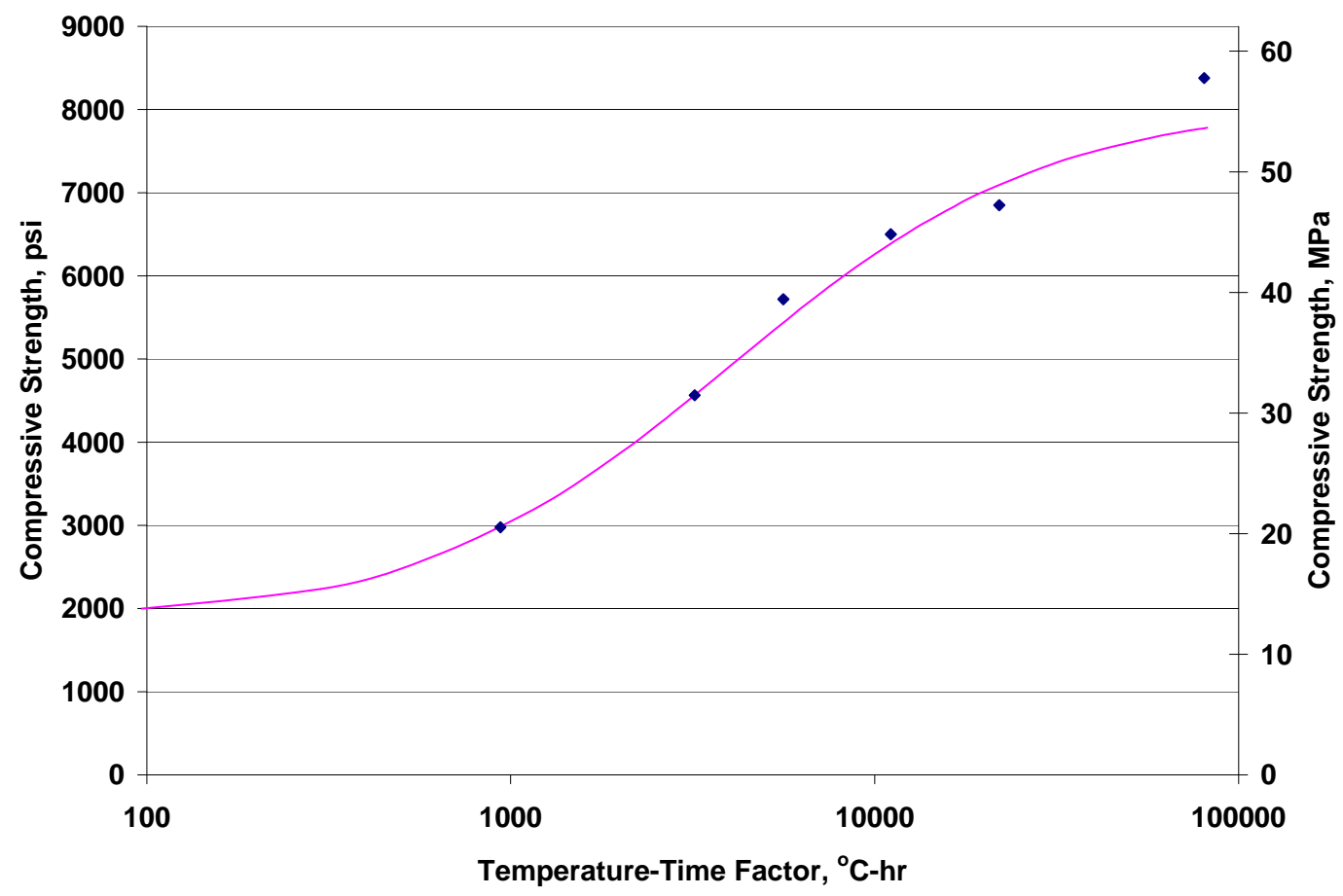

Figure 11-8 Compressive Strength Versus Temperature-Time Factor 


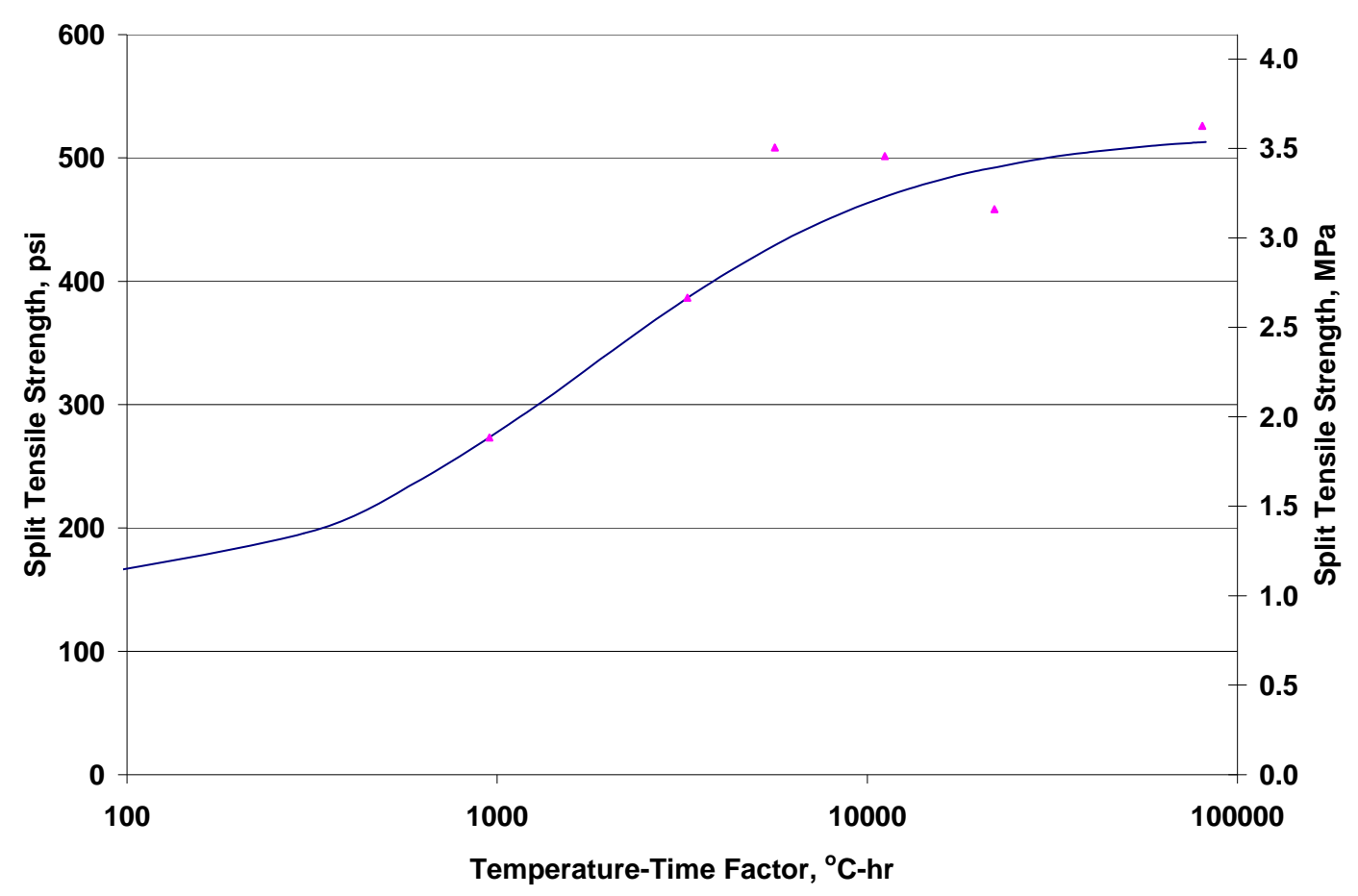

Figure 11-9 Split Tensile Strength Versus Temperature-Time Factor

\subsubsection{Predicted Slab Strength Using the Strength to Maturity Relationship}

The flexural strength-maturity relationships were used to predict the flexural strength of the slabs. The measured time-temperature history was used to calculate the value of the maturity indexes and subsequently to predict the strength at $1,4,7,14$, and 28 days. The predicted flexural strengths of the slab specimens are contained in Table 11-9 and Table 11-10. The predicted flexural strength of the slabs was then compared to the average flexural strength of the beam specimens at each test age. The percent increase of the predicted strength from the actual beam strength for each age is indicated in Table 11-11 and Table 11-12. The predicted strength of the slabs was greater than the average strength of the beams at each age. This is a result of the higher temperatures in the slab specimens that consequently produced maturity indexes that were greater at each age for the slab specimens. In general the percent increase of the predicted strength from the actual beam strength decreases with age. The slight increases from 4 to 7 days, 
and from 14 to 28 days that appear in Table 11-11 and Table 11-12 are due to the variation of the 7 and 28 day actual beam strengths from the created flexural strength-maturity relationships, as can be seen in Figure 11-7.

Table 11-9 Predicted Flexural Strength From Temperature-Time Factor

\begin{tabular}{|c|c|c|c|c|c|}
\hline \multirow{2}{*}{ Slab Specimen } & \multicolumn{5}{|c|}{ Predicted Modulus of Rupture, psi at: } \\
\cline { 2 - 6 } & 1 Day & 4 Days & 7 Days & 14 Days & 28 Days \\
\hline S14-8 & 558 & 771 & 823 & 867 & 892 \\
\hline S6-8 & 532 & 760 & 817 & 864 & 891 \\
\hline S10-8 & 545 & 768 & 820 & 864 & 891 \\
\hline S10-53D & 545 & 768 & 820 & 864 & 891 \\
\hline S10-53 & 543 & 767 & 819 & 864 & 891 \\
\hline S10-CTB & 541 & 769 & 820 & 864 & 891 \\
\hline
\end{tabular}

Table 11-10 Predicted Flexural Strength From Equivalent Age (at $23{ }^{\circ} \mathrm{C}$ )

\begin{tabular}{|c|c|c|c|c|c|}
\hline \multirow{2}{*}{ Slab Specimen } & \multicolumn{5}{|c|}{ Predicted Modulus of Rupture, psi at: } \\
\cline { 2 - 6 } & 1 Day & 4 Days & 7 Days & 14 Days & 28 Days \\
\hline S14-8 & 651 & 799 & 838 & 874 & 897 \\
\hline S6-8 & 590 & 777 & 826 & 868 & 895 \\
\hline S10-8 & 620 & 792 & 832 & 870 & 896 \\
\hline S10-53D & 619 & 793 & 832 & 869 & 895 \\
\hline S10-53 & 614 & 791 & 831 & 868 & 895 \\
\hline S10-CTB & 611 & 794 & 832 & 869 & 896 \\
\hline
\end{tabular}

Table 11-11 Predicted Slab Strength to Measured Beam Strength

\begin{tabular}{|c|c|c|c|c|c|}
\hline \multirow{2}{*}{ Slab Specimen } & \multicolumn{5}{|c|}{ Percent Increase in Strength Using Temperature-Time Factor } \\
\cline { 2 - 6 } & 1 Day & 4 Days & 7 Days & 14 Days & 28 Days \\
\hline S14-8 & 7.26 & 3.21 & 4.37 & 0.73 & 1.48 \\
\hline S6-8 & 2.30 & 1.78 & 3.67 & 0.40 & 1.40 \\
\hline S10-8 & 4.80 & 2.80 & 4.04 & 0.48 & 1.42 \\
\hline S10-53D & 4.72 & 2.88 & 4.00 & 0.40 & 1.37 \\
\hline S10-53 & 4.34 & 2.77 & 3.94 & 0.37 & 1.38 \\
\hline S10-CTB & 4.02 & 2.96 & 4.06 & 0.42 & 1.42 \\
\hline
\end{tabular}


Table 11-12 Predicted Slab Strength to Measured Beam Strength

\begin{tabular}{|c|c|c|c|c|c|}
\hline \multirow{2}{*}{ Slab Specimen } & \multicolumn{5}{|c|}{ Percent Increase in Strength Using Equivalent Age (at 23 $\left.{ }^{\circ} \mathbf{C}\right)$} \\
\cline { 2 - 6 } & 1 Day & 4 Days & 7 Days & 14 Days & 28 Days \\
\hline S14-8 & 25.1 & 7.06 & 6.26 & 1.60 & 2.04 \\
\hline S6-8 & 13.3 & 4.00 & 4.76 & 0.94 & 1.90 \\
\hline S10-8 & 19.2 & 6.05 & 5.56 & 1.12 & 1.94 \\
\hline S10-53D & 18.9 & 6.23 & 5.52 & 0.98 & 1.85 \\
\hline S10-53 & 18.0 & 5.98 & 5.39 & 0.93 & 1.86 \\
\hline S10-CTB & 17.3 & 6.30 & 5.60 & 1.00 & 1.94 \\
\hline
\end{tabular}

The strength-maturity relationship using the equivalent age maturity index predicted a greater rate of strength gain than the strength-maturity relationship using the temperature-time maturity index. The difference was the largest at the age of 1-day and decreased with age to a difference of about 5 psi at 28 days. The rate of strength gain predicted from the temperature-time maturity index was lower because the Nurse-Saul maturity function does not increase the rate constant of cement hydration as much as the Arrhenius function at curing temperatures above the reference temperature. The Nurse-Saul function assumes that the rate constant increases linearly with temperature while the Arrhenius function assumes that the rate constant increases nonlinearly (and more rapidly than the Nurse-Saul function) with temperature, as indicated in Section 9.3.4. Therefore because the curing temperatures of the slabs were higher than the curing temperature at which the strength-maturity relationship was established, the Arrhenius function produced relatively higher maturity indexes and strength estimates. The rate of strength gain predicted by the Arrhenius function is considered to be more accurate because it has been demonstrated to be able to account for the affects of temperature on strength gain over a wide range of temperatures as indicated in Section 9.3.4

\subsection{Compression Wave (P-wave) Velocity Results}

11.5.1 Measurement of Beam and Cylinder Specimens

\subsubsection{1 $\underline{\text { Results }}$}

The P-wave velocity in the beam and cylinder test specimens for the pre-construction test program was measured at ages of 1, 4, 7, 14, 28, and 103 days. Four test methods were used as 
discussed in Section 10.3.5.2 and outlined in Table 10-3. At each testing age, two beam specimens and two cylinder specimens, referred to as control specimens, were tested. In addition the P-wave velocity of the specimens that were destructively tested to determine the flexural and compressive strength was measured. Appendix L contains a complete list of the individual Pwave velocity results from each specimen. The P-wave velocity measured using the pulse velocity test method is required to be reported to the nearest $10 \mathrm{~m} / \mathrm{s}$ by ASTM C 597 Standard Test Method for Pulse Velocity Through Concrete. To maintain consistency, the P-wave velocity measurements for each of the test methods were rounded to the nearest $10 \mathrm{~m} / \mathrm{s}$. The average Pwave velocity and standard deviation measured in the beam and cylinder specimens for each age is presented in Table 11-13. The average P-wave velocity is reported to the nearest $1 \mathrm{~m} / \mathrm{s}$.

Table 11-13 Pre-Construction Average P-Wave Velocity

\begin{tabular}{|c|c|c|c|c|c|c|c|}
\hline \multirow{2}{*}{$\begin{array}{c}\text { Measurement } \\
\text { Technique }\end{array}$} & & \multicolumn{6}{|c|}{ Age, Days } \\
\hline & & 1 & 4 & 7 & 14 & 28 & 103 \\
\hline \multirow{2}{*}{\begin{tabular}{|l|} 
Direct \\
Transmission \\
Pulse Velocity \\
(Beams)
\end{tabular}} & \begin{tabular}{|l} 
P-Wave \\
Velocity, m/s \\
\end{tabular} & 4222 & 4550 & 4686 & 4794 & 4850 & 4930 \\
\hline & \begin{tabular}{|l|} 
Standard \\
Deviation, $\mathrm{m} / \mathrm{s}$
\end{tabular} & 40.2 & 45.8 & 8.9 & 13.4 & 23.5 & 15.8 \\
\hline \multirow{2}{*}{$\begin{array}{l}\text { Direct } \\
\text { Transmission } \\
\text { Pulse Velocity } \\
\text { (Cylinders) }\end{array}$} & $\begin{array}{l}\text { P-Wave } \\
\text { Velocity, m/s }\end{array}$ & 4195 & 4483 & 4625 & 4695 & 4775 & 4960 \\
\hline & \begin{tabular}{|l|} 
Standard \\
Deviation, $\mathrm{m} / \mathrm{s}$
\end{tabular} & 46.5 & 124.5 & 66.6 & 28.9 & 46.5 & 29.4 \\
\hline \multirow{2}{*}{$\begin{array}{l}\text { Surface Method } \\
\text { Using Acoustic } \\
\text { Emission } \\
\text { Equipment } \\
\text { (Beams) }\end{array}$} & $\begin{array}{l}\text { P-Wave } \\
\text { Velocity, m/s }\end{array}$ & 4114 & 4506 & 4560 & 4692 & 4748 & 4850 \\
\hline & \begin{tabular}{|l|} 
Standard \\
Deviation, m/s
\end{tabular} & 144.5 & 101.4 & 103.0 & 39.6 & 52.6 & 89.4 \\
\hline \multirow{2}{*}{$\begin{array}{l}\text { Surface } \\
\text { Transmission } \\
\text { Pulse Velocity } \\
\text { (Beams) }\end{array}$} & \begin{tabular}{|l|} 
P-Wave \\
Velocity, $\mathrm{m} / \mathrm{s}$
\end{tabular} & 3930 & 4280 & 4320 & 4388 & 4566 & 4632 \\
\hline & \begin{tabular}{|l|} 
Standard \\
Deviation, $\mathrm{m} / \mathrm{s}$
\end{tabular} & 80.0 & 68.9 & 46.4 & 27.7 & 40.4 & 87.6 \\
\hline \multirow{2}{*}{$\begin{array}{l}\text { Impact-Echo } \\
\text { (Beams) }\end{array}$} & \begin{tabular}{|l} 
P-Wave \\
Velocity, m/s
\end{tabular} & 3828 & 3820 & 3832 & 3832 & 4382 & $\sim$ \\
\hline & \begin{tabular}{|l|} 
Standard \\
Deviation, $\mathrm{m} / \mathrm{s}$
\end{tabular} & 11.0 & 0.0 & 11.0 & 11.0 & 11.0 & $\sim$ \\
\hline \multirow{2}{*}{$\begin{array}{l}\text { Impact-Echo } \\
\text { (Cylinders) }\end{array}$} & \begin{tabular}{|l|} 
P-Wave \\
Velocity, m/s \\
\end{tabular} & 3568 & 3867 & 4170 & 4010 & 4163 & $\sim$ \\
\hline & \begin{tabular}{|l|} 
Standard \\
Deviation, $\mathrm{m} / \mathrm{s}$
\end{tabular} & 12.6 & 5.8 & $\sim$ & 167.9 & 17.1 & $\sim$ \\
\hline
\end{tabular}

$1 \mathrm{~m} / \mathrm{s}=3.28 \mathrm{ft} / \mathrm{s}$ 
The increase in the P-wave velocity with age, as measured in direct transmission pulse velocity, is shown in Figure 11-10. In the figure, the average and the individual P-wave velocity results from both the beams and cylinders, and the overall average P-wave velocity results are shown. The relationship between P-wave velocity and age shows in increase over time similar to the relationship between strength and age, as shown in Figure 11-1 and Figure 11-2. As with strength, the P-wave velocity increases more rapidly in the first 7 days. This increase tapers off from 7 to 14 days and again from 14 to 28 days. This similarity, as discussed in Section 9.3.3, is one of the reasons why the P-wave velocity can be correlated to concrete strength.

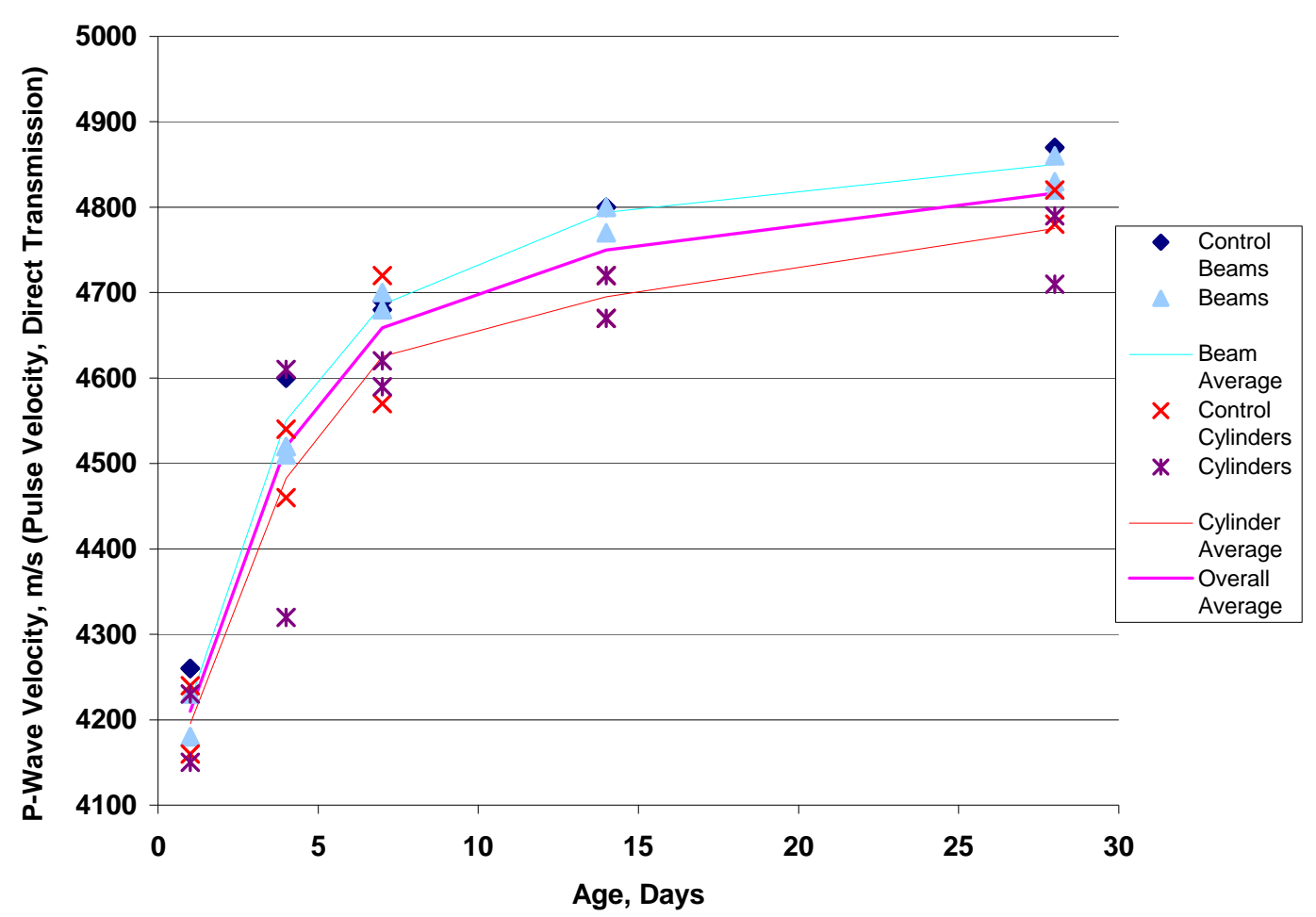

Figure 11-10 P-Wave Velocity vs. Age

Figure 11-10 and Table 11-13 indicate that the average cylinder P-wave velocity is less than the average beam P-wave velocity, as measured by direct transmission pulse velocity test method, at every age except at 103 days. The reason for this difference is not clearly understood. The maturity of the specimens, as shown in Table 11-6, is very similar at each age and visual inspection of the cylinder and beam specimens after strength testing revealed no noticeable 
differences. The larger systematic error in the beam specimens may account for some of the difference, but the magnitude of the systematic error is not large enough to account for the entire difference between the measured P-wave velocities. The greater variability (higher standard deviations) of the measured the cylinder P-wave velocities may also account for the difference.

\subsubsection{Effect of Systematic Error}

The systematic error in P-wave velocity measurements indicates the precision to which the Pwave velocity is determined. Systematic error in P-wave velocity measurements occurs due to the limits of the techniques used to measure the length and transit time, or the length and frequency (when the impact-echo test method is used to measure the P-wave velocity). For example if the total systematic error is $5 \mathrm{~m} / \mathrm{s}$, and the measured P-wave velocity is $4000 \mathrm{~m} / \mathrm{s}$, the reported P-wave velocity should be $4000 \pm 5 \mathrm{~m} / \mathrm{s}$. The confidence in the measured P-wave velocity value is therefore increased as the systematic error in the test method decreases. The systematic error is shown in Table 11-14 and Table 11-15.

The impact-echo test method had the greatest amount of systematic error. This was caused by the frequency resolution (explained in more detail in Section 11.7.2) used during the testing. The value of the frequency resolution was in general too large to detect the increase in P-wave velocity with time. As shown in Table 11-13, the impact-echo tests performed on the beams essentially did not measure an increase in P-wave velocity from Day 1 to Day 14, and the impact-echo tests performed on the cylinders essentially did not measure an increase in P-wave velocity from Day 7 to Day 28. If a smaller frequency resolution had been used, it would have reduced the systematic error and permitted smaller increases in P-wave velocity to be measured.

The high frequency resolution also resulted in the small standard deviations for the impactecho tests. The high frequency resolution caused all of the similar type specimens to have the same peak frequency at any given age (except for the cylinder specimens at 14 days). Therefore the calculated P-wave velocity was practically the same (and the standard deviation was small). 
The P-wave velocity only varied in response to the small differences in specimen length within the same specimen type.

Table 11-14 Systematic Error in Measurement of P-Wave Velocity

\begin{tabular}{|c|c|c|c|c|c|c|c|}
\hline & & Test & Length \\
Test Method & $\begin{array}{c}\text { Increment, } \\
\text { Specimen }\end{array}$ & $\begin{array}{c}\text { Time } \\
\text { increment, } \\
\text { ms }\end{array}$ & $\begin{array}{c}\text { Maximum } \\
\text { Due to } \\
\text { Length, \% }\end{array}$ & $\begin{array}{c}\text { Maximum } \\
\text { Due to } \\
\text { Time, \% }\end{array}$ & Total*, \% & Total+ m/s \\
\hline $\begin{array}{c}\text { Direct } \\
\text { Transmission } \\
\text { Pulse Velocity }\end{array}$ & Beams & 0.125 & $1.0 \mathrm{E}-07$ & 0.28 & 0.07 & 0.29 & 11.8 \\
\cline { 5 - 8 } & Cylinders & 0.01 & $1.0 \mathrm{E}-07$ & 0.08 & 0.13 & 0.16 & 6.23 \\
\hline $\begin{array}{c}\text { Surface } \\
\text { Method Using } \\
\text { Acoustic } \\
\text { Emission } \\
\text { Equipment }\end{array}$ & Beams & 0.04 & $5.0 \mathrm{E}-07$ & 0.45 & 0.90 & 1.00 & 40.0 \\
\hline
\end{tabular}

- Total systematic error, $\%$, is the square root sum of squares of the error due to length and the error due to time.

- Total systematic error, $\mathrm{m} / \mathrm{s}$, is based on a P-wave velocity of $4000 \mathrm{~m} / \mathrm{s}$.

Table 11-15 Systematic Error in Measurement of P-Wave Velocity

\begin{tabular}{|c|c|c|c|c|c|c|c|}
\hline \multirow{2}{*}{ Test Method } & $\begin{array}{c}\text { Test } \\
\text { Specimen }\end{array}$ & $\begin{array}{c}\text { Length } \\
\text { Increment, } \\
\text { in }\end{array}$ & $\begin{array}{c}\text { Frequency } \\
\text { Increment, } \\
\mathbf{k H z}\end{array}$ & $\begin{array}{c}\text { Maximum } \\
\text { Due to } \\
\text { Length, \% }\end{array}$ & $\begin{array}{c}\text { Maximum } \\
\text { Due to } \\
\text { Frequency, } \\
\%\end{array}$ & Total, \% & Total, m/s \\
\hline \multirow{2}{*}{ Impact Echo } & Beams & 0.125 & 0.24 & 0.28 & 7.31 & 7.32 & 293 \\
\cline { 2 - 8 } & Cylinders & 0.01 & 0.24 & 0.08 & 3.86 & 3.86 & 155 \\
\hline
\end{tabular}

- Total systematic error, $\%$, is the square root sum of squares of the error due to length and the error due to time.

- Total systematic error, $\mathrm{m} / \mathrm{s}$, is based on a P-wave velocity of $4000 \mathrm{~m} / \mathrm{s}$.

- Frequency Increment is equal to $1 / 2$ of the frequency resolution $(0.488 \mathrm{kHz}$ for these tests).

\subsubsection{Comparison of Test Methods}

It can be seen from Table 11-13 that the average P-wave velocity measured by each of the three methods that only require one surface of the test specimen to be available is less than the Pwave velocity as measured in direct transmission. This is consistent with finding of literature review contained in Chapter 4. The results from the surface method using the acoustic emission (AE) equipment are the closest to the direct transmission results. The average P-wave velocity from the AE surface method is, on average, 2.01\% lower than the average P-wave velocity from 
the direct transmission method. This difference is very similar to the difference obtained by the surface method used by Popovics et al. (1998). The similarity helps to validate the test procedure, described in Section 10.3.5.2.

The pulse velocity surface method results are the next closest to the direct transmission results. The average P-wave velocity from the pulse velocity surface method is, on average, $6.84 \%$ lower than the average P-wave velocity from the direct transmission method. This difference is not unexpected because the amplitude of the received signal is much less than in the direct mode (Naik et al, 1991).

The impact-echo test results are the furthest from the direct transmission test results. The average P-wave velocity from the impact-echo tests are, on average, $14.7 \%$ lower than the average P-wave velocity from the direct transmission method tests comparing the beam specimens, and $14.4 \%$ lower comparing the cylinder specimens. The magnitude of this difference is larger than reported in the reviewed literature. The literature had indicated that the difference in P-wave velocity should be about 4-5\% (Sansalone 1997a). However, as indicated above, the impact-echo tests had a relatively large percent error. This made it difficult to detect the changes in P-wave velocity with age and to narrowly estimate the P-wave velocity.

\subsubsection{The Strength to Compression Wave (P-wave) Velocity Relationship}

The relationship between strength and P-wave velocity was determined by plotting the average strength versus the average $\mathrm{P}$-wave velocity. Each strength type was plotted against each method of measuring the P-wave velocity. For each plot, the average strength was plotted against the average P-wave velocity (as measured in the specimens tested for strength) at each age. For example, the average compressive strength was plotted against the average P-wave velocity from the two cylinders tested in compression. However, since the P-wave velocity of the cylinders could not be determined using the surface methods, the compressive and split tensile strengths were plotted against the average P-wave velocity from the surface methods as determined from the 5 beam specimens tested at each age. 
A linear regression line was fitted to each plot of strength versus P-wave velocity.

where:

$$
y=A x+B
$$

\section{Equation 11-2}

$\mathrm{y}=$ Strength

$\mathrm{A}=$ Slope

$\mathrm{x}=\mathrm{P}$-wave Velocity

$\mathrm{B}=\mathrm{y}$-intercept

The parameters ( $A$ and $B$ ) and the corresponding $\mathrm{R}^{2}$ value for each relationship are presented in Table 11-16. In general, the linear regression equations fit the data well for the flexural and compressive strengths as evidenced by the high $\mathrm{R}^{2}$ values. The equations for the split tensile strength did not fit the data as well, with lower $\mathrm{R}^{2}$ values ranging from 0.826 to 0.721 .

Table 11-16 Strength to P-Wave Velocity Relationships

\begin{tabular}{|l|c|c|c|}
\hline \multirow{2}{*}{$\begin{array}{c}\text { Strength Type } \\
\text { Modulus of Rupture }\end{array}$} & \multicolumn{3}{|c|}{$\begin{array}{c}\text { Parameters for P-Wave Velocity from Direct Transmission Pulse } \\
\text { Velocity }\end{array}$} \\
\cline { 2 - 4 } & Slope, MPa/(m/s) & y-intercept, MPa & $\mathbf{R}^{\mathbf{2}}$ \\
\hline Compressive & 0.00358 & -11.3 & 0.973 \\
\hline Split Tensile & 0.0499 & -190 & 0.994 \\
\hline \multicolumn{2}{|c|}{ Parameters for P-Wave Velocity from Surface Transmission Pulse Velocity } \\
\hline Modulus of Rupture & 0.00233 & -7.79 & 0.942 \\
\hline Compressive & 0.00326 & -178 & 0.925 \\
\hline Split Tensile & 0.0502 & -6.84 & 0.721 \\
\hline \multicolumn{2}{|c|}{ Parameters for P-Wave Velocity from Surface Method Using Acoustic Emission Equipment } \\
\hline Modulus of Rupture & 0.00227 & -11.2 & 0.975 \\
\hline Compressive & 0.00361 & -181 & 0.932 \\
\hline Split Tensile & 0.0483 & -7.58 & 0.818 \\
\hline
\end{tabular}

The plots of flexural, compressive, and split tensile strength versus P-wave velocity as measured by direct transmission pulse velocity are given in Figure 11-11, Figure 11-12, and Figure 11-13. On each plot, the linear regression line and the $95 \%$ confidence interval for $\mu_{\mathrm{Y} \cdot \mathrm{x} *}$ (the average value of strength $(\mathrm{Y})$ at a particular value of $\mathrm{P}$-wave velocity $(\mathrm{x} *)$ ) are shown. The figures show that the $95 \%$ confidence interval is narrowest for the equation that fits the data the best (compressive strength versus $\mathrm{P}$-wave velocity, direct transmission, $\mathrm{R}^{2}=0.994$ ). The figures also show that the confidence interval is narrower for a $\mathrm{P}$-wave velocity, $\mathrm{x} *$, near the sample 
mean than for a P-wave velocity $\mathrm{x} *$ far from the sample mean. This is because the estimator of the average value of strength, $\mu_{\mathrm{Y} \cdot \mathrm{x}^{*}}$, is more precise when $\mathrm{X} *$ is near the center of the $\mathrm{x}$ values at which observations have been made than when it is far from the $\mathrm{x}$ values at which observations have been made (Devore, 1995).

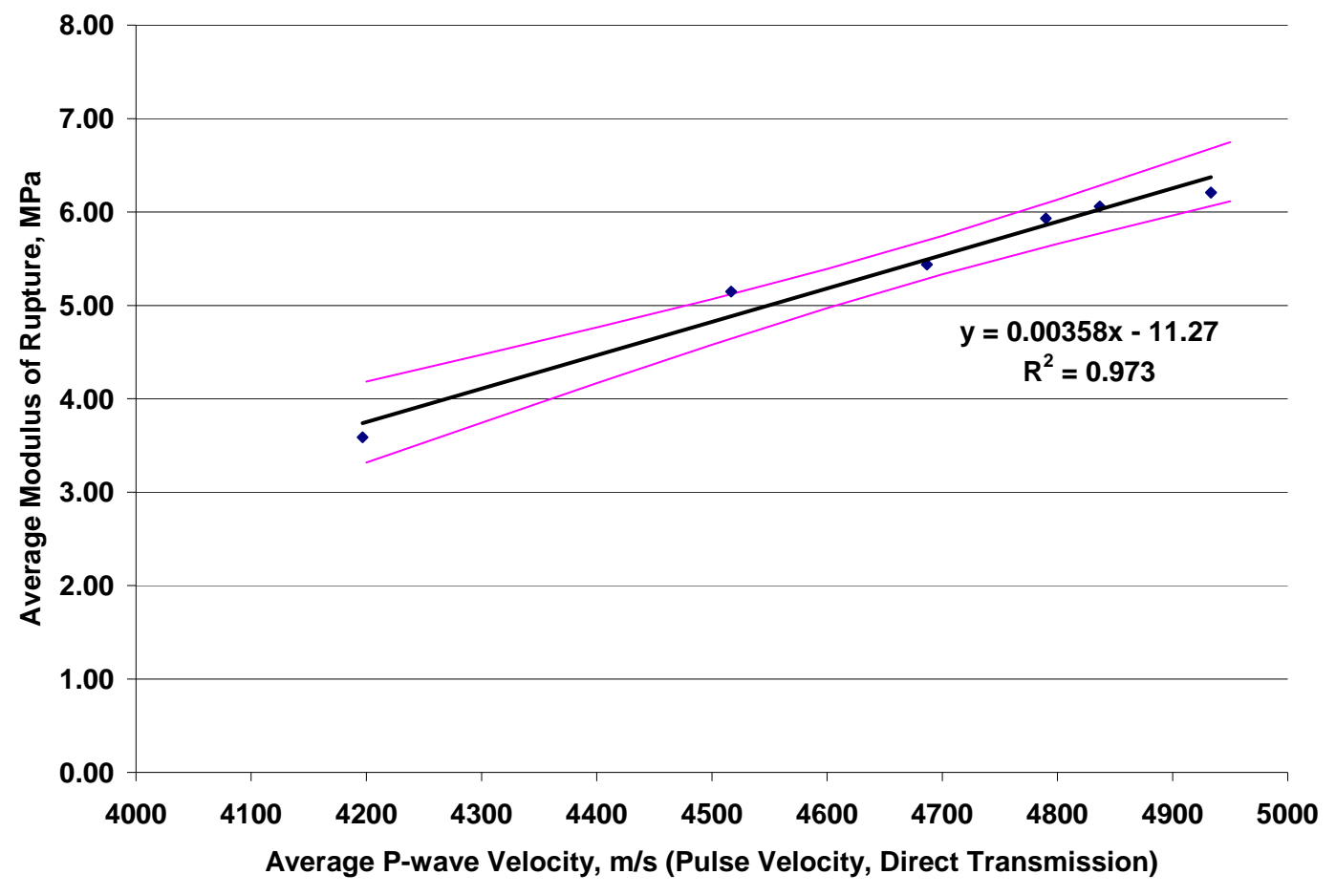

Figure 11-11 Modulus of Rupture Versus P-Wave Velocity 


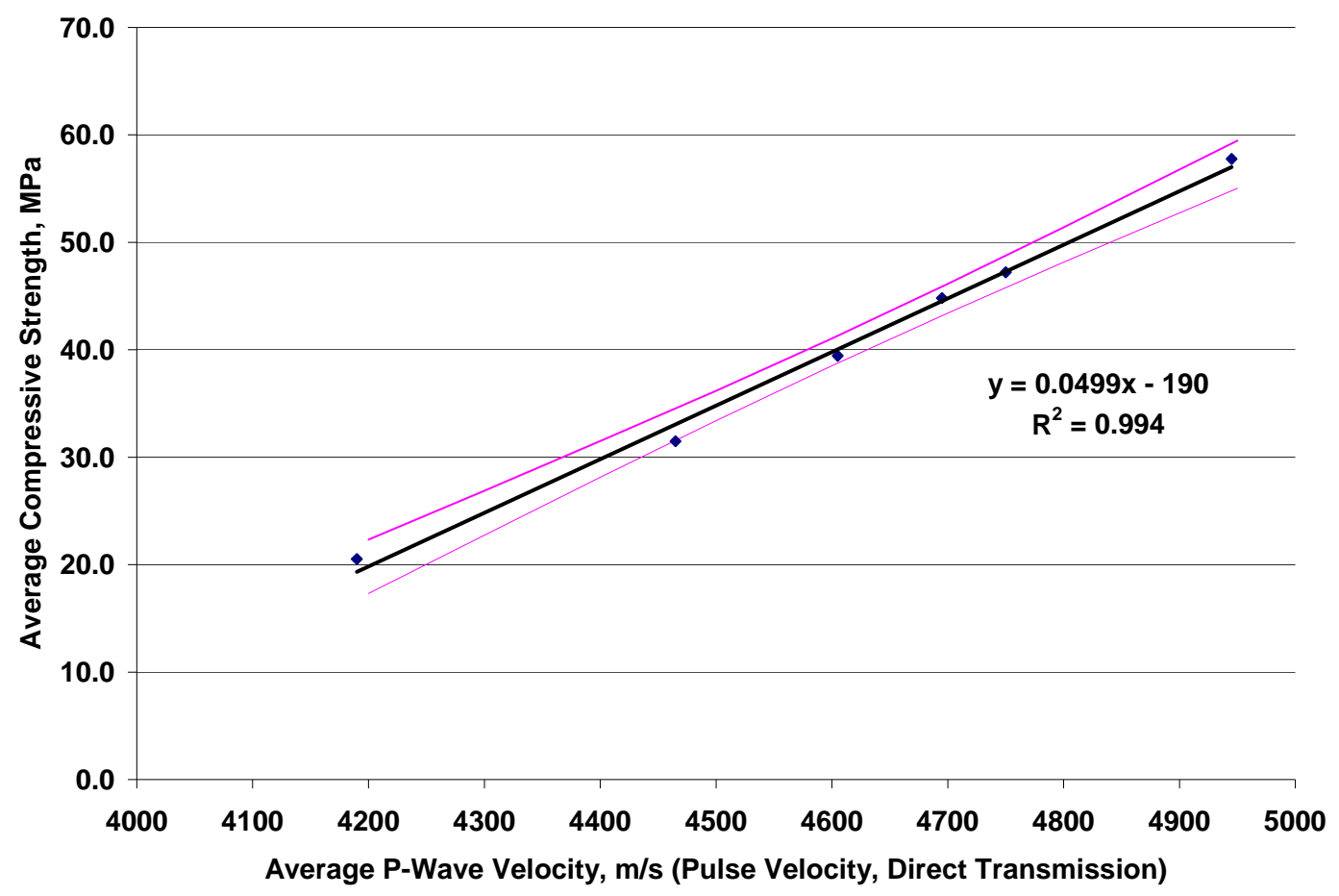

Figure 11-12 Compressive Strength Versus P-Wave Velocity

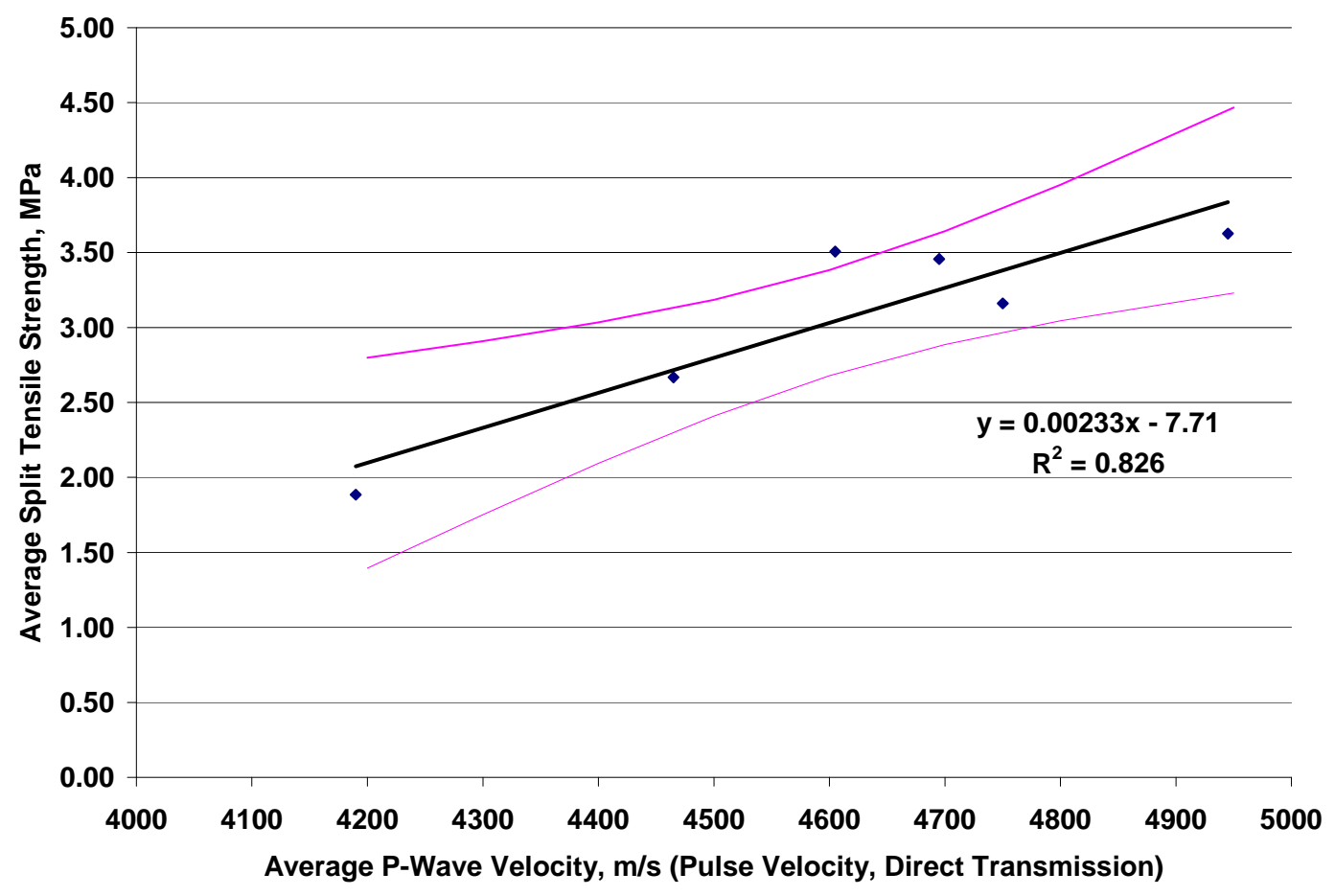

Figure 11-13 Split Tensile Strength Versus P-Wave Velocity 
The limits of the $95 \%$ confidence interval for the strength-P-wave velocity relationships (Pwave measured using direct transmission pulse velocity) can also be seen in Table 11-17. Table 11-17 shows that the range of the predicted value of strength, at a $95 \%$ confidence level, is relatively large even when the $\mathrm{R}^{2}$ value is high. This large range does not appear to make the developed relationships well suited for estimating strength. The large range appears to be caused by the including later age data in the strength-P-wave velocity relationship. It has been shown that at later ages large increases in strength occur with relatively small increases in P-wave velocity (Sturrup et al.,1984). At early ages (up to approximately 5 days) the P-wave velocity is more sensitive to strength changes. Therefore it appears that limiting the strength-P-wave velocity relationship to early ages would narrow the range of the $95 \%$ confidence interval. However a relationship developed at early ages would not be applicable at later ages (Sturrup et al.,1984).

Table 11-17 Confidence Interval for Strength-P-Wave Velocity Relationship

\begin{tabular}{|c|c|c|c|c|c|c|c|}
\hline \multirow[t]{2}{*}{ Strength Type } & \multirow[t]{2}{*}{$\mathbf{R}^{2}$} & \multirow{2}{*}{$\begin{array}{c}\text { P-wave Velocity } \\
\text { from Direct } \\
\text { Transmission } \\
\text { Pulse Velocity, } \\
\text { m/s }\end{array}$} & \multirow{2}{*}{$\begin{array}{c}\text { Average } \\
\text { Value of } \\
\text { Strength, } \\
\text { MPa }\end{array}$} & \multicolumn{2}{|c|}{$\begin{array}{c}\text { 95\% Confidence } \\
\text { Interval Limits, } \\
\text { MPa }\end{array}$} & \multicolumn{2}{|c|}{$\begin{array}{l}\text { 95\% Confidence } \\
\text { Interval Range }\end{array}$} \\
\hline & & & & Upper & Lower & MPa & psi \\
\hline \multirow{3}{*}{ Modulus of Rupture } & \multirow{3}{*}{0.973} & 4400 & 4.46 & 4.76 & 4.17 & 0.60 & 86 \\
\hline & & 4600 & 5.18 & 5.39 & 4.97 & 0.42 & 61 \\
\hline & & 4800 & 5.89 & 6.13 & 5.66 & 0.47 & 68 \\
\hline \multirow{3}{*}{ Compressive } & \multirow{3}{*}{0.994} & 4400 & 29.8 & 31.5 & 28.1 & 3.37 & 488 \\
\hline & & 4600 & 39.8 & 41.1 & 38.5 & 2.53 & 367 \\
\hline & & 4800 & 49.8 & 51.4 & 48.1 & 3.25 & 471 \\
\hline \multirow{3}{*}{ Split Tensile } & \multirow{3}{*}{0.826} & 4400 & 2.56 & 3.03 & 2.10 & 0.94 & 136 \\
\hline & & 4600 & 3.03 & 3.38 & 2.68 & 0.71 & 102 \\
\hline & & 4800 & 3.50 & 3.95 & 3.05 & 0.91 & 131 \\
\hline
\end{tabular}




\subsubsection{Measurement of Slab Specimens}

\subsubsection{Results}

As discussed in Section 10.3.5.2 and outlined in Table 10-3, the P-wave velocity of the concrete slabs was measured using the surface transmission pulse velocity test method and the surface method using the $\mathrm{AE}$ equipment at ages of 1, 4, 7, 14, and 28 days. The P-wave velocity was generally measured in two locations on the surface of each slab specimen, in the center of the tined portion, and in the center of the untined portion of the test slabs. The complete P-wave velocity measurement results are presented in Appendix L.

\subsubsection{Comparison of Test Methods}

The P-wave velocity of the slabs determined from the pulse velocity surface transmission method was significantly lower than the P-wave velocity determined from the AE surface method. For comparison, Figure 11-14 shows the results from both test methods performed on the untined surface of two of the slab specimens (S10-8 and S14-8). As indicated by Figure 11-14, the P-wave velocity from the pulse velocity surface transmission method is approximately $50 \%$ of the P-wave velocity from the AE surface method. This relationship is typical for all of the slab specimens. The discrepancy between the two test methods was not observed in the test results for the beam specimens. Several possible causes for the discrepancy were considered. 


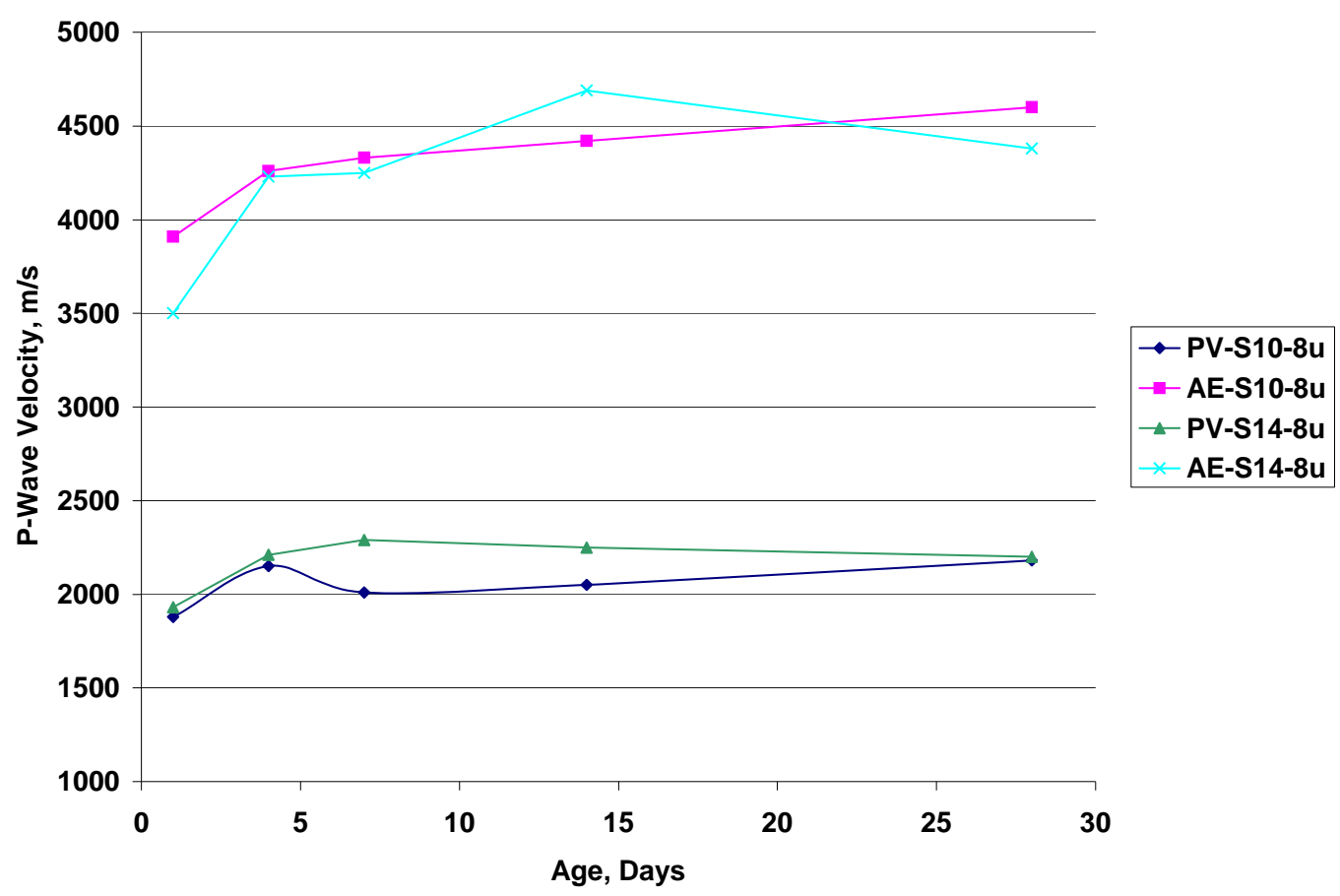

Figure 11-14 P-Wave Velocity in Slab Specimens

Inadequate or uneven consolidation at the surface of the slab specimens was considered as a cause of the low P-wave velocity for the pulse velocity surface transmission method. Inadequate or uneven consolidation could interfere with the propagation of the stress waves and increase the measured transit time thus decreasing the calculated P-wave velocity. This possibility is considered unlikely for two reasons. If inadequate or uneven consolidation existed on the surface of the slabs it should have affected both test methods. Both test methods involve the propagation of stress waves along the surface of the slabs. In addition, inspection of cores extracted from the slab specimens did not show any evidence of inadequate or uneven consolidation.

Surface drying of the slab specimens was also considered as a cause of the low P-wave velocity for the pulse velocity surface transmission method. A change in moisture content of the specimen will affect the P-wave velocity. This possibility was also dismissed because a relatively small amount of time (typically under one hour) passed between conducting the two test methods, resulting in very little to no change in the surface moisture content of the slab specimens between tests. In addition, the effects of surface drying would not be expected to 
reduce the P-wave velocity in the amount observed. This was confirmed by subsequent testing described in Chapter 13.

The pulse velocity test apparatus transducers in the surface transmission arrangement most likely were unable detect the arrival of the P-wave and instead detected the later arriving Rwave. The amplitude of the received signal in the surface transmission arrangement may only be about $3 \%$ of the signal received by the direct transmission arrangement (Naik et al, 1991). Detecting the later arriving R-wave increased the measured transit time thus decreasing the calculated velocity. A lack of full contact between the transducers and the slab test surface in combination with the lower signal amplitude appears to have prevented the detection of the arrival of the P-wave. A lack of proper contact between the transducers may also have interfered with the transmission of the stress wave. This would also increase the measured transit time. Several factors appear to have contributed to the insufficient contact between the transducers and the test slabs surface.

The texture of the surface of the slab specimens appears to have been a factor. The surface of the slabs, pictured in Figure 10-15, was fairly rough. Later comparison of the surface of the slabs to the surface of typical pavement sections revealed that the surface of the slabs was rougher than a typical pavement surface. The texture of the surface of the slabs would probably have been smoother if they had been finished with a steel bull float, similar to that used by the contractor, pictured in Figure 10-27, rather than with the smaller steel trowels, pictured in Figure 10-8. The rough surface seems to have prevented full contact between the pulse velocity test apparatus transducers and the slab surface and interfered with the transmission and reception of the stress wave. The transducers for the AE surface method were not similarly affected by the rough surface of the slabs because they are much smaller than the transducers for the surface pulse velocity test and are therefore less susceptible to the roughness of the surface. The surface pulse velocity tests performed on the beams specimens produced results comparable to the other test methods because the tested surface of the beam specimens was very smooth. The tested surface of the beams was formed against a metal surface. 
An effort was made to smooth the surface of the slabs at the age of 7 days. A small diametergrinding wheel powered by an electric drill was used. However, the grinding wheel did not significantly change the surface of the slabs and the results obtained by the surface pulse velocity test were not affected. A more extensive grinding procedure, using a coarse wheel or pad for initial grinding and a fine wheel or pad for finish grinding may have permitted full contact between the transducers and the slabs. Ward et al found that surface grinding and polishing one to three millimeters deep using fine and coarse pads reduced the variability of ultrasonic pulse velocity tests (1994).

The surface moisture content of the slab specimens also appears to have affected the coupling of the transducers to the slab surface. The surface of the slab specimens was generally dry at the time of testing. The surface of the slabs dried out quickly after the burlap was removed at the beginning of testing. The slab specimens were also generally uncovered for 2 to 3 hours while testing was conducted. However the surface of the beam specimens was saturated at the time of testing. The beams were kept moist after being removed from the water bath using wet burlap. The surface did not dry out during the time they were uncovered for testing. The moisture on the surface appeared to make coupling of the transducers to the surface easier.

\subsubsection{Compression Wave (P-wave) Versus Age Relationship}

The relationship between P-wave velocity and age in the slab specimens, as shown in Figure 11-14, is not identical to the relationship in the beam and cylinder specimens, as shown in Figure 11-10. The P-wave velocity increases rapidly at early ages for all three specimen types, however the P-wave velocity does not necessarily continue to increase in the slab specimens after 4 days, unlike the beam and cylinder specimens. After 4 days the P-wave velocity in the slab specimens does not appear to follow a particular trend. This discrepancy between the slab specimens and the beam and cylinder specimens may have been caused by a difference in moisture contents between the specimens. The beam and cylinder specimens were tested in the moist condition. The specimens were moist cured in a lime water bath located in a temperature controlled room and kept moist during the period between removal from the water bath and testing using wet 
burlap. The slab specimens were generally not tested in the moist condition. The slab specimens were cured outside, in the shade, covered with wet burlap except during testing. In addition, the amount of testing performed on the slabs at each test age resulted in the slabs being uncovered for 2 to 3 hours. The surface of the slabs dried out quickly as indicated by the change in color of the surface. The effect of moisture content on P-wave velocity is investigated more in Chapter 12.

\subsubsection{Effect of Surface Tining}

The P-wave velocity measured at the tined location was generally not the same as the P-wave velocity measured at the untined location for each slab specimen. The P-wave velocity measured at the tined location was lower than the P-wave velocity measured at the untined location in $75.7 \%$ of the measurements. This appears to indicate that the tined surface affected the ability of the test methods to accurately measure the P-wave velocity. The magnitude of the difference in P-wave velocity between the two locations was on average greater for the surface transmission pulse velocity method (tined location $303 \mathrm{~m} / \mathrm{s}$ lower) then for the AE surface method (tined location $187 \mathrm{~m} / \mathrm{s}$ lower). This indicates that the surface transmission pulse velocity method was affected to a greater degree than the AE surface method.

\subsubsection{Comparison to Other Test Methods}

The P-wave velocity of specimen S10-8 was also measured in direct transmission at the ages of 14 and 28 days. At the age of 14 days, a notch was cut out of two sides of the wood form exposing opposite sides of the specimen. The newly exposed concrete surfaces were observed to be moist. The measured direct transmission P-wave velocity was $4470 \mathrm{~m} / \mathrm{s}$. As expected, this was greater than the P-wave velocity measured using the AE surface method at both of the tined and untined locations ( 4170 and $4420 \mathrm{~m} / \mathrm{s}$ respectively). At 28 days the measured direct transmission P-wave velocity was lower than at 14 days $(4110 \mathrm{~m} / \mathrm{s})$. In addition, this P-wave velocity was equal to the velocity measured using the $\mathrm{AE}$ surface method at the tined location, and was lower than the velocity measured using the AE surface method at the untined location $(4600 \mathrm{~m} / \mathrm{s})$. However the concrete surfaces for the direct transmission test were not moist at the 
time of testing as they were at 14 days. This strongly indicates that the moisture condition of the concrete affects the measured P-wave velocity.

The P-wave velocity of the slabs was also measured by a surface method using the impactecho test system available from the FHWA Mobile Concrete Laboratory at an age of 42 and 56 days. The measurements at the age of 42 days were exclusively used to determine the slab thickness by the impact-echo test method as indicated in Section 11.7.2. The measurements at the age of 56 days were used to compare the results of this surface method to the surface method using the AE equipment. Table 11-18 indicates that the average P-wave velocity of the surface method using the FHWA equipment was lower than the average P-wave velocity of the surface method using the AE equipment, 3.4\% lower for $\mathrm{S} 10-8 \mathrm{~m}$ and $8.7 \%$ lower for $\mathrm{S} 10-8 \mathrm{u}$. The lower P-wave velocity was expected because the software used in the FHWA equipment automatically reduces the measured P-wave velocity by $4 \%$ as explained in Section 9.2.2.3. However the magnitude of the reduction for $\mathrm{S} 10-8 \mathrm{u}, 8.7 \%$, was twice as much as expected.

Table 11-18 P-Wave Velocity Comparison

\begin{tabular}{|l|l|c|c|}
\hline \multirow{2}{*}{ Measurement Technique } & & \multicolumn{2}{c|}{ Slab Test Specimen } \\
\cline { 3 - 4 } & S10-8m & S10-8u \\
\hline $\begin{array}{l}\text { Surface Method Using FHWA } \\
\text { Equipment }\end{array}$ & $\begin{array}{l}\text { Average P-Wave } \\
\text { Velocity, } \mathrm{m} / \mathrm{s}^{1}\end{array}$ & 3940 & 3925 \\
\hline $\begin{array}{l}\text { Surface Method Using Acoustic } \\
\text { Emission Equipment }\end{array}$ & $\begin{array}{l}\text { Average P-Wave } \\
\text { Velocity, } \mathrm{m} / \mathrm{s}^{2}\end{array}$ & 4080 & 4300 \\
\hline
\end{tabular}

Notes to Table 11-18:

1. Average of 8 tests.

2. Average of 13 tests for $\mathrm{S} 10-8 \mathrm{~m}, 12$ tests for $\mathrm{S} 10-8 \mathrm{u}$

\subsubsection{Predicted Slab Strength}

The flexural strength-P-wave velocity relationship using AE surface method was used to predict the flexural strength of the slabs from the measured P-wave velocity using the AE surface method. The predicted strengths of the slab specimens are contained in Table 11-19. The predicted flexural strength of the slabs was then compared to the average flexural strength of the beam specimens at each test age. The percent differences of the predicted strengths from the actual strengths are indicated in Table 11-19. The predicted strength of the slabs generally increases with age, but not always. The comparison of the predicted strength to actual beam 
strength does not appear to follow any particular trend, as in the case of the predicted strength from maturity (Table 11-11 and Table 11-12).

Table 11-19 Flexural Strength From P-Wave Velocity

\begin{tabular}{|l|l|c|c|c|c|c|}
\hline \multirow{2}{*}{$\begin{array}{c}\text { Slab } \\
\text { Specimen }\end{array}$} & \multirow{2}{*}{$\begin{array}{c}\text { Test } \\
\text { Location }\end{array}$} & \multicolumn{5}{|c|}{ Predicted MOR, psi at: } \\
\cline { 3 - 7 } & 1 Day & 4 Days & 7 Days & 14 Days & 28 Days \\
\hline S10-8 & Untined & 574 & 739 & 772 & 815 & 900 \\
\hline S10-8 & Tined & $\sim$ & 545 & 621 & 697 & 668 \\
\hline S6-8 & Untined & 564 & 716 & 782 & 763 & 933 \\
\hline S6-8 & Tined & 489 & 749 & 824 & 976 & 933 \\
\hline S14-8 & Untined & 380 & 725 & 735 & 943 & 796 \\
\hline S14-8 & Tined & 423 & 508 & 465 & 796 & 843 \\
\hline S10-53D & Untined & 579 & 763 & 791 & 876 & 914 \\
\hline S10-53D & Tined & 404 & 626 & 716 & 768 & 654 \\
\hline S10-53 & Untined & 356 & 659 & 744 & 791 & 801 \\
\hline S10-53 & Tined & 163 & 389 & 654 & 720 & 763 \\
\hline S10-CTB & Untined & 550 & 583 & 744 & 801 & 772 \\
\hline S10-CTB & Tined & 427 & 593 & 659 & 810 & 848 \\
\hline
\end{tabular}

Table 11-20 Predicted Slab Strength to Measured Beam Strength

\begin{tabular}{|l|l|c|c|c|c|c|}
\hline \multirow{2}{*}{$\begin{array}{c}\text { Slab } \\
\text { Specimen }\end{array}$} & \multirow{2}{*}{$\begin{array}{c}\text { Test } \\
\text { Location }\end{array}$} & \multicolumn{5}{|c|}{ Percent Difference from Actual Beam Strength } \\
\cline { 3 - 7 } S10-8 & Untined & 10.3 & -1.0 & -2.0 & -5.3 & 2.4 \\
\hline S10-8 & Tined & $\sim$ & -26.9 & -21.2 & -19.0 & -23.9 \\
\hline S6-8 & Untined & 8.5 & -4.1 & -0.8 & -11.3 & 6.2 \\
\hline S6-8 & Tined & -6.1 & 0.3 & 4.6 & 13.4 & 6.2 \\
\hline S14-8 & Untined & -27.0 & -2.9 & -6.8 & 9.6 & -9.4 \\
\hline S14-8 & Tined & -18.8 & -32.0 & -41.0 & -7.5 & -4.0 \\
\hline S10-53D & Untined & 11.2 & 2.2 & 0.4 & 1.9 & 4.1 \\
\hline S10-53D & Tined & -22.4 & -16.2 & -9.2 & -10.8 & -25.5 \\
\hline S10-53 & Untined & -31.5 & -11.7 & -5.6 & -8.0 & -8.9 \\
\hline S10-53 & Tined & -68.8 & -47.8 & -17.0 & -16.3 & -13.2 \\
\hline S10-CTB & Untined & 5.7 & -21.9 & -5.6 & -6.9 & -12.1 \\
\hline S10-CTB & Tined & -17.9 & -20.6 & -16.4 & -5.8 & -3.5 \\
\hline
\end{tabular}

\subsection{Slab Thickness by Coring Results}

Cores were extracted from the slab test specimens to more precisely determine the thickness of the slabs at the impact-echo test locations. Cores were able to be obtained at two of the three impact-echo test locations on each slab, in the center of the untined portion and in the middle of the slab. Cores could not be extracted from the third impact-echo test location, the middle of the 
tined portion of each slab, due to limitations of the coring apparatus. In addition a core was not obtained from the center of the untined portion of specimen S10-CTB.

The length of each core was determined in general accordance with ITM 404 using the apparatus pictured in Figure 10-22. The apparatus was used to take ten separate measurements over the surface of the core, five measurements at a time. The length of each core was taken as the average of the ten measurements. The results are presented in Table 11-21.

Multiple length measurements are necessary because the bottom surface of the cores, shown in Figure 11-15 and Figure 11-16, was generally uneven and included bonded aggregate particles from the base course even though the surface of the aggregate base course was leveled before the slabs were cast. Before the length measurements were taken, the bottom of each core was struck with a hammer with moderate force in order to dislodge particles that were not strongly bonded to the core. This process of removing bonded particles was strongly dependant upon the judgment of the operator, but appears to have been consistent with the procedure in ITM 404, which states, "Particles not substantially surrounded by mortar will be removed with a rock hammer."

The variability of the core length measurements is indicated in Table 11-21 by the range and standard deviation of the cores. The maximum range of the ten measurements taken on the cores was 1.3 inches $(33.0 \mathrm{~mm})$. The average range was 0.6 inches $(15.0 \mathrm{~mm})$. The relatively large variability in the length of the cores indicates that the thickness of the slabs was not constant over even a small area. 
Table 11-21 Core Thickness

\begin{tabular}{|c|c|c|c|c|c|c|c|}
\hline \multirow{2}{*}{$\begin{array}{c}\text { Test } \\
\text { Specimen }\end{array}$} & \multirow{2}{*}{ Location } & \multicolumn{2}{|c|}{ Average Thickness } & \multicolumn{2}{|c|}{ Range } & \multicolumn{2}{c|}{ Standard Deviation } \\
\cline { 3 - 8 } & & in & $\mathbf{m m}$ & in & $\mathbf{m m}$ & in & $\mathbf{m m}$ \\
\hline \multirow{2}{*}{ S6-8 } & Middle & 7.5 & 191 & 0.6 & 15.2 & 0.19 & 4.8 \\
\cline { 2 - 8 } & Untined & 7.9 & 201 & 1.3 & 33.0 & 0.5 & 12.7 \\
\hline \multirow{2}{*}{ S10-8 } & Middle & 10.6 & 268 & 0.3 & 7.6 & 0.08 & 2.0 \\
\cline { 2 - 8 } & Untined & 10.5 & 267 & 0.4 & 10.2 & 0.15 & 3.8 \\
\hline \multirow{2}{*}{ S10-53 } & Middle & 10.9 & 278 & 0.3 & 7.6 & 0.1 & 2.5 \\
\cline { 2 - 8 } & Untined & 11.3 & 286 & 0.4 & 10.2 & 0.16 & 4.1 \\
\hline \multirow{2}{*}{ S10-53D } & Middle & 11.3 & 287 & 1.3 & 33.0 & 0.37 & 9.4 \\
\cline { 2 - 8 } & Untined & 10.7 & 273 & 0.8 & 20.3 & 0.27 & 6.9 \\
\hline \multirow{2}{*}{ S10-CTB } & Middle & 11.1 & 282 & 0.3 & 7.6 & 0.12 & 3.0 \\
\hline \multirow{2}{*}{ S14-8 } & Middle & 15.3 & 388 & 0.6 & 15.2 & 0.2 & 5.1 \\
\cline { 2 - 8 } & Untined & 15.0 & 381 & 0.2 & 5.1 & 0.07 & 1.8 \\
\hline
\end{tabular}

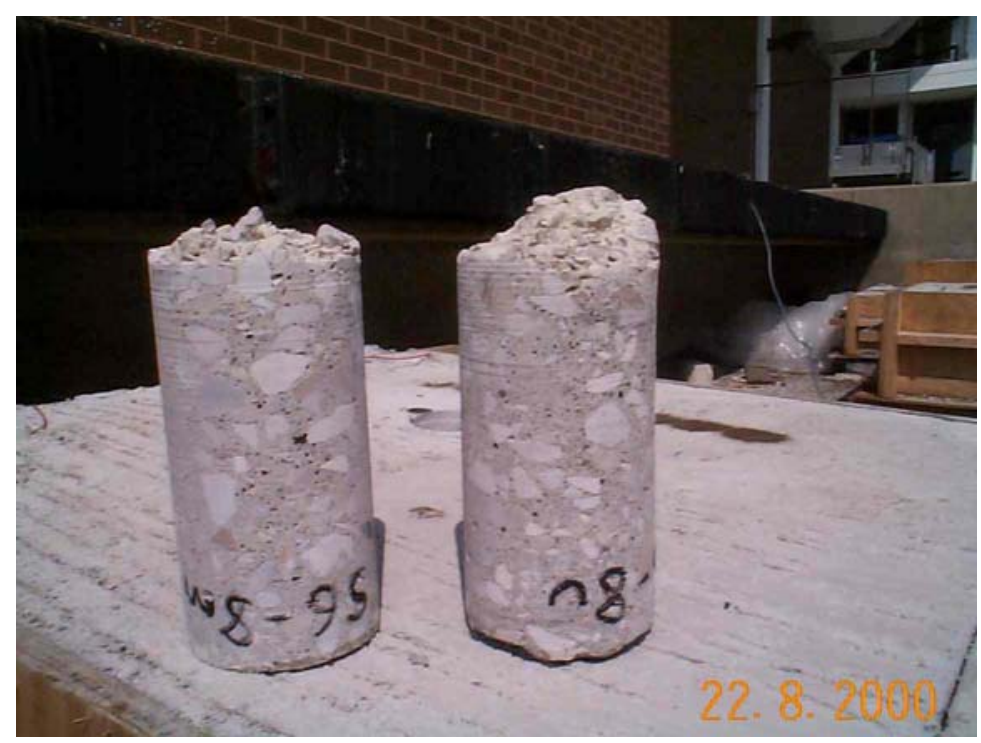

Figure 11-15 Cores Extracted From S6-8 


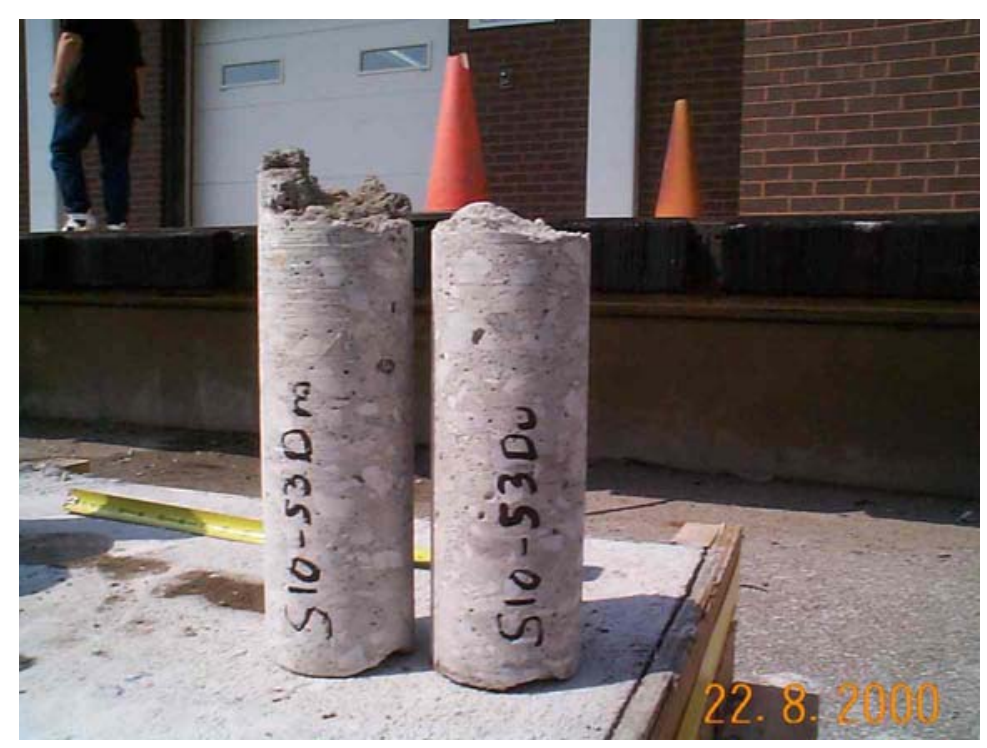

Figure 11-16 Cores Extracted From S10-53D

\section{$11.7 \quad$ Impact-Echo Results}

\subsubsection{Testing and Analysis of Recorded Data}

Impact-echo tests, described in Section 9.2.2.3, were performed on the surface of the slab specimens. The surface displacement waveform and the frequency spectrum were recorded for each test. Two to four tests were recorded at each test location at ages of 1, 4, 7, 14, and 28 days. A minimum of twelve tests were recorded at each test location on Day 42 . The test locations consisted of the center of the tined and untined portions, and the middle of the slab. The majority of the testing was conducted with the impact-echo equipment available from the INDOT, however the equipment available from the FHWA was also used on Day 42. Appendix M contains a summary of the impact-echo test results.

An analysis of the recorded data was performed for each test. First the surface displacement waveform was inspected to check the validity of the waveform. A valid waveform depicts the arrival of the $\mathrm{P}$-wave and $\mathrm{R}$-wave, followed by periodic oscillations corresponding to multiple reflections between the slab boundaries. Figure 11-17 is an example of a valid waveform. The arrival of the P-wave, which can be seen at $190 \mu \mathrm{s}$, is immediately followed by the arrival of the 
larger amplitude R-wave that resembles a single cycle sine curve. The remainder of the waveform consists of periodic oscillations. Waveforms that do not contain all of these elements have been assumed to be invalid and cannot be used to estimate thickness. Invalid waveforms can result from poor coupling of the transducer to the surface, inappropriate contact time, multiple contacts, insufficient impact force, or false triggering of the test system (Sansalone et al, 1993).

Day 42: EB-S10-8ma

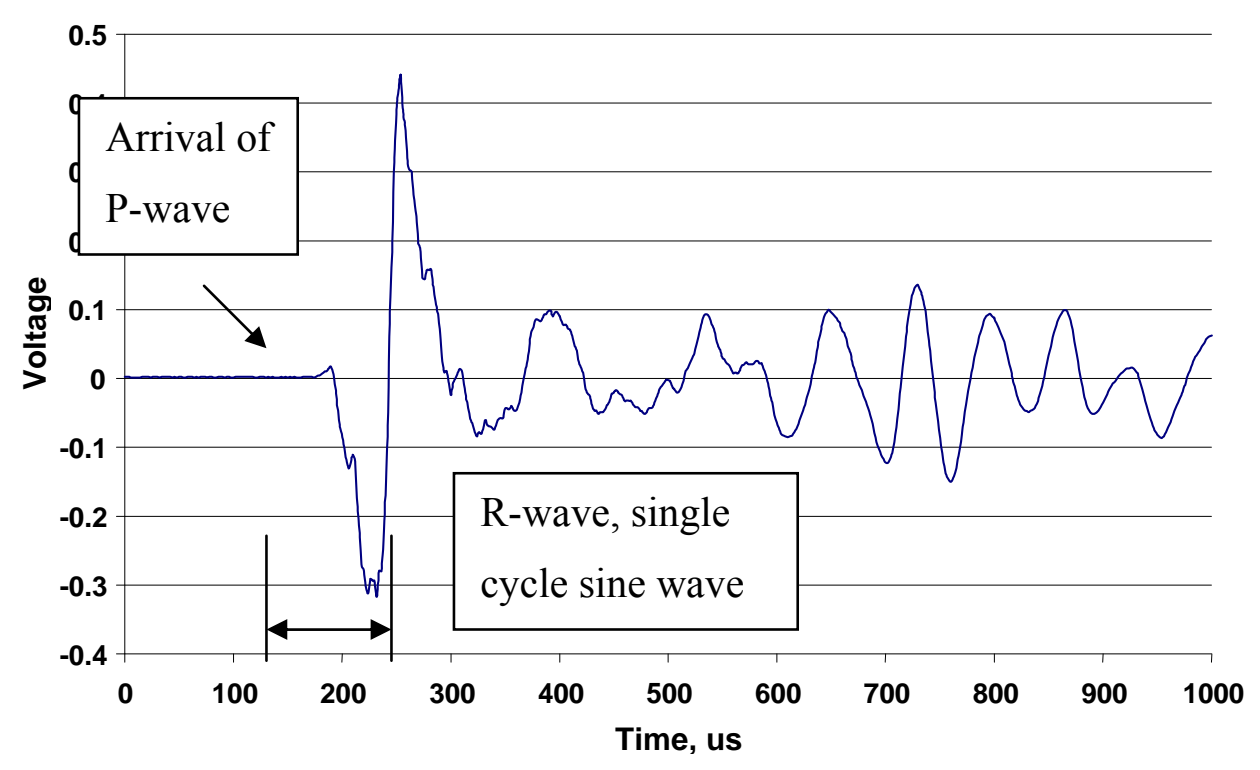

Figure 11-17 Valid Surface Displacement Waveform

A large number of the recorded tests were found to have invalid waveforms. This greatly reduced the amount of data that was useful to determine the slab thickness. The design of the hand-held scanning unit, shown in Figure 10-17, which contained both the impactor and the transducer, in conjunction with the rough surface of the slabs often made it difficult to obtain both a solid impact with sufficient force and adequate coupling of the transducer to the surface of the slab. Less difficulty in obtaining valid waveforms was experienced with the impact-echo test system available from the FHWA, in which the impactor and the transducer were separate items. The large number of invalid waveforms indicated the need to examine the waveforms during testing. The test procedure was revised on Day 42 to include inspection of the surface 
displacement waveforms during testing. If an invalid waveform occurred, it was not recorded and another test was performed. The test procedure was also revised to include recording more tests at each test location. The acquisition of several waveforms, all of which produce similar frequency spectrums, increased the confidence level in the validity of the obtained data.

If the waveform was determined to be valid, the frequency spectrum was inspected to determine the appropriate frequency to be used in Equation 3.8 to calculate the slab thickness. The frequency spectrum should contain a single high amplitude peak. The frequency of this peak is used to calculate the slab thickness. Some of the recorded spectrums, such as Figure 11-18, did contain a single high amplitude peak. However, the majority of the recorded frequency spectrums do not exhibit a single high amplitude peak. Instead, the spectrums contain more than one high amplitude peak. Figure 11-19 is an example of a multiple peak spectrum. The highest amplitude peak is at $0.98 \mathrm{kHz}$. Many of the literature sources have documented that this low frequency peak is due to the resonance of the transducer. In general, a high amplitude peak at a frequency below $2 \mathrm{kHz}$ can be attributed to the resonance of the transducer. The second highest amplitude peak in Figure 11-19 occurs at $8.06 \mathrm{kHz}$. However, peaks at 6.10, 7.32, 8.79, and 12.21 have an amplitude that is only slightly less. The peak at $7.32 \mathrm{kHz}$ most accurately corresponds to the slab thickness determined by the measurement of cores for the recorded Pwave velocity. The multiple peaks are most likely due to vibration of the slabs, due to their size, caused by the impact. The cores extracted from the slabs did not indicate excessive air voids or inadequate compaction. Motion associated with other modes of vibration can appear in the waveform when the lateral dimension of the test specimen is not significantly greater than the thickness. A lateral dimension of at least 10 times the thickness is recommended by ASTM C 1383. The ratio of lateral dimension to thickness of the test slabs varied from 2.6 to 6 . 


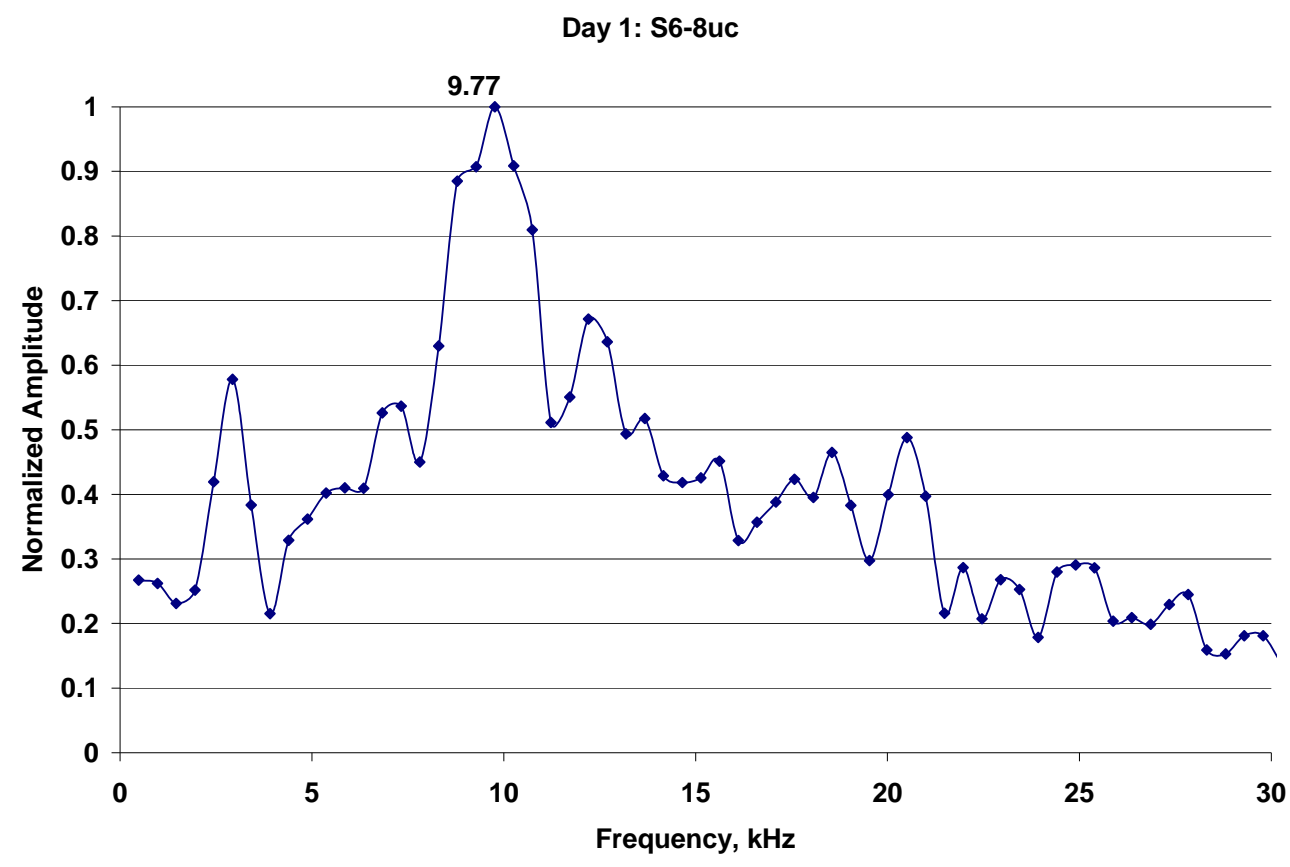

Figure 11-18 Frequency Spectrum with a Single High Amplitude Peak

Day 42: S10-53mb

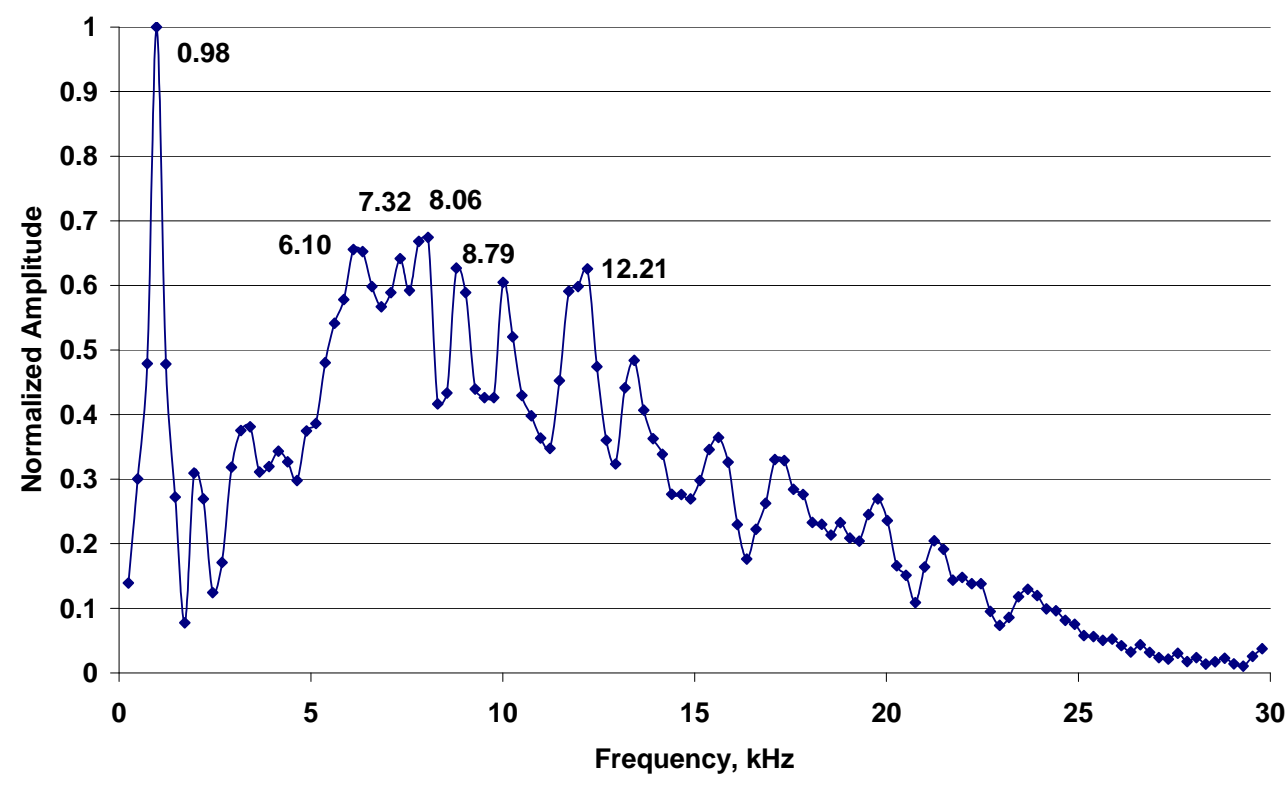

Figure 11-19 Frequency Spectrum with Multiple High Amplitude Peaks 


\subsubsection{Test Results}

The summary of each test contained in Appendix M indicates the test location, the P-wave velocity using the AE surface method (except Day 42 when the P-wave velocity was determined using the FHWA equipment), the frequency of the highest amplitude peak, the frequency of the highest amplitude peak excluding peaks due to transducer resonance, the calculated thickness using this peak, and the percent difference between the actual thickness as determined by coring (Section 11.6) and the calculated thickness. In addition, the summary indicates if a peak with an amplitude near the highest-amplitude peak corresponded more closely to the actual thickness. This peak, the corresponding thickness, and the percent difference between the actual and calculated thickness are also indicated.

The average percent difference between the actual thickness and the calculated thickness for each slab is shown in Table 11-22. The improvement in the prediction of the thickness indicates the difficulty in analyzing the recorded frequency spectrums. The multiple high amplitude peaks made it very difficult to accurately calculate the thickness. The correct peak could only be identified after the slab thickness was determined from coring.

Table 11-22 Impact-Echo Testing

\begin{tabular}{|c|c|c|c|}
\hline \multirow{2}{*}{ Test Specimen } & \multicolumn{3}{|c|}{ Average Difference, \%, Between Actual and Calculated Thickness For: } \\
\cline { 2 - 4 } & $\begin{array}{c}\text { Highest Amplitude } \\
\text { Peak, Excluding } \\
\text { Transducer Resonance }\end{array}$ & $\begin{array}{c}\text { Alternate High- } \\
\text { Amplitude Peak }\end{array}$ & Percent Improvement \\
\hline S14-8 & 18.39 & 7.95 & 10.44 \\
\hline S10-8 & 11.78 & 4.13 & 7.65 \\
\hline S6-8 & 13.80 & 5.78 & 8.02 \\
\hline S10-53D & 15.60 & 3.71 & 11.89 \\
\hline S10-53 & 11.79 & 3.64 & 8.15 \\
\hline S10-CTB & 13.77 & 3.39 & 10.38 \\
\hline
\end{tabular}

The frequency resolution used in the majority of the pre-construction impact-echo testing also made the analysis of the data difficult. The frequency resolution is the inverse of the product of the number of recorded points and the sampling interval. A smaller frequency resolution produces better-defined peaks in the frequency spectrum, resulting in less possible error in the calculation of thickness. Table 11-23 indicates the error due to the frequency resolution for each 
slab. The frequency resolution used for the majority of the pre-construction testing was 0.488 $\mathrm{kHz}$. The waveform pictured in Figure 11-18 has a frequency resolution of $0.488 \mathrm{kHz}$. The frequency resolution used for the impact-echo testing on Day 42 was $0.163 \mathrm{kHz}$. The waveform pictured in Figure 11-19 has a frequency resolution of $0.163 \mathrm{kHz}$. A comparison of the two figures demonstrates that the distance between the data points is smaller and thus the peaks are better defined with the lower resolution pictured in Figure 11-19.

Table 11-23 Percent Error Due to Frequency Resolution

\begin{tabular}{|c|c|c|c|}
\hline \multirow{2}{*}{$\begin{array}{c}\text { Frequency } \\
\text { Resolution, kHz }\end{array}$} & \multicolumn{3}{|c|}{$\begin{array}{c}\text { Percent Error in the Calculation of Thickness for a P-wave } \\
\text { Velocity of } \mathbf{4 0 0 0} \mathbf{~ m} / \mathbf{s} \text { and a Thickness of: }\end{array}$} \\
\cline { 2 - 4 } & $\mathbf{6}$ in. & $\mathbf{1 0}$ in. & $\mathbf{1 4}$ in. \\
\hline 0.488 & 1.9 & 3.1 & 4.3 \\
\hline 0.244 & 0.9 & 1.5 & 2.2 \\
\hline 0.163 & 0.6 & 1.0 & 1.4 \\
\hline
\end{tabular}

The multiple high amplitude peaks and the frequency resolution used in the majority of the impact-echo testing also make it difficult to assess the effects of the base course material, slab thickness, and surface tining on the impact-echo testing. However, general observations can be made. All of the base courses used in the pre-construction test program produced peaks in the frequency spectrum near the frequency that corresponded to the depth of the concrete slab-base course interface. Therefore it appears that the difference in acoustic impedance between the concrete slab and each of the base courses is sufficient to reflect the P-wave and produce displacements at the surface. The lowest average degree of accuracy was obtained in the tests performed on the 14 in. $(356 \mathrm{~mm})$ thick slab as shown in Table 11-22. This appears to be related to increased percent error in the frequency resolution for increasing thickness as shown in Table 11-23. The increased roughness due to the surface tining made it more difficult to obtain valid waveforms, as discussed in Section 11.7.1. However, the roughness of the test slabs does not appear to be representative of the surface of typical pavement as indicated earlier.

\subsection{Summary and Conclusions}

This chapter has presented the experimental results from the pre-construction test program. The test program assessed the use of use of the impact-echo, measurement of P-wave velocity, 
and maturity test methods to determine concrete strength and pavement thickness. The work presented in this chapter indicates the following:

- The flexural strength gain from 7 to 28 days was found to be greater than the $5 \%$ value assumed during the development of the Level 1 PRS. This indicates the need to determine and incorporate the actual strength gain of the proposed concrete mixture in the development of future PRS. The maturity test method provides a method by which this need can be accomplished.

- The split tensile strength test method does not appear well suited for AQC or QC/QA sampling and testing purposes. The test method exhibited a high degree of variability compared to the flexural and compressive strength test methods and exhibited unexpected strength gain with age.

- A second order polynomial was found to accurately represent the flexural to compressive strength relationship. This relationship is required by the PRS software if the compressive strength is to be used for AQC sampling and testing.

- The concrete temperature variation with time indicates the need to measure the temperature at regular, closely spaced intervals for use in the maturity test method. Intervals similar to those required by ASTM C 1074 appear appropriate (every $1 / 2$ hour for the first 48 hours and every hour after that).

- The greater amount of heat generated in larger specimens result in larger maturity indexes then smaller specimens at equal ages. This results in a more rapid estimate of relative strength gain for larger specimens (such as pavements) compared to smaller specimens (such as beams) using the maturity test method.

- The maturity index from the Arrhenius equation is preferred to the maturity index from the Nurse-Saul equation. It more accurately accounts for the change in the rate constant of cement hydration with temperature.

- The offset hyperbolic function was found to accurately represent the strength-maturity relationship. This function is not one of the forms of the strength-maturity relationship contained in the PRS software (Version 2.5) for when strength testing is performed before 28 days. 
- Better estimates of the $\mathrm{M}_{\mathrm{o}}$ parameter in the offset hyperbolic strength-maturity relationship can be obtained from earlier age test data.

- The correlation of the P-wave velocity to concrete strength is supported by the similarity between the strength-age relationship and the P-wave velocity-age relationship.

- Reducing the systematic error in the measurement of the P-wave velocity increases the confidence in the reported P-wave velocity. The systematic error is decreased with an increased precision in the measurement of transit time and length.

- The P-wave velocity measured by the surface method using the acoustic emission (AE) equipment was the closest to the P-wave velocity measured in direct transmission. Therefore this surface test method appears the best suited (of the methods tested) to measure the Pwave velocity when only one surface of the test specimen is available.

- A linear regression line represented the flexural and compressive strength to P-wave velocity relationships well. The $\mathrm{R}^{2}$ values ranged from 0.994 to 0.925 .

- The range of the $95 \%$ confidence interval for the predicted strength from the measured Pwave velocity was relatively large. This large range does not appear to make the developed relationships well suited for estimating strength. It is proposed that limiting the strength-Pwave velocity relationship to early ages would narrow the range of the $95 \%$ confidence interval.

- Smaller transducers appear to be easier to adequately couple to textured concrete surfaces.

- The P-wave velocity-age relationship for the laboratory moist cured specimens was not the same as for the specimens cured outdoors. The difference in moisture condition at the time of testing appears to be a significant cause for the discrepancy. The influence of moisture condition on P-wave velocity was confirmed by comparison of test results in Section 11.5.3.5.

- The predicted strengths of the slab specimens from the strength-maturity relationship do not correlate with the predicted strengths from the strength-P-wave velocity relationships.

- The thickness of a concrete specimen cast over an aggregate base can vary over even a small area. The measured thickness using drilled cores will depend upon the amount of base material left bonded to the bottom surface. 
- Inspection of surface displacement waveforms is necessary during impact-echo testing to ensure acquisition of valid waveforms.

- The interpretation of the impact-echo data was hindered by the appearance of motion associated with modes of vibration in the waveform. Motion associated with modes of vibration can occur when the lateral dimension of the test specimen is not significantly greater than the thickness.

- A smaller frequency resolution produces clearer frequency spectrums and induces less error in the calculation of thickness.

- The ability to obtain valid waveforms and determine the frequency corresponding to the slab thickness does not appear to vary for the aggregate base materials and thicknesses included in the test program.

- The roughness of the surface of the test specimens can affect the ability to obtain valid waveforms in the impact-echo test method. 


\section{CHAPTER 12: FIELD TESTING EXPERIMENTAL RESULTS}

\subsection{Introduction}

This chapter presents the experimental results from the field test program. This test program was the second of three phases of the overall test program conducted in conjunction with the implementation of a Level 1 Performance-Related Specification (PRS) on Indiana Department of Transportation (INDOT) Project R-24432. The type and number of test specimens and the mixing, casting, and curing procedures have been previously described in Sections 10.4.1 through 10.4.4. The test procedures and equipment have been previously described in Section 10.4.5.

The field test program was conducted during the construction of the concrete pavement on Project R-24432 that was built in accordance with the Level 1 PRS. In addition to the results from the tests performed specifically by Purdue for this test program, the experimental results include results from the acceptance quality characteristic (AQC) testing performed by the INDOT, quality control testing performed by the pavement contractor, and testing performed in cooperation with the Federal Highway Administration (FHWA) Mobile Concrete Laboratory.

The general objective of this test program was to assess the use of the impact-echo, compression wave (P-wave) velocity, and maturity test methods under field conditions. The original specific objectives were modified because the concrete mixture and materials used in the field test program were not the same as the concrete mixture and materials used in the preconstruction test program. The fine aggregate source and the amount of air entraining agent used changed from the pre-construction test program to the field test program. It should also be noted that it is likely that the characteristics of the cement were not constant during the first four 
sublots of the field test program, or the same as the cement used in the pre-construction test program. While the cement met the requirements for Type I cement, it is possible that variations occurred as a result of changes to the cement manufacturing process at the cement plant. The mixture and material changes meant that the strength-maturity and strength-P-wave velocity relationships that were created in the pre-construction program could not be used to directly estimate strength during the field test program. These relationships are dependant upon the constituent materials and concrete mixture proportions used to create them. The modified specific objectives for the field test program included:

- Comparing the flexural strength of beam specimens cast near the paving operations versus those cast at the batch plant.

- Assessing the use of P-wave velocity measurement methods employed in the preconstruction test program under field conditions.

- Developing the strength-maturity relationship for the constituent materials and concrete mixture proportions used in the construction of the pavement governed by the Level 1 PRS.

- Comparing the predicted flexural strength of the beam specimens from the strength-maturity relationship to the actual flexural strength obtained from testing.

- Predicting pavement strength from the strength-maturity relationship developed for the beam specimens.

- Assessing the variability of the measurement of core length test method used by the INDOT (Indiana Test Method (ITM) 402-99).

- Comparing the estimated thickness of the pavement from the impact-echo test method to the actual thickness from core measurements.

\subsection{Explanation of Field Test Program Results}

The experimental results from the field test program include the concrete flexural strength and pavement thickness results as determined by the INDOT for pavement acceptance and pay factor adjustments. These results consist of the individual, sublot average, lot average, and lot 
standard deviation test results. These test results are calculated in accordance with INDOT procedures. The procedures are as follows:

- The sublot average is the mean of individual test results for the sublot.

- The lot average for thickness is the mean of the mean length of all cores in the lot.

- The lot average for strength is the mean of the sublot average strengths.

- The lot standard deviation for thickness is the standard deviation of all the cores in the lot divided by a correction factor (see below).

- The lot standard deviation for strength is the standard deviation of sublot average divided by a correction factor (see below).

- If an individual test result value is greater than the maximum quality limit (MQL), as defined in Appendix A, the test result value is reduced to be equal to the MQL. The reduced test result value is used for acceptance and pay adjustment.

The correction factor applied to the standard deviation, employed as indicated above, is used to account for small sample sizes and obtain unbiased estimates of the actual standard deviation and depends on the number of samples. Table 12-1 contains the correction factors as contained in the INDOT 1999 Standard Specifications.

Table 12-1 Standard Deviation Correction Factors

\begin{tabular}{|c|c|}
\hline Number of Sample Values & Correction Factor \\
\hline 2 & 0.7979 \\
\hline 3 & 0.8862 \\
\hline 4 & 0.9213 \\
\hline 5 & 0.9399 \\
\hline 6 & 0.9515 \\
\hline 7 & 0.9594 \\
\hline 8 & 0.9650 \\
\hline 9 & 0.9693 \\
\hline 10 & 0.9726 \\
\hline 30 & 0.9915 \\
\hline 50 & 0.9949 \\
\hline
\end{tabular}


The standard deviation correction factor is only applied to the results used by the INDOT for pavement acceptance and pay factor adjustments. It is not applied for standard deviations calculated elsewhere in this report.

\section{$12.3 \quad$ Strength Results}

Purdue University, the FHWA, the concrete pavement contractor (Berns Construction), and the INDOT cast beam specimens during the field test program. The FHWA also cast cylinder specimens during the field test program. The flexural strength $\left(\mathrm{f}_{\mathrm{r}}{ }_{\mathrm{r}}\right)$ of the beam specimens was determined at an age of either 7 or 28 days. The split tensile strength ( $\left.\mathrm{f}_{\mathrm{sp}}\right)$ of the cylinders was determined at an age of 7-days. Table 10-6 contains a summary of the test specimens for the field test program.

As described in Sections 10.4.1 and 12.2, the flexural strength of each pavement sublot for acceptance purposes was taken as the average flexural strength at seven days of the two beam specimens cast by the INDOT. A complete list of the individual, sublot average, lot average, and lot standard deviation strength results for acceptance purposes are presented in Appendix N.

The variability of the strength results can be better seen by inspection of the combined results from the beams cast by the INDOT and by the contractor. The results from the beams cast by the contractor and the INDOT are directly comparable because they were cast at the same time and from the same sample of concrete, see Section 10.4.1. The combined average seven day flexural strength and standard deviation results for the mainline pavement with fly ash are presented in Table 12-2. The lot standard deviation is calculated from the three sublot average strengths while the lot sample standard deviation is calculated from the twelve individual strength results. 
Table 12-2 Combined Seven Day Flexural Strength Results (INDOT \& Contractor)

\begin{tabular}{|c|c|c|c|c|c|c|c|c|c|c|}
\hline \multirow[t]{2}{*}{$\begin{array}{l}\text { Lot/Sublot- } \\
\text { Location }\end{array}$} & \multicolumn{2}{|c|}{$\begin{array}{l}\text { Sublot Average } \\
\text { Strength }\end{array}$} & \multicolumn{2}{|c|}{$\begin{array}{l}\text { Sublot Standard } \\
\text { Deviation }\end{array}$} & \multicolumn{2}{|c|}{$\begin{array}{l}\text { Lot Average } \\
\text { Strength }\end{array}$} & \multicolumn{2}{|c|}{$\begin{array}{l}\text { Lot Standard } \\
\text { Deviation }\end{array}$} & \multicolumn{2}{|c|}{$\begin{array}{c}\text { Lot Sample } \\
\text { Standard } \\
\text { Deviation } \\
\end{array}$} \\
\hline & psi & MPa & psi & MPa & psi & MPa & psi & MPa & psi & MPa \\
\hline $1 / 1$ & 663 & 4.57 & 48.1 & 0.33 & \multirow{3}{*}{680} & \multirow{3}{*}{4.69} & \multirow{3}{*}{34.3} & \multirow{3}{*}{0.24} & \multirow{3}{*}{49.8} & \multirow{3}{*}{0.34} \\
\hline $1 / 2$ & 719 & 4.96 & 51.0 & 0.35 & & & & & & \\
\hline $1 / 3$ & 657 & 4.53 & 32.4 & 0.22 & & & & & & \\
\hline $2 / 1$ & 631 & 4.35 & 25.1 & 0.17 & \multirow{3}{*}{644} & \multirow{3}{*}{4.44} & \multirow{3}{*}{10.7} & \multirow{3}{*}{0.07} & \multirow{3}{*}{26.1} & \multirow{3}{*}{0.18} \\
\hline $2 / 2$ & 650 & 4.48 & 37.3 & 0.26 & & & & & & \\
\hline $2 / 3$ & 650 & 4.48 & 13.2 & 0.09 & & & & & & \\
\hline $3 / 1$ & 649 & 4.48 & 24.6 & 0.17 & \multirow{3}{*}{650} & \multirow{3}{*}{4.48} & \multirow{3}{*}{4.4} & \multirow{3}{*}{0.03} & \multirow{3}{*}{19.5} & \multirow{3}{*}{0.13} \\
\hline $3 / 2$ & 645 & 4.45 & 23.7 & 0.16 & & & & & & \\
\hline $3 / 3$ & 654 & 4.51 & 13.4 & 0.09 & & & & & & \\
\hline $4 / 1$ & 642 & 4.42 & 28.7 & 0.20 & \multirow{3}{*}{658} & \multirow{3}{*}{4.53} & \multirow{3}{*}{15.5} & \multirow{3}{*}{0.11} & \multirow{3}{*}{32.6} & \multirow{3}{*}{0.22} \\
\hline $4 / 2$ & 659 & 4.54 & 10.5 & 0.07 & & & & & & \\
\hline $4 / 3$ & 673 & 4.64 & 48.2 & 0.33 & & & & & & \\
\hline $5 / 1$ & 703 & 4.85 & 6.8 & 0.05 & \multirow{3}{*}{709} & \multirow{3}{*}{4.89} & \multirow{3}{*}{15.7} & \multirow{3}{*}{0.11} & & \\
\hline $5 / 2$ & 697 & 4.81 & 31.5 & 0.22 & & & & & 26.2 & 0.18 \\
\hline $5 / 3$ & 727 & 5.01 & 28.7 & 0.20 & & & & & & \\
\hline $6 / 1$ & 708 & 4.88 & 41.1 & 0.28 & & & & & & \\
\hline $6 / 2$ & 761 & 5.25 & 39.0 & 0.27 & 730 & 5.03 & 27.7 & 0.19 & 38.6 & 0.27 \\
\hline $6 / 3$ & 722 & 4.98 & 14.2 & 0.10 & & & & & & \\
\hline
\end{tabular}

The strength results of the first lot have the highest variability. The lot standard deviation and the lot sample standard deviation are both greater for the first lot. The variability is graphically shown by Figure 12-1. The exact cause of the greater variability in the test results for the first lot is not known. Possible causes include inadequate mixing, varying degrees of compaction between specimens, and material variability within the mixture. However it is believed that the characteristics of the cement were not constant for this first portion of the field test program. While the cement met the requirements for Type I cement, it is likely that variations occurred as a result of changes to the cement manufacturing process being made at the cement plant. Unfortunately no samples of cement were collected during the project. 


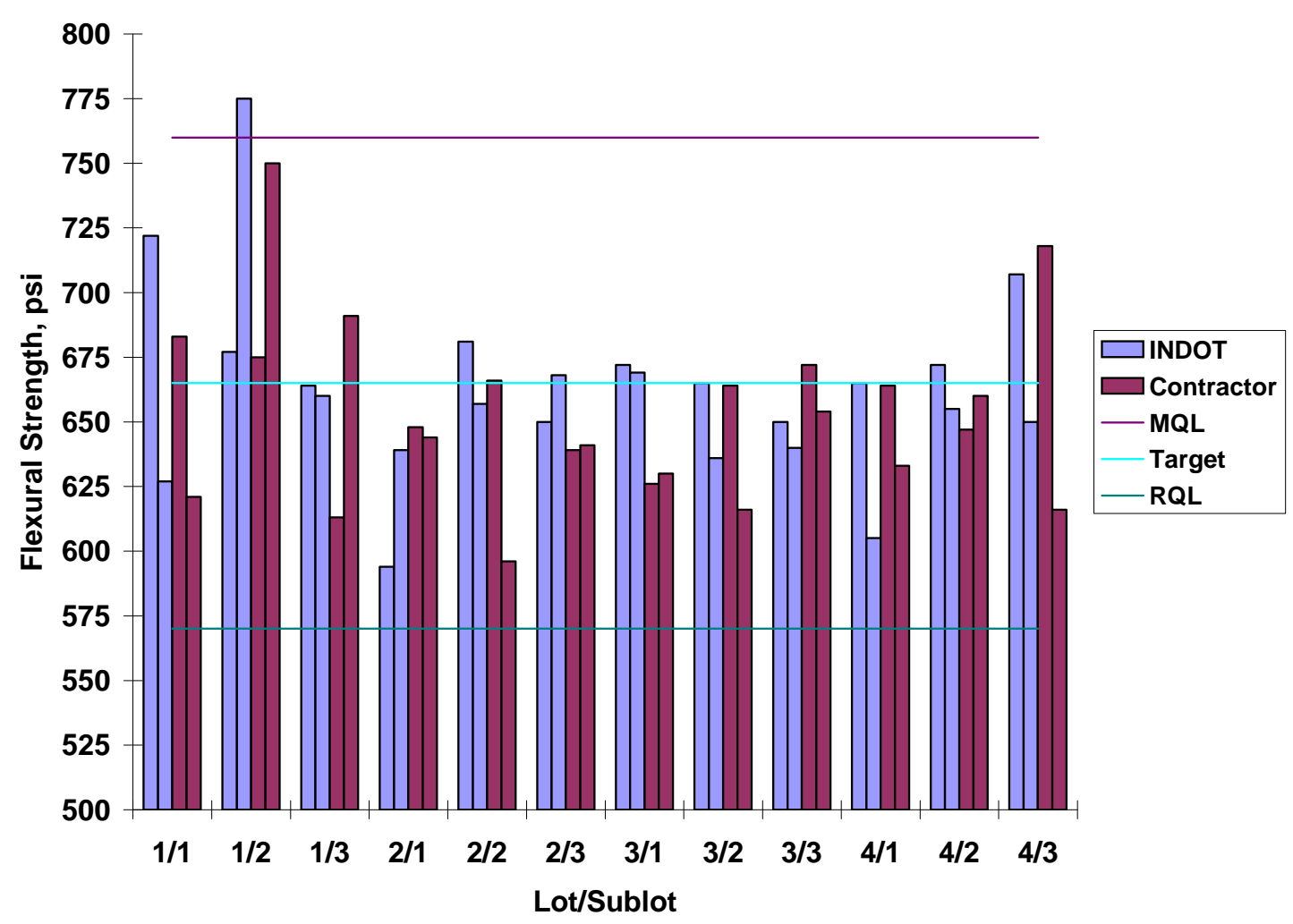

Figure 12-1 Variability of Strength Results (Mainline Pavement With Fly Ash)

The field test program included specimens that were cast at the batch plant (by INDOT, Purdue University, and the contractor) and specimens that were cast next to the as-constructed pavement from concrete sampled directly in front of the paving machine (by FHWA). Table 12-3 contains the average strength results for both specimen types at 7 and 28 days. The strength of the beam specimens cast adjacent to the pavement is not significantly different from the strength of the specimens cast at the batch plant. Therefore it does not appear that the location where the fresh concrete is sampled has a significant affect on the flexural strength. 
Table 12-3 Beam Casting Location Comparison-Strength

\begin{tabular}{|c|c|c|c|c|c|c|c|c|}
\hline \multirow{4}{*}{$\begin{array}{c}\text { Lot/ } \\
\text { Sublot } \\
\text { Location }\end{array}$} & \multicolumn{2}{|c|}{ Batch Plant } & \multicolumn{2}{c|}{ Field } & \multicolumn{2}{c|}{ Batch Plant } & \multicolumn{2}{c|}{ Field } \\
\cline { 2 - 9 } & $\begin{array}{c}\text { 7-Day } \\
\text { Sublot } \\
\text { Average } \\
\text { Strength, } \\
\text { psi }\end{array}$ & $\begin{array}{c}\text { Sublot } \\
\text { Average } \\
\text { Strength, } \\
\text { MPa }\end{array}$ & $\begin{array}{c}\text { Sublot } \\
\text { Average } \\
\text { Strength, } \\
\text { psi }\end{array}$ & $\begin{array}{c}\text { Sublot } \\
\text { Average } \\
\text { Strength, } \\
\text { MPa }\end{array}$ & $\begin{array}{c}\text { Sublot } \\
\text { Average } \\
\text { Strength, } \\
\text { psi }\end{array}$ & $\begin{array}{c}\text { Sublot } \\
\text { Average } \\
\text { Strength, } \\
\text { MPa }\end{array}$ & $\begin{array}{c}\text { Sublot } \\
\text { Average } \\
\text { Strength, } \\
\text { psi }\end{array}$ & $\begin{array}{c}\text { Sublot } \\
\text { Average } \\
\text { Strength, } \\
\text { MPa }\end{array}$ \\
\hline $1 / 3$ & 657 & 4.53 & $\sim$ & $\sim$ & 716 & 4.93 & $\sim$ & $\sim$ \\
\hline $2 / 1$ & 631 & 4.35 & 633 & 4.36 & 752 & 5.18 & 765 & 5.27 \\
\hline $2 / 2$ & 650 & 4.48 & 683 & 4.71 & 768 & 5.29 & 760 & 5.24 \\
\hline $2 / 3$ & 650 & 4.48 & 680 & 4.69 & 727 & 5.01 & 780 & 5.38 \\
\hline $3 / 1$ & 649 & 4.48 & 650 & 4.48 & $\sim$ & $\sim$ & 735 & 5.07 \\
\hline $3 / 2$ & 645 & 4.45 & 645 & 4.45 & $\sim$ & $\sim$ & 716 & 4.93 \\
\hline $3 / 3$ & 654 & 4.51 & 648 & 4.46 & $\sim$ & $\sim$ & 749 & 5.17 \\
\hline $4 / 1$ & 642 & 4.42 & 618 & 4.26 & $\sim$ & $\sim$ & 723 & 4.98 \\
\hline $4 / 2$ & 659 & 4.54 & 645 & 4.45 & $\sim$ & $\sim$ & 770 & 5.31 \\
\hline
\end{tabular}

However, it should be noted that the flexural strength will be affected if the initial curing temperatures are different. The specimens cast from concrete sampled by the paving machine were cured outside, next to the pavement for the first 24 hours, while the batch plant test specimens were cured inside a project trailer. This created the possibility of different initial curing temperatures. However, the initial curing temperatures were similar because the field test program was performed in August and the outside nighttime temperature did not fall below 18 degrees Celsius. A comparison of the temperature-time index in Table 12-4 also indicates that both casting locations experienced similar temperature histories.

Table 12-4 Beam Casting Location Comparison-Maturity

\begin{tabular}{|c|c|c|}
\hline \multirow{2}{*}{ Lot/Sublot Location } & Casting Location & $\begin{array}{c}\text { Temperature-Time Factor at 7 } \\
\text { Days, }{ }^{\circ} \mathbf{C}-\mathbf{h r}\end{array}$ \\
\hline \multirow{2}{*}{$2 / 1$} & Batch Plant & 5441 \\
\cline { 2 - 3 } & Field & 5492 \\
\hline \multirow{2}{*}{$2 / 2$} & Batch Plant & 5530 \\
\cline { 2 - 3 } & Field & 5530 \\
\hline \multirow{2}{*}{$2 / 3$} & Batch Plant & 5475 \\
\cline { 2 - 3 } & Field & 5407 \\
\hline
\end{tabular}

The increase in flexural strength from Day 7 to Day 28 is shown in Table 12-5. The strength increase is shown for both casting locations. The average strength increase for both casting locations was virtually the same (1.14 to 1.15$)$. The average strength increases for the field test 
program are slightly higher although similar to the strength increase observed in the preconstruction test program (1.11).

Table 12-5 Strength Increase

\begin{tabular}{|c|c|c|c|}
\hline \multirow{2}{*}{$\begin{array}{c}\text { Lot/Sublot- } \\
\text { Location }\end{array}$} & \multicolumn{2}{|c|}{ 28/7 Day Average Flexural Strength } \\
\cline { 2 - 4 } & $\begin{array}{c}\text { Field Test Program } \\
\text { Batch Plant } \\
\text { Specimens }\end{array}$ & Field Specimens & $\begin{array}{c}\text { Ponstruction Test } \\
\text { Program }\end{array}$ \\
\hline $1 / 3$ & 1.09 & $\sim$ & $\sim$ \\
\hline $2 / 1$ & 1.19 & 1.21 & $\sim$ \\
\hline $2 / 2$ & 1.18 & 1.11 & $\sim$ \\
\hline $2 / 3$ & 1.12 & 1.15 & $\sim$ \\
\hline $3 / 1$ & $\sim$ & 1.13 & $\sim$ \\
\hline $3 / 2$ & $\sim$ & 1.11 & $\sim$ \\
\hline $3 / 3$ & $\sim$ & 1.16 & $\sim$ \\
\hline $4 / 1$ & $\sim$ & 1.17 & 1.11 \\
\hline $4 / 2$ & $\sim$ & 1.19 & $\sim$ \\
\hline Average & 1.14 & 1.15 & $\sim$ \\
\hline
\end{tabular}

The average split tensile strengths for the cylinder specimens cast by the FHWA are presented in Table 12-6. The split tensile strengths are compared to the flexural strengths of the beams cast by the FHWA. The average split tensile to flexural strength ratio varies from 0.610 to 0.754 , with the average being 0.670 . For comparison, the ratio at seven days for the preconstruction test program was 0.645 . Similar to the pre-construction test results, the split tensile strength test results show a higher variability than the flexural strength test results, as evidenced by the larger sublot standard deviation. 
Table 12-6 Flexural to Split Tensile Strength (Seven Days)

\begin{tabular}{|c|c|c|c|c|c|}
\hline $\begin{array}{c}\text { Lot/Sublot- } \\
\text { Location }\end{array}$ & $\begin{array}{c}\text { Average } \\
\text { Flexural } \\
\text { Strength, psi }\end{array}$ & $\begin{array}{c}\text { Average } \\
\text { Flexural } \\
\text { Strength, MPa }\end{array}$ & $\begin{array}{c}\text { Average Split } \\
\text { Tensile } \\
\text { Strength, psi }\end{array}$ & $\begin{array}{c}\text { Average Split } \\
\text { Tensile } \\
\text { Strength, MPa }\end{array}$ & $\begin{array}{c}\text { Average Split } \\
\text { Tensile/ Flexural } \\
\text { Strength }\end{array}$ \\
\hline $2 / 1$ & 633 & 4.36 & 443 & 3.05 & 0.700 \\
\hline $2 / 2$ & 683 & 4.71 & 445 & 3.07 & 0.652 \\
\hline $2 / 3$ & 680 & 4.69 & 425 & 2.93 & 0.625 \\
\hline $3 / 1$ & 650 & 4.48 & 490 & 3.38 & 0.754 \\
\hline $3 / 2$ & 645 & 4.45 & 475 & 3.28 & 0.736 \\
\hline $3 / 3$ & 648 & 4.46 & 395 & 2.72 & 0.610 \\
\hline $4 / 1$ & 618 & 4.26 & 403 & 2.78 & 0.652 \\
\hline $4 / 2$ & 645 & 4.45 & 415 & 2.86 & 0.643 \\
\hline Average & 650 & 4.48 & 436 & 3.00 & 0.670 \\
\hline $\begin{array}{c}\text { Average Sublot } \\
\text { Standard } \\
\text { Deviation }\end{array}$ & 22.10 & 0.15 & 44.45 & 0.31 & $\sim$ \\
\hline
\end{tabular}

\subsection{Temperature Measurement Results}

The temperature history of the beams cast by Purdue and by the FHWA was recorded. Two thermocouples were placed in one beam for each sublot. The recorded temperatures from the two thermocouples for each specimen were averaged to get the temperature history of each specimen. For the specimens cast by Purdue, the temperature history was recorded for twenty days. Further measurement was not necessary because the temperature of the specimens was maintained virtually constant by the temperature controlled water bath. The temperature at each thermocouple was measured every minute and every ten minutes the average temperature was recorded. For the specimens cast by the FWHA the temperature history was recorded for 28 days. The temperature at each thermocouple was measured every 30 minutes for the first 48 hours and every 60 minutes afterwards.

The temperature history of the pavement, shown in Figure 12-2, was also recorded. A wooden dowel with four thermocouples was inserted into the pavement at two locations in Lot 2 of the mainline pavement with fly ash, one location in Sublot 2 and one location in Sublot 3 . The dowel was inserted 12 inches from the pavement edge. One thermocouple recorded the temperature of the ambient air. The other three thermocouples recorded the temperature of the 
pavement at one inch from the top of the pavement, the middle of the pavement, and one inch from the bottom of the pavement. Temperature measurements were recorded every 30 minutes for the first 48 hours and every 60 minutes afterwards for a period of nine days.

Figure 12-2 shows that highest recorded temperature in the pavement occurred in the middle of the pavement. The temperature near the bottom of the pavement was typically very close to the temperature of the middle of the pavement. The temperature near the top of the slab showed the most variation, changing in response to the air temperature. The initial temperature history of the middle of the pavement (thickness of 14 inch) was similar to the initial temperature history of the middle of the 14 inch slab, as shown in Figure 11-6. The initial peak temperature of the middle of the pavement was slightly higher, approximately $2^{\circ} \mathrm{C}\left(3.6^{\circ} \mathrm{F}\right)$, than the middle of the slab.

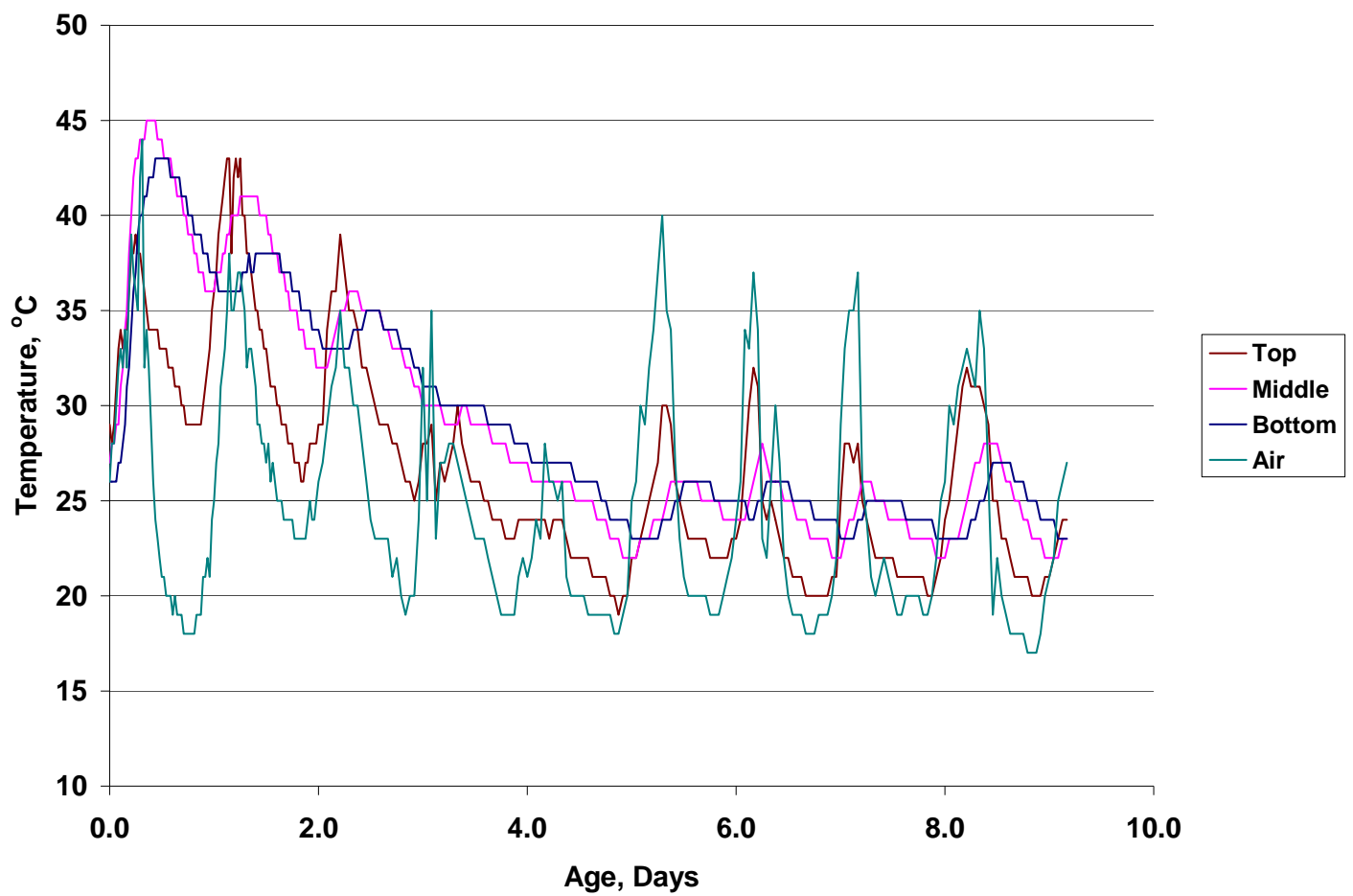

Figure 12-2 Pavement Temperature History 


\subsection{Strength to Maturity Relationship}

\subsubsection{Maturity Index}

The temperature history was used to calculate the temperature-time factor using the NurseSaul equation with a datum temperature of $-10{ }^{\circ} \mathrm{C}$ and the equivalent age at $23{ }^{\circ} \mathrm{C}$ using the Arrhenius function with a value of the activation energy divided by the gas constant (Q) of 5000 ${ }^{\circ} \mathrm{K}$. Section 11.4.1 indicates the reasoning behind the selection of these values.

The maturity indexes for the beams and the pavement are presented in Table 12-7. Similar to the results in the pre-construction test program, the temperature-time factor for the larger specimen, the pavement, is greater than the smaller beam specimen. At early ages, the maturity index calculated from the temperatures at the middle of the slab is slightly higher than the maturity index of the bottom of the slab. This is because the temperature of the middle of the slab is higher at early ages. However at the age of 7-days, the maturity index of the bottom of the slab is slightly greater than or about equal to the middle of the slab. This is because the temperature of the middle of the slab drops below the temperature of the bottom slab in response to the cooler nighttime temperatures as shown in Figure 12-2.

Table 12-7 Field Test Program Maturity Indexes

\begin{tabular}{|c|c|c|c|c|c|c|}
\hline \multirow{2}{*}{ Specimen } & \multirow{2}{*}{$\begin{array}{l}\text { Lot/Sublot } \\
\text { Location }\end{array}$} & \multirow{2}{*}{$\begin{array}{l}\text { Thermocouple } \\
\text { Location }\end{array}$} & \multicolumn{2}{|c|}{$\begin{array}{l}\text { Temperature-Time Factor, } \\
{ }^{\circ} \mathrm{C}-\mathrm{hr} \text {, at: }\end{array}$} & \multicolumn{2}{|c|}{$\begin{array}{c}\begin{array}{c}\left.\text { Equivalent Age (at } 23^{\circ} \mathrm{C}\right), \\
\text { hrs, at: }\end{array} \\
\end{array}$} \\
\hline & & & 3 Days & 7 Days & 3 Days & 7 Days \\
\hline \multirow{3}{*}{ Pavement } & \multirow{3}{*}{$2 / 2$} & Top & 3052 & 6299 & 130 & 226 \\
\hline & & Middle & 3368 & 6790 & 156 & 268 \\
\hline & & Bottom & 3309 & 6789 & 154 & 265 \\
\hline \multirow{3}{*}{ Pavement } & \multirow{3}{*}{$2 / 3$} & Top & 3123 & $\sim$ & 124 & $\sim$ \\
\hline & & Middle & 3377 & 6865 & 156 & 273 \\
\hline & & Bottom & 3353 & 6906 & 149 & 275 \\
\hline Beam & $2 / 2$ & Middle & 2439 & 5422 & 76.2 & 162 \\
\hline Beam & $2 / 3$ & Middle & 2462 & 5444 & 78.0 & 164 \\
\hline Beam & $6 / 2$ & Middle & 2340 & 5333 & 70.2 & 157 \\
\hline
\end{tabular}




\subsubsection{Predicting Beam Flexural Strength}

The strength-maturity relationship developed in the pre-construction test program was not applicable to the concrete mixture used in the field test program as indicated in Section 12.1. An attempt was made to create a strength-maturity relationship for the concrete mixture used in the field test program using the data collected by the contractor in accordance with ITM 402-99. ITM 402-99 covers the use of the maturity concept to determine when concrete pavements can be opened to traffic. The temperature-time factor (from the Nurse-Saul equation with a datum temperature of $-10{ }^{\circ} \mathrm{C}$ ) and average flexural strength are determined at four different ages, usually $24,36,48$, and 60 hours. To create the strength-maturity relationship, the temperaturetime factor and average flexural strength were determined by the pavement contractor at these four ages plus the additional age of 7 days. The offset hyperbolic function, as described in Section 11.4.1, was then fit to this data. The strength-maturity relationship, referred to as the partial strength-maturity relationship from this point forward, is shown in Figure 12-3. It should be noted that the method of data collection prevented the calculation of the equivalent age maturity index. 


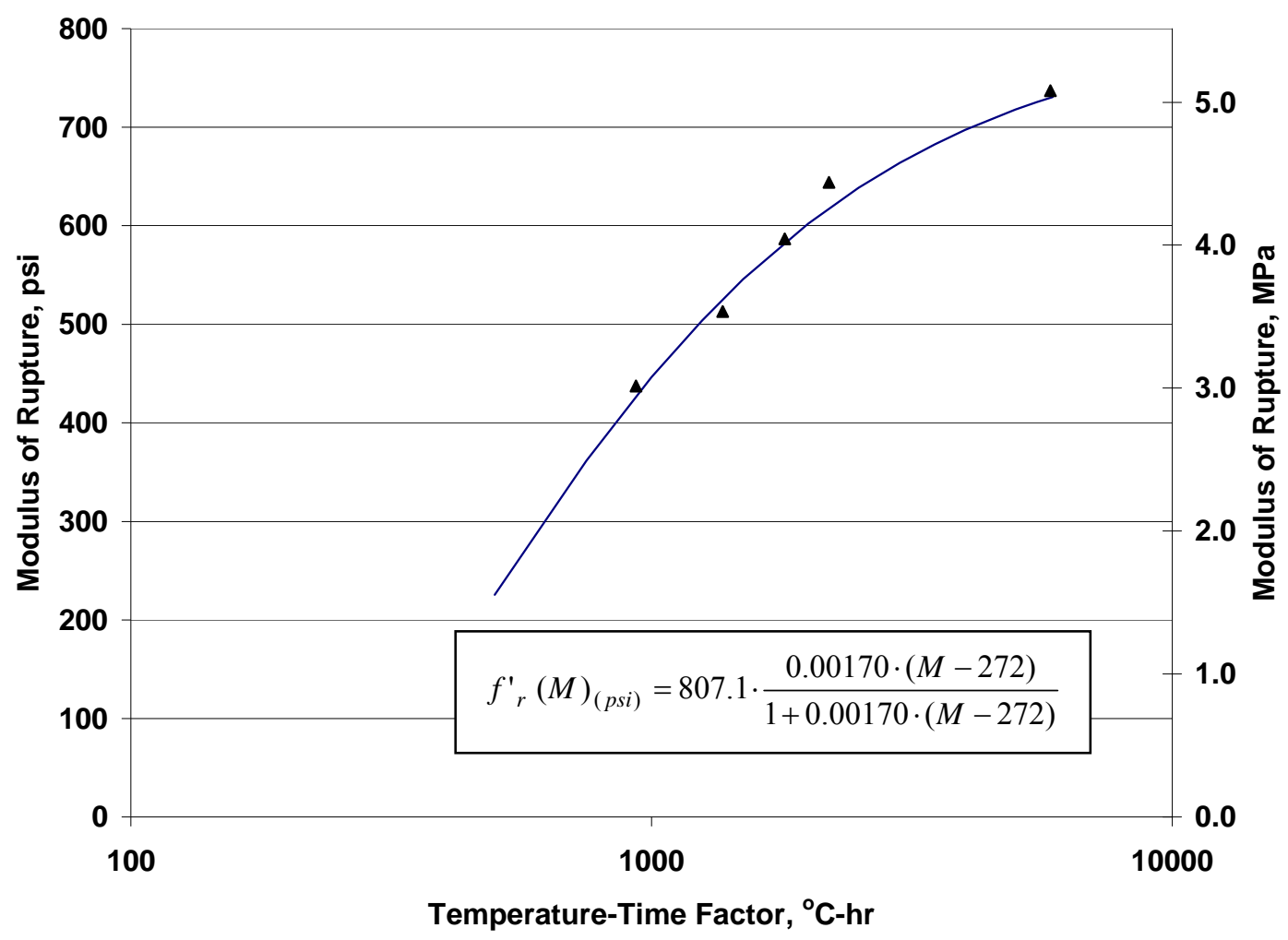

Figure 12-3 Strength-Maturity Relationship From Partial Data

The partial strength-maturity relationship was used to predict the flexural strength at seven days for the beam specimens in which the temperature history was recorded. Since the relationship was created from strength data up to seven days, strength predictions were not made for ages greater than seven days with this relationship. The strength predictions are given in Table 12-8. While the offset hyperbolic function fit the data very well, as shown in Figure 12-3, the estimates of flexural strength from the strength-maturity relationship are not very accurate. The predicted strength is on average $11.6 \%$ greater than the actual strength of the beams. A possible cause of the error in the strength estimate is the value of the limiting strength, $\mathrm{S}_{\infty}$. It has been found that the value of the limiting strength should be determined from data for equivalent ages beyond about seven days (Carino, 1984b). However, only one age was tested with an equivalent age greater than seven days, the last age tested, Day 7. Therefore, since data from a minimum of two ages is necessary to get the value of limiting strength, the value of the limiting strength for this relationship was determined using data less than seven days. The difference 
between the predicted and the actual strength could also be due to material or mixture proportion variability. This possibility is explored further in ensuing paragraphs.

Table 12-8 Beam Flexural Strength From Temperature-Time Factor

\begin{tabular}{|c|c|c|c|c|c|c|c|}
\hline \multirow{2}{*}{$\begin{array}{c}\text { Lot/ } \\
\text { Sublot } \\
\text { Location }\end{array}$} & \multirow{2}{*}{$\begin{array}{c}\text { Casting } \\
\text { Location }\end{array}$} & \multirow{2}{*}{$\begin{array}{l}\text { Age, } \\
\text { Days }\end{array}$} & \multirow{2}{*}{$\begin{array}{c}\text { Average } \\
\text { Flexural } \\
\text { Strength, } \\
\text { psi }\end{array}$} & \multicolumn{2}{|c|}{$\begin{array}{l}\text { Predicted Beam Flexural } \\
\text { Strength, psi }\end{array}$} & \multicolumn{2}{|c|}{ Percent Increase in Strength } \\
\hline & & & & $\begin{array}{c}\text { Partial } \\
\text { Relationship }\end{array}$ & $\begin{array}{c}\text { Full } \\
\text { Relationship }\end{array}$ & $\begin{array}{c}\text { Partial } \\
\text { Relationship }\end{array}$ & $\begin{array}{c}\text { Full } \\
\text { Relationship }\end{array}$ \\
\hline $1 / 3$ & Batch Plant & 7 & 657 & 725 & 698 & 10.3 & 6.24 \\
\hline \multirow{2}{*}{$2 / 1$} & Batch Plant & 7 & 631 & 725 & 697 & 14.9 & 10.4 \\
\hline & Field & 7 & 633 & 725 & 698 & 14.5 & 10.3 \\
\hline \multirow{2}{*}{$2 / 2$} & Batch Plant & 7 & 650 & 726 & 699 & 11.7 & 7.54 \\
\hline & Field & 7 & 683 & 726 & 699 & 6.30 & 2.34 \\
\hline \multirow{2}{*}{$2 / 3$} & Batch Plant & 7 & 650 & 725 & 698 & 11.6 & 7.47 \\
\hline & Field & 7 & 680 & 724 & 697 & 6.47 & 2.50 \\
\hline $3 / 1$ & Field & 7 & 650 & 729 & 702 & 12.1 & 8.00 \\
\hline $3 / 2$ & Field & 7 & 645 & 722 & 694 & 11.9 & 7.60 \\
\hline $3 / 3$ & Field & 7 & 648 & 724 & 696 & 11.7 & 7.41 \\
\hline $4 / 1$ & Field & 7 & 618 & 720 & 692 & 16.5 & 12.0 \\
\hline $4 / 2$ & Field & 7 & 645 & 715 & 686 & 10.8 & 6.36 \\
\hline $1 / 3$ & Batch Plant & 28 & 716 & $\sim$ & 778 & $\sim$ & 8.66 \\
\hline \multirow{2}{*}{$2 / 1$} & Batch Plant & 28 & 752 & $\sim$ & 778 & $\sim$ & 3.46 \\
\hline & Field & 28 & 765 & $\sim$ & 776 & $\sim$ & 1.44 \\
\hline \multirow{2}{*}{$2 / 2$} & Batch Plant & 28 & 768 & $\sim$ & 777 & $\sim$ & 1.17 \\
\hline & Field & 28 & 760 & $\sim$ & 776 & $\sim$ & 2.11 \\
\hline \multirow{2}{*}{$2 / 3$} & Batch Plant & 28 & 727 & $\sim$ & 777 & $\sim$ & 6.88 \\
\hline & Field & 28 & 780 & $\sim$ & 776 & $\sim$ & -0.51 \\
\hline $3 / 1$ & Field & 28 & 735 & $\sim$ & 777 & $\sim$ & 5.71 \\
\hline $3 / 2$ & Field & 28 & 716 & $\sim$ & 774 & $\sim$ & 8.10 \\
\hline $3 / 3$ & Field & 28 & 745 & $\sim$ & 777 & $\sim$ & 4.30 \\
\hline $4 / 1$ & Field & 28 & 723 & $\sim$ & 776 & $\sim$ & 7.33 \\
\hline $4 / 2$ & Field & 28 & 770 & $\sim$ & 776 & $\sim$ & 0.78 \\
\hline
\end{tabular}

A second strength-maturity relationship was therefore created for the concrete mixture used in the field test program by casting additional beam specimens during the paving of Lot 6 , Sublot 2 mainline pavement with fly ash. This was the second to last sublot cast before the contractor stopped including fly ash in the concrete mixture as described in Section 10.4.1. Ten beams were cast and the temperature history was recorded in one of the specimens. The casting, curing, and test procedures were the same as was used for the previous specimens cast at the batch plant. The average flexural strength was determined from two beam specimens at 1, 4, 8, 15, and 29 days (a 
scheduling error caused the strengths to be measured at 8,15 , and 29 days rather than the typical 7,14 , and 28 days). Both the temperature-time factors and the equivalent ages were calculated and the strength-maturity relationship using the offset hyperbolic function was determined from the plot of the maturity index versus average flexural strength. This strength-maturity relationship is referred to as the 'full' strength-maturity relationship to help differentiate it from the 'partial' strength-maturity relationship. The full strength-maturity relationship using the temperature-time factor is shown in Figure 12-4.

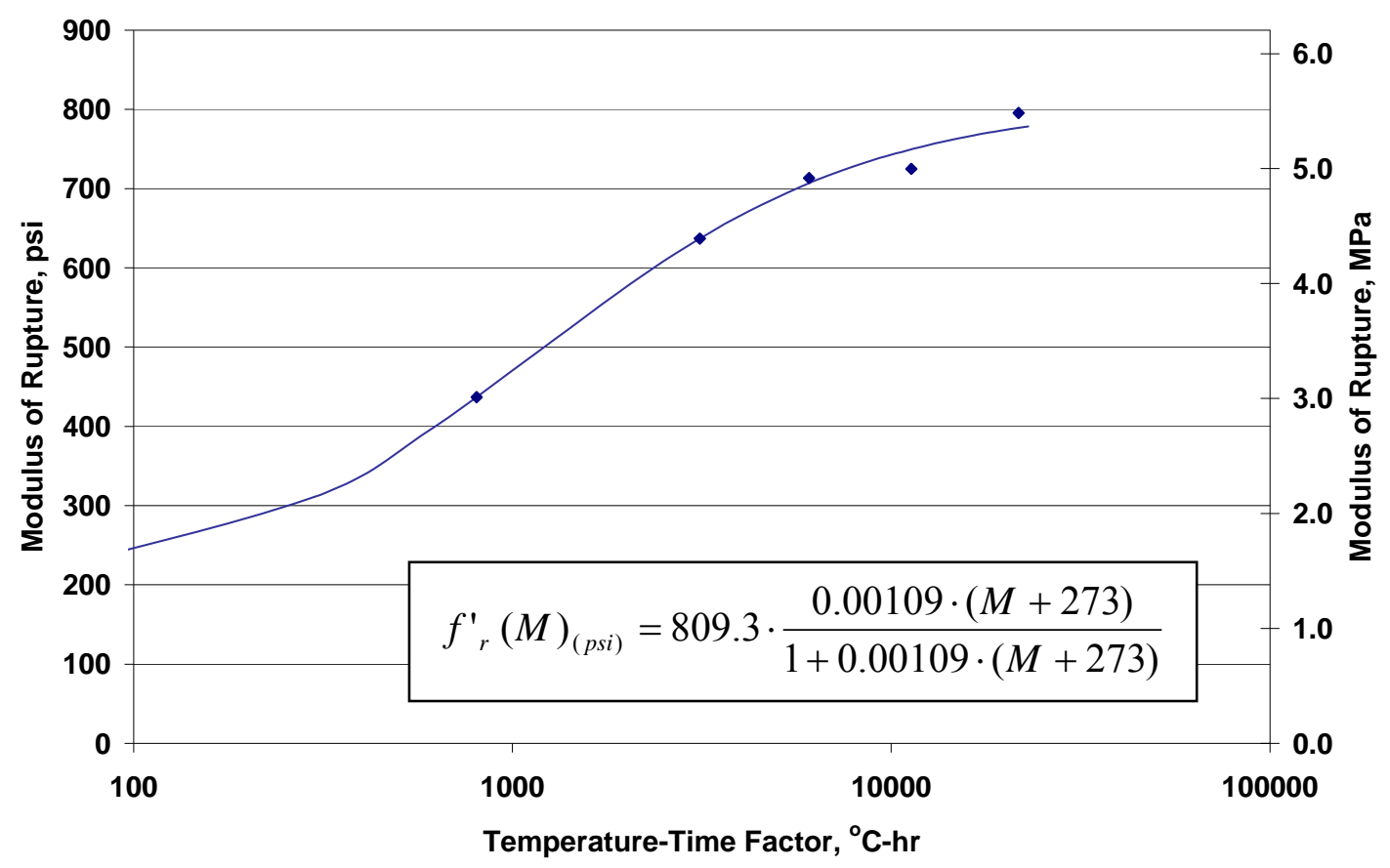

Figure 12-4 Strength-Maturity Relationship From Field Specimens

The full strength-maturity relationship was used to predict the flexural strength at seven and twenty-eight days for the beam specimens in which the temperature history was recorded. The strength predictions using the temperature-time factor are given in Table 12-8. The strength predictions for the beam specimens using the equivalent age index are not presented because they are virtually identical (within $2 \mathrm{psi}(0.014 \mathrm{MPa})$ to the predictions using the temperaturetime index. This is a result of the curing temperature of the beams being the same as the curing temperature at which the strength-maturity relationship was created. 
The estimates of flexural strength from the full strength-maturity relationship are closer to the actual beam strengths than the partial strength-maturity relationship. The predicted strength is on average $5.73 \%$ greater, $39 \mathrm{psi}(0.27 \mathrm{MPa})$, than the actual strength of the beams, compared to $11.6 \%, 75 \mathrm{psi}(0.51 \mathrm{MPa})$, greater for the partial strength-maturity relationship. For the full relationship, the predicted strengths at 28 days are on average closer to the actual strengths than the predicted strengths at 7 days, $4.1 \%, 30.1 \mathrm{psi}(0.21 \mathrm{MPa})$, compared to $7.34 \%, 47 \mathrm{psi}(0.33$ $\mathrm{MPa})$.

A possible cause of the error in the strength estimate for the full strength-maturity relationship is the value of $\mathrm{M}_{\mathrm{o}}\left(-273^{\circ} \mathrm{C}-\mathrm{hr}\right)$. As discussed in Section 11.4.1, a negative value of $\mathrm{M}_{\mathrm{o}}$ does not physically make sense. The value is expected to be slightly greater than zero. The value of $M_{o}$ should be obtained using data at very early ages (Carino 1984b). The value of $M_{o}$ was obtained from data at the age of 1 and 4 days. In contrast, a realistic value of $\mathrm{M}_{\mathrm{o}}\left(272{ }^{\circ} \mathrm{C}-\mathrm{hr}\right)$ was obtained for the 'partial' strength-maturity relationship, which had strength-maturity data for early ages $(24,36$, and 48 hours).

Other possible causes of error in the estimate of strength for both strength-maturity relationships are material and mixture proportion changes from the materials and mixture proportions used to create the strength-maturity relationship. The high variability in the strength test results from the first lot, as shown in Table 12-2 and Figure 12-1 may have been caused by changes in the quality of the materials or by changes in the mixture proportions. The strengthmaturity relationship is only valid for concrete with the same concrete mixture proportions and materials. Assessing the material variability was not possible because detailed information on the characteristics of the material was not available. However as noted in Section 12.1, it is likely that the characteristics of the cement were not constant during the field test program. It should be noted that the materials used in construction complied with INDOT requirements.

However, it was possible to verify that changes in the mixture proportions did occur. Small changes in mixture proportions are typically made in response to project conditions such 
as a change in the weather. Several mixture proportion items for seven consecutive sublots are presented in Table 12-9. The information was taken from records kept by the pavement contractor. The mixture proportion variability can be seen in Table 12-9 by observing the changes in the mixture proportions. The most notable variation, and probably the most influential with respect to the strength-maturity relationship is the variation in the water-to-cement ratio. For the seven sublots shown the water-to-cement ratio varies from as much as 0.436 to as low as 0.405 . Chapter 13 contains further discussion on the possible effects of mixture proportion variability on the estimate of strength using maturity.

Table 12-9 Mixture Proportions

\begin{tabular}{|c|c|c|c|c|c|}
\hline $\begin{array}{l}\text { Lot/Sublot } \\
\text { Location }\end{array}$ & W/C Ratio & $\begin{array}{c}\text { Air } \\
\text { Entraining } \\
\text { Agent, } \mathrm{ml} / \mathrm{m}^{3}\end{array}$ & $\begin{array}{c}\text { Water } \\
\text { Reducer, } \\
\mathrm{ml}^{\prime} / \mathrm{m}^{3}\end{array}$ & $\begin{array}{c}\text { Cement, } \\
\mathrm{kg} / \mathrm{m}^{3}\end{array}$ & $\begin{array}{c}\text { Fly Ash, } \\
\text { kg/m } \mathbf{m}^{3}\end{array}$ \\
\hline $1 / 3$ & 0.420 & 127.7 & 743.2 & 263.6 & 42.5 \\
\hline $2 / 1$ & 0.405 & 123.8 & 743.2 & 263.6 & 43.2 \\
\hline $2 / 2$ & 0.436 & 123.8 & 743.2 & 267.7 & 37.7 \\
\hline $2 / 3$ & 0.433 & 131.5 & 743.2 & 263.6 & 45.8 \\
\hline $3 / 1$ & 0.414 & 139.4 & 743.2 & 264.8 & 41.4 \\
\hline $3 / 2$ & 0.418 & 139.4 & 739.3 & 263.9 & 41.8 \\
\hline $3 / 3$ & 0.418 & 135.5 & 743.2 & 264.5 & 38.5 \\
\hline
\end{tabular}

\subsubsection{Predicting Pavement Flexural Strength}

The flexural strength-maturity relationships were used to predict the flexural strength of the pavement. The predicted strength of the pavement using the temperature-time factor (and both the partial and full relationships) is presented in Table 12-10, while the predicted strength using the equivalent age (full relationship) is presented in Table 12-11. For both indexes, the predicted flexural strength is compared to the average flexural strength of the beam specimens for the corresponding location. The predicted strength of the pavement at 7 days was greater than the average strength of the beams at 7 days. This trend was also found in the pre-construction test program where the predicted strength of the slab specimens was greater than the corresponding measured strength of the beams.

It should be noted that the flexural strength of the pavement was predicted using the maturity index corresponding to the center of the pavement profile. The maturity index corresponding to 
the center of the pavement profile was used because it was the largest index for the three locations measured. The predicted flexural strength using the maturity index corresponding to the top of the pavement (the lowest value) was approximately 6 psi (0.041 MPa) lower at seven days for both pavement locations. While the difference in the predicted strength due to the temperature measurement location at seven days is relatively small, the appropriate location in the pavement to measure the temperature is recommended for further study.

Table 12-10 Pavement Strength From Temperature-Time Factor

\begin{tabular}{|c|c|c|c|c|c|c|c|}
\hline \multirow{2}{*}{$\begin{array}{c}\text { Lot/ } \\
\text { Sublot } \\
\text { Location }\end{array}$} & \multirow{2}{*}{$\begin{array}{l}\text { Casting } \\
\text { Location }\end{array}$} & \multirow{2}{*}{$\begin{array}{l}\text { Age, } \\
\text { Days }\end{array}$} & \multirow{2}{*}{$\begin{array}{c}\text { Average } \\
\text { Beam } \\
\text { Flexural } \\
\text { Strength, } \\
\text { psi }\end{array}$} & \multicolumn{2}{|c|}{$\begin{array}{c}\text { Predicted Pavement Flexura } \\
\text { Strength, psi }\end{array}$} & \multicolumn{2}{|c|}{ Percent Increase in Strength } \\
\hline & & & & $\begin{array}{c}\text { Partial } \\
\text { Relationship }\end{array}$ & $\begin{array}{c}\text { Full } \\
\text { Relationship }\end{array}$ & $\begin{array}{c}\text { Partial } \\
\text { Relationship }\end{array}$ & $\begin{array}{c}\text { Full } \\
\text { Relationship }\end{array}$ \\
\hline \multirow{2}{*}{$2 / 2$} & Batch Plant & 7 & 650 & 740 & 716 & 13.9 & 10.17 \\
\hline & Field & 7 & 683 & 740 & 716 & 8.37 & 4.85 \\
\hline \multirow{2}{*}{$2 / 3$} & Batch Plant & 7 & 650 & 741 & 717 & 14.1 & 10.39 \\
\hline & Field & 7 & 680 & 741 & 717 & 8.96 & 5.44 \\
\hline
\end{tabular}

Table 12-11 Pavement Strength From Equivalent Age (at $23^{\circ} \mathrm{C}$ )

\begin{tabular}{|c|c|c|c|c|c|}
\hline \multirow{2}{*}{$\begin{array}{c}\text { Lot/ Sublot } \\
\text { Location }\end{array}$} & $\begin{array}{c}\text { Casting } \\
\text { Location }\end{array}$ & Age, Days & $\begin{array}{c}\text { Average Beam } \\
\text { Flexural } \\
\text { Strength, psi }\end{array}$ & $\begin{array}{c}\text { Predicted } \\
\text { Pavement } \\
\text { Flexural } \\
\text { Strength, psi }\end{array}$ & $\begin{array}{c}\text { Percent } \\
\text { Increase in } \\
\text { Strength }\end{array}$ \\
\hline \multirow{2}{*}{$2 / 2$} & Batch Plant & 7 & 650 & 737 & 13.3 \\
\cline { 2 - 6 } & Field & 7 & 683 & 737 & 7.86 \\
\hline \multirow{2}{*}{$2 / 3$} & Batch Plant & 7 & 650 & 738 & 13.6 \\
\cline { 2 - 6 } & Field & 7 & 680 & 738 & 8.5 \\
\hline
\end{tabular}

Also as observed in the pre-construction test program, the strength-maturity relationship using the equivalent age index predicted a greater rate of strength gain than the strength-maturity relationship using the temperature-time maturity index. The predicted pavement strength was an average of $21 \mathrm{psi}(0.14 \mathrm{MPa})$ greater using the equivalent age index compared to using the temperature-time index. The reasons for the higher rate of strength gain using equivalent age are discussed in Section 11.4.2. The rate of strength gain predicted by the Arrhenius function is considered to be more accurate because it has been demonstrated to be able to account for the affects of temperature on strength gain over a wide range of temperatures as indicated in Section 9.3.4 


\subsection{Measurement of Compression Wave (P-wave) Velocity Results}

\subsubsection{Beam Specimens}

The P-wave velocity of the beam specimens cast by Purdue was measured at the age of 7 and 28 days. The $\mathrm{P}$-wave velocity was measured in direct transmission using the pulse velocity test apparatus and in surface transmission using the AE test system. The equipment for both test methods was set-up on a table in the quality control project trailer near the moist curing tanks for easy access to the beam specimens. The beams were tested immediately after removal from the curing tank and were returned to the curing tank immediately after testing. The results are presented in Table O-1.

The P-wave velocity, from the direct transmission pulse velocity test method, as measured in beam specimens for Lot 1, Sublot 3 through Lot 2, Sublot 3 is plotted against the average flexural strength in Figure 12-5. At the age of 7 days, the P-wave velocity is plotted against the average flexural strength of the four beam specimens cast at the batch plant ( 2 by the INDOT and 2 by the contractor). At the age of 28 days, the P-wave velocity is plotted against the average flexural strength of the two beam specimens cast by Purdue University at the batch plant. The general linear relationship between P-wave velocity and strength as observed in the preconstruction test program can also be observed in Figure 12-5. However, as shown by the figure and the lower $\mathrm{R}^{2}$ value, the linear relationship does not fit the data as well as in the preconstruction program. The 28-day data in particular does not appear to be represented well by a linear relationship. This may be due to the decreased sensitivity of the P-wave velocity to strength at later ages, as described in Section 11.5.2 


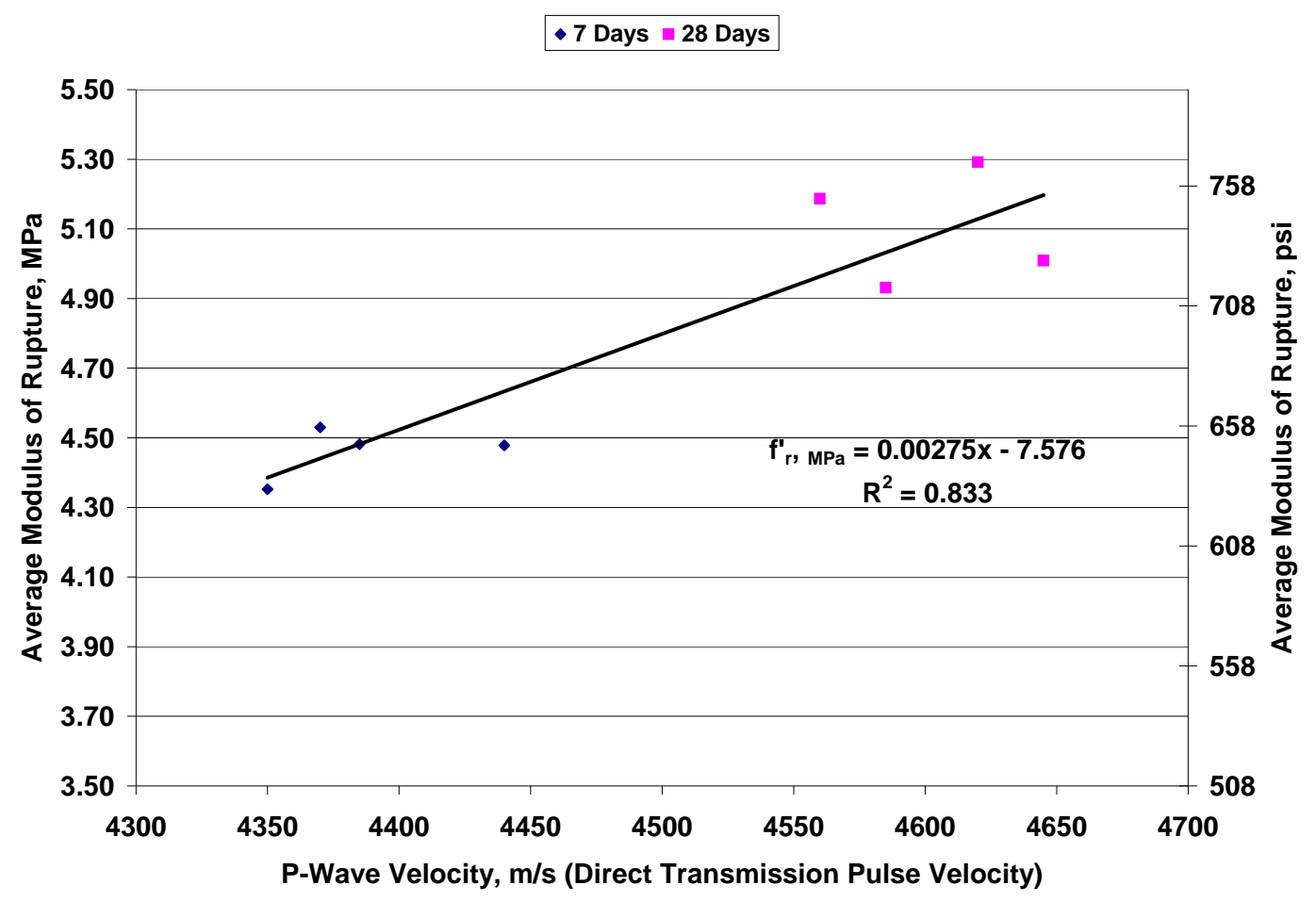

Figure 12-5 P-Wave Velocity Versus Strength (Field Specimens)

The strength of the beam specimens and the pavement was not estimated using the measured $\mathrm{P}$-wave velocity. The strength-P-wave velocity relationship established in the pre-construction test program was not applicable to the concrete mixture used in the field test program due to changes in the materials and mixture proportions, as indicated in Section 12.1. Project scheduling, equipment, and time limitations prevented the development of a strength-P-wave relationship applicable to the field test program concrete mixture.

\subsubsection{Pavement}

The P-wave velocity of the mainline pavement with fly ash was measured at sixteen of the INDOT core locations using impact-echo equipment available from the FHWA. The surface transmission method using the pulse velocity test apparatus was not used to measure the P-wave velocity because of the difficulties experienced in the pre-construction test program. The surface method using the AE equipment was not used to measure the P-wave velocity because the test 
equipment was not designed for field use. All pavement test locations were a minimum of six days old at the time of testing. The test results are contained in Table O-2.

Multiple tests were performed at each test location. Each test consisted of impacting the pavement with a small diameter sphere with the resulting surface displacements at two transducers being recorded. The test control and analysis software was then used to inspect both surface displacement waveforms. Tests with invalid surface displacement waveforms were discarded (for discussion of valid waveforms, see Section 11.7.1). The P-wave velocity as calculated by the software was also inspected. The software automatically calculated the P-wave velocity by determining the arrival of the P-wave at each transducer, calculating the corresponding transit time, dividing the known distance between the transducers by the transit time, and then multiplying by 0.96 (see Section 9.2.2.3). Many tests produced P-wave velocities that were significantly higher $(5000$ to $6000 \mathrm{~m} / \mathrm{s})$ or lower $(2000-3000 \mathrm{~m} / \mathrm{s})$ than typical P-wave velocities for concrete. These atypical tests were most likely caused by insufficient or multiple impacts, or inadequate contact between the pavement and the transducers and therefore were also discarded. The tests that indicated a reasonable P-wave velocity $(3000-4500 \mathrm{~m} / \mathrm{s}) \mathrm{with}$ valid surface displacement waveforms were recorded. The average P-wave velocity at each location was determined from the average of these recorded test results.

The repeatability of the measurement of the P-wave velocity using the impact-echo equipment available from the FHWA was poor. Excluding the tests that produced an unreasonable $\mathrm{P}$-wave velocity, neither a single value nor a small range of values of the $\mathrm{P}$-wave velocity was consistently obtained at each test location. The average standard deviation was 138 $\mathrm{m} / \mathrm{s}$. The lack of repeatability and the high variability implies that the P-wave velocity was not accurately estimated by this test method.

The high variability of the measured P-wave velocity appears to be due to the minimum surface displacement detected by the test equipment and the relatively large sampling interval used in the measurements. The minimum surface displacement that was recorded by the test system was $1.2 \mathrm{mV}$. However, depending upon the distance of the recording transducer from the 
impact source and the energy of the impact, the surface displacement caused by the P-wave can be smaller than $1.2 \mathrm{mV}$. For example, at a distance of $150 \mathrm{~mm}$, Figure 10-18 shows the displacement caused by the arrival of the P-wave as approximately $0.3 \mathrm{mV}$. It should be noted that the energy of the impact for the test recorded in Figure 10-18 was less than the energy of the impacts for the tests using the impact-echo equipment. However test system that is capable of detecting smaller surface displacements would provide more confidence in the determination of the arrival of the P-wave and therefore the estimation of the P-wave velocity.

The relatively large sampling interval used in the tests also appears to have contributed to the high variability. The test control software was set to a sampling interval of $2 \mu$ s for the P-wave velocity measurements. This meant that the software should have recorded a surface displacement, in volts, every $2 \mu \mathrm{s}$. However, later inspection of the recorded data revealed that the test system only recorded a surface displacement every $4 \mu \mathrm{s}$. The reason for the discrepancy is not known. The length of time in-between measurements appears to have made it difficult to identify the arrival of the P-wave at each transducer and therefore to estimate the P-wave velocity. Figure 10-18 shows that the arrival of the P-wave took approximately $3 \mu$ s, therefore

making it possible for the test equipment, sampling every $4 \mu \mathrm{s}$, to have missed the exact arrival.

A test system that can take measurements at closer intervals and that is capable of detecting smaller changes could improve the estimate of the P-wave velocity. The smaller sampling interval and improved sensitivity would provide more confidence in the determination of the arrival of the short duration, low amplitude P-wave. For comparison, the AE test system used in this program was capable of sampling at $0.1 \mu$ s intervals and measuring surface displacements equal to approximately $0.003 \mathrm{mV}$.

\subsection{Pavement Thickness by Coring}

The thickness of each pavement sublot for acceptance purposes was taken as the average length of two cores extracted from each sublot. The length of each core was measured in millimeters using the apparatus pictured in Figure 10-22. The measured length was converted to 
inches using the INDOT conversion of 1 inch equals 25.0 millimeters. Measurements using this conversion will be referred to as INDOT length. A complete list of the individual, sublot average, and lot average pavement thickness results for acceptance purposes are presented in Appendix P.

The length of the each core was determined in accordance with ITM 402 by taking the average of ten separate measurements, as discussed in Section 11.6. The variability of the length of each core is indicated in Table 12-12 using the standard deviation and the range. The traditional conversion of 1 inch equal to $25.4 \mathrm{~mm}$ was used in Table 12-12. Table 12-12 shows the variability for the core locations where impact-echo tests were performed. In addition the average variability for all of the cores measured for INDOT Project R-24432 are shown.

Table 12-12 Pavement Core Variability

\begin{tabular}{|c|c|c|c|c|c|c|}
\hline \multirow{2}{*}{$\begin{array}{c}\text { Lot/Sublot- } \\
\text { Location }\end{array}$} & \multicolumn{2}{|c|}{ Average Length } & \multicolumn{2}{c|}{ Standard Deviation } & \multicolumn{2}{c|}{ Range } \\
\cline { 2 - 7 } & $\mathbf{m m}$ & in & $\mathbf{m m}$ & in & $\mathbf{m m}$ & in \\
\hline $2 / 1-\mathrm{A}$ & 356 & 14.0 & 1.99 & 0.08 & 6 & 0.24 \\
\hline $2 / 1-\mathrm{B}$ & 357 & 14.1 & 2.15 & 0.08 & 8 & 0.31 \\
\hline $2 / 2-\mathrm{A}$ & 364 & 14.3 & 2.11 & 0.08 & 8 & 0.31 \\
\hline $2 / 2-\mathrm{B}$ & 359 & 14.1 & 1.93 & 0.08 & 6 & 0.24 \\
\hline $2 / 3-\mathrm{A}$ & 360 & 14.2 & 1.48 & 0.06 & 4 & 0.16 \\
\hline $2 / 3-\mathrm{B}$ & 357 & 14.0 & 2.70 & 0.11 & 10 & 0.39 \\
\hline $3 / 1-\mathrm{A}$ & 351 & 13.8 & 0.82 & 0.03 & 2 & 0.08 \\
\hline $3 / 1-\mathrm{B}$ & 357 & 14.1 & 1.70 & 0.07 & 6 & 0.24 \\
\hline $3 / 2-\mathrm{A}$ & 389 & 15.3 & 2.31 & 0.09 & 6 & 0.24 \\
\hline $3 / 2-\mathrm{B}$ & 365 & 14.4 & 5.74 & 0.23 & 16 & 0.63 \\
\hline $3 / 3-\mathrm{A}$ & 363 & 14.3 & 4.24 & 0.17 & 12 & 0.47 \\
\hline $3 / 3-\mathrm{B}$ & 354 & 13.9 & 2.07 & 0.08 & 6 & 0.24 \\
\hline $4 / 1-\mathrm{A}$ & 369 & 14.5 & 2.71 & 0.11 & 8 & 0.31 \\
\hline 4/1-B & 356 & 14.0 & 2.57 & 0.10 & 6 & 0.24 \\
\hline 4/2-A & 360 & 14.2 & 2.74 & 0.11 & 8 & 0.31 \\
\hline 4/2-B & 358 & 14.1 & 3.33 & 0.13 & 10 & 0.39 \\
\hline \multicolumn{2}{|c|}{ Average of Locations Shown } & 2.54 & 0.10 & 7.63 & 0.30 \\
\hline \multicolumn{2}{|c|}{ Average of All Locations } & 2.40 & 0.09 & 7.32 & 0.29 \\
\hline
\end{tabular}

The individual measurements are recorded to the nearest millimeter and the average core length is reported to the nearest $0.1 \mathrm{inch}$. However the length of the core can vary considerably from this average length. The average standard deviation for the entire project was 0.09 in (2.29 
$\mathrm{mm})$ and the average range was $0.29 \mathrm{in}(7.37 \mathrm{~mm})$. This implies that the thickness of the pavement varies, on average, by 0.29 inches $(7.37 \mathrm{~mm})$ in any given $12.6 \mathrm{in}^{2}\left(81.3 \mathrm{~cm}^{2}\right)$ (the surface area of a 4 in $(102 \mathrm{~mm})$ diameter core). The average range is $1 / 2$ of the average range of the core measurements from the pre-construction test program. This implies that the variability experienced in the slab core measurements, and thus in the slab thickness from the preconstruction test program was not representative of the pavement core measurements, and thus the pavement thickness. This may be due to a difference in degree of compaction of the supporting aggregate material for the test slabs compared to the pavement.

\subsection{Pavement Thickness Using Impact-Echo}

Impact-echo testing was performed on the mainline pavement with fly ash at sixteen of the INDOT core locations. The impact-echo tests were performed immediately after the P-wave velocity was measured. The testing was performed with the impact-echo equipment available from the FHWA. Multiple tests were performed at each location until a minimum of three tests with valid surface displacement waveforms were obtained. The results are contained in Appendix Q.

A frequency resolution of $0.163 \mathrm{kHz}$ was used in order to obtain a well-defined frequency spectrum and minimize the error in the calculation of thickness (see Section 11.7.2). The recorded frequency spectrums generally contained a single high amplitude peak, as shown in Figure 12-6. None of the recorded spectrums contained more than two high amplitude peaks, and the second peak, when present, corresponded to the resonance of the transducer (below $2 \mathrm{kHz}$ as indicated in Section 11.7.2). The thickness of the pavement at each location was calculated using the high amplitude peak frequency and the P-wave velocity. The results are indicated in Table 12-13. 
Lot 3, Sublot 1, Location A, Test 1

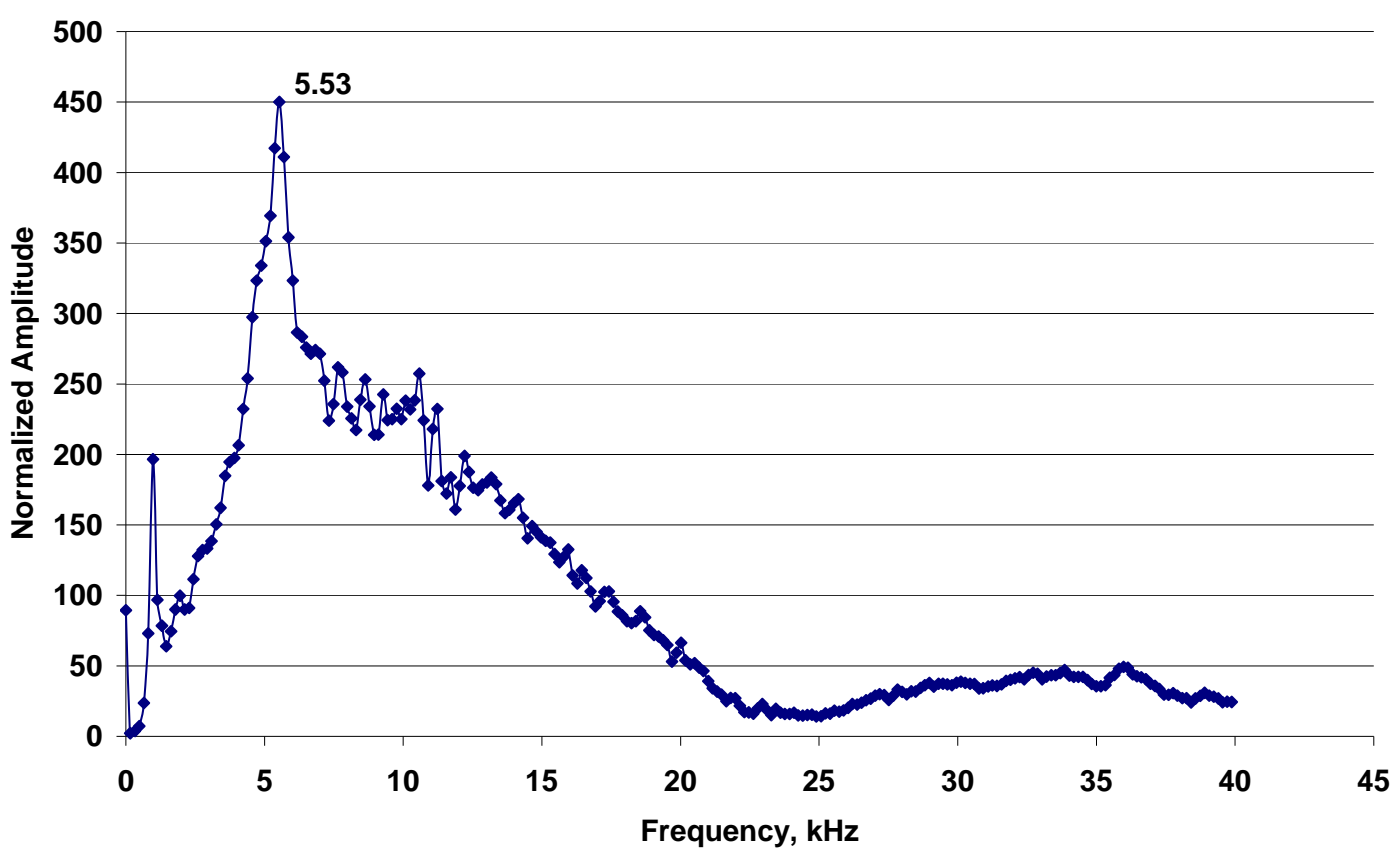

Figure 12-6 Pavement Frequency Spectrum 
Table 12-13 Predicted Pavement Thickness

\begin{tabular}{|c|c|c|c|c|c|c|}
\hline $\begin{array}{c}\text { Lot/ Sublot } \\
\text { Location }\end{array}$ & $\begin{array}{c}\text { Average P- } \\
\text { Wave } \\
\text { Velocity, } \\
\mathbf{m} / \mathbf{s}\end{array}$ & $\begin{array}{c}\text { Average } \\
\text { Frequency, } \\
\mathbf{k H z}\end{array}$ & $\begin{array}{c}\text { Predicted } \\
\text { Thickness, } \\
\mathbf{m m}\end{array}$ & $\begin{array}{c}\text { Average } \\
\text { Core } \\
\text { Thickness, } \\
\mathbf{m m}\end{array}$ & $\begin{array}{c}\text { Difference } \\
\text { (Absolute } \\
\text { Value), mm }\end{array}$ & $\begin{array}{c}\text { Difference } \\
\text { (Absolute } \\
\text { Value), in }\end{array}$ \\
\hline $2 / 1-\mathrm{A}$ & 3883 & 5.53 & 351 & 356 & 5 & 0.20 \\
\hline $2 / 1-\mathrm{B}$ & 3991 & 5.53 & 361 & 357 & 4 & 0.16 \\
\hline $2 / 2-\mathrm{A}$ & 4065 & 5.37 & 378 & 364 & 14 & 0.55 \\
\hline $2 / 2-\mathrm{B}$ & 4048 & 5.42 & 373 & 359 & 14 & 0.55 \\
\hline $2 / 3-\mathrm{A}$ & 3868 & 5.37 & 360 & 360 & 0 & 0.00 \\
\hline $2 / 3-\mathrm{B}$ & 4034 & 5.63 & 358 & 357 & 1 & 0.04 \\
\hline $3 / 1-\mathrm{A}$ & 3841 & 5.45 & 352 & 351 & 1 & 0.04 \\
\hline $3 / 1-\mathrm{B}$ & 3791 & 5.21 & 364 & 357 & 7 & 0.28 \\
\hline $3 / 2-\mathrm{A}$ & 4117 & 5.05 & 408 & 389 & 19 & 0.73 \\
\hline $3 / 2-\mathrm{B}$ & 3815 & 5.50 & 347 & 365 & 18 & 0.71 \\
\hline $3 / 3-\mathrm{A}$ & 3904 & 5.33 & 366 & 363 & 3 & 0.12 \\
\hline $3 / 3-\mathrm{B}$ & 3959 & 5.70 & 347 & 354 & 7 & 0.26 \\
\hline $4 / 1-\mathrm{A}$ & 3920 & 5.37 & 365 & 369 & 4 & 0.16 \\
\hline $4 / 1-\mathrm{B}$ & 4135 & 5.37 & 385 & 356 & 29 & 1.14 \\
\hline $4 / 2-\mathrm{A}$ & 3843 & 5.49 & 350 & 360 & 10 & 0.39 \\
\hline $4 / 2-\mathrm{B}$ & 3947 & 5.37 & 367 & 358 & 9 & 0.35 \\
\hline
\end{tabular}

The average difference between the predicted thickness and the thickness as determined from the measurement of cores was $2.5 \%$, or $9.0 \mathrm{~mm}(0.36 \mathrm{in})$. This is greater than the maximum error, $1.4 \%$ or $5.0 \mathrm{~mm}(0.20 \mathrm{in})$, for a $14 \mathrm{inch}(356 \mathrm{~mm})$ thick pavement due to the frequency resolution of $0.163 \mathrm{kHz}$. The error not due to the frequency resolution is mostly likely due to one of two causes. First, the point on the bottom of the pavement where the P-wave was reflected may not have corresponded to the average core thickness. As indicated in Section 12.7, the bottom of the cores, and therefore the bottom of the pavement, is uneven. The average range of the length of the cores for which impact-echo measurements were taken was $7.63 \mathrm{~mm}(0.30 \mathrm{in})$. The maximum possible error due to both the frequency resolution and the difference between the test location thickness and the average core thickness is illustrated in Figure 12-7. Figure 12-7 plots the average core thickness versus the predicted thickness from the impact-echo test method. The $\mathrm{x}$-error bars correspond to the maximum error due to the frequency resolution $(1.4 \%)$. The y-error bars correspond to the range of the measured core length. 


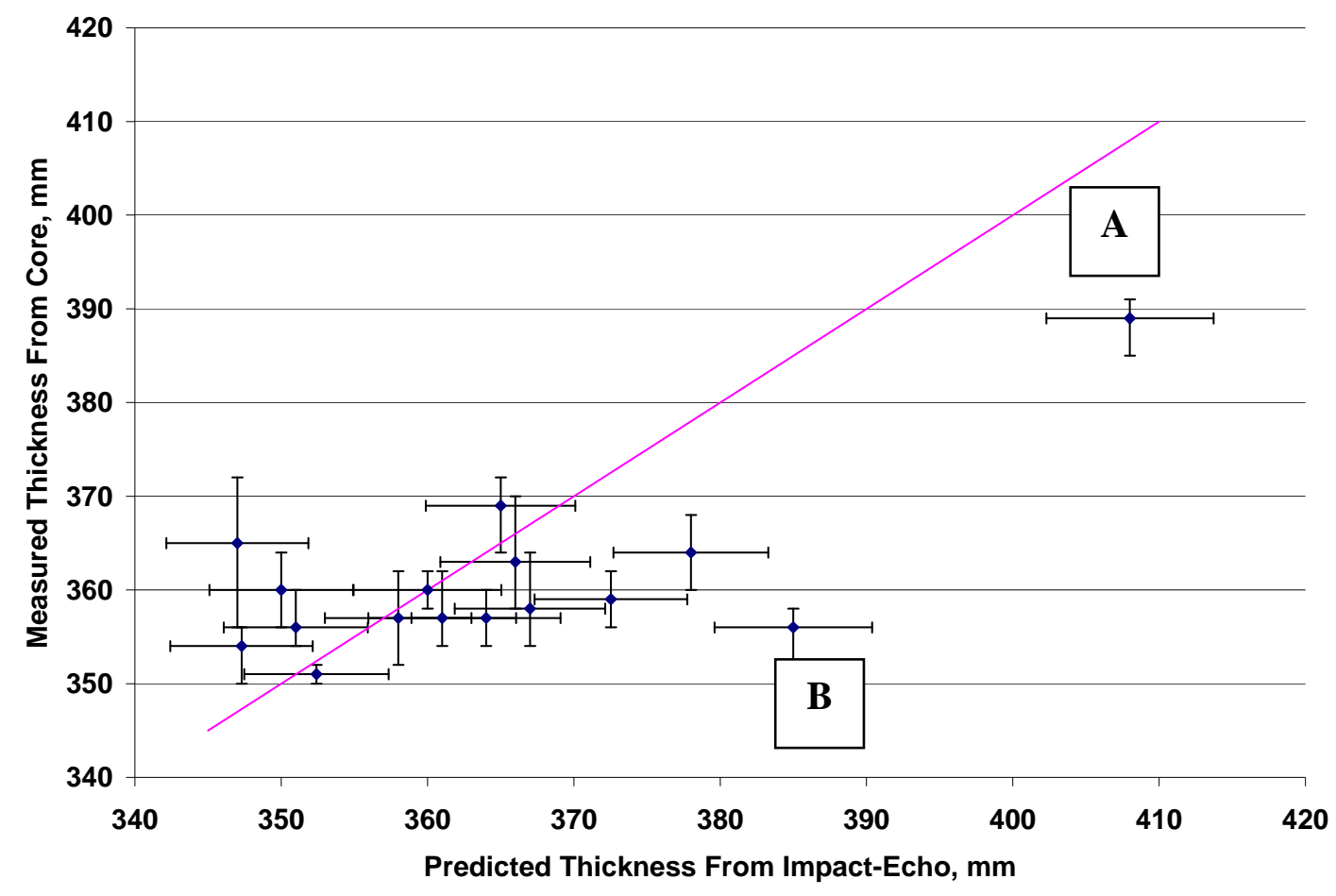

Figure 12-7 Pavement Impact-Echo Results

For seven of the test locations, the predicted thickness is within the maximum possible error due to the frequency resolution and the difference between the test location thickness and the average core thickness. However for nine of the test locations the predicted thickness is not within this error.

The second possible cause of the error not caused by the frequency resolution is that the Pwave velocity may not have been accurately determined at the core location. The high variability of the measured P-wave velocity, as indicated in Section 12.6.2, implies that the average measured P-wave velocity may not have been equal to the actual P-wave velocity of the pavement. The maximum possible error created by the difference between the measured and the actual P-wave velocity cannot be determined. However Table 12-14 indicates the error for several possible values of the difference between the measured and the actual P-wave velocity. The difference between the average observed error and the maximum error due to the frequency resolution is $1.1 \%(2.5 \%-1.4 \%)$. If the estimate of the P-wave velocity was, on average, off by $50 \mathrm{~m} / \mathrm{s}$, it would account for the $1.1 \%$ difference. 
Table 12-14 Error in Thickness Due to P-wave Velocity

\begin{tabular}{|c|c|c|c|}
\hline \multirow{2}{*}{$\begin{array}{c}\text { Difference Between } \\
\text { Measured and } \\
\begin{array}{c}\text { Actual P-Wave } \\
\text { Velocity, m/s }\end{array}\end{array}$} & \multicolumn{3}{|c|}{ Difference Between Actual and Predicted } \\
Thickness, mm \\
\cline { 2 - 4 } & \multicolumn{3}{|c|}{ in } \\
\hline 0 & 0 & 0 & 0 \\
\hline 10 & 1 & 0.04 & 0.28 \\
\hline 25 & 2 & 0.08 & 0.56 \\
\hline 50 & 4 & 0.16 & 1.12 \\
\hline 75 & 7 & 0.28 & 1.97 \\
\hline 100 & 9 & 0.35 & 2.53 \\
\hline 125 & 11 & 0.43 & 3.09 \\
\hline 150 & 13 & 0.51 & 3.65 \\
\hline
\end{tabular}

Actual P-wave velocity $=4000 \mathrm{~m} / \mathrm{s}$

Actual Thickness $=14$ in.

Closer inspection of points A and B as labeled on Figure 12-7 illustrates the effect of a difference between the measured and the actual P-wave velocity. Point A represents lot/sublot location 3/2A. The measured P-wave velocity at Point A $(4117 \mathrm{~m} / \mathrm{s})$ was significantly greater than the P-wave velocity measured at the two nearest test locations, 3/1B and 3/2B (3791 and $3815 \mathrm{~m} / \mathrm{s}$ ). If the P-wave velocity at Point A reduced to the larger value of the two adjacent test locations, the difference between the predicted thickness and the average core thickness reduces from $4.8 \%(0.73$ in or $19 \mathrm{~mm})$ to $2.8 \%(0.43$ in or $11 \mathrm{~mm})$. Similarly if the measured P-wave velocity of Point B $(4135 \mathrm{~m} / \mathrm{s})$, which represents $4 / 1 \mathrm{~B}$, is reduced to the larger value of the two adjacent test locations, the difference between the predicted thickness and the average core thickness reduces from $8.1 \%$ (1.14 in or $29 \mathrm{~mm})$ to $2.5 \%$ ( 0.35 in or $9 \mathrm{~mm})$. This suggests that if a more accurate measurement of the P-wave velocity can be obtained the estimate of thickness should improve.

\subsection{Summary}

This chapter has presented the experimental results from the field test program. The work presented in this chapter indicates the following: 
- The sampling location of the fresh concrete (at the batch plant compared to in front of the paving equipment) did not significantly influence the flexural strength. This suggests that the location where the fresh concrete is sampled has a significant affect on the flexural strength. However it does not imply that a difference in initial curing temperature will not affect the flexural strength. Specimens cured outdoors can experience different initial curing temperatures which would be expected to influence the flexural strength.

- The average strength increase from 7 to 28 days for the 9 sublots where 7 and 28 day data were available was slightly higher (1.15) than the strength increase observed in the preconstruction test program (1.11). The strength increase from 7 to 28 days for both the field and pre-construction test programs was higher than assumed in the development of the Level 1 PRS (5\%). This indicates the need to consider the actual strength gain of the proposed concrete mixture.

- Both strength-maturity relationships created during this test program consistently overestimated the strength of the beam specimens. The estimation of strength was the closest for the second (full) relationship at the age of 28 days. The values used for two of the offset hyperbolic function parameters; $\mathrm{M}_{\mathrm{o}}$ and $\mathrm{S}_{\infty}$ may have contributed to the over-estimation of strength. The error could also be due to material and mix proportion variations from the materials and proportions used to create the relationships.

- Better estimates of the $\mathrm{M}_{\mathrm{o}}$ parameter in the offset hyperbolic strength-maturity relationship can be obtained from earlier age test data. Better estimates of $\mathrm{M}_{0}$ were obtained with test results at the ages of 24, 36, and 48 hours compared to test results at the ages of 1 and 4 days (24 and 96 hours).

- The increased estimate of relative strength gain for larger specimens compared to smaller specimens using the maturity test method observed in the pre-construction test program was also observed in the field test program. The predicted strength of the pavement at 7 days was greater than the average strength of the beams at 7 days.

- The lack of repeatability and the high variability of the measurement of the P-wave velocity using the impact-echo equipment available from the FHWA indicate that the P-wave velocity was not accurately estimated by this test method. The inability to accurately estimate the P- 
wave velocity appears to be a significant contributor to the difference between the predicted thickness using the impact-echo test method and the average core thickness.

- The average range of the core measurements was $1 / 2$ of the average range of the core measurements from the pre-construction test program.

- The bottom surface of the pavement is not smooth. An indication of the variability of the thickness of the pavement can be given by the variability of the length of cores extracted from the pavement. For this project, the average range of the length of cores was 0.29 in (7.37 mm).

- The frequency spectrums recorded from the impact-echo testing performed on the pavement were much easier to interpret than the spectrums recorded during the pre-construction test program. This is a result of using the lower frequency resolution, which was only used on Day 42 of the pre-construction test program, and the absence of multiple high-amplitude peaks due to modes of vibration.

- The average difference between the predicted thickness using the impact-echo test method and the average core thickness was $2.5 \%$, or $9.0 \mathrm{~mm}$ (0.36 in).

- The exact point on the bottom of the pavement where the P-wave is reflected may not correspond to the average core thickness, therefore variability of the thickness of the pavement should be considered in the evaluation of the accuracy of the predication of pavement thickness using the impact-echo test location.

- The range of the estimated thickness of the pavement due to the frequency resolution of $0.163 \mathrm{kHz}(0.20 \mathrm{in})$ is less than the range of the thickness of the pavement determined by the measurement of cores $(0.29$ in). This implies that if the estimate of the P-wave velocity can be improved, the variability of the estimate of thickness using impact-echo test method will be comparable to the variability of the thickness as determined by the measurement of cores. 


\section{CHAPTER 13: POST CONSTUCTION EXPERIMENTAL RESULTS}

\subsection{Introduction}

This chapter presents the experimental results from the post-construction test program. This test program was the third phase of the overall test program conducted in conjunction with the implementation of a Level 1 Performance-Related Specification (PRS) on Indiana Department of Transportation (INDOT) Project R-24432. The type and number of test specimens and the mixing, casting, and curing procedures have been previously described in Sections 10.5.1 and 10.5.2. The test procedures and equipment have been previously described in Section 10.5.3.

The testing conducted in this test program was performed to address two general issues raised during the pre-construction and field test programs. First, values were assumed for the datum temperature and activation energy used in the maturity test method in the pre-construction and field test programs. However these values have been reported to vary depending upon the specific concrete mixture (Carino 1991). ASTM C 1074 recommends that for maximum accuracy the values of the datum temperature and activation energy be experimentally determined for each specific concrete mixture. Therefore testing was conducted in accordance with ASTM C 1074 to determine the appropriate values for the concrete mixture that included fly ash. The effects of using the experimentally determined values of the datum temperature and activation energy compared to using the assumed values are assessed by comparing a resulting strength-maturity relationship and predicted flexural strengths.

Second, variations in the mixture proportions typically occur in large-scale concrete construction projects and were in fact observed during the field construction test program as shown in Table 12-9. Variations in the mixture proportions can create errors in the estimate of 
strength using either strength-maturity or strength-P-wave velocity relationships. Strictly speaking these relationships are only valid for concrete with identical mixture proportions and identical constituent materials to those used to create the relationships. Testing was conducted to assess how variations in the water-to-cement ratio $(w / c)$ and amount of air entraining agent influence the maturity-based strength estimates.

The analysis of the testing conducted in this chapter considers implications of implementing the maturity test method and using the strength-P-wave velocity relationship to estimate concrete flexural strength. Three implementation methods were considered: using the maturity method by itself, using the maturity and P-wave velocity test methods in combination, and using maturity in combination with an early-age mechanical test result.

\subsection{Datum Temperature and Activation Energy Results}

The values of the datum temperature and the activation energy used in the pre-construction and field test programs were not experimentally determined. The value of the datum temperature for the Nurse-Saul function was taken as the traditional value of $-10{ }^{\circ} \mathrm{C}$ as specified by the INDOT in ITM 402. Similarly, the value of the activation energy divided by the gas constant (Q) for the Arrhenius function was taken as $5000^{\circ} \mathrm{K}$. This is the value recommended by ASTM C 1074.

To assess the values of the datum temperature and the activation energy for the concrete mixture including fly ash, compressive strength testing of mortar cubes was performed. The test procedures contained in Annex A1 of ASTM C 1074 were followed. Three sets of mortar cube specimens were cured in water baths at three different temperatures, $10^{\circ} \mathrm{C}, 22^{\circ} \mathrm{C}$, and $39^{\circ} \mathrm{C}(50$, 72 , and $102^{\circ} \mathrm{F}$ ). Compressive tests were performed at specific ages and the data was analyzed using the regression procedures described in Section A1.1.8 of ASTM C 1074. The experimentally determined value of the datum temperature was $1{ }^{\circ} \mathrm{C}$. The experimentally determined value of $\mathrm{Q}$ was $4550^{\circ} \mathrm{K}$. 
In order to compare the effects of using the experimentally determined values of the datum temperature and the activation energy versus using the assumed values, the experimental values were used to calculate revised maturity indexes for the beam specimens and pavement locations in the field construction test program (Section 12.5.1). The second strength-maturity relationship created in the field test program, referred to as the 'full' strength-maturity relationship, see Section 12.5.2, was then revised accordingly. It should be noted that because of the variability in the mixture proportions and the likely variability in the cement quality during the field test program the experimentally determined values of the datum temperature and activation energy are also somewhat approximate. However, these values can be considered a better approximation than the assumed values because they are based on testing of approximately the same concrete mixture and constituent materials.

Figure 13-1 indicates that the change in the datum temperature value resulted in a small change in the 'full' strength-maturity relationship. The value of the offset maturity $\left(\mathrm{M}_{\mathrm{o}}\right)$ increased $\left(-273\right.$ to $\left.-170{ }^{\circ} \mathrm{C}-\mathrm{hr}\right)$, while the value of the rate constant $\left(\mathrm{k}_{\mathrm{T}}\right)$ increased $(0.001088$ to $\left.0.0016471 /\left({ }^{\circ} \mathrm{C}-\mathrm{hr}\right)\right)$, and the value of the limiting strength $\left(\mathrm{S}_{\infty}\right)$ remained virtually the same ( 809.3 to $809.8 \mathrm{psi}$ ). The difference in the predicted strength from the two relationships is greater at earlier ages than it is at later ages. At $1000{ }^{\circ} \mathrm{C}-\mathrm{hr}$ the difference is $63 \mathrm{psi}(0.43 \mathrm{MPa})$, while at $10000^{\circ} \mathrm{C}$-hr the difference is $21 \mathrm{psi}(0.14 \mathrm{MPa})$. It is worth noting that the experimentally determined value of the datum temperature improved the value of $\mathrm{M}_{\mathrm{o}}$ by making it less negative. This is more consistent with the expected physical representation of $\mathrm{M}_{\mathrm{o}}$ as discussed in Section 11.4 .1 


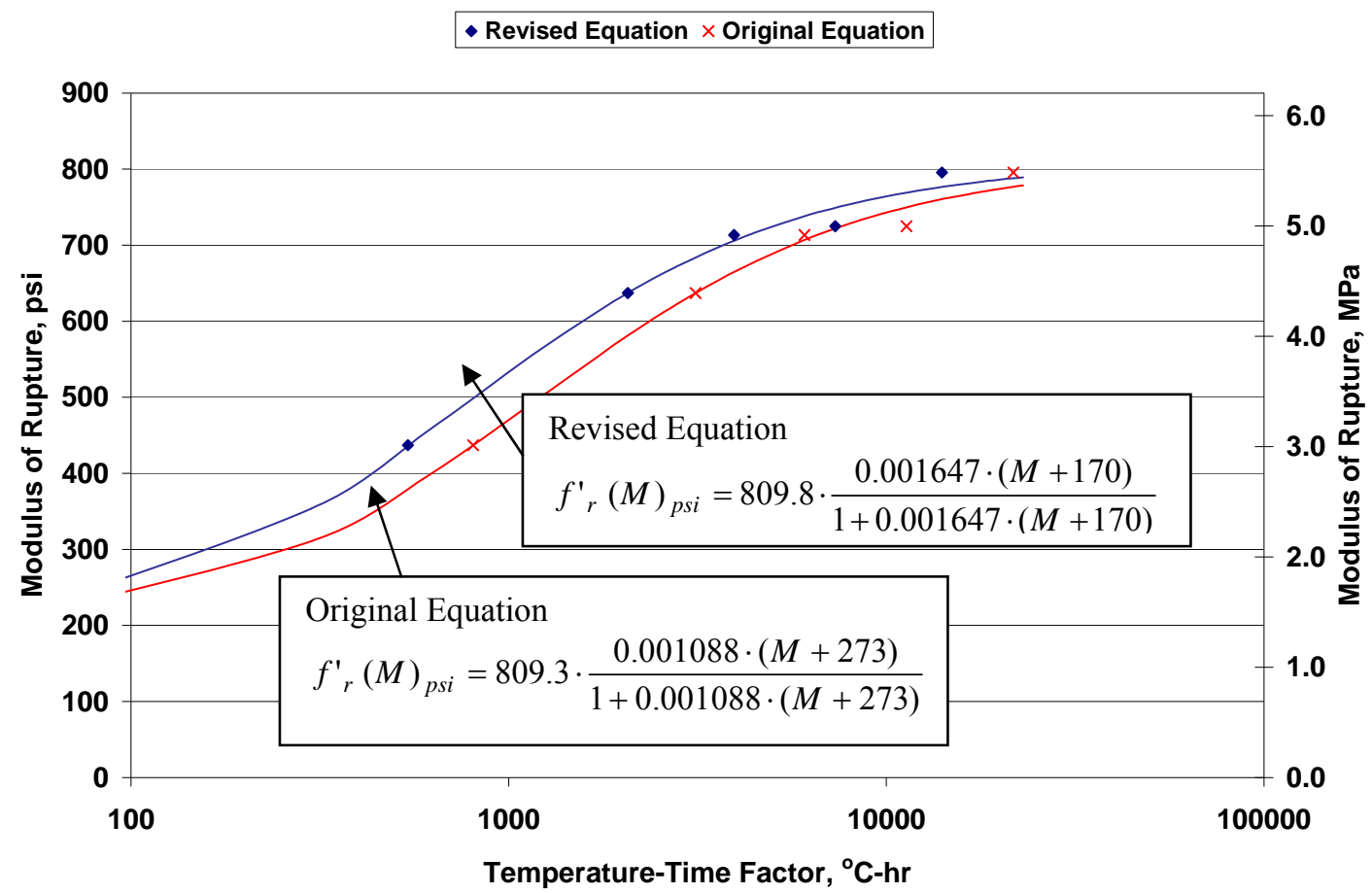

Figure 13-1 Strength-Maturity Relationships Using Temperature-Time Factor

Figure 13-2 indicates that the change in the value of the activation energy resulted in virtually no change in the 'full' strength-maturity relationship. Each of the three parameters, $\mathrm{M}_{\mathrm{o}}$, $\mathrm{k}_{\mathrm{T}}$, and $\mathrm{S}_{\infty}$, experienced very little change due to the change in the activation energy. The difference in the predicted strength from the two relationships is negligible, less than 1 psi $(0.007$ $\mathrm{MPa}$ ). The small change in the strength-maturity relationship was not unexpected because the difference between the assumed and experimentally determined value of the activation energy was relatively small (9\%). 
- Revised Equation $\times$ Original Equation

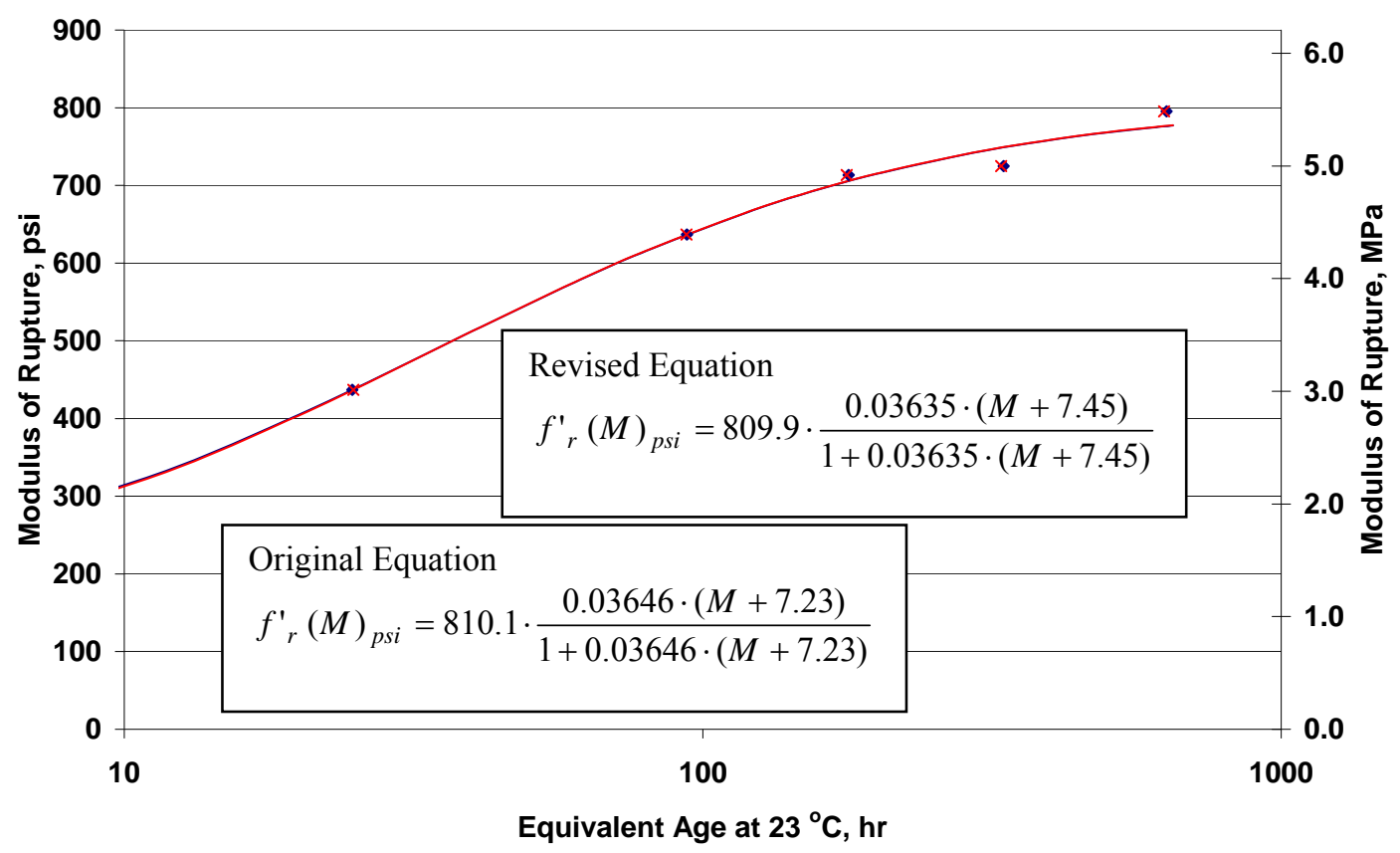

Figure 13-2 Strength-Maturity Relationships Using Equivalent Age

The revised strength-maturity relationships were used to predict the flexural strength of the beams cast at the batch plant. The predicted strengths for both the original and the revised relationships using the temperature-time factor are shown in Table 13-1. The predicted beam strengths from both the revised and the original relationships are identical. Revising the datum temperature, or the activation energy, did not change the predicted beam strength because the curing temperatures were essentially the same. The temperature history of the beams cast at the batch plant was essentially the same as the temperature history for the beam specimens from which the strength-maturity relationship was created. The strength predictions for the beam specimens using the equivalent age index are not presented because they are virtually identical to the predictions using the temperature-time index. This once again is a result of the curing temperature of the beams being the same as the curing temperature at which the strengthmaturity relationship was created. 
Table 13-1 Beam Flexural Strength From Temperature-Time Factor

\begin{tabular}{|c|c|c|c|c|c|c|c|}
\hline \multirow[b]{2}{*}{$\begin{array}{c}\text { Lot/ } \\
\text { Sublot } \\
\text { Location }\end{array}$} & \multirow[b]{2}{*}{$\begin{array}{l}\text { Casting } \\
\text { Location }\end{array}$} & \multirow[b]{2}{*}{$\begin{array}{l}\text { Age, } \\
\text { Days }\end{array}$} & \multirow{2}{*}{$\begin{array}{c}\text { Average } \\
\text { Flexural } \\
\text { Strength, } \\
\text { psi }\end{array}$} & \multicolumn{2}{|c|}{$\begin{array}{l}\text { Temperature-Time Factor } \\
{ }^{\circ} \mathrm{C}-\mathrm{hr}\end{array}$} & \multicolumn{2}{|c|}{$\begin{array}{c}\text { Predicted Flexural Strength, } \\
\text { psi }\end{array}$} \\
\hline & & & & $\begin{array}{l}\text { Datum } \\
\text { Temperature } \\
=-10^{\circ} \mathrm{C}\end{array}$ & $\begin{array}{c}\text { Datum } \\
\text { Temperature } \\
=1^{\circ} \mathrm{C}\end{array}$ & $\begin{array}{c}\text { Datum } \\
\text { Temperature } \\
=-10^{\circ} \mathrm{C}\end{array}$ & $\begin{array}{c}\text { Datum } \\
\text { Temperature } \\
=1^{\circ} \mathrm{C}\end{array}$ \\
\hline $1 / 3$ & Batch Plant & 7 & 657 & 5470 & 3611 & 698 & 698 \\
\hline $2 / 1$ & Batch Plant & 7 & 631 & 5441 & 3590 & 697 & 697 \\
\hline $2 / 2$ & Batch Plant & 7 & 650 & 5530 & 3644 & 699 & 699 \\
\hline $2 / 3$ & Batch Plant & 7 & 650 & 5475 & 3616 & 698 & 698 \\
\hline $1 / 3$ & Batch Plant & 28 & 716 & 22431 & 14747 & 778 & 778 \\
\hline $2 / 1$ & Batch Plant & 28 & 752 & 22267 & 14635 & 778 & 778 \\
\hline $2 / 2$ & Batch Plant & 28 & 768 & 21714 & 14282 & 777 & 777 \\
\hline $2 / 3$ & Batch Plant & 28 & 727 & 21574 & 14196 & 777 & 777 \\
\hline
\end{tabular}

The revised strength-maturity relationships were also used to predict the flexural strength of the pavement from the measured temperature history in the center of the pavement profile. The predicted strength of the pavement using the temperature-time factor is presented in Table 13-2, while the predicted strength using the equivalent age is presented in Table 13-3. The predicted strength of the pavement at 7 days is once again greater than the actual average strength of the beams at 7 days. This trend was also observed in the pre-construction and field test programs and is a result of the higher temperatures in the pavement caused by the larger mass of concrete and higher ambient temperature that consequently produce larger maturity indexes for the pavement compared to the beam specimens.

The predicted pavement strengths from the revised relationships vary slightly from the predicted strengths from the original relationships as shown in Table 13-2 and Table 13-3. It can also be seen that the difference between the predicted strengths using the temperature-time factor compared to the equivalent age decreases when the revised values of the datum temperature and $\mathrm{Q}$ are used. For example, for Lot 2 Sublot 2, the difference is $21 \mathrm{psi}$ (737 to $716 \mathrm{psi}$ ) using the original values, while the difference is 9 psi (733 to $724 \mathrm{psi}$ ) using the revised values. This implies that the revised values of the datum temperature and $\mathrm{Q}$ are producing more accurate estimates than the original values. 
Table 13-2 Pavement Strength From Temperature-Time Factor

\begin{tabular}{|c|c|c|c|c|c|c|c|}
\hline \multirow{2}{*}{$\begin{array}{c}\text { Lot/ } \\
\text { Sublot } \\
\text { Location }\end{array}$} & \multirow[b]{2}{*}{$\begin{array}{l}\text { Age, } \\
\text { Days }\end{array}$} & \multicolumn{2}{|c|}{$\begin{array}{l}\text { Temperature-Time Factor } \\
{ }^{\circ} \mathrm{C}-\mathrm{hr}\end{array}$} & \multicolumn{2}{|c|}{$\begin{array}{l}\text { Predicted Pavement } \\
\text { Flexural Strength, psi }\end{array}$} & \multirow[b]{2}{*}{$\begin{array}{l}\text { Casting } \\
\text { Location }\end{array}$} & \multirow{2}{*}{$\begin{array}{c}\text { Average } \\
\text { Measured } \\
\text { Beam } \\
\text { Flexural } \\
\text { Strength, } \\
\text { psi }\end{array}$} \\
\hline & & $\begin{array}{c}\text { Datum } \\
\text { Temperature } \\
=-10^{\circ} \mathrm{C}\end{array}$ & $\begin{array}{c}\text { Datum } \\
\text { Temperature } \\
=1^{\circ} \mathrm{C}\end{array}$ & $\begin{array}{c}\text { Datum } \\
\text { Temperature } \\
=-10{ }^{\circ} \mathrm{C}\end{array}$ & $\begin{array}{c}\text { Datum } \\
\text { Temperature } \\
=1^{\circ} \mathrm{C}\end{array}$ & & \\
\hline \multirow{2}{*}{$2 / 2$} & \multirow{2}{*}{7} & \multirow{2}{*}{6790} & \multirow{2}{*}{4943} & \multirow{2}{*}{716} & \multirow{2}{*}{724} & Batch Plant & 650 \\
\hline & & & & & & Field & 683 \\
\hline \multirow{2}{*}{$2 / 3$} & \multirow{2}{*}{7} & \multirow{2}{*}{6865} & \multirow{2}{*}{5017} & \multirow{2}{*}{717} & \multirow{2}{*}{725} & Batch Plant & 650 \\
\hline & & & & & & Field & 680 \\
\hline
\end{tabular}

Table 13-3 Pavement Strength From Equivalent Age (at $23^{\circ} \mathrm{C}$ )

\begin{tabular}{|c|c|c|c|c|c|c|c|}
\hline \multirow{2}{*}{$\begin{array}{c}\text { Lot/ } \\
\text { Sublot } \\
\text { Location }\end{array}$} & \multirow[b]{2}{*}{$\begin{array}{l}\text { Age, } \\
\text { Days }\end{array}$} & \multicolumn{2}{|c|}{\begin{tabular}{|c|}
$\begin{array}{c}\left.\text { Equivalent Age (at } 23^{\circ} \mathrm{C}\right) \\
\text { hrs }\end{array}$ \\
\end{tabular}} & \multicolumn{2}{|c|}{$\begin{array}{l}\text { Predicted Pavement } \\
\text { Flexural Strength, psi } \\
\end{array}$} & \multirow{2}{*}{$\begin{array}{l}\text { Casting } \\
\text { Location }\end{array}$} & \multirow{2}{*}{$\begin{array}{c}\text { Average } \\
\text { Measured } \\
\text { Beam } \\
\text { Flexural } \\
\text { Strength, psi }\end{array}$} \\
\hline & & $\begin{array}{c}\text { Activation } \\
\text { Energy = } \\
5000^{\circ} \mathrm{K}\end{array}$ & $\begin{array}{c}\text { Activation } \\
\text { Energy = } \\
4550^{\circ} \mathrm{K}\end{array}$ & $\begin{array}{c}\text { Activation } \\
\text { Energy = } \\
5000^{\circ} \mathrm{K}\end{array}$ & $\begin{array}{c}\text { Activation } \\
\text { Energy = } \\
4550^{\circ} \mathrm{K}\end{array}$ & & \\
\hline \multirow{2}{*}{$2 / 2$} & \multirow{2}{*}{7} & \multirow{2}{*}{268} & \multirow{2}{*}{256} & \multirow{2}{*}{737} & \multirow{2}{*}{733} & Batch Plant & 650 \\
\hline & & & & & & Field & 683 \\
\hline \multirow{2}{*}{$2 / 3$} & \multirow{2}{*}{7} & \multirow{2}{*}{273} & \multirow{2}{*}{260} & \multirow{2}{*}{738} & \multirow{2}{*}{734} & Batch Plant & 650 \\
\hline & & & & & & Field & 680 \\
\hline
\end{tabular}

\subsection{Mixture Proportion Variation Results}

Testing was conducted to assess how variations in the water-to-cement ratio $(\mathrm{w} / \mathrm{c})$ and amount of air entraining agent influence the estimate of strength. Slight variations in the mixture proportions typically occur in large-scale concrete construction projects. Six mixture proportion variations from a design mixture proportion were considered. Table 13-4 provides a summary of the mixture variations, while a complete description of the test specimens is given in Section 10.5.1. The materials used for this testing were the same as the materials used during the field test program. Mixture $\mathrm{C}$ has the same composition as the design mixture used for the Level 1 PRS mainline pavement without fly ash. Mixtures A, B, D, E, and G have a different water-tocement ratio and Mixture $\mathrm{F}$ contains a greater amount of air entraining agent while having the same water-to-cement ratio as the design mixture. The range of water-to-cement ratios included in this testing was selected based on the variability observed in the field test program as shown in Table 12-9. 
Table 13-4 Mixture Proportions

\begin{tabular}{|c|c|c|c|c|c|c|c|}
\hline \multirow[b]{2}{*}{$\begin{array}{c}\text { Mixture } \\
\text { Information }\end{array}$} & \multicolumn{7}{|c|}{ Mixture } \\
\hline & A & B & $\begin{array}{c}\text { C } \\
\text { (Design) }\end{array}$ & D & $\mathbf{E}$ & $\mathbf{F}$ & G \\
\hline $\begin{array}{l}\text { Water/Cement } \\
\text { Ratio }\end{array}$ & 0.40 & 0.41 & 0.42 & 0.43 & 0.44 & 0.42 & 0.47 \\
\hline $\begin{array}{l}\text { Air Entraining } \\
\text { Agent, } \mathrm{ml} / \mathrm{m}^{3}\end{array}$ & 145 & 145 & 145 & 145 & 145 & 160 & 145 \\
\hline
\end{tabular}

A summary of the average flexural strength, P-wave velocity, and temperature-time factors are presented in Table 13-5, Table 13-6, and Table 13-7 respectively. The complete results are presented in Table R-1.

Table 13-5 Flexural Strength

\begin{tabular}{|c|c|c|c|c|c|c|c|c|}
\hline \multirow{2}{*}{ Mixture } & \multirow{2}{*}{ Units } & \multicolumn{7}{|c|}{ Age, Days } \\
\cline { 3 - 9 } & & $\mathbf{1}$ & $\mathbf{1 . 5}$ & $\mathbf{3}$ & $\mathbf{7}$ & $\mathbf{1 4}$ & $\mathbf{2 8}$ & $\mathbf{5 7}$ \\
\hline \multirow{2}{*}{$\mathrm{A}$} & $\mathrm{psi}$ & $\sim$ & $\sim$ & $\sim$ & $\sim$ & $\sim$ & 924 & $\sim$ \\
\cline { 2 - 9 } & $\mathrm{MPa}$ & $\sim$ & $\sim$ & $\sim$ & $\sim$ & $\sim$ & 6.37 & $\sim$ \\
\hline \multirow{2}{*}{$\mathrm{B}$} & $\mathrm{psi}$ & $\sim$ & $\sim$ & $\sim$ & 842 & $\sim$ & 893 & $\sim$ \\
\cline { 2 - 9 } & $\mathrm{MPa}$ & $\sim$ & $\sim$ & $\sim$ & 5.80 & $\sim$ & 6.16 & $\sim$ \\
\hline \multirow{2}{*}{$\mathrm{C}$} & $\mathrm{psi}$ & 495 & 659 & 741 & 783 & 792 & 813 & 927 \\
\cline { 2 - 9 } & $\mathrm{MPa}$ & 3.41 & 4.54 & 5.11 & 5.40 & 5.46 & 5.61 & 6.39 \\
\hline \multirow{2}{*}{$\mathrm{D}$} & $\mathrm{psi}$ & $\sim$ & $\sim$ & $\sim$ & 756 & $\sim$ & 775 & $\sim$ \\
\cline { 2 - 9 } & $\mathrm{MPa}$ & $\sim$ & $\sim$ & $\sim$ & 5.21 & $\sim$ & 5.34 & $\sim$ \\
\hline \multirow{2}{*}{$\mathrm{E}$} & $\mathrm{psi}$ & $\sim$ & $\sim$ & $\sim$ & 729 & $\sim$ & 830 & $\sim$ \\
\cline { 2 - 9 } & $\mathrm{MPa}$ & $\sim$ & $\sim$ & $\sim$ & 5.02 & $\sim$ & 5.72 & $\sim$ \\
\hline \multirow{2}{*}{$\mathrm{F}$} & $\mathrm{psi}$ & $\sim$ & $\sim$ & $\sim$ & 779 & $\sim$ & 868 & $\sim$ \\
\cline { 2 - 9 } & $\mathrm{MPa}$ & $\sim$ & $\sim$ & $\sim$ & 5.37 & $\sim$ & 5.98 & $\sim$ \\
\hline \multirow{2}{*}{$\mathrm{G}$} & $\mathrm{psi}$ & $\sim$ & $\sim$ & $\sim$ & 705 & $\sim$ & $\sim$ & $\sim$ \\
\cline { 2 - 9 } & $\mathrm{MPa}$ & $\sim$ & $\sim$ & $\sim$ & 4.86 & $\sim$ & $\sim$ & $\sim$ \\
\hline
\end{tabular}

Table 13-6 P-Wave Velocity, m/s

\begin{tabular}{|c|c|c|c|c|c|c|c|}
\hline \multirow{2}{*}{ Mixture } & \multicolumn{7}{|c|}{ Age, Days } \\
\cline { 2 - 8 } & $\mathbf{1}$ & $\mathbf{1 . 5}$ & $\mathbf{3}$ & $\mathbf{7}$ & $\mathbf{1 4}$ & $\mathbf{2 8}$ & $\mathbf{5 7}$ \\
\hline $\mathrm{A}$ & $\sim$ & $\sim$ & 4667 & 4830 & $\sim$ & 4931 & $\sim$ \\
\hline $\mathrm{B}$ & $\sim$ & $\sim$ & 4622 & 4733 & $\sim$ & 4863 & $\sim$ \\
\hline $\mathrm{C}$ & 4288 & 4440 & 4497 & 4679 & 4631 & 4790 & 4859 \\
\hline $\mathrm{D}$ & $\sim$ & $\sim$ & 4398 & 4553 & $\sim$ & 4680 & $\sim$ \\
\hline E & $\sim$ & $\sim$ & 4378 & 4478 & $\sim$ & 4701 & $\sim$ \\
\hline F & $\sim$ & $\sim$ & 4501 & 4546 & $\sim$ & 4791 & $\sim$ \\
\hline G & $\sim$ & $\sim$ & 4232 & 4395 & $\sim$ & $\sim$ & $\sim$ \\
\hline
\end{tabular}


Table 13-7 Temperature-Time Factor, ${ }^{\circ} \mathrm{C}-\mathrm{hr}$

\begin{tabular}{|c|c|c|c|c|c|c|c|}
\hline \multirow{2}{*}{ Mixture } & \multicolumn{7}{|c|}{ Age, Days } \\
\cline { 2 - 8 } & $\mathbf{1}$ & $\mathbf{1 . 5}$ & $\mathbf{3}$ & $\mathbf{7}$ & $\mathbf{1 4}$ & $\mathbf{2 8}$ & $\mathbf{5 7}$ \\
\hline $\mathrm{A}$ & $\sim$ & $\sim$ & $\sim$ & $\sim$ & $\sim$ & 19518 & $\sim$ \\
\hline $\mathrm{B}$ & $\sim$ & $\sim$ & $\sim$ & 5314 & $\sim$ & 20062 & $\sim$ \\
\hline $\mathrm{C}$ & 854 & 1379 & 2371 & 5107 & 10181 & 19871 & 40079 \\
\hline $\mathrm{D}$ & $\sim$ & $\sim$ & $\sim$ & 5264 & $\sim$ & 20027 & $\sim$ \\
\hline $\mathrm{E}$ & $\sim$ & $\sim$ & $\sim$ & 5208 & $\sim$ & 18175 & $\sim$ \\
\hline $\mathrm{F}$ & $\sim$ & $\sim$ & $\sim$ & 5133 & $\sim$ & 19968 & $\sim$ \\
\hline $\mathrm{G}$ & $\sim$ & $\sim$ & $\sim$ & 5086 & $\sim$ & $\sim$ & $\sim$ \\
\hline
\end{tabular}

A strength-maturity relationship was created using the data for the design mixture, Mixture C, for the ages of 1 through 28 days. The relationship is shown in Figure 13-3 along with the data for the other mixtures. The test data for Mixture $\mathrm{C}$ at the age of 57 days was not used in the strength-maturity relationship because the strength gain from 28 to 57 days was not consistent with the rest of the data as can be seen in Figure 13-3. It should also be noted that the strengthmaturity relationship, which includes an additional early-age data point (at 1.5 days), has a realistic value of $\mathrm{M}_{\mathrm{o}}\left(498.4^{\circ} \mathrm{C}-\mathrm{hr}\right)$.

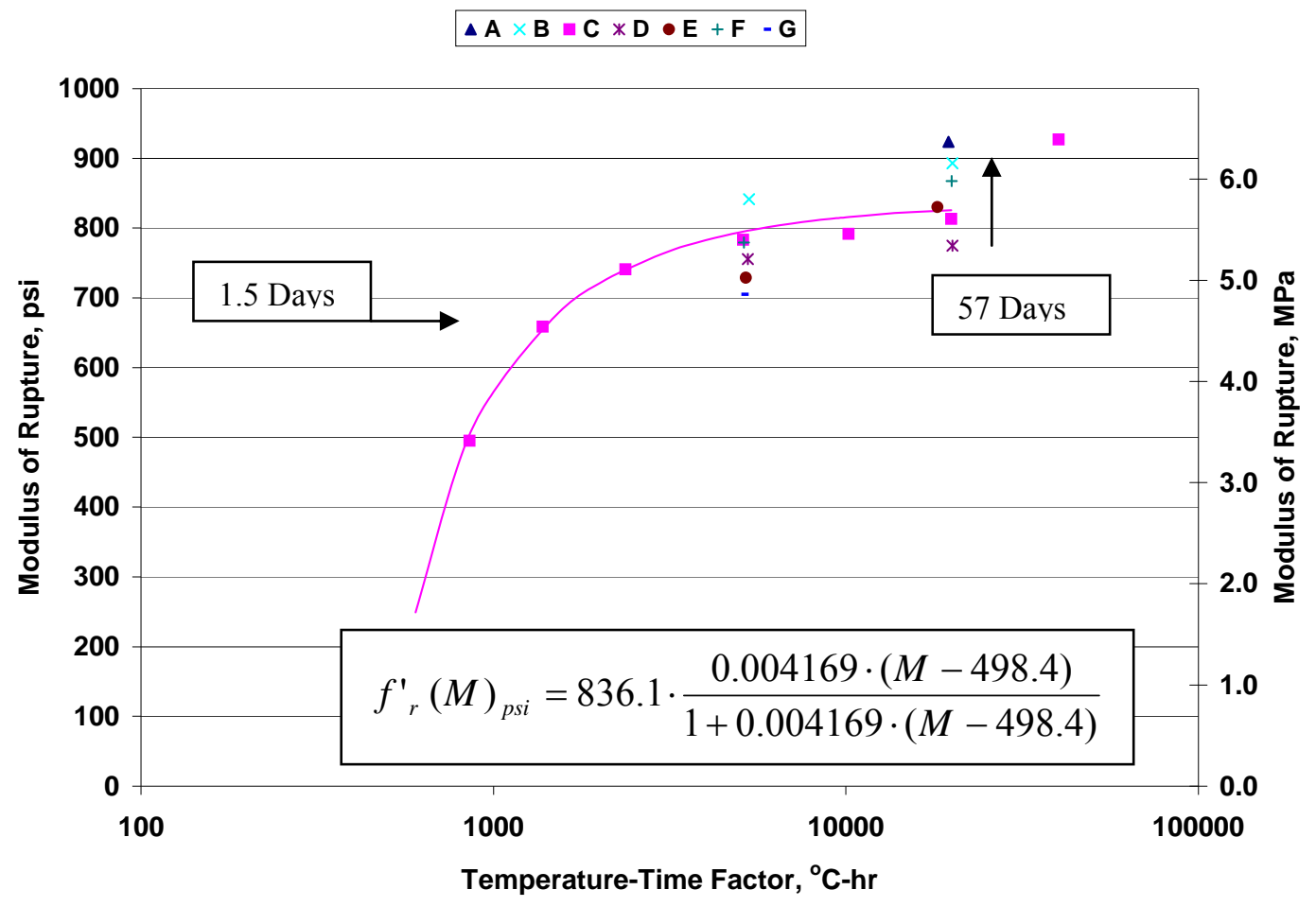

Figure 13-3 Strength-Maturity Relationship 
Table 13-5 and Figure 13-4 show that as expected, the 7 day strength decreases with increasing water-to-cement ratio and increased amount of air entraining agent. However Figure 13-5 shows an unexpected relationship between strength and water-to-cement ratio at Day 28. The average strength of Mixtures E and F are unexpectedly greater than Mixture C. Mixture E has a higher water-to-cement ratio and Mixture $\mathrm{F}$ has more air entraining agent than Mixture $\mathrm{C}$, therefore the strength of these mixtures were expected to be lower than Mixture C. Since multiple batches were required for each mixture type due to the size of the mixer, a possible cause of the unexpected behavior is that differences between batches of the same mixture type occurred. It is possible that a uniform condition of moisture for the aggregates was not obtained, thereby leading to an incorrect determination of the amount of free water on the aggregate and the water-to-cement ratio of the Day 28 specimens for Mixtures E and F.

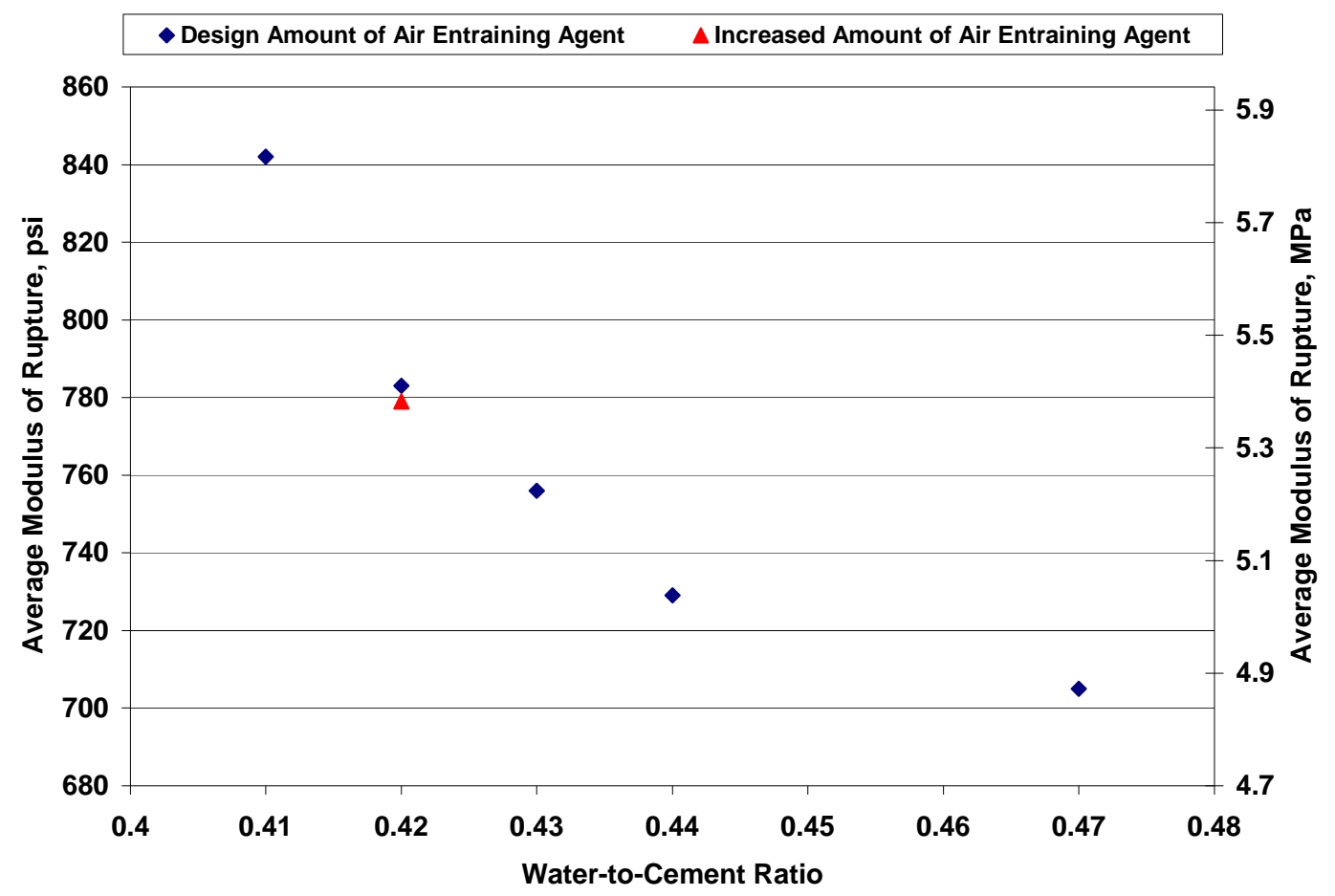

Figure 13-4 Modulus of Rupture Versus Water-to-Cement Ratio at Seven Days 


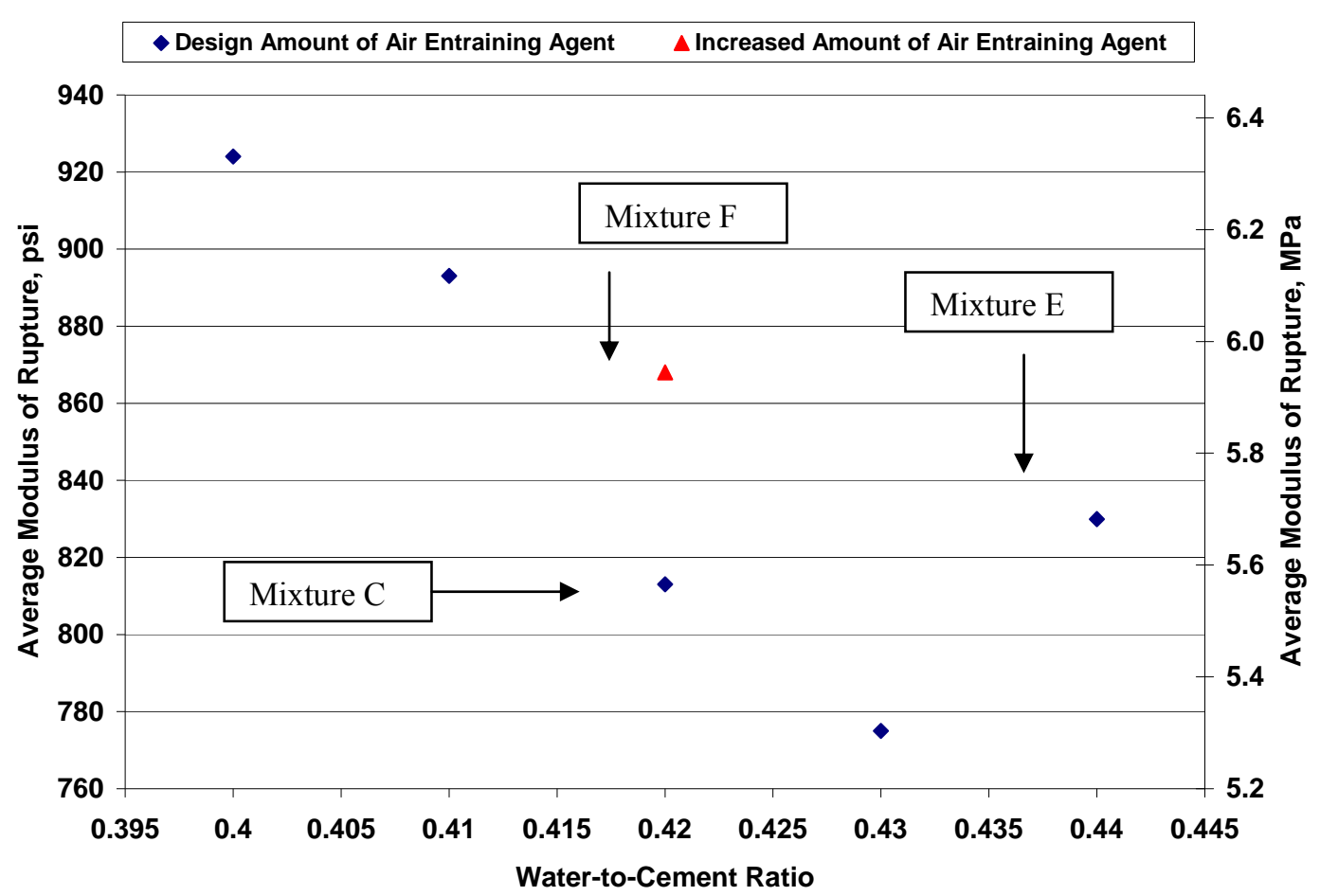

Figure 13-5 Modulus of Rupture Versus Water-to-Cement Ratio at 28 Days

Table 13-8 shows the difference between the actual average flexural strength of the specimens for the mixture proportion variations (Mixtures A, B, D, E, F, and G) and the predicted strength from the strength-maturity relationship created for Mixture C. Except for Mixture $\mathrm{E}$ the difference is larger at 28 days than at 7 days. The table illustrates that even small changes in the water-to-cement ratio (0.01 to 0.02$)$ can introduce significant error in the estimate of strength.

The predicted strength divided by the actual strength is plotted against the water-to-cement ratio in Figure 13-6. The figure indicates that the strength-maturity relationship generally underestimates strength for mixtures with a water-to-cement ratio less than the design ratio, which is conservative, and overestimates strength for mixtures with a water-to-cement ratio greater than the design, which is not conservative. The method of implementing the strengthmaturity relationship should therefore guard against the not conservative estimates of strength. 
Table 13-8 Mixture Proportion Variation Flexural Strength Comparison

\begin{tabular}{|c|c|c|c|c|c|c|}
\hline Mixture & Day & $\begin{array}{c}\text { Temperature-Time } \\
\text { Factor }{ }^{\circ} \mathrm{C}-\mathrm{hr}\end{array}$ & $\begin{array}{c}\text { Predicted } \\
\text { Strength, psi }\end{array}$ & $\begin{array}{c}\text { Actual } \\
\text { Strength, psi }\end{array}$ & $\begin{array}{c}\text { Absolute } \\
\text { Difference, } \\
\text { psi }\end{array}$ & $\begin{array}{c}\text { Percent } \\
\text { Difference }\end{array}$ \\
\hline $\begin{array}{c}\mathrm{A} \\
\mathrm{w} / \mathrm{c}=0.40\end{array}$ & 28 & 19518 & 826 & 924 & 98 & 11.9 \\
\hline \multirow{2}{*}{$\begin{array}{c}\mathrm{B} \\
\mathrm{w} / \mathrm{c}=0.41\end{array}$} & 7 & 5314 & 796 & 842 & 46 & 5.7 \\
\hline & 28 & 20062 & 826 & 893 & 67 & 8.1 \\
\hline \multirow{2}{*}{$\begin{array}{c}\mathrm{D} \\
\mathrm{w} / \mathrm{c}=0.43 \\
\end{array}$} & 7 & 5264 & 796 & 756 & 40 & 5.1 \\
\hline & 28 & 20027 & 826 & 775 & 51 & 6.2 \\
\hline \multirow{2}{*}{$\begin{array}{c}\mathrm{E} \\
\mathrm{w} / \mathrm{c}=0.44\end{array}$} & 7 & 5208 & 796 & 729 & 67 & 8.4 \\
\hline & 28 & 18175 & 825 & 830 & 5 & 0.6 \\
\hline \multirow{2}{*}{$\begin{array}{c}\mathrm{F} \\
\mathrm{w} / \mathrm{c}=0.42\end{array}$} & 7 & 5133 & 795 & 779 & 16 & 2.0 \\
\hline & 28 & 19968 & 826 & 868 & 42 & 5.0 \\
\hline $\begin{array}{c}\mathrm{G} \\
\mathrm{w} / \mathrm{c}=0.47\end{array}$ & 7 & 5086 & 795 & 705 & 89 & 11.3 \\
\hline
\end{tabular}

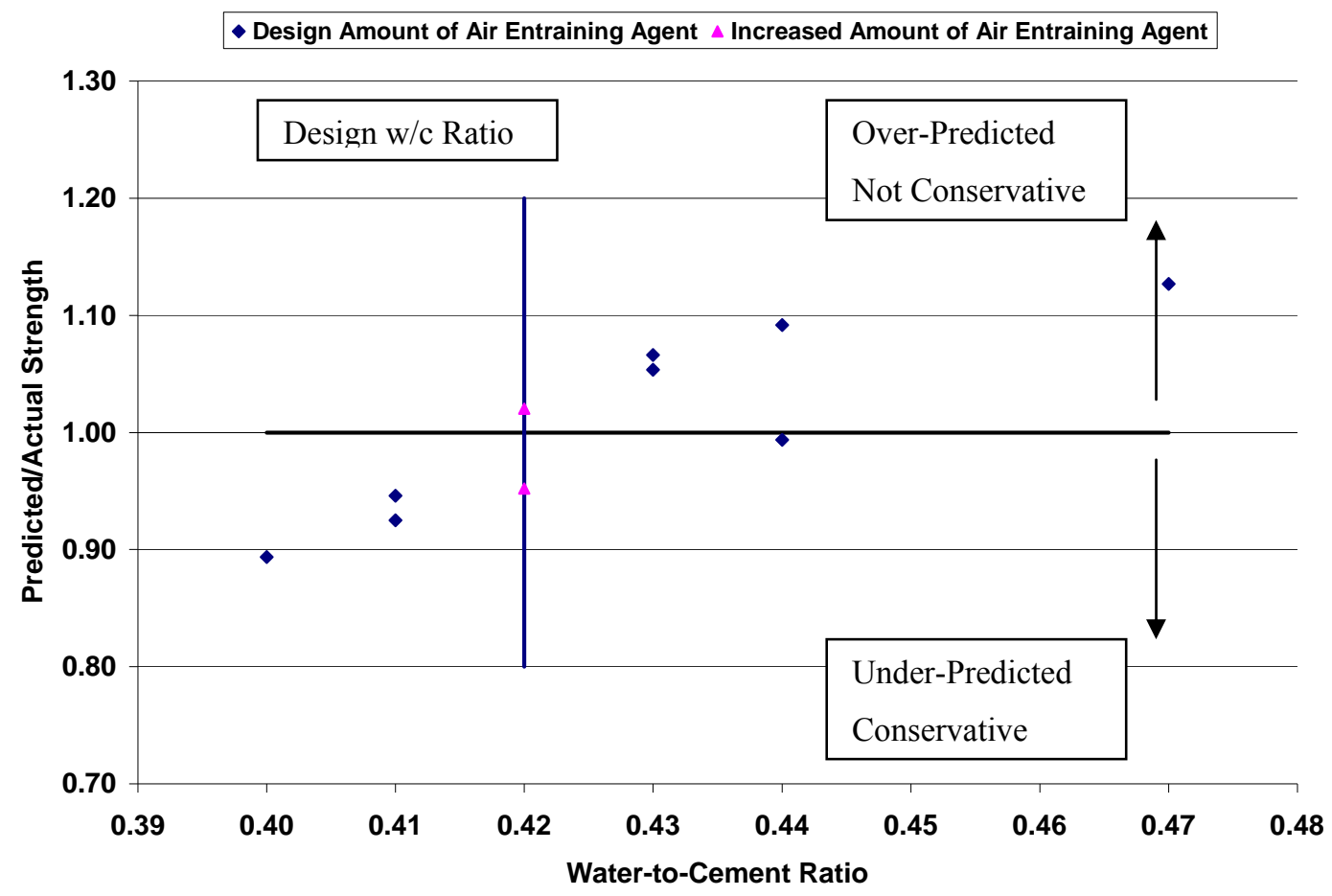

Figure 13-6 Ratio of Predicted Versus Actual Flexural Strength

Two strength-P-wave velocity relationships for Mixture $\mathrm{C}$ were created. The first relationship was created using the entire set of data and is shown in Figure 13-7. The data points for the mixture variations are also shown. The linear strength-P-wave velocity relationship for the entire set of data for Mixture $\mathrm{C}$ does not fit the data as well as the linear relationships created in the 
pre-construction test program. The $\mathrm{R}^{2}$ value is 0.904 , compared to 0.973 in the pre-construction test program (Table 11-16). The relatively poor fit for this first relationship does not appear to make it well suited for estimating strength and makes it difficult to assess the effects of mixture proportion variations on the strength estimate.

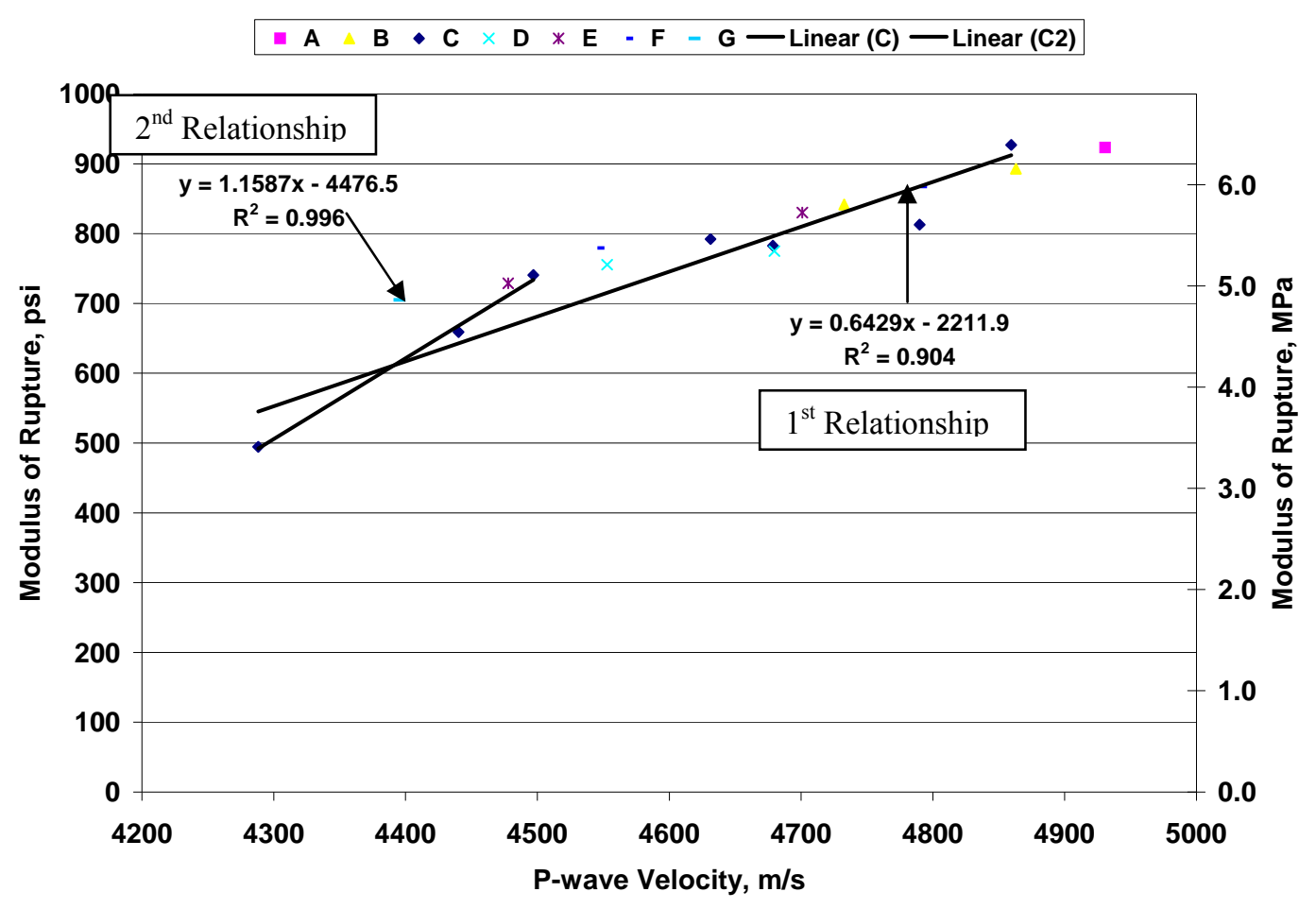

Figure 13-7 Strength-P-Wave Velocity Relationships

The second strength-P-wave velocity relationship for Mixture C, shown in Figure 13-7, was created using only the data for the ages of $1,1.5$, and 3 days. This linear relationship fits the data very well, as evidenced by the high $\mathrm{R}^{2}$ value of 0.996 . As discussed in Section 11.5.2, at early ages the $\mathrm{P}$-wave velocity is more sensitive to strength changes and therefore a strength-P-wave velocity relationship created using only early-age data should provide a better estimate of strength. Strength data was not obtained for the mixture variations at the ages of 1, 1.5, and 3 days to compare to the second strength-P-wave velocity relationship. However Table 13-6 shows that the P-wave velocity decreased with increasing water-to-cement ratio and increased amount of air entraining agent. This indicates that small variations in water-to-cement ratio and amount 
of air entraining agent would introduce error in the estimate of strength using a strength-P-wave velocity relationship.

The apparent change in the relationship between the P-wave velocity and the modulus of rupture may be related to the mode in which the specimens fractured. The strong linear relationship between the modulus of rupture and the P-wave velocity appears to occur only up to an age of 5 to 7 days. At approximately this time the method of fracture observed in the beam specimens occurs to change from a crack that primarily occurs through the paste to a crack that propagates through the aggregate. Further investigation of the affects of the method of fracture on the P-wave velocity is recommended.

\subsection{Analysis of Maturity and P-Wave Velocity Test Methods}

This section discusses several methods by which the maturity and P-wave velocity test methods could be implemented to determine flexural strength in concrete pavement construction. It also summarizes issues that must be addressed before these test methods could be implemented in field practice.

\subsubsection{Methods of Implementation}

\subsubsection{Stand Alone Maturity}

The maturity test method could be used by itself to estimate the concrete flexural strength. The strength-maturity relationship is developed prior to the need to estimate strength. The temperature history of the specimen for which strength is to be estimated is then recorded and the maturity index is calculated. The maturity index value is then input into the strength-maturity relationship and the strength is predicted. More detailed procedures have been previously presented in Chapters 3, 4, 5, and 6 . The predictions of flexural strength using the maturity method by itself for the specimens with small changes in mixture proportions have been previously presented in Table 13-8. 
However, it should be noted that Carino indicates that it is not prudent to rely solely on measurements of maturity to estimate strength (1991b). Several factors exist that can lead to errors in the estimated strength including:

- Errors in mixture proportioning and material quality variation.

- High early-age temperatures that reduce the ultimate strength of the concrete.

- Improper curing conditions that could cause hydration to stop.

- The use of an activation energy or datum temperature that is not representative of the concrete mixture.

Procedures could be implemented that would reduce and limit the error in the estimation of strength due to these factors. Further discussion concerning these factors is contained in Section 13.4.2.

\subsubsection{Combined Maturity and P-Wave Velocity Measurements}

This section describes how maturity and P-wave velocity techniques can be used jointly to improve the accuracy of strength predictions. In this approach, one test method is used to improve the reliability of the strength estimated by means of another test alone. Two methods of using both test methods are presented. The advantage of using the maturity and P-wave velocity methods is a function of the differences between the test methods. The strength estimated from the maturity method is a function of time and temperature. This product is related to the cement chemistry and chemical reactions of hydrations. However the strength estimated from the Pwave velocity is a function of the structure of the material, including the density, air voids, and the aggregate contribution.

In the first method, the measured P-wave velocity is used to verify the estimate of strength from the maturity test method. When the estimate of strength from the strength-P-wave velocity relationship equals or exceeds the estimate of strength from the strength-maturity relationship, the estimate of strength from the maturity test method would be considered validated. If the estimate of strength was less than the estimate from the maturity test method, additional action would be required. 
This method is illustrated using the strength-maturity relationship given in Figure 13-3 and the strength-P-wave velocity relationship given in Figure 13-7, which was created using the entire set of data. (Even though the strength-P-wave velocity relationship created using only the early age data fits the data much better, it could not be used to illustrate this method because early-age strength data for the mixture variations was not measured.) Using this method the strength from the maturity method would not be validated for; Mixture D at 7 and 28 days, Mixture E at 7 and 28 days, Mixture $\mathrm{F}$ at 7 days, and Mixture $\mathrm{G}$ as shown in Table 13-9. It is noteworthy that all of these cases are not conservative predictions as shown in Figure 13-6. The importance of this finding is discussed later in this section.

Table 13-9 Combined Maturity and P-Wave Velocity - Method 1

\begin{tabular}{|c|c|c|c|c|c|}
\hline \multirow{2}{*}{ Mixture } & Day & $\begin{array}{c}\text { Measured P-Wave } \\
\text { Velocity, m/s }\end{array}$ & $\begin{array}{c}\text { Predicted } \\
\text { Strength From P- } \\
\text { Wave Velocity, } \\
\text { psi }\end{array}$ & $\begin{array}{c}\text { Predicted } \\
\text { Strength From } \\
\text { Maturity, psi }\end{array}$ & $\begin{array}{c}\text { Actual } \\
\text { Strength, psi }\end{array}$ \\
\hline \multirow{2}{*}{ A } & 28 & 4931 & 958 & 826 & 924 \\
\hline \multirow{2}{*}{ B } & 7 & 4733 & 831 & 796 & 842 \\
\cline { 2 - 6 } & 28 & 4863 & 915 & 826 & 893 \\
\cline { 2 - 6 } & 7 & 4553 & 715 & $796^{*}$ & 756 \\
\hline \multirow{2}{*}{ E } & 7 & 4680 & 797 & $826^{*}$ & 775 \\
\hline \multirow{2}{*}{ F } & 7 & 4478 & 667 & $796^{*}$ & 729 \\
\cline { 2 - 6 } & 28 & 4701 & 810 & $825^{*}$ & 830 \\
\hline G & 7 & 4546 & 711 & $795^{*}$ & 779 \\
\hline
\end{tabular}

* Not Validated, Additional Action is Required

In the second method, the P-wave velocity is predicted from the measured maturity and the strength-maturity and strength-P-wave velocity relationships. Equations 5-1 and 5-2 can be rearranged into the following equation to predict the P-wave velocity corresponding to the measured maturity:

$$
x(M)=S_{\infty} \cdot \frac{k_{T} \cdot\left(M-M_{o}\right)}{A \cdot\left(1+k_{T} \cdot\left(M-M_{o}\right)\right.}-\frac{B}{A}
$$


where:

$$
\begin{aligned}
& \mathrm{S}_{\infty}=\text { limiting strength } \\
& \mathrm{k}_{\mathrm{T}}=\text { rate constant } \\
& \mathrm{M}=\text { maturity } \\
& \mathrm{M}_{\mathrm{o}}=\text { offset maturity } \\
& \mathrm{A}=\text { Slope } \\
& \mathrm{x}=\mathrm{P} \text {-wave Velocity } \\
& \mathrm{B}=\text { y-intercept }
\end{aligned}
$$

If the predicted P-wave velocity was greater than the measured $\mathrm{P}$-wave velocity, additional action would be required. The strength-maturity relationship given in Figure 13-3 and the strength-P-wave velocity relationship given in Figure 13-7 created using the entire set of data are again used to illustrate the method. The results are the same as in the first method, with the strength from the maturity method not being validated for; Mixture D at 7 and 28 days, Mixture E at 7 and 28 days, Mixture $F$ at 7 days, and Mixture $G$ as shown in Table 13-10.

Table 13-10 Combined Maturity and P-Wave Velocity - Method 2

\begin{tabular}{|c|c|c|c|c|}
\hline \multirow{2}{*}{ Mixture } & Day & $\begin{array}{c}\text { Temperature-Time } \\
\text { Factor }{ }^{\circ} \mathbf{C}-\mathbf{h r}\end{array}$ & $\begin{array}{c}\text { Measured P- } \\
\text { Wave Velocity, } \\
\mathbf{m} / \mathbf{s}\end{array}$ & $\begin{array}{c}\text { Predicted P- } \\
\text { Wave Velocity, } \\
\mathbf{m} / \mathbf{s}\end{array}$ \\
\hline A & 28 & 19518 & 4931 & 4725 \\
\hline \multirow{2}{*}{ B } & 7 & 5314 & 4733 & 4679 \\
\cline { 2 - 5 } & 28 & 20062 & 4863 & 4725 \\
\hline \multirow{2}{*}{ D } & 7 & 5264 & 4553 & $4679^{*}$ \\
\cline { 2 - 5 } & 28 & 20027 & 4680 & $4725^{*}$ \\
\cline { 2 - 5 } E & 7 & 5208 & 4478 & $4678^{*}$ \\
\hline \multirow{2}{*}{ F } & 7 & 18175 & 4701 & $4724^{*}$ \\
\hline G & 7 & 5133 & 4546 & $4677^{*}$ \\
\hline
\end{tabular}

* Not Validated, Additional Action is Required

It is difficult to be sure if the use of the measurement of P-wave velocity test method in combination with the maturity test method is an improvement over the use of the maturity test method alone. This is because the strength-P-wave velocity relationship used in the above illustrations does not fit the data very well. However it is interesting to note that when using the 
maturity method alone, the predicted strength was greater than the actual strength in 5 of the 10 cases. As shown in Table 13-11, both methods of using the measurement of P-wave velocity and maturity in combination indicated that in each of these 5 cases the tests would not be considered valid and further investigation would be required. Of the 5 cases where the predicted strength using the maturity method alone was less than the actual strength, only 1 of the cases was indicated to not be valid using the combined methods. This appears to indicate that the combined methods will able to determine when the prediction of strength is exceeding the actual strength of the specimen.

Table 13-11 Combined Method of Analysis

\begin{tabular}{|c|c|c|c|c|c|c|}
\hline Mixture & Day & $\begin{array}{c}\text { Predicted } \\
\text { Strength From } \\
\text { Maturity, psi }\end{array}$ & $\begin{array}{c}\text { Actual } \\
\text { Strength, psi }\end{array}$ & $\begin{array}{c}\text { Predicted } \\
\text { Strength / } \\
\text { Actual } \\
\text { Strength }\end{array}$ & $\begin{array}{c}\text { Validated by } \\
\text { Combined } \\
\text { Method 1 }\end{array}$ & $\begin{array}{c}\text { Validated by } \\
\text { Combined } \\
\text { Method 2 }\end{array}$ \\
\hline \multirow{2}{*}{$\mathrm{A}$} & 28 & 826 & 924 & 0.89 & Yes & Yes \\
\hline \multirow{2}{*}{$\mathrm{B}$} & 7 & 796 & 842 & 0.95 & Yes & Yes \\
\cline { 2 - 7 } & 28 & 826 & 893 & 0.92 & Yes & Yes \\
\hline \multirow{2}{*}{$\mathrm{D}$} & 7 & 796 & 756 & 1.05 & No & No \\
\cline { 2 - 7 } & 28 & 826 & 775 & 1.07 & No & No \\
\hline \multirow{2}{*}{$\mathrm{E}$} & 7 & 796 & 729 & 1.09 & No & No \\
\cline { 2 - 7 } & 28 & 825 & 830 & 0.99 & No & No \\
\hline \multirow{2}{*}{$\mathrm{F}$} & 7 & 795 & 779 & 1.02 & No & No \\
\cline { 2 - 7 } & 28 & 826 & 868 & 0.95 & Yes & Yes \\
\hline \multirow{2}{*}{$\mathrm{G}$} & 7 & 795 & 705 & 1.13 & No & No \\
\hline
\end{tabular}

\subsubsection{Early-Age Test Result In Combination With Nondestructive Test}

The two methods described above estimate the strength directly from a measured value(s) (maturity or maturity and P-wave velocity) An early-age third-point flexural test result could also be used in combination with the measured value(s) to estimate a later-age strength. Using an early-age test result could help prevent errors in the estimate of later-age strength. It could also provide early-age feedback to the contractor. Early-age feedback is beneficial to contractors because it allows them to make adjustments quicker, if desired.

One approach would be to use the early-age test result to verify that the pavement flexural strength is acceptable at the early-age. A later-age estimate of strength, determined using the 
early-age test result and the strength-maturity relationship, would then be used to determine any payment adjustment to the contractor (based on the modeling performed by the PRS software).

The method would include measuring the maturity and flexural strength at an early-age, 3 days for example, and the maturity at the age that the strength is to be estimated, 28 days for example. The following equation would then be able to be used to estimate the 28 day strength;

$$
\left.f_{r}^{\prime}(28 \text { days })=f^{\prime}{ }_{r} \text { (3days) }\right) \cdot \frac{1+k_{T} \cdot\left(M_{3}-M_{o}\right)}{1+k_{T} \cdot\left(M_{28}-M_{o}\right)} \cdot \frac{M_{28}-M_{o}}{M_{3}-M_{o}} \quad \text { Equation 13-2 }
$$

where:

$\mathrm{k}_{\mathrm{T}}=$ rate constant

$\mathrm{M}_{3}=$ maturity at 3 days

$\mathrm{M}_{28}=$ maturity at 28 days

$\mathrm{M}_{\mathrm{o}}=$ offset maturity

This method is illustrated in Table 13-12 using the measured strength at 7-days, the measured maturity at 7 days, and the measured maturity at 28 days of the mixture variation specimens. The predicted strength is closer to the actual strength using the early-age method compared to using maturity alone for 3 out of the 4 cases. The case where using the maturity test method alone produced a better estimate occurred for Mixture E. However it should be noted that the strength at 28 days for Mixture E was unexpectedly low, as shown in Figure 13-5.

Table 13-12 Early-Age Test Result Method

\begin{tabular}{|c|c|c|c|c|c|c|c|c|}
\hline \multirow[t]{2}{*}{ Mixture } & \multicolumn{2}{|c|}{$\begin{array}{l}\text { Temperature-Time } \\
\text { Factor, }{ }^{\circ} \mathrm{C}-\mathrm{hr}\end{array}$} & \multirow{2}{*}{$\begin{array}{c}\text { Actual } \\
\text { Strength } \\
\text { At } 7 \text { Days, } \\
\text { psi }\end{array}$} & \multirow{2}{*}{$\begin{array}{c}\text { Predicted } \\
\text { Strength } \\
\text { Using } \\
\text { Early-Age } \\
\text { Test } \\
\text { Result At } \\
28 \text { Days, } \\
\text { psi }\end{array}$} & \multirow{2}{*}{$\begin{array}{c}\text { Actual } \\
\text { Strength } \\
\text { At } 28 \\
\text { Days, psi }\end{array}$} & \multirow[t]{2}{*}{$\begin{array}{c}\text { Percent } \\
\text { Difference }\end{array}$} & \multirow{2}{*}{$\begin{array}{c}\text { Predicted } \\
\text { Strength } \\
\text { Using } \\
\text { Maturity } \\
\text { Alone At } \\
28 \text { Days, } \\
\text { psi }\end{array}$} & \multirow{2}{*}{$\begin{array}{c}\text { Percent } \\
\text { Difference } \\
\text { Using } \\
\text { Maturity } \\
\text { Alone }\end{array}$} \\
\hline & 7 Days & 28 Days & & & & & & \\
\hline B & 5314 & 20062 & 842 & 873 & 893 & 2.3 & 893 & 8.1 \\
\hline $\mathrm{D}$ & 5264 & 20027 & 756 & 784 & 775 & 1.2 & 775 & 6.2 \\
\hline $\mathrm{E}$ & 5208 & 18175 & 729 & 756 & 830 & 9.8 & 830 & 0.6 \\
\hline $\mathrm{F}$ & 5133 & 19968 & 779 & 809 & 868 & 7.2 & 868 & 5.0 \\
\hline
\end{tabular}


It should be noted that the later-age maturity of beam specimens can be easily computed as the sum of the measured early-age maturity and the product of the curing temperature of the water bath and the time difference between the early-age measurement and the later-age measurement. This is true because after the initial temperature rise in the beam specimen due to the heat of hydration, the temperature of the specimen will be the same as the temperature of the water bath. Therefore the constant temperature of the water bath and the time between the calculation of the early-age maturity index and the time at which the strength is to be estimated can be used to calculate the increase in maturity from the measured early-age maturity.

\subsubsection{Maturity Test Method Implementation Issues}

Several issues would have to be addressed before the maturity test method could be implemented for acceptance purposes of pavement flexural strength. The majority of these issues have been discussed in the preceding chapters, however for convenience they are summarized below.

- The form of the maturity index must be chosen. Although many state department of transportations currently use the temperature-time index from the Nurse-Saul equation, the equivalent age index from the Arrhenius equation is recommended because it has been demonstrated to be able to more accurately account for the affects of temperature on strength gain over a wide range of temperatures.

- The strength-maturity relationship must be created prior to the time the strength is to be estimated (prior to the start of pavement construction). This may require mixing and testing to be performed prior to the start of construction.

- Currently many agencies assume a value for the datum temperature. For example, the INDOT assumes a value of $-10^{\circ} \mathrm{C}$ for the datum temperature. However the value of the datum temperature or the activation energy should be determined for the specific concrete mixture for maximum accuracy in the estimate of strength. This value can be determined by testing of mortar cubes. 
- The number of test specimens used to determine the average strength at each test age during the creation of the strength-maturity relationship must be determined. Currently the INDOT requires two specimens to be tested at each age. However the large variability in the flexural strength experienced during this study indicates that more specimens should be tested at each age.

- The value of $M_{o}$ in the strength-maturity relationship should be obtained from strength data at early ages. The value of $\mathrm{M}_{\mathrm{o}}$ represents the maturity at which strength development is assumed to begin. Good estimates of $\mathrm{M}_{\mathrm{o}}$ were typically obtained from strength data less than 3 days. Therefore it is recommended that strength data be obtained for at least two ages less than 3 days to ensure a good estimate of $\mathrm{M}_{0}$. At this time is should be noted that early-age data is currently required by the INDOT for the use of maturity to open concrete pavements to traffic and as such this data may be already available.

- The concrete temperature should be measured at regular, closely spaced, intervals. As the time in-between temperature measurements increases, so will the error in the estimate of temperature increase. Currently the INDOT does not require the temperature to be measured at regular, closely spaced, intervals. Intervals similar to those required by ASTM C 1074 appear appropriate (every $1 / 2$ hour for the first 48 hours and every hour after that).

- The strength-maturity relationship is specific to the materials and concrete mixture proportions used to create the relationship. Variations in material quality and mixture proportions can create error in estimate of strength. Allowable limits need to be established for the permissible variation in mixture proportions and material characteristics when estimating strength using a strength-maturity relationship. In addition the risk of using these methods should be assessed for comparison to the risk that is inherently associated with the currently employed test methods.

\subsubsection{Measurement of P-Wave Velocity Implementation Issues}

Several issues would have to be addressed before the P-wave velocity test method could be implemented in a standard specification. The majority of these issues have been discussed in the preceding chapters. They are summarized below. 
- The strength-P-wave velocity relationship is more sensitive to strength changes at early-ages. Therefore a strength-P-wave velocity relationship created using only early age data may provide a better estimate of strength. The reason for the change in sensitivity may be related to the change in the type of fracture pattern that is seen, however more testing is needed in this area. The relationship developed at early ages is not recommended to estimate strength at later ages.

- The test equipment and procedures that are able to produce repeatable results are necessary. This requires short sampling intervals and accurate distance measurements.

- The moisture content of the specimens used to create the strength-P-wave velocity relationship should be the same as the moisture content in the specimens for which strength is to be estimated. A strength-P-wave velocity relationship created using laboratory moistcured specimens may not be directly applicable to specimens cured under field conditions due to differences in moisture content.

- The strength-P-wave velocity relationship is specific to the materials and concrete mixture proportions used to create the relationship. Variations in material quality and mixture proportions can create error in estimate of strength. Limits would need to be established for the permissible variation in mixture proportions and material characteristics when estimating strength using a strength-P-wave velocity relationship.

\subsection{Summary}

This chapter has presented the experimental results from the post construction test program. The work presented in this chapter indicates the following:

- The experimentally determined values of the datum temperature and the activation energy divided by the gas constant $(\mathrm{Q})$ were different from the values assumed in the preconstruction and field test programs. The experimentally determined value of the datum temperature was $1{ }^{\circ} \mathrm{C}$. The experimentally determined value of $\mathrm{Q}$ was $4550{ }^{\circ} \mathrm{K}$. 
- Using the revised values of the datum temperature and Q did not change the predicted beam strength. This occurs as a result of the beam curing temperature being essentially the same as the reference curing temperature.

- The decrease in the difference between the predicted strengths from the temperature-time factor and the equivalent age when the revised values of the datum temperature and $\mathrm{Q}$ are used implies that the revised values are producing more accurate estimates than the original values.

- The small changes in the water-to-cement ratio and amount of air entraining agent introduced error into the estimate of strength from the strength-maturity relationship created for the design mixture, Mixture C. The amount of the absolute difference between the predicted strength and the measured strength varied from $0.6 \%$ to $11.9 \%$.

- Two strength-P-wave velocity relationships for Mixture $\mathrm{C}$ were created. The first relationship did not fit the data as well as the relationships created in the pre-construction test program as evidenced by a decreased $\mathrm{R}^{2}$ value ( 0.904 , compared to 0.973 ). The relatively poor fit for this first relationship does not appear to make it well suited for estimating strength and makes it difficult to assess the effects of mixture proportion variations on the strength estimate. The second strength-P-wave velocity relationship, created using only the data for the ages of 1 , 1.5 , and 3 days, fit the data very well $\left(\mathrm{R}^{2}\right.$ value of 0.996$)$. Strength data was not obtained for the mixture variations at the ages of $1,1.5$, and 3 days to compare to the second strength-Pwave velocity relationship.

- The strength-P-wave velocity relationship created using all of the strength-P-wave data for Mixture $\mathrm{C}$ did not fit the data very well. As a result, assessing the effects of mixture proportion variations on the estimate of strength was difficult.

- The strength-P-wave velocity relationship created using early-age strength-P-wave data for Mixture $\mathrm{C}$ fit the data very well. Observing the change in $\mathrm{P}$-wave velocity between different mixture proportions at the age of 3 days indicates that small mixture proportion variations would introduce error in the estimate of strength.

- Three methods of implementing the maturity and P-wave velocity test methods were presented. Both the combined use of maturity and P-wave velocity measurements and the 
use of an early-age test result in combination with the maturity test method appear to have advantages over using the maturity test method alone.

- Several issues were presented that would need to be addressed before either the maturity or P-wave velocity test methods should be implemented in a specification. 


\section{CHAPTER 14: CONCLUSIONS AND RECOMMENDATIONS}

\subsection{Introduction}

The objectives of this study were to evaluate the sensitivity of life-cycle cost model inputs in Performance Related Specifications (PRS), to investigate the use of in-situ, nondestructive test methods to determine concrete pavement quality characteristics for use in a PRS, and to investigate the impact of PRS on contractors and agencies in the construction of concrete pavements. Chapter 1 provided an introduction to this study. Chapter 2 contained an overview of the implementation of PRS in Indiana. Chapter 3 persented a review of life-cycle cost modeling concepts. Chapter 4 provided a review of the deterioration models that are used in PRS. Chapter 5 compared and contrasted PRS with other contracting strategies. Chapters 6 and 7 presented a sensitivity analysis of PRS software. Chapter 8 discussed the implications of PRS. Chapter 9 presented the results of a review of available literature on nondestructive test methods to determine concrete strength and pavement thickness. Chapter 10 outlined the experimental test program. Chapters 11, 12, and 13 presented the results from the experimental test programs conducted to assess the use of the impact-echo, compression (P-wave) velocity, and maturity test methods for the purposes of determining concrete pavement quality. This chapter summarizes the conclusions presented in this study and recommends areas for further research.

\subsection{Life-Cycle Cost Analysis}

PRS are based on the ability to predict the post-construction life-cycle cost of pavements based on the design of agency and the certain Acceptable Quality Characteristics (AQCs) that are measures of construction quality. Life-cycle cost analysis (LCCA) has been used in infrastructure projects, particularly as a decision tool for economic analysis of competing design 
alternatives. PRS distinguishes itself from other LCCA applications because it is used in the construction phase of the project. The use of LCCA in PRS also provides a rational basis for payment adjustments. Disadvantages of LCCA include the reliance on inputs such as the discount factor and user costs, which can be difficult to accurately estimate. Specifically, this study has highlighted the use of LCCA and its benefits, and therefore this study further encourages the use of LCCA in infrastructure investment and management.

\subsection{Pavement Distress Modeling}

This study conducted a review of pavement distress modeling, which is used in PRS to predict the performance and the life-cycle cost of the pavement. The models currently included in PRS software include transverse joint spalling, transverse joint faulting, transverse fatigue cracking, and increasing roughness. These models were found for the most part to reflect the commonly occurring distresses in Indiana pavements, as shown by a survey of professionals in the industry and a previous study of concrete pavements. However, it has been noted by the Program Development Division of the Indiana Department of Transportation (INDOT) that pavements are often replaced for reasons other than structural failure. For example, many pavements designed in the 1960s have exceeded their design traffic loads earlier than expected, making them functionally obsolete. Other pavements have also experienced material failure, although aggregate specifications have been recently modified to correct this problem. This study has specifically noted that although the distress models may not be proven to be $100 \%$ accurate, the pair-wise comparison of life-cycle costs in PRS tends to correct for inaccuracies in prediction modeling.

\subsection{PRS and Other Innovative Contracting Strategies}

PRS are found to be an innovative contracting strategy, as they overcome many of the different difficulties in current QC/QA specifications. They provide a rational basis for pay adjustments and provide incentives that encourage better quality control. PRS can be used in 
conjunction with Design-Build and $\mathrm{A}+\mathrm{B}$ Bidding, providing assurance that quality is adequately balanced with time and performance.

\subsection{Life-Cycle Cost Analysis Software Inputs}

In the course of this study, the inputs necessary to run a life-cycle simulation on pavement projects in Indiana were tabulated. Specifically, the climatic data for each INDOT subdistrict was collected, and the typical ranges of many pavement design and maintenance procedures were documented. It was found that the most vital inputs in the software include:

- $\quad$ number of average annual air freeze-thaw cycles

- $\quad$ percentage of user costs included in the life-cycle cost calculation, and - $\quad$ the expected bid price.

Results of analyses show that many of the inputs included in the life-cycle simulation software, while necessary for the calculations, have less than $1 \%$ impact on the total life-cycle cost when modified within the expected ranges. This leads to some simplification of PRS implementation, as not all of the inputs necessary for the software must be entirely accurate for PRS to be effective. It is noted that the Acceptable Quality Characteristics (AQC) values assumed by Indiana may be more conservative than the average values used to design the software.

This study specifically made the implementation of PRS in Indiana easier through the analysis of the important software inputs and the collection of data necessary to run the program.

\subsection{Impacts on Agencies and Contractors}

This study illustrated how PRS can give a competitive edge to contractors who have demonstrated good quality control. An awareness of the potential incentives for AQCs in PRS will have an effect of driving bid prices down. This study has presented how the design value for the target strength has a great impact on the pay factors in PRS. Furthermore, this study showed how an offset target will actual encourage the performance the agencies desire. 
In this study, contractors were given an illustration for effectively designing production to target a specific life-cycle cost, rather than merely meeting the minimum requirements of the specification. A cost function was developed for optimizing the cost of the pavement based on strength and thickness to provide a given specified performance in terms of a life-cycle cost.

\subsection{Strength Development}

The increase in flexural strength from 7 to 28 days was found to be greater than the $5 \%$ value assumed during the development of the Level 1 PRS. This indicates the need to determine and incorporate the actual strength gain of the proposed concrete mixture in the development of future PRS. The maturity test method provides a method by which this need can be accomplished.

The split tensile strength test method does not appear well suited for AQC or QC/QA sampling and testing purposes. The results obtained using this test method exhibited a high degree of variability compared to the flexural and compressive strength test results and exhibited unexpected strength increase with age in the pre-construction test program.

The sampling location of the fresh concrete (at the batch plant compared to in front of the paving equipment) did not significantly influence the flexural strength. The initial curing location (inside a project trailer compared to outside next to the pavement) also did not significantly influence strength, however the maximum difference in initial curing temperatures was only $4{ }^{\circ} \mathrm{C}\left(7.2^{\circ} \mathrm{F}\right)$.

Small variations in mixture proportions will introduce error in the estimate of strength using strength-maturity and strength-P-wave velocity relationships. Both the combined use of the maturity and measurement of P-wave velocity test methods and the use of an early-age test result in combination with the maturity test method appear to have advantages over using the maturity 
test method alone. However, several issues would be required to be addressed before the maturity and measurement of P-wave velocity test methods could be implemented.

\subsection{Temperature and Heat Development}

The observed concrete temperature variation with time indicates the need to measure the temperature at regular, closely spaced intervals for use in the maturity test method. Intervals similar to those required by ASTM C 1074 appear appropriate (every $1 / 2$ hour for the first 48 hours and every hour after that).

The greater amount of heat generated in larger specimens results these samples having greater maturity indexes then those for smaller specimens at equal ages. This results in a more rapid relative strength gain for larger volume specimens (such as pavements) compared to smaller volume beam specimens using the maturity test method.

\subsection{Maturity Test Method}

The maturity index from the Arrhenius equation is preferred to the maturity index from the Nurse-Saul equation. It has been previously demonstrated to more accurately account for the change in the rate constant of cement hydration with temperature.

The experimentally determined values of the datum temperature and the activation energy divided by the gas constant were different from the values assumed in the pre-construction and field test programs. The experimentally determined value of the datum temperature was $1{ }^{\circ} \mathrm{C}$. The experimentally determined value of Q was $4550{ }^{\circ} \mathrm{K}$.

When the revised values of the datum temperature and Q were used in the post-construction test program, a decrease in the difference between the predicted strengths from the temperaturetime factor and the equivalent age occurred. This implies that the revised values are producing more accurate estimates than the original values. 
The offset hyperbolic function was found to accurately represent the strength-maturity relationship. This function is not one of the forms of the strength-maturity relationship contained in the PRS software (PaveSpec version 2.5) for when strength testing is performed before 28 days.

More accurate estimates of the $\mathrm{M}_{\mathrm{o}}$ parameter in the offset hyperbolic strength-maturity relationship are important with respect to strength predictions and can be obtained by utilizing early-age test data. Better estimates of $\mathrm{M}_{\mathrm{o}}$ were obtained with test results collected at the ages of 24,36 , and 48 hours compared to test results taken only at the ages of 1 and 4 days (24 and 96 hours).

Both of the strength-maturity relationships created during the field test program consistently over-estimated the strength of the beam specimens. The estimation of strength was the closest for the second (full) relationship at the age of 28 days. The values used for two of the offset hyperbolic function parameters; $\mathrm{M}_{\mathrm{o}}$ and $\mathrm{S}_{\infty}$ may have contributed to the over-estimation of strength. The error could also be due to material variations and mixture proportion variations from the materials and proportions used to create the relationships.

\subsection{Measurement of Compression Wave (P-wave) Velocity}

The P-wave velocity measured by the surface method using the acoustic emission (AE) equipment was the closest to the P-wave velocity measured using the direct transmission method in the pre-construction test program. Altering the test equipment to measure the surfacedisplacement waveform at both transducers may increase the suitability of this test method for measuring the P-wave velocity when only one surface of the test specimen is available.

Difficulty in obtaining repeatable results was experienced when the impact-echo equipment available from the FHWA was used to measure the P-wave velocity of the concrete. This appears to be due to the parameters of the test equipment (the minimum detectable surface displacement 
and the relatively large sampling interval). This reduced confidence in this test method and indicates that the P-wave velocity may not have been accurately measured by this test method.

Measuring the P-wave velocity of concrete requires good coupling of the transducers to the concrete surface. Coupling is made easier when smooth surfaces are available and small diameter transducers are used.

\subsection{Flexural Strength-P-Wave Velocity Relationship}

The linear flexural strength-P-wave velocity relationships created using data from ages of 1 to 28 days do not appear well suited for estimating strength. The width of the $95 \%$ confidence interval for the predicted strength for the strength-P-wave velocity relationship created in the pre-construction test program was relatively large. In addition, the $\mathrm{R}^{2}$ value for the strength-Pwave velocity relationships was less than the $\mathrm{R}^{2}$ value for the strength-maturity relationships. These items indicate that these strength-P-wave velocity relationships do not provide a precise estimate of strength.

The strength-P-wave velocity relationship created in the post-construction test program using only the data for ages of $1,1.5$, and 3 days fit the data very well $\left(\mathrm{R}^{2}\right.$ value of 0.996$)$. This relationship appears to be better suited for estimating strength compared to strength-P-wave velocity relationships created using data from a wider range of ages.

The moisture condition of the test specimen will change the P-wave velocity and affect the estimate of strength using strength-P-wave velocity relationships. The moisture content of the specimens used to create the strength-P-wave velocity relationships should be the same as the moisture content in the specimens for which the strength is to be estimated in order to obtain accurate estimates of strength. 


\subsection{Impact-Echo Test Method}

The bottom surface of concrete cast over an aggregate base is not smooth. An indication of the variability of the thickness of the concrete can be given by the variability of the length of cores extracted from the concrete. The variability of the length of cores will depend upon the criteria used to determine the amount of base course material that is bonded to the bottom of the core that must be removed. The average range of the length of cores for the field test program was 0.29 in $(7.37 \mathrm{~mm})$.

Inspection of surface displacement waveforms is necessary during impact-echo testing to ensure acquisition of valid waveforms. The roughness of the surface of the test specimens can affect the ability to obtain valid waveforms in the impact-echo test method. A smaller frequency resolution produces clearer frequency spectrums and induces less error in the calculation of thickness using the impact-echo test method.

The ability to obtain valid waveforms and to determine the frequency corresponding to the slab thickness does not appear to vary for the aggregate base materials and thicknesses included in the pre-construction test program. The interpretation of the test results in the pre-construction test program was made difficult by the appearance of motion associated with modes of vibration in the waveform.

The average difference between the predicted thickness using the impact-echo test method and the average core thickness in the field test program was $2.5 \%$, or $9.0 \mathrm{~mm}(0.36 \mathrm{in})$. The exact point on the bottom of the pavement where the P-wave is reflected may not correspond to the average core thickness, therefore variability of the thickness of the pavement should be considered in the evaluation of the accuracy of the predication of pavement thickness using the impact-echo test location.

The measured P-wave velocity appears to be a significant contributor to the difference between the predicted thickness using the impact-echo test method and the average core 
thickness in the field test program. This is supported by the relatively high variability and poor repeatability of the measurement technique used in the field test program.

The range of the estimated thickness of the pavement due to the frequency resolution of $0.163 \mathrm{kHz}(0.20 \mathrm{in})$ is less than the range of the thickness of the pavement determined by the measurement of cores ( 0.29 in). This implies that if the estimate of the P-wave velocity can be improved, the variability of the estimate of thickness using impact-echo test method will be comparable to the variability of the thickness as determined by the measurement of cores. 


\subsection{Recommendations for Further Study}

The implementation of PRS is hindered by the lack of experience of agencies and contractors with these specifications. Further research is needed to provide an educational program that explains PRS to parties involved and promotes the use of PRS in concrete construction. As more PRS are implemented, a long-term study to document the improvements in pavement performance and agency and contractor satisfaction is recommended.

Further study is recommended to improve the distress prediction models in PRS, which could include more AQCs such as water-to-cement ratio, base layer properties, and the impacts of drainage design on the model. Also, the distress models could be updated to include the impacts water-reducing admixtures and supplemental cements.

Further study is also recommended to identify the appropriate location in the pavement to measure the temperature for use in the maturity test method. While the observed difference in the predicted strength due to the temperature measurement location at seven days was relatively small, approximately $6 \mathrm{psi}(0.041 \mathrm{MPa})$, the appropriate location in the pavement to measure the temperature should be determined.

The strength-maturity and strength-P-wave velocity relationships are specific to the materials and concrete mixture proportions used to create the relationship. Further study is recommended to assess the affects of material characteristics on the estimate of strength. Material characteristics that are known to significantly affect strength, such as cement composition and aggregate gradation, are specifically recommended for further study.

Further study is recommended to develop methods to rapidly identify material characteristics and concrete mixture proportions at the time of placement. More closely monitored and controlled material characteristics and concrete mixture proportions on a large scale pavement construction project could ensure the applicability of the strength-maturity and strength-P-wave velocity relationships. 
Obtaining an accurate measurement of the P-wave velocity is critical to using the P-wave velocity data to estimate strength and to the accuracy of the estimate of thickness in the impactecho test method. Further study is recommended to assemble and test a system that can produce repeatable results with low variability in a field environment. 


\section{REFERENCES}

Al-Mansour, A.I. and Sinha, K.C. "Economic Analysis of Effectiveness of Pavement Preventative Maintenance.” Transportation Research Record 1442. Washington, D.C.: Transportation Research Board, 1994.

American Concrete Institute. "Simplified Version of the Recommended Practice for Evaluation of Strength Test Results of Concrete." ACI 214.3R-88. 1997.

American Concrete Pavement Association (ACPA). "Pavement Rehabilitation Strategy Selection." Concrete Paving Technology TB015P. Skokie, Illinois: ACPA, 1993.

American Concrete Pavement Association (ACPA). "The Concrete Paving Technology Restoration Guide-Procedures for Preserving Concrete Pavements.” Concrete Paving Technology TB020P. Skokie, Illinois: ACPA, 1997.

American Concrete Pavement Association (ACPA). "Life Cycle Cost Analysis: A Guide for Comparing Alternate Pavement Designs.” Engineering Bulletin EB220P. Skokie, Illinois: ACPA, 2002.

Arditi, D.A., and Messiha, H.M. "Life-Cycle Costing in Municipal Organizations." Journal of Infrastructure Systems, ASCE, Vol. 5, No. 1, March 1999.

Ball, C.G. and Childs, L.D. "Tests of Joints for Concrete Pavements." Research and Development Bulletin RD026.01P. Skokie, Illinois: Portland Cement Association, 1975.

Beckemeyer, C. "Alternate Financing-New Requirements and the Same Old Story." Eye on ERES, Vol. 8, No. 1. 2001.

Bower, D. M. "Innovative Contracting Procedures." Conference Proceedings: Engineering 21st Century Highways, San Francisco, April 1988.

Byers, Mike, American Concrete Pavement Association (ACPA). Personal correspondence. September 18, 2002.

Carino, N.J., "Laboratory Study of Flaw Detection in Concrete by the Pulse-Echo Method", In Situ/Nondestructive Testing of Concrete, Malhotra, V.M., Ed., American Concrete Institute, SP82, Detroit, 1984(a). 
Carino, N.J., "The maturity method: theory and application", ASTM Journal of Cement, Concrete, and Aggregates, Winter 61, 1984(b).

Carino, N.J., Sansalone, M., and Hsu, N. N., "Flaw Detection in Concrete by Frequency Spectrum Analysis of Impact-Echo Waveforms", International Advances in Nondestructive Testing, W.J. McGonnagle, Ed., Gordon \& Breach, New York, 1986, pp. 117-146.

Carino, N. J., "Pullout Test", CRC Handbook on Nondestructive Testing of Concrete, Malhotra, V.M. and Carino, N. J., Ed., CRC Press, Florida, 1991(a), pp. 39-82.

Carino, N. J., "The Maturity Method", CRC Handbook on Nondestructive Testing of Concrete, Malhotra, V.M. and Carino, N. J., Ed., CRC Press, Florida, 1991(b), pp. 101-146.

Carino, N. J. and Tank, R. C., "Maturity Functions for Concretes Made with Various Cements and Admixtures", ACI Materials Journal 1992, Vol. 89, Iss. 2, pp. 188-196.

Chamberlin, W.P. "Performance-Related Specifications for Highway Construction and Rehabilitation." NCHRP Synthesis of Highway Practice 212. Transportation Research Board. 1995.

Chengju, G., "Maturity of Concrete: Method for Predicting Early-Stage Strength", ACI Materials Journal 1989, Vol. 86, Iss. 4, pp. 341-353.

Clemena, G. G. and Steele, R. E., "Measurements of the Thickness of In-Place Concrete with Microwave Reflection", Virginia Transportation Research Council, VTRC 88-R16, Charlottesville, VA, 1988.

Clemena, G. G., "Short-Pulse Radar Methods", CRC Handbook on Nondestructive Testing of Concrete, Malhotra, V.M. and Carino, N.J., Ed., CRC Press, Florida, 1991, pp. 253-274.

Clough, R. H. Construction Contracting, 5th ed. John Wiley \& Sons, Albuquerque, NM, 1986.

Cormier, B., Thebeau, D., Duchesne, L., Dault, Y., Beckemeyer, C., and Darter, M. "A Concrete Pavement Project with a 10-Year Performance Guarantee in Quebec." 7th International Conference on Concrete Pavements, Orlando, FL. September 2001.

Darter, M.I., Abdelrahman, M., Okamoto, P.A. and Smith, K.D., "Performance-Related Specifications for Concrete Pavements: Volume I-Development of a Prototype PerformanceRelated Specification", FHWA-RD-93-042, Washington, D.C., Federal Highway Administration, 1993.

Darter, M.I., Abdelrahman, Hoerner, T., Phillips, M., Smith, K.D., and M., Okamoto, P.A., "Performance-Related Specifications for Concrete Pavements: Volume II-Appendix A, B, and C”, FHWA-RD-93-043, Washington, D.C., Federal Highway Administration, 1993. 
Darter, M.I. and Barenberg, E.J. "Design of Zero-Maintenance Plain Jointed Concrete Pavement, Vol. II - Design Manual.” FHWA-RD-77-11.Washington, D.C.: Federal Highway Administration, June 1977.

Darter, M.I., Khazanovich, L., Snyder, M., Rao, S., and Hallin, J. "Development and Calibration of a Mechanistic Design Procedure for Jointed Plain Concrete Pavements." Orlando, Florida: 7th International Conference on Concrete Pavements, September 2001.

Dave, Kumar. INDOT Pavement Design Division. Personal email, October 16, 2001.

Devore, Jay L., "Probability and Statistics for Engineering and the Sciences", Fourth Edition, International Thomson Publishing Company, 1995.

Ehlen, M.A. "BridgeLCC 1.0 Users Manual: Life-Cycle Costing Software for Preliminary Bridge Design.” Gaithersburg, MD: National Institute of Standards and Technology, 1999.

Embacher, R. A., and Snyder, M.B. "Life-Cycle Cost Comparison of Asphalt and Concrete Pavements on Low-Volume Roads - Case Study Comparisons." Transportation Research Record 1749. Washington, D.C: Transportation Research Board, 2001.

Federal Highway Administration, Transportation Asset Management Research and Technology. "Findings of the Infrastructure Renewal Working Group, National Research and Technology Partnership Forum, 2001.” FHWA-IF-02-013.

Federal Highway Administration. "BRIEFING - FHWA Initiatives to Encourage Quality Through Innovative Contracting Practices.” July 9, 2002.

Federal Highway Administration. "Improving Transportation Investment Decisions Through Life-Cycle Cost Analysis.” 2003.

Frangopol, D.M., Lin, K.L., and Estes, A.C. "Life-Cycle Cost Design of Deteriorating Structures.” Journal of Structural Engineering, ASCE, Vol. 123, No. 10, 1997.

Freiesleben Hanson, P. and Pedersen, J., "Maturity Computer for Controlled Curing and Hardening of Concrete", Nordisk Betong (Stockholm), Vol. 21, 1977, pp. 19-34.

Ganji, V., Gucunski, N., and Nazarian, S., “Automated Inversion Procedure for Spectral Analysis of Surface Waves", Journal of Geotechnical and Geoenvironmental Engineering, Vol. 124, Iss. 8, 1998, pp. 757-770. 
Gharaibeh, N.G., Kopac, P.A., and Darter, M.I. "Effect of Variability and Central Tendency in Performance-Related Specifications for Concrete Pavements." Orlando, Florida: 7th International Conference on Concrete Pavements, September 2001.

Gharaibeh, N.G., Stefanski, J., and Darter, M.I. "Evaluation of Concrete Pavement Construction Scenarios under PRS." Washington, D.C.: 81st Annual Meeting of the Transportation Research Board, January 2002.

Gordon, C. M.. "Choosing Appropriate Construction Contracting Method." Journal of Construction Engineering, ASCE, Vol. 120, No. 1. 1994

Graveen. C. "Nondestructive Test Methods to Assess Pavement Quality For Use in a Performance-Related Specification." Master's thesis. West Lafayette, IN: Purdue University, May 2001.

Gulen, S., Nagle, J., Weaver, J., and Gallivan, V. "Determination of Practical ESALs Per Truck Values on Indiana Roads." West Lafayette, IN: Joint Transportation Research Program, December 2000.

Hancher, D. E. "Contracting Methods for Highway Construction." Transportation Research News, no. 205, Nov-Dec 1999.

Harrison, R., Waalkes, S., and Wilde, W.J. "A Life Cycle Cost Analysis of Rigid Pavements." Project summary report 1739-S. Center for Transportation Research, University of Texas at Austin. 1999.

Hastak, M. and Halpin, D. "Assessment of Life-Cycle Benefit-Cost of Composites in Construction." Journal of Composites for Construction, ASCE, Vol. 4, No. 3, 2000.

Hoerner, T.E. and Darter, M.I., "Guide to Developing Performance-Related Specifications for PCC Pavements, Volume 1: Practical Guide, Final Report and Appendix A", FHWA-RD-98155, Federal Highway Administration, Feb. 1999, 191 pages.

Hoerner, T.E., Darter, M.I., Tarr, S.M., and Okamoto, P.A. "Guide to Developing PerformanceRelated Specifications for PCC Pavements, Volume II: Appendix B - Field Demonstrations", FHWA-RD-98-156. Washington, D.C.: Federal Highway Administration, February 1999.

Hoerner, T.E., Darter, M.I., Khazanovich, L., Titus-Glover, L., and Smith, K.L. "Improved Prediction Models for PCC Pavement Performance-Related Specifications, Volume I: Final Report." FHWA-RD-00-130. Washington, D.C.: Federal Highway Administration, September 2000.

Hoerner, T.E. and Darter, M.I. "Improved Prediction Models for PCC Pavement PerformanceRelated Specifications, Volume II: PaveSpec 3.0 User's Guide." FHWA-RD-00-131. Washington, D.C.: Federal Highway Administration, September 2000. 
Howard, W.E., Bell, L.C., and McCormick, R.E.. "Economic Principles of Contractor Compensation." Journal of Management in Engineering, Vol. 13, No. 5, 1997.

Huang, Y.H. Pavement Analysis and Design. New Jersey: Prentice Hall, Inc., 1993.

Hughes, C.S. "Variability of Highway Pavement Construction." NCHRP Synthesis of Highway Practice 232. Transportation Research Board. 1996.

Indiana Department of Transportation, Division of Program Development. "2000 Annual Average Daily Traffic Volumes."

Indiana Department of Transportation. "Indiana Design Manual, Chapter 52 - Pavement and Underdrain Design Elements.” 2002.

Indiana Department of Transportation. "1999 Standard Specifications."

Intermodal Surface Transportation Efficiency Act of 1991 (ISTEA). United States statues at large, Vol. 105, part 3, U.S. GPO, Washington, D.C., 1914-2207.

Karaoguz, M., Bilgutay, N., Akgul, T., and Popovics, S., "Ultrasonic Testing of Concrete using Split Spectrum Processing", Material Evaluation, Vol. 57, Iss. 11, Nov. 1999, pp. 1183-1190.

Khazanovich, L., Darter, M.I., and Smith, K.D. “Transverse Crack Deterioration Model for JRCP." 6th International Conference on Concrete Pavement Design and Rehabilitation. West Lafayette: Purdue University, 1997.

Kirk, S.J., and Dell'Isola, A.J. Life Cycle Costing for Design Professionals. 2nd Edition. McGraw-Hill, New York, NY, 1995.

Knudsen, T., "The dispersion model for hydration of Portland cement. I. General Concepts", Cement Concr. Res., Vol 14, No. 622, 1984.

Knutson, M. J. "Portland Cement Concrete Pavement in the 21st Century." Conference Proceedings: Engineering 21st Century Highways, San Francisco, April 1988.

Koehler, B., Hentges, G., and Mueller, W., "Improvement of Ultrasonic Testing of Concrete by Combining Signal Conditioning Methods, Scanning Laser Vibrometer and Space Averaging Techniques", NDT \& E International 1998, Vol. 31, Iss. 4, pp. 281-287.

Kopac, P.A. "Performance-Related Specifications: A Cooperative Effort to Improve Pavement Quality." Washington, D.C.: US Department of Transportation, 1997.

Kopac, P.A. "Making Roads Better and Better.” Public Roads, Vol.66, No.1. July/August 2002. 
Krause, M., Barmann, M., Frielinghaus, R., Kretzschmar, F., Kroggel, O., Langenberg, K. J., Maierhofer, C., Muller, W., Neisecke, J., Schickert, M., Schmitz, V., Wiggenhauser, H., and Wollbold, F., "Comparison of pulse-echo methods for testing concrete", NDT \& E International 1997, Vol. 30, Iss. 4, pp. 195-204.

Lin, J. and Sansalone, M., "Impact-Echo Response of Hollow Cylindrical Concrete Structures Surrounded by Soil and Rock: Part 1-Numerical Studies", Geotechnical Testing Journal, Vol. 17, No. 2, 1994, pp. 207-219.

Lin, J. and Sansalone, M., "Impact-Echo studies of Interfacial Bond Quality in Concrete. 1. Effects of Unbonded Fraction of Area", ACI Materials Journal, Vol. 93, No. 3, 1996, pp. 223232.

Lin, J. and Sansalone, M., "A Procedure for Determining P-Wave Speed in Concrete for Use in Impact-Echo Testing Using a Rayleigh Wave Speed Measurement Technique", Innovations in Non-Destructive Testing of Concrete, Pessiki, S. and Olson, L., Ed., American Concrete Institute, SP-168, Michigan, 1997, pp. 137-165.

Malhotra, V. M. and Carette, G. G., "Penetration Resistance Methods", CRC Handbook on Nondestructive Testing of Concrete, Malhotra, V.M. and Carino, N. J., Ed., CRC Press, Florida, 1991, pp. 19-38.

Maser, K. R., "Ground Penetrating Radar Survey of Pavement Thickness on MN/Road Sections", Minnesota Department of Transportation, Report No. MN/RC-95/06, November 1994.

McFarland, W.F. "Benefit Analysis for Pavement Design Systems.” Report 123-13. Austin, TX: Texas Highway Department, 1972.

Midwestern Regional Climate Center. Cooperative program of the Illinois State Water Survey and the National Climatic Data Center (National Oceanic and Atmospheric Administration, U.S, Department of Commerce). www.mcc.sws.uiuc.edu. March, 2003.

Mindess, S. and J.F. Young. Concrete. New Jersey: Prentice-Hall, Inc., 1981.

Naik, T. R., and Malhotra, V. M., "The Ultrasonic Pulse Velocity Method", CRC Handbook on Nondestructive Testing of Concrete, Malhotra, V.M. and Carino, N. J., Ed., CRC Press, Florida, 1991, pp. 169-188.

Nantung, T. Personal interview. West Lafayette, IN, June 6th, 2002.

National Snow and Ice Data Center (NSIDC). Global Annual Freezing and Thawing Indices. NSIDC Distributed Active Archive Center, University of Colorado at Boulder. 1998. 
Nazarian, S., Stokoe, K. H., and Hudson, W. R., "Use of Analysis of Surface Waves Method for Determination of Moduli and Thickness of Pavement Systems", Transportation Research Record, Vol. 930, 1983, pp. 38-45.

Nazarian, S., Baker, M. R., and Crain, K., "Developing and Testing a Seismic Pavement Analyzer" Tech. Rep. SHRP-H-375 Strategic Highway Research Program, Washington D. C., 1993.

Neil, J. M.. “Incentives - Powerful Tools for Owners.” Cost Engineering, Vol. 33, No. 1, 1991.

Nelson, R. O. “Utah’s I-15 Design-Build Project.” Public Roads, Vol. 61, No. 3. Federal Highway Administration, 1997.

Office of Asset Management. "Performance-Related Specifications: Next Step in Pavement Quality." Federal Highway Administration, 2001. FHWA-IF-02-006.

Office of Highway Policy Information (OHPI). "Highway Statistics 2001: Federal-Aid Highway Length.” Federal Highway Administration, 2002.

Ohrn, L.G. and Schexnayder, C. "Effect of Performance-Related Specifications on Highway Construction." ASCE Practice Periodical on Structural Design and Construction, Vol. 2, No. 4. November 1997.

Okamoto, P.A., Wu, C.L., Tarr, S.M., Darter, M.I., and Smith, K.D., "Performance-Related Specifications for Concrete Pavements: Volume III-Appendix D and E", FHWA-RD-93-044, Washington, D.C., Federal Highway Administration, 1993.

Papagiannakis, T. and Delwar, M. "Computer Model for Life-Cycle Cost Analysis for Roadway Pavements.” Journal of Computing in Civil Engineering, ASCE, Vol. 15, No. 2, April 2001.

Pessiki, S. P. and Carino, N. J., "Measurement of the Setting Time and Strength of Concrete by the Impact-Echo Method", Report No. NBSIR 87-3575, National Bureau of Standards, Washington, D.C., July 1987, 109 pages.

Pessiki, S. P. and Carino, N. J., Setting Time and Strength of Concrete Using the Impact-Echo Test Method", ACI Materials Journal 1988, Vol. 85, Iss. 5, pp. 389-399.

Pessiki, S. P. and Johnson, M. R., "Nondestructive Evaluation of Early-Age Concrete Strength in Plate Structures by the Impact-Echo Method”, ACI Materials Journal 1996, Vol. 93, No. 3, pp. 260-271.

Popovics, J. S., Song, W., Achenbach, J. D., Lee, J. H., and Andre, R. F., “One-Sided Stress Wave Velocity Measurement in Concrete", Journal of Engineering Mechanics, Vol. 124, Iss. 12, 1998, pp. 1346-1353. 
Popovics, J. S., Achenbach, J., and Song, W., "Application of New Ultrasound and Sound Generation Methods for Testing Concrete Structures", Magazine of Concrete Research 1999, Vol. 51, Iss. 1, pp. 35-44.

Portland Cement Association. "Concrete Paving - 100 Years of Progress Through Innovation." Concrete in Highway Transportation, No. 10, November 1991.

"PRS - Getting Beyond the Talk." Unpublished.

Qixian, L. and Bungey, J. H., "Using Compression Wave Ultrasonic Transducers to Measure the Velocity of Surface Waves and Hence Determine Dynamic Modulus of Elasticity for Concrete", Construction and Building Materials 1996, Iss. 10, pp. 237-242.

Queiroz, C.A.V., Hudson, W.R., Visser, A.T., and Butler Jr., B.C. “A Stable, Consistent, and Transferable Roughness Scale for Worldwide Standardization." Transportation Research Record 997. Washington, D.C.: Transportation Research Board, 1984.

Radzikowski, H.A. "Developments in Equipment for Highway Construction." Better Roads, Vol. 71, No. 1. January 2001. Reprinted from February 1960.

Rao, S., Yu, H.T., and Darter, M.I. "The Longevity and Performance of Diamond-Ground Pavements." Research and Development Bulletin RD118.01P. Skokie, Illinois: Portland Cement Association, 1999.

Roesset, J. M., Chang, D., Stokoe, K. H., and Aouad, M., "Modulus and Thickness of the Pavement Surface Layer from SASW Tests", Transportation Research Record 1260, 1990, pp. 53-63.

RSMeans. "Heavy Construction Cost Data." 15th edition. Kingston, Massachusetts: R.S. Means Co., Inc., 2000.

Sansalone, M. and Carino, N.J., "Laboratory and Field Studies of the Impact-Echo Method for Flaw Detection in Concrete", Nondestructive Testing, Lew, H.S., Ed., American Concrete Institute, SP-112, Detroit, 1988, pp. 1-20.

Sansalone, M. and Carino, N.J., "Stress Wave Propagation Methods", CRC Handbook on Nondestructive Testing of Concrete, Malhotra, V.M. and Carino, N.J., Ed., CRC Press, Florida, 1991, pp. 275-304.

Sansalone, M. and Pratt, D.G., "Theory and Operation Manual for the Impact-Echo Field System”, Vol. 1, $2^{\text {nd }}$ Edition, Jan. 1993.

Sansalone, M., Lin, J., and Streett, W.B., "A Procedure for Determining Concrete Pavement Thickness Using P-Wave Speed Measurements and the Impact-Echo Method", Innovations in 
Non-Destructive Testing of Concrete, Pessiki, S. and Olson, L., Ed., American Concrete Institute, SP-168, Michigan, 1997, pp. 167-184.

Sansalone, M., Lin, J., and Streett, W. B., "A Procedure for Determining P-Wave Speed in Concrete for Use in Impact-echo Testing Using a P-Wave Speed Measurement Technique", ACI Materials Journal 1997, Vol. 94, Iss. 6, pp. 531-539.

Sayers, M.W., Gillespie, T.D., and Queiroz, C.A.V. "The International Road Roughness Experiment: A Basis for Establishing a Standard Scale for Road Roughness Measurements." Transportation Research Record 1084. Washington, D.C.: Transportation Research Board, 1986.

Senadheera, S.P. and Zollinger, D.G. "Framework for Incorporation of Spalling in Design of Concrete Pavements." Transportation Research Record 1449. Washington, D.C.: Transportation Research Board, 1994.

Shilstone, J.M. "Performance-Based Specifications for the Concrete Portion of Concrete Pavements." Washington, D.C.: 79th Annual Meeting of the Transportation Research Board, January 2000.

Slater, R. E. "LCCA Interim Policy Statement." Federal Highway Administration. FHWA Docket No. 94-15. Issued July 11, 1994.

Slater, R.E. "Life-cycle Cost Analysis.” FHWA Docket No. 94-15. Federal Register Vol. 61, No. 182. Washington, D.C.: Federal Highway Administration, 1996.

Strategic Highway Research Program (SHRP). "Distress Identification Manual for the LongTerm Pavement Performance Project." SHRP-P-338. Washington, D.C.: National Research Council, 1993.

Sturrup, V.R., Vecchio, F.J., and Caratin, H., "Pulse Velocity as a Measure of Concrete Compressive Strength", Malhotra, V.M., Ed., American Concrete Institute, SP-82, Detroit, 1984, pp. 201-227.

Swanlund, M. "Smoother Roads Playbook: A Winning Strategy for Concrete Pavements." Focus, September 2000. Washington, D.C.: Federal Highway Administration.

Thomas, M.D.A. and Bentz, E.C. "Life-365: Computer Program for Predicting the Service Life and Life-Cycle Costs of Reinforced Concrete Exposed to Chlorides." Software Manual. Concrete Corrosion Inhibitors Association, 2000.

Titus-Glover, L., Darter, M.I., Mallela, J. "Modeling Transverse Joint Spalling for Jointed Plain Concrete Pavement." Orlando, Florida: 7th International Conference on Concrete Pavements, September 2001. 
Transportation Equity Act for the 21st Century (TEA-21). Federal Highway Administration, 1998.

TRB Circular \#494. “Durability of Concrete.” Washington, D.C.: Transportation Research Board/National Research Council, 1999.

TRB Circular E-C037. "Glossary of Highway Quality Assurance Terms." Washington, D.C.: Transportation Research Board/National Research Council, 2002.

Tymvios, N., McCullouch, B, and Sinha, K.C. "An Initial Evaluation of Design-Build Highway Projects Performed by the Indiana Department of Transportation." FHWA/IN/JTRP-2002/21. West Lafayette, IN: Joint Transportation Research Program, 2002.

U.S. Department of Energy, Office of Environmental Management. "Standard life-cycle cost savings analysis methodology for deployment of innovative technologies." Washington, D.C.: Federal Energy Technology Center, 1998.

U.S. Department of Energy, Office of Energy Efficiency and Renewable Energy. "Executive Order 13123: Greening the Government Through

Efficient Energy Management: Guidance Documents for Federal Agencies." Washington, D.C.: U.S. DOE, December 2000.

Utah Technology Transfer Center (UTTC). "Best Practices Guide for Innovative Contracting Procedures." Logan, UT. 2003.

Voigt, G. "Concrete Pavement Distresses." Slides. American Concrete Pavement Association (ACPA). 1996.

Waalkes, S. "Measuring Pavement Smoothness." Concrete Construction. December 2001.

Walls, J. III, and M. R. Smith. "Life-cycle Cost Analysis in Pavement Design." FHWA-SA-98079. Washington, D.C.: Federal Highway Administration, 1998.

Wang, L. and Zollinger, D.G. "A Mechanistic Design Framework for Spalling Distress." Washington, D.C.: 79th Annual Meeting of the Transportation Research Board, January 2000.

Ward, M.A. and Langan, B.W., "Strength Evaluation of In-Situ Concrete by Rebound Hammer and Core Testing", Cement Concrete, and Aggregates 1994, Vol. 16, No. 2, pp. 181-185.

Weed, R. M., "Statistical Specification Development", FHWA/NJ-88-017, Trenton: New Jersey Department of Transportation, 1989.

Weed, R.M. "The Proof is in the Pavement." Civil Engineering, Vol. 63, No. 8. August, 1993. 
Weiss, W.J. "Condition Assessment, Repair, and Life-Cycle Assessment of Infrastructure Materials." Class Notes. Purdue University, 2001.

Wendell Cox Consultancy. "Highway and Motor Fact Book." Belleville, IL: The Public Purpose, 2003.

Weseman, W.A. and Erickson, J.K.. "Future of Quality Assurance." Conference Proceedings: Engineering 21st Century Highways, San Francisco, April 1988.

Wu, C.L., Mack, J.W., Okamoto, P.A., and Packard, R.G. "Prediction of Faulting of Joints in Concrete Pavements." 5th International Conference on Concrete Pavement Design and Rehabilitation. West Lafayette: Purdue University, 1993.

Yun, C. H., Choi, K. R., Kim, S. Y., and Song, Y. C., "Comparative Evaluation of Nondestructive Test Methods for In-Place Strength Determination", Nondestructive Testing, Lew, H.S., Ed., American Concrete Institute, SP-112, Detroit, 1988, pp. 111-136.

Zayed, T.M., Chang, L.M., Fricker, J.D. "Life-Cycle Cost Based Maintenance Plan for Steel Bridge Protection Systems." Journal of Performance of Constructed Facilities, ASCE, Vol. 16, No. 2, 2002.

Zimmerman, K.A., Smith, K.D., and Grogg, M.G. "Applying Economic Concepts from Lifecycle Cost Analysis to Pavement Management Analysis." Transportation Research Record 1699. Washington, D.C.: Transportation Research Board, 2000.

Zollinger, D.G., Senadheera, S.P., and Tang, T. "Spalling of Continuously Reinforced Concrete Pavements." Journal of Transportation Engineering, Vol. 120, No. 3, 1994. 
These definitions are originally from in Hoerner (1999), however they were adapted as necessary by the Indiana Department of Transportation (INDOT) for inclusion in the contract documents for the first and second PRS projects.

Acceptance Quality Characteristics (AQC's) - Inherent measurable pavement characteristics that significantly affect pavement performance, are under the direct control of the contractor, and are measurable at or near the time of construction.

Analysis Period - Period of time over which future M \& R costs are to be considered in an LCC analysis. The analysis period is typically defined as twice the chosen initial pavement design life.

AQC Target Values - Department-chosen AQC means and standard deviations that define the department's desired quality (the AQC quality for which the department is willing to pay 100 percent of the bid price).

As-Constructed Lot Life-Cycle Cost $\left(\mathrm{LCC}_{\mathrm{CON}}\right)$ - The estimated post-construction LCC used to represent the as-constructed pavement lot quality. This value is based (in part) on the measured as-constructed $\mathrm{AQC}$ values (means and standard deviations).

As-Constructed Pavement - The actual concrete pavement constructed by the Contractor. The as-constructed quality level of each pavement lot is assessed based on AQC sampling and testing (using defined $\mathrm{AQC}$ acceptance procedures) of the as-constructed pavement.

As-Designed Lot Life-Cycle Cost ( $\left.\mathrm{LCC}_{\mathrm{DES}}\right)$ - The estimated post-construction LCC used to represent the as-designed pavement quality. This value is based on the as-designed AQC target values (means and standard deviations) selected by the department.

As-Designed Pavement - The desired concrete pavement, as defined by the department. The desired quality level of the pavement is specified in terms of target as-designed AQC means and standard deviations.

Constant Values - Project-specific variables required by the distress indicator and cost models that do not differ between the as-designed and as-constructed pavements. These variables define many of the pavement's characteristics and can be grouped into general categories such as traffic, project location and description, climatic conditions, design and support, load transfer, and $M \& R$ unit costs.

Distress Indicator - A measure of the condition of an existing pavement section at a particular point in time. These key pavement distresses are used to define pavement performance. Distress indicators included in the current PRS approach include transverse slab cracking, transverse joint faulting, transverse joint spalling, and pavement smoothness over time. Within the PRS, the distress indicators are predicted (over a chosen analysis period) using the best available empirical or mechanistic models. Model inputs include project-specific constant values and representative mean values of the selected AQC's. 
In-situ Sampling - AQC sampling procedures in which samples are taken directly from or on the in-place concrete pavement (e.g., cores and surface profile measurement).

Initial Design Life - Amount of time for which the chosen pavement design is expected to carry traffic loads without the application of an AC overlay, PCC overlay, or diamond grinding.

Life-Cycle Cost (LCC) - The estimated cumulative present worth cost of a pavement lot over a specified analysis period. The LCC, as used in PRS, may include estimated future maintenance, rehabilitation, and user costs over a chosen analysis period. The initial construction cost is not included in the LCC since it is identical for both the as-designed and the as-constructed pavements. LCC values are expressed in units of present worth dollars (PW\$) per kilometer.

Lot - A discrete quantity of constructed payment to which an acceptance procedure (and corresponding pay adjustment is applied. All pavement placed within a lot should consist of the same mix design and material sources, should be subjected to the same support conditions (base type, base thickness, subbase type, subbase thickness, subgrade treatment), and should consist of the same design characteristics (joint spacing, drainage, shoulder type, dowel-bar diameter, traffic, and AQC design values).

Lot Width - The lot width is defined as the total width of pavement, one or more traffic lanes, being placed at one time in the mainline paving process. This paving width is also referred to as a construction pass, since it describes the total width of pavement being placed in one pass of the paving train.

Maintenance Activities - Routine activities performed as preventive measures. This maintenance is typically applied at certain fixed intervals of time over the life of a pavement lot (commonly on an annual basis). Examples of maintenance activities include transverse crack and joint sealing.

Maintenance and Rehabilitation (M \& R) Plan - The defined set of rules used to predict the type and timing of future $M \& R$ activities. Expected localized and global rehabilitation activities are determined based on chosen trigger values applied to each distress indicator. Maintenance activities are applied by defining the amount and application frequency (e.g., seal 100 percent of the transverse joints every 2 years).

Maximum Quality Limit (MQL) - Department-chosen maximum limit for acceptable AQC specimen sample quality. If an AQC specimen sample value is measured to have greater quality than the defined MQL, the representative specimen sample value (used in the acceptance procedures) is set equal to the defined MQL (i.e., the Contractor does not receive credit for quality provided in excess of the MQL).

Pay Adjustment - The actual pay adjustment (incentive or disincentive in PW\$) for the asconstructed lot. The computation of the lot pay adjustments is different in Level 1 and Level 2 PRS. 
Pay Factor (PF) - The percent of the bid price that the Contractor is paid for the construction of a concrete pavement lot.

Performance-Related Specifications (PRS) - Construction specifications placed on key materials and construction AQC's (e.g., concrete strength, pavement thickness) that have been demonstrated to correlate strongly with long-term pavement performance. These specifications are based on quantified relationships (or mathematical models) that relate measured AQC's to subsequent pavement performance and the corresponding costs.

Present Worth (PW) Method - A discounted cash flow analysis that involves the conversion of all of the present and future costs to a base of today's costs. Expected future costs are translated into equivalent present worth costs.

Quality Assurance (QA) - All those planned and systematic actions necessary to provide adequate confidence that a product or service will satisfy given requirements of quality. Within an organization, QA serves as a management tool. In contractual situations, QA serves to provide confidence in the supplier.

Quality Control (QC) - The sum total of activities performed by the seller (producer, manufacturer, or contractor) to make sure that a product meets contract specification requirements. Within the context of highway construction, QC includes materials handling and construction procedures; calibration and maintenance of equipment; production process control; and any sampling, testing, and inspection done for these purposes.

Rejectable Quality Limit (RQL) - Department-chosen minimum limit for acceptable AQC specimen sample quality. If an AQC specimen sample value is measured to have poorer quality than the defined RQL, AQC re-testing procedures will apply.

Sublot - A portion of a lot. Each lot is divided into sublots of approximately equal surface area. Sublot lengths are selected so that one or more samples may be taken from each sublot for each considered AQC. The minimum sublot length cannot be less than $2000 \mathrm{~m}^{2}$ (to accommodate the measurement of initial smoothness). Any section of lesser length will be added to the preceding sublot. Note that in PRS, measurements for all AQC's must be obtained from each sublot so that performance can be predicted. 
APPENDIX B SOFTWARE (PAVESPEC VERSION 2.5) INPUT DATA 
Table B-1 Input Data for PaveSpec (Version 2.5)

\begin{tabular}{|c|c|c|}
\hline No. & $\begin{array}{l}\text { Model Input } \\
\text { Required }\end{array}$ & $\begin{array}{l}\text { Input Values } \\
\text { Provided } \\
\text { By INDOT }\end{array}$ \\
\hline 1 & Traffic direction & $\begin{array}{l}\text { North and south } \\
\text { bound }\end{array}$ \\
\hline 2 & Lane configuration & $\begin{array}{l}6 \text { lanes divided (by } \\
\text { barrier wall) }\end{array}$ \\
\hline 3 & Lane width & $12.0 \mathrm{ft}$ \\
\hline 4 & $\begin{array}{l}\text { All lanes to be } \\
\text { accepted by PRS }\end{array}$ & Yes \\
\hline 5 & $\begin{array}{l}\text { Inner lane cracking } \\
\text { as } \% \text { of outer lane }\end{array}$ & 100 \\
\hline 6 & Outer lane widening & No \\
\hline 7 & Road location & Urban \\
\hline 8 & Project length & $7979 \mathrm{ft}$ \\
\hline 9 & Design life & 30 years \\
\hline 10 & Pavement Type & $\begin{array}{l}\text { Jointed Plain } \\
\text { (JCJP), Doweled }\end{array}$ \\
\hline 11 & Dowel bar diameter & $1.5 \mathrm{in}$. \\
\hline 12 & $\begin{array}{l}\text { Transverse joint } \\
\text { spacing }\end{array}$ & $6 \mathrm{~m}$ \\
\hline 13 & $\begin{array}{l}\text { PCC modulus of } \\
\text { elasticity }\end{array}$ & $3.4 \times 10^{6} \mathrm{psi}$ \\
\hline 14 & Joint sealant type & Silicone \\
\hline 15 & Base Type & $\begin{array}{l}\text { Crushed stone, } \\
\text { gravel or slag \# } \\
\text { 53D) }\end{array}$ \\
\hline 16 & Base permeability & Permeable \\
\hline 17 & $\begin{array}{l}\text { Modulus of subgrade } \\
\text { reaction }\end{array}$ & $100 \mathrm{psi} / \mathrm{in}$ \\
\hline 18 & $\begin{array}{l}\text { Design traffic } \\
\text { measure to be used }\end{array}$ & ADT \\
\hline 19 & $\begin{array}{l}\text { Year of traffic } \\
\text { information } \\
\text { considered }\end{array}$ & 1 \\
\hline 20 & $\begin{array}{l}\text { Traffic loading at } \\
\text { that year }\end{array}$ & $\mathrm{ADT}=90,700$ \\
\hline 21 & Traffic growth rate & $1.5 \%$ \\
\hline 22 & Traffic growth type & Compound \\
\hline 23 & $\begin{array}{l}\text { ESAL:ADT - } \\
\text { directional factor }\end{array}$ & $50 \%$ \\
\hline 24 & Percentage of trucks & $11 \%$ \\
\hline 25 & $\begin{array}{l}\text { Average truck load } \\
\text { equivalency factor }\end{array}$ & $\begin{array}{l}1.115 \text { ESAL's per } \\
\text { truck }\end{array}$ \\
\hline 26 & $\begin{array}{l}\text { Average annual } \\
\text { freezing index }\end{array}$ & $100^{\circ} \mathrm{F}$-days \\
\hline 27 & $\begin{array}{l}\text { Average annual } \\
\text { number of wet days }\end{array}$ & 126 days \\
\hline 28 & $\begin{array}{l}\text { Average annual } \\
\text { freeze-thaw cycles }\end{array}$ & 15 \\
\hline
\end{tabular}

\begin{tabular}{|c|c|c|}
\hline No. & $\begin{array}{l}\text { Model Input } \\
\text { Required }\end{array}$ & $\begin{array}{l}\text { Input Values } \\
\text { Provided } \\
\text { By INDOT }\end{array}$ \\
\hline 29 & $\begin{array}{l}\text { Average annual } \\
\text { number of days over } \\
90^{\circ} \mathrm{F}\end{array}$ & 18 days \\
\hline 30 & Presence of salt & Yes \\
\hline 31 & $\begin{array}{l}\text { Climate zone } \\
\text { description }\end{array}$ & Wet-freeze \\
\hline 32 & $\begin{array}{l}\text { Distress indicators to } \\
\text { be modeled }\end{array}$ & $\begin{array}{l}\text { Transverse slab } \\
\text { cracking } \\
\text { Decreasing } \\
\text { smoothness }\end{array}$ \\
\hline 33 & $\begin{array}{l}\text { Acceptance quality } \\
\text { characteristics to be } \\
\text { considered }\end{array}$ & $\begin{array}{l}\text { Concrete strength } \\
\text { Slab thickness } \\
\text { Initial smoothness }\end{array}$ \\
\hline 34 & $\begin{array}{l}\text { Sample type to be } \\
\text { used }\end{array}$ & Beams \\
\hline 35 & $\begin{array}{l}\text { Timing of cores (if } \\
\text { appropriate) }\end{array}$ & $\mathrm{N} / \mathrm{A}$ \\
\hline 36 & $\begin{array}{l}\text { Sampling locations } \\
\text { per sublot }\end{array}$ & 1 \\
\hline 37 & $\begin{array}{l}\text { Samples per } \\
\text { sampling location }\end{array}$ & 2 \\
\hline 38 & $\begin{array}{l}\text { Target time of } \\
\text { testing* }\end{array}$ & $\begin{array}{l}\text { 28-days (Testing } \\
\text { will be conducted at } \\
7 \text { days, however the } \\
28 \text { day strength, i.e. } \\
\text { the maturity, will } \\
\text { be determined } \\
\text { outside of the } \\
\text { program.) }\end{array}$ \\
\hline 39 & $\begin{array}{l}\text { Test Maturity (if not } \\
\text { 28-days in No. } 38 \\
\text { above) }\end{array}$ & N/A \\
\hline 40 & $\begin{array}{l}\text { Core to cylinder } \\
\text { relationship (if } \\
\text { required) }\end{array}$ & N/A \\
\hline 41 & $\begin{array}{l}\text { Laboratory-created } \\
\text { maturity equation (if } \\
\text { required) }\end{array}$ & N/A \\
\hline 42 & $\begin{array}{l}\text { Compressive to } \\
\text { flexural relationship } \\
\text { (if required) }\end{array}$ & N/A \\
\hline 43 & Sample type & Independent cores \\
\hline 44 & Timing of samples & After 4-days \\
\hline 45 & $\begin{array}{l}\text { Sampling locations } \\
\text { per sublot }\end{array}$ & 2 \\
\hline 46 & $\begin{array}{l}\text { Samples per } \\
\text { sampling location }\end{array}$ & 1 \\
\hline 47 & $\begin{array}{l}\text { Indicator of } \\
\text { smoothness over time } \\
\text { to be used }\end{array}$ & $\begin{array}{l}\text { International } \\
\text { roughness index } \\
\text { (IRI) }\end{array}$ \\
\hline
\end{tabular}




\begin{tabular}{|c|c|c|}
\hline No. & $\begin{array}{l}\text { Model Input } \\
\text { Required }\end{array}$ & $\begin{array}{l}\text { Input Values } \\
\text { Provided } \\
\text { By INDOT }\end{array}$ \\
\hline 48 & $\begin{array}{l}\text { Initial smoothness } \\
\text { indicator to be used }\end{array}$ & $\begin{array}{l}\text { Profile index ( } 0.2- \\
\text { inch blanking band) }\end{array}$ \\
\hline 49 & $\begin{array}{l}\text { Initial to 'over-time' } \\
\text { translation equation } \\
\text { to be used }\end{array}$ & $\begin{array}{l}\text { Linear equation }(\mathrm{y} \\
=3.11 \mathrm{x}+36.4) \\
\text { (Equation from } \\
\text { Volume } 1 .)\end{array}$ \\
\hline 50 & $\begin{array}{l}\text { Number of pass } \\
\text { locations per sublot }\end{array}$ & 2 \\
\hline 51 & $\begin{array}{l}\text { Number of passes per } \\
\text { sampling location }\end{array}$ & 2 \\
\hline 52 & $\begin{array}{l}\text { Profilograph } \\
\text { reduction method }\end{array}$ & Manual \\
\hline 53 & $\begin{array}{l}\text { Concrete strength } \\
\text { mean* }\end{array}$ & 700 psi - flexural \\
\hline 54 & $\begin{array}{l}\text { Concrete strength } \\
\text { standard deviation* }\end{array}$ & $50 \mathrm{psi}$ \\
\hline 55 & Slab thickness mean & 14.0 in. \\
\hline 56 & $\begin{array}{l}\text { Slab thickness } \\
\text { standard deviation }\end{array}$ & $0.5 \mathrm{in}$. \\
\hline 57 & $\begin{array}{l}\text { Initial smoothness } \\
\text { mean }\end{array}$ & $7 \mathrm{in} / \mathrm{mile}$ \\
\hline 58 & $\begin{array}{l}\text { Initial smoothness } \\
\text { standard deviation }\end{array}$ & $3 \mathrm{in} / \mathrm{mile}$ \\
\hline 59 & $\begin{array}{l}\text { Maintain transverse } \\
\text { joints }\end{array}$ & Yes \\
\hline 60 & $\begin{array}{l}\% \text { of transverse joints } \\
\text { to be sealed (if yes in } \\
\text { no. } 59 \text { above) }\end{array}$ & $40 \%$ \\
\hline 61 & $\begin{array}{l}\text { Regularity of } \\
\text { maintenance (if yes } \\
\text { in no. } 59 \text { above) }\end{array}$ & 5 \\
\hline 62 & $\begin{array}{l}\text { Maintain longitudinal } \\
\text { joints }\end{array}$ & Yes \\
\hline 63 & $\begin{array}{l}\% \text { of longitudinal } \\
\text { joints to be sealed (if } \\
\text { yes in no. } 62 \text { above) }\end{array}$ & $25 \%$ \\
\hline 64 & $\begin{array}{l}\text { Regularity of } \\
\text { maintenance (if yes } \\
\text { in no. } 62 \text { above) }\end{array}$ & 5 \\
\hline 65 & $\begin{array}{l}\text { Maintain transverse } \\
\text { cracks }\end{array}$ & Yes \\
\hline 66 & $\begin{array}{l}\% \text { of transverse } \\
\text { cracks to be sealed (if } \\
\text { yes in no. } 65 \text { above) }\end{array}$ & $100 \%$ \\
\hline 67 & $\begin{array}{l}\text { Regularity of } \\
\text { maintenance (if yes } \\
\text { in no. } 65 \text { above) }\end{array}$ & 3 \\
\hline
\end{tabular}

\begin{tabular}{|c|c|c|}
\hline No. & $\begin{array}{l}\text { Model Input } \\
\text { Required }\end{array}$ & $\begin{array}{l}\text { Input Values } \\
\text { Provided } \\
\text { By INDOT }\end{array}$ \\
\hline 68 & $\begin{array}{l}\text { Define localized } \\
\text { rehabilitation plan }\end{array}$ & $\begin{array}{l}\text { 1. Always do full- } \\
\text { depth repairs to } \\
100 \% \text { of spalled } \\
\text { joints. } \\
2 \text {. If cumulative } \\
\text { percentage of } \\
\text { cracked slabs } \\
\text { exceeds } 10 \% \text { then } \\
\text { consider the sublot } \\
\text { failed. } \\
3 \text {. If cumulative } \\
\text { percentage of } \\
\text { spalled joints } \\
\text { exceeds } 10 \% \text { then } \\
\text { consider the sublot } \\
\text { failed. } \\
4 . \text { If average } \\
\text { transverse joint } \\
\text { faulting exceeds } \\
0.25 \text { inch then } \\
\text { consider the sublot } \\
\text { failed. } \\
5 . \text { If percent failed } \\
\text { sublots exceeds } \\
25 \% \text { then begin } \\
\text { global rehabilitation } \\
\text { Scenario } 1 .\end{array}$ \\
\hline 69 & $\begin{array}{l}\text { Repair spalled joints } \\
\text { prior to global } \\
\text { rehabilitation }\end{array}$ & Yes \\
\hline 70 & $\begin{array}{l}\% \text { of spalled joints to } \\
\text { be repaired (if yes in } \\
\text { no. } 69 \text { above) }\end{array}$ & $100 \%$ \\
\hline 71 & $\begin{array}{l}\text { Description of repair } \\
\text { to be undertaken (if } \\
\text { yes in no. } 69 \text { above) }\end{array}$ & Partial depth repairs \\
\hline 72 & $\begin{array}{l}\text { Repair cracked slabs } \\
\text { prior to global } \\
\text { rehabilitation }\end{array}$ & Yes \\
\hline 73 & $\begin{array}{l}\% \text { of cracked slabs to } \\
\text { be repaired (if yes in } \\
\text { no. } 72 \text { above) }\end{array}$ & $100 \%$ \\
\hline 74 & $\begin{array}{l}\text { Description of repair } \\
\text { to be undertaken (if } \\
\text { yes in no. } 72 \text { above) }\end{array}$ & $\begin{array}{l}\text { Partial slab } \\
\text { replacements }\end{array}$ \\
\hline 75 & $\begin{array}{l}\text { Description of 1st } \\
\text { global rehabilitation } \\
\text { to apply }\end{array}$ & AC overlay \\
\hline 76 & $\begin{array}{l}\text { Assumed life of 1st } \\
\text { global rehabilitation }\end{array}$ & 7 years \\
\hline
\end{tabular}




\begin{tabular}{|c|c|c|}
\hline No. & $\begin{array}{l}\text { Model Input } \\
\text { Required }\end{array}$ & $\begin{array}{l}\text { Input Values } \\
\text { Provided } \\
\text { By INDOT }\end{array}$ \\
\hline 77 & $\begin{array}{l}\text { Smoothness at start } \\
\text { and end of 1st global } \\
\text { rehabilitation }\end{array}$ & $90-200$ \\
\hline 78 & $\begin{array}{l}\text { Description of 2nd } \\
\text { global rehabilitation } \\
\text { to apply (if required) }\end{array}$ & AC overlay \\
\hline 79 & $\begin{array}{l}\text { Assumed life of 2nd } \\
\text { global rehabilitation }\end{array}$ & 7 years \\
\hline 80 & $\begin{array}{l}\text { Smoothness at start } \\
\text { and end of } 2 \text { nd global } \\
\text { rehabilitation }\end{array}$ & $95-200$ \\
\hline 81 & $\begin{array}{l}\text { Description of 3rd } \\
\text { global rehabilitation } \\
\text { to apply (if required) }\end{array}$ & AC overlay \\
\hline 82 & $\begin{array}{l}\text { Assumed life of 3rd } \\
\text { global rehabilitation }\end{array}$ & 5 years \\
\hline 83 & $\begin{array}{l}\text { Smoothness at start } \\
\text { and end of 3rd global } \\
\text { rehabilitation }\end{array}$ & $100-200$ \\
\hline 84 & $\begin{array}{l}\text { Description of } 4 \text { th } \\
\text { global rehabilitation } \\
\text { to apply (if required) }\end{array}$ & AC overlay \\
\hline 85 & $\begin{array}{l}\text { Assumed life of } 4 \text { th } \\
\text { global rehabilitation } \\
\text { (years) }\end{array}$ & 3 \\
\hline 86 & $\begin{array}{l}\text { Smoothness at start } \\
\text { and end of 4th global } \\
\text { rehabilitation }\end{array}$ & $105-200$ \\
\hline 87 & $\begin{array}{l}\text { Cost of transverse } \\
\text { joint sealing }\end{array}$ & $\$ 1.20$ per $\mathrm{ft}$ \\
\hline 88 & $\begin{array}{l}\text { Cost of longitudinal } \\
\text { joint sealing }\end{array}$ & $\$ 1$ per ft \\
\hline 89 & $\begin{array}{l}\text { Cost of transverse } \\
\text { crack sealing }\end{array}$ & $\$ 1$ per $\mathrm{ft}$ \\
\hline 90 & $\begin{array}{l}\text { User percentage cost } \\
\text { to include }\end{array}$ & $1 \%$ \\
\hline 91 & $\begin{array}{l}\text { Year to use for user } \\
\text { cost inflation }\end{array}$ & 1999 \\
\hline 92 & $\begin{array}{l}\text { Cost of full-depth } \\
\text { repairs of transverse } \\
\text { joints }\end{array}$ & $\$ 159{\text { per } y d^{2}}^{2}$ \\
\hline 93 & $\begin{array}{l}\text { Cost of partial-depth } \\
\text { repairs of transverse } \\
\text { joints }\end{array}$ & $\$ 364{\text { per } y d^{2}}^{2}$ \\
\hline 94 & $\begin{array}{l}\text { Cost of slab } \\
\text { replacement }\end{array}$ & N/A \\
\hline 95 & $\begin{array}{l}\text { Cost of partial slab } \\
\text { replacement }\end{array}$ & $\$ 135{\text { per } y d^{2}}^{2}$ \\
\hline 96 & $\begin{array}{l}\text { Cost of AC overlay } \\
\text { (if selected in no. } 75 \text {, } \\
78,81 \text { or } 84 \text { ) }\end{array}$ & $\begin{array}{l}\$ 11 \text { per yd } d^{2}\left(1^{\text {st }}=\right. \\
\$ 9,2^{\text {nd }}=\$ 11.20,3^{\text {rd }} \\
=\$ 21.08)\end{array}$ \\
\hline
\end{tabular}

\begin{tabular}{|c|c|c|}
\hline No. & $\begin{array}{l}\text { Model Input } \\
\text { Required }\end{array}$ & $\begin{array}{l}\text { Input Values } \\
\text { Provided } \\
\text { By INDOT }\end{array}$ \\
\hline 97 & $\begin{array}{l}\text { Cost of PCC overlay } \\
\text { (if selected in no. } 75 \text {, } \\
78,81 \text { or } 84 \text { ) }\end{array}$ & N/A \\
\hline 98 & $\begin{array}{l}\text { Cost of diamond } \\
\text { grinding (if selected } \\
\text { in no. } 75,78,81 \text { or } \\
84 \text { ) }\end{array}$ & $\mathrm{N} / \mathrm{A}$ \\
\hline 99 & Annual Inflation Rate & $3 \%$ \\
\hline 100 & Annual Interest Rate & $6 \%$ \\
\hline 101 & $\begin{array}{l}\text { Assumed width of } \\
\text { full depth repair of } \\
\text { transverse joint. }\end{array}$ & $6 \mathrm{ft}$ \\
\hline 102 & $\begin{array}{l}\text { Assumed width of } \\
\text { partial depth repair of } \\
\text { transverse joint }\end{array}$ & $6 \mathrm{ft}$ \\
\hline 103 & $\begin{array}{l}\text { Assumed width of } \\
\text { partial slab } \\
\text { replacement }\end{array}$ & $6 \mathrm{ft}$ \\
\hline 104 & $\begin{array}{l}\text { Number of lots to } \\
\text { simulate at each } \\
\text { factorial point }\end{array}$ & 500 \\
\hline 105 & $\begin{array}{l}\text { Minimum number of } \\
\text { sublots per lot to } \\
\text { simulate }\end{array}$ & 3 \\
\hline 106 & $\begin{array}{l}\text { Maximum number of } \\
\text { sublots per lot to } \\
\text { simulate }\end{array}$ & 3 \\
\hline 107 & $\begin{array}{l}\text { Average bid price per } \\
\text { pavement area }\end{array}$ & $\$ 20 / y d^{2}$ \\
\hline 108 & Analysis life & 60 years \\
\hline 109 & Lowest mean value* & 600 psi at 28 -days \\
\hline 110 & Highest mean value* & 800 psi at 28 days \\
\hline 111 & $\begin{array}{l}\text { Total number of } \\
\text { mean values }\end{array}$ & 9 \\
\hline 112 & $\begin{array}{l}\text { Lowest standard } \\
\text { deviation }\end{array}$ & $30 \mathrm{psi}$ \\
\hline 113 & $\begin{array}{l}\text { Highest standard } \\
\text { deviation }\end{array}$ & 80 psi \\
\hline 114 & $\begin{array}{l}\text { Total number of } \\
\text { standard deviations }\end{array}$ & 6 \\
\hline 115 & Lowest mean value & 13 in. \\
\hline 116 & Highest mean value & 15 in. \\
\hline 117 & $\begin{array}{l}\text { Total number of } \\
\text { mean values }\end{array}$ & 9 \\
\hline 118 & $\begin{array}{l}\text { Lowest standard } \\
\text { deviation }\end{array}$ & $0.25 \mathrm{in}$. \\
\hline 119 & $\begin{array}{l}\text { Highest standard } \\
\text { deviation }\end{array}$ & $0.75 \mathrm{in.}$ \\
\hline 120 & $\begin{array}{l}\text { Total number of } \\
\text { standard deviations }\end{array}$ & 7 \\
\hline 121 & Lowest mean value & $5 \mathrm{in} / \mathrm{mile}$ \\
\hline
\end{tabular}




\begin{tabular}{|c|l|l|}
\hline No. & \multicolumn{1}{|c|}{$\begin{array}{c}\text { Model Input } \\
\text { Required }\end{array}$} & \multicolumn{1}{|c|}{$\begin{array}{c}\text { Input Values } \\
\text { Provided } \\
\text { By INDOT }\end{array}$} \\
\hline 122 & Highest mean value & $10 \mathrm{in} / \mathrm{mile}$ \\
\hline 123 & $\begin{array}{l}\text { Total number of } \\
\text { mean values }\end{array}$ & 6 \\
\hline 124 & $\begin{array}{l}\text { Lowest standard } \\
\text { deviation }\end{array}$ & $0 \mathrm{in} / \mathrm{mile}$ \\
\hline
\end{tabular}

\begin{tabular}{|c|l|l|}
\hline No. & \multicolumn{1}{|c|}{$\begin{array}{c}\text { Model Input } \\
\text { Required }\end{array}$} & \multicolumn{1}{|c|}{$\begin{array}{c}\text { Input Values } \\
\text { Provided } \\
\text { By INDOT }\end{array}$} \\
\hline 125 & $\begin{array}{l}\text { Highest standard } \\
\text { deviation }\end{array}$ & $4.5 \mathrm{in} / \mathrm{mile}$ \\
\hline 126 & $\begin{array}{l}\text { Total number of } \\
\text { standard deviations }\end{array}$ & 6 \\
\hline
\end{tabular}

* Flexural Strength inputs are based on the age of 28-days. The values were adjusted to the age of 7-days for use in Table 2-1. 
APPENDIX C SOFTWARE (PAVESPEC VERSION 3.0) INPUT DATA 
Table C-1 Input Data for PaveSpec (Version 3.0)

\begin{tabular}{|c|c|c|c|c|}
\hline No. & Input & Ranges & Value & Source \\
\hline 1 & Specification Level & $\begin{array}{c}\text { Level } 1 \text { only, } \\
\text { Level } 1 \text { and Level } 2\end{array}$ & Develop a level 1 spec. only & User \\
\hline 2 & Traffic direction & $\begin{array}{l}\text { E, W, N, S, } \\
\text { E\&W, N\&S }\end{array}$ & North and south bound & Pavement Design \\
\hline 3 & Lane configuration & $\begin{array}{l}\text { 2-10 lanes, } \\
\text { (un)divided }\end{array}$ & 6 lanes, divided & Pavement Design \\
\hline 4 & Lane width & $9-12$ feet & 12 feet & Pavement Design \\
\hline 5 & $\begin{array}{c}\text { Lanes to be accepted } \\
\text { by PRS }\end{array}$ & All / Some & All & Pavement Design \\
\hline 6 & Shoulder type & $\begin{array}{l}\text { Widened lane / Tied } \\
\text { PCC / Asphalt / Other }\end{array}$ & Tied PCC & Pavement Design \\
\hline 7 & $\begin{array}{l}\text { Stress Load Transfer } \\
\text { Efficiency }\end{array}$ & $5-24 \%$ & $20 \%$ & Pavement Design \\
\hline 8 & $\begin{array}{c}\text { Inner lane cracking as } \\
\% \text { of outer lane }\end{array}$ & $0-100 \%$ & $100 \%$ & Pavement Design \\
\hline 9 & Road location & Urban / Rural & Urban & Pavement Design \\
\hline 10 & Project length & - & 9893 feet & Pavement Design \\
\hline 11 & Design life & $20-60$ years & 30 years & Pavement Design \\
\hline 12 & $\begin{array}{c}\text { Pavement Type } \\
\text { (Jointed Plain } \\
\text { Concrete Pavement, } \\
\text { only) }\end{array}$ & Doweled / Undoweled & Doweled & Pavement Design \\
\hline 13 & Dowel bar diameter & $1.0-1.5$ in. & 1.5 in. & Pavement Design \\
\hline 14 & $\begin{array}{l}\text { Transverse joint } \\
\text { spacing }\end{array}$ & $7-30 \mathrm{ft}$. & $18 \mathrm{ft}$. & Pavement Design \\
\hline 15 & $\begin{array}{l}\text { PCC modulus of } \\
\text { elasticity }\end{array}$ & $3 \times 10^{6}-8 \times 10^{6} \mathrm{psi}$ & $3.4 \times 10^{6} \mathrm{psi}$ & Pavement Design \\
\hline 16 & Joint sealant type & $\begin{array}{l}\text { None / Liquid asphalt / } \\
\text { Silicone / Performed } \\
\text { compression seal }\end{array}$ & Silicone & $\begin{array}{l}\text { Materials and } \\
\text { Tests }\end{array}$ \\
\hline 17 & $\begin{array}{l}\text { Modulus of Subgrade } \\
\text { Reaction (static k- } \\
\text { value) }\end{array}$ & $45-1200 \mathrm{psi} / \mathrm{in}$ & $100 \mathrm{psi} / \mathrm{in}$ & Pavement Design \\
\hline 18 & water-cement ratio & $0.36-0.50$ & 0.42 & Pavement Design \\
\hline 19 & $\begin{array}{l}\text { Percent Subgrade } \\
\text { Material passing the } \\
\# 200 \text { sieve }\end{array}$ & $0-100 \%$ & $88 \%$ & Pavement Design \\
\hline 20 & Base permeability & (Non)permeable & Permeable & $\begin{array}{l}\text { (FHWA) } \\
\text { Pavement }\end{array}$ \\
\hline 21 & Base thickness & $0-10 \mathrm{in.}$ & 9 in. & $\begin{array}{l}\text { (FHWA) } \\
\text { Pavement }\end{array}$ \\
\hline 22 & $\begin{array}{l}\text { Base modulus of } \\
\text { elasticity }\end{array}$ & $30,000-50,000 \mathrm{psi}$ & $30,000 \mathrm{psi}$ & Pavement Design \\
\hline 23 & PCC-base interface & (Un)bonded & Unbonded & Pavement Design \\
\hline
\end{tabular}




\begin{tabular}{|c|c|c|c|c|}
\hline No. & Input & Ranges & Value & Source \\
\hline 24 & $\begin{array}{l}\text { Base erodibility } \\
\text { factor }\end{array}$ & $0.5-5.0$ & 5.0 & $\begin{array}{c}\text { Pavement Design } \\
\text { and FHWA-RD- } \\
00-131\end{array}$ \\
\hline 25 & $\begin{array}{l}\text { Design traffic } \\
\text { measure } \\
\text { to be used }\end{array}$ & $\mathrm{ESAL}^{3} / \mathrm{ADT}^{4}$ & ADT & Pavement Design \\
\hline 26 & $\begin{array}{l}\text { Year of traffic } \\
\text { information } \\
\text { considered }\end{array}$ & $1-100$ & 1 & User \\
\hline 27 & $\begin{array}{c}\text { Traffic loading at that } \\
\text { year }\end{array}$ & $\begin{array}{c}10,000-200,000 \\
\text { ADT }\end{array}$ & $\mathrm{ADT}=61,200$ & Pavement Design \\
\hline 28 & Traffic growth rate & $0-9 \%$ & $2.53 \%$ & Pavement Design \\
\hline 29 & Traffic growth type & Simple / Compound & Compound & $\begin{array}{c}\text { Materials and } \\
\text { Tests }\end{array}$ \\
\hline 30 & $\begin{array}{c}\text { ESAL:ADT - } \\
\text { directional factor }\end{array}$ & $0-100 \%$ & $50 \%$ & $\begin{array}{l}\text { Materials and } \\
\text { Tests }\end{array}$ \\
\hline 31 & Percentage of trucks & $0-100 \%$ & $15 \%$ & Pavement Design \\
\hline 32 & $\begin{array}{l}\text { Percentage of trucks } \\
\text { in outer lane }\end{array}$ & $0-100 \%$ & $99 \%$ & Pavement Design \\
\hline 33 & $\begin{array}{l}\text { Average truck load } \\
\text { equivalency factor }\end{array}$ & $0.9-2.0$ & 1.15 ESALs per truck & Pavement Design \\
\hline 34 & $\begin{array}{l}\text { Average annual } \\
\text { freezing index }\end{array}$ & $\begin{array}{c}0-3000^{\circ} \mathrm{F} \text {-days } \\
\text { (national) } \\
0-500^{\circ} \mathrm{F}-\text { days } \\
\text { (Indiana) }\end{array}$ & $0^{\circ} \mathrm{F}$-days & $\begin{array}{c}\text { National Snow } \\
\text { and Ice Data } \\
\text { Center and } \\
\text { FHWA-RD-00- } \\
131\end{array}$ \\
\hline 35 & $\begin{array}{l}\text { Average Annual } \\
\text { Precipitation }\end{array}$ & $\begin{array}{c}2-137 \text { inches } \\
\text { (national) } \\
36-49 \text { inches } \\
\text { (Indiana) }\end{array}$ & 44.5 inches & $\begin{array}{c}\text { Midwestern } \\
\text { Regional Climate } \\
\text { Center }\end{array}$ \\
\hline 36 & $\begin{array}{l}\text { Average annual air } \\
\text { freeze-thaw cycles }\end{array}$ & $\begin{array}{l}0-110(\text { national }) \\
65-102(\text { Indiana })\end{array}$ & 65 cycles & $\begin{array}{c}\text { Midwestern } \\
\text { Regional Climate } \\
\text { Center }\end{array}$ \\
\hline 37 & $\begin{array}{c}\text { Average annual } \\
\text { number of days over } \\
90^{\circ} \mathrm{F} / 32^{\circ} \mathrm{C}\end{array}$ & $\begin{array}{c}0-189 \text { (national) } \\
7-42 \text { (Indiana) }\end{array}$ & 33.2 days & $\begin{array}{c}\text { Midwestern } \\
\text { Regional Climate } \\
\text { Center }\end{array}$ \\
\hline 38 & $\begin{array}{c}\text { Climate zone } \\
\text { description }\end{array}$ & $\begin{array}{c}\text { Dry or Wet and } \\
\text { Freeze or Non-freeze }\end{array}$ & $\begin{array}{c}\text { Wet- } \\
\text { Non-freeze }\end{array}$ & $\begin{array}{c}\text { FHWA-RD-00- } \\
131\end{array}$ \\
\hline
\end{tabular}

\footnotetext{
${ }^{3}$ Equivalent Single-Axle Loading
}

${ }^{4}$ Average Daily Traffic 


\begin{tabular}{|c|c|c|c|c|}
\hline No. & Input & Ranges & Value & Source \\
\hline 39 & $\begin{array}{l}\text { Distress indicators to } \\
\text { be modeled }\end{array}$ & $\begin{array}{c}\text { Transverse Joint } \\
\text { Faulting, Transverse } \\
\text { Joint Spalling, } \\
\text { Transverse Slab } \\
\text { Cracking, Decreasing } \\
\text { Smoothness }\end{array}$ & $\begin{array}{l}\text { Transverse Joint Spalling } \\
\text { Transverse Slab Cracking, } \\
\text { Decreasing Smoothness }\end{array}$ & User \\
\hline 40 & $\begin{array}{l}\text { Acceptance quality } \\
\text { characteristics to be } \\
\text { considered }\end{array}$ & $\begin{array}{l}\text { Concrete Strength, } \\
\text { Slab Thickness, } \\
\text { Air Content, } \\
\text { Initial Smoothness, } \\
\text { Percent Consolidation } \\
\text { around Dowels }\end{array}$ & $\begin{array}{l}\text { Concrete Strength, } \\
\text { Slab Thickness, } \\
\text { Air Content, } \\
\text { Initial Smoothness }\end{array}$ & User \\
\hline 41 & $\begin{array}{c}\text { Sample types to be } \\
\text { used }\end{array}$ & $\begin{array}{c}\text { Cores / Cylinders / } \\
\text { Beams }\end{array}$ & Beams & ITM \\
\hline 42 & $\begin{array}{l}\text { Timing of cores (if } \\
\text { appropriate - see no. } \\
41 \text { above) (days) }\end{array}$ & - & N/A & N/A \\
\hline 43 & $\begin{array}{l}\text { Sampling locations } \\
\text { per sublot (number) }\end{array}$ & - & 1 & ITM \\
\hline 44 & $\begin{array}{l}\text { Samples per sampling } \\
\text { location (number) }\end{array}$ & - & 2 & ITM \\
\hline 45 & Target time of testing & $\begin{array}{c}\text { 3-days / 5-days / 7- } \\
\text { days / } 14 \text {-days /28- } \\
\text { days }\end{array}$ & $\begin{array}{l}\text { 28-days (Testing will be } \\
\text { conducted at } 7 \text { days, } \\
\text { however the } 28 \text { day strength, } \\
\text { i.e. the maturity, will be } \\
\text { determined outside of the } \\
\text { program.) }\end{array}$ & $\mathrm{SAC}$ \\
\hline 46 & Test Maturity & $\begin{array}{c}\text { (deg. F-hours, deg. C- } \\
\text { hours) }\end{array}$ & N/A & N/A \\
\hline 47 & $\begin{array}{l}\text { Core to cylinder } \\
\text { relationship }\end{array}$ & Linear equation & N/A & N/A \\
\hline 48 & $\begin{array}{l}\text { Laboratory-created } \\
\text { maturity equation (if } \\
\text { required) }\end{array}$ & $\begin{array}{c}\text { Linear equation/ } \\
\text { Second-order } \\
\text { polynomial equation/ } \\
\text { Third-order } \\
\text { polynomial equation/ } \\
\text { Exponential equation/ } \\
\text { Logarithmic equation/ } \\
\text { Power equation }\end{array}$ & N/A & N/A \\
\hline
\end{tabular}

\footnotetext{
${ }^{5}$ model coefficient $\mathrm{A}=0.5$
} 


\begin{tabular}{|c|c|c|c|c|}
\hline No. & Input & Ranges & Value & Source \\
\hline 49 & $\begin{array}{l}\text { Compressive to } \\
\text { flexural relationship }\end{array}$ & $\begin{array}{c}\text { Linear equation/ } \\
\text { Second-order } \\
\text { polynomial equation/ } \\
\text { Third-order } \\
\text { polynomial equation/ } \\
\text { Exponential equation/ } \\
\text { Logarithmic equation/ } \\
\text { Power equation }\end{array}$ & N/A & N/A \\
\hline 50 & Sample type & $\begin{array}{l}\text { Use strength cores } \\
\text { (if applicable)/ } \\
\text { Independent cores/ } \\
\text { Probe/ Ground } \\
\text { penetrating radar }\end{array}$ & Independent cores & ITM \\
\hline 51 & $\begin{array}{c}\text { Timing of samples } \\
\text { (days) }\end{array}$ & - & 4-days & ITM \\
\hline 52 & $\begin{array}{l}\text { Number of samples } \\
\text { per sublot }\end{array}$ & - & 2 & ITM \\
\hline 53 & $\begin{array}{c}\text { Number of Replicates } \\
\text { per sample }\end{array}$ & - & 1 & ITM \\
\hline 54 & Sample type & $\begin{array}{l}\text { Cores/ Air pressure } \\
\text { meter/ Danish air void } \\
\text { analyzer }\end{array}$ & Air pressure meter & ITM \\
\hline 55 & $\begin{array}{c}\text { Timing of samples } \\
\text { (days) }\end{array}$ & (if cores used) & N/A & ITM \\
\hline 56 & $\begin{array}{l}\text { Sampling locations } \\
\text { per sublot (number) }\end{array}$ & - & 2 & ITM \\
\hline 57 & $\begin{array}{l}\text { Samples per sampling } \\
\text { location (number) }\end{array}$ & - & 1 & ITM \\
\hline 58 & $\begin{array}{l}\text { Initial smoothness } \\
\text { indicator to be used }\end{array}$ & $\begin{array}{c}\text { International } \\
\text { roughness index (IRI)/ } \\
\text { Profile index }(0.2 \text {-inch } \\
\text { blanking band)/ } \\
\text { Profile index }(0.0 \text {-inch } \\
\text { blanking band) }\end{array}$ & $\begin{array}{l}\text { "Profile index ( } 0.2 \text {-inch } \\
\text { blanking band)" }\end{array}$ & ITM \\
\hline 59 & $\begin{array}{l}\text { Initial smoothness } \\
\text { Relationship } \\
\text { (equation) }\end{array}$ & $\begin{array}{c}\text { Linear equation/ } \\
\text { Second-order } \\
\text { polynomial equation/ } \\
\text { Third-order } \\
\text { polynomial equation/ } \\
\text { Exponential equation/ } \\
\text { Logarithmic equation/ } \\
\text { Power equation }\end{array}$ & $\begin{array}{c}\mathrm{y}=3.11 \mathrm{x}+36.4 \text { (Equation } \\
\text { from Volume 1.) }\end{array}$ & SAC \\
\hline 60 & $\begin{array}{c}\text { Number of Pass } \\
\text { Locations Per Sublot } \\
\text { (number) }\end{array}$ & - & 1 & ITM \\
\hline 61 & $\begin{array}{l}\text { Pass Location } \\
\text { Description }\end{array}$ & (Text box) & RWP & ITM \\
\hline 62 & $\begin{array}{l}\text { Number of Replicates } \\
\text { Per Pass Location } \\
\text { (number) }\end{array}$ & - & 2 & ITM \\
\hline
\end{tabular}




\begin{tabular}{|c|c|c|c|c|}
\hline No. & Input & Ranges & Value & Source \\
\hline 63 & $\begin{array}{c}\text { Timing of Samples } \\
\text { (describe) }\end{array}$ & (Text box) & N/A & ITM \\
\hline 64 & $\begin{array}{c}\text { Profilograph } \\
\text { reduction method }\end{array}$ & Manual/ Computerized & Manual & User \\
\hline 65 & $\begin{array}{l}\text { Timing of samples } \\
\text { (days) (Level } 1 \text { and } \\
\text { Level 2) }\end{array}$ & - & N/A & N/A \\
\hline 66 & $\begin{array}{l}\text { Sampling locations } \\
\text { per sublot (number) }\end{array}$ & - & N/A & N/A \\
\hline 67 & $\begin{array}{l}\text { Samples per sampling } \\
\text { location (number) }\end{array}$ & - & N/A & N/A \\
\hline 68 & $\begin{array}{l}\text { Determine target } \\
\text { LCC... }\end{array}$ & $\begin{array}{c}\text { Through Simulation / } \\
\text { Using AQC Means } \\
\text { Only }\end{array}$ & $\begin{array}{c}\text { Estimate LCC through } \\
\text { simulation }\end{array}$ & User \\
\hline 69 & $\begin{array}{l}\text { Concrete strength } \\
\text { sample method }\end{array}$ & $\begin{array}{l}\text { Means only / } \\
\text { Distribution }\end{array}$ & Distribution & User \\
\hline 70 & $\begin{array}{l}\text { Concrete strength } \\
\text { mean (psi, MPa) }\end{array}$ & $500-800 \mathrm{psi}$ & 650 psi (flexural) & Pavement Design \\
\hline 71 & $\begin{array}{l}\text { Concrete strength } \\
\text { standard deviation } \\
\text { (psi, MPa) }\end{array}$ & $20-80 \mathrm{psi}$ & 40 psi & Research \\
\hline 72 & $\begin{array}{c}\text { Slab thickness sample } \\
\text { method }\end{array}$ & $\begin{array}{l}\text { Means only / } \\
\text { Distribution }\end{array}$ & Distribution & User \\
\hline 73 & $\begin{array}{l}\text { Slab thickness mean } \\
\text { (in, mm) }\end{array}$ & $10-16$ in. & $15.0 \mathrm{in}$ & Pavement Design \\
\hline 74 & $\begin{array}{l}\text { Slab thickness } \\
\text { standard deviation } \\
\text { (in, } \mathrm{mm})\end{array}$ & $0-1$ in. & $0.5 \mathrm{in}$. & Research \\
\hline 75 & $\begin{array}{c}\text { Air content sample } \\
\text { method }\end{array}$ & $\begin{array}{l}\text { Means only / } \\
\text { Distribution }\end{array}$ & Distribution & User \\
\hline 76 & Air content mean & $4-10 \%$ & $6.50 \%$ & Pavement Design \\
\hline 77 & $\begin{array}{c}\text { Air content standard } \\
\text { deviation }\end{array}$ & $0-2 \%$ & $0.5 \%$ & Research \\
\hline 78 & $\begin{array}{l}\text { Initial smoothness } \\
\text { sample method }\end{array}$ & $\begin{array}{l}\text { Means only / } \\
\text { Distribution }\end{array}$ & Distribution & User \\
\hline 79 & $\begin{array}{c}\text { Initial smoothness } \\
\text { mean (in/mile, } \\
\mathrm{mm} / \mathrm{km})\end{array}$ & $0-20$ in. $/$ mile & $7 \mathrm{in} / \mathrm{mile}$ & Pavement Design \\
\hline 80 & $\begin{array}{l}\text { Initial smoothness } \\
\text { standard deviation } \\
\text { (in } / \mathrm{mile}, \mathrm{mm} / \mathrm{km} \text { ) }\end{array}$ & $0-10$ in. $/$ mile & 3 in./mile & Research \\
\hline 81 & $\begin{array}{l}\text { Percent consolidation } \\
\text { around dowels } \\
\text { sample method }\end{array}$ & N/A & N/A & N/A \\
\hline 82 & $\begin{array}{l}\text { Percent consolidation } \\
\text { around dowels mean }\end{array}$ & N/A & N/A & N/A \\
\hline
\end{tabular}




\begin{tabular}{|c|c|c|c|c|}
\hline No. & Input & Ranges & Value & Source \\
\hline 83 & $\begin{array}{l}\text { Percent consolidation } \\
\text { around dowels } \\
\text { standard deviation }\end{array}$ & N/A & N/A & N/A \\
\hline 84 & $\begin{array}{l}\text { Maintain transverse } \\
\text { joints }\end{array}$ & Yes / No & Yes & $\begin{array}{c}\text { Pavement } \\
\text { Management }\end{array}$ \\
\hline 85 & $\begin{array}{l}\% \text { of transverse joints } \\
\text { to be sealed }\end{array}$ & $0-100 \%$ & $40 \%$ & $\begin{array}{c}\text { Pavement } \\
\text { Management }\end{array}$ \\
\hline 86 & $\begin{array}{l}\text { Regularity of } \\
\text { maintenance }\end{array}$ & $5-15$ years & 5 years & $\begin{array}{c}\text { Pavement } \\
\text { Management }\end{array}$ \\
\hline 87 & $\begin{array}{l}\text { Maintain longitudinal } \\
\text { joints }\end{array}$ & Yes / No & Yes & $\begin{array}{c}\text { Pavement } \\
\text { Management }\end{array}$ \\
\hline 88 & $\begin{array}{l}\text { \% of longitudinal } \\
\text { joints to be sealed }\end{array}$ & $0-100 \%$ & $25 \%$ & $\begin{array}{c}\text { Pavement } \\
\text { Management }\end{array}$ \\
\hline 89 & $\begin{array}{l}\text { Regularity of } \\
\text { maintenance }\end{array}$ & $5-15$ years & 5 years & $\begin{array}{c}\text { Pavement } \\
\text { Management }\end{array}$ \\
\hline 90 & $\begin{array}{l}\text { Maintain transverse } \\
\text { cracks }\end{array}$ & Yes / No & Yes & $\begin{array}{c}\text { Pavement } \\
\text { Management }\end{array}$ \\
\hline 91 & $\begin{array}{c}\% \text { of transverse } \\
\text { cracks to be sealed }\end{array}$ & $0-100 \%$ & $100 \%$ & $\begin{array}{c}\text { Pavement } \\
\text { Management }\end{array}$ \\
\hline 92 & $\begin{array}{l}\text { Regularity of } \\
\text { maintenance }\end{array}$ & $3-10$ years & 3 years & $\begin{array}{c}\text { Pavement } \\
\text { Management }\end{array}$ \\
\hline 94 & $\begin{array}{l}\text { Repair spalled joints } \\
\text { prior to global } \\
\text { rehabilitation }\end{array}$ & Yes / No & Yes & Roadway Mgmt \\
\hline 95 & $\begin{array}{c}\% \text { of spalled joints to } \\
\text { be repaired } \\
\text { (if required) }\end{array}$ & $0-100 \%$ & $100 \%$ & Roadway Mgmt \\
\hline 96 & $\begin{array}{l}\text { Description of repair } \\
\text { to be undertaken (if } \\
\text { required) }\end{array}$ & $\begin{array}{l}\text { Partial depth repairs/ } \\
\text { Full depth repairs }\end{array}$ & Partial depth repairs & Roadway Mgmt \\
\hline 97 & $\begin{array}{l}\text { Repair cracked slabs } \\
\text { prior to global } \\
\text { rehabilitation }\end{array}$ & Yes / No & Yes & Roadway Mgmt \\
\hline 98 & $\begin{array}{l}\% \text { of cracked slabs to } \\
\text { be repaired } \\
\text { (if required) }\end{array}$ & $0-100 \%$ & $100 \%$ & Roadway Mgmt \\
\hline 99 & $\begin{array}{l}\text { Description of repair } \\
\text { to be undertaken (if } \\
\text { required) }\end{array}$ & $\begin{array}{c}\text { Partial slab } \\
\text { replacements/ Full } \\
\text { slab replacements }\end{array}$ & Partial slab replacements & Roadway Mgmt \\
\hline 100 & $\begin{array}{l}\text { Description of 1st } \\
\text { global rehabilitation } \\
\text { to apply }\end{array}$ & $\begin{array}{l}\text { AC overlay/ PCC } \\
\text { overlay/ Diamond } \\
\text { grinding }\end{array}$ & AC overlay & Roadway Mgmt \\
\hline 101 & $\begin{array}{l}\text { Assumed life of 1st } \\
\text { global rehabilitation }\end{array}$ & $3-12$ years & 7 years & Roadway Mgmt \\
\hline 102 & $\begin{array}{l}\text { Smoothness at start } \\
\text { and end of } 1 \text { st global } \\
\text { rehabilitation } \\
\text { (in/mile) }\end{array}$ & $50-300 \mathrm{in} / \mathrm{mile}$ & $90-200 \mathrm{in} / \mathrm{mile}$ & Roadway Mgmt \\
\hline
\end{tabular}




\begin{tabular}{|c|c|c|c|c|}
\hline No. & Input & Ranges & Value & Source \\
\hline 103 & $\begin{array}{l}\text { Description of 2nd } \\
\text { global rehabilitation } \\
\text { to apply (if required) }\end{array}$ & $\begin{array}{l}\text { AC overlay/ PCC } \\
\text { overlay/ Diamond } \\
\text { grinding }\end{array}$ & AC overlay & Roadway Mgmt \\
\hline 104 & $\begin{array}{l}\text { Assumed life of 2nd } \\
\text { global rehabilitation }\end{array}$ & $3-12$ years & 7 years & Roadway Mgmt \\
\hline 105 & $\begin{array}{l}\text { Smoothness at start } \\
\text { and end of 2nd global } \\
\text { rehabilitation }\end{array}$ & $50-300 \mathrm{in} / \mathrm{mile}$ & $95-200 \mathrm{in} / \mathrm{mile}$ & Roadway Mgmt \\
\hline 106 & $\begin{array}{l}\text { Description of 3rd } \\
\text { global rehabilitation } \\
\text { to apply (if required) }\end{array}$ & $\begin{array}{l}\text { AC overlay/ PCC } \\
\text { overlay/ Diamond } \\
\text { grinding }\end{array}$ & AC overlay & Roadway Mgmt \\
\hline 107 & $\begin{array}{l}\text { Assumed life of 3rd } \\
\text { global rehabilitation } \\
\text { (years) }\end{array}$ & $3-12$ years & 5 years & Roadway Mgmt \\
\hline 108 & $\begin{array}{l}\text { Smoothness at start } \\
\text { and end of 3rd global } \\
\text { rehabilitation }\end{array}$ & $50-300 \mathrm{in} / \mathrm{mile}$ & $100-200 \mathrm{in} / \mathrm{mile}$ & Roadway Mgmt \\
\hline 109 & $\begin{array}{l}\text { Description of 4th } \\
\text { global rehabilitation } \\
\text { to apply (if required.) }\end{array}$ & $\begin{array}{l}\text { AC overlay/ PCC } \\
\text { overlay/ Diamond } \\
\text { grinding }\end{array}$ & AC overlay & Roadway Mgmt \\
\hline 110 & $\begin{array}{c}\text { Assumed life of } 4 \text { th } \\
\text { global rehabilitation } \\
\text { (years) }\end{array}$ & $3-12$ years & 3 years & Roadway Mgmt \\
\hline 111 & $\begin{array}{l}\text { Smoothness at start } \\
\text { and end of 4th global } \\
\text { rehabilitation }\end{array}$ & $50-300$ in $/$ mile & $105-200 \mathrm{in} / \mathrm{mile}$ & Roadway Mgmt \\
\hline 112 & $\begin{array}{l}\text { Transverse joint } \\
\text { sealing }\end{array}$ & $\$ 0.99-\$ 1.50$ per ft. & $\$ 1.20$ per $\mathrm{ft}$ & $\begin{array}{l}\text { Contracts and } \\
\text { Construction }\end{array}$ \\
\hline 113 & $\begin{array}{l}\text { Longitudinal joint } \\
\text { sealing }\end{array}$ & $\$ 0.99$ - \$1.09 per ft. & $\$ 1.00$ per $\mathrm{ft}$ & $\begin{array}{l}\text { Contracts and } \\
\text { Construction }\end{array}$ \\
\hline 114 & $\begin{array}{c}\text { Transverse crack } \\
\text { sealing } \\
\end{array}$ & $\$ 0.50-\$ 2.85$ per ft. & $\$ 1.00$ per $\mathrm{ft}$ & $\begin{array}{l}\text { Contracts and } \\
\text { Construction }\end{array}$ \\
\hline 115 & $\begin{array}{l}\text { Full-depth repairs of } \\
\text { transverse joints }\end{array}$ & $\begin{array}{l}\$ 40-\$ 287 \\
\text { per sq. yd }\end{array}$ & $\begin{array}{c}\$ 159 \\
\text { per sq. yd }\end{array}$ & $\begin{array}{l}\text { Contracts and } \\
\text { Construction }\end{array}$ \\
\hline 116 & $\begin{array}{l}\text { Partial-depth repairs } \\
\text { of transverse joints }\end{array}$ & $\begin{array}{l}\$ 65-\$ 126 \\
\text { per sq. yd }\end{array}$ & $\begin{array}{c}\$ 364 \\
\text { per sq. yd }\end{array}$ & $\begin{array}{l}\text { Contracts and } \\
\text { Construction }\end{array}$ \\
\hline 117 & Full slab replacement & N/A & N/A & N/A \\
\hline 118 & $\begin{array}{l}\text { Partial slab } \\
\text { replacement }\end{array}$ & $\begin{array}{l}\$ 25-\$ 125 \\
\text { per sq. yd }\end{array}$ & $\begin{array}{c}\$ 135 \\
\text { per sq. yd }\end{array}$ & $\begin{array}{l}\text { Contracts and } \\
\text { Construction }\end{array}$ \\
\hline 119 & $\begin{array}{c}\text { Asphalt concrete } \\
\text { overlay }\end{array}$ & $\begin{array}{c}\$ 6-\$ 26 \\
\text { per sq. yd }\end{array}$ & $\begin{array}{c}\$ 11 \\
\text { per sq. yd }\end{array}$ & $\begin{array}{l}\text { Contracts and } \\
\text { Construction }\end{array}$ \\
\hline 120 & $\begin{array}{l}\text { Portland cement } \\
\text { concrete overlay }\end{array}$ & N/A & N/A & N/A \\
\hline 121 & Diamond grinding & N/A & N/A & N/A \\
\hline 122 & Annual inflation rate & $2-6 \%$ & $3 \%$ & User \\
\hline 123 & Annual interest rate & $4-10 \%$ & $6 \%$ & User \\
\hline
\end{tabular}




\begin{tabular}{|c|c|c|c|c|}
\hline No. & Input & Ranges & Value & Source \\
\hline 124 & $\begin{array}{l}\text { Assumed width of } \\
\text { full depth repair of } \\
\text { transverse joint }\end{array}$ & - & $6 \mathrm{ft}$ & User \\
\hline 125 & $\begin{array}{l}\text { Assumed width of } \\
\text { partial depth repair of } \\
\text { transverse joint }\end{array}$ & - & $6 \mathrm{ft}$ & User \\
\hline 126 & $\begin{array}{l}\text { Assumed partial slab } \\
\text { replacement }\end{array}$ & - & $6 \mathrm{ft}$ & User \\
\hline 127 & $\begin{array}{l}\text { User cost percentage } \\
\text { to include }\end{array}$ & $0-5 \%$ & $2 \%$ & User \\
\hline 128 & Year of construction & - & 2002 & User \\
\hline 129 & $\begin{array}{l}\text { Number of lots to } \\
\text { simulate at each } \\
\text { factorial point }\end{array}$ & $500-1000$ & 500 & $\begin{array}{c}\text { FHWA-RD-00- } \\
131\end{array}$ \\
\hline 130 & $\begin{array}{l}\text { Minimum number of } \\
\text { sublots per lot to } \\
\text { simulate }\end{array}$ & - & 3 & $\begin{array}{c}\text { FHWA-RD-00- } \\
131\end{array}$ \\
\hline 131 & $\begin{array}{l}\text { Maximum number of } \\
\text { sublots per lot to } \\
\text { simulate }\end{array}$ & - & 3 & $\begin{array}{c}\text { FHWA-RD-00- } \\
131\end{array}$ \\
\hline 132 & $\begin{array}{l}\text { Average bid price per } \\
\text { pavement area }\end{array}$ & $\$ 18$ - $\$ 40 /$ sq. yd. & $\$ 20 /$ sq.yd. & $\begin{array}{l}\text { Contracts and } \\
\text { Const. }\end{array}$ \\
\hline 133 & Analysis life & $40-120$ years & 70 years & User \\
\hline 134 & $\begin{array}{l}\text { Lowest mean value } \\
\text { (psi, MPa) }\end{array}$ & - & 575 psi at 28 -days & SAC \\
\hline 135 & $\begin{array}{l}\text { Highest mean value } \\
\text { (psi, MPa) }\end{array}$ & - & 800 psi at 28 days & SAC \\
\hline 136 & $\begin{array}{l}\text { Total number of } \\
\text { mean values }\end{array}$ & - & 10 & SAC \\
\hline 137 & $\begin{array}{c}\text { Lowest standard } \\
\text { deviation }(\mathrm{psi}, \mathrm{MPa})\end{array}$ & - & $20 \mathrm{psi}$ & SAC \\
\hline 138 & $\begin{array}{c}\text { Highest standard } \\
\text { deviation (psi, MPa) }\end{array}$ & - & 80 psi & SAC \\
\hline 139 & $\begin{array}{c}\text { Total number of } \\
\text { standard deviations }\end{array}$ & - & 4 & SAC \\
\hline 140 & $\begin{array}{l}\text { Lowest mean value } \\
\text { (in, cm) }\end{array}$ & - & $14.0 \mathrm{in.}$ & SAC \\
\hline 141 & $\begin{array}{l}\text { Highest mean value } \\
\text { (in, cm) }\end{array}$ & - & $16.0 \mathrm{in.}$ & SAC \\
\hline 142 & $\begin{array}{l}\text { Total number of } \\
\text { mean values }\end{array}$ & - & 11 & SAC \\
\hline 143 & $\begin{array}{l}\text { Lowest standard } \\
\text { deviation (in, cm) }\end{array}$ & - & $0.25 \mathrm{in.}$ & SAC \\
\hline 144 & $\begin{array}{l}\text { Highest standard } \\
\text { deviation (in, cm) }\end{array}$ & - & $0.75 \mathrm{in.}$ & SAC \\
\hline 145 & $\begin{array}{c}\text { Total number of } \\
\text { standard deviations }\end{array}$ & - & 3 & SAC \\
\hline
\end{tabular}




\begin{tabular}{|c|c|c|c|c|}
\hline No. & Input & Ranges & Value & Source \\
\hline 146 & $\begin{array}{c}\text { Lowest mean value } \\
(\%)\end{array}$ & - & 4.0 & SAC \\
\hline 147 & $\begin{array}{l}\text { Highest mean value } \\
(\%)\end{array}$ & - & 10.0 & SAC \\
\hline 148 & $\begin{array}{c}\text { Total number of } \\
\text { mean values }\end{array}$ & - & 13 & SAC \\
\hline 149 & $\begin{array}{c}\text { Lowest standard } \\
\text { deviation }(\%)\end{array}$ & - & 0.5 & SAC \\
\hline 150 & $\begin{array}{l}\text { Highest standard } \\
\text { deviation }(\%)\end{array}$ & - & 2 & SAC \\
\hline 151 & $\begin{array}{c}\text { Total number of } \\
\text { standard deviations }\end{array}$ & - & 4 & SAC \\
\hline 152 & $\begin{array}{l}\text { Lowest mean value } \\
\text { (in } / \mathrm{mile}, \mathrm{mm} / \mathrm{km} \text { ) }\end{array}$ & - & $3 \mathrm{in} / \mathrm{mile}$ & SAC \\
\hline 153 & $\begin{array}{l}\text { Highest mean value } \\
\text { (in/mile, } \mathrm{mm} / \mathrm{km} \text { ) }\end{array}$ & - & $10 \mathrm{in} / \mathrm{mile}$ & SAC \\
\hline 154 & $\begin{array}{c}\text { Total number of } \\
\text { mean values }\end{array}$ & - & 8 & SAC \\
\hline 155 & $\begin{array}{c}\text { Lowest standard } \\
\text { deviation (in/mile, } \\
\mathrm{mm} / \mathrm{km} \text { ) }\end{array}$ & - & 0 in./mile & SAC \\
\hline 156 & $\begin{array}{c}\text { Highest standard } \\
\text { deviation (in } / \text { mile, } \\
\mathrm{mm} / \mathrm{km} \text { ) }\end{array}$ & - & $4.5 \mathrm{in} . / \mathrm{mile}$ & SAC \\
\hline 157 & $\begin{array}{c}\text { Total number of } \\
\text { standard deviations }\end{array}$ & - & 4 & SAC \\
\hline 158 & $\begin{array}{c}\text { Lowest mean value } \\
(\%)\end{array}$ & N/A & N/A & N/A \\
\hline 159 & $\begin{array}{l}\text { Highest mean value } \\
(\%)\end{array}$ & N/A & N/A & N/A \\
\hline 160 & $\begin{array}{c}\text { Total number of } \\
\text { mean values }\end{array}$ & N/A & N/A & N/A \\
\hline 161 & $\begin{array}{c}\text { Lowest standard } \\
\text { deviation (\%) }\end{array}$ & N/A & N/A & N/A \\
\hline 162 & $\begin{array}{l}\text { Highest standard } \\
\text { deviation (\%) }\end{array}$ & N/A & N/A & N/A \\
\hline 163 & $\begin{array}{c}\text { Total number of } \\
\text { standard deviations }\end{array}$ & N/A & N/A & N/A \\
\hline
\end{tabular}


APPENDIX D INDOT AGGREGATE GRADATION 
Table D-1 INDOT Coarse Aggregate Gradation

\begin{tabular}{|l|c|c|c|}
\hline \multirow{2}{*}{ Sieve Size } & \multicolumn{3}{|c|}{ Coarse Aggregate Sizes (Percent Passing) } \\
\cline { 2 - 4 } & INDOT No. 8 & INDOT No. 53 & INDOT No. 53D \\
\hline $37.5 \mathrm{~mm}(1 \mathrm{1} / \mathrm{in}$. $)$ & 100 & 100 & 100 \\
\hline $25 \mathrm{~mm}(1 \mathrm{in.})$ & 100 & $80-100$ & $70-90$ \\
\hline $19 \mathrm{~mm}(3 / 4 \mathrm{in})$. & $75-95$ & $70-90$ & $50-70$ \\
\hline $12.5 \mathrm{~mm}(1 / 2 \mathrm{in})$. & $40-70$ & $55-80$ & $35-50$ \\
\hline $9.5 \mathrm{~mm}(3 / 8 \mathrm{in})$. & $20-50$ & $\sim$ & $\sim$ \\
\hline $4.75 \mathrm{~mm}($ No. 4$)$ & $0-15$ & $35-60$ & $20-40$ \\
\hline $2.36 \mathrm{~mm}$ (No. 8$)$ & $0-10$ & $25-50$ & $15-35$ \\
\hline $600 \mu \mathrm{m}$ (No. 30$)$ & $\sim$ & $12-30$ & $5-20$ \\
\hline $75 \mu \mathrm{m}$ (No. 200 & $\sim$ & $5-10$ & $0-6$ \\
\hline
\end{tabular}

Table D-2 INDOT Fine Aggregate Gradation

\begin{tabular}{|c|c|}
\hline \multirow{2}{*}{ Sieve Size } & Fine Aggregate Sizes (Percent Passing) \\
\cline { 2 - 2 } & INDOT No. 23 \\
\hline $9.5 \mathrm{~mm}(3 / 8$ in.) & 100 \\
\hline $4.75 \mathrm{~mm}$ (No. 4) & $95-100$ \\
\hline $2.36 \mathrm{~mm}$ (No. 8) & $80-100$ \\
\hline $1.18 \mathrm{~mm}$ (No. 16) & $50-85$ \\
\hline $600 \mu \mathrm{m}$ (No. 30) & $25-60$ \\
\hline $300 \mu \mathrm{m}$ (No. 50) & $5-30$ \\
\hline $150 \mu \mathrm{m}$ (No. 100$)$ & $0-10$ \\
\hline $75 \mu \mathrm{m}$ (No. 200 & $0-3$ \\
\hline
\end{tabular}

The source for both tables is the INDOT Standard Specifications 1999. 
APPENDIX E PRE-CONSTRUCTION MIXTURE DESIGN 
Table E-1 Design Factors

\begin{tabular}{|l|l|}
\hline \multicolumn{1}{|c|}{ Design Factor } & \multicolumn{1}{c|}{ Amount } \\
\hline Cement Content & $264.0 \mathrm{~kg} / \mathrm{m}^{3}\left(445 \mathrm{lb} / \mathrm{yd}^{3}\right)$ \\
Fly Ash Content & $41.53 \mathrm{~kg} / \mathrm{m}^{3}\left(69.9 \mathrm{lb} / \mathrm{yd}^{3}\right)$ \\
W/C Ratio & 0.42 \\
Air Content & $6.5 \%$ \\
Fine Aggregate/Total Aggregate & $47.0 \%$ \\
Air Entraining Content & $80.00 \mathrm{ml} / \mathrm{m}^{3}\left(2.07 \mathrm{oz} / \mathrm{yd}^{3}\right)$ \\
Water Reducer Content & $2.44 \mathrm{ml} / \mathrm{kg} \mathrm{cement}(0.0374 \mathrm{oz} / \mathrm{lb})$ \\
\hline
\end{tabular}

Table E-2 Materials

\begin{tabular}{|l|l|l|}
\hline \multicolumn{1}{|c|}{ Material } & \multicolumn{1}{|c|}{ Type } & \multicolumn{1}{c|}{ Source } \\
\hline Cement & Type 1 & Lonestar \\
Fly Ash & Class C & Mineral Solutions \\
Fine Aggregate & \#23 Sand & M.M. Waverly \\
Coarse Aggregate & $\# 8$ Stone & M.M. Kent. Ave. \\
Air Entrainment & Dairavair 1400 & W. R. Grace \\
Water Reducer & WRDA 82 & W. R. Grace \\
\hline
\end{tabular}

Table E-3 Batch Proportions (7.25 m³ 9.48 yd $^{3}$ )

\begin{tabular}{|l|l|}
\hline \multicolumn{1}{|c|}{ Material } & \multicolumn{1}{c|}{ Batch Size } \\
\hline Sand & $6813 \mathrm{~kg}(15020 \mathrm{lb})$ \\
Coarse Aggregate & $7176 \mathrm{~kg}(15820 \mathrm{lb})$ \\
Cement & $1911 \mathrm{~kg}(4213 \mathrm{lb})$ \\
Fly ash & $310 \mathrm{~kg}(683 \mathrm{lb})$ \\
Air Entraining Agent & $562 \mathrm{ml}(19.0 \mathrm{oz})$ \\
Water Reducer & $5412 \mathrm{ml}(183.0 \mathrm{oz})$ \\
Water & $644 \mathrm{~L} \mathrm{(170} \mathrm{gallons)}$ \\
Free Water (Water Above SSD Condition in Aggregates) & $41.23 \mathrm{~kg}(90.90 \mathrm{lb})$ \\
W/C Ratio & 0.425 \\
\hline
\end{tabular}


APPENDIX F FRESH CONCRETE PROPERTIES (PRE-CONSTRUCTION \& FIELD TEST PROGRAMS) 
Table F-1 Pre-Construction Test Program Fresh Concrete Properties

\begin{tabular}{|l|c|c|}
\hline \multicolumn{1}{|c|}{ Property } & $\begin{array}{c}\text { Measured by Contractor at } \\
\text { Batch Plant }\end{array}$ & $\begin{array}{c}\text { Measured by Purdue after } \\
\text { Transportation to INDOT } \\
\text { Materials and Tests Division }\end{array}$ \\
\hline Air Content, \% & $7.0 \%$ & $6.3 \%$ \\
\hline Unit Weight, $\mathrm{lb} / \mathrm{ft}^{3}$ & 142.4 & 145.9 \\
\hline Slump, inch & $\mathrm{NM}$ & 0.5 \\
\hline Water to Cement Ratio & 0.425 & $\mathrm{NM}$ \\
\hline
\end{tabular}

Note:

1. NM - Not Measured

Table F-2 Field Test Program Fresh Concrete Properties

\begin{tabular}{|l|c|c|c|c|}
\hline \multirow{2}{*}{\multicolumn{1}{|c|}{ Property }} & Lot 1 & \multicolumn{3}{c|}{ Lot 2 } \\
\cline { 2 - 5 } & Sublot 3 & Sublot 1 & Sublot 2 & Sublot 3 \\
\hline Air Content, \% & 6.9 & 7.3 & 6.7 & 6.8 \\
\hline Batch Yield & 1.018 & 1.010 & 1.008 & 1.007 \\
\hline Water to Cement Ratio & 0.420 & 0.405 & 0.436 & 0.433 \\
\hline
\end{tabular}


APPENDIX G PRE-CONSTRUCTION CASTING AND CURING PROCEDURES 
1. Measure fresh concrete properties

Air content - ASTM C 231 (Pressure method)

Slump - ASTM C 143

Unit Weight - ASTM C 138

Obtain copy of batch sheet

- Workload - 1 person

- Equipment required - Slump cone, rod, ruler, air meter, and strike-off bar.

2. Cast 24 cylinder specimens $(6 \times 12$ in.)

Mold in accordance with ASTM C 31

Label each specimen

Place concrete in two equal layers

Vibrate each layer. Use three insertions of the vibrator at different points for each layer. For the upper layer, the vibrator shall penetrate the layer below by approximately 1 inch.

Tap the side of the mold 10 to 15 times with a mallet after vibrating each layer.

Strike off the surface of the mold with the tamping rod to produce a flat surface that is level with the edge of the mold.

Finish the surface of the mold with a trowel.

After all specimens are cast, cover with plastic and wet burlap.

Reserve 2 specimens for temperature sensors.

- Workload - 3-4 people

2 people filling molds with concrete

1 person vibrating concrete

1 person tapping the sides of the molds

- Equipment required - Cylinder molds, form oil, internal vibrator, mallet, tamping rod, trowel

3. Cast 23 beam specimens $(6 \times 6 \times 21$ in.)

Mold in accordance with ASTM C 31.

Lightly coat mold with mineral oil

Place concrete in one layer

Compact by internal vibration. Insert the vibrator at three equally spaced locations along the center-line of the long dimension.

Tap the side of the mold 10 to 15 times with a mallet after vibration.

Strike off the surface of the mold with the tamping rod to produce a flat surface that is level with the edge of the mold.

Finish the surface of the mold with a trowel.

After all specimens are cast, cover with plastic and wet burlap. 
Reserve 1 specimen for two temperature sensors

- Workload 3-4 people

2 people filling molds with concrete

1 person vibrating concrete

1 person tapping the sides of the molds

- Equipment required - Beam molds, form oil, internal vibrator, mallet, tamping rod, and a trowel.

4. Cast slab specimens

Prior to day of casting

Note: Slabs must be placed close to one another, leaving only walking space between adjacent slabs, to minimize distance to time-temperature recording device.

Make marks on the inside of the forms on all four sides to indicate the top of the base course and the top of the concrete.

Place the base course material in the form up to the mark in two layers.

Compact each layer with a tamper.

Level the surface as best as possible.

Mark the side of the formwork with type of base material.

- Workload - 1 person

\section{Day of casting}

Place concrete in layers. Mark the side of the forms to indicate height of each layer. 1 layer for the 6 in. thick slab

2 equal layers for the 10 and 14 in. thick slabs

Compact each layer by vibration. Insert the vibrator at 6 inch intervals.

Strike off the surface of the form with wood $2 \times 4$ to produce a flat surface that is level with the edge of the form.

Float the surface of the slab to produce a flat even surface.

Make sure temperature sensor is in place before floating is finished.

When surface of slab can support finger pressure, tine $1 / 2$ of the surface of each slab, leave the other $1 / 2$ of the slabs with a smooth surface.

Mark the side of each slab. (Type of base material, thickness of slab)

Cover with plastic and wet burlap

- Workload - 3-4 people

2 people filling forms with concrete

1 person vibrating concrete 
- Equipment required - Wood formwork, tamper, vibrator, wood $2 \times 4$, trowel, and a tining device.

5. Temperature sensors

Cylinders

Place 1 temperature sensor in each of 2 cylinder specimens. Place the sensor in the center of the cross-sectional area at the mid-depth of the cylinder.

Tape the thermocouple wire to the side of the specimen to prevent accidental pullout.

\section{$\underline{\text { Beams }}$}

Place 2 temperature sensors in 1 beam specimen. Place sensors at the third points of the beam at the mid-depth of the specimen.

Tape the thermocouple wire to the side of the specimen to prevent accidental pullout.

$\underline{\text { Slabs }}$

Place 2 temperature sensors in each slab. Place sensors in adjacent corners, $1 \mathrm{ft}$. away from each form edge.

Tape the thermocouple wire to the side of the specimen to prevent accidental pullout. Connect temperature sensors to recording device.

Turn recording device on (connect battery wire)

- Workload - 1 person 
APPENDIX H COMPRESSIVE STRENGTH TEST PROCEDURES 


\section{Adapted From ASTM C 39}

Note: Keep specimens covered with moist burlap after removal from curing until testing.

1. Record the specimen identification number.

2. Measure the diameter of the cylinder at the mid-height of the specimen to the nearest $0.01 \mathrm{inch}$. Take two measurements at right angles to each other and determine the average diameter.

3. Measure the length of the cylinder.

4. Cap the cylinder.

5. Re-measure the length of the cylinder. (Not required if unbonded caps are used.)

6. Wipe the bearing faces of the testing machine clear of debris and place the test specimen on the lower bearing block.

7. Lower the upper bearing block, aligning the test specimen with center of thrust of the upper bearing block. Rotate the movable portion of the upper bearing block to obtain uniform seating.

8. Apply the load at a rate of $35 \mathrm{psi} / \mathrm{s}(2100 \mathrm{psi} / \mathrm{min})$. This is equal to $990 \mathrm{lb} / \mathrm{s}(59,400$ $\mathrm{lb} / \mathrm{min}$ ) for a $6 \mathrm{in}$. diameter cylinder. Note, ASTM C 39 permits a range of loading rate from 20 to $50 \mathrm{psi} / \mathrm{s}$. A higher rate of loading is permitted up to $1 / 2$ of the anticipated load.

9. Record the maximum load and type of failure. 
APPENDIX I FLEXURAL TEST PROCEDURES 


\section{Adapted From ASTM C 78}

Note: Keep specimens covered with moist burlap after removal from curing until testing.

1. Record the specimen identification number. Record the location and type of any defects in the specimen.

2. Mark the third points on the specimen. (The span length shall be 18 in.)

3. Place the specimen on the bottom bearing blocks. The specimen shall be on its side with respect to the position as molded.

4. Place the top bearing blocks on the specimen and lower the upper table of the testing machine to just above the top bearing block assembly.

5. Apply the load at a rate of $150 \mathrm{psi} / \mathrm{min}(2.5 \mathrm{psi} / \mathrm{s})$. This is equal to $1800 \mathrm{lb} / \mathrm{min}$ $(30 \mathrm{lb} / \mathrm{s})$ for a span length of $18 \mathrm{in}$. Note, ASTM C 78 permits a range of 125 to $175 \mathrm{psi} / \mathrm{min}$.

6. Record the failure load and location.

7. Measure the width and depth of the specimen to the nearest 0.05 in at the failure location.

8. Record if the failure occurred through aggregate or cement paste. 
APPENDIX J SPLIT TENSILE TEST PROCEDURES 


\section{Taken From ASTM C 496}

Note: Keep specimens covered with moist burlap after removal from curing until testing.

1. Record the specimen identification number. Record the location and type of any defects in the specimen.

2. Draw diametral lines on each end of the specimen.

3. Measure the diameter to the nearest 0.01 inch and length of the specimen to the nearest 0.1 inch.

4. Place the specimen on a plywood strip. Position the specimen so that the lines marked on the ends of the specimen are centered and vertical over the plywood strip.

5. Place a second plywood strip on top of the specimen. Position the specimen so the plywood strip is centered on lines marked on the ends of the specimen.

6. Position the assembly so that lines marked on the ends of the specimen are aligned with the center of the upper bearing plate. Center the supplementary bearing bar, if one is used.

7. Apply the load at a rate of $150 \mathrm{psi} / \mathrm{min}(2.5 \mathrm{psi} / \mathrm{s})$. This is equal to $16,960 \mathrm{lb} / \mathrm{min}$ for a 6 x 12 in. cylinder. Note, ASTM C 496 permits a range of loading rate from 100 to $200 \mathrm{psi} / \mathrm{min}$.

8. Record the failure load and type of failure. 
APPENDIX K ELASTIC MODULUS AND POISSON'S RATIO TEST PROCEDURES 


\section{Taken From ASTM C 469}

Note: Keep specimens covered with moist burlap after removal from curing until testing.

1. Record the specimen identification number.

2. Measure the diameter of the cylinder at the mid-height of the specimen to the nearest 0.01 inch. Take two measurements at right angles to each other and determine the average diameter.

3. Measure the length of the cylinder to the nearest $0.1 \mathrm{inch}$.

4. Cap the cylinder.

5. Re-measure the length of the cylinder. (Not required if unbonded caps are used.)

6. Attach the strain-measuring equipment to the specimen.

7. Wipe the bearing faces of the testing machine clear of debris and place the test specimen on the lower bearing block.

8. Lower the upper bearing block, aligning the test specimen with center of thrust of the upper bearing block. Rotate the movable portion of the upper bearing block to obtain uniform seating.

9. Load specimen until the applied load is $40 \%$ of the ultimate compressive load (as determined from compression testing of equivalent cylinder). Apply the load at a rate of $35 \mathrm{psi} / \mathrm{s}$ (2100 psi/min). This is equal to $990 \mathrm{lb} / \mathrm{s}(59,400 \mathrm{lb} / \mathrm{min})$ for a $6 \mathrm{in}$. diameter cylinder. Observe the performance of the gages and correct any unusual behavior. Unload the specimen at the same rate.

10. Perform two more loading cycles to $40 \%$ of the ultimate load. Record, without interruption of loading, the applied load and strain at a longitudinal strain of 50 millionths (0.000050) and at an applied load of $40 \%$ of the ultimate load. 
APPENDIX L PRE-CONSTRUCTION RESULTS 
See Table 10-2 for an explanation of the test specimen identification procedure.

Table L-1 Pre-Construction Strength and P-Wave Velocity Results (Beams \& Cylinders)

\begin{tabular}{|c|c|c|c|c|c|c|c|c|}
\hline \multirow[b]{2}{*}{$\begin{array}{c}\text { Test } \\
\text { Specimen }\end{array}$} & \multirow[b]{2}{*}{$\begin{array}{l}\text { Age, } \\
\text { Days }\end{array}$} & \multicolumn{4}{|c|}{ P-wave Velocity, m/s by: } & \multicolumn{3}{|c|}{ Strength } \\
\hline & & $\begin{array}{c}\text { Direct } \\
\text { Transmission } \\
\text { Pulse Velocity }\end{array}$ & $\begin{array}{c}\text { Surface } \\
\text { Pulse } \\
\text { Velocity }\end{array}$ & $\begin{array}{c}\text { AE } \\
\text { Surface } \\
\text { Wave }\end{array}$ & $\begin{array}{c}\text { Impact } \\
\text { Echo }\end{array}$ & $\begin{array}{c}\text { Modulus } \\
\text { of } \\
\text { Rupture, } \\
\text { psi }\end{array}$ & $\begin{array}{l}\text { Compressive } \\
\text { Strength, psi }\end{array}$ & $\begin{array}{c}\text { Split } \\
\text { Tensile, } \\
\text { psi }\end{array}$ \\
\hline B23C & 1 & 4260 & 3930 & 4040 & 3840 & $\sim$ & $\sim$ & $\sim$ \\
\hline B24C & 1 & 4260 & 4010 & 4190 & 3840 & $\sim$ & $\sim$ & $\sim$ \\
\hline B22 & 1 & 4180 & $\sim$ & 3920 & 3820 & 558 & $\sim$ & $\sim$ \\
\hline $\mathrm{B} 21$ & 1 & 4230 & $\sim$ & 4120 & 3820 & 499 & $\sim$ & $\sim$ \\
\hline B20 & 1 & 4180 & 3850 & 4300 & 3820 & 504 & $\sim$ & $\sim$ \\
\hline $\mathrm{C} 22 \mathrm{C}$ & 1 & 4240 & $\sim$ & $\sim$ & 3550 & $\sim$ & $\sim$ & $\sim$ \\
\hline $\mathrm{C} 21 \mathrm{C}$ & 1 & 4160 & $\sim$ & $\sim$ & 3580 & $\sim$ & $\sim$ & $\sim$ \\
\hline $\mathrm{C} 20$ & 1 & 4230 & $\sim$ & $\sim$ & 3570 & $\sim$ & 2935 & $\sim$ \\
\hline C19 & 1 & 4150 & $\sim$ & $\sim$ & 3570 & $\sim$ & 3021 & $\sim$ \\
\hline C18 & 1 & $\sim$ & $\sim$ & $\sim$ & $\sim$ & $\sim$ & $\sim$ & 292 \\
\hline C11 & 1 & $\sim$ & $\sim$ & $\sim$ & $\sim$ & $\sim$ & $\sim$ & 255 \\
\hline $\mathrm{B} 23 \mathrm{C}$ & 4 & 4600 & 4260 & 4450 & 3820 & $\sim$ & $\sim$ & $\sim$ \\
\hline $\mathrm{B} 24 \mathrm{C}$ & 4 & 4600 & 4330 & 4470 & $\sim$ & $\sim$ & $\sim$ & $\sim$ \\
\hline B1 & 4 & 4520 & 4370 & 4530 & 3820 & 741 & $\sim$ & $\sim$ \\
\hline B3 & 4 & 4510 & 4240 & 4410 & 3820 & 736 & $\sim$ & $\sim$ \\
\hline B2 & 4 & 4520 & 4200 & 4670 & 3820 & 763 & $\sim$ & $\sim$ \\
\hline $\mathrm{C} 22 \mathrm{C}$ & 4 & 4540 & $\sim$ & $\sim$ & $\sim$ & $\sim$ & $\sim$ & $\sim$ \\
\hline $\mathrm{C} 21 \mathrm{C}$ & 4 & 4460 & $\sim$ & $\sim$ & 3870 & $\sim$ & $\sim$ & $\sim$ \\
\hline C9 & 4 & 4320 & $\sim$ & $\sim$ & 3860 & $\sim$ & 4888 & $\sim$ \\
\hline C16 & 4 & 4610 & $\sim$ & $\sim$ & 3870 & $\sim$ & 4242 & $\sim$ \\
\hline C17 & 4 & $\sim$ & $\sim$ & $\sim$ & $\sim$ & $\sim$ & $\sim$ & 408 \\
\hline C12 & 4 & $\sim$ & $\sim$ & $\sim$ & $\sim$ & $\sim$ & $\sim$ & 366 \\
\hline B23C & 7 & 4680 & 4280 & 4540 & 3820 & $\sim$ & $\sim$ & $\sim$ \\
\hline $\mathrm{B} 24 \mathrm{C}$ & 7 & 4690 & 4360 & 4610 & 3820 & $\sim$ & $\sim$ & $\sim$ \\
\hline B19 & 7 & 4700 & 4290 & 4390 & 3840 & 832 & $\sim$ & $\sim$ \\
\hline B7 & 7 & 4680 & 4380 & 4650 & 3840 & 771 & $\sim$ & $\sim$ \\
\hline B4 & 7 & 4680 & 4290 & 4610 & 3840 & 762 & $\sim$ & $\sim$ \\
\hline $\mathrm{C} 22 \mathrm{C}$ & 7 & 4720 & $\sim$ & $\sim$ & $\sim$ & $\sim$ & $\sim$ & $\sim$ \\
\hline $\mathrm{C} 21 \mathrm{C}$ & 7 & 4570 & $\sim$ & $\sim$ & 4170 & $\sim$ & $\sim$ & $\sim$ \\
\hline C6 & 7 & 4620 & $\sim$ & $\sim$ & $\sim$ & $\sim$ & 5723 & $\sim$ \\
\hline $\begin{array}{ll}\mathrm{C} 5 \\
\end{array}$ & 7 & 4590 & $\sim$ & $\sim$ & $\sim$ & $\sim$ & 5717 & $\sim$ \\
\hline $\mathrm{C} 4$ & 7 & $\sim$ & $\sim$ & $\sim$ & $\sim$ & $\sim$ & $\sim$ & 466 \\
\hline C7 & 7 & $\sim$ & $\sim$ & $\sim$ & $\sim$ & $\sim$ & $\sim$ & 551 \\
\hline B23C & 14 & 4800 & 4360 & 4720 & 3820 & $\sim$ & $\sim$ & $\sim$ \\
\hline $\mathrm{B} 24 \mathrm{C}$ & 14 & 4800 & 4390 & 4660 & 3820 & $\sim$ & $\sim$ & $\sim$ \\
\hline
\end{tabular}




\begin{tabular}{|c|c|c|c|c|c|c|c|c|}
\hline B8 & 14 & 4800 & 4410 & 4710 & 3840 & 886 & $\sim$ & $\sim$ \\
\hline B9 & 14 & 4800 & 4360 & 4640 & 3840 & 875 & $\sim$ & $\sim$ \\
\hline B18 & 14 & 4770 & 4420 & 4730 & 3840 & 820 & $\sim$ & $\sim$ \\
\hline $\mathrm{C} 22 \mathrm{C}$ & 14 & 4720 & $\sim$ & $\sim$ & 4140 & $\sim$ & $\sim$ & $\sim$ \\
\hline $\mathrm{C} 21 \mathrm{C}$ & 14 & 4670 & $\sim$ & $\sim$ & 4170 & $\sim$ & $\sim$ & $\sim$ \\
\hline $\mathrm{C} 8$ & 14 & 4720 & $\sim$ & $\sim$ & 3870 & $\sim$ & 6558 & $\sim$ \\
\hline C1 & 14 & 4670 & $\sim$ & $\sim$ & 3860 & $\sim$ & 6443 & $\sim$ \\
\hline $\mathrm{C} 2$ & 14 & $\sim$ & $\sim$ & $\sim$ & $\sim$ & $\sim$ & $\sim$ & 557 \\
\hline C3 & 14 & $\sim$ & $\sim$ & $\sim$ & $\sim$ & $\sim$ & $\sim$ & 446 \\
\hline $\mathrm{B} 23 \mathrm{C}$ & 28 & 4870 & 4550 & 4670 & 4370 & $\sim$ & $\sim$ & $\sim$ \\
\hline B24C & 28 & 4870 & 4580 & 4780 & 4370 & $\sim$ & $\sim$ & $\sim$ \\
\hline B16 & 28 & 4860 & 4630 & 4770 & 4390 & 863 & $\sim$ & $\sim$ \\
\hline B10 & 28 & 4820 & 4540 & 4720 & 4390 & 934 & $\sim$ & $\sim$ \\
\hline B5 & 28 & 4830 & 4530 & 4800 & 4390 & 839 & $\sim$ & $\sim$ \\
\hline $\mathrm{C} 22 \mathrm{C}$ & 28 & 4820 & $\sim$ & $\sim$ & 4140 & $\sim$ & $\sim$ & $\sim$ \\
\hline $\mathrm{C} 21 \mathrm{C}$ & 28 & 4780 & $\sim$ & $\sim$ & 4170 & $\sim$ & $\sim$ & $\sim$ \\
\hline C15 & 28 & 4790 & $\sim$ & $\sim$ & 4180 & $\sim$ & 6812 & $\sim$ \\
\hline C13 & 28 & 4710 & $\sim$ & $\sim$ & 4160 & $\sim$ & 6885 & $\sim$ \\
\hline C14 & 28 & $\sim$ & $\sim$ & $\sim$ & $\sim$ & $\sim$ & $\sim$ & 445 \\
\hline C10 & 28 & $\sim$ & $\sim$ & $\sim$ & $\sim$ & $\sim$ & $\sim$ & 472 \\
\hline B23C & 103 & 4920 & 4610 & 4800 & $\sim$ & $\sim$ & $\sim$ & $\sim$ \\
\hline B24C & 103 & 4930 & 4500 & 4830 & $\sim$ & $\sim$ & $\sim$ & $\sim$ \\
\hline B15 & 103 & 4910 & 4650 & 4960 & $\sim$ & 860 & $\sim$ & $\sim$ \\
\hline B14 & 103 & 4950 & 4740 & 4920 & $\sim$ & 905 & $\sim$ & $\sim$ \\
\hline B12 & 103 & 4940 & 4660 & 4740 & $\sim$ & 936 & $\sim$ & $\sim$ \\
\hline $\mathrm{C} 22 \mathrm{C}$ & 103 & 4990 & $\sim$ & $\sim$ & $\sim$ & $\sim$ & 8518 & $\sim$ \\
\hline $\mathrm{C} 21 \mathrm{C}$ & 103 & 4960 & $\sim$ & $\sim$ & $\sim$ & $\sim$ & 8240 & $\sim$ \\
\hline \begin{tabular}{|l}
$\mathrm{C} 26$ \\
\end{tabular} & 103 & 4970 & $\sim$ & $\sim$ & $\sim$ & $\sim$ & $\sim$ & 593 \\
\hline C25 & 103 & 4920 & $\sim$ & $\sim$ & $\sim$ & $\sim$ & $\sim$ & 459 \\
\hline
\end{tabular}


Table L-2 Pre-Construction P-Wave Velocity Results, m/s (Slabs)

\begin{tabular}{|c|c|c|c|c|c|c|c|c|c|c|}
\hline \multirow[b]{2}{*}{$\begin{array}{c}\text { Test } \\
\text { Specimen }\end{array}$} & \multicolumn{2}{|c|}{ Day 1} & \multicolumn{2}{|c|}{ Day 4} & \multicolumn{2}{|c|}{ Day 7} & \multicolumn{2}{|c|}{ Day 14} & \multicolumn{2}{|c|}{ Day 28} \\
\hline & $\begin{array}{c}\text { Pulse } \\
\text { Velocity } \\
\text { Surface } \\
\text { Method }\end{array}$ & $\begin{array}{c}\text { AE } \\
\text { Surface } \\
\text { Wave } \\
\text { Method }\end{array}$ & $\begin{array}{c}\text { Pulse } \\
\text { Velocity } \\
\text { Surface } \\
\text { Method }\end{array}$ & $\begin{array}{c}\text { AE } \\
\text { Surface } \\
\text { Wave } \\
\text { Method }\end{array}$ & $\begin{array}{c}\text { Pulse } \\
\text { Velocity } \\
\text { Surface } \\
\text { Method }\end{array}$ & $\begin{array}{c}\text { AE } \\
\text { Surface } \\
\text { Wave } \\
\text { Method }\end{array}$ & \begin{tabular}{|c} 
Pulse \\
Velocity \\
Surface \\
Method
\end{tabular} & $\begin{array}{c}\text { AE } \\
\text { Surface } \\
\text { Wave } \\
\text { Method }\end{array}$ & $\begin{array}{c}\text { Pulse } \\
\text { Velocity } \\
\text { Surface } \\
\text { Method }\end{array}$ & $\begin{array}{c}\text { AE } \\
\text { Surface } \\
\text { Wave } \\
\text { Method }\end{array}$ \\
\hline S10-53Du & NS & 3920 & 2040 & 4310 & 2250 & 4370 & 2240 & 4550 & 2230 & 4630 \\
\hline S10-53Dt & NS & 3550 & NS & 4020 & NS & 4210 & NS & 4320 & NS & 4080 \\
\hline $\mathrm{S} 10-53 \mathrm{u}$ & NS & 3450 & 1940 & 4090 & 1950 & 4270 & 2810 & 4370 & 2060 & 4390 \\
\hline $\mathrm{S} 10-53 \mathrm{t}$ & NS & 3040 & NS & 3520 & NS & 4080 & NS & 4220 & NS & 4310 \\
\hline $\mathrm{S} 10-\mathrm{CTBu}$ & NS & 3860 & 2210 & 3930 & 2080 & 4270 & 2510 & 4390 & 2190 & 4330 \\
\hline S10-CTBt & NS & 3600 & NS & 3950 & NS & 4090 & NS & 4410 & NS & 4490 \\
\hline $\mathrm{S} 10-8 \mathrm{u}$ & 1880 & 3910 & 2150 & 4260 & 2010 & 4330 & 2050 & 4420 & 2180 & 4600 \\
\hline $\mathrm{S} 10-8 \mathrm{t}$ & NS & NS & NS & 3850 & 1900 & 4010 & 1930 & 4170 & 2000 & 4110 \\
\hline S14-8u & 1930 & 3500 & 2210 & 4230 & 2290 & 4250 & 2250 & 4690 & 2200 & 4380 \\
\hline S14-8t & NS & 3590 & NS & 3770 & 1820 & 3680 & 2190 & 4380 & 1940 & 4480 \\
\hline S6-8u & 1930 & 3890 & 2720 & 4210 & 2810 & 4350 & 3010 & 4310 & 2150 & 4670 \\
\hline S6-8t & NS & 3730 & NS & 4280 & 1800 & 4440 & 2310 & 4760 & 2330 & 4670 \\
\hline S6-8m & NS & NS & NS & NS & NS & NS & 3210 & NS & NS & NS \\
\hline
\end{tabular}

Note:

The P-wave velocity for S10-8 by the pulse velocity direct method at Days 14 and 28 was 4470 and $4110 \mathrm{~m} / \mathrm{s}$ respectively.

$\mathrm{NS}=$ Not Sampled

Table L-3 Pre-Construction Elastic Modulus and Poisson's Ratio Results

\begin{tabular}{|c|c|c|c|}
\hline Test Specimen & Age, Days & Elastic Modulus, psi & Poisson's Ratio \\
\hline C9 & 4 & $2.13 \times 10^{6}$ & 0.18 \\
\hline C5 & 7 & $2.16 \times 10^{6}$ & 0.19 \\
\hline C1 & 14 & $2.45 \times 10^{6}$ & 0.20 \\
\hline C15 & 28 & $2.52 \times 10^{6}$ & 0.18 \\
\hline C22C & 103 & $2.72 \times 10^{6}$ & 0.20 \\
\hline
\end{tabular}


APPENDIX M PRE-CONSTUCTION IMPACT-ECHO TEST RESULTS 
Table M-1 Test Specimen S14-8

\begin{tabular}{|c|c|c|c|c|c|c|c|c|c|}
\hline \multirow[t]{2}{*}{ Day } & \multirow[t]{2}{*}{$\begin{array}{c}\text { Test } \\
\text { Location }\end{array}$} & \multirow[t]{2}{*}{$\begin{array}{c}\text { P-Wave } \\
\text { Velocity, } \\
\mathbf{m} / \mathbf{s}^{1,2}\end{array}$} & $\begin{array}{c}\text { Highest } \\
\text { Amplitude } \\
\text { Peak }^{3}\end{array}$ & \begin{tabular}{|c|} 
Highest \\
Amplitude \\
Peak \\
Excluding \\
Transducer \\
Resonance
\end{tabular} & \multirow[t]{2}{*}{\begin{tabular}{|c|} 
Slab \\
Thickness, \\
in
\end{tabular}} & \multirow[t]{2}{*}{$\begin{array}{c}\text { Percent } \\
\text { Difference } \\
\text { in } \\
\text { Thickness } \\
4\end{array}$} & \multirow[t]{2}{*}{$\begin{array}{c}\text { Alternate } \\
\text { High } \\
\text { Amplitude } \\
\text { Peak } \\
\text { Frequency, } \\
\text { kHz }\end{array}$} & \multirow[t]{2}{*}{$\begin{array}{c}\text { Slab } \\
\text { Thickness } \\
\text { From } \\
\text { Alternate } \\
\text { Peak, in }\end{array}$} & \multirow[t]{2}{*}{\begin{tabular}{|} 
Percent \\
Difference \\
in \\
Thickness
\end{tabular}} \\
\hline & & & \multicolumn{2}{|c|}{ Frequency, kHz } & & & & & \\
\hline \multirow[t]{6}{*}{1} & Tined & 3590 & 4.88 & 4.88 & 14.48 & & 4.88 & 14.48 & \\
\hline & & & 4.88 & 4.88 & 14.48 & & 4.88 & 14.48 & \\
\hline & & & Invalid & & & & & & \\
\hline & Untined & 3500 & 4.88 & 4.88 & 14.12 & 5.9 & 4.88 & 14.12 & 5.9 \\
\hline & & & Invalid & & & & & & \\
\hline & & & 4.88 & 4.88 & 14.12 & 5.9 & 4.88 & 14.12 & 5.9 \\
\hline \multirow[t]{5}{*}{4} & Tined & 3770 & 4.39 & 4.39 & 16.90 & & 5.86 & 12.66 & \\
\hline & & & Invalid & & & & & & \\
\hline & & & Invalid & & & & & & \\
\hline & Untined & 4230 & 4.88 & 4.88 & 17.06 & 13.8 & 4.88 & 17.06 & 13.8 \\
\hline & & & Invalid & & & & & & \\
\hline \multirow[t]{10}{*}{7} & Tined & 3680 & 6.84 & 6.84 & 10.59 & & 4.88 & 14.84 & \\
\hline & & & Invalid & & & & & & \\
\hline & Untined & 4250 & 4.88 & 4.88 & 17.14 & 14.3 & 4.88 & 17.14 & 14.3 \\
\hline & & & Invalid & & & & & & \\
\hline & & & 4.39 & 4.39 & 19.06 & 27.0 & 4.39 & 19.06 & 27.0 \\
\hline & & & Invalid & & & & & & \\
\hline & Middle & 3965 & Invalid & & & & & & \\
\hline & & & Invalid & & & & & & \\
\hline & & & 1.46 & 4.88 & 15.99 & 4.5 & 4.88 & 15.99 & 4.5 \\
\hline & & & 4.88 & 4.88 & 15.99 & 4.5 & 4.88 & 15.99 & 4.5 \\
\hline \multirow[t]{6}{*}{14} & Tined & 4380 & 5.37 & 5.37 & 16.06 & & 5.37 & 16.06 & \\
\hline & & & 5.37 & 5.37 & 16.06 & & 5.37 & 16.06 & \\
\hline & Untined & 4690 & 5.37 & 5.37 & 17.19 & 14.6 & 6.35 & 14.54 & 3.1 \\
\hline & & & 5.37 & 5.37 & 17.19 & 14.6 & 6.35 & 14.54 & 3.1 \\
\hline & Middle & 4535 & 9.77 & 9.77 & 9.14 & 40.3 & 6.84 & 13.05 & 14.7 \\
\hline & & & 4.88 & 4.88 & 18.29 & 19.6 & 6.84 & 13.05 & 14.7 \\
\hline \multirow[t]{7}{*}{28} & Tined & 4480 & 5.37 & 5.37 & 16.42 & & 5.37 & 16.42 & \\
\hline & & & 5.37 & 5.37 & 16.42 & & 5.37 & 16.42 & \\
\hline & Untined & 4380 & 5.37 & 5.37 & 16.06 & 7.0 & 5.37 & 16.06 & 7.0 \\
\hline & & & Invalid & & & & & & \\
\hline & Middle & 4430 & 4.88 & 4.88 & 17.87 & 16.8 & 4.88 & 17.87 & 16.8 \\
\hline & & & 4.88 & 4.88 & 17.87 & 16.8 & 4.88 & 17.87 & 16.8 \\
\hline & & & 4.88 & 4.88 & 17.87 & 16.8 & 4.88 & 17.87 & 16.8 \\
\hline \multirow[t]{3}{*}{42} & Middle & 4130 & 0.98 & 7.16 & 11.35 & 25.8 & 5.05 & 16.10 & 5.2 \\
\hline & & & 0.81 & 7.16 & 11.35 & 25.8 & 5.05 & 16.10 & 5.2 \\
\hline & & & 0.98 & 7.16 & 11.35 & 25.8 & 5.05 & 16.10 & 5.2 \\
\hline
\end{tabular}




\begin{tabular}{|c|c|c|c|c|c|c|c|}
\hline & 1.14 & 7.16 & 11.35 & 25.8 & 5.05 & 16.10 & 5.2 \\
\hline & 1.14 & 7.16 & 11.35 & 25.8 & 5.05 & 16.10 & 5.2 \\
\hline & 0.81 & 7.16 & 11.35 & 25.8 & 5.05 & 16.10 & 5.2 \\
\hline & 1.14 & 7.16 & 11.35 & 25.8 & 5.70 & 14.26 & 6.8 \\
\hline & 1.14 & 7.16 & 11.35 & 25.8 & 5.70 & 14.26 & 6.8 \\
\hline & 7.16 & 7.16 & 11.35 & 25.8 & 5.70 & 14.26 & 6.8 \\
\hline Middle 5 & 10.74 & 10.74 & 7.57 & 50.5 & 5.37 & 15.14 & 1.0 \\
\hline & 9.77 & 9.77 & 8.32 & 45.6 & 4.88 & 16.66 & 8.9 \\
\hline & 4.88 & 4.88 & 16.66 & 8.9 & 4.88 & 16.66 & 8.9 \\
\hline & 8.30 & 8.30 & 9.80 & 36.0 & 5.37 & 15.14 & 1.0 \\
\hline & 5.37 & 5.37 & 15.14 & 1.0 & 5.37 & 15.14 & 1.0 \\
\hline & 4.88 & 4.88 & 16.66 & 8.9 & 4.88 & 16.66 & 8.9 \\
\hline & 4.88 & 4.88 & 16.66 & 8.9 & 4.88 & 16.66 & 8.9 \\
\hline & 5.37 & 5.37 & 15.14 & 1.0 & 5.37 & 15.14 & 1.0 \\
\hline & 5.37 & 5.37 & 15.14 & 1.0 & 5.37 & 15.14 & 1.0 \\
\hline & 4.88 & 4.88 & 16.66 & 8.9 & 4.88 & 16.66 & 8.9 \\
\hline & & & Avg & 18.4 & & & 7.9 \\
\hline
\end{tabular}

Note 1: AE Surface method, except Day 42 is from FWHA impact-echo surface method

Note 2: The P-Wave velocity for Days 7, 14, and 28, middle, is the average of the tined and untined locations.

Note 3: Invalid tests were determined by inspection of the displacement waveform.

Note 4: Actual Thickness; Untined $=15.0$ in., Middle $=15.2$ in., Tined $=$ Not Measured

Note 5: Tests performed with FHWA impact-echo equipment 
Table M-2 Test Specimen S10-8

\begin{tabular}{|c|c|c|c|c|c|c|c|c|c|}
\hline \multirow[t]{2}{*}{ Day } & \multirow[t]{2}{*}{$\begin{array}{c}\text { Test } \\
\text { Location }\end{array}$} & \multirow[t]{2}{*}{$\begin{array}{c}\text { P-Wave } \\
\text { Velocity, } \\
\text { m/s } 1,2\end{array}$} & $\begin{array}{c}\text { Highest } \\
\text { Amplitude } \\
\text { Peak }^{3}\end{array}$ & \begin{tabular}{|c} 
Highest \\
Amplitude \\
Peak \\
Excluding \\
Transducer \\
Resonance
\end{tabular} & \multirow[t]{3}{*}{$\begin{array}{c}\text { Slab } \\
\text { Thickness, } \\
\text { in }\end{array}$} & \multirow[t]{3}{*}{$\begin{array}{c}\text { Percent } \\
\text { Difference } \\
\text { in } \\
\text { Thickness } \\
4\end{array}$} & \multirow[t]{2}{*}{\begin{tabular}{|} 
Alternate \\
High \\
Amplitude \\
Peak \\
Frequency, \\
kHz
\end{tabular}} & \multirow[t]{3}{*}{$\begin{array}{c}\text { Slab } \\
\text { Thickness } \\
\text { From } \\
\text { Alternate } \\
\text { Peak, in }\end{array}$} & \multirow[t]{2}{*}{\begin{tabular}{|} 
Percent \\
Difference \\
in \\
Thickness
\end{tabular}} \\
\hline & & & \multicolumn{2}{|c|}{ Frequency, kHz } & & & & & \\
\hline \multirow[t]{6}{*}{1} & Tined & & Invalid & & & & & & \\
\hline & & & Invalid & & & & & & \\
\hline & & & Invalid & & & & & & \\
\hline & Untined & 3910 & 7.32 & 7.32 & 10.51 & 0.14 & 7.32 & 10.51 & 0.14 \\
\hline & & & 7.32 & 7.32 & 10.51 & 0.14 & 7.32 & 10.51 & 0.14 \\
\hline & & & 7.32 & 7.32 & 10.51 & 0.14 & 7.32 & 10.51 & 0.14 \\
\hline \multirow[t]{4}{*}{4} & Tined & 3850 & Invalid & & & & & & \\
\hline & & & Invalid & & & & & & \\
\hline & Untined & 4260 & Invalid & & & & & & \\
\hline & & & Invalid & & & & & & \\
\hline \multirow[t]{6}{*}{7} & Tined & 4010 & Invalid & & & & & & \\
\hline & & & Invalid & & & & & & \\
\hline & Untined & 4330 & Invalid & & & & & & \\
\hline & & & Invalid & & & & & & \\
\hline & Middle & 4170 & 0.98 & 7.81 & 10.51 & 0.10 & 7.81 & 10.51 & 0.10 \\
\hline & & & Invalid & & & & & & \\
\hline \multirow[t]{7}{*}{14} & Tined & 4170 & Invalid & & & & & & \\
\hline & & & Invalid & & & & & & \\
\hline & Untined & 4420 & 7.81 & 7.81 & 11.14 & 6.10 & 7.81 & 11.14 & 6.10 \\
\hline & & & 7.81 & 7.81 & 11.14 & 6.10 & 7.81 & 11.14 & 6.10 \\
\hline & Middle & 4295 & 7.81 & 7.81 & 10.83 & 3.10 & 7.81 & 10.83 & 3.10 \\
\hline & & & 0.98 & 7.81 & 10.83 & 3.10 & 7.81 & 10.83 & 3.10 \\
\hline & & & 7.81 & 7.81 & 10.83 & 3.10 & 7.81 & 10.83 & 3.10 \\
\hline \multirow[t]{11}{*}{28} & Tined & 4110 & Invalid & & & & & & \\
\hline & & & Invalid & & & & & & \\
\hline & & & Invalid & & & & & & \\
\hline & Untined & 4600 & 0.98 & 6.35 & 14.26 & 35.81 & 8.3 & 10.91 & 3.90 \\
\hline & & & 6.35 & 6.35 & 14.26 & 35.81 & 8.3 & 10.91 & 3.90 \\
\hline & & & 6.35 & 6.35 & 14.26 & 35.81 & 7.81 & 11.59 & 10.42 \\
\hline & & & 6.35 & 6.35 & 14.26 & 35.81 & 8.3 & 10.91 & 3.90 \\
\hline & Middle & 4355 & Invalid & & & & & & \\
\hline & & & Invalid & & & & & & \\
\hline & & & Invalid & & & & & & \\
\hline & & & 11.23 & 11.23 & 7.63 & 27.30 & 7.81 & 10.98 & 4.54 \\
\hline \multirow[t]{3}{*}{\begin{tabular}{|l|}
42 \\
\end{tabular}} & Middle & 4080 & 8.95 & 8.95 & 8.97 & 14.54 & 7.98 & 10.06 & 4.15 \\
\hline & & & 1.14 & 8.95 & 8.97 & 14.54 & 7.98 & 10.06 & 4.15 \\
\hline & & & 1.14 & 8.95 & 8.97 & 14.54 & 7.98 & 10.06 & 4.15 \\
\hline
\end{tabular}




\begin{tabular}{|c|c|c|c|c|c|c|c|}
\hline & 0.81 & 8.95 & 8.97 & 14.54 & 7.98 & 10.06 & 4.15 \\
\hline & 1.14 & 8.14 & 9.87 & 6.03 & 7.16 & 11.22 & 6.83 \\
\hline & 0.98 & 8.14 & 9.87 & 6.03 & 7.49 & 10.72 & 2.12 \\
\hline & 0.81 & 8.95 & 8.97 & 14.54 & 7.98 & 10.06 & 4.15 \\
\hline \multirow[t]{6}{*}{ Middle $^{5}$} & 8.3 & 8.3 & 9.68 & 7.84 & 8.3 & 9.68 & 7.84 \\
\hline & 8.3 & 8.3 & 9.68 & 7.84 & 8.3 & 9.68 & 7.84 \\
\hline & 7.81 & 7.81 & 10.28 & 2.06 & 7.81 & 10.28 & 2.06 \\
\hline & 1.22 & 8.06 & 9.96 & 5.10 & 8.06 & 9.96 & 5.10 \\
\hline & 1.22 & 8.15 & 9.85 & 6.15 & 8.15 & 9.85 & 6.15 \\
\hline & & & Avg & 11.78 & & & 4.13 \\
\hline
\end{tabular}

Note 1: AE surface method, except Day 42 is from FWHA impact-echo surface method Note 2: The P-Wave velocity for Days 7, 14, and 28, middle, is the average of the tined and untined locations.

Note 3: Invalid tests were determined by inspection of the displacement waveform.

Note 4: Actual Thickness; Untined $=10.5$ in., Middle $=10.5$ in., Tined $=$ Not Measured

Note 5: Tests performed with FHWA impact-echo equipment 
Table M-3 Test Specimen S6-8

\begin{tabular}{|c|c|c|c|c|c|c|c|c|c|}
\hline \multirow[t]{2}{*}{ Day } & \multirow[t]{2}{*}{$\begin{array}{c}\text { Test } \\
\text { Location }\end{array}$} & \multirow[t]{2}{*}{$\begin{array}{c}\text { P-Wave } \\
\text { Velocity, } \\
\mathbf{m} / \mathbf{s}\end{array}$} & $\begin{array}{c}\text { Highest } \\
\text { Amplitude } \\
\text { Peak }^{3}\end{array}$ & \begin{tabular}{|c|} 
Highest \\
Amplitude \\
Peak \\
Excluding \\
Transducer \\
Resonance \\
\end{tabular} & \multirow[t]{2}{*}{$\begin{array}{c}\text { Slab } \\
\text { Thickness, } \\
\text { in }\end{array}$} & \multirow[t]{2}{*}{$\mid \begin{array}{c}\text { Percent } \\
\text { Difference } \\
\text { in } \\
\text { Thickness } \\
4\end{array}$} & \multirow[t]{2}{*}{$\begin{array}{l}\text { Alternate } \\
\text { High } \\
\text { Amplitude } \\
\text { Peak } \\
\text { Frequency, } \\
\text { kHz }\end{array}$} & \multirow[t]{3}{*}{$\begin{array}{c}\text { Slab } \\
\text { Thickness } \\
\text { From } \\
\text { Alternate } \\
\text { Peak, in }\end{array}$} & \multirow[t]{2}{*}{\begin{tabular}{|} 
Percent \\
Difference \\
in \\
Thickness
\end{tabular}} \\
\hline & & & \multicolumn{2}{|c|}{ Frequency, kHz } & & & & & \\
\hline \multirow[t]{6}{*}{1} & Tined & 3730 & Invalid & & & & & & \\
\hline & & & Invalid & & & & & & \\
\hline & & & Invalid & & & & & & \\
\hline & Untined & 3890 & 9.77 & 9.77 & 7.84 & 0.79 & 9.77 & 7.84 & 0.79 \\
\hline & & & 9.77 & 9.77 & 7.84 & 0.79 & 9.77 & 7.84 & 0.79 \\
\hline & & & 9.77 & 9.77 & 7.84 & 0.79 & 9.77 & 7.84 & 0.79 \\
\hline \multirow[t]{6}{*}{4} & Tined & 4280 & Invalid & & & & & & \\
\hline & & & Invalid & & & & & & \\
\hline & & & 0.98 & 9.28 & 9.08 & & 11.23 & 7.50 & \\
\hline & Untined & 4210 & 9.28 & 9.28 & 8.93 & 13.04 & 10.25 & 8.09 & 2.34 \\
\hline & & & Invalid & & & & & & \\
\hline & & & Invalid & & & & & & \\
\hline \multirow[t]{8}{*}{7} & Tined & 4440 & 2.92 & 2.92 & 29.93 & & 9.77 & 8.95 & \\
\hline & & & Invalid & & & & & & \\
\hline & Untined & 4350 & Invalid & & & & & & \\
\hline & & & 11.23 & 11.23 & 7.63 & 3.48 & 11.23 & 7.63 & 3.48 \\
\hline & & & 10.25 & 10.25 & 8.35 & 5.75 & 10.25 & 8.35 & 5.75 \\
\hline & Middle & 4395 & Invalid & & & & & & \\
\hline & & & Invalid & & & & & & \\
\hline & & & Invalid & & & & & & \\
\hline \multirow[t]{9}{*}{14} & Tined & 4760 & Invalid & & & & & & \\
\hline & & & Invalid & & & & & & \\
\hline & & & Invalid & & & & & & \\
\hline & Untined & 4310 & 1.46 & 9.77 & 8.68 & 9.92 & 9.77 & 8.68 & 9.92 \\
\hline & & & 9.77 & 9.77 & 8.68 & 9.92 & 11.23 & 7.55 & 4.37 \\
\hline & & & 11.23 & 11.23 & 7.55 & 4.37 & 11.23 & 7.55 & 4.37 \\
\hline & Middle & 4535 & 0.98 & 10.74 & 8.31 & 10.83 & 12.21 & 7.31 & 2.52 \\
\hline & & & 0.98 & 10.74 & 8.31 & 10.83 & 12.21 & 7.31 & 2.52 \\
\hline & & & 10.74 & 10.74 & 8.31 & 10.83 & 12.21 & 7.31 & 2.52 \\
\hline \multirow[t]{9}{*}{28} & Tined & 4670 & 2.93 & 2.93 & 31.38 & & 15.63 & 5.88 & \\
\hline & & & 10.74 & 10.74 & 8.56 & & 13.67 & 6.72 & \\
\hline & & & 0.98 & 11.7 & 7.86 & & 16.6 & 5.54 & \\
\hline & Untined & 4670 & Invalid & & & & & & \\
\hline & & & Invalid & & & & & & \\
\hline & & & 10.74 & 10.74 & 8.56 & 8.35 & 12.21 & 7.53 & 4.70 \\
\hline & Middle & 4670 & 0.98 & 11.23 & 8.19 & 9.15 & 11.23 & 8.19 & 9.15 \\
\hline & & & 13.67 & 13.67 & 6.72 & 10.34 & 11.23 & 8.19 & 9.15 \\
\hline & & & 11.23 & 11.23 & 8.19 & 9.15 & 11.23 & 8.19 & 9.15 \\
\hline
\end{tabular}




\begin{tabular}{|c|c|c|c|c|c|c|c|c|c|}
\hline & & & 11.23 & 11.23 & 8.19 & 9.15 & 11.23 & 8.19 & 9.15 \\
\hline \multirow[t]{16}{*}{42} & Middle & 4010 & 1.22 & 29.33 & 2.69 & 64.12 & 11.23 & 7.03 & 6.28 \\
\hline & & & 0.98 & 11.23 & 7.03 & 6.28 & 11.23 & 7.03 & 6.28 \\
\hline & & & 1.22 & 13.67 & 5.77 & 23.01 & 11.47 & 6.88 & 8.24 \\
\hline & & & 13.67 & 13.67 & 5.77 & 23.01 & 11.47 & 6.88 & 8.24 \\
\hline & & & 1.22 & 13.42 & 5.88 & 21.57 & 11.47 & 6.88 & 8.24 \\
\hline & & & 1.22 & 13.67 & 5.77 & 23.01 & 11.47 & 6.88 & 8.24 \\
\hline & & & 1.14 & 13.67 & 5.77 & 23.01 & 11.56 & 6.83 & 8.95 \\
\hline & & & 0.81 & 13.67 & 5.77 & 23.01 & 11.56 & 6.83 & 8.95 \\
\hline & Middle $^{5}$ & & 12.70 & 12.70 & 6.22 & 17.13 & 11.23 & 7.03 & 6.28 \\
\hline & & & 8.79 & 8.79 & 8.98 & 19.74 & 10.74 & 7.35 & 2.00 \\
\hline & & & 13.18 & 13.18 & 5.99 & 20.14 & 11.23 & 7.03 & 6.28 \\
\hline & & & 12.70 & 12.70 & 6.22 & 17.13 & 11.23 & 7.03 & 6.28 \\
\hline & & & 12.70 & 12.70 & 6.22 & 17.13 & 11.23 & 7.03 & 6.28 \\
\hline & & & 11.23 & 11.23 & 7.03 & 6.28 & 11.23 & 7.03 & 6.28 \\
\hline & & & 12.70 & 12.70 & 6.22 & 17.13 & 11.23 & 7.03 & 6.28 \\
\hline & & & 11.23 & 11.23 & 7.03 & 6.28 & 11.23 & 7.03 & 6.28 \\
\hline & & & & & Avg & 13.80 & & & 5.78 \\
\hline
\end{tabular}

Note 1: AE surface method, except Day 42 is from FWHA impact-echo surface method Note 2: The P-Wave velocity for Days 7, 14, and 28, middle, is the average of the tined and untined locations.

Note 3: Invalid tests were determined by inspection of the displacement waveform.

Note 4: Actual Thickness; Untined $=7.9$ in., Middle $=7.5$ in., Tined $=$ Not Measured

Note 5: Tests performed with FHWA impact-echo equipment 
Table M-4 Test Specimen S10-53

\begin{tabular}{|c|c|c|c|c|c|c|c|c|c|}
\hline \multirow[t]{2}{*}{ Day } & \multirow[t]{2}{*}{$\begin{array}{c}\text { Test } \\
\text { Location }\end{array}$} & \multirow[t]{2}{*}{$\begin{array}{l}\text { P-Wave } \\
\text { Velocity, } \\
\mathrm{m} / \mathrm{s}^{1,2}\end{array}$} & $\begin{array}{l}\text { Highest } \\
\text { Amplitude }^{\text {Peak }^{3}}\end{array}$ & \begin{tabular}{|c|} 
Highest \\
Amplitude \\
Peak \\
Excluding \\
Transducer \\
Resonance \\
\end{tabular} & \multirow[t]{3}{*}{$\begin{array}{c}\text { Slab } \\
\text { Thickness, } \\
\text { in }\end{array}$} & \multirow[t]{3}{*}{$\begin{array}{c}\text { Percent } \\
\text { Difference } \\
\text { in } \\
\text { Thickness } \\
4\end{array}$} & \multirow[t]{2}{*}{$\begin{array}{c}\text { Alternate } \\
\text { High } \\
\text { Amplitude } \\
\text { Peak } \\
\text { Frequency, } \\
\text { kHz }\end{array}$} & \multirow[t]{3}{*}{$\begin{array}{c}\text { Slab } \\
\text { Thickness } \\
\text { From } \\
\text { Alternate } \\
\text { Peak, in }\end{array}$} & \multirow[t]{2}{*}{\begin{tabular}{|} 
Percent \\
Difference \\
in \\
Thickness
\end{tabular}} \\
\hline & & & \multicolumn{2}{|c|}{ Frequency, kHz } & & & & & \\
\hline \multirow[t]{5}{*}{4} & Tined & 3520 & Invalid & & & & & & \\
\hline & & & 13.67 & 13.67 & 5.07 & & 5.86 & 11.82 & \\
\hline & & & Invalid & & & & & & \\
\hline & Untined & 4090 & Invalid & & & & & & \\
\hline & & & Invalid & & & & & & \\
\hline \multirow[t]{6}{*}{\begin{tabular}{|l|}
7 \\
\end{tabular}} & Tined & 4080 & 7.32 & 7.32 & 10.97 & & 7.32 & 10.97 & \\
\hline & & & 7.32 & 7.32 & 10.97 & & 7.32 & 10.97 & \\
\hline & Untined & 4270 & 7.32 & 7.32 & 11.48 & 1.62 & 7.32 & 11.48 & 1.62 \\
\hline & & & 7.32 & 7.32 & 11.48 & 1.62 & 7.32 & 11.48 & 1.62 \\
\hline & Middle & 4175 & 0.98 & 8.79 & 9.35 & 14.22 & 6.84 & 12.02 & 10.23 \\
\hline & & & 8.79 & 8.79 & 9.35 & 14.22 & 6.84 & 12.02 & 10.23 \\
\hline \multirow[t]{7}{*}{14} & Tined & 4220 & Invalid & & & & & & \\
\hline & & & Invalid & & & & & & \\
\hline & & & 0.98 & 7.32 & 11.35 & & 7.32 & 11.35 & \\
\hline & Untined & 4370 & 7.32 & 7.32 & 11.75 & 4.00 & 7.32 & 11.75 & 4.00 \\
\hline & & & 7.32 & 7.32 & 11.75 & 4.00 & 7.32 & 11.75 & 4.00 \\
\hline & Middle & 4295 & 7.81 & 7.81 & 10.83 & 0.68 & 7.81 & 10.83 & 0.68 \\
\hline & & & 7.81 & 7.81 & 10.83 & 0.68 & 7.81 & 10.83 & 0.68 \\
\hline \multirow[t]{7}{*}{28} & Tined & 4310 & Invalid & & & & & & \\
\hline & & & Invalid & & & & & & \\
\hline & Untined & 4390 & 7.32 & 7.32 & 11.81 & 4.47 & 7.32 & 11.81 & 4.47 \\
\hline & & & 7.32 & 7.32 & 11.81 & 4.47 & 7.32 & 11.81 & 4.47 \\
\hline & Middle & 4350 & 13.67 & 13.67 & 6.26 & 42.53 & 7.81 & 10.96 & 0.59 \\
\hline & & & 0.98 & 13.67 & 6.26 & 42.53 & 7.81 & 10.96 & 0.59 \\
\hline & & & 1.46 & 7.8 & 10.98 & 0.72 & 8.79 & 9.74 & 10.63 \\
\hline \multirow[t]{12}{*}{42} & Middle & 3960 & 1.14 & 6.53 & 11.94 & 9.52 & 7.81 & 9.98 & 8.43 \\
\hline & & & 0.98 & 8.06 & 9.67 & 11.27 & 7.32 & 10.65 & 2.30 \\
\hline & & & 12.21 & 12.21 & 6.38 & 41.43 & 7.32 & 10.65 & 2.30 \\
\hline & & & 0.73 & 7.81 & 9.98 & 8.43 & 7.81 & 9.98 & 8.43 \\
\hline & & & 0.73 & 6.6 & 11.81 & 8.36 & 7.32 & 10.65 & 2.30 \\
\hline & & & 0.81 & 7.98 & 9.77 & 10.38 & 7.32 & 10.65 & 2.30 \\
\hline & Middle $^{5}$ & & 1.14 & 6.51 & 11.97 & 9.86 & 7.32 & 10.65 & 2.30 \\
\hline & & & 6.18 & 6.18 & 12.61 & 15.72 & 7.32 & 10.65 & 2.30 \\
\hline & & & 6.18 & 6.18 & 12.61 & 15.72 & 7.32 & 10.65 & 2.30 \\
\hline & & & 1.30 & 7.98 & 9.77 & 10.38 & 7.32 & 10.65 & 2.30 \\
\hline & & & 1.14 & 7.98 & 9.77 & 10.38 & 7.32 & 10.65 & 2.30 \\
\hline & & & 1.14 & 7.98 & 9.77 & 10.38 & 7.32 & 10.65 & 2.30 \\
\hline
\end{tabular}




\begin{tabular}{|l|l|l|l|l|l|l|l|l|}
\hline & & 7.98 & 7.98 & 9.77 & 10.38 & 7.32 & 10.65 & 2.30 \\
\hline & & 1.14 & 7.98 & 9.77 & 10.38 & 7.32 & 10.65 & 2.30 \\
\hline
\end{tabular}

Note 1: AE surface method, except Day 42 is from FWHA impact-echo surface method

Note 2: The P-Wave velocity for Days 7, 14, and 28, middle, is the average of the tined and untined locations.

Note 3: Invalid tests were determined by inspection of the displacement waveform.

Note 4: Actual Thickness; Untined $=11.3$ in., Middle $=10.9$ in., Tined $=$ Not Measured

Note 5: Tests performed with FHWA impact-echo equipment 
Table M-5 Test Specimen S10-53D

\begin{tabular}{|c|c|c|c|c|c|c|c|c|c|}
\hline \multirow[t]{2}{*}{ Day } & \multirow[t]{2}{*}{$\begin{array}{c}\text { Test } \\
\text { Location }\end{array}$} & \multirow[t]{2}{*}{$\begin{array}{c}\text { P-Wave } \\
\text { Velocity, } \\
\text { m/s } 1,2\end{array}$} & $\begin{array}{c}\text { Highest } \\
\text { Amplitude } \text { Peak }^{3}\end{array}$ & \begin{tabular}{|c|} 
Highest \\
Amplitude \\
Peak \\
Excluding \\
Transducer \\
Resonance
\end{tabular} & \multirow[t]{2}{*}{$\begin{array}{c}\text { Slab } \\
\text { Thickness, } \\
\text { in }\end{array}$} & \multirow[t]{3}{*}{$\begin{array}{c}\text { Percent } \\
\text { Difference } \\
\text { in } \\
\text { Thickness } \\
4\end{array}$} & \multirow[t]{2}{*}{$\begin{array}{c}\text { Alternate } \\
\text { High } \\
\text { Amplitude } \\
\text { Peak } \\
\text { Frequency, } \\
\text { kHz }\end{array}$} & \multirow[t]{2}{*}{$\begin{array}{c}\text { Slab } \\
\text { Thickness } \\
\text { From } \\
\text { Alternate } \\
\text { Peak, in }\end{array}$} & \multirow[t]{2}{*}{\begin{tabular}{|} 
Percent \\
Difference \\
in \\
Thickness
\end{tabular}} \\
\hline & & & \multicolumn{2}{|c|}{ Frequency, kHz } & & & & & \\
\hline \multirow[t]{6}{*}{4} & Tined & 4020 & Invalid & & & & & & \\
\hline & & & Invalid & & & & & & \\
\hline & & & Invalid & & & & & & \\
\hline & Untined & 4310 & Invalid & & & & & & \\
\hline & & & 7.32 & 7.32 & 11.59 & 8.32 & 8.3 & 10.22 & 4.47 \\
\hline & & & 3.42 & 3.42 & 24.81 & 131.85 & 6.84 & 12.40 & 15.92 \\
\hline \multirow[t]{8}{*}{7} & Tined & 4210 & Invalid & & & & & & \\
\hline & & & Invalid & & & & & & \\
\hline & Untined & 4370 & Invalid & & & & & & \\
\hline & & & 7.32 & 7.32 & 11.75 & 9.83 & 7.32 & 11.75 & 9.83 \\
\hline & & & 7.82 & 7.82 & 11.00 & 2.81 & 7.82 & 11.00 & 2.81 \\
\hline & Middle & 4290 & 6.84 & 6.84 & 12.35 & 9.26 & 6.84 & 12.35 & 9.26 \\
\hline & & & Invalid & & & & & & \\
\hline & & & Invalid & & & & & & \\
\hline \multirow[t]{7}{*}{14} & Tined & 4320 & Invalid & & & & & & \\
\hline & & & Invalid & & & & & & \\
\hline & & & Invalid & & & & & & \\
\hline & Untined & 4550 & 0.98 & 7.81 & 11.47 & 7.18 & 7.81 & 11.47 & 7.18 \\
\hline & & & 0.98 & 7.81 & 11.47 & 7.18 & 7.81 & 11.47 & 7.18 \\
\hline & Middle & 4435 & 0.49 & 7.81 & 11.18 & 1.08 & 7.81 & 11.18 & 1.08 \\
\hline & & & 1.46 & 9.77 & 8.94 & 20.92 & 7.81 & 11.18 & 1.08 \\
\hline \multirow[t]{7}{*}{28} & Tined & 4080 & 9.77 & 9.77 & 8.22 & & 7.81 & 10.28 & \\
\hline & & & 9.77 & 9.77 & 8.22 & & 7.81 & 10.28 & \\
\hline & Untined & 4630 & Invalid & & & & & & \\
\hline & & & Invalid & & & & & & \\
\hline & & & Invalid & & & & & & \\
\hline & Middle & 4355 & 7.81 & 7.81 & 10.98 & 2.86 & 7.81 & 10.98 & 2.86 \\
\hline & & & 7.81 & 7.81 & 10.98 & 2.86 & 7.81 & 10.98 & 2.86 \\
\hline \multirow[t]{9}{*}{42} & Middle & 3720 & 1.14 & 6.35 & 11.53 & 2.05 & 6.35 & 11.53 & 2.05 \\
\hline & & & 1.30 & 6.51 & 11.25 & 0.46 & 6.51 & 11.25 & 0.46 \\
\hline & & & 1.30 & 8.95 & 8.18 & 27.59 & 6.35 & 11.53 & 2.05 \\
\hline & & & 1.30 & 6.35 & 11.53 & 2.05 & 6.35 & 11.53 & 2.05 \\
\hline & & & 1.14 & 6.35 & 11.53 & 2.05 & 6.35 & 11.53 & 2.05 \\
\hline & & & 1.14 & 6.35 & 11.53 & 2.05 & 6.35 & 11.53 & 2.05 \\
\hline & & & 8.95 & 8.95 & 8.18 & 27.59 & 6.35 & 11.53 & 2.05 \\
\hline & & & 8.79 & 8.79 & 8.33 & 26.28 & 6.35 & 11.53 & 2.05 \\
\hline & & & 6.35 & 6.35 & 11.53 & 2.05 & 6.35 & 11.53 & 2.05 \\
\hline
\end{tabular}




\begin{tabular}{|l|l|l|l|l|l|l|l|l|l|}
\hline & & & 0.98 & 7.95 & 9.21 & 18.49 & 6.18 & 11.85 & 4.86 \\
\hline & & & 0.98 & 7.95 & 9.21 & 18.49 & 6.35 & 11.53 & 2.05 \\
\hline & & & 1.14 & 7.95 & 9.21 & 18.49 & 6.35 & 11.53 & 2.05 \\
\hline & & & 1.14 & 7.95 & 9.21 & 18.49 & 6.35 & 11.53 & 2.05 \\
\hline & & & 0.98 & 7.95 & 9.21 & 18.49 & 6.35 & 11.53 & 2.05 \\
\hline & & 1.14 & 7.8 & 9.39 & 16.92 & 6.35 & 11.53 & 2.05 \\
\hline
\end{tabular}

Note 1: AE surface method, except Day 42 is from FWHA impact-echo surface method

Note 2: The P-Wave velocity for Days 7,14 , and 28 , middle, is the average of the tined and untined locations.

Note 3: Invalid tests were determined by inspection of the displacement waveform.

Note 4: Actual Thickness; Untined $=10.7$ in., Middle $=11.3$ in., Tined $=$ Not Measured

Note 5: Tests performed with FHWA impact-echo equipment 
Table M-6 Test Specimen S10-CTB

\begin{tabular}{|c|c|c|c|c|c|c|c|c|c|}
\hline \multirow[t]{2}{*}{ Day } & \multirow[t]{2}{*}{$\begin{array}{c}\text { Test } \\
\text { Location }\end{array}$} & \multirow[t]{2}{*}{$\begin{array}{c}\text { P-Wave } \\
\text { Velocity, } \\
\text { m/s } \mathbf{s}^{1,2}\end{array}$} & $\begin{array}{c}\text { Highest } \\
\text { Amplitude } \\
\text { Peak }^{3}\end{array}$ & \begin{tabular}{|c|} 
Highest \\
Amplitude \\
Peak \\
Excluding \\
Transducer \\
Resonance \\
\end{tabular} & \multirow[t]{2}{*}{$\begin{array}{c}\text { Slab } \\
\text { Thickness, } \\
\text { in }\end{array}$} & \multirow[t]{3}{*}{$\begin{array}{c}\text { Percent } \\
\text { Difference } \\
\text { in } \\
\text { Thickness } \\
4\end{array}$} & \multirow[t]{2}{*}{$\begin{array}{c}\text { Alternate } \\
\text { High } \\
\text { Amplitude } \\
\text { Peak } \\
\text { Frequency, } \\
\text { kHz }\end{array}$} & \multirow[t]{2}{*}{$\begin{array}{c}\text { Slab } \\
\text { Thickness } \\
\text { From } \\
\text { Alternate } \\
\text { Peak, in }\end{array}$} & \multirow[t]{2}{*}{$\begin{array}{c}\text { Percent } \\
\text { Difference } \\
\text { in } \\
\text { Thickness }\end{array}$} \\
\hline & & & \multicolumn{2}{|c|}{ Frequency, kHz } & & & & & \\
\hline \multirow[t]{5}{*}{4} & Tined & 3950 & Invalid & & & & & & \\
\hline & & & Invalid & & & & & & \\
\hline & Untined & 3930 & Invalid & & & & & & \\
\hline & & & Invalid & & & & & & \\
\hline & & & Invalid & & & & & & \\
\hline \multirow[t]{6}{*}{7} & Tined & 4090 & 0.98 & 8.79 & 9.16 & & 6.84 & 11.77 & \\
\hline & & & 0.98 & 8.79 & 9.16 & & 6.84 & 11.77 & \\
\hline & Untined & 4270 & 0.49 & 7.32 & 11.48 & & 7.32 & 11.48 & \\
\hline & & & 7.32 & 7.32 & 11.48 & & 7.32 & 11.48 & \\
\hline & Middle & 4180 & 7.81 & 7.81 & 10.54 & 5.08 & 7.81 & 10.54 & 5.08 \\
\hline & & & 7.81 & 7.81 & 10.54 & 5.08 & 7.81 & 10.54 & 5.08 \\
\hline \multirow[t]{8}{*}{14} & Tined & 4410 & Invalid & & & & & & \\
\hline & & & Invalid & & & & & & \\
\hline & & & Invalid & & & & & & \\
\hline & Untined & 4390 & Invalid & & & & & & \\
\hline & & & Invalid & & & & & & \\
\hline & Middle & 4400 & 0.98 & 7.81 & 11.09 & 0.09 & 7.81 & 11.09 & 0.09 \\
\hline & & & 7.81 & 7.81 & 11.09 & 0.09 & 7.81 & 11.09 & 0.09 \\
\hline & & & 0.98 & 7.81 & 11.09 & 0.09 & 7.81 & 11.09 & 0.09 \\
\hline \multirow[t]{6}{*}{28} & Tined & 4490 & 0.98 & 8.79 & 10.06 & & 8.79 & 10.06 & \\
\hline & & & 8.79 & 8.79 & 10.06 & & 8.79 & 10.06 & \\
\hline & Untined & 4330 & Invalid & & & & & & \\
\hline & & & Invalid & & & & & & \\
\hline & Middle & 4410 & 7.32 & 7.32 & 11.86 & 6.84 & 7.32 & 11.86 & 6.84 \\
\hline & & & 7.32 & 7.32 & 11.86 & 6.84 & 7.32 & 11.86 & 6.84 \\
\hline \multirow[t]{12}{*}{42} & Middle & 3840 & 9.11 & 9.11 & 8.30 & 25.25 & 6.51 & 11.61 & 4.61 \\
\hline & & & 9.11 & 9.11 & 8.30 & 25.25 & 6.67 & 11.33 & 2.10 \\
\hline & & & 9.11 & 9.11 & 8.30 & 25.25 & 6.51 & 11.61 & 4.61 \\
\hline & & & 9.11 & 9.11 & 8.30 & 25.25 & 6.51 & 11.61 & 4.61 \\
\hline & & & 9.11 & 9.11 & 8.30 & 25.25 & 6.51 & 11.61 & 4.61 \\
\hline & & & 9.11 & 9.11 & 8.30 & 25.25 & 6.51 & 11.61 & 4.61 \\
\hline & & & 0.81 & 7.98 & 9.47 & 14.66 & 6.67 & 11.33 & 2.10 \\
\hline & & & 7.98 & 7.98 & 9.47 & 14.66 & 6.51 & 11.61 & 4.61 \\
\hline & & & 7.98 & 7.98 & 9.47 & 14.66 & 6.67 & 11.33 & 2.10 \\
\hline & & & 1.14 & 7.98 & 9.47 & 14.66 & 6.67 & 11.33 & 2.10 \\
\hline & & & 7.81 & 7.81 & 9.68 & 12.80 & 6.67 & 11.33 & 2.10 \\
\hline & & & 0.98 & 7.98 & 9.47 & 14.66 & 6.67 & 11.33 & 2.10 \\
\hline
\end{tabular}


Note 1: AE surface method, except Day 42 is from FWHA impact-echo surface method

Note 2: The P-Wave velocity for Days 7, 14, and 28, middle, is the average of the tined and untined locations.

Note 3: Invalid tests were determined by inspection of the displacement waveform.

Note 4: Actual Thickness; Middle $=11.1$ in., Untined and Tined $=$ Not Measured

Note 5: Tests performed with FHWA impact-echo equipment 
APPENDIX N INDOT CONCRETE STRENGTH RESULTS (PROJECT R-24432) 
Table N-1 INDOT Flexural Strength-Mainline Pavement with Fly Ash

\begin{tabular}{|c|c|c|c|c|c|c|}
\hline $\begin{array}{c}\text { Lot/Sublot- } \\
\text { Location }\end{array}$ & Date Cast & $\begin{array}{l}\text { Location } \\
\text { Sampled }\end{array}$ & $\begin{array}{c}\text { Strength, } \\
\text { psi }\end{array}$ & $\begin{array}{c}\text { Sublot } \\
\text { Average, } \\
\text { psi }\end{array}$ & $\begin{array}{c}\text { Lot } \\
\text { Average, } \\
\text { psi }\end{array}$ & $\begin{array}{c}\text { Lot } \\
\text { Standard } \\
\text { Deviation, } \\
\text { psi }\end{array}$ \\
\hline $1 / 1-\mathrm{A}$ & $07 / 10 / 00$ & $24+655$ & 722 & \multirow{2}{*}{675} & \multirow{6}{*}{688} & \multirow{6}{*}{38.28} \\
\hline 1/1-B & $07 / 10 / 00$ & $24+655$ & 627 & & & \\
\hline $1 / 2-\mathrm{A}$ & $07 / 12 / 00$ & $24+445$ & 677 & \multirow{2}{*}{726} & & \\
\hline $1 / 2-B$ & $07 / 12 / 00$ & $24+445$ & 775 & & & \\
\hline $1 / 3-A$ & $07 / 24 / 00$ & $24+150$ & 664 & \multirow{2}{*}{662} & & \\
\hline $1 / 3-B$ & $07 / 24 / 00$ & $24+150$ & 660 & & & \\
\hline $2 / 1-A$ & $07 / 24 / 00$ & $23+915$ & 594 & \multirow{2}{*}{617} & \multirow{6}{*}{648} & \multirow{6}{*}{31.46} \\
\hline 2/1-B & $07 / 24 / 00$ & $23+915$ & 639 & & & \\
\hline $2 / 2-A$ & $07 / 25 / 00$ & $23+552$ & 681 & \multirow{2}{*}{669} & & \\
\hline $2 / 2-B$ & $07 / 25 / 00$ & $23+552$ & 657 & & & \\
\hline $2 / 3-A$ & $07 / 25 / 00$ & $23+330$ & 650 & \multirow{2}{*}{659} & & \\
\hline $2 / 3-B$ & $07 / 25 / 00$ & $23+330$ & 668 & & & \\
\hline $3 / 1-A$ & $07 / 26 / 00$ & $23+075$ & 669 & \multirow{2}{*}{671} & \multirow{6}{*}{655} & \multirow{6}{*}{15.14} \\
\hline 3/1-B & $07 / 26 / 00$ & $23+075$ & 672 & & & \\
\hline $3 / 2-\mathrm{A}$ & $07 / 26 / 00$ & $22+730$ & 665 & 651 & & \\
\hline $3 / 2-B$ & $07 / 26 / 00$ & $22+730$ & 636 & 651 & & \\
\hline $3 / 3-A$ & $08 / 01 / 00$ & $22+645$ & 650 & 645 & & \\
\hline 3/3-B & $08 / 01 / 00$ & $22+645$ & 640 & 645 & & \\
\hline $4 / 1-\mathrm{A}$ & $08 / 02 / 00$ & $23+275$ & 665 & 635 & \multirow{6}{*}{659} & \multirow{6}{*}{24.93} \\
\hline 4/1-B & $08 / 02 / 00$ & $23+275$ & 605 & 635 & & \\
\hline $4 / 2-A$ & $08 / 04 / 00$ & $23+863$ & 672 & 664 & & \\
\hline $4 / 2-B$ & $08 / 04 / 00$ & $23+863$ & 655 & & & \\
\hline $4 / 3-A$ & $10 / 10 / 00$ & $22+675$ & 707 & \multirow{2}{*}{679} & & \\
\hline $4 / 3-B$ & $10 / 10 / 00$ & $22+675$ & 650 & & & \\
\hline $5 / 1-\mathrm{A}$ & $10 / 10 / 00$ & $22+982$ & 708 & \multirow{2}{*}{701} & \multirow{6}{*}{708} & \multirow{6}{*}{11.85} \\
\hline 5/1-B & $10 / 10 / 00$ & $22+982$ & 693 & & & \\
\hline $5 / 2-A$ & $10 / 11 / 00$ & $23+335$ & 666 & \multirow{2}{*}{704} & & \\
\hline $5 / 2-B$ & $10 / 11 / 00$ & $23+335$ & 741 & & & \\
\hline $5 / 3-A$ & $10 / 11 / 00$ & $23+575$ & 725 & \multirow{2}{*}{720} & & \\
\hline $5 / 3-B$ & $10 / 11 / 00$ & $23+575$ & 715 & & & \\
\hline 6/1-A & $10 / 11 / 00$ & $23+875$ & 728 & \multirow{2}{*}{691} & \multirow{6}{*}{725} & \multirow{6}{*}{44.91} \\
\hline $6 / 1-B$ & $10 / 11 / 00$ & $23+875$ & 654 & & & \\
\hline $6 / 2-A$ & $10 / 12 / 00$ & $24+325$ & 722 & \multirow{2}{*}{769} & & \\
\hline $6 / 2-B$ & $10 / 12 / 00$ & $24+325$ & 815 & & & \\
\hline $6 / 3-A$ & $10 / 12 / 00$ & $24+435$ & 701 & \multirow{2}{*}{714} & & \\
\hline $6 / 3-B$ & $10 / 12 / 00$ & $24+435$ & 727 & & & \\
\hline
\end{tabular}


Table N-2 INDOT Flexural Strength-Shoulder Pavement with Fly Ash

\begin{tabular}{|c|c|c|c|c|c|c|}
\hline $\begin{array}{l}\text { Lot/Sublot- } \\
\text { Location }\end{array}$ & Date Cast & $\begin{array}{l}\text { Location } \\
\text { Sampled }\end{array}$ & $\begin{array}{l}\text { Strength, } \\
\text { psi }\end{array}$ & $\begin{array}{c}\text { Sublot } \\
\text { Average, } \\
\text { psi }\end{array}$ & $\begin{array}{c}\text { Lot } \\
\text { Average, } \\
\text { psi }\end{array}$ & $\begin{array}{c}\text { Lot } \\
\text { Standard } \\
\text { Deviation, } \\
\text { psi }\end{array}$ \\
\hline $1 / 1-\mathrm{A}$ & $07 / 10 / 00$ & $24+473$ & 708 & \multirow{2}{*}{693} & \multirow{6}{*}{659} & \multirow{6}{*}{33.07} \\
\hline 1/1-B & $07 / 10 / 00$ & $24+473$ & 677 & & & \\
\hline $1 / 2-\mathrm{A}$ & $07 / 12 / 00$ & $23+913$ & 638 & \multirow{2}{*}{639} & & \\
\hline $1 / 2-\mathrm{B}$ & $07 / 12 / 00$ & $23+913$ & 640 & & & \\
\hline $1 / 3-\mathrm{A}$ & $07 / 24 / 00$ & $24+150$ & 645 & \multirow{2}{*}{645} & & \\
\hline $1 / 3-B$ & $07 / 24 / 00$ & $24+150$ & 645 & & & \\
\hline $2 / 1-\mathrm{A}$ & $07 / 24 / 00$ & $23+116$ & 715 & \multirow{2}{*}{740} & \multirow{6}{*}{697} & \multirow{6}{*}{47.16} \\
\hline $2 / 1-\mathrm{B}$ & $07 / 24 / 00$ & $23+116$ & 765 & & & \\
\hline $2 / 2-\mathrm{A}$ & $07 / 25 / 00$ & $22+910$ & 700 & \multirow{2}{*}{695} & & \\
\hline $2 / 2-B$ & $07 / 25 / 00$ & $22+910$ & 690 & & & \\
\hline $2 / 3-A$ & $10 / 14 / 00$ & $22+780$ & 649 & \multirow{2}{*}{657} & & \\
\hline $2 / 3-\mathrm{B}$ & $10 / 14 / 00$ & $22+780$ & 664 & & & \\
\hline
\end{tabular}

Table N- 3 INDOT Flexural Strength-Mainline Pavement without Fly Ash

\begin{tabular}{|c|c|c|c|c|c|}
\hline Date Cast & $\begin{array}{l}\text { Location } \\
\text { Sampled }\end{array}$ & Strength, psi & $\begin{array}{c}\text { Sublot } \\
\text { Average, psi }\end{array}$ & $\begin{array}{c}\text { Lot Average, } \\
\text { psi }\end{array}$ & $\begin{array}{l}\text { Lot Standard } \\
\text { Deviation, psi }\end{array}$ \\
\hline $10 / 19 / 00$ & $23+975$ & 653 & \multirow{2}{*}{674} & \multirow{6}{*}{698} & \multirow{6}{*}{32.02} \\
\hline $10 / 19 / 00$ & $23+975$ & 694 & & & \\
\hline $10 / 19 / 00$ & $23+500$ & 691 & \multirow{2}{*}{691} & & \\
\hline $10 / 19 / 00$ & $23+500$ & 691 & & & \\
\hline $10 / 20 / 00$ & $23+100$ & 701 & \multirow{2}{*}{729} & & \\
\hline $10 / 20 / 00$ & $23+100$ & 757 & & & \\
\hline $10 / 23 / 00$ & $22+690$ & 741 & \multirow{2}{*}{727} & \multirow{2}{*}{727} & \multirow{2}{*}{$\sim$} \\
\hline $10 / 23 / 00$ & $22+690$ & 712 & & & \\
\hline
\end{tabular}


Table N- 4 INDOT Flexural Strength-Shoulder Pavement without Fly Ash

\begin{tabular}{|c|c|c|c|c|c|c|}
\hline $\begin{array}{c}\text { Lot/Sublot- } \\
\text { Location }\end{array}$ & Date Cast & $\begin{array}{l}\text { Location } \\
\text { Sampled }\end{array}$ & $\begin{array}{l}\text { Strength, } \\
\text { psi }\end{array}$ & $\begin{array}{c}\text { Sublot } \\
\text { Average, } \\
\text { psi }\end{array}$ & $\begin{array}{c}\text { Lot } \\
\text { Average, } \\
\text { psi }\end{array}$ & $\begin{array}{c}\text { Lot } \\
\text { Standard } \\
\text { Deviation, } \\
\text { psi }\end{array}$ \\
\hline $1 / 1-\mathrm{A}$ & $10 / 16 / 00$ & $23+190$ & 658 & \multirow{2}{*}{652} & \multirow{6}{*}{687} & \multirow{6}{*}{40.96} \\
\hline $1 / 1-\mathrm{B}$ & $10 / 16 / 00$ & $23+190$ & 646 & & & \\
\hline $1 / 2-A$ & $10 / 17 / 00$ & $23+840$ & 685 & \multirow{2}{*}{685} & & \\
\hline $1 / 2-B$ & $10 / 17 / 00$ & $23+840$ & 685 & & & \\
\hline $1 / 3-\mathrm{A}$ & $10 / 18 / 00$ & $24+475$ & 726 & \multirow{2}{*}{725} & & \\
\hline $1 / 3-B$ & $10 / 18 / 00$ & $24+475$ & 723 & & & \\
\hline $2 / 1-\mathrm{A}$ & $10 / 20 / 00$ & $22+920$ & 668 & \multirow{2}{*}{696} & \multirow{4}{*}{712} & \multirow{4}{*}{29.69} \\
\hline $2 / 1-B$ & $10 / 20 / 00$ & $22+920$ & 723 & & & \\
\hline $2 / 2-\mathrm{A}$ & $10 / 27 / 00$ & $24+785$ & 683 & \multirow{2}{*}{729} & & \\
\hline $2 / 2-B$ & $10 / 27 / 00$ & $24+785$ & 775 & & & \\
\hline
\end{tabular}


APPENDIX O FIELD TEST PROGRAM P-WAVE VELOCITY RESULTS 
Table O-1 Beam P-Wave Velocity Results

\begin{tabular}{|c|c|c|c|c|c|c|}
\hline \multirow{3}{*}{$\begin{array}{l}\text { Lot/ Sublot } \\
\text { Location }\end{array}$} & \multirow{3}{*}{ Cast By } & \multirow{3}{*}{$\begin{array}{l}\text { Age, } \\
\text { Days }\end{array}$} & \multicolumn{2}{|c|}{ P-wave Velocity, m/s by: } & \multirow{2}{*}{\multicolumn{2}{|c|}{ Modulus of Rupture }} \\
\hline & & & \multirow{2}{*}{$\begin{array}{c}\text { Direct } \\
\text { Transmission } \\
\text { Pulse Velocity }\end{array}$} & \multirow{2}{*}{$\begin{array}{c}\text { Surface Using } \\
\text { AE } \\
\text { Equipment }\end{array}$} & & \\
\hline & & & & & psi & MPa \\
\hline $1 / 3-\mathrm{A}$ & Purdue & 7 & 4370 & 4230 & & \\
\hline $1 / 3-A$ & INDOT & 7 & & & 664 & 4.58 \\
\hline $1 / 3-B$ & INDOT & 7 & & & 660 & 4.55 \\
\hline $1 / 3-A$ & Contractor & 7 & & & 613 & 4.23 \\
\hline $1 / 3-B$ & Contractor & 7 & & & 691 & 4.76 \\
\hline $2 / 1-\mathrm{A}$ & Purdue & 7 & 4350 & 4390 & & \\
\hline $2 / 1-B$ & Purdue & 7 & 4350 & & & \\
\hline $2 / 1-\mathrm{A}$ & INDOT & 7 & & & 594 & 4.10 \\
\hline $2 / 1-B$ & INDOT & 7 & & & 639 & 4.41 \\
\hline $2 / 1-\mathrm{A}$ & Contractor & 7 & & & 648 & 4.47 \\
\hline 2/1-B & Contractor & 7 & & & 644 & 4.44 \\
\hline $2 / 2-\mathrm{A}$ & Purdue & 7 & 4390 & 4440 & & \\
\hline $2 / 2-\mathrm{B}$ & Purdue & 7 & 4380 & & & \\
\hline $2 / 2-\mathrm{A}$ & INDOT & 7 & & & 681 & 4.70 \\
\hline $2 / 2-B$ & INDOT & 7 & & & 657 & 4.53 \\
\hline $2 / 2-\mathrm{A}$ & Contractor & 7 & & & 666 & 4.59 \\
\hline $2 / 2-\mathrm{B}$ & Contractor & 7 & & & 596 & 4.11 \\
\hline $2 / 3-A$ & Purdue & 7 & 4430 & 4050 & & \\
\hline $2 / 3-B$ & Purdue & 7 & 4450 & & & \\
\hline $2 / 3-A$ & INDOT & 7 & & & 650 & 4.48 \\
\hline $2 / 3-\mathrm{B}$ & INDOT & 7 & & & 668 & 4.61 \\
\hline $2 / 3-A$ & Contractor & 7 & & & 639 & 4.41 \\
\hline 2/3-B & Contractor & 7 & & & 641 & 4.42 \\
\hline $1 / 3-A$ & Purdue & 28 & 4520 & 4410 & 752 & 5.18 \\
\hline $1 / 3-\mathrm{B}$ & Purdue & 28 & 4650 & & 679 & 4.68 \\
\hline $2 / 1-A$ & Purdue & 28 & 4530 & 4430 & 736 & 5.08 \\
\hline 2/1-B & Purdue & 28 & 4590 & & 768 & 5.30 \\
\hline $2 / 2-A$ & Purdue & 28 & 4610 & 4490 & 786 & 5.42 \\
\hline $2 / 2-\mathrm{B}$ & Purdue & 28 & 4630 & & 749 & 5.16 \\
\hline $2 / 3-A$ & Purdue & 28 & 4640 & 4540 & 718 & 4.95 \\
\hline $2 / 3-B$ & Purdue & 28 & 4650 & & 735 & 5.07 \\
\hline
\end{tabular}


Table O-2 Pavement P-Wave Velocity Results

\begin{tabular}{|c|c|c|c|c|c|c|c|c|c|}
\hline \multirow{2}{*}{$\begin{array}{c}\text { Lot/ } \\
\text { Sublot } \\
\text { Location }\end{array}$} & \multirow[b]{2}{*}{ Station } & \multicolumn{7}{|c|}{ P-Wave Velocity, m/s } & \multirow{2}{*}{$\begin{array}{c}\text { Standard } \\
\text { Deviation, } \\
\text { m/s }\end{array}$} \\
\hline & & Test 1 & Test 2 & Test 3 & Test 4 & Test 5 & Test 6 & Average & \\
\hline $2 / 1-\mathrm{A}$ & $23+930$ & 3840 & 3556 & 3840 & 3945 & 3945 & 4174 & 3883 & 201 \\
\hline $2 / 1-\mathrm{B}$ & $23+795$ & 3945 & 3646 & 4056 & 4299 & 3945 & 4056 & 3991 & 213 \\
\hline $2 / 2-\mathrm{A}$ & $23+695$ & 4056 & 3740 & 4056 & 4299 & 4174 & $\sim$ & 4065 & 208 \\
\hline $2 / 2-\mathrm{M}$ & $23+550$ & 3945 & 3840 & 4056 & 4056 & 3740 & $\sim$ & 3927 & 138 \\
\hline $2 / 2 \mathrm{~B}$ & $23+475$ & 4056 & 4431 & 3840 & 3740 & 4174 & $\sim$ & 4048 & 274 \\
\hline $2 / 3-\mathrm{M}$ & $23+330$ & 4056 & 4056 & 3945 & 3945 & 3840 & $\sim$ & 3968 & 91 \\
\hline $2 / 3 \mathrm{~A}$ & $23+290$ & 3945 & 3740 & 3840 & 3945 & $\sim$ & $\sim$ & 3868 & 98 \\
\hline $2 / 3 \mathrm{~B}$ & $23+200$ & 3945 & 3945 & 3945 & 4299 & $\sim$ & $\sim$ & 4034 & 177 \\
\hline $3 / 1-\mathrm{A}$ & $23+000$ & 3840 & 3740 & 3945 & 3840 & $\sim$ & $\sim$ & 3841 & 84 \\
\hline $3 / 1-B$ & $22+900$ & $\sim$ & 3945 & 3740 & 3740 & 3740 & $\sim$ & 3791 & 103 \\
\hline $3 / 2-A$ & $22+830$ & 3945 & 4174 & 4174 & 4174 & $\sim$ & $\sim$ & 4117 & 115 \\
\hline $3 / 2-B$ & $22+975$ & 3740 & 3840 & 3840 & 3840 & $\sim$ & $\sim$ & 3815 & 50 \\
\hline $3 / 3-A$ & $22+730$ & 4056 & 3945 & 3840 & 3840 & 3840 & $\sim$ & 3904 & 96 \\
\hline $3 / 3-B$ & $23+100$ & 3840 & 4056 & 3646 & 4299 & 4174 & 3740 & 3959 & 257 \\
\hline $4 / 1-\mathrm{A}$ & $23+415$ & 3840 & 4056 & 3945 & $\sim$ & 3840 & $\sim$ & 3920 & 103 \\
\hline $4 / 1-B$ & $23+675$ & $\sim$ & 4056 & 4174 & 4174 & $\sim$ & $\sim$ & 4135 & 68 \\
\hline $4 / 2-\mathrm{A}$ & $23+905$ & 3840 & 3840 & 3646 & 3945 & 3945 & $\sim$ & 3843 & 122 \\
\hline 4/2-B & $24+165$ & 3945 & 3840 & 4056 & 3945 & $\sim$ & $\sim$ & 3947 & 88 \\
\hline
\end{tabular}


APPENDIX P INDOT PAVEMENT THICKNESS RESULTS (PROJECT R-24432) 
The thickness values in italics indicates that the test result value was greater than the maximum quality limit (MQL) and was therefore set equal to the MQL as indicated in Section 11.2.

Table P-1 INDOT Thickness-Mainline Pavement with Fly Ash

\begin{tabular}{|c|c|c|c|c|c|c|}
\hline $\begin{array}{c}\text { Lot/Sublot- } \\
\text { Location }\end{array}$ & $\begin{array}{l}\text { Location } \\
\text { Sampled }\end{array}$ & $\begin{array}{c}\text { Thickness, } \\
\text { mm }\end{array}$ & $\begin{array}{c}\text { INDOT } \\
\text { Thickness, } \\
\text { in }\end{array}$ & $\begin{array}{c}\text { Sublot } \\
\text { Average, } \\
\text { in }\end{array}$ & $\begin{array}{c}\text { Lot } \\
\text { Average, } \\
\text { in }\end{array}$ & $\begin{array}{l}\text { Lot Standard } \\
\text { Deviation, in }\end{array}$ \\
\hline $1 / 1-\mathrm{A}$ & $24+742$ & 395 & 15.0 & \multirow{2}{*}{14.7} & \multirow{6}{*}{14.5} & \multirow{6}{*}{0.28} \\
\hline $1 / 1-B$ & $24+448$ & 361 & 14.4 & & & \\
\hline $1 / 2-A$ & $24+398$ & 358 & 14.3 & \multirow{2}{*}{14.4} & & \\
\hline $1 / 2-B$ & $24+613$ & 362 & 14.5 & & & \\
\hline $1 / 3-A$ & $24+160$ & 366 & 14.6 & \multirow{2}{*}{14.5} & & \\
\hline $1 / 3-B$ & $24+005$ & 358 & 14.3 & & & \\
\hline $2 / 1-\mathrm{A}$ & $23+950$ & 356 & 14.2 & \multirow{2}{*}{14.3} & \multirow{6}{*}{14.4} & \multirow{6}{*}{0.14} \\
\hline $2 / 1-B$ & $23+797$ & 357 & 14.3 & & & \\
\hline $2 / 2-A$ & $23+693$ & 364 & 14.6 & \multirow{2}{*}{14.5} & & \\
\hline $2 / 2-B$ & $23+675$ & 359 & 14.4 & & & \\
\hline $2 / 3-A$ & $23+290$ & 360 & 14.4 & \multirow{2}{*}{14.4} & & \\
\hline $2 / 3-B$ & $23+198$ & 357 & 14.3 & & & \\
\hline $3 / 1-\mathrm{A}$ & $23+000$ & 351 & 14.0 & \multirow{2}{*}{14.2} & \multirow{6}{*}{14.4} & \multirow{6}{*}{0.37} \\
\hline $3 / 1-B$ & $22+900$ & 357 & 14.3 & & & \\
\hline $3 / 2-A$ & $22+830$ & 389 & 15.0 & 148 & & \\
\hline $3 / 2-B$ & $22+656$ & 365 & 14.6 & 14.0 & & \\
\hline $3 / 3-A$ & $22+730$ & 363 & 14.5 & 14 & & \\
\hline $3 / 3-B$ & $22+100$ & 354 & 14.2 & 14.4 & & \\
\hline $4 / 1-A$ & $23+416$ & 369 & 14.8 & 145 & \multirow{6}{*}{14.5} & \multirow{6}{*}{0.27} \\
\hline 4/1-B & $23+675$ & 356 & 14.2 & $14 . J$ & & \\
\hline $4 / 2-A$ & $23+903$ & 360 & 14.4 & \multirow{2}{*}{14.4} & & \\
\hline $4 / 2-B$ & $24+165$ & 358 & 14.3 & & & \\
\hline $4 / 3-A$ & $22+675$ & 369 & 14.8 & \multirow{2}{*}{14.7} & & \\
\hline $4 / 3-B$ & $22+801$ & 365 & 14.6 & & & \\
\hline $5 / 1-\mathrm{A}$ & $22+945$ & 353 & 14.1 & \multirow{2}{*}{14.2} & \multirow{6}{*}{14.2} & \multirow{6}{*}{0.10} \\
\hline $5 / 1-B$ & $23+100$ & 357 & 14.3 & & & \\
\hline $5 / 2-\mathrm{A}$ & $23+290$ & 357 & 14.3 & \multirow{2}{*}{14.2} & & \\
\hline $5 / 2-\mathrm{B}$ & $23+400$ & 352 & 14.1 & & & \\
\hline $5 / 3-A$ & $23+545$ & 354 & 14.2 & \multirow{2}{*}{14.3} & & \\
\hline $5 / 3-\mathrm{B}$ & $23+660$ & 357 & 14.3 & & & \\
\hline $6 / 1-A$ & $23+800$ & 362 & 14.5 & \multirow{2}{*}{14.5} & \multirow{4}{*}{14.4} & \multirow{4}{*}{0.22} \\
\hline $6 / 1-B$ & $23+975$ & 360 & 14.4 & & & \\
\hline $6 / 2-A$ & $24+150$ & 356 & 14.2 & \multirow{2}{*}{14.4} & & \\
\hline $6 / 2-B$ & $24+300$ & 366 & 14.6 & & & \\
\hline
\end{tabular}




\begin{tabular}{|l|l|l|l|l|l|l|}
\hline $6 / 3-\mathrm{A}$ & $24+430$ & 364 & 14.6 & \multirow{2}{*}{14.4} & & \\
\cline { 1 - 4 } $6 / 3-\mathrm{B}$ & $24+731$ & 352 & 14.1 & & & \\
\hline $7 / 1-\mathrm{A}$ & $24+786$ & 368 & 14.7 & 14.7 & 14.7 & $\sim$ \\
\hline
\end{tabular}

Table P-2 INDOT Thickness-Shoulder Pavement with Fly Ash

\begin{tabular}{|c|c|c|c|c|c|c|}
\hline $\begin{array}{l}\text { Lot/Sublot- } \\
\text { Location }\end{array}$ & $\begin{array}{l}\text { Location } \\
\text { Sampled }\end{array}$ & $\begin{array}{c}\text { Thickness, } \\
\text { mm }\end{array}$ & $\begin{array}{c}\text { INDOT } \\
\text { Thickness, } \\
\text { in }\end{array}$ & $\begin{array}{c}\text { Sublot } \\
\text { Average, } \\
\text { in }\end{array}$ & $\begin{array}{c}\text { Lot } \\
\text { Average, } \\
\text { in }\end{array}$ & $\begin{array}{l}\text { Lot Standard } \\
\text { Deviation, in }\end{array}$ \\
\hline $1 / 1-\mathrm{A}$ & $24+650$ & 396 & 15.0 & \multirow{2}{*}{14.9} & \multirow{6}{*}{14.6} & \multirow{6}{*}{0.29} \\
\hline 1/1-B & $24+375$ & 370 & 14.8 & & & \\
\hline $1 / 2-\mathrm{A}$ & $24+005$ & 365 & 14.6 & \multirow{2}{*}{14.4} & & \\
\hline $1 / 2-\mathrm{B}$ & $23+650$ & 355 & 14.2 & & & \\
\hline $1 / 3-A$ & $23+300$ & 362 & 14.5 & \multirow{2}{*}{14.6} & & \\
\hline $1 / 3-\mathrm{B}$ & $23+263$ & 368 & 14.7 & & & \\
\hline $2 / 1-\mathrm{A}$ & $23+000$ & 361 & 14.4 & \multirow{2}{*}{14.6} & \multirow{6}{*}{14.3} & \multirow{6}{*}{0.57} \\
\hline $2 / 1-B$ & $23+996$ & 367 & 14.7 & & & \\
\hline $2 / 2-A$ & $22+850$ & 335 & 13.4 & \multirow{2}{*}{13.6} & & \\
\hline $2 / 2-B$ & $24+180$ & 344 & 13.8 & & & \\
\hline $2 / 3-A$ & $22+700$ & 366 & 14.6 & \multirow{2}{*}{14.7} & & \\
\hline $2 / 3-B$ & $22+945$ & 368 & 14.7 & & & \\
\hline
\end{tabular}

Table P-3 INDOT Thickness-Mainline Pavement without Fly Ash

\begin{tabular}{|c|c|c|c|c|c|c|}
\hline $\begin{array}{l}\text { Lot/Sublot- } \\
\text { Location }\end{array}$ & $\begin{array}{l}\text { Location } \\
\text { Sampled }\end{array}$ & $\begin{array}{c}\text { Thickness, } \\
\text { mm }\end{array}$ & $\begin{array}{c}\text { INDOT } \\
\text { Thickness, } \\
\text { in }\end{array}$ & $\begin{array}{c}\text { Sublot } \\
\text { Average, } \\
\text { in }\end{array}$ & $\begin{array}{c}\text { Lot } \\
\text { Average, } \\
\text { in }\end{array}$ & $\begin{array}{l}\text { Lot Standard } \\
\text { Deviation, in }\end{array}$ \\
\hline $1 / 1-\mathrm{A}$ & $24+431$ & 379 & 15.0 & \multirow{2}{*}{14.6} & \multirow{6}{*}{14.6} & \multirow{6}{*}{0.41} \\
\hline 1/1-B & $23+887$ & 355 & 14.2 & & & \\
\hline $1 / 2-\mathrm{A}$ & $23+660$ & 365 & 14.6 & \multirow{2}{*}{14.5} & & \\
\hline $1 / 2-B$ & $23+245$ & 361 & 14.4 & & & \\
\hline $1 / 3-A$ & $22+891$ & 376 & 15.0 & \multirow{2}{*}{14.6} & & \\
\hline $1 / 3-\mathrm{B}$ & $24+375$ & 353 & 14.1 & & & \\
\hline $2 / 1-A$ & $24+743$ & 355 & 14.2 & \multirow{2}{*}{14.3} & \multirow{2}{*}{14.3} & \multirow{2}{*}{0.18} \\
\hline 2/1-B & $24+282$ & 360 & 14.4 & & & \\
\hline
\end{tabular}


Table P-4 INDOT Thickness-Shoulder Pavement without Fly Ash

\begin{tabular}{|c|c|c|c|c|c|c|}
\hline $\begin{array}{c}\text { Lot/Sublot- } \\
\text { Location }\end{array}$ & $\begin{array}{l}\text { Location } \\
\text { Sampled }\end{array}$ & $\begin{array}{c}\text { Thickness, } \\
\text { mm }\end{array}$ & $\begin{array}{c}\text { INDOT } \\
\text { Thickness, } \\
\text { in }\end{array}$ & $\begin{array}{c}\text { Sublot } \\
\text { Average, } \\
\text { in }\end{array}$ & $\begin{array}{c}\text { Lot } \\
\text { Average, } \\
\text { in }\end{array}$ & $\begin{array}{l}\text { Lot Standard } \\
\text { Deviation, in }\end{array}$ \\
\hline $1 / 1-\mathrm{A}$ & $23+230$ & 364 & 14.6 & \multirow{2}{*}{14.4} & \multirow{6}{*}{14.5} & \multirow{6}{*}{0.28} \\
\hline $1 / 1-B$ & $23+600$ & 355 & 14.2 & & & \\
\hline $1 / 2-\mathrm{A}$ & $23+860$ & 362 & 14.5 & \multirow{2}{*}{14.5} & & \\
\hline $1 / 2-B$ & $24+115$ & 361 & 14.4 & & & \\
\hline $1 / 3-A$ & $24+360$ & 363 & 14.5 & \multirow{2}{*}{14.8} & & \\
\hline $1 / 3-B$ & $24+694$ & 421 & 15.0 & & & \\
\hline $2 / 1-\mathrm{A}$ & $23+763$ & 337 & 13.5 & \multirow{2}{*}{14.1} & \multirow{3}{*}{14.4} & \multirow{3}{*}{0.88} \\
\hline $2 / 1-B$ & $23+000$ & 364 & 14.6 & & & \\
\hline $2 / 2-\mathrm{A}$ & $22+747$ & 377 & 15.0 & 15.0 & & \\
\hline
\end{tabular}


APPENDIX Q FIELD TEST PROGRAM IMPACT-ECHO RESULTS 
Table Q-1 Impact-Echo Frequency Results

\begin{tabular}{|c|c|c|c|c|c|c|c|c|}
\hline \multirow{2}{*}{$\begin{array}{c}\text { Lot/ Sublot } \\
\text { Location }\end{array}$} & \multirow{2}{*}{ Station } & Test 1 & Test 2 & Test 3 & Test 4 & Test 5 & Test 6 & Average \\
\cline { 3 - 9 } & & & & & & & & \\
\hline 2/1-A & $23+930$ & 5.53 & 5.53 & 5.53 & $\sim$ & $\sim$ & $\sim$ & 5.53 \\
\hline $2 / 1-\mathrm{B}$ & $23+795$ & 5.53 & 5.53 & 5.53 & $\sim$ & $\sim$ & $\sim$ & 5.53 \\
\hline $2 / 2-\mathrm{A}$ & $23+695$ & 5.37 & 5.37 & 5.37 & $\sim$ & $\sim$ & $\sim$ & 5.37 \\
\hline $2 / 2-\mathrm{B}$ & $23+475$ & 5.37 & 5.37 & 5.37 & 5.53 & 5.53 & 5.37 & 5.42 \\
\hline $2 / 3-\mathrm{A}$ & $23+290$ & 5.37 & 5.37 & 5.37 & 5.37 & $\sim$ & $\sim$ & 5.37 \\
\hline $2 / 3-\mathrm{B}$ & $23+200$ & 5.53 & 5.70 & 5.70 & 5.53 & 5.70 & $\sim$ & 5.63 \\
\hline $3 / 1-\mathrm{A}$ & $23+000$ & 5.53 & 5.53 & 5.37 & 5.37 & $\sim$ & $\sim$ & 5.45 \\
\hline $3 / 1-\mathrm{B}$ & $22+900$ & 5.21 & 5.21 & 5.21 & $\sim$ & $\sim$ & $\sim$ & 5.21 \\
\hline $3 / 2-\mathrm{A}$ & $22+830$ & 5.05 & 5.05 & 5.05 & 5.05 & 5.05 & $\sim$ & 5.05 \\
\hline $3 / 2-\mathrm{B}$ & $22+975$ & 5.37 & 5.53 & 5.53 & 5.53 & 5.53 & $\sim$ & 5.50 \\
\hline $3 / 3-\mathrm{A}$ & $22+730$ & 5.21 & 5.37 & 5.37 & 5.37 & $\sim$ & $\sim$ & 5.33 \\
\hline $3 / 3-\mathrm{B}$ & $23+100$ & 5.70 & 5.70 & 5.70 & $\sim$ & $\sim$ & $\sim$ & 5.70 \\
\hline $4 / 1-\mathrm{A}$ & $23+415$ & 5.37 & 5.37 & 5.37 & $\sim$ & $\sim$ & $\sim$ & 5.37 \\
\hline $4 / 1-\mathrm{B}$ & $23+675$ & 5.37 & 5.37 & 5.37 & 5.37 & $\sim$ & $\sim$ & 5.37 \\
\hline $4 / 2-\mathrm{A}$ & $23+905$ & 5.53 & 5.53 & 5.37 & 5.53 & $\sim$ & $\sim$ & 5.49 \\
\hline $4 / 2-\mathrm{B}$ & $24+165$ & 5.37 & 5.37 & 5.37 & $\sim$ & $\sim$ & $\sim$ & 5.37 \\
\hline
\end{tabular}


APPENDIX R POST-CONSTRUCTION TEST RESULTS 
Table R-1 Mixture Variation Test Results

\begin{tabular}{|c|c|c|c|c|c|c|c|}
\hline Mixture & ID & $\begin{array}{l}\text { Test Age, } \\
\text { Days }\end{array}$ & $\begin{array}{l}\text { Test } \\
\text { Time }\end{array}$ & $\begin{array}{c}\text { Test Age, } \\
\text { hours }\end{array}$ & $\begin{array}{c}\text { Pulse } \\
\text { Velocity, } \\
\text { m/s }\end{array}$ & $\begin{array}{l}\text { Temperature- } \\
\text { Time Factor, } \\
\text { C-hr }\end{array}$ & $\begin{array}{l}\text { Modulus of } \\
\text { Rupture, psi }\end{array}$ \\
\hline \multirow{6}{*}{ A } & $1 \mathrm{~A}$ & 3 & $14: 30$ & 76 & 4651 & $\sim$ & $\sim$ \\
\hline & $1 \mathrm{~B}$ & 3 & $14: 30$ & 76 & 4684 & $\sim$ & $\sim$ \\
\hline & $1 \mathrm{~A}$ & 7 & $16: 00$ & 174 & 4814 & $\sim$ & $\sim$ \\
\hline & $1 \mathrm{~B}$ & 7 & $16: 00$ & 174 & 4846 & $\sim$ & $\sim$ \\
\hline & $1 \mathrm{~A}$ & 28 & $10: 30$ & 669 & 4901 & 19518 & 906 \\
\hline & $1 \mathrm{~B}$ & 28 & $10: 30$ & 669 & 4960 & 19518 & 941 \\
\hline \multirow{6}{*}{ B } & $2 \mathrm{~A}$ & 3 & $14: 30$ & 75 & 4628 & $\sim$ & $\sim$ \\
\hline & $3 \mathrm{~A}$ & 3 & $14: 30$ & 74 & 4615 & $\sim$ & $\sim$ \\
\hline & $3 \mathrm{~A}$ & 7 & $13: 30$ & 169 & 4736 & 5314 & 927 \\
\hline & $3 \mathrm{~B}$ & 7 & $13: 30$ & 169 & 4730 & 5314 & 757 \\
\hline & $2 \mathrm{~A}$ & 28 & $11: 00$ & 668 & 4855 & 20062 & 891 \\
\hline & $2 \mathrm{~B}$ & 28 & 11:00 & 668 & 4871 & 20062 & 895 \\
\hline \multirow{17}{*}{$\mathrm{C}$} & $4 \mathrm{~A}$ & 1 & 13:00 & 23 & 4288 & 854 & 487 \\
\hline & $4 \mathrm{~B}$ & 1 & 13:00 & 23 & 4289 & 854 & 502 \\
\hline & $17 \mathrm{~A}$ & 1.5 & $10: 00$ & 41 & 4427 & 1379 & 659 \\
\hline & $17 \mathrm{~B}$ & 1.5 & $9: 30$ & 41 & 4460 & $\sim$ & $\sim$ \\
\hline & $17 \mathrm{C}$ & 1.5 & $9: 30$ & 41 & 4433 & $\sim$ & $\sim$ \\
\hline & $5 \mathrm{~A}$ & 3 & $16: 30$ & 73 & 4526 & 2371 & 756 \\
\hline & $5 \mathrm{~B}$ & 3 & $16: 30$ & 73 & 4468 & 2371 & 726 \\
\hline & 17B & 7 & $16: 00$ & 167 & 4740 & 5107 & 862 \\
\hline & $17 \mathrm{C}$ & 7 & $16: 00$ & 167 & 4725 & 5107 & 773 \\
\hline & $20 \mathrm{~A}$ & 7 & 19:30 & 167 & 4636 & 5107 & 772 \\
\hline & $20 \mathrm{~B}$ & 7 & 19:30 & 167 & 4614 & 5107 & 724 \\
\hline & $6 \mathrm{~A}$ & 14 & $16: 30$ & 333 & 4633 & 10181 & 801 \\
\hline & $6 \mathrm{~B}$ & 14 & $16: 30$ & 333 & 4630 & 10181 & 784 \\
\hline & $7 \mathrm{~A}$ & 28 & 11:00 & 665 & 4802 & 19871 & 807 \\
\hline & $7 \mathrm{~B}$ & 28 & $11: 00$ & 665 & 4778 & 19871 & 819 \\
\hline & $6 \mathrm{C}$ & 57 & $17: 00$ & 1362 & 4820 & 39537 & 920 \\
\hline & $7 \mathrm{C}$ & 57 & $17: 00$ & 1364 & 4899 & 40622 & 934 \\
\hline \multirow{8}{*}{$\mathrm{F}$} & $12 \mathrm{~A}$ & 3 & $11: 30$ & 72 & 4507 & $\sim$ & $\sim$ \\
\hline & $13 \mathrm{~A}$ & 3 & $11: 30$ & 72 & 4421 & $\sim$ & $\sim$ \\
\hline & $15 \mathrm{~A}$ & 3 & $16: 30$ & 71 & 4524 & $\sim$ & $\sim$ \\
\hline & $15 \mathrm{~B}$ & 3 & $16: 30$ & 71 & 4557 & $\sim$ & $\sim$ \\
\hline & $13 \mathrm{~A}$ & 7 & $12: 00$ & 166 & 4563 & 5133 & 779 \\
\hline & 13B & 7 & $12: 00$ & 166 & 4530 & 5133 & 779 \\
\hline & $15 \mathrm{~A}$ & 28 & $17: 00$ & 671 & 4775 & 19968 & 828 \\
\hline & $15 \mathrm{~B}$ & 28 & $17: 00$ & 671 & 4807 & 19968 & 907 \\
\hline \multirow{3}{*}{ D } & $8 \mathrm{~A}$ & 3 & $10: 30$ & 72 & 4442 & $\sim$ & $\sim$ \\
\hline & $9 \mathrm{~A}$ & 3 & $10: 30$ & 72 & 4354 & $\sim$ & $\sim$ \\
\hline & $8 \mathrm{~A}$ & 7 & $10: 30$ & 168 & 4559 & 5264 & 814 \\
\hline
\end{tabular}




\begin{tabular}{|c|c|c|c|c|c|c|c|}
\hline \multirow{5}{*}{} & $8 \mathrm{~B}$ & 7 & $10: 30$ & 168 & 4547 & 5264 & 697 \\
\cline { 2 - 8 } & $9 \mathrm{~A}$ & 28 & $10: 30$ & 668 & 4663 & 20027 & 800 \\
\cline { 2 - 8 } & $9 \mathrm{~B}$ & 28 & $10: 30$ & 668 & 4696 & 20027 & 749 \\
\hline \multirow{5}{*}{$\mathrm{E}$} & $10 \mathrm{~A}$ & 3 & $10: 30$ & 71 & 4338 & $\sim$ & $\sim$ \\
\cline { 2 - 8 } & $16 \mathrm{~A}$ & 3 & $16: 30$ & 70 & 4382 & $\sim$ & $\sim$ \\
\cline { 2 - 8 } & $16 \mathrm{~B}$ & 3 & $16: 30$ & 70 & 4413 & $\sim$ & $\sim$ \\
\cline { 2 - 8 } & $10 \mathrm{~A}$ & 7 & $11: 00$ & 167 & 4490 & 5208 & 726 \\
\cline { 2 - 8 } & $10 \mathrm{~B}$ & 7 & $11: 00$ & 167 & 4466 & 5208 & 731 \\
\cline { 2 - 8 } & $16 \mathrm{~A}$ & 28 & $17: 00$ & 670 & 4688 & 18175 & 831 \\
\cline { 2 - 8 } & $16 \mathrm{~B}$ & 28 & $17: 00$ & 670 & 4714 & 18175 & 830 \\
\hline \multirow{6}{*}{$\mathrm{G}$} & $18 \mathrm{~A}$ & 3 & $16: 00$ & 70 & 4248 & $\sim$ & $\sim$ \\
\cline { 2 - 8 } & $18 \mathrm{~B}$ & 3 & $16: 00$ & 70 & 4215 & $\sim$ & 734 \\
\cline { 2 - 8 } & $18 \mathrm{~A}$ & 7 & $16: 30$ & 166 & 4387 & 5086 & 676 \\
\cline { 2 - 8 } & $18 \mathrm{~B}$ & 7 & $16: 30$ & 166 & 4403 & 5086 & $\sim$ \\
\hline
\end{tabular}


APPENDIX S FIELD TEST PROGRAM IMPACT-ECHO RESULTS 
Table Q-2 Impact-Echo Frequency Results

\begin{tabular}{|c|c|c|c|c|c|c|c|c|}
\hline \multirow{2}{*}{$\begin{array}{c}\text { Lot/ Sublot } \\
\text { Location }\end{array}$} & \multirow{2}{*}{ Station } & Test 1 & Test 2 & Test 3 & Test 4 & Test 5 & Test 6 & Average \\
\cline { 3 - 10 } & & & & & & & & \\
\hline 2/1-A & $23+930$ & 5.53 & 5.53 & 5.53 & $\sim$ & $\sim$ & $\sim$ & 5.53 \\
\hline $2 / 1-\mathrm{B}$ & $23+795$ & 5.53 & 5.53 & 5.53 & $\sim$ & $\sim$ & $\sim$ & 5.53 \\
\hline 2/2-A & $23+695$ & 5.37 & 5.37 & 5.37 & $\sim$ & $\sim$ & $\sim$ & 5.37 \\
\hline $2 / 2-\mathrm{B}$ & $23+475$ & 5.37 & 5.37 & 5.37 & 5.53 & 5.53 & 5.37 & 5.42 \\
\hline $2 / 3-\mathrm{A}$ & $23+290$ & 5.37 & 5.37 & 5.37 & 5.37 & $\sim$ & $\sim$ & 5.37 \\
\hline $2 / 3-\mathrm{B}$ & $23+200$ & 5.53 & 5.70 & 5.70 & 5.53 & 5.70 & $\sim$ & 5.63 \\
\hline $3 / 1-\mathrm{A}$ & $23+000$ & 5.53 & 5.53 & 5.37 & 5.37 & $\sim$ & $\sim$ & 5.45 \\
\hline $3 / 1-\mathrm{B}$ & $22+900$ & 5.21 & 5.21 & 5.21 & $\sim$ & $\sim$ & $\sim$ & 5.21 \\
\hline $3 / 2-\mathrm{A}$ & $22+830$ & 5.05 & 5.05 & 5.05 & 5.05 & 5.05 & $\sim$ & 5.05 \\
\hline $3 / 2-\mathrm{B}$ & $22+975$ & 5.37 & 5.53 & 5.53 & 5.53 & 5.53 & $\sim$ & 5.50 \\
\hline $3 / 3-\mathrm{A}$ & $22+730$ & 5.21 & 5.37 & 5.37 & 5.37 & $\sim$ & $\sim$ & 5.33 \\
\hline $3 / 3-\mathrm{B}$ & $23+100$ & 5.70 & 5.70 & 5.70 & $\sim$ & $\sim$ & $\sim$ & 5.70 \\
\hline $4 / 1-\mathrm{A}$ & $23+415$ & 5.37 & 5.37 & 5.37 & $\sim$ & $\sim$ & $\sim$ & 5.37 \\
\hline $4 / 1-\mathrm{B}$ & $23+675$ & 5.37 & 5.37 & 5.37 & 5.37 & $\sim$ & $\sim$ & 5.37 \\
\hline $4 / 2-\mathrm{A}$ & $23+905$ & 5.53 & 5.53 & 5.37 & 5.53 & $\sim$ & $\sim$ & 5.49 \\
\hline $4 / 2-\mathrm{B}$ & $24+165$ & 5.37 & 5.37 & 5.37 & $\sim$ & $\sim$ & $\sim$ & 5.37 \\
\hline
\end{tabular}


APPENDIX T CONTRACT FROM PRS PROJECT \#1 - INDIANAPOLIS, IN (PROJECT R-24432) 


\section{SECTION 501 -- QUALITY CONTROL/QUALITY ASSURANCE, QC/QA, FOR PORTLAND CEMENT CONCRETE PAVEMENT, PCCP, INCORPORATING PERFORMANCE RELATED SPECIFICATION PAY FACTORS}

501.01 Description. This document consists of a Performance-Related Specification, PRS, and QC/QA procedures for acceptance and payment on portland cement concrete pavement, PCCP, placed on a prepared subgrade or subbase in accordance with 105.03.

The pavement is divided into one or more lots for acceptance and payment adjustment purposes. Each defined lot will be accepted independently based on Acceptance Quality Characteristics, AQC's, using sampling and testing procedures conducted on that section of pavement. Acceptance of as-constructed pavement lots will be based on the following AQC's: concrete flexural strength, pavement thickness, and air content. Initial smoothness acceptance will be based on 0.1 mile $(0.16 \mathrm{~km})$ increments. The Contractor shall receive no price adjustments for a lot if the estimated quality of construction exactly equals the target as-designed pavement parameters as described in Appendix II. If the estimated quality of construction for a lot exceeds or is below the target as-designed pavement parameters, the Contractor shall receive a pay adjustment for the lot (incentive or disincentive) provided the minimum level of quality is provided. The amount of the pay adjustment is determined based on a comparison of the initial bid price and the estimated post-construction Life Cycle Cost, LCC, determined independently for both the as-designed and as-constructed pavements. All calculations for the LCC-based pay adjustments shall be performed using the pay factor adjustment as described in 501.31.

Appendix I provides a brief description of the acronyms and terms used in performance related specifications.

501.02 Quality Control. The mixture for PCCP shall be produced by an approved plant in accordance with ITM 405, transported, and placed according to a Quality Control Plan, QCP, prepared and submitted by the Contractor in accordance with ITM 803, for PCCP. The QCP shall be submitted to the Engineer at least 15 days prior to commencing PCCP paving operations.

An American Concrete Institute certified concrete field-testing technician, grade 1, shall be on site to direct all sampling and testing.

A common testing facility shall be provided for both production control and acceptance testing.

It should be noted that the Contractor is encouraged to use the HIPERPAV computer program to aide in determining if/when early-age cracking may occur and is encouraged to report their findings. For further information on the HIPERPAV package the Contractor can contact Transtec at 512-451-6233 or Ted Ferragut at 703-836-1671. 


\section{MATERIALS}

501.03 Materials. Materials shall be in accordance with the following:

Admixtures 912.03

Coarse Aggregate, Class AP, Size No. 8* ..................................904.02

Fine Aggregate, Size No. 23* 904.01

Fly Ash $\quad 901.02$

Ground Granulated Blast Furnace Slag .901 .03

Portland Cement 901.01(b)

Water.

* Or gradation as identified in the QCP

501.04 Concrete Mix Design. A concrete mix design, CMD, shall be in accordance with 501.05 and shall be verified by a trial batch in accordance with 501.06. The CMD shall be submitted in a format acceptable to the Engineer and include the following:

(a) a list of all ingredients

(b) the source of all materials

(c) the gradation of the aggregates

(d) the absorption of the aggregates

(e) the SSD bulk specific gravity of the aggregates

(f) the specific gravity of pozzolan

(g) the batch mass (weights)

(h) the names of all admixtures

(i) the admixture dosage rates and the manufacturer's recommended range

A change to any source of material requires a new CMD.

A CMD, in accordance with 502.03, may be used at gaps for public road approaches, driveways, or other permitted breaks. Concrete from commercial plants shall be produced in accordance with 502.05 .

501.05 Concrete Mix Criteria. The CMD shall produce workable concrete mixtures having the following properties:

Minimum portland cement content................... $260 \mathrm{~kg} / \mathrm{m}^{3}\left(440 \mathrm{lbs} / \mathrm{yd}^{3}\right)$

Maximum water/cementitious ratio.................... 0.450

Minimum portland cement/fly ash ratio................ 3.2 by mass (weight)

Minimum portland cement/GGBFS ratio.............. 2.3 by mass (weight) 
Target air content range............................... $6.5 \%$

Minimum flexural strength.......................... $3800 \mathrm{kPa}(550 \mathrm{psi})$ at 7 days

For the purposes of PRS simulations, the Rejectable Quality Limit (RQL) will be defined as a flexural strength of $3800 \mathrm{kPa}(550 \mathrm{psi})$ at 7 days as determined using third point loading. Detailed information is provided in Appendix II, section II-6, to determine how the equivalent 28 -day flexural strength is determined.

The Contractor may elect to use fine and coarse aggregates in accordance with 904.01(g) and 904.02(e), or may propose the use of alternate gradations. If alternate gradations are proposed, the QCP shall specify the tolerances of material passing each sieve. In either case, $100 \%$ of the coarse aggregate shall pass the $25 \mathrm{~mm}$ (1 in.) sieve. The combined amount of fine and coarse aggregates passing the $75 \mu \mathrm{m}$ (No. 200) sieve shall be from $0 \%$ to $2.0 \%$ for sand and gravel, and from $0 \%$ to $2.5 \%$ for sand and crushed stone or crushed slag.

The fine aggregate shall be at least $35 \%$ but not more than $50 \%$ of the total mass (weight) of the aggregate in each cubic meter (cubic yard). Proportions will be based upon Saturated Surface Dry, SSD, aggregates.

Absorption tests shall be performed on the fine aggregate in accordance with AASHTO T 84 and on the coarse aggregate in accordance with AASHTO T 85 and 904.03(f). Absorption test results for a particular size of aggregate that differ by more than 1.0 percentage point from the Department's source value shall be investigated. The Contractor shall report any differences that exceed $1.0 \%$ to the Department. The Contractor's results shall be used when calculating the water/cementitious ratio.

Fly ash or GGBFS used as an additive, or cements type IP, type IS, type IP-A, and type IS-A, may only be incorporated in the concrete mix between April 1 and October 15 of the same calendar year. If type IP, type IP-A, type IS or type IS-A cements are to be used, the minimum portland cement content shall be increased to $300 \mathrm{~kg} / \mathrm{m}^{3}\left(500 \mathrm{lbs} / \mathrm{yd}^{3}\right)$ and the use of fly ash or GGBFS as an additive will not be permitted.

Water reducing admixture type $\mathrm{A}$, or water reducing and retarding admixture type $\mathrm{D}$, may be used in PCCP. However, admixture type A shall not be used in conjunction with admixture type D.

501.06 Trial Batch Demonstration. A trial batch shall be produced and tested by the Contractor's certified technician to verify that the CMD meets the concrete mix criteria. The concrete shall be batched within the proportioning tolerances of 507.02(b). The Engineer will test the trial batch and provide the Contractor with the results. The trial batch shall be of sufficient quantity to allow the Contractor and the Engineer to perform all required tests from the same batch. Trial batch concrete shall not be used for 
more than one test, except the concrete used for the unit mass (weight) may be used to conduct the air content test.

The target unit mass (weight) and water/cementitious ratio of the plastic concrete shall be determined by the trial batch. The flexural strength shall be determined by averaging a minimum of two beam breaks.

Test results shall be added to the CMD and submitted to the Engineer. Test results of trial batches from previous contracts may be substituted in-lieu of a demonstration.

501.07 Lots and Sublots. Lots will be defined as $6000 \mathrm{~m}^{2}\left(7,200 \mathrm{yd}^{2}\right)$ of PCCP. Lots will be further subdivided into sublots of $2000 \mathrm{~m}^{2}\left(2,400 \mathrm{yd}^{2}\right)$ of PCCP within a lot. Partial sublots of $400 \mathrm{~m}^{2}\left(480 \mathrm{yd}^{2}\right)$ or less will be added to the previous sublot. Partial sublots greater than $400 \mathrm{~m}^{2}\left(480 \mathrm{yd}^{2}\right)$ constitute a full sublot. Partial lots of two sublots constitute a full lot. Partial lots of one sublot are to be added to the previous lot.

501.08 Acceptance. Acceptance of PCCP for flexural strength, air content, unit mass (weight), water/cementitious ratio, and thickness will be determined on the basis of tests performed or evaluated by the Engineer in accordance with 505. The Engineer will randomly select the location within each sublot for sampling in accordance with ITM 802. Smoothness of the PCCP will be determined in accordance with ITM 901.

The random sample(s) per sublot shall be of sufficient quantity to perform all of the required tests and obtained in accordance with AASHTO T 141. Concrete and necessary labor for sampling shall be furnished as required by the Engineer. The test results of the sublots for each lot will be averaged and shall be in accordance with 501.05 and 501.06, except the lot average for thickness shall be in accordance with 501.26. Test results are to be shared in a timely manner.

\begin{tabular}{|c|c|c|c|}
\hline $\begin{array}{c}\text { Test or } \\
\text { Determination }\end{array}$ & Frequency & Test Method & Precision \\
\hline $\begin{array}{c}\text { 7-Day Flexural } \\
\text { Strength }\end{array}$ & Two beams per sublot & AASHTO T 97 & $10 \mathrm{kPa}$ (1 psi) \\
\hline Air Content & One per sublot & AASHTO T 152 & 0.1 \\
\hline Unit Weight & One per sublot & AASHTO T 121 & 1 \\
\hline Smoothness & RWP of each lane & ITM 901 & 0.1 \\
\hline $\begin{array}{c}\text { Water/Cementitious } \\
\text { Ratio }\end{array}$ & Once per week & ITM 403 & 0.001 \\
\hline Thickness & Two per sublot & ITM 404 & 0.1 \\
\hline
\end{tabular}

Rounding will be in accordance with ASTM E 29 using the rounding method.

\section{CONSTRUCTION REQUIREMENTS}


501.09 General. Equipment for PCCP shall be in accordance with 507.

501.10 Preparation of Grade. The subgrade shall be shaped to the required grade and section, free from all ruts, corrugations, or other irregularities, and uniformly compacted and approved in accordance with 207.

501.11 Preparation of Subbase. Subbase, if required, shall be placed and shaped to the required grade and section in accordance with 304 .

501.12 Placement. Placement of PCCP shall be by the slip-formed or formed methods with equipment specified in 507.04. The subgrade or subbase shall be uniformly moist at the time of PCCP placement. Excessively dry subgrade or subbase shall be sprinkled with water. Dowel bars shall be coated with a bond breaking material and the coating shall be evident at the time of placement.

501.13 Process Control. The Engineer and Contractor will jointly review the operations to ensure compliance with the QCP. Continuous violations of compliance with the QCP will result in suspension of paving operations.

501.14 Concrete Mixing and Transportation. Concrete shall be mixed and delivered by one of the following:

(a) Central mixed concrete shall be completely mixed in a stationary mixer and transported in a truck agitator, truck mixer at agitating speed, or non-agitating equipment.

(b) Shrink mixed concrete shall be partially mixed in a stationary mixer and the mixing completed during transportation in a truck mixer.

(c) Transit mixed concrete shall be completely mixed in a truck mixer.

Discharge from non-agitating equipment shall be completed within 30 minutes of mixing the water, cement, and aggregates. Discharge from a truck agitator or a truck mixer shall be completed within 90 minutes of mixing the water, cement, and aggregates.

Concrete shall be uniformly mixed when delivered to the job site. The Engineer may conduct additional testing to verify uniformity of the mixture. Additional testing will consist of slump tests taken in accordance with AASHTO T 119 at approximately the $1 / 4$ and $3 / 4$ points of a load. If the slumps differ by more than $25 \mathrm{~mm}$ ( 1 in.) when the average slump is $75 \mathrm{~mm}$ ( $3 \mathrm{in}$.) or less, or by more than $50 \mathrm{~mm}(2 \mathrm{in}$.) when the average slump is greater than $75 \mathrm{~mm}$ ( $3 \mathrm{in}$.), paving operations may be suspended while the mixing process is jointly reviewed and problems resolved by the Engineer and the Contractor. 
Wash water shall not be used as a portion of the mixing water.

When concrete is delivered in transit mixers, additional water to increase the workability of a load may be added within 45 min of initial mixing per the QCP. Any addition of water shall be noted on the batch ticket and shall not occur as a continuing operation.

501.15 Weather Limitations. PCCP shall not be placed on frozen subgrade or subbase. PCCP shall be placed when the ambient temperature is $2^{\circ} \mathrm{C}\left(35^{\circ} \mathrm{F}\right)$ and above, unless procedures outlined in the QCP for lower temperatures are followed. Prior to attaining opening to traffic strengths in accordance with 501.23, sufficient means shall be taken to prevent the PCCP from freezing.

501.16 Placing Concrete. The batches shall be deposited so as to have a uniform mix and require as little re-handling as possible. The plastic concrete shall not be segregated during placement. Dowel bars and assemblies shall not be displaced during placement of concrete.

Concrete shall be thoroughly consolidated against the faces of all forms or adjacent concrete surfaces. Hand placed concrete shall be thoroughly consolidated with the use of a vibrator. Vibrators shall not operate in any one location so as to bring excessive mortar to the surface, and shall not come in contact with a dowel bar assembly, subgrade, subbase, or forms.

Concrete shall be placed around manholes or similar structures in accordance with 720 .

The Contractor shall be responsible for the protection of the existing joints from the intrusion of fresh concrete mortar, and for any damage to existing pavement caused by the operation of mechanical equipment. Concrete materials that fall on or are worked into the joints or surface tines of an existing pavement shall be removed immediately.

Concrete shall not be mixed, placed, or finished when the natural light is insufficient, unless an adequate and approved artificial lighting system is operated in accordance with the QCP.

The Contractor shall have available at all times sufficient materials for the protection of unhardened PCCP from the effects of rain. Covering material such as burlap or polyethylene sheeting shall be provided. When rain appears imminent, paving operations shall stop. All available personnel shall be used to cover the PCCP.

501.17 CMD Adjustments. The target water/cementitious ratio and target unit weight may be adjusted during the first lot of each year's production. 
Adjustments to the dosage amount of admixtures will be permitted; however, a new CMD will be required for the addition or deletion of an admixture.

The fine aggregate to total aggregate ratio may be adjusted by $\pm 3 \%$ within the limits of 501.05 .

501.18 Joints. Joints shall be in accordance with 503 .

501.19 Finishing. PCCP shall be finished in accordance with 504.

501.20 Curing. PCCP shall be cured with an approved white pigmented liquid membrane forming compound. Alternative methods of curing may be approved by the Engineer. Curing shall be in accordance with 504. For formed PCCP, immediately after the forms are removed, the sides of the PCCP shall be cured.

501.21 Form Removal. Forms may be removed as soon as the PCCP has hardened sufficiently to prevent edge spalling or other damage. Form pullers shall not be supported on the PCCP during form removal operations.

501.22 Pavement Inspection. The Contractor and Engineer will conduct an inspection of the new PCCP for any damage, including freezing or random cracks. The inspection and all necessary repairs shall be completed prior to opening the pavement to non-construction traffic. All random, full-depth cracks in the PCCP shall be corrected in accordance with 503.06. All other damages shall be repaired by approved methods.

501.23 Opening to Traffic. The Contractor shall be responsible for controlling the opening of the PCCP to construction and non-construction traffic and include the procedures in the QCP. Pavement inspection will be completed in accordance with 501.22 .

(a) Construction. Construction vehicles or equipment will be allowed on the PCCP after 10 days or when flexural tests indicate a modulus of rupture of $3800 \mathrm{kPa}$ (550 psi) or greater. ITM 402 may be used as an alternate method to determine the flexural strength. All construction vehicles or equipment that may damage the PCCP shall not be used on the PCCP unless adequate protection is provided. Approved joint cutting saws may be operated on the PCCP.

(b) Non-Construction. PCCP may be opened to traffic after 14 days. The PCCP may be opened earlier if test beams or ITM 402 indicate a modulus of rupture of 3800 $\mathrm{kPa}$ (550 psi) or greater. If adequate strengths are not met within 14 days, an investigation by the Engineer and Contractor will be conducted to determine if the PCCP is deficient. Resolutions for all deficiencies will be developed at the completion of the investigation. Cracks and joints shall be sealed in accordance with 503.05 and the PCCP cleaned prior to opening to traffic. 
501.24 Shoulder Corrugations. PCCP shoulders shall have formed or milled corrugations, if shown on the plans.

(a) Formed Corrugations. Formed corrugations consist of formed depressions in newly constructed PCCP shoulders. The corrugations shall be formed by means of a corrugated float.

(b) Milled Corrugations. Milled corrugations consist of cutting smooth strips in existing or newly constructed shoulders. The smooth strips shall be made by a cutting machine that provides a series of cuts without tearing or snagging. The equipment shall include guides to maintain uniformity and consistency in the alignment of the strips.

The operation shall be coordinated such that milled materials do not encroach on pavement lanes carrying traffic and all milled materials are disposed of in accordance with 104.07.

\subsection{Pavement Smoothness.}

\section{(a) Sampling and Testing of Initial Smoothness.}

The pavement smoothness will be measured by means of a profilograph, a $4.9 \mathrm{~m} \mathrm{(16}$ $\mathrm{ft})$ long straightedge, or a $3 \mathrm{~m}(10 \mathrm{ft})$ long straightedge.

The profilograph shall be used on all full-width pavement lanes of $75 \mathrm{~m}(250 \mathrm{ft})$ or longer and having a design speed greater than $70 \mathrm{~km} / \mathrm{h}(45 \mathrm{mph})$, unless otherwise specified.

If a pay item, profilograph, PCCP, is included in the contract, the Contractor shall furnish, calibrate, and operate an approved profilograph in accordance with ITM 901. The profilogram produced shall become the property of the Department. The profilograph shall remain the property of the Contractor. When a profilograph is not included as a pay item, the Department will furnish, calibrate, and operate the profilograph.

A $4.9 \mathrm{~m}(16 \mathrm{ft})$ long straightedge shall be used on all full-width pavement lanes shorter than $75 \mathrm{~m}(250 \mathrm{ft})$, tapers, within $15 \mathrm{~m}(50 \mathrm{ft})$ of bridge ends, within $15 \mathrm{~m}(50 \mathrm{ft})$ of an existing pavement that is being joined, ramps, or having a design speed of $70 \mathrm{~km} / \mathrm{h}$ (45 mph) or less, unless otherwise specified.

The $3 \mathrm{~m} \mathrm{(10} \mathrm{ft)} \mathrm{long} \mathrm{straightedge} \mathrm{shall} \mathrm{be} \mathrm{used} \mathrm{for} \mathrm{transverse} \mathrm{slopes,} \mathrm{approaches,} \mathrm{and}$ crossovers.

A minimum of one pavement profile in the RWP shall be determined for each lane within each $0.16 \mathrm{~km}(0.1 \mathrm{mile})$ increment. The location of a wheel path shall be $1 \mathrm{~m} \mathrm{(3}$ $\mathrm{ft}$ ) from the pavement edge and parallel to the center of the mainline paving. For 
widened pavements, the outer wheel path shall be $1 \mathrm{~m}(3 \mathrm{ft})$ from the pavement edge stripe rather than the pavement edge. Each profile shall terminate $15 \mathrm{~m}(50 \mathrm{ft})$ from each bridge approach pavement or existing pavement that is joined to the new pavement. The Profile Index (PI) determined for each profile shall be converted to a standard unit of $\mathrm{mm} / 0.16 \mathrm{~km}$ (in./ $0.1 \mathrm{mi}$ ).

As soon as the PCCP has cured sufficiently, the smoothness may be checked. Profile testing shall be completed prior to opening the pavement to traffic. The Department may direct that the pavement profile be tested within $24 \mathrm{~h}$ following placement. When profile testing is consistently outside pavement surface tolerances the paving operation shall be discontinued until an amended QCP is submitted. An initial profile index will be determined from the profilogram of this profile. The initial profile index for areas requiring replacement will be adjusted to include the results of a profilogram of all replaced areas.

Pavement smoothness variations outside specified tolerances shall be corrected by grinding with a groove type cutter or by replacement. Grinding will not be permitted until the PCCP is 10 days old or until the test indicates a modulus of rupture of $3800 \mathrm{kPa}$ (550 psi) or greater. The grinding of the pavement to correct the profile shall be accomplished in either the longitudinal or the transverse direction. The PCCP texture after grinding shall be uniform. If the grinding operation reduces the tining grooves to a depth of less than $1.5 \mathrm{~mm}$ (1/16 in.) and the longitudinal length of the removal area exceeds $4.5 \mathrm{~m}(15 \mathrm{ft})$, or two or more areas are within $9.0 \mathrm{~m}(30 \mathrm{ft})$ of each other, the PCCP shall be retextured in accordance with 504.03.

Pavement smoothness variations shall be corrected to be in accordance with the smoothness requirements in the following table.

\begin{tabular}{|c|c|}
\hline \multicolumn{2}{|c|}{ RQL PAVEMENT SMOOTHNESS TOLERANCES } \\
\hline Testing Method & Specified Tolerance \\
\hline Profilograph & \\
\hline $\begin{array}{l}\text { Design speeds greater than } 70 \mathrm{~km} / \mathrm{h} \\
(45 \mathrm{mph})\end{array}$ & $\begin{array}{l}25 \mathrm{~mm} / 0.16 \mathrm{~km}(1.0 \mathrm{in} . / 0.1 \mathrm{mi}) \\
\text { profile index or less }\end{array}$ \\
\hline $\begin{array}{l}\text { Design speeds } 70 \mathrm{~km} / \mathrm{h}(45 \mathrm{mph}) \text { or } \\
\text { less }\end{array}$ & $\begin{array}{l}40 \mathrm{~mm} / 0.16 \mathrm{~km}(1.6 \mathrm{in} . / 0.1 \mathrm{mi}) \\
\text { profile index or less }\end{array}$ \\
\hline $\begin{array}{l}4.9 \mathrm{~m}(16 \mathrm{ft}) \text { Straightedge } \\
\text { All pavements }\end{array}$ & $6 \mathrm{~mm}(1 / 4$ in. $)$ or less \\
\hline $3 \mathrm{~m}(10 \mathrm{ft})$ Straightedge & $3 \mathrm{~mm}(1 / 8$ in. $)$ or less \\
\hline
\end{tabular}

When the profilograph is being used, in addition to the requirements for the profile index, all areas having a high or low point deviation in excess of $8 \mathrm{~mm}(0.3 \mathrm{in}$. $)$ shall be corrected. Verifying profilograph measurements will be taken only in the $0.16 \mathrm{~km}(0.1$ mi) length sections where corrections have been performed. 


\section{(b) Pavement Initial Smoothness Acceptance and Pay Adjustment.}

The target, or desired, pavement smoothness quality, is defined in Appendix II. An as-constructed project smoothness quality that differs from the target pavement smoothness quality will be accepted with price adjustments (incentive or disincentive) in accordance with 501.28(d).

For the profile index, the RQL will be greater than the MQL due to the nature of the

measurement. Therefore, the lower the profile index, the better the quality. The following procedures shall apply to initial smoothness acceptance:

- All profile index values equal to or larger than the MQL and less than or equal to the RQL, as described in the proceeding table, will be used for acceptance.

- All profile index values less than the MQL are defined as being equal to the MQL, and the MQL limit will be used for acceptance.

- If a profile index exceeds the RQL, the pavement shall be corrected to be in accordance with the smoothness RQL requirements. If grinding is used to bring the pavement smoothness into accordance with the RQL limits, the pavement smoothness will be the RQL limit and not the smoothness measured after grinding

501.26 Pavement Thickness. The desired target pavement thickness, as defined by mean and standard deviation pavement thickness values, shall be in accordance with Appendix II. An as-constructed lot with a pavement thickness quality that differs from the target pavement thickness quality will be accepted with price adjustments (incentive or disincentive) in accordance with $501.28(\mathrm{c})$, provided the pavement meets the minimum RQL as described in Appendix II.

\section{(a) Sampling and Testing of Pavement Thickness.}

PCCP thickness will be determined after all corrective grinding has been performed. The Contractor shall obtain cores at the locations determined by the Engineer in accordance with ITM 802. Cores, $100 \mathrm{~mm}$ (4 in.) in diameter, shall be taken in the presence of the Engineer for the full depth of the PCCP. The Engineer will take immediate possession of the cores. Cores shall not be taken within $150 \mathrm{~mm}$ (6 in.) of the edge of pavement, within $75 \mathrm{~mm}$ (3 in.) of longitudinal joints, within $0.6 \mathrm{~m}(2.0 \mathrm{ft})$ of contraction joints, or within $1.5 \mathrm{~m}(5 \mathrm{ft})$ of a transverse construction joint. Cores shall be measured in accordance with ITM 404. Core holes shall be filled in accordance with 506.

If a core measurement reveals that the pavement is more than $13 \mathrm{~mm}(0.5 \mathrm{in}$.) deficient in thickness, additional cores shall be taken at $6.0 \mathrm{~m}(20 \mathrm{ft})$ intervals on each 
side of the original core. These additional cores shall be on a line that passes through the original core and is parallel to the centerline of the pavement. The coring shall continue in both directions at $6.0 \mathrm{~m}(20 \mathrm{ft})$ intervals until two successive cores indicate a thickness deficiency of $13 \mathrm{~mm}(0.5 \mathrm{in}$.) or less, or where cores can no longer be taken in the new PCCP.

\section{(b) Pavement Thickness Acceptance and Pay Adjustment.}

The thickness of the as-constructed pavement will be determined by measurements taken on cores extracted from each sublot making up an as-constructed pavement lot. The as constructed pavement thickness quality, as defined by mean and standard deviation values, will be measured for a given lot. An as-constructed lot with a pavement thickness quality that differs from the target pavement thickness quality will be accepted with price adjustments (incentive or disincentive).

For pavement thickness, the sample thickness shall meet the AQC limits (RQL and MQL) for each core value within a sublot. With regards to RQL and MQL values (as defined in Appendix II), the following procedure will apply:

- If a pavement thickness value is greater than the defined MQL, the measured core pavement thickness value shall be reduced to be equal to the chosen MQL. The reduced core pavement thickness value (MQL) shall be used for acceptance.

- All pavement thickness values greater than or equal to the RQL, and less than or equal to the MQL, will be used directly for acceptance. The pavement thickness mean (including any adjustments) are then used in conjunction with 501.31 for determining the pay factor for a given lot. The thickness of the PCCP for each lot will be the average lengths of all cores from the lot.

- If a pavement thickness value is less than the defined RQL, re-testing will be done. Pavement thickness re-testing procedures will be as follows:

If a pavement thickness value is less than the defined RQL, additional cores shall be taken at $6.0 \mathrm{~m}(20 \mathrm{ft})$ intervals on each side of the original core. These additional cores shall be on a line that passes through the original core and is parallel to the centerline of

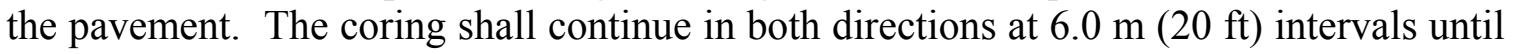
two successive cores indicate that the pavement thickness meets the RQL or where cores can no longer be taken in the new PCCP.

When a single core indicates a thickness less than the RQL, the investigation will be expanded to include adjoining PCCP. The additional cores shall be taken from the adjoining traffic lanes or shoulders at the same station at which the first core or cores indicated the deficiency, whether the lane was paved at the same time or not. 
The width of adjudicated PCCP shall be the width of pavement lane in which the deficiency occurs. Pavement that has been replaced shall be investigated for thickness.

(c) PCCP Removal. Where two adjacent cores indicate a thickness less than the RQL, the PCCP shall be removed and replaced. Non-adjacent cores indicating a thickness deficiency of less than the RQL do not require removal and replacement.

The limits of removal and replacement shall extend from the deficient core to the transverse joint location nearest the first additional core indicating a sufficient pavement thickness in both directions.

(d) PCCP Thickness when PCCP Pavement was Removed and Replaced. The thickness of the PCCP for each lot will be taken as the average lengths of all cores from the lot. Where PCCP has been removed and replaced the initial core lengths will be discarded. Cores of the replaced PCCP will be taken to ensure adequate thickness. In addition, a new core random location will be selected for determining the pay factor. This new core location shall not be in the replaced pavement. Any core measurements exceeding MQL will be recorded as the MQL. Calculations will be to the nearest $2.5 \mathrm{~mm}$ (0.1 in.).

501.27 Tolerance. Plastic unit weight, water/cementitious ratio, flexural beam, and air content tests will be performed during PCCP operations.

(a) Plastic Unit Weight. Sublots shall not vary by more than $\pm 3.0 \%$ from the target unit mass (weight). A stop paving order will be issued if the plastic unit mass (weight) exceeds $\pm 3.0 \%$ from the target plastic unit mass (weight). Paving operations shall not resume until satisfactory changes are made or an alternate CMD is used.

Calculations for the plastic unit mass (weight) in $\mathrm{kg} / \mathrm{m}^{3}$ will be made and reported to the nearest whole unit (calculations in $1 \mathrm{bs} / \mathrm{yd}^{3}$ will be made and reported to the nearest figure in the tenth).

(b) Water to Cementitious Ratio. The weekly water to total cementitious materials ratio shall not vary more than \pm 0.030 of the target value or exceed 0.450 . A stop paving order will be issued if the test results exceed these values. Paving operations shall not resume until satisfactory changes are made or an alternate CMD is used.

Calculations for water to cementitious ratio will be made and reported to the nearest figure in the third decimal place.

(c) Flexural Strength. Average 7-day lot values of $4000 \mathrm{kPa}$ (550 psi) and above shall be achieved. Price adjustments for values shall be made in accordance with 501.28. 
(d) Air Content. The average air content should not fall outside the range of $4.5 \%$ to $10.0 \%$. The range of sublot air values shall not exceed $2.5 \%$. Price adjustment for values shall be made in accordance with 501.28

Calculations for the air content will be made and reported to the nearest figure in the first decimal place.

\subsection{Pay Adjustment.}

Pay adjustment shall be in accordance with Appendix II.

(a) Flexural Strength. The as constructed concrete strength is defined by mean and standard deviation values computed for a given lot. Concrete strength values are determined for each sample location within each sublot (average of two beams at a given sampling location). The target concrete strength shall be in accordance with Appendix II. An as-constructed lot with a concrete strength quality that differs from the target concrete strength quality will be accepted with price adjustments (incentive or disincentive) in accordance with 501.31.

Flexural strength values at 7 days will be determined for each beam using the method described above. The 7-day measured strengths will be converted to 28 day equivalent values using Appendix II, section II-6. With regards to RQL and MQL values (as defined in Appendix II), the following procedure will apply:

- If a flexural strength value is greater than the defined MQL, the measured strength value will be reduced to be equal to the chosen MQL. The reduced strength value will be used for acceptance.

- All flexural strength values greater than or equal to the RQL, and less than or equal to the MQL, will be used directly for acceptance. The flexural strength values are used to determine the pay factor for a given lot in accordance with 501.31 .

- If the average flexural strength is lower than the RQL, the material will be adjudicated as a failed material in accordance with normal Department practice as listed in 105.03.

The flexural strength values are averaged within each sampling location to give flexural strength values for each sublot. The flexural strength values are averaged between each sublot to give an average flexural strength values and standard deviations for each lot.

When the average flexural strength is greater than or equal to the RQL, Table II-2 in Appendix II will be used to determine the pay adjustment for the lot. If the sublot is 
completely removed, the test value from the replacement sublot will replace the original test value.

(b) Air Content. The as constructed concrete air content is defined by mean and standard deviation values computed for a given lot. Concrete air content values are determined from two sample locations within each sublot. The target concrete air content shall be in accordance with Appendix II. An as-constructed lot with a concrete air content quality that differs from the target concrete air content quality will be accepted with price adjustments (incentive or disincentive) in accordance with 501.31.

With regards to RQL and MQL values (as defined in Appendix II), the following procedure will apply:

- If an air content value is equal to or within the range of the defined MQL's this value will be used directly for acceptance. The air content values are used to determine the pay factor for a given lot in accordance with 501.31.

- If the average air content is outside the range of the MQL, the material will be adjudicated as a failed material in accordance with normal Department practice as listed in 105.03 .

The air content values are averaged within each sampling location to give air content values for each sublot. The air content values are averaged between each sublot to provide an average air content and standard deviation for each lot.

When the average air content is in the range specified by the MQL, Table II-4 in Appendix II will be used to determine the pay adjustment for the lot.

If a sublot value is less than $4.5 \%$ or greater than $10.0 \%$, the PCCP will be adjudicated as a failed material in accordance with normal Department practice as listed in 105.03. For a sublot completely removed, the sublot test value from the replacement sublot will replace the original test value.

(c) Thickness. When the average pavement thickness is greater than the RQL, Table II-3 in Appendix II will be used to determine the pay adjustment for the lot in accordance with 501.25.

(d) Smoothness. When the average pavement smoothness is less than the RQL, Table II-4 in Appendix II will be used to determine the pay adjustment for the lot. When corrective action has been taken to achieve the RQL the pay factor will not exceed $98.0 \%$. If corrective action is required to remove one high or low point deviation in excess of $8 \mathrm{~mm}(0.3 \mathrm{in}$.) with an overall length of less than $4.5 \mathrm{~m}(15 \mathrm{ft})$ in a $0.16 \mathrm{~km}(0.1$ mile) section, no adjustment will be made to the pay factor to consider the specimen as ground (i.e., one bump grind is permitted per $0.16 \mathrm{~km}(0.1 \mathrm{mi})$. In both cases the pay adjustment will be made in accordance with 501.25 . 
501.29 Appeals. If the Contractor does not agree with the acceptance test results, a request may be made in writing for additional tests for a sublot(s) or lot. The basis of the appeal shall include applicable QC test results showing acceptable quality results and shall be submitted within five calendar days of receipt of the Department's written results for that lot. Upon review of the appeal, the Engineer may accept the PCCP in accordance with 105.03 or accept the appeal.

The re-testing procedures for flexural strength and air content are described separately below. Thickness and smoothness cannot be appealed.

(a) Flexural Strength. Appeals will not be considered unless QC test results indicate a discrepancy of at least a $350 \mathrm{kPa}$ (50 psi) difference between the Department's and the Contractor's tests and the PCCP is below the RQL. Upon approval for the additional testing, the Contractor shall obtain cores, as directed, in the presence of the Engineer.

The Engineer will determine the location of the cores within the appealed and adjacent sublots using the same CMD. The location of the cores will be at the center of a lane at the acceptance sample location. Cores shall not be taken over dowels or within $1.5 \mathrm{~m}(5 \mathrm{ft})$ of a header. Two cores shall be taken in each sublot for the full depth of pavement and shall be $100 \mathrm{~mm}$ (4 in.) in diameter. All core holes shall be filled with portland cement concrete within $24 \mathrm{~h}$ of drilling. If adjacent sublots were produced using different CMDs, the matter will be adjudicated as a failed material in accordance with normal Department practice as listed in 105.03.

Each core will be tested for split tensile strength in accordance with ASTM C 496. The cores will be submerged in lime-saturated water prior to testing for a minimum of $40 \mathrm{~h}$.

The average core split tensile strength will be determined for the appealed and adjacent sublots. Flexural strength will be calculated as follows.

$$
F_{D}=S_{D} \times\left[\frac{F_{A 1}}{2 S_{A 1}}+\frac{F_{A 2}}{2 S_{A 2}}\right]
$$

where:

$\mathrm{F}_{\mathrm{D}}=$ flexural strength of the appealed sublot

$\mathrm{F}_{\mathrm{A} 1}=$ flexural strength of the previous adjacent sublot

$\mathrm{F}_{\mathrm{A} 2}=$ flexural strength of the subsequent adjacent sublot

$\mathrm{S}_{\mathrm{D}}=$ split tensile strength of the appealed sublot

$\mathrm{S}_{\mathrm{A} 1}=$ split tensile strength of the previous adjacent sublot

$\mathrm{S}_{\mathrm{A} 2}=$ split tensile strength of the subsequent adjacent sublot 
(b) Air Content. Appeals will not be considered unless QC test results indicate greater than a $0.5 \%$ difference between the Department's and the Contractor's tests. Upon approval for the additional testing, the Contractor shall obtain core(s) as directed in the presence of the Engineer.

The Engineer will determine the location of the core(s) within the appealed sublot(s). The location of the core will be at the center of a lane at the acceptance sample location. A core shall not be taken over dowels or within $1.5 \mathrm{~m}(5 \mathrm{ft})$ of a header. One $100 \mathrm{~mm}$ (4 in.) diameter full depth core shall be taken from the pavement for each sublot appealed. All core holes shall be filled with PCC within $24 \mathrm{~h}$ of drilling.

The air content for a sublot will be the hardened concrete air content determined from the core in accordance with ITM 401.

501.30 Method of Measurement. PCCP will be measured by the square meter (square yard) of the thickness specified. The area of PCCP will be the planned width multiplied by the length of the pavement, or as directed in writing. The width of the pavement will be as shown on the typical cross section of the plans. The length of the pavement will be measured parallel to the surface of the pavement along the centerline of the roadway or ramp, excluding paving exceptions as shown on the plans.

Milled PCCP shoulder corrugations will be measured by the meter (linear foot) of shoulder milled, measured parallel to the centerline of the roadway. Formed shoulder corrugations will not be measured.

501.31 Basis of Payment. Pay adjustments will be determined using the Level 1 pay adjustment methods as outlined in Appendix II using equation II-1.

Computed AQC lot means and standard deviations are used to define the quality of the as-constructed lot and will be used as the basis of computed pay adjustments.

The total payment to the Contractor for the as-constructed lot will be determined as described in Appendix II using equation II-2.

The accepted quantities of PCCP will be paid for at the adjusted Contractor unit price per square meter (square yard) for the thickness specified, complete in place.

Furnishing, calibrating, and operating the profilograph, and furnishing profile information will be paid for at the contract lump sum price for profilograph, PCCP.

Milled PCCP corrugations will be paid for at the contract unit price per meter (linear foot), when specified.

Payment for pavement thickness, determinations will be made at the contract lump sum price for coring PCCP. 
An extra work agreement in accordance with 109.05 will be developed to adjust the cost of QC/QA-PCCP when the final QC/QA-PCCP quantity differs from the bid quantity by more than $2000 \mathrm{~m}^{2}$ (2400 sq yd). This adjustment covers the cost of cores for the adjusted quantity of QC/QA-PCCP. The adjustment, plus or minus, will be based on the difference in the number of sublots, rounded to the nearest full sublots, times $\$ 100$.

Payment will be made under:

\section{Pay Item Pay Unit}

Milled PCCP Corrugations $\mathrm{m}(\mathrm{LFT})$

Coring, PCCP

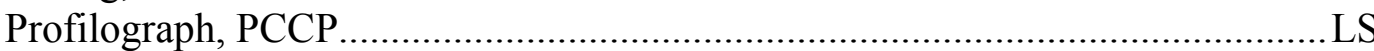

QC/QA, PRS, PCCP, 352 mm (14.1 in.) ........................................ $\mathrm{m}^{2}$ (SYS)

Smoothness, mm/0.16 km, (in/0.1 mi) ........................................m $(0.1 \mathrm{mi})$

The cost of trial batch demonstrations shall be included in the cost of PCCP.

The price for profilograph, PCCP will be full compensation regardless of how often the profilograph is used or how many profilograms are produced.

No payment will be made for deficient PCCP directed to be removed. No payment will be made for the removal of the deficient PCCP. Deficient PCCP is a pavement that fails to meet the RQL for Strength, Pavement Thickness, or Air Content.

The cost of corrections for pavement smoothness and re-texturing shall be included in the cost of PCCP.

The cost of all cores for determination of pavement thickness shall be included in the costs of other pay items. The cost of coring and refilling of the pavement holes for appeals shall be included in the cost of PCCP.

The cost of incorporating formed corrugations in PCCP shoulders shall be included in the cost of PCCP.

Traffic control for appeals shall be supplied with no additional payment.

Removal and replacement of PCCP damaged by freezing shall be completed with no additional payment. 


\section{APPENDIX I: GENERAL DEFINITIONS COMMON IN PERFORMANCE- RELATED SPECIFICATIONS (FROM FHWA RD-98-155)}

The following acronyms are used in this specification:

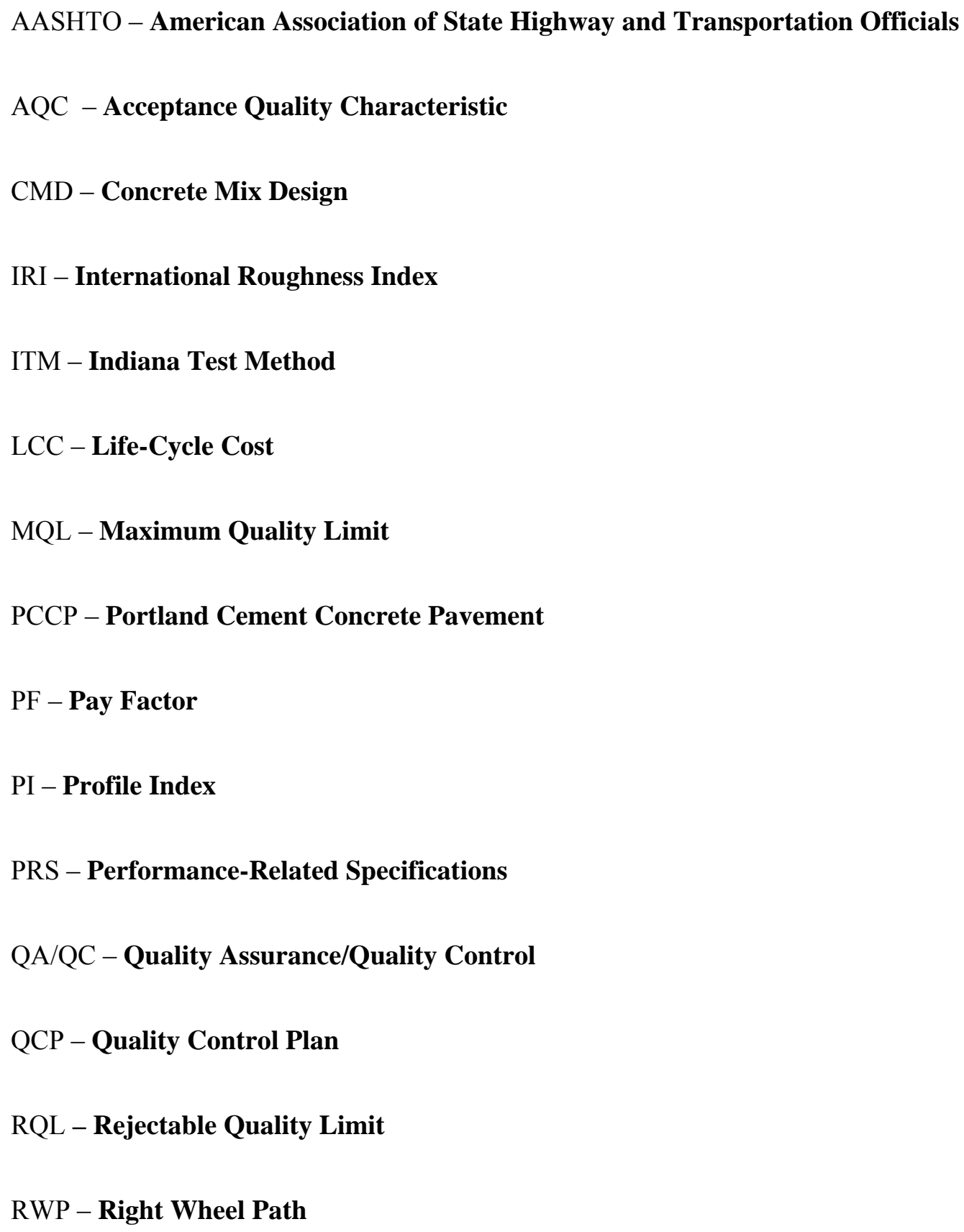




\section{SSD - Saturated Surface Dry}

The following definitions are applicable to this specification:

\section{Acceptance Quality Characteristics (AQC's)}

Inherent measurable pavement characteristics that significantly affect pavement performance, are under the direct control of the contractor, and are measurable at or near the time of construction. AQC's considered under the current Level 1 PRS include concrete strength, pavement thickness, air content, and initial smoothness.

\section{AQC Target Values}

Department-chosen AQC means and standard deviations that define the department's desired quality (i.e., the AQC quality for which the department is willing to pay 100 percent of the bid price).

\section{As-Constructed Lot Life-Cycle Cost (LCC CON $_{\text {) }}$}

The estimated post-construction LCC used to represent the as-constructed pavement lot quality. This value is based in part on the measured as-constructed AQC values (means and standard deviations).

\section{As-Constructed Pavement}

The actual concrete pavement constructed by the Contractor. The as-constructed quality level of each pavement lot is assessed based on AQC sampling and testing (using defined AQC acceptance procedures) of the as-constructed pavement.

\section{As-Designed Lot Life-Cycle Cost (LCC DES $_{\text {) }}$}

The estimated post-construction LCC used to represent the as-designed pavement quality. This value is based on the as-designed AQC target values (means and standard deviations) selected by the department.

\section{As-Designed Pavement}

The desired concrete pavement, as defined by the department. The desired quality level of the pavement is specified in terms of target as-designed AQC means and standard deviations.

\section{Construction Pass}

The defining width of an ongoing paving operation. This definition is used since the width of paving may consist of more than one traffic lane.

\section{In Situ Sampling}

AQC sampling procedures in which samples are taken directly from or on the in-place concrete pavement (e.g., cores and surface profile measurement).

\section{Initial Design Life}


Amount of time for which the chosen pavement design is expected to carry traffic loads without the application of an AC overlay, PCC overlay, or diamond grinding.

\section{Life-Cycle Cost (LCC)}

The estimated cumulative present worth cost of a pavement lot over a specified analysis period. The LCC, as used in PRS, may include estimated future maintenance, rehabilitation, and user costs over a chosen analysis period. The initial construction cost is not included in the LCC since it is identical for both the as-designed and the asconstructed pavements. LCC values are expressed in units of present worth dollars (PW\$) per kilometer.

\section{Lot Width}

The lot width is defined as the total width of pavement, one or more traffic lanes, being placed at one time in the mainline paving process. This paving width is also referred to as a construction pass, since it describes the total width of pavement being placed in one pass of the paving train. The entire width of a widened lane is included; however, shoulders are to be excluded.

\section{Maximum Quality Limit (MQL)}

Department-chosen maximum limit for acceptable AQC specimen sample quality. If an AQC specimen sample value is measured to have greater quality than the defined MQL, the representative specimen sample value (used in the acceptance procedures) is set equal to the defined MQL (i.e., the Contractor does not receive credit for quality provided in excess of the MQL). For concrete strength, pavement thickness, and percent consolidation around dowels, better quality than the MQL is identified by specimen sample values greater than the MQL; however, for initial smoothness, better quality than the MQL is identified by specimen sample values less than the MQL. There is no MQL defined for entrained air content.

\section{PaveSpec 3.0}

The revised PRS specification simulation software developed under this research project. This software is used to demonstrate the PRS approach by simulating pavement performance, determining corresponding LCC's, generating preconstruction output, and computing pay adjustments.

\section{Pay Adjustment}

The actual pay adjustment (incentive or disincentive in PW\$) for the as-constructed lot.

Level 1 Pay Adjustment - The Level 1 pay adjustment is computed using the determined Level 1 lot composite pay factor (CPF).

\section{Pay Factor (PF)}

The percent of the bid price that the Contractor is paid for the construction of a concrete pavement lot. 


\section{Performance-Related Specifications (PRS)}

Construction specifications placed on key materials and construction AQC's (e.g., concrete strength, pavement thickness) that have been demonstrated to correlate strongly with long-term pavement performance. These specifications are based on quantified relationships (or mathematical models) that relate measured AQC's to subsequent pavement performance and the corresponding costs.

\section{Quality Assurance (QA)}

All those planned and systematic actions necessary to provide adequate confidence that a product or service will satisfy given requirements of quality.

\section{Quality Control (QC)}

The sum total of activities performed by the seller (producer, manufacturer, or contractor) to make sure that a product meets contract specification requirements. Within the context of highway construction, QC includes materials handling and construction procedures; calibration and maintenance of equipment; production process control; and any sampling, testing, and inspection done for these purposes.

\section{Rejectable Quality Limit (RQL)}

Department-chosen minimum limit for acceptable AQC specimen sample quality. If an $\mathrm{AQC}$ specimen sample value is measured to have poorer quality than the defined RQL, AQC re-testing procedures will apply. For concrete strength and pavement thickness poorer quality than the RQL is identified by specimen sample values less than the RQL; however, for initial smoothness, poorer quality than the RQL is identified by specimen sample values greater than the RQL. (Note: thickness and smoothness cannot be appealed.)

\section{Sample Mean}

The average of $\mathrm{n}$ random AQC sample values. This sample mean is computed using the following equation.

$$
\operatorname{MEAN}_{\text {SAMPLES }}=\Sigma\left(x_{\mathrm{i}}\right) / n
$$

Where;

MEAN $_{\text {SAMPLES }}=$ The computed mean of $n$ random AQC samples.

$x_{\mathrm{i}}=1$ to $\mathrm{n}$ random sample values.

$n=$ Total number of random samples.

\section{Sample Standard Deviation}

An estimate of the true population standard deviation, $\sigma$. If this estimate is to be unbiased, a correction factor must be applied. This unbiased sample standard deviation is computed using the following equation. 
$\operatorname{SD}_{\text {SAMPLES }}=\left(\left\{\left[\Sigma\left(x_{i}-\text { MEAN }_{\text {SAMPLES }}\right)^{2}\right] /(n-1)\right\}\right)^{0.5} / \mathrm{C}_{\mathrm{SD}}$

Where;

$\mathrm{SD}_{\text {SAMPLES }}=$ The computed unbiased standard deviation of all of the random sample values.

MEAN $_{\text {SAMPLES }}=$ The computed mean of all of the random sample values.

$n=$ Total number of random samples.

$x_{\mathrm{i}}=1$ to $\mathrm{n}$ sample values.

$\mathrm{C}_{\mathrm{SD}}=$ Correction factor based on the total sample size, $\mathrm{n}$, used to obtain unbiased estimates of the actual lot sample standard deviation, $\sigma$. Appropriate $\mathrm{C}_{\mathrm{SD}}$ values are determined using the following table.

Correction factors used to obtain unbiased estimates of the actual standard deviation.

\begin{tabular}{||c|c||}
\hline $\begin{array}{c}\text { Number of Sample } \\
\text { Values, } \mathrm{n}\end{array}$ & $\begin{array}{c}\text { Correction } \\
\text { Factor, } \mathrm{C}_{\mathrm{SD}}\end{array}$ \\
\hline 2 & 0.7979 \\
\hline 3 & 0.8862 \\
\hline 4 & 0.9213 \\
\hline 5 & 0.9399 \\
\hline 6 & 0.9515 \\
\hline 7 & 0.9594 \\
\hline 8 & 0.9650 \\
\hline 9 & 0.9693 \\
\hline 10 & 0.9726 \\
\hline 30 & 0.9915 \\
\hline 50 & 0.9949 \\
\hline
\end{tabular}

\section{Sample Value}

An AQC value used to represent one sample location within a sublot. A representative sample value may be the direct measured value from one test taken at a sample location (no replicate test result values, i.e., $m=1$ ), or equal to the mean of $m$ replicate test result values (from $m$ replicate tests) taken at the same sample location.

\section{Test Result Value}

The computed AQC value from one AQC test. For concrete strength and pavement thickness this is the testing result from one sample. For initial smoothness, this is the value obtained from one pass of the profilograph. 
APPENDIX U CONTRACT FROM PRS PROJECT \#2 - CLARKESVILLE, IN (PROJECT R-25715) 


\title{
APPENDIX I: PERFORMANCE-RELATED SPECIFICATION FOR USE IN DETERMINING PAY FACTOR ADJUSTMENTS
}

\author{
PREPARED FOR: R-25175, I-65, CLARKSVILLLE, IN
}

\section{I-1 Document Description}

This document is intended to provide a detailed listing of the pay factors used on this project. It should be noted that the values used in this appendix are contract specific, as such, the pay factor adjustments reported herein only pertain to Project R-25175 (I65 from SR 139, from $1.7 \mathrm{~km}$ north of SR 131 to $1.7 \mathrm{~km}$ north of I-265).

Individual pay factor tables are contained in this appendix for the four AQC's chosen for inclusion in these specifications. This includes flexural strength, pavement thickness, air content, and pavement smoothness.

\section{I-2 Acceptance Quality Characteristic (AQC) Values}

Table I-1 describes the Acceptance Quality Characteristic (AQC) target values, which were used to define the desired pavement quality for use in the target as-designed LCC calculations. The target means and standard deviations represent the quality for which $100 \%$ of the bid price will be paid. The rejectable quality limit (RQL) represents the minimum quality that can be accepted before re-testing or removal procedures apply (see Sections 501.25, 501.26, and 501.27). The MQL represents the maximum quality for which credit can be earned. If a specimen has a quality characteristic greater than the MQL, the specimen value is set equal to the MQL.

Table I-1: Design AQC Values

\begin{tabular}{|l|c|c|c|c|}
\hline \multicolumn{1}{|c|}{$\begin{array}{c}\text { AQC } \\
\text { Value }\end{array}$} & $\begin{array}{c}\text { Target } \\
\text { Mean }\end{array}$ & $\begin{array}{c}\text { Target Standard } \\
\text { Deviation }\end{array}$ & $\begin{array}{c}\text { Rejectable } \\
\text { Quality Limit } \\
(\mathrm{RQL})\end{array}$ & $\begin{array}{c}\text { Maximum } \\
\text { Quality Limit } \\
(\mathrm{MQL})\end{array}$ \\
\hline Strength* & $650 \mathrm{psi}$ & $40 \mathrm{psi}$ & $<550 \mathrm{psi}$ & $800 \mathrm{psi}$ \\
\hline Thickness & $14.1 \mathrm{in}$. & $0.5 \mathrm{in}$ & $<13 \mathrm{in}$. & $16 \mathrm{in}$. \\
\hline Air Content & $6.5 \%$ & $1.0 \%$ & $<4.5 \mathrm{or}>9.5 \%$ & None \\
\hline Smoothness & $0.7 \mathrm{in} . / 0.1 \mathrm{mile}$ & $0.3 \mathrm{in} . / 0.1 \mathrm{mile}$ & $>1.0 \mathrm{in} / 0.1 \mathrm{mile}$ & $0.3 \mathrm{in} . / 0.1 \mathrm{mile}$ \\
\hline
\end{tabular}

* Note: Flexural strength is based on a 28 day equivalent strength value as described in section I-6 


\section{I-3 Composite Pay Factor}

The composite pay factor (CPF) equation combines the four individual pay factors (i.e., strength, thickness, air content, and smoothness) into a single pay factor for the lot. The individual strength, thickness, air content, and smoothness pay factors are determined in I-4a, I-4b, I-4c, and I-4d respectively. The composite pay factor for this pay item is as given in Equation I-1.

$$
\mathrm{CPF}_{\text {MAINLINE }}=\left(\mathrm{PF}_{\mathrm{STRENGTH}}+\mathrm{PF}_{\mathrm{THICKNESS}}+\mathrm{PF}_{\mathrm{AIR}}+\mathrm{PF}_{\mathrm{SMOOTHNESS}}\right) / 4 \quad \text { Equation I-1 }
$$

Once the composite pay factor (CPF) is determined, a pay factor adjustment for the lot can be made using the relationship provided in Equation I-2.

$$
\mathrm{PAY}_{\mathrm{LOT}}=\mathrm{BID} \times \mathrm{CPF}_{\mathrm{MAINLINE}} / 100 \times \mathrm{LOT}_{\text {area }}
$$

Equation I-2

PAY $_{\text {LOT }}$ is the adjusted payment paid to the contractor for the as-constructed lot in dollars, BID is the contractors unit bid price in $\$ / \mathrm{m}^{2}$ and LOT area is the actual asconstructed lot area in $\mathrm{m}^{2}$.

\section{I-4 Individual Pay Factors}

\section{I-4a 28 Day Equivalent Flexural Strength Pay Factor}

In accordance with 501.31, the strength pay factor ( $\left.\mathrm{PF}_{\mathrm{STRENGTH}}\right)$ for each lot will be determined using Table I-2, based on the mean and standard deviation values determined for an as-constructed lot as adjusted to account for 28 day equivalent strength. The chosen pay factor will be taken as the first mean in the table that is less than or equal to the as constructed value.

The mean and standard deviation for the measured 7-day strength will be determined in accordance with Section 501.28. This strength will be converted to a 28 day equivalent strength using equation I-3.

$$
f_{28-\text { Equivalent }}=f_{7} \times C
$$

Equation I-3

$\mathrm{C}$ is a constant that can be determined from a series of tests as described in section I-6 of this document. In addition to multiplying the mean strengths by this correction factor the standard deviation will also be multiplied by this number. If the contractor chooses not to determine the factor $\mathrm{C}$ for their $\mathrm{CMD}$, they can use a value of 1.05.

Table I-2 provides pay factors for a range of typical as-constructed means and standard deviations. It should be noted that the maximum pay factor in Table I-2 is $\mathrm{X} \%$. 
Table I-2: 28 Day Equivalent Strength Payment Factors (Percentage)

\begin{tabular}{|c|c|c|c|c|c|c|}
\cline { 2 - 7 } \multicolumn{1}{c|}{} & \multicolumn{7}{c|}{ 28 Day Flexural Strength (psi) } \\
\cline { 2 - 7 } \multicolumn{1}{c|}{} & \multicolumn{7}{c|}{ Standard Deviation } \\
\cline { 2 - 7 } \multicolumn{1}{c|}{} & 30 & 40 & 50 & 60 & 70 & 80 \\
\hline 550 & 64.7 & 63.8 & 63.4 & 61.2 & 60.1 & 55.9 \\
\hline 575 & 75.9 & 74.5 & 74.2 & 72.5 & 71.0 & 67.7 \\
\hline 600 & 85.8 & 84.1 & 83.9 & 82.6 & 80.8 & 78.4 \\
\hline 625 & 94.5 & 92.6 & 92.5 & 91.6 & 89.6 & 87.8 \\
\hline 650 & 102.0 & 100.0 & 100.0 & 99.4 & 97.3 & 96.1 \\
\hline 675 & 108.4 & 106.6 & 106.5 & 106.0 & 104.0 & 103.2 \\
\hline 700 & 113.5 & 112.0 & 111.8 & 111.6 & 109.7 & 109.1 \\
\hline 725 & 117.4 & 116.4 & 116.1 & 115.9 & 114.3 & 113.9 \\
\hline 750 & 120.1 & 119.7 & 119.2 & 119.2 & 117.8 & 117.5 \\
\hline 775 & 121.6 & 121.9 & 121.3 & 121.2 & 120.3 & 119.9 \\
\hline 800 & 121.9 & 123.2 & 122.3 & 122.2 & 121.7 & 121.1 \\
\hline
\end{tabular}

Some rounding issues exist and this may be too severe on the top side

\section{$\underline{\text { I-4b Thickness Pay Factor }}$}

In accordance with 501.31, the thickness pay factor for each lot will be determined using Table I-3, based on mean and standard deviation values determined for a given as-constructed lot. The mean and standard deviation for each lot will be determined in accordance with 501.28. The chosen pay factor will be taken as the first mean in the table that is less than or equal to the as constructed value. Table I-3 provides pay factors for a range of typical as-constructed means and standard deviations. It should be noted that the maximum pay factor in Table I-3 is $\mathrm{X} \%$ 
Table I-3: Pavement Thickness Pay Factors (Percentage)

\begin{tabular}{|c|c|c|c|c|c|}
\cline { 2 - 6 } \multicolumn{1}{c|}{} & \multicolumn{5}{c|}{ Thickness (in) } \\
\cline { 2 - 6 } \multicolumn{1}{c|}{} & \multicolumn{5}{c|}{ Standard Deviation } \\
\cline { 2 - 6 } & 0.25 & 0.38 & 0.5 & 0.625 & 0.75 \\
\hline 13 & 91.3 & 91.7 & 91.2 & 91.7 & 91.3 \\
\hline 13.1 & 92.1 & 92.5 & 92.2 & 92.5 & 92.1 \\
\hline 13.2 & 93.0 & 93.3 & 93.1 & 93.3 & 93.0 \\
\hline 13.3 & 93.9 & 94.1 & 94.0 & 94.1 & 93.8 \\
\hline 13.4 & 94.7 & 100.0 & 94.9 & 94.9 & 94.6 \\
\hline 13.5 & 95.6 & 95.7 & 95.8 & 95.7 & 95.4 \\
\hline 13.6 & 96.5 & 96.5 & 96.7 & 96.5 & 96.2 \\
\hline 13.7 & 97.3 & 97.3 & 97.6 & 97.3 & 97.0 \\
\hline 13.8 & 98.1 & 98.1 & 98.4 & 98.1 & 97.8 \\
\hline 13.9 & 99.0 & 98.8 & 99.3 & 98.9 & 98.6 \\
\hline 14 & 99.8 & 99.6 & 100.1 & 99.7 & 99.4 \\
\hline 14.1 & 100.6 & 100.3 & 100.9 & 100.5 & 100.2 \\
\hline 14.2 & 101.5 & 101.1 & 101.8 & 101.3 & 101.0 \\
\hline 14.3 & 102.3 & 101.8 & 102.6 & 102.1 & 101.8 \\
\hline 14.4 & 103.1 & 102.6 & 103.3 & 102.9 & 102.6 \\
\hline 14.5 & 103.9 & 103.3 & 104.1 & 103.7 & 103.4 \\
\hline 14.6 & 104.7 & 104.0 & 104.9 & 104.5 & 104.2 \\
\hline 14.7 & 105.5 & 104.7 & 105.6 & 105.3 & 105.0 \\
\hline 14.8 & 106.3 & 105.4 & 106.4 & 106.1 & 105.8 \\
\hline 14.9 & 107.1 & 106.1 & 107.1 & 106.9 & 106.6 \\
\hline 15 & 107.8 & 106.8 & 107.8 & 107.7 & 107.4 \\
\hline 15.1 & 108.6 & 107.5 & 108.5 & 108.5 & 108.2 \\
\hline 15.2 & 109.4 & 108.1 & 109.2 & 109.3 & 109.0 \\
\hline 15.3 & 110.1 & 108.8 & 109.9 & 110.1 & 109.9 \\
\hline 15.4 & 110.9 & 109.5 & 110.6 & 110.9 & 110.7 \\
\hline 15.5 & 111.6 & 110.1 & 111.3 & 111.7 & 111.5 \\
\hline 15.6 & 112.4 & 110.8 & 111.9 & 112.5 & 112.3 \\
\hline 15.7 & 113.1 & 111.4 & 112.5 & 113.3 & 113.1 \\
\hline 15.8 & 113.9 & 112.1 & 113.2 & 114.1 & 113.9 \\
\hline 15.9 & 114.6 & 112.7 & 113.8 & 114.9 & 114.7 \\
\hline 16 & 115.3 & 113.3 & 114.4 & 115.7 & 115.5 \\
\hline
\end{tabular}

smoothing functions are needed and we need to establish the maximum thickness

\section{$\underline{\text { I-4c Air Content Pay Factor }}$}

In accordance with 501.31, the air content pay factor $\left(\mathrm{PF}_{\mathrm{AIR}}\right)$ for each lot will be determined using Table I-3, based on mean and standard deviation values determined for a given as-constructed lot. The mean and standard deviation for each lot will be determined in accordance with $501.28 \mathrm{~b}$. Table I-3 provides pay factors for a range of 
typical as-constructed means and standard deviations. The chosen pay factor will be taken as the first mean in the table that is less than or equal to the as constructed value. It should be noted that the maximum pay factor in Table I-3 is X\%

Table I-4: Pavement Air Content Pay Factors

\begin{tabular}{|c|c|c|c|c|}
\cline { 2 - 5 } \multicolumn{1}{c|}{} & \multicolumn{4}{c|}{ Air Content (\%) } \\
\cline { 2 - 5 } \multicolumn{1}{c|}{} & \multicolumn{4}{|c|}{ Standard Deviation } \\
\cline { 2 - 5 } & 0.5 & 1.0 & 1.5 & 2.0 \\
\hline 4.5 & 11.3 & 0.0 & 0.0 & 0.0 \\
\hline 5.0 & 41.1 & 29.4 & 21.2 & 11.8 \\
\hline 5.5 & 66.7 & 55.4 & 44.9 & 32.1 \\
\hline 6.0 & 88.1 & 77.4 & 65.7 & 50.6 \\
\hline 6.5 & 105.4 & 100.0 & 83.4 & 67.3 \\
\hline 7.0 & 118.5 & 110.0 & 98.2 & 82.2 \\
\hline 7.5 & 127.4 & 120.6 & 110.0 & 95.3 \\
\hline 8.0 & 132.2 & 127.2 & 118.8 & 106.6 \\
\hline 8.5 & 132.7 & 130.0 & 124.6 & 116.2 \\
\hline 9.0 & 129.1 & 129.0 & 127.5 & 123.9 \\
\hline 9.5 & 121.4 & 124.1 & 127.3 & 129.8 \\
\hline
\end{tabular}

Note this has some issues and may be a little coarse and overly severe I am also a little concerned that this continually increases and does not come down, this is a wrong message to send

\section{I-4d Smoothness Pay Factor}

In accordance with 501.31, the smoothness pay factor for each lot will be determined using Table I-4, based on the mean values determined for a given as-constructed lot.

The mean smoothness for each lot will be determined for the entire lot. It should be noted that this differs from the determination of the other pay factors where sublots are used for computing lot averages. For smoothness determination, the entire lot will be divided into $0.1 \mathrm{mi}$. increments (or near equivalents as determined by the engineer) and the profilograph will be performed as described in ITM 901. The profilogram(s) will be divided into $0.1 \mathrm{mi}$ increments and the average of the $0.1 \mathrm{mi}$ measurements will be reported as the average smoothness for a given lot. The shoulder will not be considered as a lane for any smoothness calculations. If the geometry of a lot is such that it prohibits smoothness calculations to be performed on greater than $25 \%$ of the area of the lot the $\mathrm{PF}_{\mathrm{SMOOTHNESS}}$ is to be taken as $100 \%$ ). Smoothness will be determined using profilograph measurements taken before any corrective grinding is performed. Table I-4 provides pay factors for a range of typical as-constructed means for pavements either ground or unground. It should be noted that the maximum pay factor in Table I-4 is X\%. (I think this is an improvement, however we will need to discuss and we will need to discuss the grinding penalty and the area chosen $(25 \%)$ to avoid difficulties with shoulders) 


\section{Table I-4: Smoothness Payment Factors (Percentage)}

\begin{tabular}{|c|c|c|}
\cline { 2 - 3 } \multicolumn{1}{c|}{} & \multicolumn{2}{c|}{ Smoothness (in/0.1mi) } \\
\cline { 2 - 3 } & Unground & Ground \\
\hline 0.3 & 106.4 & 104.4 \\
\hline 0.4 & 105.2 & 103.2 \\
\hline 0.5 & 103.9 & 101.9 \\
\hline 0.6 & 102.6 & 100.6 \\
\hline 0.7 & 101.3 & 100.0 \\
\hline 0.8 & 100.1 & 98.1 \\
\hline 0.9 & 98.8 & 96.8 \\
\hline 1.0 & 97.5 & 95.5 \\
\hline
\end{tabular}

Note design not at 0 - must be fixed

Note: The chosen pay factor will be taken as the first mean in the table that is greater than or equal to the as constructed value. No Standard Deviation is used in the determination of the pay factor for smoothness.

\section{I-5 AQC Samples and Testing Method}

Test samples are taken for each AQC value in order to determine the quality of the asconstructed pavement. The following table indicates the type of samples required for strength and thickness determinations and the test procedure for smoothness determination.

\begin{tabular}{|c|c|c|c|c|}
\hline AQC Value & $\begin{array}{c}\text { Samples and } \\
\text { Test Procedure }\end{array}$ & $\begin{array}{c}\text { Sample } \\
\text { Locations per } \\
\text { Sublot }\end{array}$ & $\begin{array}{c}\text { Number of } \\
\text { samples at Each } \\
\text { Location. }\end{array}$ & Target Mean \\
\hline Strength & Beams & 1 & 2 & $650 \mathrm{psi}$ \\
\hline Thickness & Cores & 2 & 1 & $14.1 \mathrm{in}$. \\
\hline Air Content & $\begin{array}{c}\text { Hardened Air } \\
\text { or High } \\
\text { Pressure (ITM } \\
\text { 401) }\end{array}$ & 1 or 2 & 1 & $\begin{array}{c}6.5 \% \text { Plastic or } \\
7.38 \%\end{array}$ \\
\hline Smoothness & $\begin{array}{c}\text { Profile Index } \\
\left(\begin{array}{c}0.2 \text { in blanking } \\
\text { band })\end{array}\right.\end{array}$ & $\begin{array}{c}1 \text { pass/lane } \\
\text { RWP }\end{array}$ & 1 & $0.7 \mathrm{in} / 0.1 \mathrm{mile}$ \\
\hline
\end{tabular}

* linear traverse, plastic, high pressure. I have questions on how we will relate either the LCC predictions. We will also need to discuss the target mean for thickness. According to design after rounding this is 15 in according to design before rounding this is 14.1 in

\section{I-6 Procedure for Determining the Strength Multiplication Constant C}


The following procedure describes how a contractor can determine the strength multiplication factor for a concrete mixture design. It should be noted that if the contractor elects not to perform these tests a value of 1.05 can be used.

\section{Option \#1: Ratio of 7-Day and 28-Day Strength}

The Contractor can test 6 flexural beams in accordance with AASHTO T 97 using standard laboratory curing procedures. Three of the beams will be tested at an age of 7 days, while 3 of the beams will be tested at an age of 28 days. The strength multiplication constant $\mathrm{C}$ can be computed as the ratio of the average 28 day and 7 day strengths.

$$
C=\frac{f_{28-D a y}}{f_{7-\text { Day }}}
$$

Equation I-4

\section{Option \#2: Using Maturity to Predict Strength}

An alternative to this approach would be to develop a strength-maturity relationship for each concrete mixture. This would have the advantage in that the contractors could start to more realistically determine what the strengths of the pavement is in the field.

The contractor can test 12 flexural beams in accordance with AASHTO T 97 using standard laboratory curing procedures. Two beams will be tested at ages of 1, 2, 3, 7, 28 and 56 days. In addition to recording the strength of the beams, the contractor will determine the temperature history of the beams using a thermocouple embedded in the beams. In addition to determining the strength at each age the contractor will report the maturity (i.e., the area under the time-temperature graph). This information will them be fit using equation I-5.

$$
\mathrm{f}(t)=f_{\infty} \frac{A\left(\mathrm{TTF}-\mathrm{TTF}_{0}\right)}{1-A\left(\mathrm{TTF}-\mathrm{TTF}_{0}\right)}
$$

Equation I-5

where $f(t)$ is the strength at any age, $f_{\infty}$ is the theoretical infinite strength, $A$ is the rate constant, TTF is the Time Temperature Factor at any time, and $\mathrm{TTF}_{0}$ is the time at which concrete begins to gain strength. Once the constants in this equation are determined it is possible to predict the strength of any concrete under any temperature history.

A description of how these factors can be determined is described below.

Note if this is the option we will choose I will add the appropriate procedures here - Cut and Paste from Cole 
Assuming the concrete beams will be stored under standard laboratory conditions and the time of set is relatively small the strength correction factor $\mathrm{C}$ can be computed using Equation I-6.

$$
C \cong \frac{1-4000 \mathrm{~A}}{0.25-4000 \mathrm{~A}}
$$

Equation I-6

I have listed 2 testing options here. Option \#1 will be the simplest testing procedure, however Option \#2 will provide the opportunity to enable contractors to determine more from their mixtures very soon after they are placed. I will discuss the benefits of each and we can decide at a later time. 
APPENDIX V FINAL PAY FACTORS AND EXTRA PAY FOR PRS PROJECT \#2, AS GIVEN BY THE CONTRACTOR - CLARKSVILLE, IN (PROJECT R-25715) 


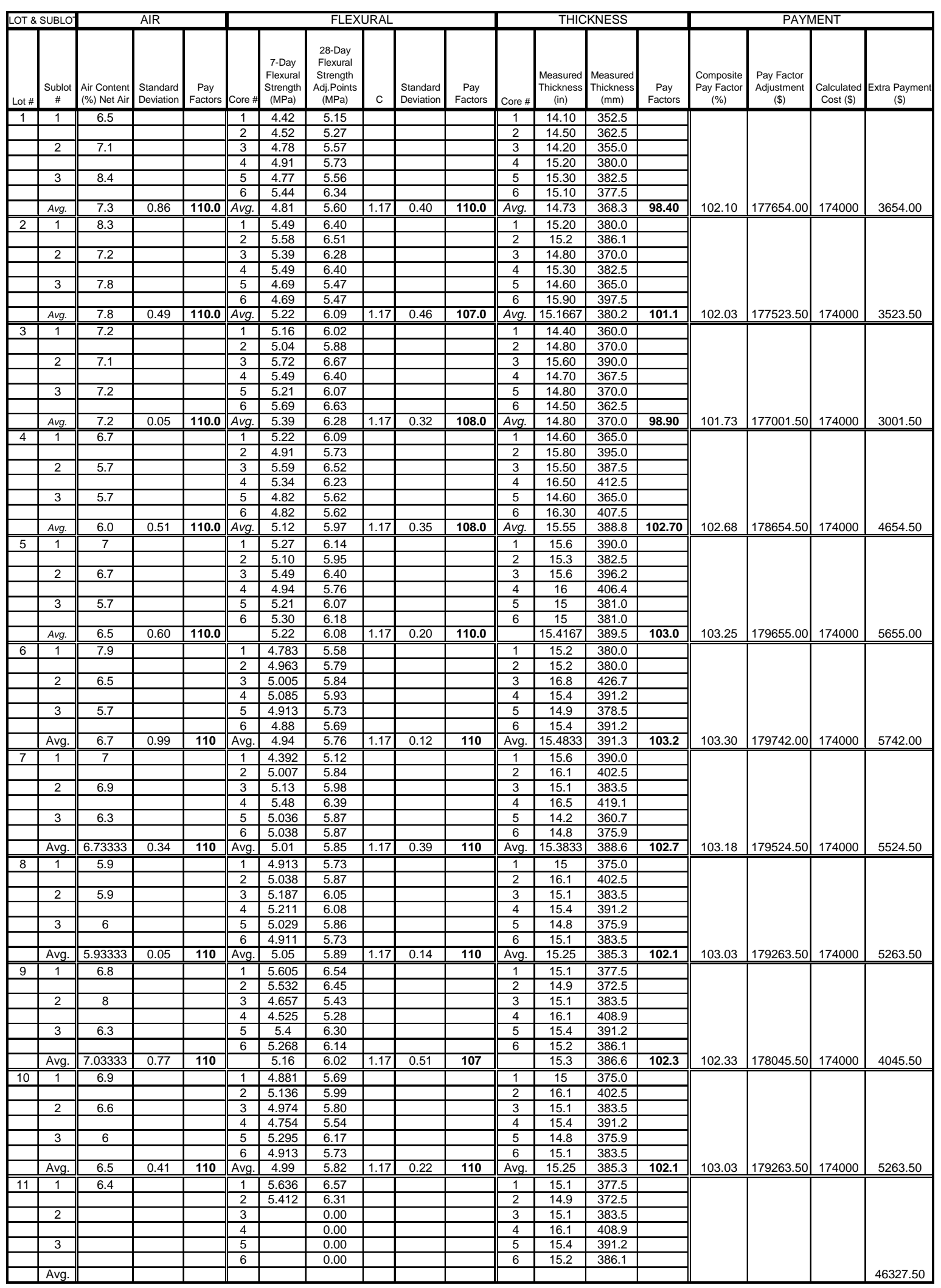




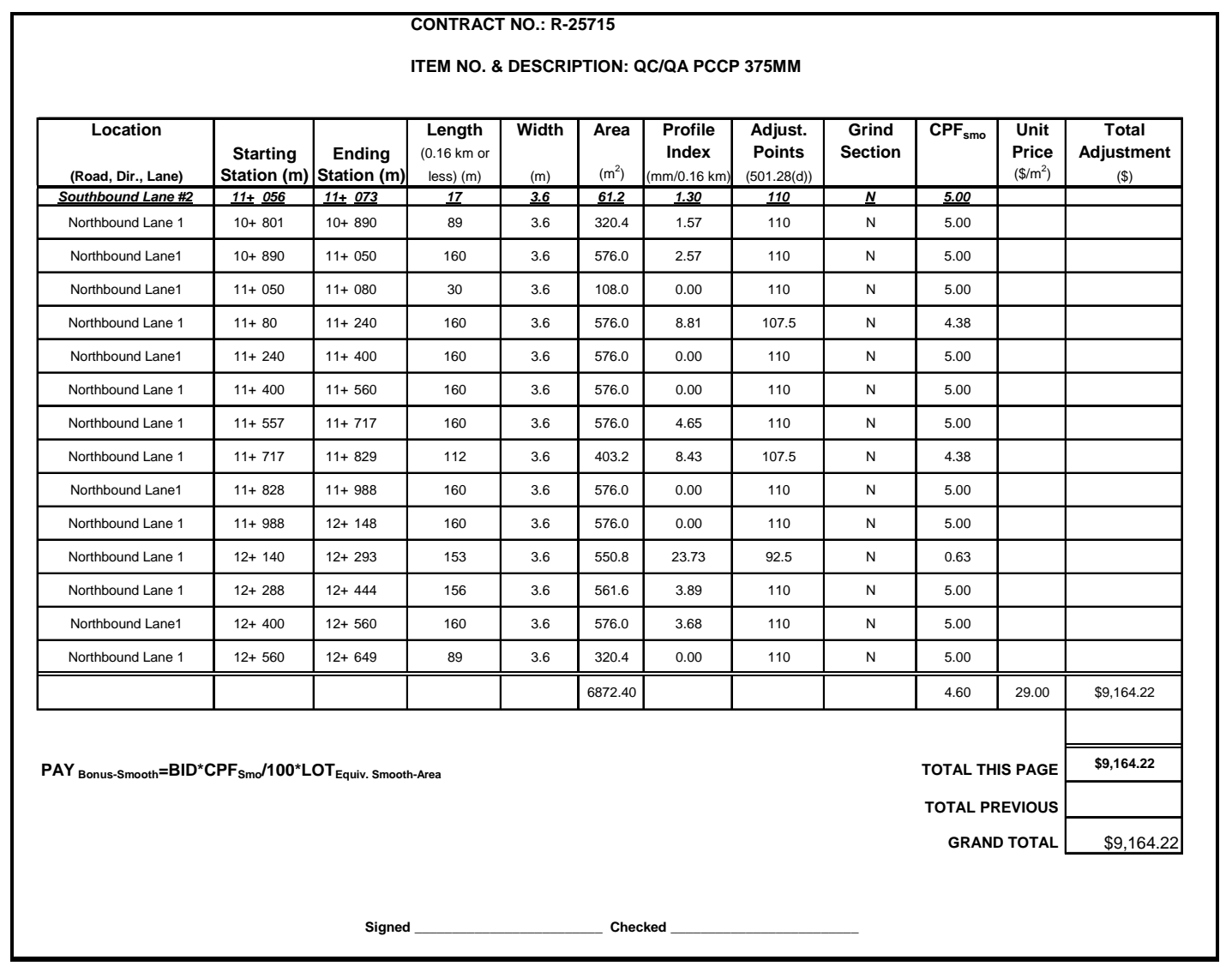

CONTRACT NO.: R-25715

ITEM NO. \& DESCRIPTION: QC/QA PCCP 375MM

\begin{tabular}{|c|c|c|c|c|c|c|c|c|c|c|c|}
\hline $\begin{array}{c}\text { Location } \\
\text { (Road, Dir., Lane) }\end{array}$ & $\begin{array}{c}\text { Starting } \\
\text { Station }(\mathrm{m})\end{array}$ & $\begin{array}{c}\text { Ending } \\
\text { Station }(\mathrm{m})\end{array}$ & $\begin{array}{l}\text { Length } \\
(0.16 \mathrm{~km} \text { or } \\
\text { less })(\mathrm{m})\end{array}$ & $\begin{array}{l}\text { Width } \\
(\mathrm{m})\end{array}$ & $\begin{array}{c}\text { Area } \\
\left(\mathrm{m}^{2}\right)\end{array}$ & \begin{tabular}{|c|}
$\begin{array}{c}\text { Profile } \\
\text { Index } \\
(\mathrm{mm} / 0.16 \mathrm{~km})\end{array}$ \\
\end{tabular} & $\begin{array}{l}\text { Adjust. } \\
\text { Points } \\
\text { (501.28(d)) }\end{array}$ & $\begin{array}{l}\text { Grind } \\
\text { Section }\end{array}$ & $\mathrm{CPF}_{\text {smo }}$ & \begin{tabular}{l|} 
Unit \\
Price \\
$\left(\$ / \mathrm{m}^{2}\right)$
\end{tabular} & $\begin{array}{c}\text { Total } \\
\text { Adjustment } \\
(\$)\end{array}$ \\
\hline Southbound Lane \#2 & $11+056$ & $11+073$ & $\underline{17}$ & 3.6 & 61.2 & 1.30 & 110 & $\underline{\underline{N}}$ & 5.00 & & \\
\hline Northbound Lane 1 & $12+804$ & $12+964$ & 160 & 3.6 & 576.0 & 5.66 & 110 & $\mathrm{~N}$ & 5.00 & & \\
\hline Northbound Lane1 & $12+964$ & $13+124$ & 160 & 3.6 & 576.0 & 20.55 & 95 & $\mathrm{~N}$ & 1.25 & & \\
\hline Northbound Lane1 & $13+124$ & $13+284$ & 160 & 3.6 & 576.0 & 16.18 & 100 & $\mathrm{~N}$ & 2.50 & & \\
\hline Northbound Lane1 & $13+284$ & $13+444$ & 160 & 3.6 & 576.0 & 24.27 & 92.5 & $\mathrm{~N}$ & 0.63 & & \\
\hline Northbound Lane1 & $13+444$ & $13+604$ & 160 & 3.6 & 576.0 & 8.01 & 107.5 & $\mathrm{~N}$ & 4.38 & & \\
\hline Northbound Lane1 & $13+604$ & $13+641$ & 37 & 3.6 & 133.2 & 6.15 & 110 & $\mathrm{~N}$ & 5.00 & & \\
\hline North Bound Lane 2 & $12+798$ & $12+840$ & 42 & 3.6 & 151.2 & 6.96 & 110 & $\mathrm{~N}$ & 5.00 & & \\
\hline Northbound Lane 2 & $12+840$ & $13+000$ & 160 & 3.6 & 576.0 & 14.27 & 102.5 & $\mathrm{~N}$ & 3.13 & & \\
\hline North Bound Lane 2 & $13+0$ & $13+160$ & 160 & 3.6 & 576.0 & 15.02 & 100 & $\mathrm{~N}$ & 2.50 & & \\
\hline North Bound Lane 2 & $13+160$ & $13+320$ & 160 & 3.6 & 576.0 & 9.81 & 107.5 & $\mathrm{~N}$ & 4.38 & & \\
\hline North Bound Lane 2 & $13+320$ & $13+480$ & 160 & 3.6 & 576.0 & 2.51 & 110 & $\mathrm{~N}$ & 5.00 & & \\
\hline Northbound Lane 2 & $13+480$ & $13+640$ & 160 & 3.6 & 576.0 & 9.93 & 107.5 & $\mathrm{~N}$ & 4.38 & & \\
\hline North Bound Lane 3 & $13+440$ & $13+600$ & 160 & 3.6 & 576.0 & 9.27 & 107.5 & $\mathrm{~N}$ & 4.38 & & \\
\hline North Bound Lane 3 & $13+600$ & $13+643$ & 43 & 3.6 & 154.8 & 1.02 & 110 & $\mathrm{~N}$ & 5.00 & & \\
\hline & & & & & 6775.20 & & & & 3.75 & 29.00 & $\$ 7,368.03$ \\
\hline \multirow{2}{*}{\multicolumn{9}{|c|}{$\mathrm{PAY}_{\text {Bonus-Smooth }}=\mathrm{BID}^{*} \mathrm{CPF}_{\mathrm{Smo}} / 100^{*} \mathrm{LOT}_{\text {Equiv. Smooth-Area }}$}} & \multirow{2}{*}{\multicolumn{2}{|c|}{$\begin{array}{c}\text { TOTAL THIS PAGE } \\
\text { TOTAL PREVIOUS } \\
\text { GRAND TOTAL }\end{array}$}} & (\$7,368.03 \\
\hline & & & & & & & & & & & $\$ 16,020.51$ \\
\hline
\end{tabular}




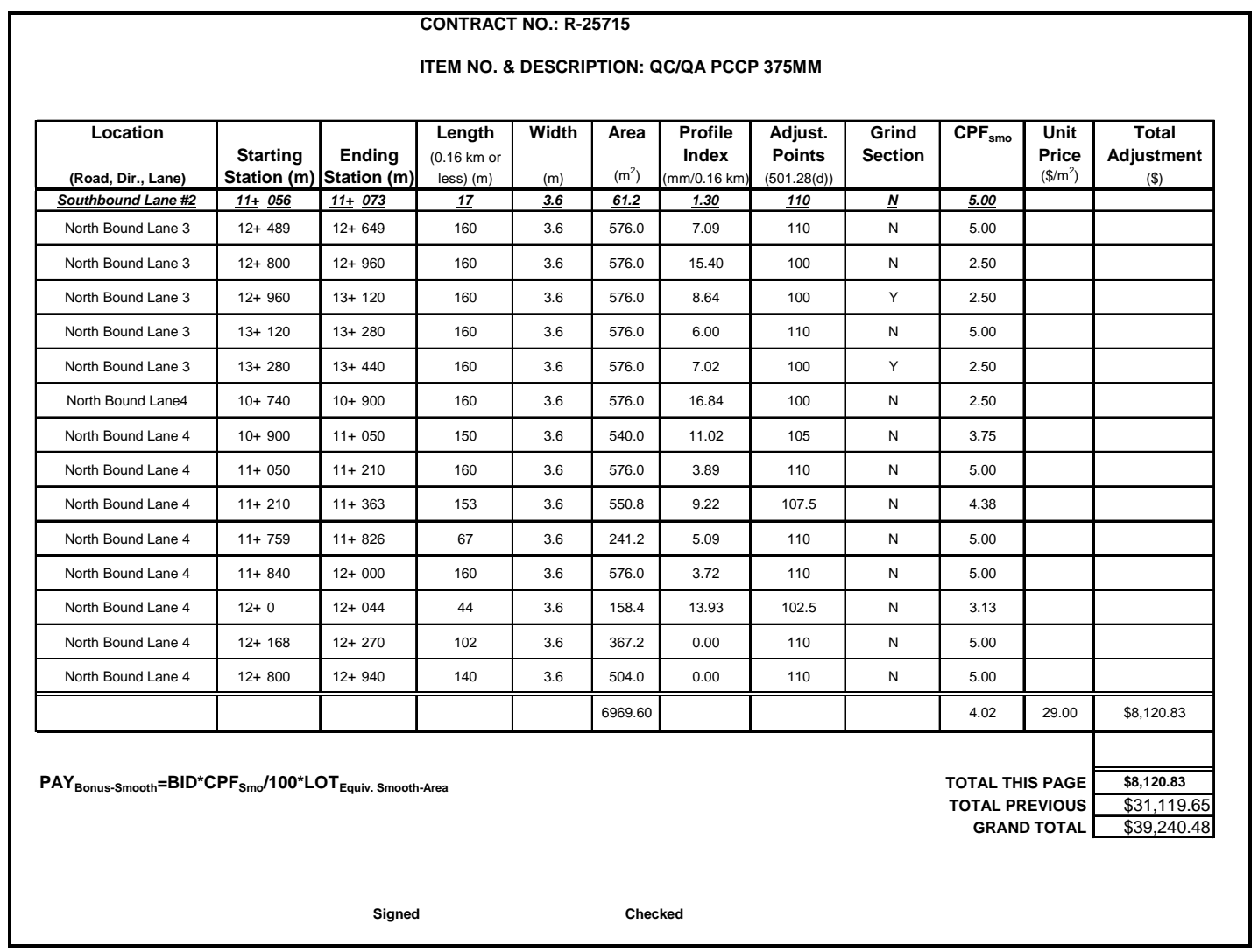

\section{CONTRACT NO.: R-25715}

ITEM NO. \& DESCRIPTION: QC/QA PCCP 375MM

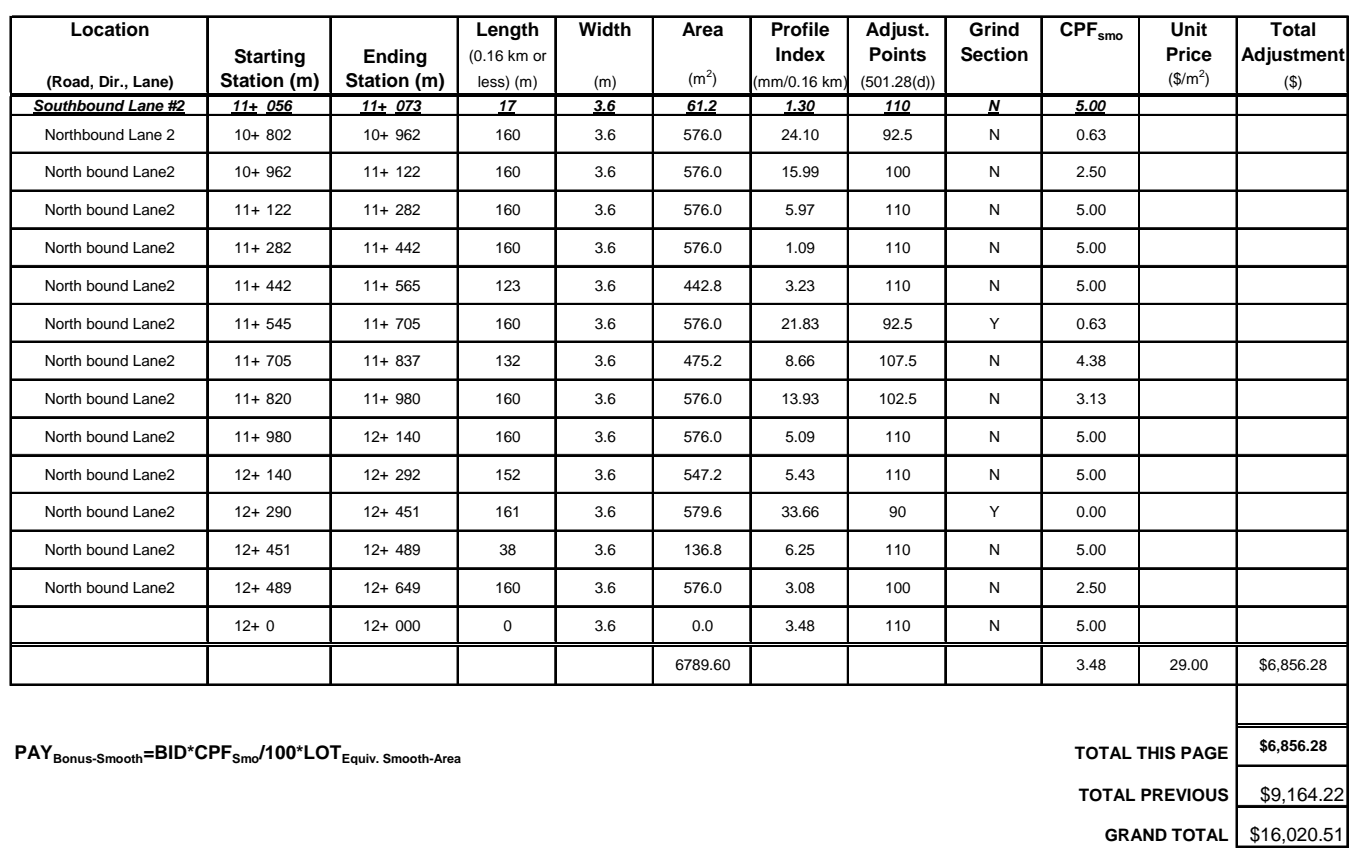


CONTRACT NO.: R-25715

ITEM NO. \& DESCRIPTION: QCIQA PCCP 375MM

\begin{tabular}{|c|c|c|c|c|c|c|c|c|c|c|c|}
\hline $\begin{array}{c}\text { Location } \\
\text { (Road, Dir., Lane) }\end{array}$ & $\begin{array}{c}\text { Starting } \\
\text { Station }(\mathrm{m})\end{array}$ & $\begin{array}{c}\text { Ending } \\
\text { Station (m) }\end{array}$ & $\begin{array}{l}\text { Length } \\
(0.16 \mathrm{~km} \text { or } \\
\text { less })(\mathrm{m})\end{array}$ & $\begin{array}{l}\text { Width } \\
\text { (m) }\end{array}$ & $\begin{array}{l}\text { Area } \\
\left(\mathrm{m}^{2}\right)\end{array}$ & \begin{tabular}{|c|}
$\begin{array}{c}\text { Profile } \\
\text { Index } \\
(\mathrm{mm} / 0.16 \mathrm{~km})\end{array}$ \\
\end{tabular} & $\begin{array}{l}\text { Adjust. } \\
\text { Points } \\
\text { (501.28(d)) }\end{array}$ & $\begin{array}{c}\text { Grind } \\
\text { Section }\end{array}$ & $\mathrm{CPF}_{\text {smo }}$ & $\begin{array}{l}\text { Unit } \\
\text { Price } \\
\left(\$ / \mathrm{m}^{2}\right)\end{array}$ & \begin{tabular}{|c|} 
Total \\
Adjustment \\
(\$)
\end{tabular} \\
\hline Southbound Lane \#2 & $11+056$ & $11+073$ & 17 & 3.6 & 61.2 & 1.30 & 110 & $\underline{\underline{N}}$ & 5.00 & & \\
\hline North Bound Lane3 & $10+728$ & $11+791$ & 63 & 3.6 & 226.8 & 1.12 & 110 & $\mathrm{~N}$ & 5.00 & & \\
\hline North Bound Lane3 & $10+791$ & $11+951$ & 160 & 3.6 & 576.0 & 2.44 & 110 & $\mathrm{~N}$ & 5.00 & & \\
\hline North Bound Lane3 & $10+951$ & $11+111$ & 160 & 3.6 & 576.0 & 2.21 & 110 & $N$ & 5.00 & & \\
\hline North Bound Lane3 & $11+111$ & $11+271$ & 160 & 3.6 & 576.0 & 1.02 & 110 & $N$ & 5.00 & & \\
\hline North Bound Lane3 & $11+271$ & $11+431$ & 160 & 3.6 & 576.0 & 18.85 & 95.5 & $\mathrm{Y}$ & 1.38 & & \\
\hline North Bound Lane3 & $11+431$ & $11+591$ & 160 & 3.6 & 576.0 & 7.87 & 110 & $\mathrm{~N}$ & 5.00 & & \\
\hline North Bound Lane3 & $11+590$ & $11+662$ & 72 & 3.6 & 259.2 & 11.15 & 105 & $N$ & 3.75 & & \\
\hline North Bound Lane3 & $11+662$ & $11+822$ & 160 & 3.6 & 576.0 & 11.11 & 105 & $\mathrm{~N}$ & 3.75 & & \\
\hline Northbound Lane 3 & $11+822$ & $11+828$ & 6 & 3.6 & 21.6 & 0.00 & 110 & $\mathrm{~N}$ & 5.00 & & \\
\hline North Bound Lane3 & $11+828$ & $11+988$ & 160 & 3.6 & 576.0 & 9.82 & 107.5 & $\mathrm{~N}$ & 4.38 & & \\
\hline North Bound Lane3 & $11+988$ & $12+148$ & 160 & 3.6 & 576.0 & 18.80 & 95.5 & $N$ & 1.38 & & \\
\hline North Bound Lane3 & $12+152$ & $12+291$ & 139 & 3.6 & 500.4 & 12.94 & 105 & $\mathrm{~N}$ & 3.75 & & \\
\hline Northbound Lane 3 & $12+290$ & $12+444$ & 154 & 3.6 & 554.4 & 5.89 & 110 & $N$ & 5.00 & & \\
\hline Northboound Lane3 & $12+427$ & $12+489$ & 62 & 3.6 & 223.2 & 2.92 & 110 & $N$ & 5.00 & & \\
\hline & & & & & 6393.60 & & & & 4.17 & 29.00 & $\$ 7,731.12$ \\
\hline \multirow{2}{*}{\multicolumn{9}{|c|}{$\mathrm{PAY}_{\text {Bonus-Smooth }}=\mathrm{BID}^{*} \mathrm{CPF}_{\mathrm{Smo}} / 100^{*} \mathrm{LOT}_{\text {Equiv. Smooth-Area }}$}} & \multirow{2}{*}{\multicolumn{2}{|c|}{$\begin{array}{r}\text { TOTAL THIS PAGE } \\
\text { TOTAL PREVIOUS } \\
\text { GRAND TOTAL }\end{array}$}} & 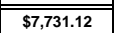 \\
\hline & & & & & & & & & & & $\$ 23,388.54$ \\
\hline
\end{tabular}

Signed

Checked

CONTRACT NO.: R-25715

ITEM NO. \& DESCRIPTION: QC/QA PCCP 375MM

\begin{tabular}{|c|c|c|c|c|c|c|c|c|c|c|c|}
\hline $\begin{array}{c}\text { Location } \\
\text { (Road, Dir., Lane) }\end{array}$ & $\begin{array}{c}\text { Starting } \\
\text { Station (m) }\end{array}$ & $\begin{array}{c}\text { Ending } \\
\text { Station (m) }\end{array}$ & $\begin{array}{l}\text { Length } \\
(0.16 \mathrm{~km} \text { or } \\
\text { less) }(\mathrm{m}) \\
\end{array}$ & $\begin{array}{l}\text { Width } \\
\text { (m) }\end{array}$ & $\begin{array}{l}\text { Area } \\
\left(\mathrm{m}^{2}\right)\end{array}$ & \begin{tabular}{|c|}
$\begin{array}{c}\text { Profile } \\
\text { Index } \\
(\mathrm{mm} / 0.16 \mathrm{~km})\end{array}$ \\
\end{tabular} & $\begin{array}{c}\text { Adjust. } \\
\text { Points } \\
(501.28(\mathrm{~d})) \\
\end{array}$ & $\begin{array}{l}\text { Grind } \\
\text { Section }\end{array}$ & $\mathrm{CPF}_{\text {smo }}$ & $\begin{array}{l}\text { Unit } \\
\text { Price } \\
\left(\$ / \mathrm{m}^{2}\right) \\
\end{array}$ & \begin{tabular}{|c|} 
Total \\
Adjustment \\
$(\$)$
\end{tabular} \\
\hline Southbound Lane \#2 & $\underline{11+056}$ & $\underline{11+073}$ & $\underline{17}$ & 3.6 & $\underline{61.2}$ & 1.30 & $\underline{110}$ & $\underline{\underline{N}}$ & 5.00 & & \\
\hline North Bound Lane 4 & $12+940$ & $13+100$ & 160 & 3.6 & 576.0 & 13.84 & 102.5 & $\mathrm{~N}$ & 3.13 & & \\
\hline North Bound Lane 4 & $13+100$ & $13+260$ & 160 & 3.6 & 576.0 & 4.24 & 110 & $\mathrm{~N}$ & 5.00 & & \\
\hline \multirow[t]{13}{*}{ North Bound Lane 4} & $13+260$ & $13+420$ & 160 & 3.6 & 576.0 & 2.67 & 110 & $\mathrm{~N}$ & 5.00 & & \\
\hline & $10+0$ & $10+000$ & 0 & 3.6 & 0.0 & 15.99 & 100 & $\mathrm{~N}$ & 2.50 & & \\
\hline & $11+0$ & $11+000$ & 0 & 3.6 & 0.0 & 5.97 & 110 & $\mathrm{~N}$ & 5.00 & & \\
\hline & $11+000$ & $11+000$ & 0 & 3.6 & 0.0 & 1.09 & 110 & N & 5.00 & & \\
\hline & $11+0$ & $11+000$ & 0 & 3.6 & 0.0 & 3.22 & 110 & $\mathrm{~N}$ & 5.00 & & \\
\hline & $12+000$ & $12+000$ & 0 & 3.6 & 0.0 & 3.89 & 110 & $\mathrm{~N}$ & 5.00 & & \\
\hline & $12+0$ & $12+000$ & 0 & 3.6 & 0.0 & 6.25 & 110 & $\mathrm{~N}$ & 5.00 & & \\
\hline & $12+0$ & $12+000$ & 0 & 3.6 & 0.0 & 5.89 & 110 & $\mathrm{~N}$ & 5.00 & & \\
\hline & $12+0$ & $12+000$ & 0 & 3.6 & 0.0 & 2.69 & 110 & $\mathrm{~N}$ & 5.00 & & \\
\hline & $12+0$ & $12+000$ & 0 & 3.6 & 0.0 & 3.89 & 110 & N & 5.00 & & \\
\hline & $12+0$ & $12+000$ & 0 & 3.6 & 0.0 & 6.25 & 110 & N & 5.00 & & \\
\hline & $12+0$ & $12+000$ & 0 & 3.6 & 0.0 & 5.89 & 110 & $\mathrm{~N}$ & 5.00 & & \\
\hline & & & & & 1728.00 & & & & 4.69 & 29.00 & $\$ 2,349.00$ \\
\hline \multirow{2}{*}{\multicolumn{9}{|c|}{$\mathrm{PAY}_{\text {Bonus-Smooth }}=\mathrm{BID}^{*} \mathrm{CPF} \mathrm{Smo}_{\mathrm{Smo}} / 100^{*} \mathrm{LOT}_{\text {Equiv. Smooth-Area }}$}} & \multirow{2}{*}{\multicolumn{2}{|c|}{$\begin{array}{r}\text { TOTAL THIS PAGE } \\
\text { TOTAL PREVIOUS } \\
\text { GRAND TOTAL }\end{array}$}} & $\$ 2,349.00$ \\
\hline & & & & & & & & & & & $\begin{array}{l}\$ 39,240.48 \\
\$ 41,589.48\end{array}$ \\
\hline
\end{tabular}

Signed

Checked 